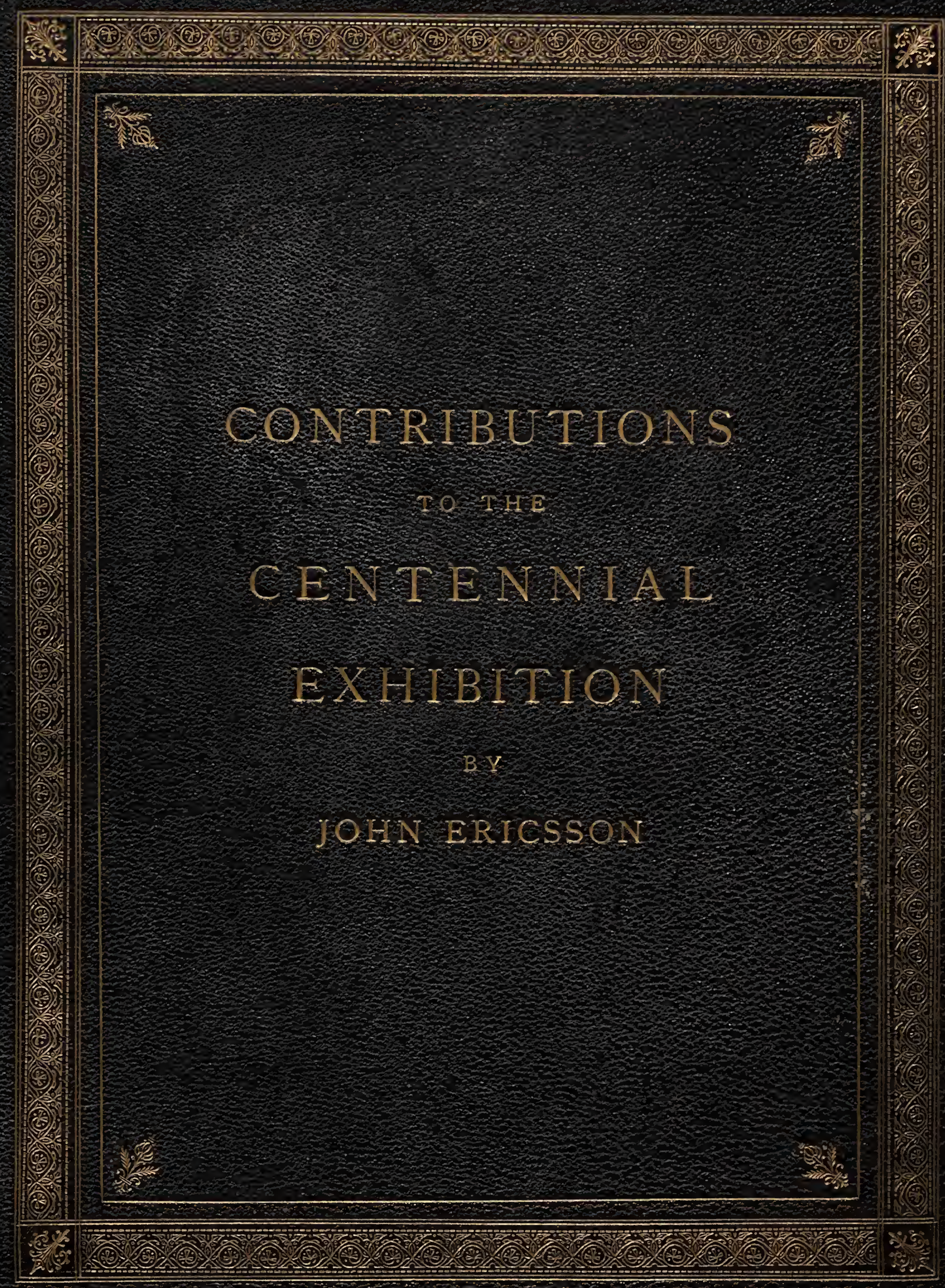




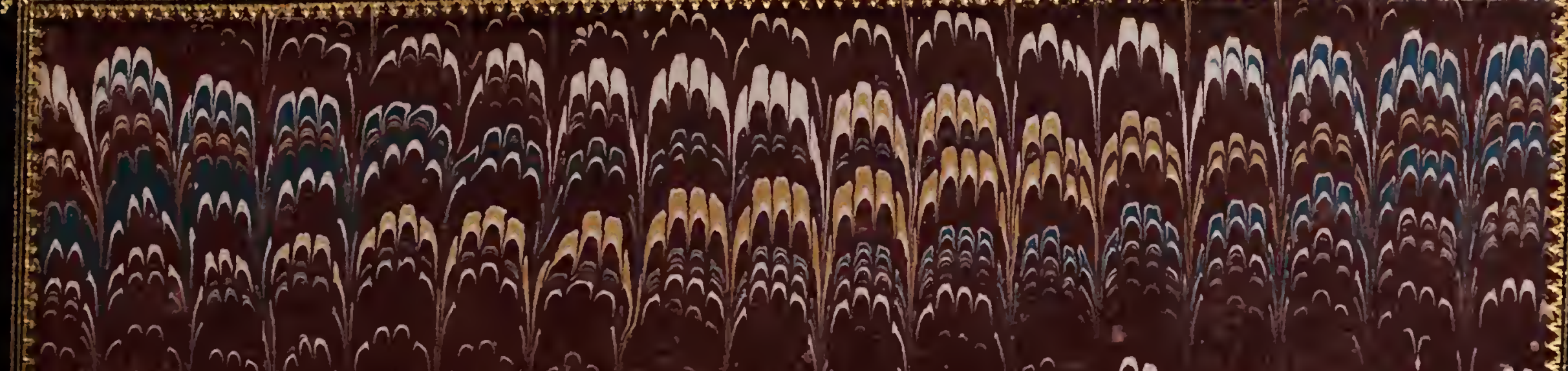

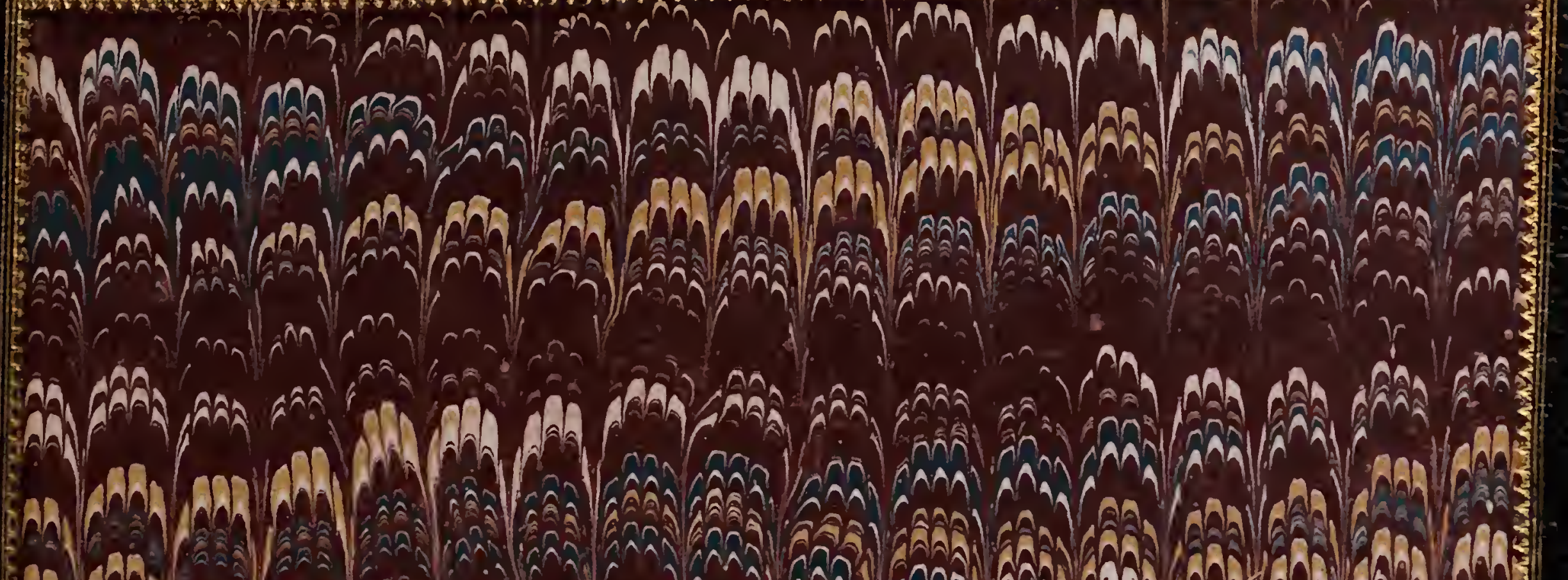

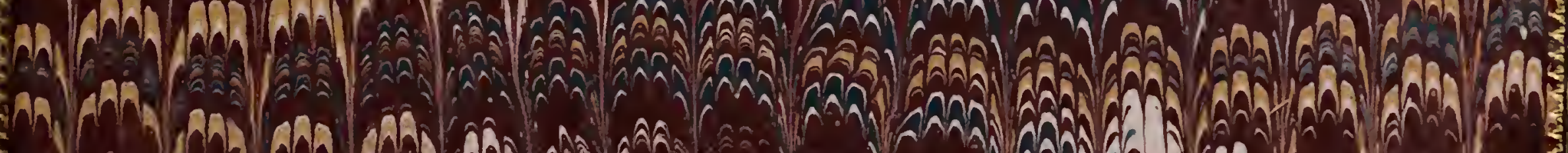

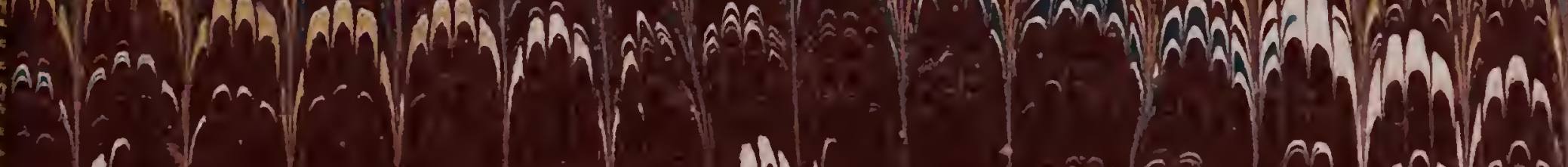

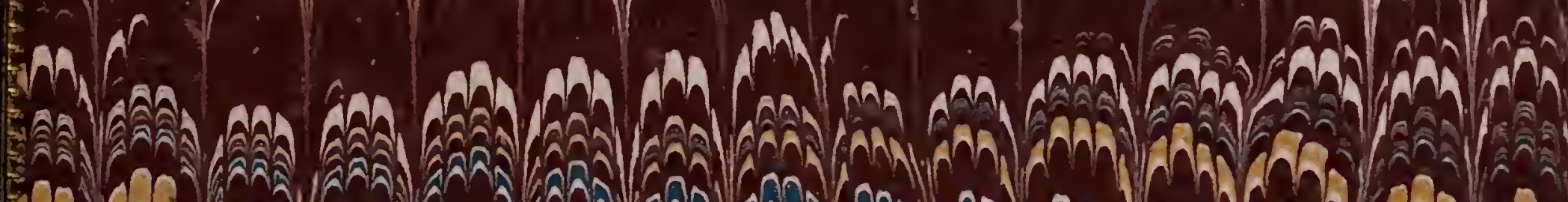

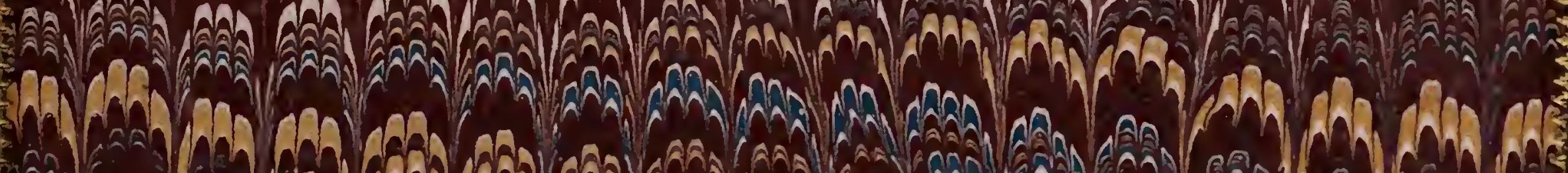

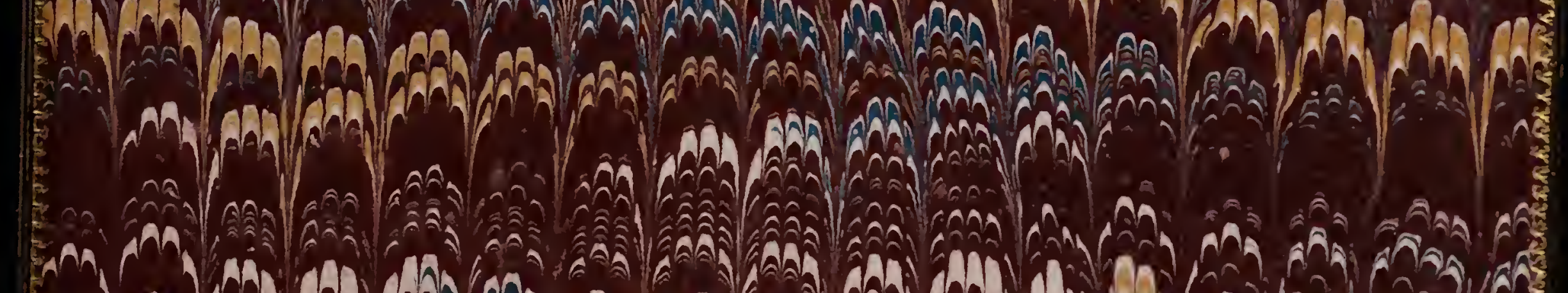

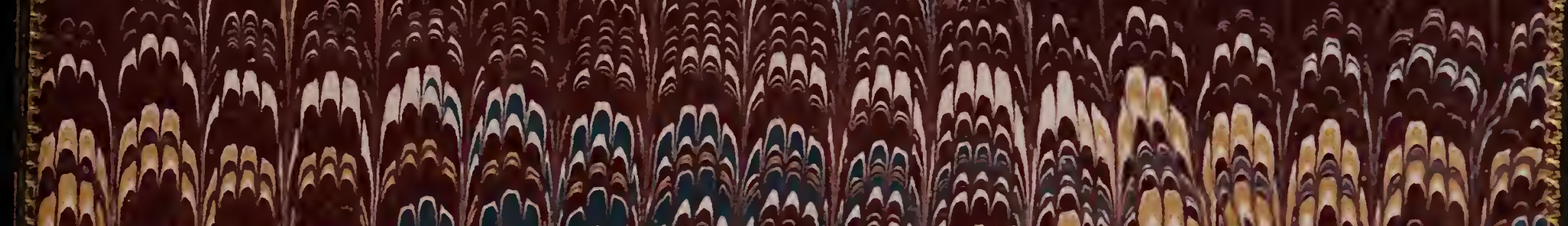

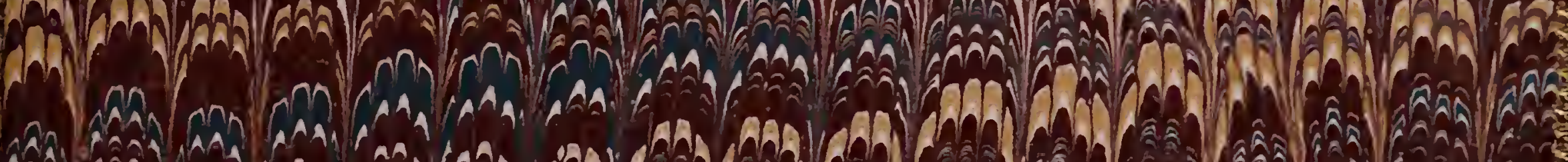

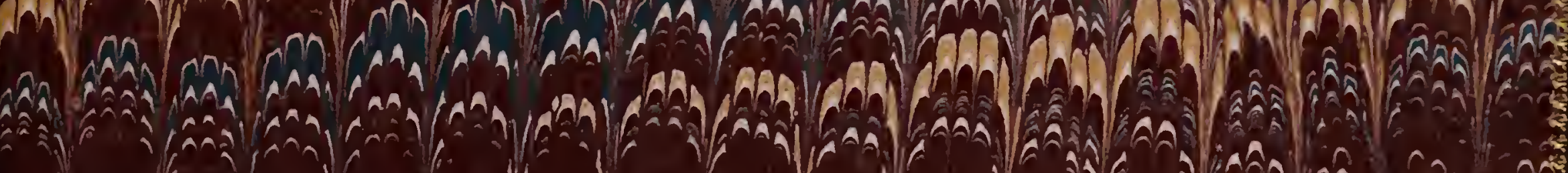

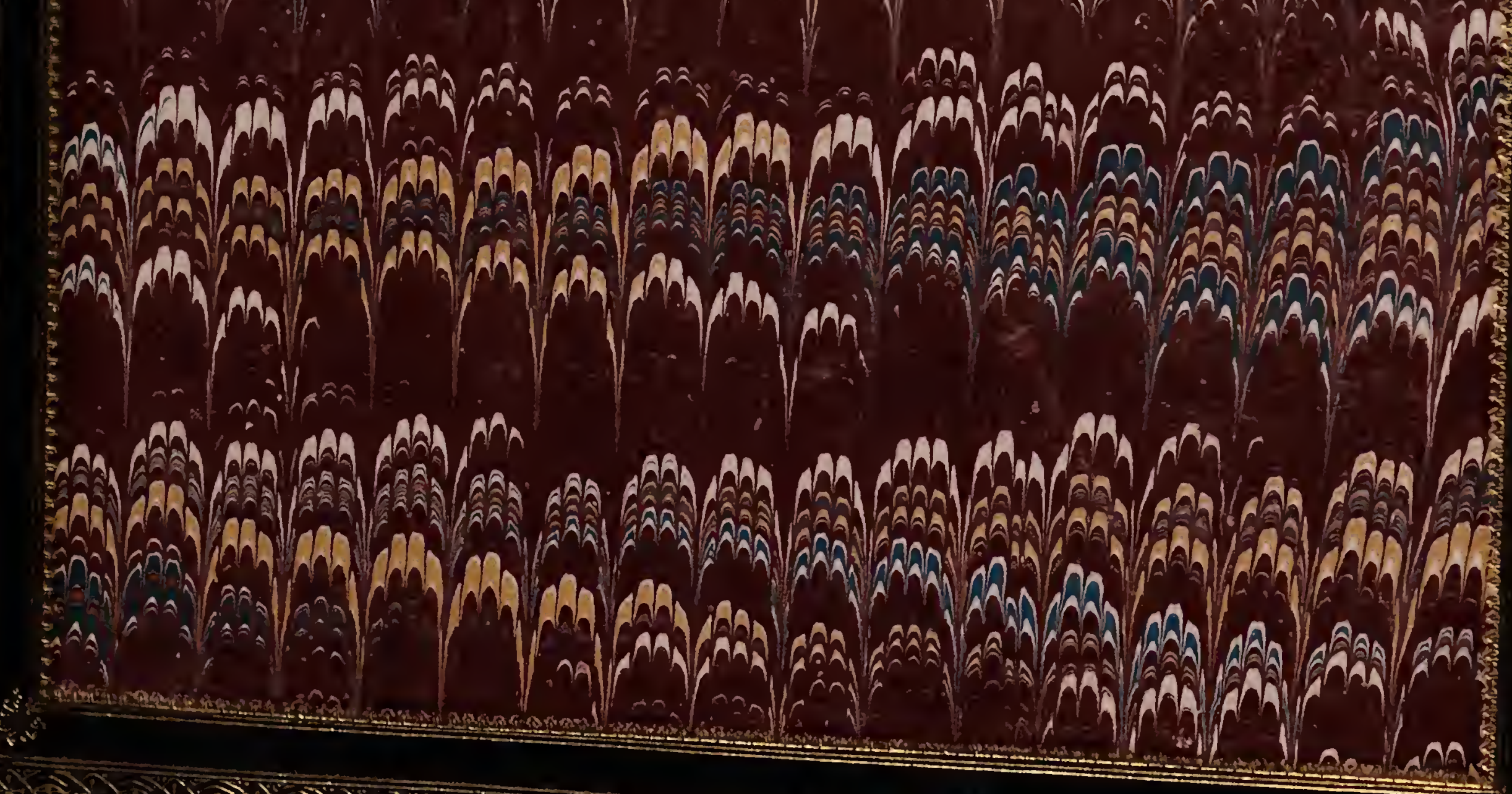










\section{CONTRIBUTIONS}

TO THE

\section{CENTENIIAL EXIIIBITION.}

$13 \mathrm{Y}$

JOHN ERIOSSON, LI.D.,

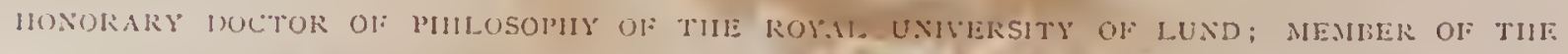
ROYAL ACADEMY OI: SCILNCLS, STOCKHOIAI; MEMIBE OI: TIIE ROYAL ACADEMY OI:

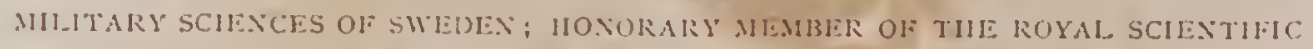
SUCIETY OI UISAIA; ANI MISAIBER OI VARIOUS OTIER SCIENTIIIC MSTITUIIONS IN TEUROIL AND AMERICA ;

KXIGIT COMAANISK, WTH THE RIRAND CKOSS, OI TUE ORUER OI NORUSTJERNAN; KXIIIT COMMANIMR OF DAXIEIRO(; HRST CLASS; KNIUHT COMMANDER OF ISABEI. IA CATOSICA KXIGHT COMMAXEK OF SANCT' OLAF; AND KNKIHT OIF THE ORDIE OI IASA.

- NEW YORK:

PRINTED FOR THE AUTHOR AT “THE NATION" PRESS.

1876. 


\section{INTRODUCTION.}

'The Commissioner's of the Centennial Exhibition having' omitted to invite me to exhibit the results of my labor's comnected with mechanics and physics, a gap in their record of material progress exceeding one-third of a century has been occasioned. I have therefore deemed it proper. to publish a statement of my principal labors during the last third of the century, the achievements of which the promoters of the Centennial Exhibition have called upon the civilized world to recognize.

The nature of the labors referred to will be seen by the following account of philosophical instruments, engines, and other structures described and illustrated in this work -riz: Apparatus for measuring the intensity of radiant heat at given distances. Instrument for measuring radiant heat emitted by concave spherical radiators within exhausted 
enclosures. Instrument showing the rate of cooling of is heated body within in exhausted cold enclosure. Instrument showing the rate of heating of a cold body within an exhausted heated enclosure. Instrument showing the rate of cooling of an incandescent sphere within an exhausted cold enclosure. Instrument for measuring the drinumic: energy developed by radiant heat at different intensities. Actinometer, for measuring the temperature developed by solar radiation. Solar Calorimeter, for measuring the dynamic energy developed by solal radiation. Portable Solar Calorimeter. Parallactic mechanisn, for measuring the in. tensity of radiation from different parts of the solar disc. Instrument for measuring the radiant power of the solar envelope. Instrument for measuring the actual intensity of the sun's rays. Solar. Pyrometer, for measuring the temperature of the solar surface. Apparatus for measuring the radiant intensity of flames. Instrmment for measuring radi. ation from incandescent planes at different angles. Instrument for measuring the radiation from different zones of incaudescent spheres. Calorimeter, for measuring the dynamic energy developed by radiation from fused iron. Apparatus for measuring radiant heat by means of the thermo. electric pile. Barometric Actinometer, for measuring the temperature developed by solar radiation. Apparatus for ascertaining the conductivity of mercury. Concave spherical 
radiator, for testing the accuracy of the solar pyrometer. Instrument for measuring the reflective power of silver and other metals. Rapid-indication Actinometer, for measuring the temperature developed by solar radiation. Apparatus for ascertaining the diathermancy of flames. Dynamic Register, for measuring the relative power of currents of water and vapor. Distance-instrument, for measuring distances at sea. Steam fire-engine, designed 1841. Engines of the United States stemnship Princeton, built at Philadelphia, 1s42. Twelve-inch wroughtiron gun and carriage mounted on board the Princeton, 1843. Iron-clad cupola vessel, designed 1854. Surface-condenser for marine engines, patented 1849, built at New York. Experimental caloric engine, built at New York, 18.̌1. Caloric engine for domestic purposes, extensively introduced in Europe and America. 'The iron-clad turret-vessel Monitor, built at New York, 1861. Turret-vessels of the Passaic class, built at New York and other places, 1862. The Monitor engine, applied to the entire iron-clad fleet of the United States during the war. The tmret-vessel Dictator, built at New York, 186\%. Carriages for heavy ordnance, designed 1861, built at numerous mechanical establishments in the United States. Pivot-carriages of the Spanish gunboats, built at New York, 1869. Rotary gun-earriage and transit platform, built at New York, 1873. Gun-carriage for coast defence, designed 
1861, built at New York. Independent twin screw-engines of the thirty Spanish gunboats, built at New York, 1869. New system of naval attack, published 1870. Movable torpedo, built at New York, 1873. Air-compressor for the transmission of mechanical power; built at New York, 1873. Solar engine, actuated by the interrention of steam, built at New York, 1870. Solar engine, actuated by the inter. vention of atmospheric air, built at New York, 1872.

The foregoing, it should be observed, relates to work carried out by me on American soil. It has no reference. to my labors in England from 1826 to 1839 comnected with locomotion, steam navigation, motive engines, and other branches of mechanical and civil engineering. Nor does it contain a complete elumeration of the original mechanical inventions carried into practice by me in the United States -models of which would have been presented at the Cen. temial Exhibition had its promoters desired me to furnish a record of my share in the progress of mechanical engineering during the last thirty-seven years of the first century of the Republic.

As our space only admits of a brief reference to the mechanical inventions adverted to and not described or illus. trated in this work, the following statement is appencled, furnishing an outline of the principal structures omittedriz: Engines of the twin-screw steamship Clarion, built at 
New York, 18tu, consisting of two vertical cylinders, placed fore and aft in the vessel, actuating the cranks of the screw-shafts by inclined connecting-rods. Vertical single engines, actuating twin screws, built at New York, 1842, applicd to several freight vessels on the Delaware and Raritan Canal. Single horizontal back-action engine, built 1S43, applied to the United States screw-steaner Legaré. Inclined screw-engines, built 1843, applied to the steamship Massachusetts, the steam-cylinders of which were placed near the deck at the ship's sides, secured to diagonal timbers bolted to the planking. Centrifugal suctionfan, built 1843, operated by an independent engine, for producing draught in marine boilers by drawing the air through the furnaces and flues, and forcing the products of combustion into the chimney. Inclined engines, built 1844, applied to the bark Jith, the connecting-rods operating at right angles to each other and coupled to a common crank-pin on the propeller-shaft. Vertical engines, built 1844, applied to the twin-screw vessel Midas (the first screw-vessel to round the Cape of Good Hope), the power being transmitted to the propeller-shafts by vertical connecting-rods actuated by horizontal beams placed transversely under the deck. Vertical engines applied to numerous screw-vessels employed on the coast and inland waters of the United States, the cylinder's being placed perpen- 
dicularly above the propeller-shaft, the comnecting-rods act. ing downwards-a form of engine now employed in nearly all sei-going steamers, but at that time (about 1844) severely criticised by mane engineers. Lingines of the twinscrew ship Mamora, built 1843, consisting of vertical stean-cylinders which, by means of heams working nuller the deck and rertical connecting-rods, imparted inderen. dent motion to the propeller-shafts. Horizontal high-pres. sure and condensing engine of the twin-screw steann-tug $R$. B. Forbes, built 184t, prorided with detached condenser and air-pump actuated by an independent engine-a ressel which, during a series of years, rendered valuable service on the coast of Massachusetts by towing and relieving ships in distress. Compound stationary engine, actuated by rery high pressure, in which the stram was expanded to the utmost extent, elaborately described by Dr. Jarduer, who devoted much time to its theoretical consideration. Horizontal engine applied to the screw-ressel Primero, actuated by a mixture of steam and atmospheric air. Stationary engines actuated by highly superheated steam, the pistons of which were single-acting and thoroughly protected against the injurious effect of high temperature. Experimental street-car, propelled by a double caloric engine. Hoisting machines, actuated by cold compressed air, applied to several warehouses in New York. Small motors, actuated by cold 
compressed air, successfully applied to the sewing-machines of a large establishment in New York, intended to establish the fact that the present injurious physical exertion of sewing-women may economically be dispensed with.

Regarding the descriptions and illustrations of the caloric engines contained in this work, it is proper to observe that they relate only to some of the engines which I have built, at least ten different types, mulike those described, having been constructed and practically tested. Nor have I yet wholly suspended the labors connected with this safe and econonical engine. 'The fact that it requires no water, and that its prineiple is not incompatible with the desirable employment of very high temperature-apart from the important ciremstance that the use of atmospheric air admits of returning at each stroke, by the process of regeneration, the heat not converted into mechanical work during the previous movement of the working piston-justify continued endeavors to perfect this remarkable motor.

J. ERIUSiox.

NEW Yokk, September, 1876. 



\section{CONTENTS.}

CHAPTER PAGE

T.-Transmission of Radint Heat, • . . . 1

II.-Radition á Different Temperatures, • • 17

III.-Intensity of Solate Radition, . . . . 52

IV.-Periodic Variation of the Intensity of SolaA

Radiation, . . . . . . . . . 75

V.-Mechanicat Fnergy of Solar Radition, 91

VI.-Thermat Engrgy transmiteded to the Earth bY

Radiation frong Difenterest Parts of the

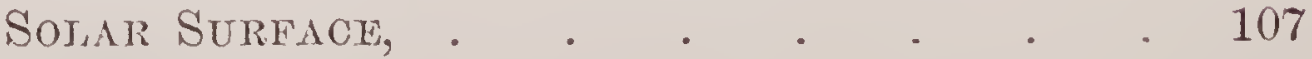

VII. -Tim: Source of Sotan Enfrgy, . • • • • 137

VIII.-Raditring Power and Depth of the Solar

Atrosphere, . . . . . . . 153

IX.-The Feebientess of SolaA Radiation Denon-

S'TRATED, . . . . . . . . . 166 
X.-'Tlemperature or trite Solar Surface,

XI.-Radition from Ixcandesonet Phanes, . . 209

XII.-Radition from INoandeschét Spinzes, . . 220)

XIIT.-Radition from Fused Iron, . . . . 22?

XIV.-Radiant Heat measured by the Thermo-ElacTRIC MFIIOI, . . . . . . 23:

XV.-The 'Thermoheliometer, . . . . . 254

XVI.-Barometric ACtinomitek, . . . . . 266

XVII.-Conductivity of Mercury, . . . . 27j

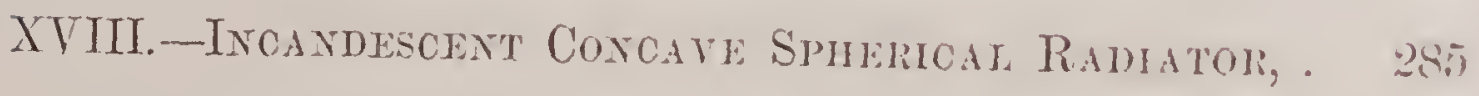

XIX.-Reflectre Power of Shlyet axd othel: METALS,

XX.-Rapid-indication Actinometer, . . . 310

XXI.-Solar Radition axd Diatimemancy of Flames, 317

XXII.-Constancy of Rotation of the Earti INCOM-

PATIBLE WITH SOLAR INFLUENCE, .

XXIII.-Distance Instrument, For Measuring DisTANCES A'T SEA,

XXIV.-The Stean Fire-Evgrne, . . . . . 386

XXV.-The Steanship Princeton, . . . . . 391

XXVI.-TWELVE-INCIT Wrough'T-IRON GUN AND CARRIAGE, 
XXVII.-Apphontion of the Submerged Propeliter for Commeiriat, Purposes, . . . 404 XXVTII.-Iron-chad Steam Batetery, with Revolaving Cupola, submited to EMreror NapoLEOX III., • . . . . . . 410

XXIX.-Sulfach-Condenser, operated by TndepenDENT S'TEAM Powek, . . . . . 417

XXX.-The Caloric Engine- Application of Heated AIr as a Motor, . . . 425

XXXT.-Catoric Exgine for Donleste Purposes, • 439 XXXII.-The Montor System or Irox-clads, . . 460

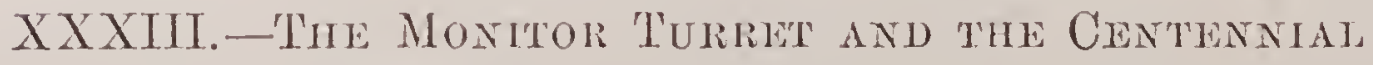

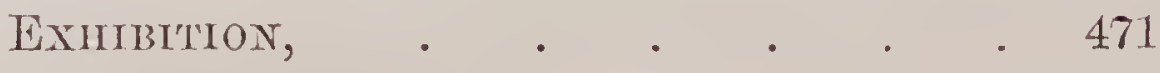
XXXIV.-The Monitor ENgrne, . . . . . 478 XXXV.—The Monitor Dictator, . • . . 492 XXXVI.-The Monitor Turrel and tule Casmate, . 498 XXXVII.-Carriages for Hiavy Ordnance, • . 505 XXXVIII.-Pivo' Carmages of the 'Thméty Spanish Gunbonts, . . . . . . . . 510 XXXIX.-Rotary Gun-Carrige and Transt' Plat'FORM, • • . XL.-Gun-Carriag for Const Defence, . . 521 
XLI.-The Thrme Spanish Gunboat's AND THEIR Engines, . . . . . . 52\%

XLII.-A NEW SYS'EM OF NAVAI ATTACK, . . . 532

XliI.-Submarine Warfare-'Tim Movable 'lorpedo, 540 XLTV.-Transmission of Menanical Power by ComPRESSTED AIR, . . . . . . . 549 XLV.-Sun Power-The Solar Engine, . . 558 


\section{LIST OF PLATES.}

PLATE

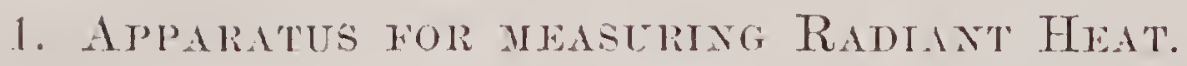

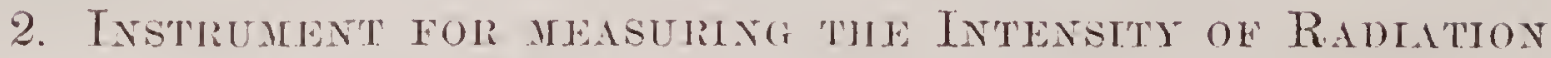
Fron Exclosen CoNCATE Ranhtors.

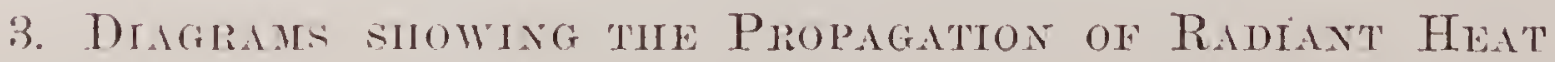
THROUGII SPACE.

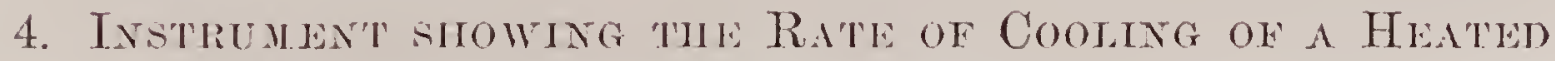

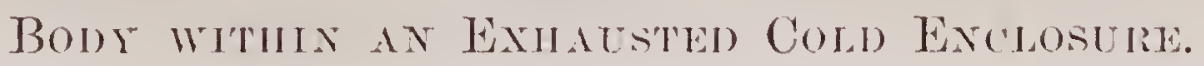

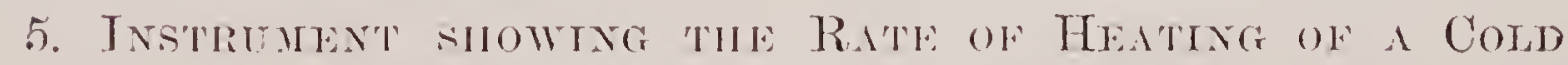

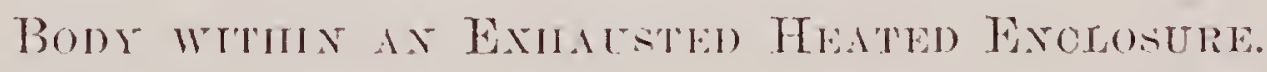

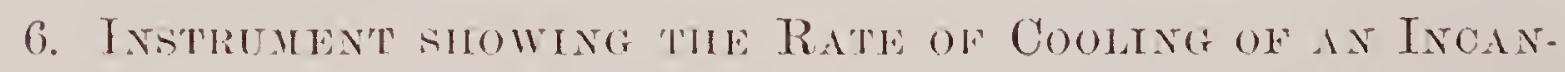

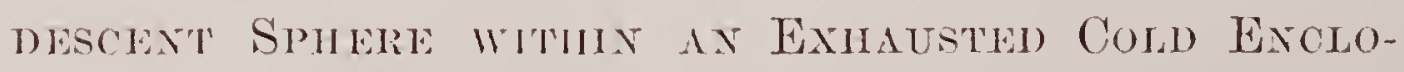
SURT.

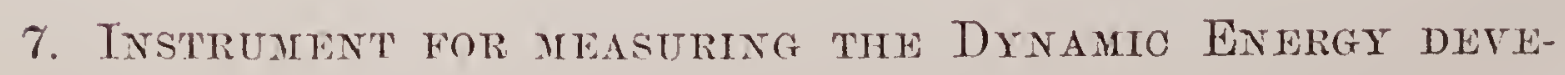
LOPED BY RADIANT HFAT. 
PLATE

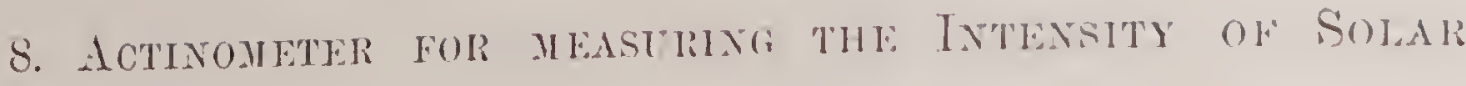
RADATION.

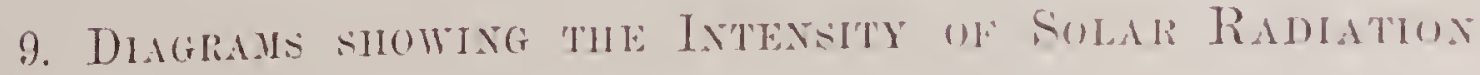

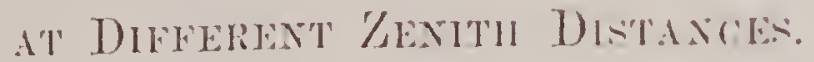

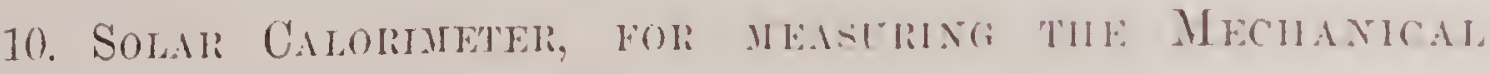
Extegr of Solate Ramatios.

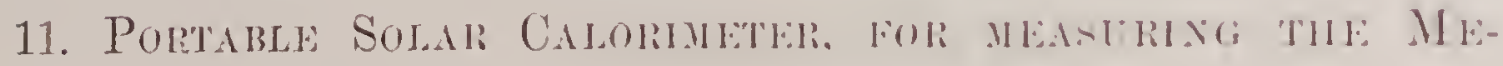

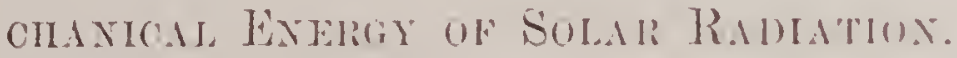

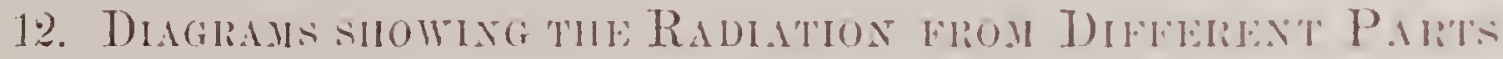
OF THE: SOLAR DISC.

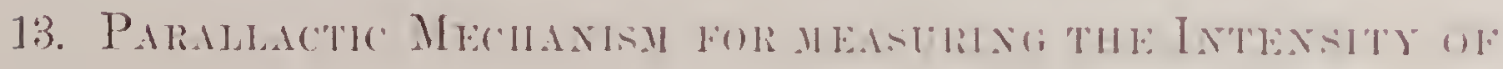

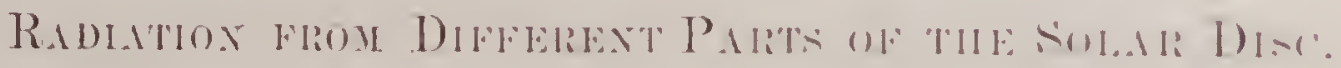

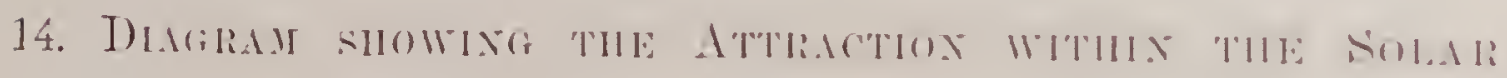

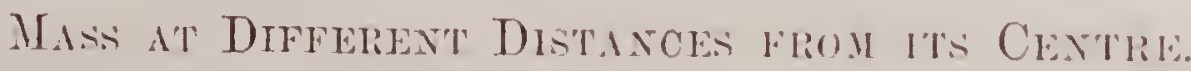

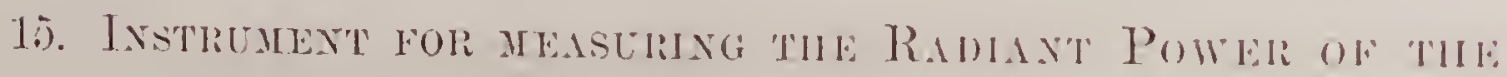
SOLAR ATMOSpHERT:

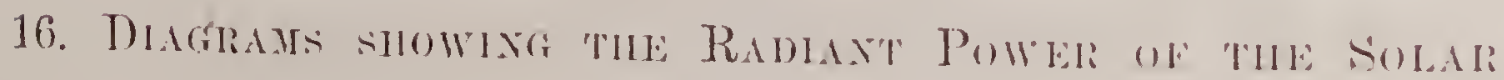
ATMOSPIIERT.

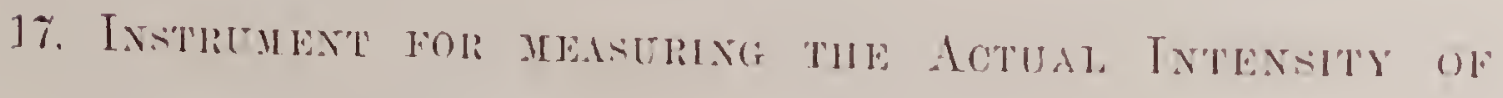
THE SUY's RAYs.

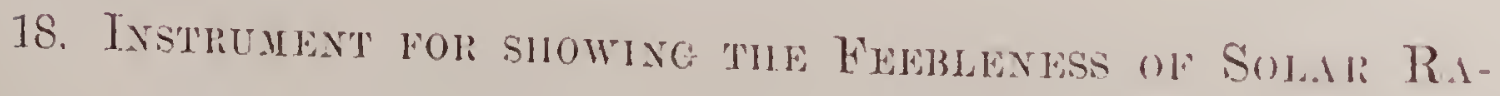
DIATION. 
IISTE

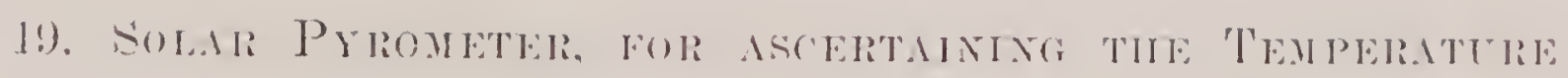

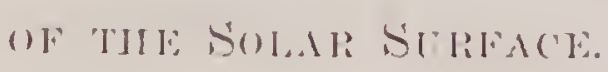

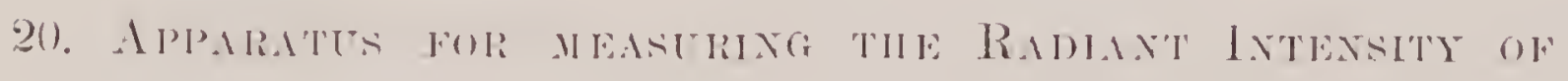
FI... 1 IIS.

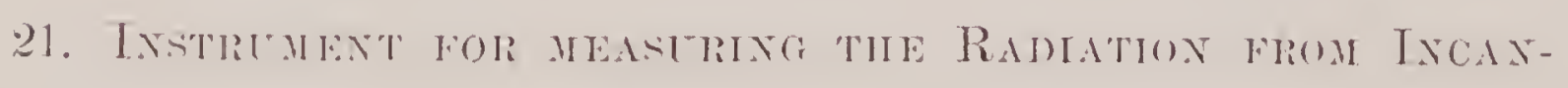

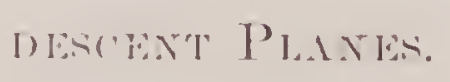

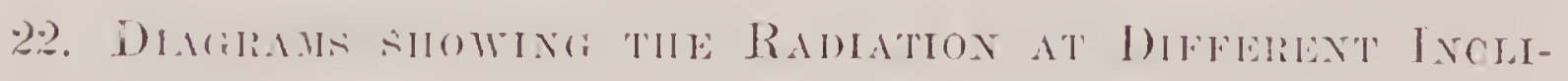

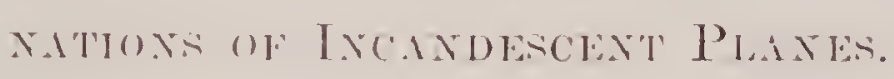

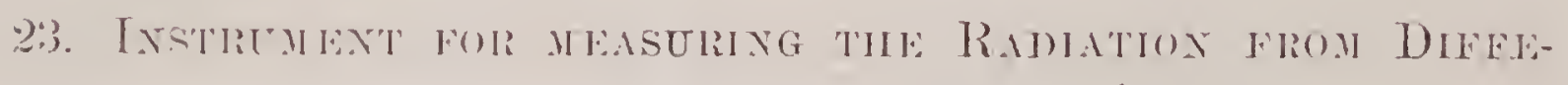

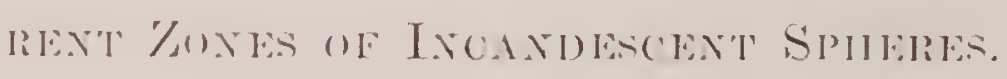

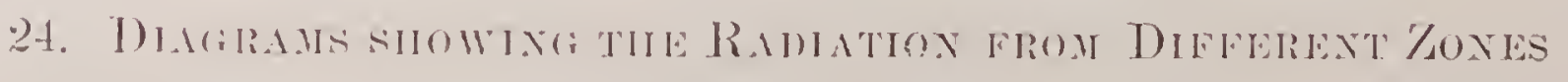

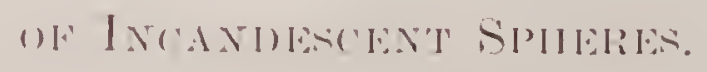

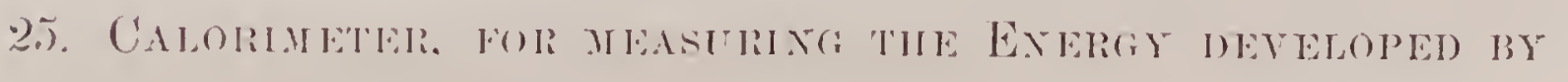

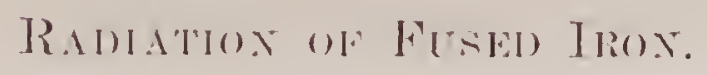

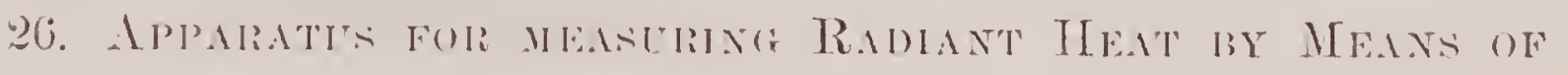

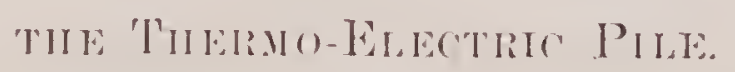

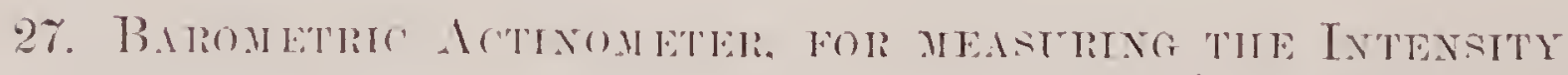
OF SOLAR R.MIIATION.

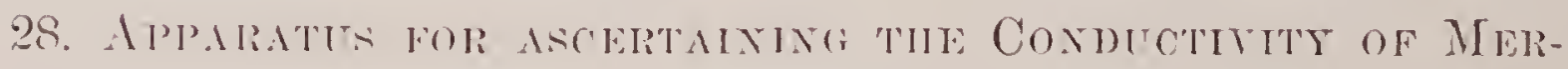
GTY.

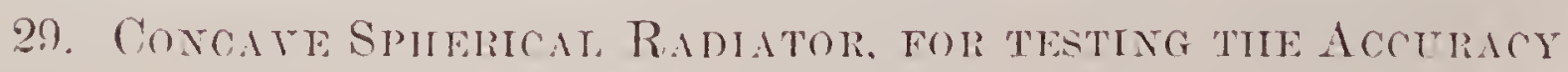
of the Solat Prlometer. 
PLATE

30. Instrumext for masuricg the Reflactre PoWtile of Shlier aND OTHER MeTal.

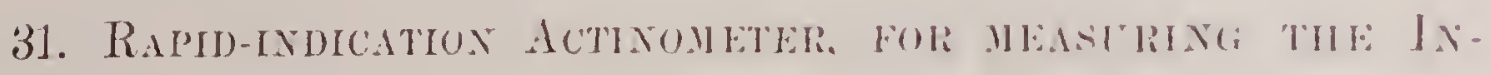
TEASTTY OE SOLAR R.IDIATOX.

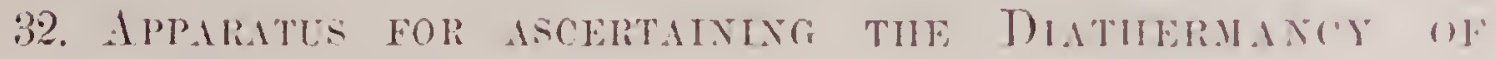
FLAMES.

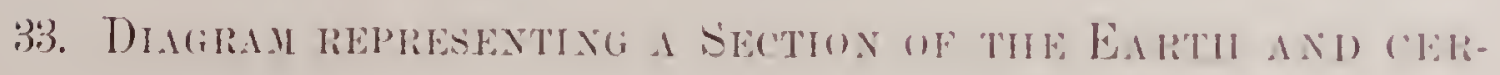
TAIN RIVER B.ISINS.

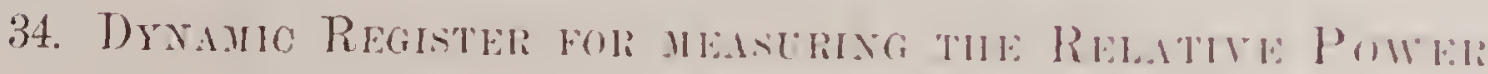
OF CURrexts of WATER ANT Y.APOR.

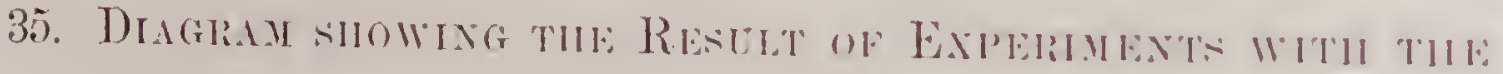
Dyxame Register.

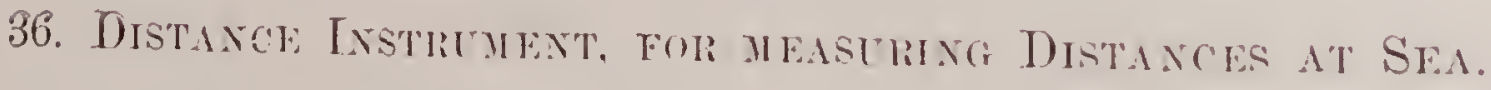

37. Stean Frre-Excine.

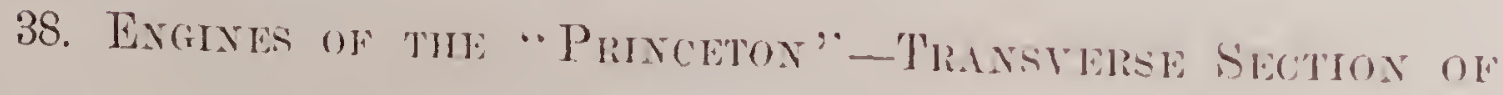
Semi-Cydanderin and Piston.

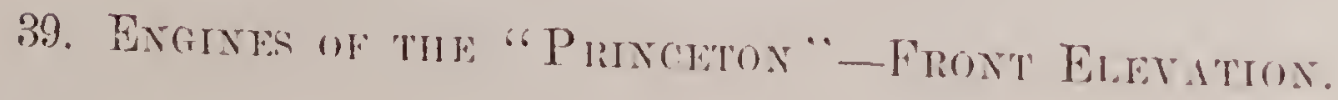

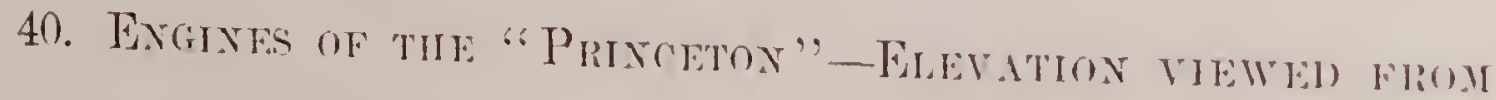
THE STERT.

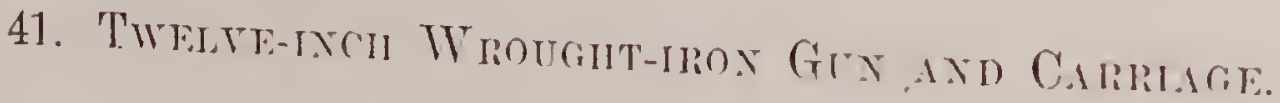

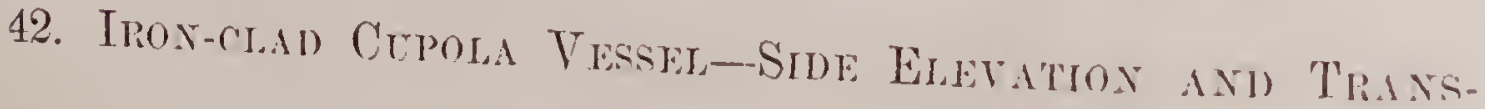
VERSE SECTIOA. 
PLATE

43. Sitrale Condexier.

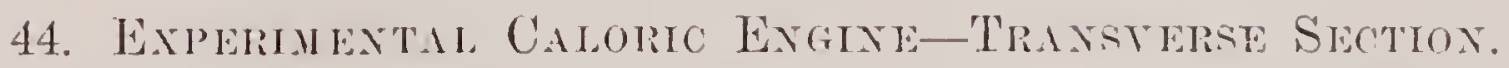

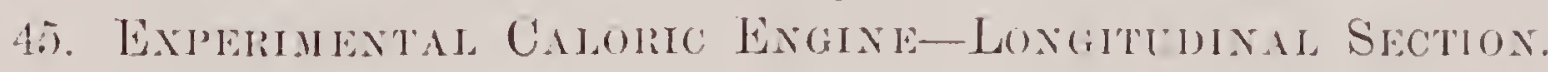

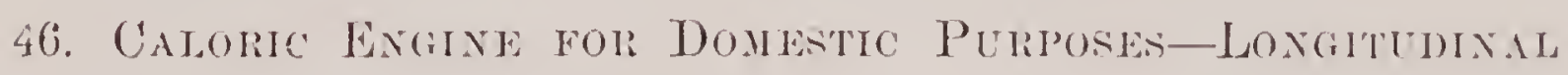
SECTIOA.

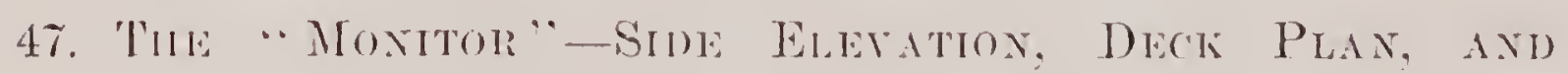

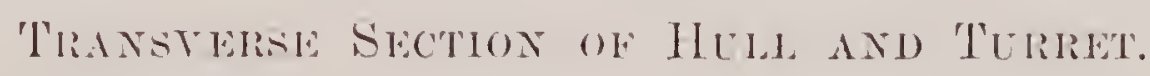

48. MontTol "WREHAWKEN" AT SEA.

49. Moxitor of the "Passale" Ciass-Side Eufration and Thansterse Segrox of Turret and PilotHotsi:

50. 'Thl: Moxitor Exghe-Top Thew.

51. The Monitol Exgine-Front Elevation.

52. Moxitor "Drctator" - Side Elevation axd Deck Plax.

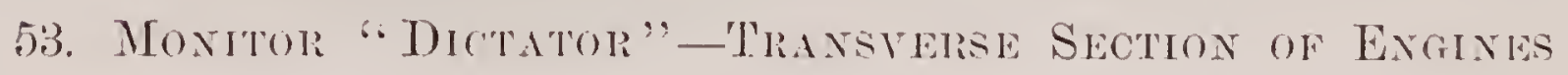
ANI) SHIP.

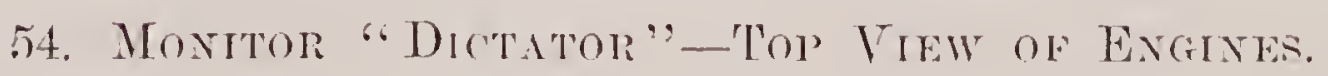

6). MoxtTOR "DICTATOR" ON THE STOCKS, PREPARED. FOR Lationita.

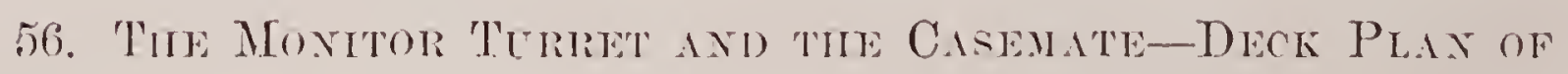
a Monitol: With Two Turrets--Deck Plan of time

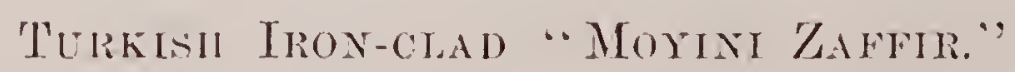


PLATE

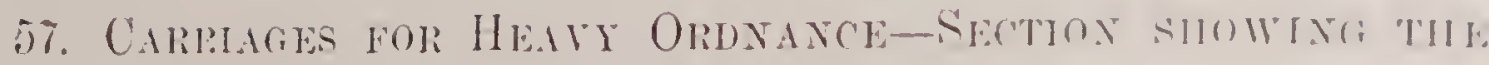

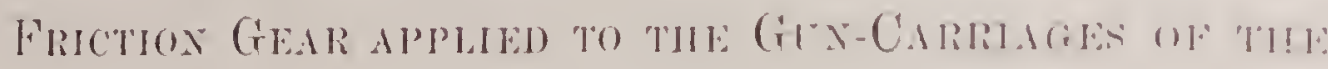

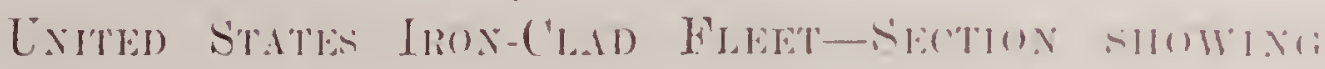

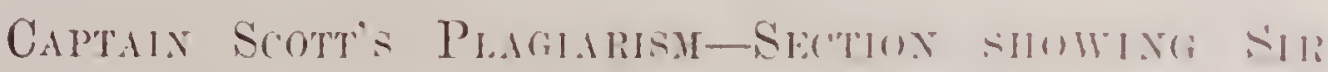

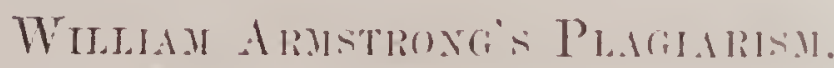

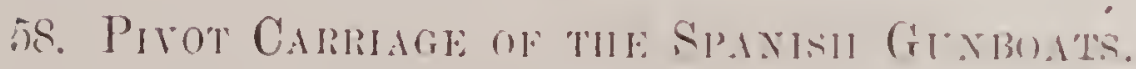

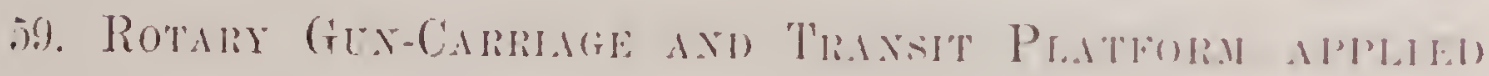

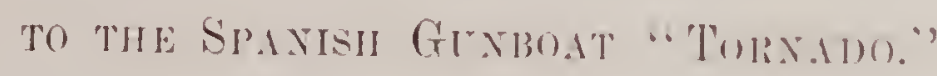

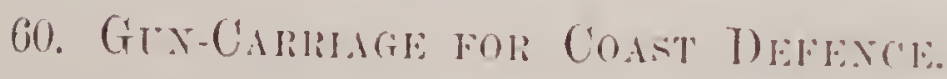

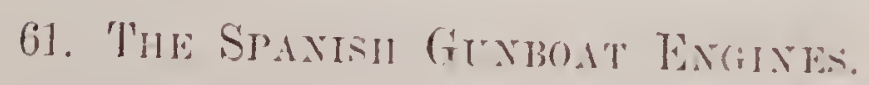

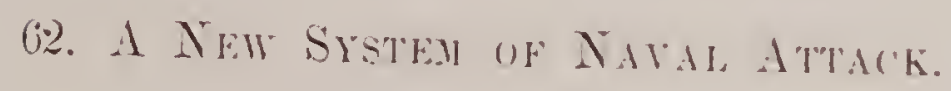

63. Movabis: Torpiono.

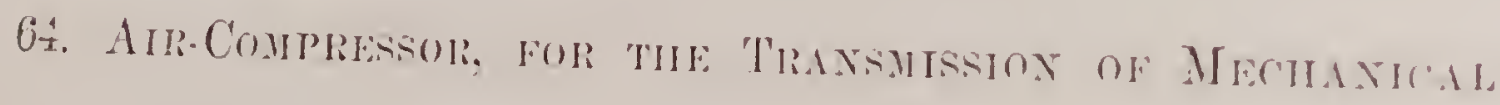
POWh-PERSPCTIV TIEW.

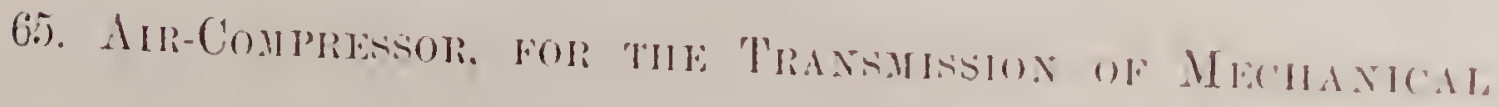

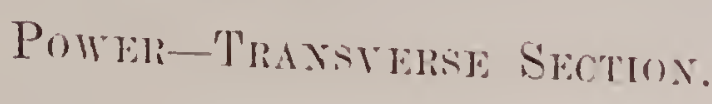

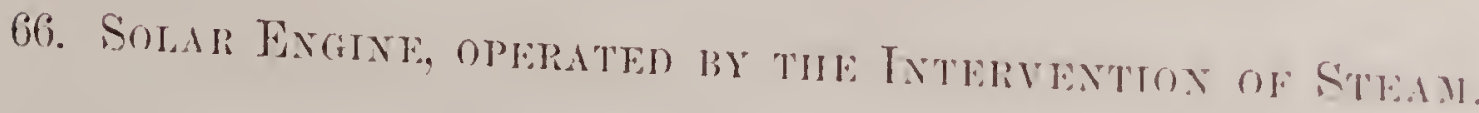

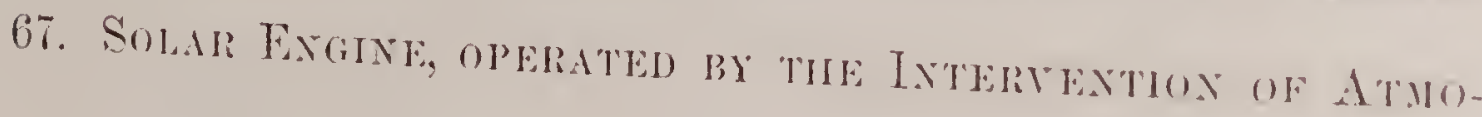
SPIERIC AIR. 


\section{CHAPTER I.}

'TRANSMISSION OF RADIANT HEAT.

No phenomenon connected with radiant heat supposed to have been thoroughly investigated is so imperfectly understood as its propagation through space. The recognized doctrine, which asserts that the temperature imparted to substances exposed to radiant heat diminishes in the inverse ratio of the square of the distance from the radiating body, is true only of a sphere of perfectly uniform temperature at the surface, if the distance be computed from the centre of the sphere. The temperature produced by radiation of spheres which are not uniformly heated at all points of their surface, and of other bodies of whatever form, we have no exact means of ascertaining, although the distance and the temperature of the radiating body be accurately known. Nor will it avail if, in addition to the assumed known uniform temperature and accurate knowledge of distance, we also know the dimensions of the radiator. In fine, notwithstanding our knowledge of these elements, an attempt to solve the problem will be fruitless, 


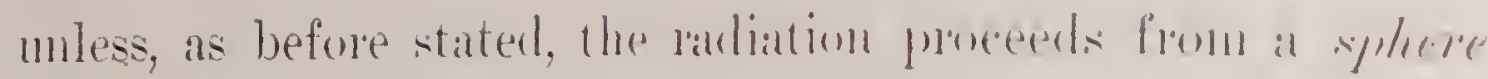

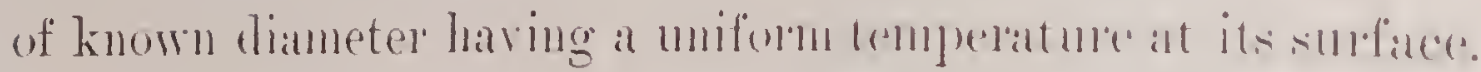
According to Melloni's theory, which Professor Tymall and

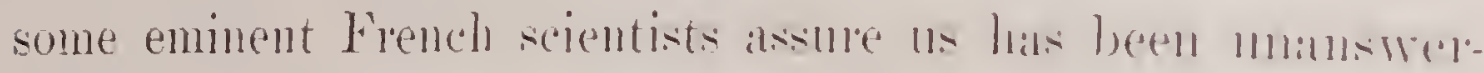
ably demonstrated by the celebnated Italian, the matter is rery simple, namely: the temperature at intermestiate prints

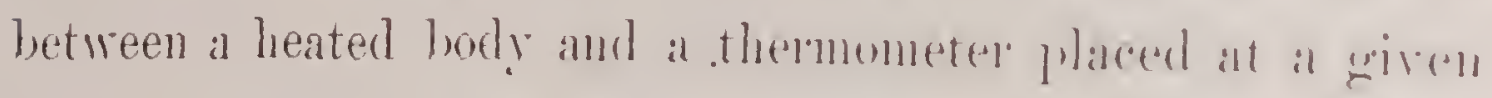
distance, exposed to, and indicating the intensity of the ranliant

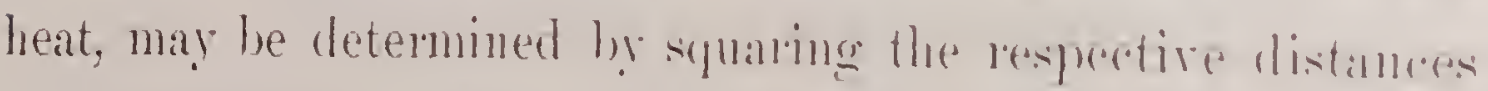
from the radiator: The proluets, it is asserted, will slow the inverse ratio of the intensities, and conserymently the templearat ture at the intermediate points, due to their distance from the radiating surface. The question heing of great priatioal importance, I have examined the merits of Mellonit's now of establishing the infallitility of the mepromeded doctrine that the temperatme imprated to borlies expresed on moliant leat are in the inverse lation of the distances between thes radiating surface and those boties. The illustration shown on the first plate represents an anpallatus comstructed for the purpose of testing practically whether the experiment referred to hy Professon Tymlall in "Heat as a Morle of Motion " really. furnishes positive evidence of the correctuess of Melloniti theory accepted by the distingnished experimentalist ambl by certain French anthors a represents the section of a reed. angular ressel filled with loot water, the face of heing conated

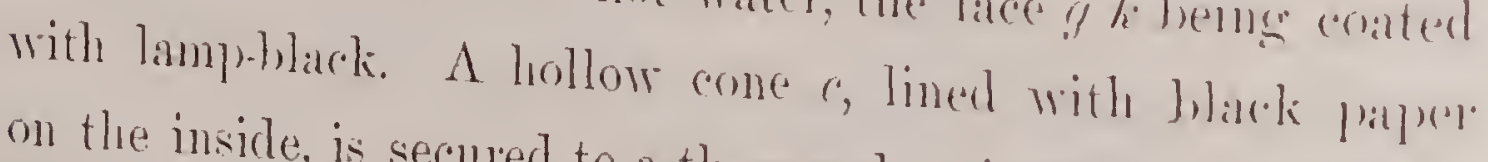
on the inside, is secured to a thermo-electrife pile a', sulplunted by an apdropriate stand shiding in at grome formed at the 
top of anct parallel with, the centre line of the tahle on which the apparatus is placed. It will be evident that this arrangement prevents any change of direction of the axis of the cone which should be right ang!nlar to the heated ressel, during the morement of the pile. Melloni asserts that if the cone $c$ he mored towalds the heated ressel, say to the position b, the needle of the galvinometer comnected with the pile will remain stationaly. His accepted reasoning defining the law which governs the trunsmission of ratiant heat being based solely on the correctuess of this assumption, I have carried ont an elaborate series of experiments to ascertain if the needle of the galvalometel remains absolutely stationary as shown by Prof. 'Tymalll dning the exhibitions at the Royal Institution, mentioned in his work on heat before allucled to. The result extablisles the fact most positively that the neelle does not remain stationary as assmmed, and that the deflection which thes place increases considerably as the pile is alvanced torards the heated ressel. That such shouk be the case will be evident on dne reflection. A careful inspection of the diagram shows that, because the points a and d of the radiating surface are not equidistant from $c^{\prime}$, the radiant heat which they emit cammot affect the face of the pile alike. The extent of the irregularity may be approximately deter. mined by squaring the distances $g a^{\prime}$ and $d c^{\prime}$. Now, the proportion of these distances, as shown by the diagram, is 20 to 19 , hence the radiant heat transmitted to the pile from the points ! and d will rary in the inverse ratio of the products of the stated mumbers, vi\%: ats 361 to 400 . In view of 
this great difference of intensity of the heat transmitted to the face of the pile from different points of the rarliating surface, the readers of "Heat as a Mode of Motion" may with propriety ask if the intensity indicated by the galvanometer comnected with the thermo-electric pile during the reported experiments at the Royal Institution was that due to the radiant heat transmitted from y in the line of of $c$, or that transmitted from $d$ along $d c^{\prime}$.

On thenretical grounds, therefore, Mellonis demonstration is quite unsatisfactory. Several imperfections of a unacticil nature, inseparable from the methor arlopted by the ltalian physicist, demand consideration, all tending to agroravate the theoretical defects. The black paper which lines the inside of the hollow cone b, being very light and incaplahle of reflect.

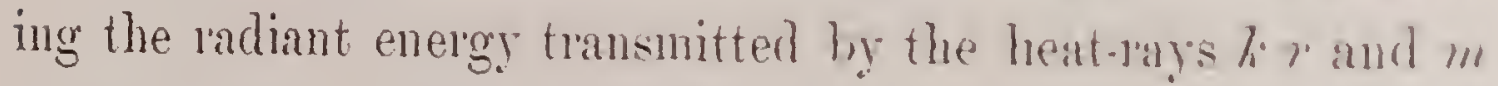
$o$, will at once become heated, consequently the air contained within the cone will speedily have its temperature raised by convection. The heat thus received will ralliate towards the face of the pile and thereby contribute to disturb the indi. cation, already seriously affected by the difference of temperature consequent on the rarying intensities of the radiant heat transmitted. The relative intensity imprated to the black paper within the cone l, and that transmitted to the pile li. may be ascertained by squaring the length of the heat-rays $d o$ and $d b$. The diagram shows that these lengths are an 3 to 5 ; hence, by squaring and inversion, we find that the temperature imparted by the radiant heat at o will be greater than that at $b^{\prime}$ in the proportion of 25 to 9 . Black paper 
being a powerful radiator, while air has very small specific heat, it will be perceived that the rolume within the cone will rapidly beeome heated by convection, as alrearly stated, and therefore the temperature of the face of the pile will be elevated to a rlegree far beyond that which it would attain by the direct radiation of the ressel a. Before presenting a demonstration proring the fallacy of Melloni': assertion, that the temperatures imparted to bodies exposed to radiant heat are "inversely as the square of the distances letween the radiating surface and those bodies," I propose to give a detailed statement of the elaborate experiments before adverted to, instituted for the purpose of showing mactically that the assertion which forms the basis of the accepted doctrine is false, and that the hollow cone c camnot be moved to the position b withont increasing the deflection of the needle of the galranometer connected with the thermo-pile. It has alrearly been stated that, in order to insure perfect parallelism during the movement, the stand which supports the cone and pile slides in a groove parallel with the table on which the radiating ressel $a$ is placed, and at right angles to the face of the latter. A scale h, divided into inches, is attached to the side of the table for the purpose of showing the distance between the pile and the ressel ", the face of the latter coinciding with the zero of the scale. The mode of conducting the experiment will be seen by the following brief explanation. The hollow cone $c$ was placed so that the vertical line of the face $c^{\prime}$ corresponded with the last division of the scale, a screen being introduced for the purpose of shutting off the radiation 
from the blackened fice of the ressel "l. Maintaining the watel in the latter at a constant temperatme of $1: 30^{\circ}$ ahove that of the surrounding atmosphere, it was fomml on remoring the screen that the needle of the galramometrom mored 4.7 dege. from zero during an interval of 30 seconds forme the moment, of exposing the fince of the pile to the ratiater. 'The vessel a was then removed and andied into an anjoining romen to

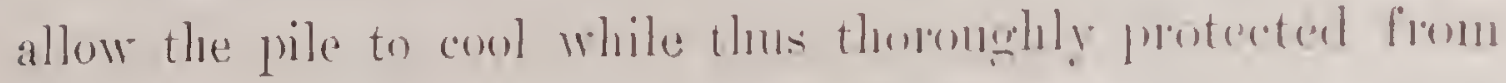
the radiation of the heated vessel. In the meamime, al spiritlamp was applied moler the rensel in order to make gond the heat lost during the precerling "peration. Sulticount fime having elapsed to allow the pile to cond, the vescel was again

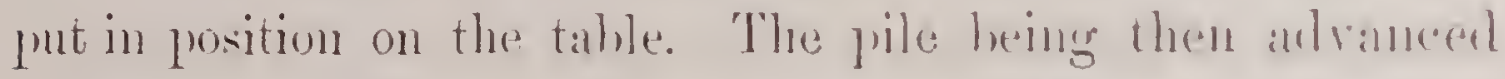
to the 10th division, and the serees withlrawn, the nexelle: moved 5.05 deg. from zero in the sime time as lufore, vi\%, 30 seconds. The ressel mas remored at thirl time into the adjoming romm, the temperature raked to the lixed point, the pile allowed to cool, and the vessel placed in position as before. The pile being now adrancerl to the jh division on the scale, and the screen laised, the nealle moved 5.5.) deg. from zero in the stipulated time of 30 seconds. It will be seen then that, so far from lemanimg stationary, the deflection of the needle of the galvanometer incleases very conl. siderably as the pile is advanced towards the radiator. The. important fact remains to be noticed, that the needle conti. nues to move rapilly after the expiration of 30 seconds from the time of exposing the pile to the radiator ; a circumstance furnishing additional evidence of the montisfactory nature of 
Melloni's method. In onder to ascertain the exact extent of deflection of the needle, refered to, 1110 distinct sets of expeliments were male, the mean result of which is exhibited in the accompanying table. The position of the needle of the

\begin{tabular}{|c|c|c|c|}
\hline \multirow{2}{*}{ True. } & \multicolumn{3}{|c|}{ Distance and Defieftion. } \\
\hline & 20 ins. & $10 \mathrm{ins.}$ & 5ins. \\
\hline Seconds. & Iteg. & Deg. & Deg. \\
\hline 30 & 4.70 & 5. (5) & 0.5 .5 \\
\hline 60 & 4.30 & 5. $(x)$ & (6.75) \\
\hline 90 & 4.50 & 5.70 & 8.25 \\
\hline 120 & 4.75 & (i.2i & $10.1 \%$ \\
\hline
\end{tabular}

galranometer, it will he seen, was recorded at the expriation of $30,60,90$, and 120 seconds. $\Lambda$ glance at the table pioves the correctness of the objections previons? laised against the detail of Melloni's al'rangenent, especially the disturbing influences of the rays projected against the interion of the cone from points beyond the area whose radiation is supposed alone to affect the pile. IIrring thus practically shown the fallacy of the assumption on which the Italian physicist bases his ductrine, I will now prove its mommolness ly the process of demonstration. For this pmpose let us suppose that an incandescent cylindrical block 7. (see illustration Plate 1) connposed of cast irom. 6 inches in dianeter, be suspended at such a height that its axis passes though the centre of the bulb of a thermometer m, held hy a hracket $m^{\prime}$ sliding in a groore 
similar to that formed at the opposite end of the table, before described. A scale n, divided into eguall partes, is attached to the side of the table, the zero of this scale concinling with the vertical line drawn from the face of the incandescent cylin. drical block l; while the last division corresponds with the vertical line passing through the centre of the bull of the thermometer $m$. Actual trial shows that, if the incandescent iron block be suspended while its temperature is $1,2000^{\circ}$, the thermometer exposed to its radiant heat will indicate $2.2^{\circ}$ above that of the surrounding atmosphere when the block has conled so far that its differential temperature las become renduced to 1,000. Now, agreeably to Melloni's doctrine, the thermometer $m$, if advanced to the 10th division of the scale, will indicate a differential temperature of $\frac{20^{2} \times 22}{10^{2}}=88^{\circ}$; if advanced to the 5th division, $\frac{20^{2} \times 22}{5^{2}}=352^{\circ}$; if further advanced to the $2 d$ division, $\frac{20^{2} \times 22}{2^{2}}=2,200^{\circ}$; and, lastly, if advanced to the 1st division on the scale, the thermometer will indicate an intensity of $\frac{20^{2} \times 22}{1}=8,800^{\circ}$. The temperature of the incin. descent radiating block being only $1,000^{\circ}$, we have thus demon. strated the utter fallacy of Melloni's theory, based on the result of imperfect experiments with hollow cones and thermopiles exposed to radiant heat. In view of the foregoing facts writers on radiant heat will do well to expunge this erroneous theory from their works. Practical men, not suspecting that the law of inverse squares is inapplieable to short distances, frequently 
commit selous mistakes in calculating the effect of placing incindescent bodies at certanin distances firom structures intended to be heated. But Mellonits levice, although incar fahle of elucilating the principles which govern the trinsmission of maliant heat, posiensen grealt value, as it proves

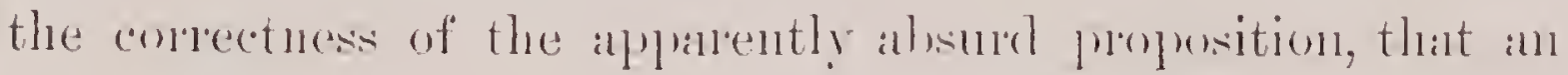
increase of the surfice of a radiator is cappilble of elevating the temperature of a substance exposed to ladiant heat with. ont increasing the temperature of the radiator. 'The innortance of this finct cannot well be orerstated. It contradicts cortain molern speculations rogarding radiant heat, and it aftorkis a landmark which, thongh it does not point out what we seek, guands against taking the womg course.

'The defects of Melloni's method, and its madequacy to solve the problem under comsideration, suggest the question: Is it prossible to determine, by calculation, what temperature substances will acquire by being placed at valrous distances from the surface of a heated boly of known temperature and dimensions, the sides of which ance straight and parallel ? We are compelled to adnit that tle question thus juesented cammot be satisfactorily answered, because cach point of the racliating surfice, in consequence of varying distance, transmits a different degree of intensity to the exposed substances. 'The difficulty of solution is increased on account of the stipulated form; the inferior intensity transmitted fiom the corners of the ratiator rendering the question exceedingly complicated. A radiating plane surface of circular form somewhat simplifies the question; yet the lifficulty remains of doiling with the 


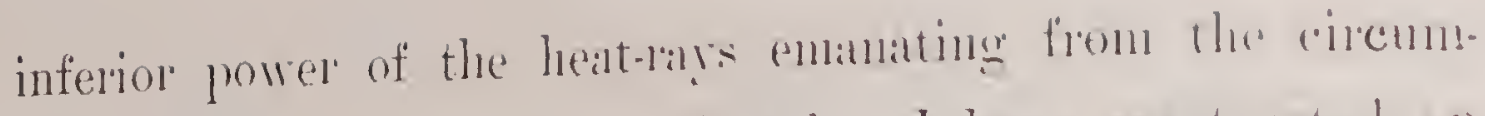
ference. 'To arereone this dithenlty, I lisve constructed an

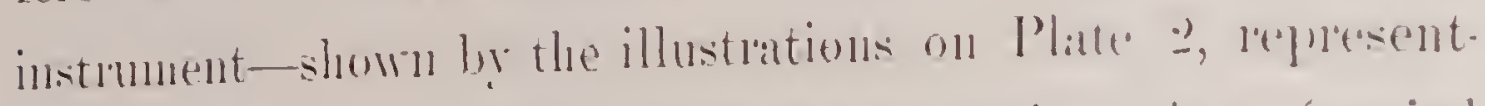
ing a longitudinal section and a pelspertive riew (copreal from a photograpls)-in which the radiating sulfiree is cont(ave, folming latrt of a sphele whose centlis is situated nealle

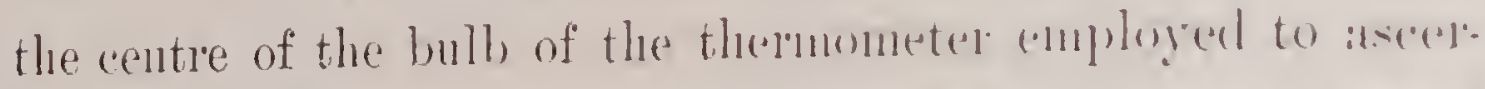
tain the intensity of the ralliant leat. But this experlient of employing a concare spherical smofice, erery [kint of which is equidistant from the bulb of the themenometer, flerents any change of distance between the same and the ramliatule dming experiments. I hare accomblingly intoduced fom dis.

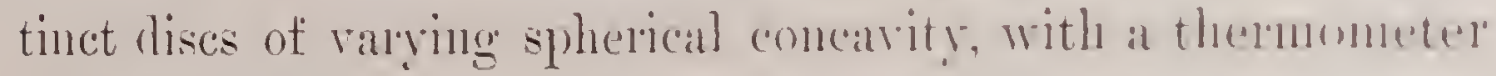

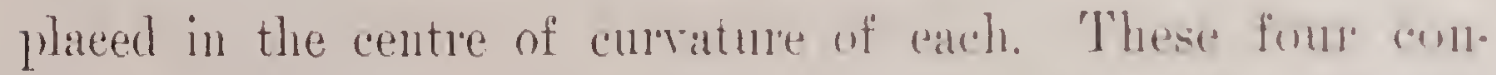
cave discs form the sides of an then resel filled with nil,

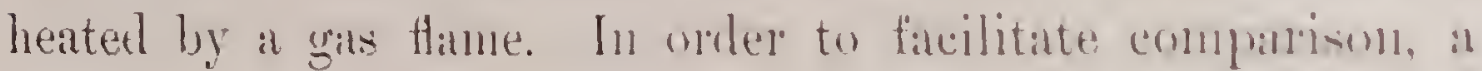
regular gradation of curvature has been ardonted; the latclius of the deepest concarity being 3 in., the next being 6 in., then $9 \mathrm{in}$, and, lastly, $12 \mathrm{in}$. for the least concavity. It will be evident that, owing to the difference of curvature, each disc will present a different extent of radiating surface, if a uniform size be employed, thereby rendering comparisons be. tween the indicated intensities quite laborious. To obriate this, the diameters of the several discs have been so proportioned that the superficial measurement of each is precisely alike. The disc of the least cmrature is 4 in. in dianeter; the remaining three being respectively $3.982 \mathrm{in.,} 3.939 \mathrm{in.}$ and 3.757 in. diameter. Much pains has been bestowed on the 
workmanship in onder to obtain concavities of precisely equal areas. The objections raised in subsequent chapters against conducting experiments with the solar calorimeter and actino. meter in the presence of the disturbing influence of the sur. romuling air, apply with equal force to the apparatus now heing considered. Accordingly, the heater, with its four concave radiating discs and thermometers, are enclosed in an exhausted chamber, as will be seen by reference to the longi. tudinal section. Evidently, the heat reflected by the sirles of this chamber towards the bulbs of the enclosed thermometers, will determine their zero precisely as in the instruments referred to; hence, it is indispensable that this chamber should be maintained at a constant temperature. This is effected hy surrounding the same with an extermal open ressel filled with water kept at a temperature of 60 deg. Fahr. during experiments. The object of adopting 60 deg. is that of facilitating comprarisons with solar intensity, the zero of nyy actinometer being also (io) deg. above Fahrenheit's zero. Let us now consider briefly the leading properties of the illustrited device. In the first place, the radiating concave surfaces, as well as the bulbs of the thermometers, are surromeles by the ether alone, and therefore cammot suffer any loss of heat by conrection. Secondly; the intensity of the radiant heat received from all prints of each concave surface will be precisely alike, becanse those points ane acquidistant from their respec. tive thermonneters. Thirdly; the concave surfaces presenting equal areas being composed of the sime materials of miform thickness. and heing heated by the same medium, will enit 


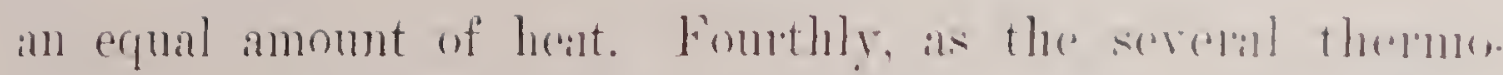

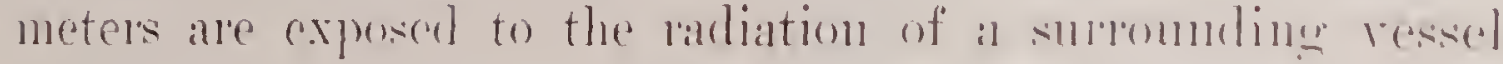
kept at 6 in dege., they will arequire that temperatme before fire is applied to the heater. In conserquence of this. the increase of temperature, after heating, will finmish a true comm. parative measure of the energy of the lad lant heat transmitted from the concare radiator's to the hultes of the thermonester's.

The prevailing opinion that there is a concentration of heat in the forens of spherical ratliatora, will be mreed als an objection against the described methor of measuring landiant heat. A careful eximination of this question will therefore be necen. sary. Fig. t, Plate be represents a concalve splerical radiator. o being the focus, $n$ o the axis, and a b a section of the riuliator.

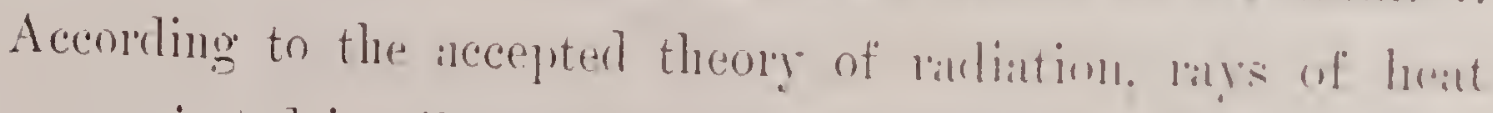
are projected in all directions from erery print of the rulliat. ing surfice. In order, therefore, to demonstrate that there is no concentration of heat in the focus. we hase merely to draw radial lines representing the heatrays from proints do and f on the concave surface, as shown on the diagram. It will be seen on close examination that there is only a single las? $d c$ emitted from the point $d$, which is lirected tomands the focus $c$; the ray $f^{\prime} c$ being the only one directed from the point $f$. The other heat-rily from the points $d$ and $f$ diverge in all directions, and interect every part of the fiold la: ?; thus dispersing the radiant heat nomply miformly over a very large surface. The curve on, struck from the point f', clearly shows that all the heat-rays below c, projected from ff, are shorter than those directed to the focus from the silns proint. 
and therefore impart a higher temprature to the plane to 7 than that transmitted to the forms. It will be needless to enter on a detailed computation of the temperature at the intersections of the valrions rays with the plane $k l$, an a mere inspection of the diagram distinctly shows that the forms a receives no increase of heat on account of being the centre of the spherical randiator. Indeed, if we substitute a flane circular disc extending from a to b, a greater amomt of licat will be transmitted to a thermometer placed at $c$, than with the spherical surfice represented; the only important difference between a pline and a concave radiator being that a thermometer placed in the focus of the latter receives an equal degree of heat fiom anch point of the concave surface.

Investigations conducted by means of the illustrated instrument prove that the intensity of heat transmitted by the racli. ation of concare spherical surfaces of equal temperature, presenting equal areas and haring different curvature, is in the inverse ratio of the square of their radii, provided the sub. stance which receives the raliant heat is placed in the focus of the radiating surface. This inportant fact in connection with the previous demonstrations showing the fallacy of the propounded doctrine that the intensity of radiation diminishes in the inverse ration of the square of the distance, between plane radiaters and the recipients of their radiant heat, enables us now to consider the proposition contained in our introductory remarks, vi\%. that the assumed lan is trie only of a sphere of perfectly miform temperature at the surface, if the distance to the recipient of the radiating hat be computed 
from the rentre of the heated sphere. Suppose that s, Fing. 5) represents a solid sphere of metal minintained at a comstant temperature and suspended in the centre of an exhmusted

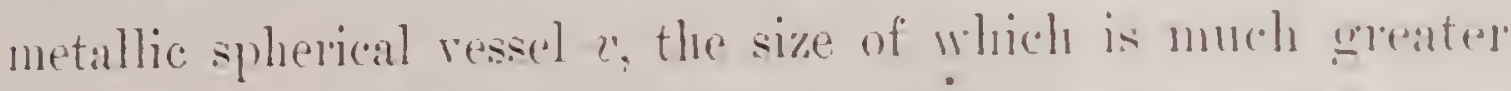
than that of the solid sphere: a and " l being latial lines

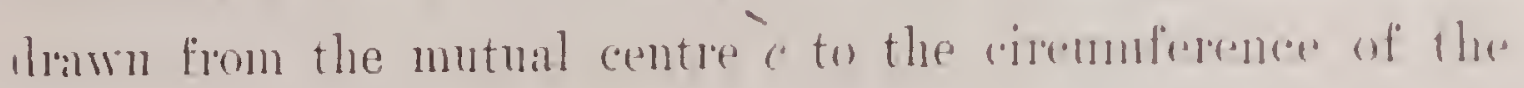
exhausted ressel. The heated splere heimg maintained alt at uniform temperature while the spherical resorel is exhlumstenl. and therely freed from any distmbling influemere of intermal currents of air, it will he erident that the internsits of radiant heat, thus transmitted from the sphere thromeh the ether alone.

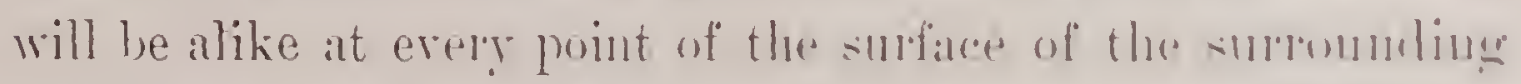
spherical ressel. It needs no demonstration to pure that the temperature resulting form radiation against the lattog will be less than that of the central sphere in propurtions to the area presented by each. In other words, the humprature will be inversely as the areas of the two sylieres. On the sumduess of this proposition depends the correctuess of the alecepted doetrine relating to the propagation of lieat and light through space. The remarkible fact must not be orelookerl, that this proposition takes no cognizance of llistemes: and that it enables us to determine the temperatme of the surrounding sphere if we know the temperature of the central one, merely hy companing their relative areses, hasing our computation on the proportion they hear to each other ; the interrening space, whether it he 1 mile, or 1,000 miles, being an element exclubled from om calculation.

That rays of light and heat meet with no appreciable 
resistance in their passigge through the ether is an irresistible inference to be drawn from the fiact that the intensity bears at direct proportion to the aree oree which the rayss are dis. persed. The common expression that "the intensity of light and heat varies inversely as the square of the distances" leads to the supposition that distume is an elenent to be taken into account in estimating the intensity of radiant heat. That this is an aror will be rearlily perceived if we reflect on the fact, just referred to, that the intensity of the rays diminishes in the exuct proportion to the areas over which they are dispersed. It is self-evident that if distance, per se, in any way affected the question, the intensities could not thus depend solely on the extent of the areus over which the rays are diffused. Much misapprehension would be prevented if the law relating to radliant heat were thus expressed: The inten. sities are inversely as the areas over which the rays are dispersed. Sir Isaac Newton, referring to the intensity of the sun's radiant heat at different distances, thus clearly defines the question: "The heat of the sun (at various distances) is as the density of its rays." He also states that the densities of the diverging rays are "reciprocally as the square of the distance from the centre of the sun," a fact which obviously has nothing to do with the main proposition, as it simply results from certain geometrical relations, viz, that the areas of transverse sections of a cone are as the square of the distances from the apex.

I will now briefly show why the theory of Newton, sup. posed to have been proved by Melloni, is true, under certain 


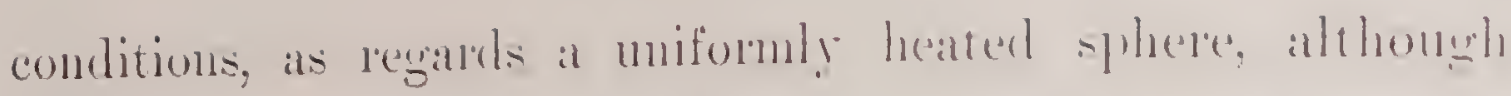

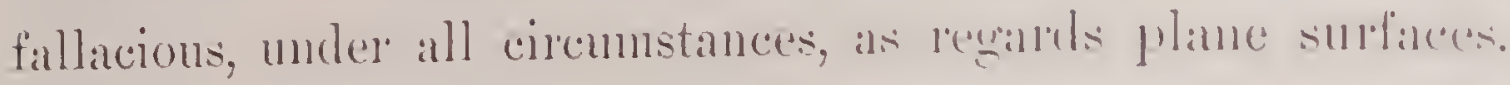
Referring again to Fig. j, let us assmue that the spllere s repuresents the sun, the semi-dianeter of which is t:2(i,2):-2 miles; and that $a b v$ represents the earthis ondit redinced to a circle whose radius corresponds with the cantlis mean distance from the sun's centre, vi\%, 91,400,000 miles. Now, the are $e f$ is to the arc $a b$ as the ladial line $c e$ representing the sun's ladius, is to a a, representing the cantli's distance form the sum's centre. According to the stated dimansions, there. fore, $c$ e is to $c$ a as 1 to $214.4 t$; hence, lengalling a c l as a cone of vely small base, the area of $e f$ is to that of 1 l, as 1 (o) the square of $214.4 t=45,984$. Accordingly, the tempreature of the heated central sphere s will be t.j,9st times grealtel than the temperature which it imparts by radiation to the surrounding sphere a l 2 .

We have now fully estublished the fact that, althongh the extent of the radiating and recipient surfaces, in connection with the temperature of the former, determines the temperarture transmitted to the latter, wholly independent of distance, yet, as regards the sun, it is true that the temperature pro. duced by the radiant heat of his rays is inversely as the square of the distance from his centre, the same law applying to all spleses having a miform temperature at the surface. 


\section{CHAPTER II.}

RADIATION AT DIFEERENT 'TEMPERATURES.

Sir Isanc Newtor supposed that a heated body would lose by radiation at each instant a quantity of heat propor. tionate to the excess of its temperature above that of the surrounding medium. Modern physicists, basing their reasoning on the result of MM. Dulong and Petit's experinents, contend that Newton's supposition is erroneous. Prof. Balfour Stewart in his "Elementary Treatise on Heat," published at Oxford 1871, in support of his assertion that Newton's doctrine is false, presents the following extract from the rork of Dulong and Petit:

Excess of Temperature of the Thermometer.

${ }^{\circ} \mathrm{C}$.

240

220

200
Velocity of Cooling.

${ }^{\circ} \mathrm{C}$.

10.69

8.81

7.40 
Excess of Temperature of the Thermometer.

o 1 . 180 160

140

120

100
Velocity of Cooling.

${ }^{\circ} \mathrm{C}$.

(i.10)

4.89

3.88

3.02

2.30

1.74

"We see at once from this table," says the anthor of the "Elementary 'Treatise on Teat," "that the Jaw of Newton does not hold, for according to it the velocity of conlines fur an excess of 200 degr. shomll he precisely domble of that for an excess of 100 deg.; now we find that it is more than three times as much." "The rate of conling exhihiterl in this tathlo being at valumce with the laws which govern the cunision and absorption of radiant heat, I have instituted a series of experiments in order to test the correctness of the tabulatod rates accepted by Prof. Stewint. The initiny proceeding of the investigation was that of ascertaining the late of cooling at temperatures below $200^{\circ} \mathrm{F}$, for which purpose I constructer the apparatus shown on Pl. $t$, Fig. 1, representing three concent. tric spherical ressels placed within each other. As the llaw ing shows the dutal of the untire mechanism, a bref descrip)tion will suffice. $a$ a is a spherical ressel 7 inches in diameter, applied within an exterior casing b. A spherical radiator c, t inches in diameter, composed of rery thin copper, and coated with lamp-black, is sustained in the contre of the splierical ressel a by means of two rertical tubes 7 and $m$, composed 
of very thin netal, communicating with the interior of the rad liator. The upper tube is large enough to adnit the bulb of a thermoneter, the lower one being only sufficiently large to accommodate a small axle, to which is attached a pardllewheel provided with curved paddles arranged in such a manner that the bulb of the thermometer miny be inserted consider. ably beyond the centre of the sphere, as shown in the illus. tration. The external casing $b$ is provided with nozzles g and d, to which tubes are attached for circulating cold water through the intervening space during experiments. The an is exhausted from the spherical enclosure a a through the tube li, which passes across the said intervening space. 'The radi. ating sphere o being filled with water, it will be perceived that the centrifugal action of the padilles of the wheel applied within wili produce a continuous current from the centre towards the circunference, the fluid successively passing over and coning in contact with the thin splerical shell, then returning to the centre to be again thrown off by the centrifugial action. The rotary motion of the water thus kept up without intermission round the cylindricil bulb of the thermometer', will evidently render its indication prompt and reliable. It is hardly necessary to observe that the rapid presentation of fresh particles of water, promoted by the action of the padilles, will effectually prevent the reduction of temperature proceeding fister at the circunference than at the centre; lence the radiation at the surface will, in rirtue of the continuous interchlamge of particles, affect alnost simul. taneously every molecule within the sphere. It will be seen, 
therefore, that the total energy of radiation will be remelered arailable in reducing the temperature of the contents of the radiator, and that the central thermometer will inclicate, at every instant, the precise degree of temperature of the entir. mass. It might be supposed that the motion of the watter within the sphere, consequent on the action of the pardillewheel, would produce an elevation of temperature sufficient to render the indication of the themometer inaccurate. Before commencing the experiments, several trials were accordingly instituted to ascertain if at the requisite speed, of tmins per. minute, heat could be produced. The result las proved positively that no appreciable elevation of temperiture takes place. The diameter of the wheel being 3.4 ins, the maximum sperel of the particles of water produced hy the rotation scareely reaches 3.5 ins. per second, a relocity willently too small to generate appreciable heat.

The mode of conducting the experiment will be seen hy the following statement: A capacious wooden cistern, charmerl with water and crushed ice, is comnecter by small flexibl. tubes to the nozzles $g$ and $d$ on opposite sides of the exterinil vessel $b$, a pump being applied between the sair nozzles and the cistern, by means of which the cold water is forced throurh the apparatus and ultimately returned to the source of supply:

In view of the great importance of the question at issur the investigation has been conducted with the utmost call', four operators having been enployed to carry ont the experiments, the labor being thus divided: 1st operator regulates the temperature of the water in the cistern by continual agiti- 
tion and supply of crushed ice from time to time; 2d operator works the pump at a uniform late; $3 d$ operator, after having charged the central sphere with boiling water, turns the paddlewheel, reads the thermoneter, and announces the temperature for each degree, at the instant when the top of the mercurial column is covered by half the thickness of the line on the scale; the 4th operator, provided with a Casella chronograph, records the time and temperature. It should be observed that, notwithstanding this procedure, there is a slight irregularity in the ratio of temperature and time, the increment for each degree not being quite uniform. Obviously the most practised eye, though assisted by the magnifying-glass, cannot determine exactly at what moment the top of the falling column is half covered by the line on the thermometric scale. Again, a perfectly graduated thermometer camnot be obtained. The discrepancy referred to is, however, so small that it cannot readily be detected in the diagram. It will be proper to state that, in constructing the several tables contained in this chapter, a correction has been introduced agreeably to Regnault's method of correcting the irregularities inseparable from thermometric observations. Refering to the annexed tables, marked $A$, it will be noticed that the rate at which the spherical radiator cools has been recorded for each degree of differential temperature from $150^{\circ}$ to $15^{\circ}$. The temperature of the surrounding cold vessel, it will be seen, is entered in the first column; the temperature of the radiating sphere in the second, and its excess of temperature in the third column. The number of seconds occupied in reduring the 


\begin{tabular}{|c|c|c|c|c|c|c|c|c|c|}
\hline \multirow{2}{*}{ 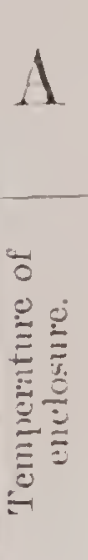 } & \multicolumn{8}{|c|}{ 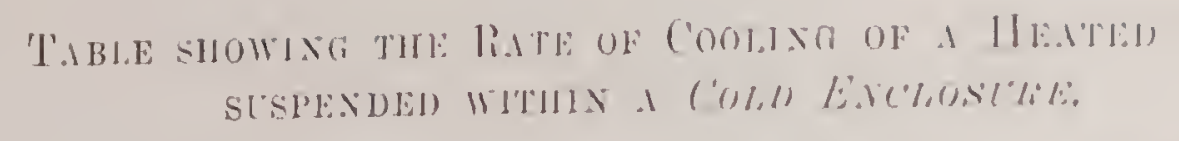 } & Buा: \\
\hline & 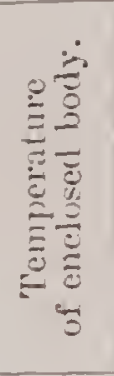 & 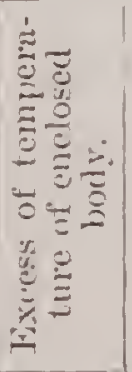 & 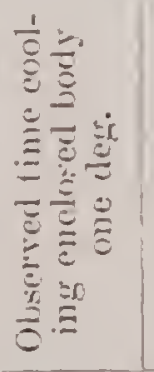 & 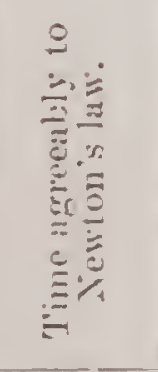 & 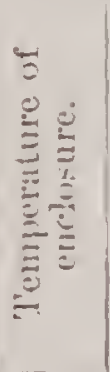 & 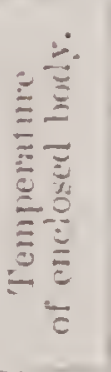 & 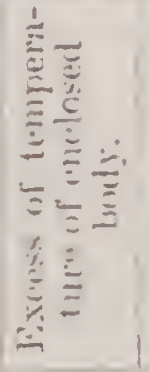 & 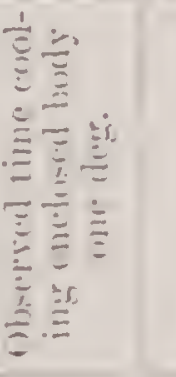 & 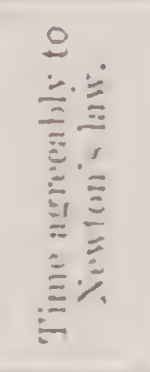 \\
\hline$F\left(c_{2} h_{2}\right.$ & ${ }^{\circ}$ Futh. & Fulh. & $\operatorname{secs}$ & Secs. & Fuh. & Fish. & Fuh. & rees & sice. \\
\hline 33 & $18: 3$ & 1.0 & 37.7 & $42 .(11$ & $3 ; 3$ & 160 & $1: 7$ & $+7 .: 3$ & (1!). (i) \\
\hline 33 & 182 & $14 !$ & 38.1 & $f(2.2)$ & ;:3 & 1.09 & $1: 3$ & 47.8 & .511 .14 \\
\hline 33 & 181 & 148 & 38.5 & 4..人 & :3i3 & 1.5 & זיבין & $4: .3$ & ill. 14 \\
\hline 33 & 180 & 147 & : & 42.86 & $: 3: 3$ & $1.7 i$ & 124 & 4.8 & (1). \\
\hline 33 & $17 \%$ & 146 & $39 . .3$ & $4: 3.16 ;$ & 333 & $1.5 i$ & $1: 3$ & $1 ! 1.3$ & il. 21 ; \\
\hline $3: 3$ & 178 & $14 . \overline{-}$ & 39. 1 & $43.41 i$ & 333 & 1.i. & 1.20 & . & $51.1 \mathrm{is}$ \\
\hline 33 & 177 & 144 & $f(1) .1$ & 43.76 & $: 33$ & 1.74 & 1.1 & i 11.8 & .i2. 11 \\
\hline 33 & 170 & $14: 3$ & $4(1 .)$. & $41.19 \%$ & 33 & 1.i; & $1 \div 0$ & . & $\therefore$....i \\
\hline $3: 3$ & 17.5 & 142 & 40.9 & 44.38 & 333 & 1.0 & $11 ! 1$ & i1.3 & O3.3.111 \\
\hline 333 & 174 & 141 & 41.3 & 44.60 & 33 & 1.11 & 118 & 万) & $\pi 3.44$ \\
\hline 33 & 173 & 140 & 41.7 & $4 \pi .02$ & 33 & 1.51 & $11 \%$ & i2.:3 & 50.390 \\
\hline 33 & 172 & 139 & 42.1 & 45.34 & 33 & 149 & 116 & . & 54.37 \\
\hline 33 & 171 & 138 & 42.5 & $4 \pi .6 r$ & 33 & 148 & $11 \%$ & .):3.3 & 24.84 \\
\hline 33 & 170 & 137 & 42.9 & 46.01 & $3: 3$ & 147 & 114 & (5) 3.9 & 515.3:3 \\
\hline 33 & 169 & 136 & 43.3 & 46.34 & 33 & $14 i$ & 113 & $\therefore 4.5$ & 1.1.8. \\
\hline 33 & 168 & 13\%) & 43.7 & 46.69 & 833 & 14.5 & 112 & 5.1 & iff.:32: \\
\hline 333 & 167 & 134 & 44.1 & $47 .(1)+$ & $3: 3$ & $1+4$ & 111 & 5.5 .7 & $\therefore 9.833$ \\
\hline 33 & 166 & 133 & $44.5)$ & $47.39)$ & $: 3: 3$ & $1-1: 3$ & 110 & ici..3 & 67.33 .1 \\
\hline :3:3 & $1(6 i)$ & 132 & +4.9 & 47.75 & (3:3) & 142 & $10 ! ?$ &.$x(i .9$ & . \\
\hline $33: 3$ & $16 . t$ & $1: 31$ & 45.3 & 48.12 & $3: 3$ & $1+1$ & 108 & 57.5 & is.t? \\
\hline :3:3 & $16: 3$ & 1301 & 4.). $S$ & 48.49 & 393 & $1-f 1)$ & $10 \%$ & 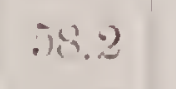 & .8 .97 \\
\hline $3: 3$ & $16 ; 2$ & $12 ?$ & 46.3 & $48.8 \%$ & 333 & $1:: 9$ & 1196 & 淁.! & 2. \\
\hline 33 & 161 & 128 & 46.8 & 49.25 & $3: 3$ & $1: 38$ & 10.5 & .89 .6 & (i) (1). (1) \\
\hline
\end{tabular}




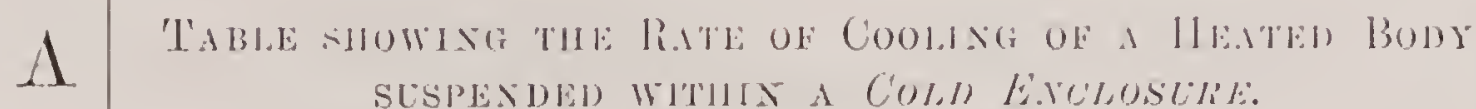

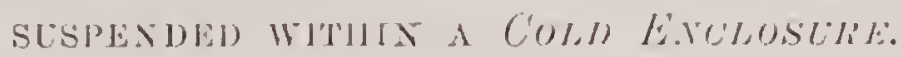

\begin{tabular}{|c|c|c|c|c|c|c|c|c|c|}
\hline 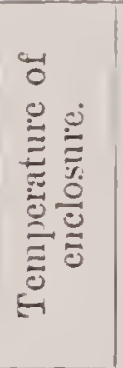 & 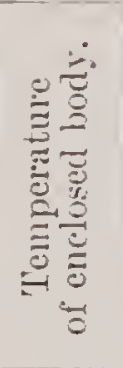 & 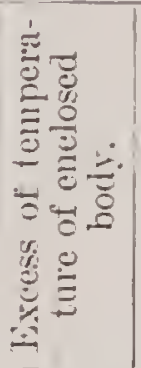 & 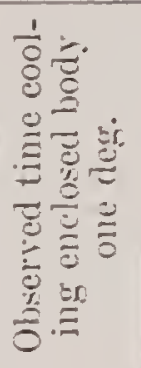 & 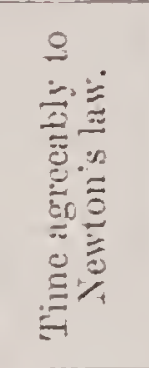 & 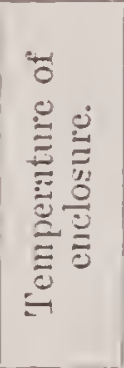 & 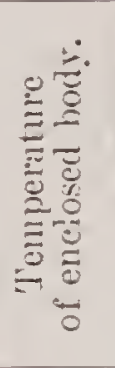 & 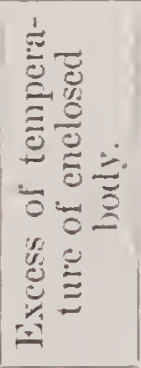 & 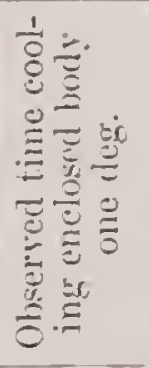 & 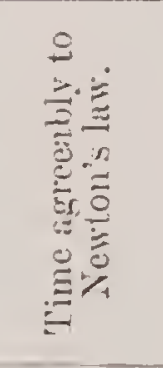 \\
\hline${ }^{\circ}$ Fith. & ${ }^{\circ}$ Futh & ${ }^{\circ}$ Fuh. & Secs. & Secis. & - Fich. & ${ }^{\circ}$ Fuk. & - Fah. & $S \in c s$. & Secs. \\
\hline 333 & 133 & 1()$+4$ & $(60) .3$ & (io.67 & $3: 3$ & 114 & 81 & S0.S & 7S.01 \\
\hline $3: 3$ & 136 & $10: 3$ & 61.0 & 61.27 & $3: 3$ & 113 & so & 81.9 & 78.99 \\
\hline $3: 3$ & 135 & $1(1) 2$ & 61.7 & (i1.8\% & $3: 3$ & 112 & 79) & 83.1 & $8(1.010$ \\
\hline$: 3: 3$ & 134 & 101 & (6i).4 & $(92.45$ & $3: 3$ & 111 & 78 & 84.3 & 81.03 \\
\hline 333 & $13: 3$ & $1(x)$ & $0 ; 3.2$ & 63.11 & $3: 3$ & 110 & 97 & 85.5 & 82.109 \\
\hline $3: 3$ & 132 & 99 & (34.0) & 63.76 & 33 & 109 & 70 & 86.7 & $8: 3.18$ \\
\hline $3: 3$ & 131 & 98 & $6+.8$ & 64.41 & 33 & 108 & i.) & S8.0 & 84.29 \\
\hline $3: 3$ & 130 & 97 & (6.). (j & (6.). 18 & 33 & 107 & $7 t$ & 89.3 & 8.). 44 \\
\hline $3: 3$ & 129 & 96 & 66.4 & (6.). 76 & 33 & 106 & 73 & 90.6 & 86.62 \\
\hline 33 & 128 & $9 \tilde{5}$ & 67.2 & $66.46 ;$ & 33 & 105 & $\gamma 2$ & 91.9 & 87.83 \\
\hline $3: 3$ & $12 \%$ & 94 & 68.0 & $6 \% .16$ & 33 & 104 & 81 & 93.3 & $89.0 \mathrm{~S}$ \\
\hline 33 & 126 & 93 & 68.9 & 67.89 & 33 & 103 & 70 & 94.7 & 90.36 \\
\hline 33 & 125 & 92 & 69.8 & 68.63 & 33 & 102 & 69 & 96.1 & 91.68 \\
\hline 33 & 124 & 91 & 70.7 & 69.39 & 33 & 101 & 68 & 97.5 & 93.04 \\
\hline 33 & 123 & 90 & 71.6 & 70.17 & 33 & 100 & $6 \%$ & 99.0 & 94.44 \\
\hline 33 & $12: 2$ & 89 、 & 72.5 & 70.96 & 33 & 99 & 66 & 100.5 & 95.88 \\
\hline 33 & 121 & 88 & 83.5 & 71.77 & 33 & 98 & (6.) & 102.0 & 97.36 \\
\hline $3: 3$ & 120 & 87 & 74.5 & 72.60 & 33 & 97 & $6 t$ & 103.6 & 98.89 \\
\hline 33 & \rfloor 19 & 86 & 55.5 & 83.45 & 33 & 96 & 63 & $10 \div .2$ & 100.48 \\
\hline 33 & 118 & 85 & 76.5 & 74.32 & 33 & $9 \tilde{5}$ & 62 & 106.9 & 102.11 \\
\hline 33 & $11 \gamma$ & St & $\pi \% .5$ & 75.21 & 33 & 94 & 61 & 108.6 & 103.80 \\
\hline 33 & 116 & 83 & 78.6 & 76.12 & 33 & 93 & (ii) & 110.4 & 10.5 .55 \\
\hline 33 & $11 \%$ & 82 & 79.7 & $7 \% .05$ & 33 & 92 & 58 & 112.3 & $10 \% .35$ \\
\hline
\end{tabular}




\begin{tabular}{|c|c|c|c|c|c|c|c|c|c|}
\hline 1 & 'T’1 & LE SII & $\begin{array}{l}1 \mathrm{Xg} \\
\text { SPENA }\end{array}$ & $\begin{array}{l}\text { IE RAT } \\
\text { ED WITI }\end{array}$ & $\begin{array}{l}\text { OF } \\
x A\end{array}$ & $\begin{array}{l}\text { LINit } \\
\text { L, l) } 1\end{array}$ & $\begin{array}{l}114 \\
10 \%(1)\end{array}$ & 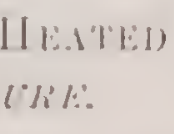 & \\
\hline '0 & 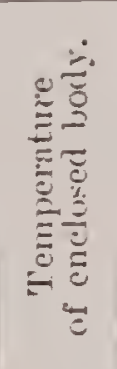 & 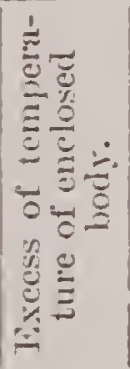 & 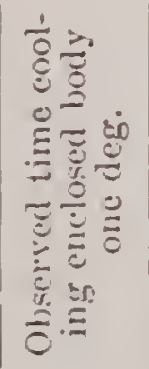 & 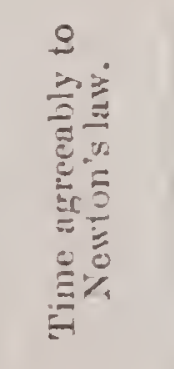 & 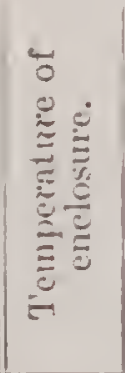 & 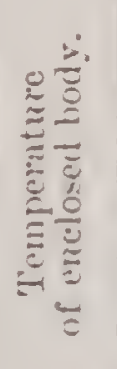 & 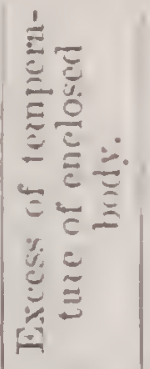 & 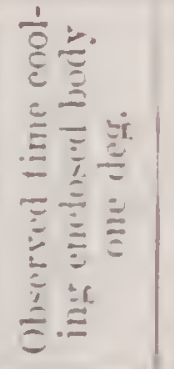 & 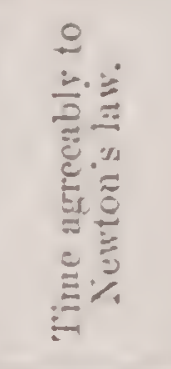 \\
\hline 'F Fah. & " $F a^{\prime} t$. & ${ }^{\circ} F u h$. & secs. & $\operatorname{Sec} 8$ & - Fiah. & ${ }^{\circ}$ Futh. & - Fials. & secter. & Srectid \\
\hline 33 & 91 & is & 114.3 & 109.22 & $3 ; 3$ & (ii) & $36 i$ & $18 !) . !$ & $17(i . !)(1)$ \\
\hline 33 & 90 & $\pi$ & 116.4 & 111.1.j & $3: 3$ & 68 & :ii & $19 . \pi .1$ & $14: .18: 3$ \\
\hline 33 & 89) & 56 & 118.6 & 113.1.5 & $3: 3$ & (ii & 34 & $\because(1) \therefore$ & 157.16 \\
\hline 33 & SS & $5 \pi$ & 120.9 & 11.5 .23 & 33 & $6 i 0^{\circ}$ & $: 3: 3$ & 207.2 & 1!1:3.2:3 \\
\hline 33 & 87 & 54 & $12: 3.3$ & 117.38 & $3: 3$ & (6.) & $3: 2$ & 213.0 & $11111.36 ;$ \\
\hline 33 & 86 & 53 & $12: .8$ & 119.62 & $3: 3$ & (it) & 31 & 2.211 .2 & $2(15.11)$ \\
\hline $3: 3$ & 8.) & $.2 \%$ & 128.4 & 121.94 & $3: 3$ & (ii) & :31 & 207.4 & $21: . .4$ \\
\hline 33 & 84 & ) 1 & 131.1 & 124.35 & $3: 3$ & (i:) & $\cdot ? !)$ & $2: 3.1 .1$ & $20(1,3.5$ \\
\hline 33 & $8: 3$ & 50 & 133.9 & 126.87 & $3: 3$ & (i) & 28 & 213.4 & 2036 \\
\hline 33 & S: & 49 & 136.8 & 129.48 & $3: 3$ & (6) & $2 i$ & 2.2 .3 & $2: 36.98$ \\
\hline 33 & 81 & 48 & 139.9 & 132.21 & 33 & 59 & $26 ;$ & $2(; 1.9$ & 246.27 \\
\hline 33 & So & 47 & 143.1 & 135.05 & 33 & 58 & 25 & 272.2 & $2: 6.32$ \\
\hline 33 & 79 & 46 & 146.5 & 138.02 & 33 & 57 & 24 & 283.3 & 267.23 \\
\hline 33 & is & 45 & 150.0 & 141.12 & 33 & 56 & $2: 3$ & 295.4 & 279.11 \\
\hline 33 & $7 \gamma$ & 44 & 153.7 & 144.37 & 33 & $5 \%$ & $2:$ & 3018.7 & 290.09 \\
\hline 33 & 76 & 43 & $15 \% .5$ & 147.76 & 33 & 54 & 21 & $3: 2: 3.4$ & $3(16.34$ \\
\hline 33 & 75 & 42 & 161.5 & 151.32 & 33 & 53 & 20 & 3339.7 & 322.05 \\
\hline 33 & $\pi 4$ & 41 & 16.5 .7 & 155.06 & 33 & 62 & 19) & 357.9 & 339.46 \\
\hline $3: 3$ & 73 & 40 & $1 \% 0.1$ & 158.99 & 33 & i) & 18 & 378.3 & $3 \%) .86$ \\
\hline 33 & 72 & 39 & 174.7 & $16: 3.12$ & 33 & 5) & $1 \%$ & 401.2 & 380.60 \\
\hline $3: 3$ & 71 & 38 & $179 . \overline{5}$ & $16 \% .47$ & 33 & 49 & 16 & 426.9 & 40.5 .16 \\
\hline 33 & 70 & 37 & 181.6 & 172.06 & 33 & 48 & 15 & 455.7 & 433.10 \\
\hline
\end{tabular}


temperature of the ranliating sphere one degree is recorder in the fourth column. The fifth column eontains the number' of seconds which would be requisite to reduce the temperature one degree if the cooling preceded at the rate shom hy the Newtomian law.

Let us now exanine the diagram Fig. 2, attached to the illustration, in which the length of the ordinates of the curve b) "'puresent the observed tine for each degree of differential trmperature, while the orlinates of the curve a d represent the time that would elapse if the rate of cooling were in exact accordance with Newton's doctrine-namely, if the times were inrersely as the differential temperatures. The rertical line in Fig. 2, on which the ordinates represcnting the time of cooling have heen projected, is divided into degrees of Fall. renheit, showing the differential temperatule, riz., the excess of temperature of the raliating spliere above that of the surrounding cold reseel. A careful inspection of this diagram and of the Tables A, renders argument unnecessary to show that our experimental investigation has established the correctness of Newton's assumption that a rarliating body loses at each instant a quantity of heat proportionate to the excess of its temperature above that of the smounding medium. It will be shown hereafter that the slight discrepancy inclicated by the different length of the ordinates of the curres $a d$ and b $c$ is owing to the rariation of enissive power of the radiator, cansed by the difference of molecular motion resulting from change of temperature, and the consequent change of dimensions, of the radiator. Dulong and Petit's formula being based 
on the table presented at the commencement of this chinter, copied from Prof. Stewart's "Elementary Treatise on Heat" (compared also with the French original), I have deened it important to examine cirrefully whether the rates of cooling presented in the said table are consistent. The result of this examination is shown in the accomplanying table, in which the 1st column contains the differential temperature of the radiator; the 2 d column contains the corresponding rate of cooling for each minute, established ly Dulong and I'otit; while the $3 d$ and the columms show the ratio of difference.

\begin{tabular}{|c|c|c|c|}
\hline $240^{\circ}$ & $11^{\circ} .69$ & & \\
\hline 220 & 8.81 & 1.88 & 0.47 \\
\hline 200 & 7.40 & 1.41 & 0.11 \\
\hline 180 & 0.70 & 1.310 & 009 \\
\hline 160 & 4.89 & 1.21 & () 20 \\
\hline 140 & 3.88 & 1.01 & 015 \\
\hline 120 & 3.02 & 0.86 & \\
\hline 100 & 2.30 & 0.72 & 0.14 \\
\hline 80 & 1.74 & 0.56 & \\
\hline 1 & 2 & 3 & 4 \\
\hline
\end{tabular}

The inconsistency and irregularity of the rates of cooling exhibited by the figures in the two last columms prove the unre. liable character of the temperatures inserted in the two first columns. We are warranted in concluding that a doctrine 


\begin{tabular}{|c|c|c|c|c|c|c|c|c|}
\hline 13 & \multicolumn{7}{|c|}{ 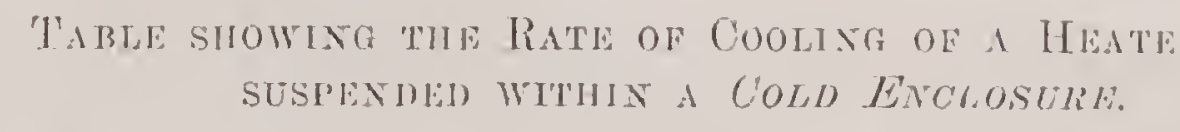 } & BODY \\
\hline 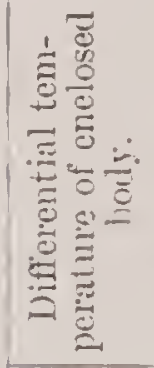 & 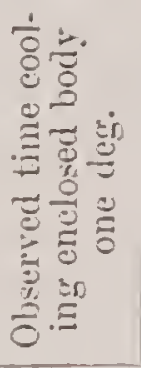 & 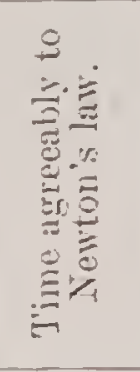 & 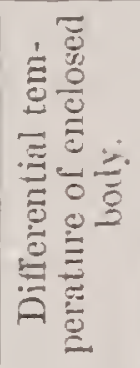 & 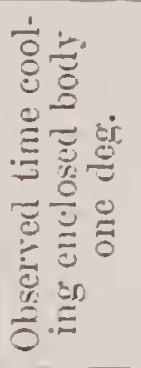 & 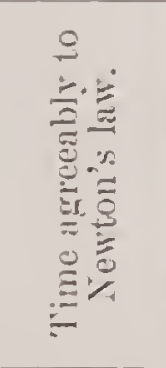 & 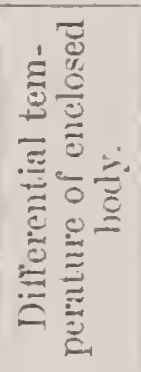 & 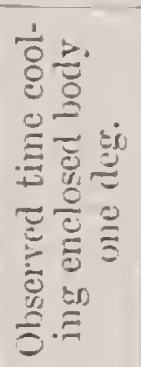 & 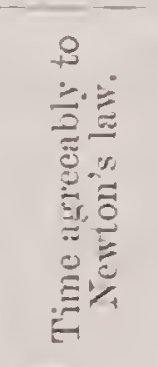 \\
\hline Cent. & Secs. & Secs. & Cent. & Secs. & secs. & Cent. & Secs. & sics. \\
\hline 83 & 38.1 & +2.29 & 57 & (i1.6 & $(31 . \pi)$ & 31 & 119.9 & $17+.39$ \\
\hline 82 & 38.8 & $4 \div .81$ & 56 & 62.9 & 62.86 & 30 & 124.3 & 118.27 \\
\hline 81 & 39.5 & 43.34 & 65 & $6+.3$ & 64.01 & 29 & 128.9 & 122.41 \\
\hline 80 & 40.3 & 43.59 & 54 & 6.5 .7 & (6). 21 & 28 & 1333.9 & 126.84 \\
\hline 79 & 41.0 & 44.45 & 53 & 67.2 & 66.46 & 27 & 139.3 & 131.65 \\
\hline 78 & 41.7 & 45.02 & 52 & 68.7 & 67.74 & 26 & 145.2 & 136.81 \\
\hline $7 \%$ & 42.4 & 45.60 & 51 & $\gamma(0.3$ & 69.09 & 25 & 151.5 & $1+2.411$ \\
\hline 76 & $4: 3.1$ & 40.20 & $\overline{5}()$ & $7: 0$ & $\tau(1) .48$ & 24 & 158.3 & 148.46 \\
\hline 75 & 43.5 & 46.82 & $4 ! 1$ & 73.7 & 71.94 & 23 & 165.7 & 155.06 \\
\hline 74 & 44.5 & 47.40 & 48 & 75.5 & 73.45 & 22 & 173.5 & 162.27 \\
\hline 73 & 45.3 & 48.12 & 47 & $7 \% .3$ & $\% \pi .02$ & 21 & 182.6 & 180.18 \\
\hline 72 & 46.1 & 48.80 & 46 & 79.2 & 76.68 & 20 & 192.1 & 178.91 \\
\hline$\gamma 1$ & 47.0 & 49.49 & 45 & 81.2 & 78.40 & 19 & 202.4 & 185.59 \\
\hline 80 & 47.9 & 50.20 & 44 & S3.3 & $S 0.20$ & 18 & $213 . \overline{5}$ & 199.36 \\
\hline (6) & 48.8 & 50.93 & 43 & $85 . \tilde{5}$ & 82.09 & 17 & $225 . \%$ & 211.44 \\
\hline 6s & 49.8 & 51.68 & 42 & 87.7 & 84.07 & 16 & 239.4 & 225.08 \\
\hline 67 & 50.7 & 52.45 & 41 & 90.0 & 80.14 & 15 & 255.2 & 240.61 \\
\hline 66 & 51.6 & 53.25 & 40 & 92.4 & 88.32 & 14 & 273.6 & 258.44 \\
\hline 65 & 52.5 & 54.09 & 39 & 94.9 & 90.62 & 13 & 205.4 & 279.11 \\
\hline 64 & 53.5 & 54.94 & $3 S$ & 97.5 & 93.04 & 12 & 321.1 & 303.38 \\
\hline 63 & 54.5 & 5.5 .82 & 37 & 100.2 & 95.58 & 11 & 351.6 & 332.27 \\
\hline 62 & 55.6 & 56.73 & 36 & $10: 3.0$ & 98.28 & 10 & 388.1 & 367.25 \\
\hline 61 & 56.7 & $5 \% .67$ & 35 & 106.0 & 101.12 & 9 & 432.5 & 410.45 \\
\hline 60 & 57.8 & 58.64 & 34 & 109.1 & 104.15 & S & 487.9 & 465.11 \\
\hline 59 & 59.0 & 59.64 & 33 & 112.3 & 107.35 & $\gamma$ & Tก. & $5: 36.71$ \\
\hline 58 & 60.3 & 60.47 & 32 & 115.9 & 110.76 & 6 & 656.3 & 634.33 \\
\hline
\end{tabular}


based on such unsatisfactory premises camnot be sommd. How. fan this inference is correct will he seen presontly by a coml. parison between the ratio of conling at high tempreratures, deduced from XIM. Duleng and Petit's formulal, and the actunl rate shown by an incamblesent cast-irens sphere anclused within

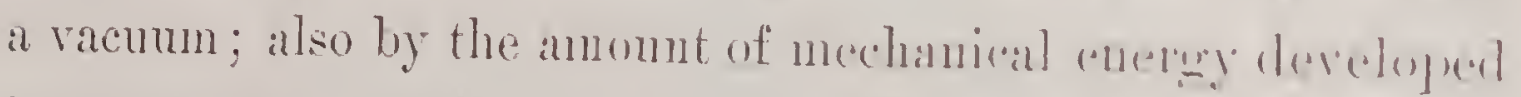
by the radiation of fused cast irom. The tomperatures inserteal in the table manked B, relating to the experiments muler and sideration, have heen redueed to the cintigrate scale for the purpose of facilitating direct companison with the result of Dulong and Petit's resenrches.

The question has frepuently heen asked, whether. Newtong is law holds for increase of temperature when a cold lundy is exposed to the ranliation of a sumenumling lost modium. In order to decide the question, experinentally; whether the times

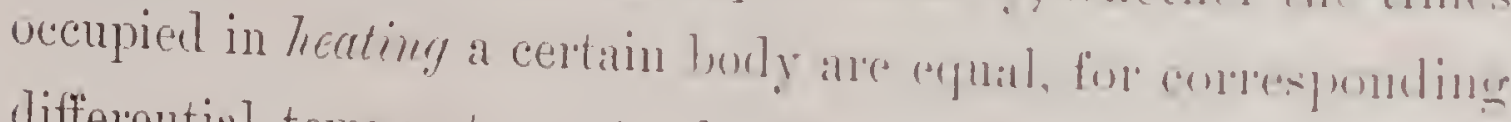
differential temperatures, to the times occupied in conling the same body, a modified apparatus has been construncted (see illustration shown on Plate 5, Fig. :3). The means atopted for measuring the temperature and producing circulation within the central splere being identical with those of the apparatus already describerl, it will only be necessany to point out that the exhansted vessel a a which surrounds the central spllome $c$ is immersed in water contained in a cylindrical rertical boiler b, open at the top and heated ly means of a spinit. lamp applied under its bottom. The experinents with this modified apparatus have been conducted in the following manner: The water in the boiler having been brought to 


\begin{tabular}{|c|c|c|c|c|c|c|c|c|c|}
\hline \multirow{2}{*}{ 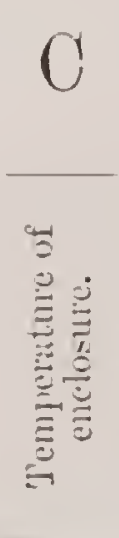 } & \multicolumn{9}{|c|}{ 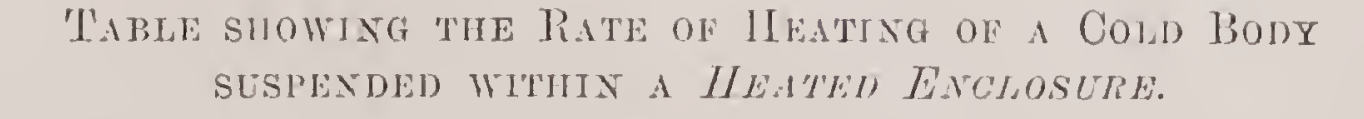 } \\
\hline & 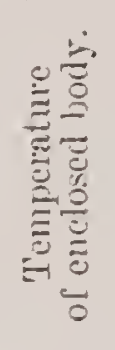 & 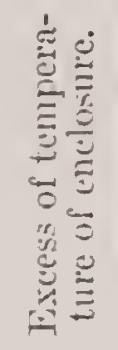 & 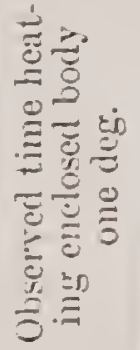 & 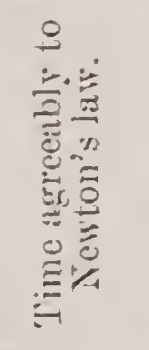 & 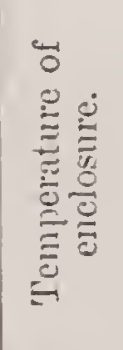 & 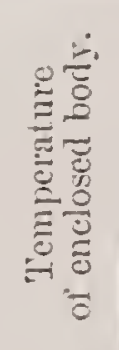 & 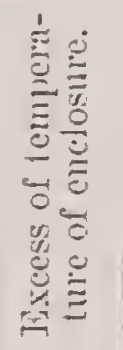 & 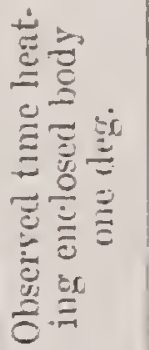 & 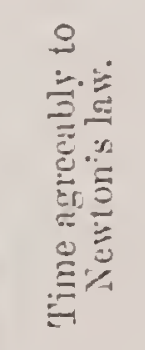 \\
\hline Fuk. & ${ }^{\circ}$ Fall. & ${ }^{\circ}$ Fuh. & Secs. & Secs. & o Futh. & - Futh. & Full. & Secs. & Secs. \\
\hline 212 & $3 \pi$ & $17 \%$ & 29.1 & $20.0 \mathrm{~S}$ & 212 & 64 & 148 & 35.6 & 34.41 \\
\hline 212 & 38 & 174 & 29.3 & 29.25 & 212 & (ii) & $1+7$ & $3 ; 5.9$ & 34.64 \\
\hline 212 & 89 & 173 & 29.5 & 29.42 & 212 & 66 & 146 & 36.3 & 34.88 \\
\hline $21: 2$ & 40 & 172 & 29.7 & 29.59 & 212 & 67 & 145 & 36.5 & 35.12 \\
\hline 212 & 41 & 171 & 29.9 & 20.76 & 212 & 68 & $1+4$ & 36.8 & $3 \overline{3} .36$ \\
\hline 212 & 42 & 170 & 30.1 & $29.9+4$ & 212 & 69 & 143 & $3 \% .1$ & 35.61 \\
\hline 212 & 43 & 169 & 30.3 & 30.12 & 212 & 70 & 142 & 37.4 & 35.86 \\
\hline 212 & 14 & 168 & 30.5 & 30.29 & 212 & 71 & 141 & 37.7 & 36.12 \\
\hline 212 & 4) & 167 & 30.7 & 30.48 & 212 & 72 & 140 & 38.0 & 36.38 \\
\hline 212 & 46 & 160 & 30.9 & 30.66 & 212 & 73 & 139 & 38.3 & 36.64 \\
\hline 212 & 47 & 16.5 & 31.1 & 30.5 .5 & 212 & 74 & 138 & 38.6 & 36.91 \\
\hline 212 & 48 & $16+$ & 31.3 & 31.04 & 212 & 75 & 137 & 38.9 & 37.18 \\
\hline $21 \%$ & 49 & 163 & 31.5 & 31.23 & 212 & 76 & 136 & 39.2 & 37.46 \\
\hline 212 & 50 & 162 & 31.7 & 31.42 & 212 & 87 & 135 & 39.5 & 37.74 \\
\hline 212 & 51. & 161 & 31.9 & 31.62 & 212 & 78 & 134 & 39.5 & 38.02 \\
\hline 212 & $\pi 2$ & 160 & 32.1 & 31.82 & 212 & 79) & 1333 & 40.1 & 38.30 \\
\hline 212 & (5) & 159 & 32.3 & 32.02 & 212 & 80 & 132 & 40.4 & 38.59 \\
\hline 212 & 54 & 1) 8$. & $3: 2.6$ & 32.22 & 212 & 81 & 131 & 40.7 & 3S.SS \\
\hline 212 & 5.5 & 1.57 & 30.9 & 32.43 & 212 & $8: 2$ & 130 & 41.0 & 39.18 \\
\hline 212 & 5) & 156 & 33.2 & $32.6 t$ & 212 & $8: 3$ & 129 & 41.3 & 39.49 \\
\hline 212 & 57 & $15 \%$ & 33.5 & 39.85 & 212 & 84 & 128 & 41.6 & 39.80 \\
\hline 212 & is & 154 & 33.8 & 333.06 & 212 & 85 & 127 & 41.9 & 40.12 \\
\hline 212 & 69 & 153 & $3+.1$ & 33.28 & 212 & 86 & 126 & 42.2 & 40.44 \\
\hline $21 \%$ & 60) & 152 & 34.4 & 33.50 & 212 & 87 & 12:5 & 42.5 & 40.76 \\
\hline 212 & 61 & 151 & 34.7 & 33.79 & 212 & 88 & 124 & 42.8 & 41.00 \\
\hline 212 & 62 & 150 & 35.0 & 33.05 & 212 & S9 & $12: 3$ & 43.1 & 41.43 \\
\hline 212 & 63 & 149 & 35.3 & 34.18 & 212 & 90 & 122 & 43.5 & 41.77 \\
\hline
\end{tabular}




\begin{tabular}{|c|c|c|c|c|c|c|c|c|c|}
\hline \multirow{2}{*}{$\frac{C}{C}$} & \multicolumn{8}{|c|}{ 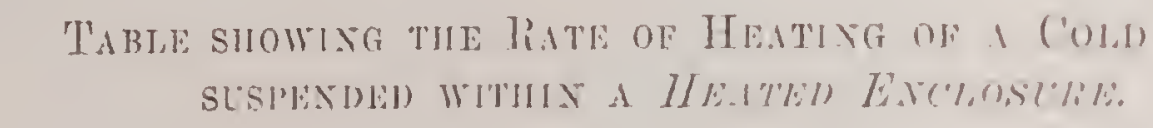 } & Bom \\
\hline & 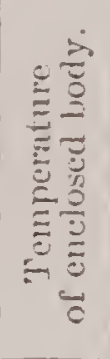 & 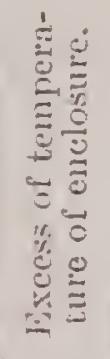 & 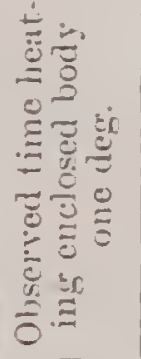 & 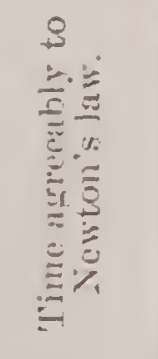 & 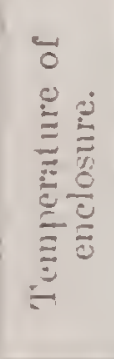 & 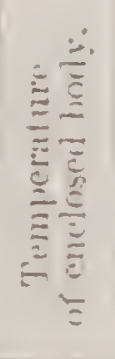 & 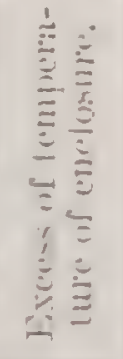 & 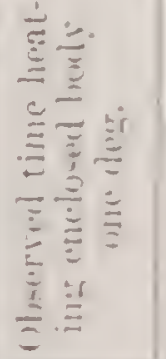 & 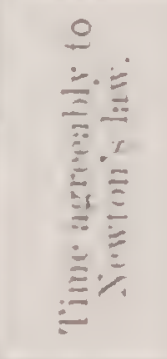 \\
\hline Fath. & - Fulk. & - Fulk. & Sec8. & Secs. & ${ }^{\circ}$ Full. & "Fint. & Fink. & secis. & sices. \\
\hline 212 & 91 & $1: 1$ & 43.0 & 42.12 & 212 & 118 & !) & i.5. 4 & $i 1.2$ \\
\hline 212 & 92 & 120 & 44.8 & $12.4 \%$ & $21: 2$ & 119 & $9: 3$ & i.i.! & 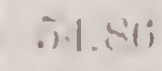 \\
\hline 212 & 93 & 119 & 44.7 & $42.8: 3$ & 212 & $1 \geq 0$ & !!. & iti.t & .5 .16 \\
\hline 212 & 94 & 118 & 45.1 & 43.19 & $\because 12$ & 121 & 91 & $i(i .4$ & ix.11s \\
\hline 212 & 95 & $11 \%$ & 45.5 & 43.56 & $91 \%$ & 102 & !) & 57.1 & ini.il) \\
\hline 212 & 96 & 116 & 4.7 .9 & 43.94 & 212 & 1.3:3 & B!) & $.7 \% ! !$ & iT.:Bi, \\
\hline 212 & $9 \tau$ & 115 & $4(i .3$ & 44.302 & 212 & $1 \cong 4$ & Si' & 沾.ム & is. 110 \\
\hline 212 & 98 & 114 & $4(i . \gamma$ & 44.21 & $21 \%$ & 105 & 87 & i. 1 & is.lis \\
\hline 212 & 99 & 113 & 47.1 & fi. 11 & $21: 2$ & $1 \div(;$ & sil; & C). 7 & -19.836 \\
\hline 212 & 100 & 112 & 47.5 & 45.51 & $\because 12$ & 127 & 8.5 & li1).: & (il).111; \\
\hline 212 & 101 & 111 & 47.9 & 4.7 .93 & 212 & $1: S$ & St & 60.9 & (i). is \\
\hline 212 & 102 & 110 & 48.3 & $4(3.35)$ & 212 & $12 !)$ & $8: 3$ & $61.5)$ & (i).S1 \\
\hline 212 & $111: 3$ & 109 & 48.7 & 46.78 & 212 & $1: 311$ & 82 & $(i 9.1$ & $(i \cdot) .27$ \\
\hline 212 & 104 & 108 & 49.1 & 47.21 & 212 & $1: 31$ & il & 60.7 & (ii.). (1)-1 \\
\hline 212 & $10 \%$ & $10 \%$ & $49 . \tilde{5}$ & $47.65)$ & 21.2 & $1: 3: 2$ & $8(1)$ & (i:3. 4 & (ii). 8.1 \\
\hline 212 & 11)( & 106 & 49.9 & 48.10 & 212 & $1: 3: 3$ & 7!) & 6.1 .1 & (it. (ii) \\
\hline 212 & 107 & 1105 & $5(1.3$ & 48.56 & 212 & $1: 3 t$ & 78 & (i-1.S & (i.). $4 i$ \\
\hline $21 \%$ & 1118 & 10) $t$ & i)(0.7 & 49.1133 & 212 & 135 & 77 & (i). .5) & $6(i, 3 \cdot 3 \cdot 1$ \\
\hline 212 & 109 & $10: 3$ & 5) 1.1 & 49.51 & 212 & $1: 36$ & $\tau 6$ & $(j 6.2$ & $(j i .2)$. \\
\hline 212 & 110 & 102 & 51.5 & $50 .(1)$ & 212 & $1: 37$ & ij & $6(i .9)$ & (is. 1? \\
\hline $21 \%$ & 111 & 101 & 5) 1.9 & 50.50 & 212 & 1.38 & $7-1$ & $(i \pi .7$ & (j9.11. \\
\hline 210 & 112 & 100 & 52.4 & ()1.(1) & 212 & $1: 3 !)$ & 73 & (6).. & $\pi(1),(11)$ \\
\hline $21 \%$ & $11: 3$ & 99 & 52.0 & (5) 1.52 & 212 & 140 & $8: 2$ & $(j !) .33$ & 71).98 \\
\hline 212 & 114 & 98 & 5). 3.4 & $52 .(15)$ & 212 & 141 & 81 & 711. 1 & 71.98 \\
\hline $21 ?$ & 115 & 97 & 53.9 & 52.50 & $21 \%$ & $14 \%$ & (1) & $7(1.9)$ & Ti.112 \\
\hline 212 & 116 & 96 & $51 . \pm$ & (5:). $1 t$ & 212 & 1.1:3 & (i)! & 21.8 & $9.4 .(19)$ \\
\hline $21 \%$ & 117 & 9.5 & 54.9 & 503.80 & 212 & 144 & lis & 72.7 & $75.1 ! 1$ \\
\hline
\end{tabular}




\begin{tabular}{|c|c|c|c|c|c|c|c|c|c|}
\hline \multirow{2}{*}{$\frac{C}{(1}$} & \multicolumn{9}{|c|}{ 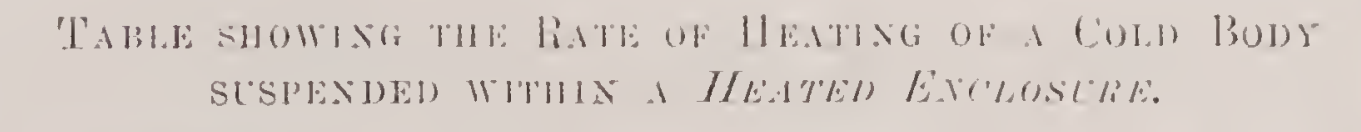 } \\
\hline & 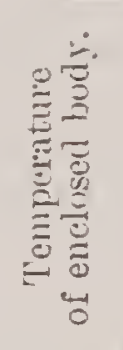 & 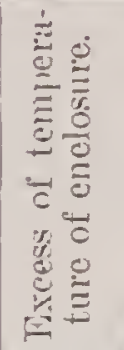 & 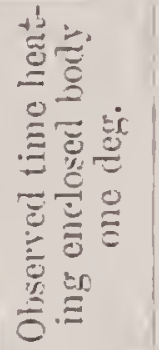 & 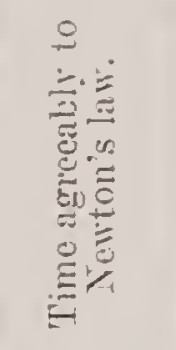 & 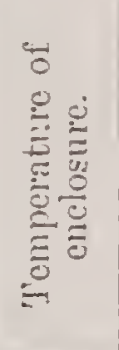 & 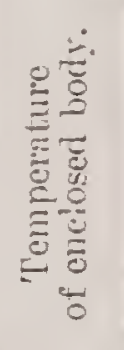 & 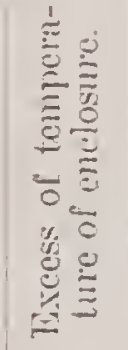 & 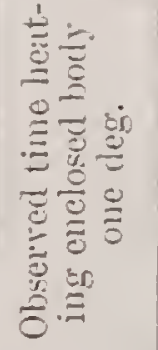 & 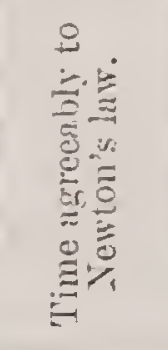 \\
\hline${ }^{\circ}$ Futh. & 'Fah. & ${ }^{\circ}$ Fulh. & Secr. & Sccs. & - Foh. & 'Fah. & - Futh. & Sects. & Secs. \\
\hline 212 & 145 & $(j \%$ & 73.6 & $\gamma(j .33)$ & $21 \%$ & 172 & 40 & 118.7 & 128.48 \\
\hline 212 & 146 & 66 & 74.5 & $\gamma \% .48$ & 212 & $17: 3$ & 39 & 121.6 & 131.82 \\
\hline 212 & 147 & (6i) & (5).5 & 78.68 & 212 & 174 & 38 & 124.6 & 135.338 \\
\hline 212 & 148 & $6+$ & 76.5 & 79.92 & 212 & 17.5 & 37 & 127.8 & 139.04 \\
\hline 212 & 149 & $6: 3$ & $7 \% .6$ & 81.20 & 212 & 176 & 36 & 131.2 & 142.96 \\
\hline 212 & 150 & 62 & \% 8.6 & 82.62 & 212 & $17 i$ & 3.1 & 134.8 & $14 \% .10$ \\
\hline 212 & 151 & 61 & 79.7 & S3.SS & 212 & 178 & 34 & 138.6 & $1 \% 1.49$ \\
\hline 212 & 152 & 60 & 80.8 & S5.20 & 212 & 179 & 33 & 142.6 & $15(6.15)$ \\
\hline 212 & 153 & i) & 82.0 & $S 6.70$ & 212 & 180 & $3: 2$ & 146.9 & 161.11 \\
\hline 212 & 154 & is & 83.2 & 88.26 & 212 & 181 & 31 & 151.5 & 166.39 \\
\hline 212 & 15)$. & 57 & 84.5 & $89.8 \%$ & 212 & $18 \%$ & 30 & 106.4 & 172.033 \\
\hline 212 & 156 & 56 & 85.8 & 91.44 & 212 & 183 & 29 & 161.6 & 178.07 \\
\hline 212 & $15 \%$ & 55 & S7.2 & 93.12 & 212 & 184 & $2 S$ & $16 \% .1$ & 184.54 \\
\hline 212 & 158 & 54 & 88.6 & 94.86 & 212 & 185 & 27 & 172.9 & 191.51 \\
\hline 212 & 159 & 53 & 90.1 & 96.66 & 212 & $1 S 6^{\circ}$ & 26 & 179.1 & 199.01 \\
\hline 212 & 160 & 52 & 91.7 & 98.54 & 212 & 187 & 25 & 185.7 & $20 \% .14$ \\
\hline 212 & 161 & 51 & 93.4 & 100.50 & 212 & 188 & 24 & 192.7 & 215.95 \\
\hline 212 & 162 & 50 & 95.2 & 102.53 & 212 & 189 & 23 & 200.3 & 245.55 \\
\hline 212 & 163 & 49 & 97.1 & 104.64 & 212 & 190 & 22 & 208.7 & 236.05 \\
\hline 212 & 164 & 48 & 99.1 & 106.84 & 212 & 191 & 21 & 218.1 & 247.56 \\
\hline 212 & $16 \tilde{n}$ & 47 & 101.2 & 109.14 & 212 & 192 & 20 & 228.7 & 260.26 \\
\hline 212 & 166 & 46 & 103.4 & 111.54 & 212 & 193 & 19 & 240.7 & 274.32 \\
\hline 212 & 167 & 45 & 105.7 & 114.05 & 212 & 194 & 18 & 254.7 & 289.99 \\
\hline 212 & 168 & 44 & 108.1 & 116.66 & 212 & $19 \pi$ & 17 & 269.6 & 307.57 \\
\hline 212 & 169 & 43 & 110.6 & 119.41 & 212 & 196 & 16 & 287.0 & 327.42 \\
\hline 212 & 170 & 42 & 113.2 & 122.29 & 212 & 197 & $1 \tilde{5}$ & 300.8 & 350.00 \\
\hline 212 & 171 & 41 & 115.9 & 125.31 & & & & & \\
\hline
\end{tabular}




\begin{tabular}{|c|c|c|c|c|c|c|c|c|}
\hline $\mathrm{C}^{2}$ & \multicolumn{7}{|c|}{ 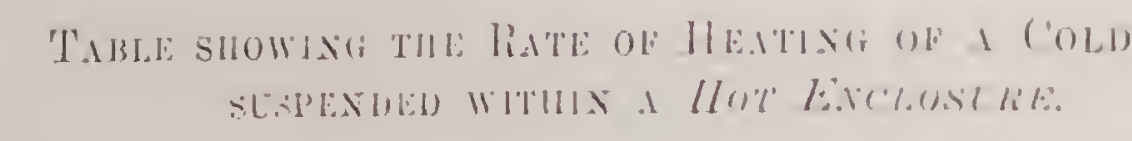 } & \\
\hline 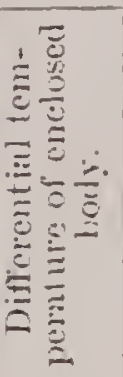 & 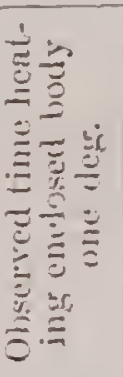 & 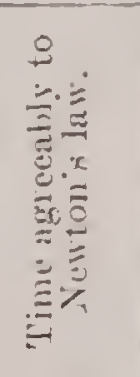 & 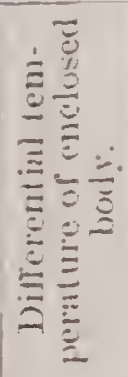 & $\begin{array}{l}0 \\
0\end{array}$ & 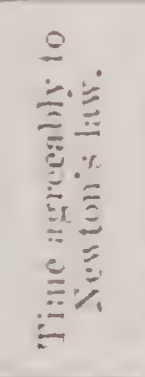 & 。 & 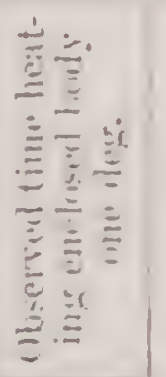 & 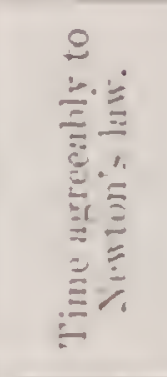 \\
\hline - Cení. & Seck. & Sece. & - Cent. & sects. & secrs. & - Cent. & Seers. & seres. \\
\hline 9 \% & $2 ! 3.3$ & 29.22 & (ii & 4.2 & 42. (1) & 33 & 7.4 .4 & $7 i .21$ \\
\hline 96 & 29.6 & 20.52 & $6 i f$ & $4+4.9$ & 4:3.14 & $33 i$ & iri.l & $7 ! 1.10$ \\
\hline 95 & 30.0 & 29.83 & 6.j) & ti. (i & $4: 3.11$ & 3.5 & is.11 & (il. \\
\hline 94 & 30.3 & 30.1 .5 & 64 & $f(i, t$ & $4+.+(1)$ & $: 3-4$ & $7 ! 9)$ & $54.11 ;$ \\
\hline 3:3 & 30.7 & 30.48 & 63 & 47.1 & 4.11 & $: 33$ & 80.0 & sir. \\
\hline 92 & 31.1 & 30.81 & 6:2 & 47.8 & 4i. ist & 32. & $S 4.2$ & $89.5(1)$ \\
\hline 91 & 31.4 & $31.1 \%$ & 61 & 48.5 & $f(i,(i))$ & 31 & sirili & (1.). +1 \\
\hline 90 & 31.8 & 31.50 & (6) & 40.3 & 17.38 & 801 & 89.2 & (i).it \\
\hline 89 & 32.2 & 31.80 & 5)! & $.3(1)$ & (5. & ?!) & {$[1.911$} & $(15, !)$ \\
\hline 88 & 32.6 & 32.22 & 58 & i) & $4 ! 9.10: 3$ & 24 & 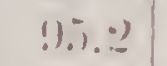 & $1119 . .8: 3$ \\
\hline 87 & 33.1 & $32.61)$ & $5 \pi$ & 51.4 & $4 !) .9(1)$ & 27 & ! 15.7 & J11(i.33!) \\
\hline 86 & 33.6 & 32.99 & $5(j$ & (i2. & .)(1). (1) & 26 & $1(10 .)$. & $1111.56 \mathrm{i}$ \\
\hline 85 & 34.2 & 33.38 & 5 & 5) 3.1 & 51.73 & 25 & 106.6 & $11 \% .(1)$ \\
\hline 84 & 34.8 & 33.78 & 54 & 54.11 & 52.69 & 24 & 111.1 & 119.97 \\
\hline 83 & 35.3 & 34.18 & 53 & 54.9 & 53.70 & 23 & 11.5 .9 & 125.31 \\
\hline 82 & 35.8 & 34.59 & 52 & 55.7 & 54.74 & 22 & 121.0 & 131.133 \\
\hline 81 & 36.4 & 3.5 .02 & 51 & 56.6 & 5.5 .83 & 21 & 126.6 & $1337.53: 3$ \\
\hline so & 36.9 & 35.46 & 50 & 57.6 & 56.96 & 20) & 132.7 & 144.58 \\
\hline 79 & 37.4 & 35.91 & 49 & 58.6 & 58.13 & 19 & $1: 39.4$ & 152.40 \\
\hline 78 & 38.0 & 36.38 & 48 & 59.7 & 59.36 & 18 & 146.9 & 161.11 \\
\hline 77 & 38.5 & 36.86 & 47 & 60.8 & 60.63 & 17 & $15 \% .4$ & 170.87 \\
\hline 76 & 39.0 & 37.34 & 46 & 61.9 & 61.96 & 16 & $16+.9$ & 181.89 \\
\hline 75 & 39.6 & 37.84 & 45) & 63.0 & 63.3.5 & 15 & 17)+t$. & 194.44 \\
\hline 74 & 40.1 & $38.3 \%$ & 44 & 64.2 & 64.81 & 14 & $18 \% .1$ & 2118.84 \\
\hline 73 & 40.7 & 38.88 & 43 & 6.5 .5 & 66.34 & 13 & $20(1) .3$ & 225.55 \\
\hline 72 & 41.2 & 39.42 & $4 \%$ & 66.8 & 67.91 & 12 & 216.3 & 24.5 .16 \\
\hline 71 & 41.8 & 39.98 & 41 & 68.2 & 69.61 & 11 & 233.9 & 268.52 \\
\hline 70 & 42.3 & 40.56 & 40 & 69.6 & 71.37 & 10 & 26() .7 & 296.77 \\
\hline 69 & 42.9 & 41.16 & 39 & 71.1 & 73.23 & 9 & 291.0 & $3: 31.69$ \\
\hline 68 & 43.5 & 41.77 & 38 & 72.7 & 75.19 & 8 & 327.3 & 375.90 \\
\hline
\end{tabular}


the boiling point, cold water, as near the freezing point at possible, is pumper into the central sphere, through suitable pipes (the thermometer hiring been previously removed). The operation of charging with cold water should be performed quickly, and the thermometer inserted as soon as the sphere is full. The reading should then commence without a monent's delay, the temperature being announced for each degree, and, together with the time, recorded by the operator attending the chronograph, precisely as before stated with reference to the process of ascertaining the time of cooling. The result of the experinent with the aplaratus under consideration will be found by inspecting the annexed tables C together with the diagram attached to the illustration, see Fig. 4, in which the ordinates of the curve $a$ b' $b$ represent the observed time for each degree of difterential temperitture, while the ordinates of the curve $a a^{\prime}$ c represent the time that would elapse if the rate of heating were in exact accordance with Newton's doetrine. The small anount of the discrepancy shown by the diagram and table, at differential temperatures exceeding $75^{\circ} \mathrm{F}$., proves that the energy raries in accordance with dynamical laws, whether heat be parted with by radiation towards a cooler body, or whether heat be received from a ratlating surrounding medium of higher temperature. The pereeptible discrepancy at low differential temperature exhibited in the diagram, namely, the (n) served times being shorter than the theoretical times, is (swing to the mavoidable conduction of heat from the boiler' to the cold central sphere through the comnecting tubes 


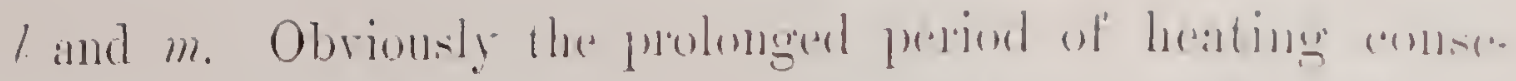

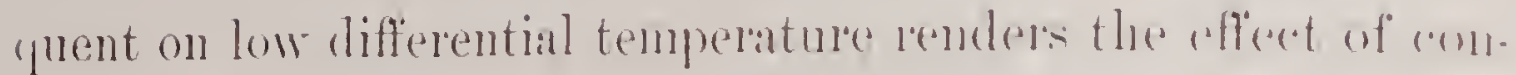
duction appreciable, as imlicated by the diagram. Onr experi. ments, then, establish the fact that motil the emisive pown is changed by disturbing canses, the encery dereloped hy radiation increases in the exact ratio of the differential tom. peratures.

It is proper to mention that one of the mincipml ohjerets of my investigations relating to the relocity of comling hy ranliation, has been that of disproring the correctness of the assmmp. tion which certain eminent plysicists have based on l)ulumen

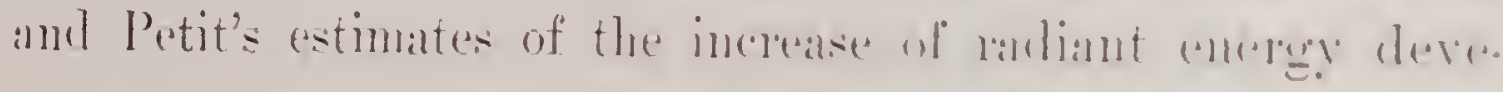

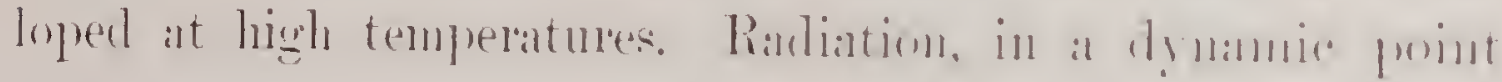

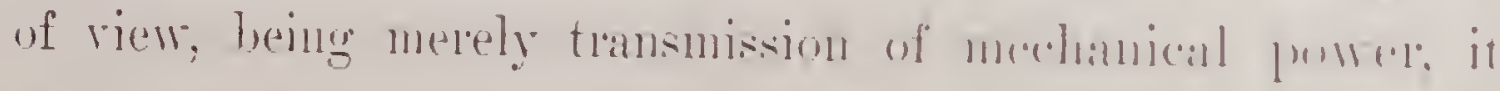

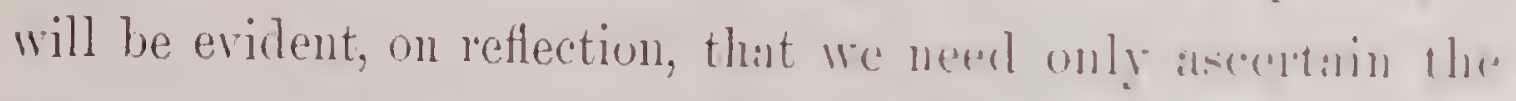
number of themal units dereloped in a rom time, hy it given amount of radiating surface maintained at a certain trull. perature, in order to determine the intensity which I)nlong ann Petit endearored to deduce from the relocity of cooling shown by the contraction of mercury and other fluids. It must be inferred, from their having adopted a metlont so nusitisfactory, that these physicists overlooked the fact thilt radiant intensity is most accurately measured by ascertiniuns the amount of thermal energy dereloped in a giren lime: and that they deemed it impossible to determine, by direct means, the relocity of cooling of imomlescent borlies. It canll. not be supposed that such skilful experimentalists as Dnlomo and Petit questioned the practicalbility of suspending an in. 
candescent borly within at racumm suromeded by a conling medimn. Why; then, it ma! be asked, din! they not resort to that obrions method which, if adopted, would at onee have convinced them of the fallacy of their formula assigning a fabulous rate of relocity of cooling to incundescent bodles? Wre must infer that they did not deem it practicalble to construct an instrument hy which the temperature of the enclosed incindescent body could be ancintately meat

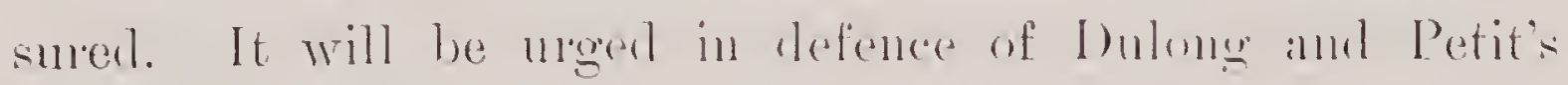
method, that the time acenpled in cooling cammot be alseres-

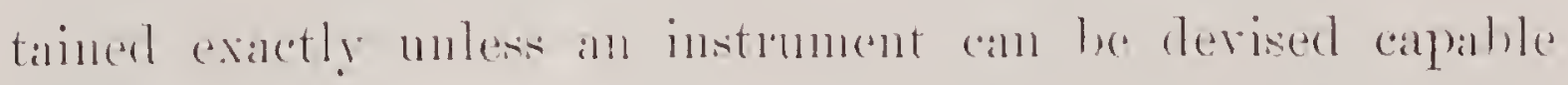
of showing the temperature of incindescent bolies. This objection, apparently valid since we posess no reliable and delicite pyrometer; falls to the gromol before the fact that, at a constant distance, the temperatures imparted to a-thermoncter hy radiation are proportionate to the temperatures of the radiator; and that consequently the velocity of cooling of a rarliator at any temperature whatever may he ascertained by a distant themometer as correctly as by one in actual contact. Before entering on a description of the method, before referred to, of measuring the radiant energy at high temperatures by ascertaining the amount of thermal cnergy developer in a given time by a given area, I will now briefly describe an instrument constructed in accorlance with the fact just mentioner, that the temperatures of a recipient of radiant heat are proportionate to the temperatures of the radiator. The illustration on Plate 6, Fig. 5, represents a vertical section and top view of the instrument referred to, by means of 
which the relocity of conling of an incandescent horly may be ascertained witl perfect alceuracy. Description: a u, sphe. ricul ressel composed of thin copper: conted with lamphlalick on the inside and provided with a coret l, fitting ail-tight iganist the top side of a ring secured to the upper part of the spherical ressel, the corer and the ring heing around together in order to dispense with parkings. c c an open eylindrical ressel through which a comstant stran of cold water is circulated by means of a force-pump and thexible tubes attached at 1 and o, these tubes communicating with al cis. teren in which water is mantamed at a constant lomperatmes

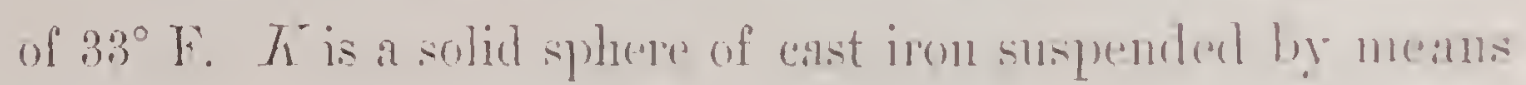

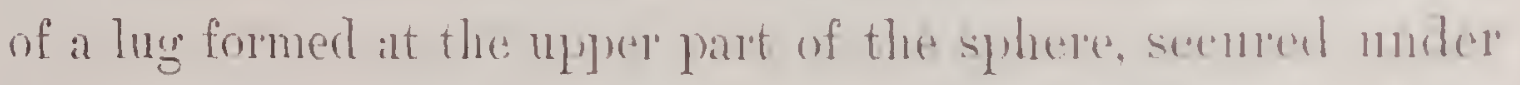
the corer b as shown by the drawing. A brass stopple !" fitting andight in a conical socket formed in the heture-ment

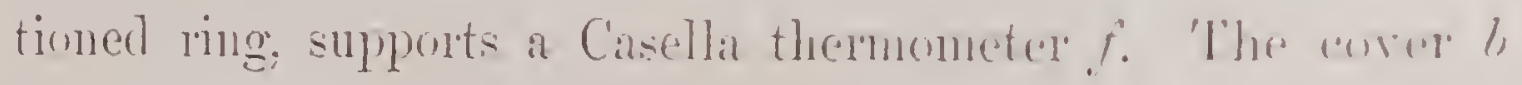
is provided with a rertical landle $b$ in order to facilitate the operation of inserting the solid sphere $K$, after being huated and suspended under the corer. 'The air is exhausted from the spherical ressel by means of a large air-pump, a stopcock being inserted in the exhaust pipe at 7 . The mole of operation will be readily molerstood by the following explanation. The solid cast-iron sphere being brought to noilly white heat in an air-furnace, is removed by suitable tongs and suspended under the corer b, which latter is quickly put in position over the opening of the spherical vessel. 'The air-pump is put in rapid motion immediately after putting on the cover; a few strokes of the witer-punl being required 
to fill the cistern " $a$ to the height shown in the drawing: These operations being performed with due diligence, practice has shown that the temperature of the incandescent sphere will not fall below $1,600^{\circ} \mathrm{F}$. before the racum is sufticiently complete to admit of recording the indicated temperatures. 'The thermometer of being secured firmly in the stopple $g$, may of course be inserterl very quickly, an innortant circunstance, since the bulb, in order to save time, should be previously heated to nearly maximum temperature. We have already pointed out that, agreeably to the laws which govern the transmission of radiant heat, the temperatures produced by radiation at constant distances are proportionate to the tem. peratures of the radiating body. It will be readily perceived, therefore, that the thermometer of will correctly indicate the rate of cooling of the suspended incandescent sphere. But in order to prove the fallacy of Dulong and Petit's estimate of the rate of cooling at high temperatures, we must also ascertain the temperature of the sphere itself. Bearing in mind that the temperature of the recipient of radiant heat is proportionate to that of the radiator, it will be perceived, on reflection, that we can previously determine the ratio between the temperature of the sphere $K$ and that of the record. ing thermometer f. Evidently this ratio may be ascertained at temperatures which admit of the employment of ordinary mereurial thermometers, hence the determination may be very exact. It will be readily understool that the thermometer intended for our investigation may be placed at such a dis. tance from a radiating spherical ressel containing mereury 
manintaned at at temperatme of 400 , that its indieations shall

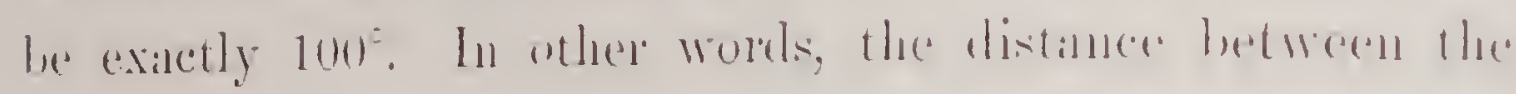
ladiator and the recording thermonter may be surele that the temperature of the former shall be exactly foml times gromites than the temperature of the latter. Som, if we resume the spherical ressel refered to and sulstitute and incombleserent sphere whose diameter correspunds with the ont-ide diambete

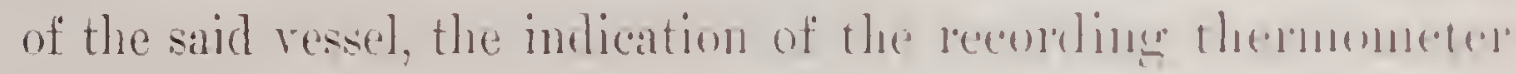

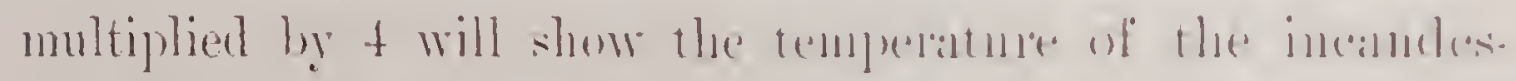

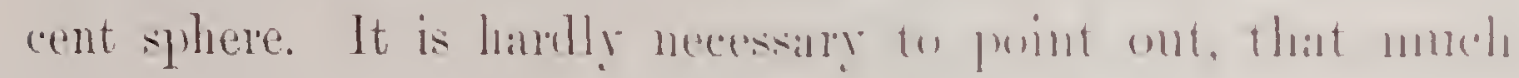

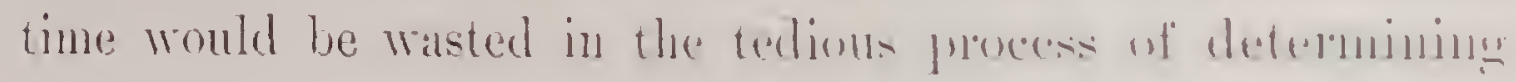

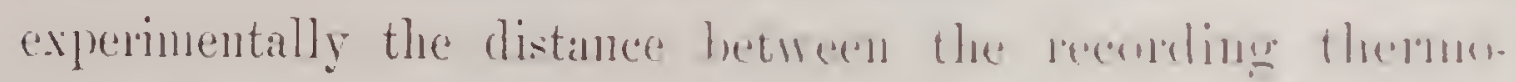
meter and the ralliator, necessary to canse an indication of the former cxactly one-fometh of the temperatume of the littlere Obrivusly a less symmetrical coeflicient mill answer neally ats well as the one mentioned. Let us themefono ascolatin, approximately, how near the recording themmoneter maly he placed from an incindescent sphere of the intended size, in order that the mereury in the bulb may not be brought to boiling heat. Having determined the distance of the thermo. meter as stated, we may, without further experimenting, construct our instrument as shown by the illustration. 'The splecrical vessel containing mercury being then introcluced and a vacuum formed within the surnouding enclosme, the temperature of the said spherical vessel, compared with the tempe. rature indicated by the recording thermoneter, will of course determine the coefficient of the instrument. 'The following brief explanation of the procedure will suffice. Suppose that 
the temperature of the mercury in the spherical vessel is $40 y^{\circ}$, while that indicated by the recording thermometer is $98^{\circ}$. 'The ratio of temperature between the radiator' and the recording thermometer will then be as 409 to 98 ; and hence the refficient sought will be $\frac{409}{9 S}=4.173$. Consequently, if we suspend the incindescent sphere $K$ within the enclosure as befure directed, and find by observation that the recording thermometer indicates $401^{\circ}$, we then learn that the temperature of the enclosed incindescent body, at the moment of observation, is $4.173 \times 401=1,673^{\circ} \mathrm{F}$. The means thus afforded of measuring, with great exactness, the temperature and ranliant intensity of incimlescent bodies, camnot firil to ficilitate future themic investigations.

The result of our experiments with the suspended incandescent sphere, will be fonnd recorded in the annexed set of tables, the first series, marked D, being constructed to the Finhenheit scale, while the second series $\mathrm{E}$ has been reduced to the Centigrade scale. The first column in Table D shows the temperature of the enclosure, the temperature of the radi. ating sphere being inserted in the second column. The excess of temperature of the radiator over that of the surrounding cold ressel will be found in the third column, the time actrr. ally occupied in redueing the temperature of the radiator $10^{\circ}$ F. being entered in the fourth column. The time of cooling, agreeably to the Newtonian law, will be fomm in the fifth and last column. The mode of constructing the tahlus will be reatily comprehended by referring to previous explant- 
CIIN!'. II.

\begin{tabular}{|c|c|c|c|c|c|c|c|c|c|}
\hline \multirow{2}{*}{ 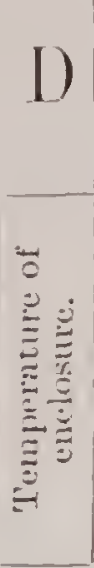 } & \multicolumn{9}{|c|}{ 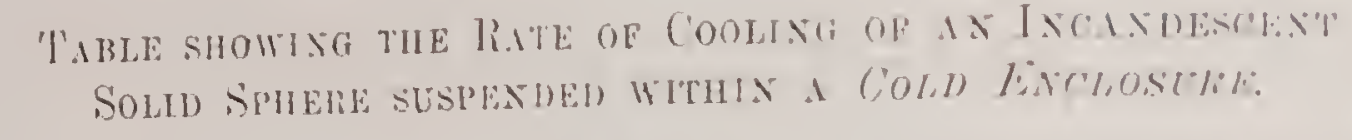 } \\
\hline & 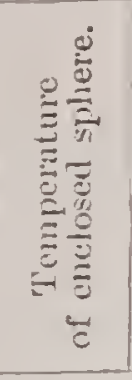 & 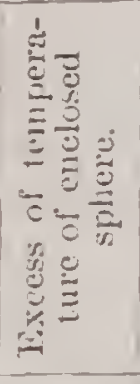 & 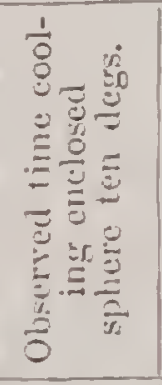 & $\begin{array}{l}0 \\
0\end{array}$ & 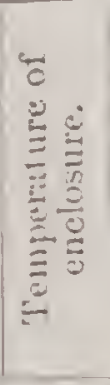 & 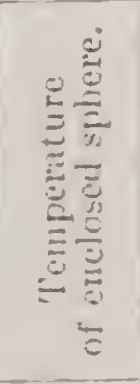 & 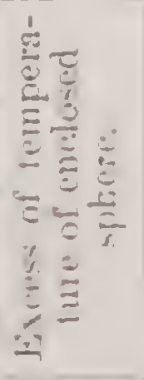 & 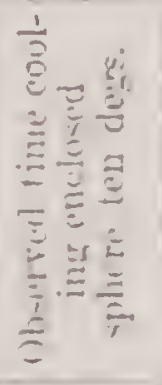 & 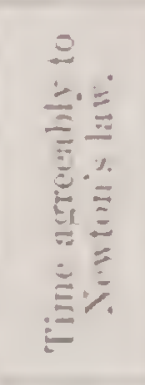 \\
\hline Falh. & ${ }^{\circ} F u t h$. & $F$ ith. & Secs. & Secs. & - Sult. & - Fith. & Fuh. & $\therefore e s$. & sind \\
\hline $3 t$ & 1600 & 1566 & $2.24+4$ & $21.9 \%$ & 3.1 & $1: 200$ & 1.981; & $811.8 \%$ & $26\left(i_{i}\right)$ \\
\hline 34 & 1590 & 1.50 & 2.45 & 2.2 .11 & 34 & 13111 & 1276 & $: 31.17$ & $2\left(i, S_{i}\right)$ \\
\hline 34 & 1.580 & $15+6$ & 2.2 .72 & 2.2 .25 & 34 & $1: 3(k)$ & $1: 966$ & 31.58 & $27.116 i$ \\
\hline 34 & $15 \%$ & 1.536 & 22.96 & $2 \cdot 2.319$ & 34 & 1290 & 12.56 & $\because 2.1111$ & 27.27 \\
\hline 34 & 1560 & $15: 6$ & $2: 3.21$ & 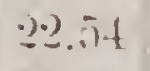 & $\therefore 4$ & 1280 & 1216 & $: 30.42$ & 27.18 \\
\hline 34 & 1550 & 1516 & 23.46 & 2.965 & $3-k$ & $12 \pi(1$ & 12336 & 30.64 & 7.711 \\
\hline 34 & 1.540 & 1600 & 23.72 & 2.2.5:3 & $3+$ & $1 \geq t 50$ & 1226 & $: 3: 3.28$ & 27.119 \\
\hline 34 & 1.53. & 1496 & 23.95 & 2.298 & 34 & 19:5) & $1: 11 ;$ & 33.3 .72 & $\therefore 1.1$ \\
\hline 34 & 1520 & 1480 & 24.2 .5 & $2: 3.1: 3$ & 31 & 12.11 & $1: 2116$ & 1.16 & $8 .: 2$ \\
\hline 34 & $1: 10$ & 1476 & 24.12 & $2: 3.28$ & 34 & $1 \div 3010$ & $11 ! 16 ;$ & $: 34.61$ & $\therefore$ (i) \\
\hline 34 & 1.500 & 1466 & 24.80 & $2: 3.14$ & 34 & 1.2.211 & 1180 & $: 3.1 .1)($; & S.. 1 \\
\hline 34 & 1490 & 1456 & $2 \% .08$ & 23.160 & 34 & 1210 & 1186 & 3.5 .50 & (9.18 \\
\hline 34 & 1480 & 1446 & 25.37 & 23.76 & 34 & $1: 200$ & $11160^{\circ}$ & (3.).89! & $2 !) .301$ \\
\hline $3 t$ & 1470 & 1436 & 25.66 & 23.92 & 34 & 1190 & 11.30 & $: 36.47$ & (9). \\
\hline 34 & 1460 & 1426 & 25.96 & 24.08 & 34 & 1180 & & & \\
\hline 34 & 1450 & 1416 & 26.26 & $2+.2 .5$ & $: 34$ & 1170 & 11336 & 37.44 & $3(1.118$ \\
\hline 34 & 1440 & 1406 & 26.57 & 24.42 & 34 & 1160 & 1126 & 37.94 & \\
\hline $3+$ & $14: 30$ & 1396 & 26.88 & 24.09 & 34 & 1150 & 1116 & $: 38.44$ & :3(1.(i) \\
\hline 34 & 1420 & 1386 & 27.211 & 24.87 & 34 & 1140 & 11116 & $: 8.95$ & 1.68 \\
\hline $3 t$ & 1410 & 1376 & $27.5 \%$ & 24.95 & 34 & $11: 30$ & 1096 & 39.47 & 1.1 .7 \\
\hline 34 & 1400 & 13360 & $27.8 \%$ & $2.5 .1: 3$ & 34 & 1120 & 1086 & 40.110 & $1.4: 3$ \\
\hline $3 t$ & 1839() & 13 inte & 28.18 & 2.5 .80 & 34 & 11111 & $10 \pi 6$ & $4(1.5)$ & $: 31.71$ \\
\hline $3 t$ & $1: 380$ & $1: 346$ & $28.6 \%$ & 25.48 & 34 & $11(x)$ & 101606 & +1.18 & $: 30.9(1)$ \\
\hline 34 & 1:37: & 1336 & 28.87 & $2 \pi .67$ & 34 & 1)(1)90 & $10.5)$ & 41. (ii) & $: 3: 2.311$ \\
\hline 34 & $13(j ;)$ & $1: 326$ & 29.23 & 25.86 & 84 & $1(1) 80$ & 1046 & $4: 1 ! 1$ & $: 3 \cdot 2$ (ii) \\
\hline $3 \cdot 1$ & $1: 3,3)$ & $13: 16$ & 29.619 & $2(j .0 ;)$ & 34 & $10 \%(1)$ & $10 ; 36$ & 4.2. & $: 3: .91$ \\
\hline 泣 & 1340 & 1306 & 25.98 & 20.0 .0 & $: 34$ & $10(6 ; i)$ & 11190 & $4: 3.34$ & :3:3.?.? \\
\hline 34 & $1: 3: 30$ & 1296 & $31) .37$ & $26.4 . j$ & :it & 10.01 & 11116 & 43.983 & 333.614 \\
\hline
\end{tabular}




\begin{tabular}{|c|c|c|c|c|c|c|c|c|c|}
\hline \multirow{2}{*}{ 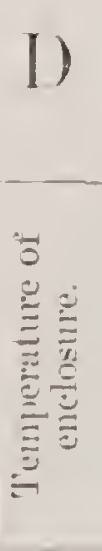 } & \multicolumn{9}{|c|}{ 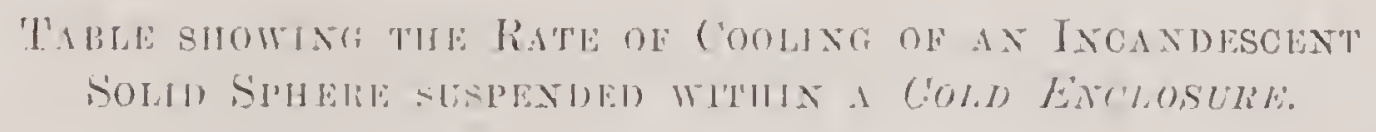 } \\
\hline & 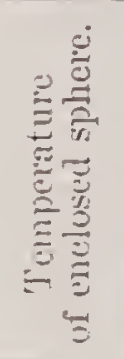 & 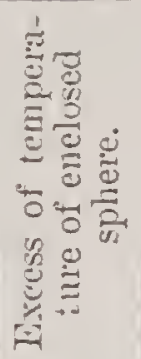 & 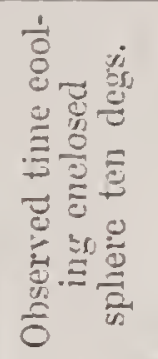 & 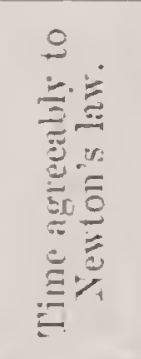 & 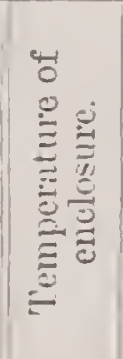 & 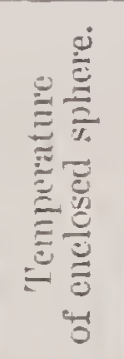 & 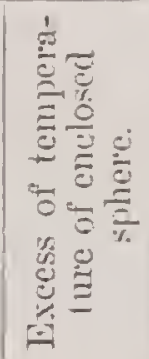 & 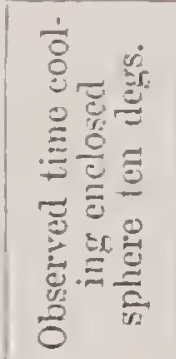 & 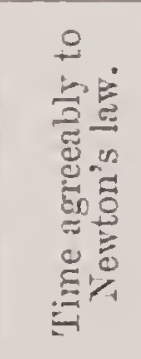 \\
\hline Fuh. & "Fith. & 'Finh. & Sees. & Secr. & DFath. & "Futh. & - Faht. & Secs. & Secs. \\
\hline 34 & 1040 & 1006 & 44.53 & 33.80 & 34 & 760 & 726 & 72.05 & 46.42 \\
\hline$: 34$ & 10.30 & 996 & 45.15 & 34.19 & $: 34$ & 750 & 716 & 73.66 & 47.04 \\
\hline 34 & 1020 & 986 & $45.79)$ & 34.53 & 34 & 740 & 706 & 75.33 & 47.68 \\
\hline 34 & 1010 & 976 & 46.45 & 38.57 & $3+t$ & 730 & 690 & 78.06 & 48.34 \\
\hline 34 & 1000 & 960 & 47.12 & 35.22 & 34 & 720 & 686 & 78.85 & 49.01 \\
\hline 34 & 990 & 9.56 & 47.81 & 8\%. & 34 & 710 & 676 & 80.70 & 49.71 \\
\hline 34 & 980 & 946 & 45.52 & 35.94 & 34 & 700 & 666 & 82.61 & 50.43 \\
\hline 34 & 970 & 936 & 40.24 & 36.31 & 34 & 690 & 656 & 84.58 & 51.16 \\
\hline 34 & 960 & 926 & 49.98 & 36.69 & 84 & 680 & 646 & 86.61 & 5) 1.92 \\
\hline 34 & 950 & 916 & 50.74 & 37.08 & 34 & 670 & 636 & 88.71 & 52.80 \\
\hline 34 & 940 & 906 & 51.533 & 37.45 & 34 & 660 & 626 & $90 . S S$ & 53.50 \\
\hline 34 & 930 & 896 & 52.35 & $3 \% .89$ & 34 & 650 & 616 & 93.12 & 54.33 \\
\hline 34 & 920 & 886 & $5: 20$ & 38.30 & 34 & 640 & 6010 & 95.43 & 55.18 \\
\hline 34 & 910 & 876 & .04 .08 & 38.72 & 34 & 630 & .506 & 97.81 & 56.07 \\
\hline 34 & 900 & 866 & 54.99 & $30.1 \%$ & 34 & 620 & 586 & 100.26 & 56.98 \\
\hline $3-4$ & 890 & 5.5 & 55.933 & 39.59 & 34 & 610 & 576 & 102.78 & 57.92 \\
\hline 34 & SSO & 846 & 56.90 & 40.04 & 34 & 600 & 566 & 105.37 & 58.90 \\
\hline 34 & 870 & 836 & 57.91 & 40.51 & 34 & 590 & 506 & 108.03 & 59.91 \\
\hline 34 & 860 & 826 & is.96 & 40.98 & 34 & 580 & 546 & 110.76 & 60.95 \\
\hline 34 & 850 & 816 & 60.15 & 41.48 & 34 & 580 & 536 & 113.50 & 62.03 \\
\hline 34 & 840 & 806 & 61.18 & 41.97 & 34 & 500 & 526 & 116.48 & 6.3 .15 \\
\hline 34 & 830 & 796 & 6.2 .36 & 42.48 & 34 & 550 & 510 & 119.37 & 64.80 \\
\hline 34 & $S: 0$ & 786 & $(33.59$ & 43.00 & 34 & 540 & 506 & $12: 38$ & 65.50 \\
\hline 34 & 810 & 766 & 64.57 & 43.53 & $3 t$ & 530 & 496 & 125.46 & $66.75)$ \\
\hline 34 & $S O O$ & 766 & 66.20 & 44.08 & 34 & 520 & 486 & 128.61 & 68.05 \\
\hline 34 & 790 & 756 & 67.58 & $44.6 \%$ & 34 & 510 & 476 & 131.88 & $(99.40$ \\
\hline 34 & 780 & 746 & $(69.01$ & 45.22 & 34 & 500 & 466 & 135.13 & 70.80 \\
\hline 34 & 780 & 736 & 80.5() & 45.81 & & & & & \\
\hline
\end{tabular}




\begin{tabular}{|c|c|c|c|c|c|c|c|}
\hline \multirow{2}{*}{ 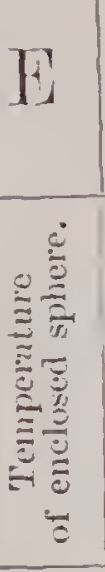 } & \multicolumn{7}{|c|}{ 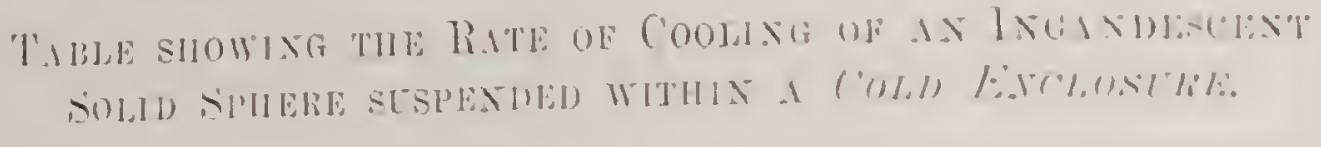 } \\
\hline & 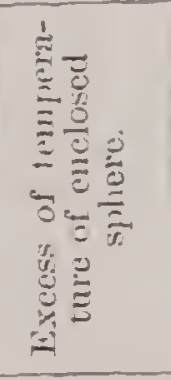 & 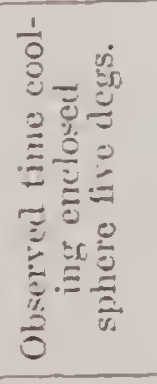 & 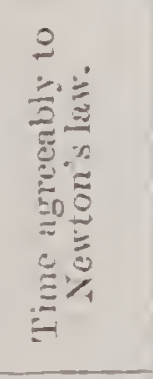 & 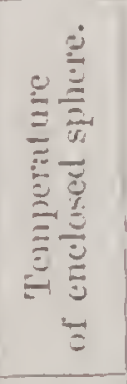 & 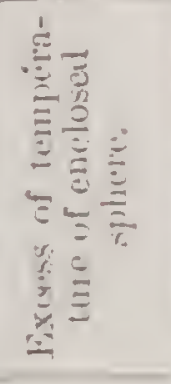 & 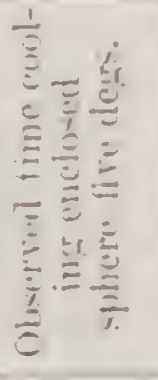 & 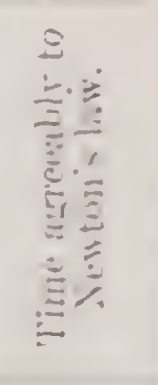 \\
\hline c cont. & - Cent. & Secs. & Secs. & - cont. & " cent. & sers & seen. \\
\hline 890 & 771.12 & 22.18 & 21.94 & 73.5 & ifli.1.2 & :31). $(0 ;\}$ & 26 (6) \\
\hline $88 \%$ & $\gamma(\mathrm{i} .1)$ & 20.39 & 22.06 & $7: 30$ & i11.1? & $:(1) .19 !)$ & $2(i .71 ;$ \\
\hline 880 & 761.12 & 2.261 & $2 \cdot 2.1 !$ & 7.2.5 & Fili.12 & :31.31; & $21 ;. ! 1.1$ \\
\hline 87.5 & 750.12 & 2).(8,3$ & 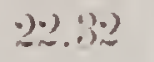 & $i \cdot 11$ & i(1). 1.2 & $31.7: 3$ & $=8.1: 3$ \\
\hline 870 & 751.12 & $2: 3.05$ & 22.44 & i1.i & $6 ! 10.12$ & 32.11 & 27.83 \\
\hline $86 \%$ & $i 40.12$ & $23.2 \%$ & 22.57 & 7111 & (iill.1) & $3: 2 .+4$ & $\because 7.01$ \\
\hline 860 & $7+1.12$ & $2: 49$ & 2.70 & 70.0 & risti. ! & ד & 27.01 \\
\hline $85 \%$ & 736.12 & 283.73 & $22.8: 3$ & $71) 0$ & $601.1 \%$ & $: 33.266$ & 27.811 \\
\hline 8.5$)$ & $\tau 31.12$ & $2: 3.96$ & $20.9 \%$ & (69). & (itili.1. & :iis.(ii) & 28.12 \\
\hline Sti) & 726.12 & 24.20 & $2: 3.11$ & (i)100 & (iiil.1.) & 34.11 .5 & ה:::2 \\
\hline 840 & 721.12 & 24.44 & 23.25 & (is.) & (ifiti. 1.2 & 34.4 .1 & 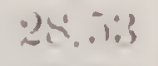 \\
\hline 83.5 & 816.12 & 24.69 & 23.39 & 680 & $6(i 1.12$ & $34.81 i$ & 25.74 \\
\hline $8: 30$ & 711.12 & $24.9 \pm$ & 23.53 & $67 . j$ & $6.5(5.12$ & 35.27 & 28.95 \\
\hline 825 & 706.12 & 25.20 & 23.67 & $6 \%$ & (6.) 1.1:2 & 3.). (i!) & \\
\hline 820 & $7(01.12$ & $2 \pi .46$ & $2: 3.81$ & $6(6.5)$ & $6+6.12$ & $: 3(i .11$ & $2(9.39$ \\
\hline 815 & 696.12 & 25.73 & 23.96 & 660 & $6+1.12$ & 3li.int & $99.6 \mathrm{~L}$ \\
\hline$\$ 10$ & $691.1 \%$ & 26.00 & 24.11 & (65) & $63(1.12$ & 汸.5s & 29.84 \\
\hline $8(0)$ & 686.12 & $26.2 S$ & 24.26 & 850 & $(; 331.12$ & 37.42 & $30.17 \%$ \\
\hline 800 & 681.12 & 26.56 & 24.41 & 645 & $626.1 \div$ & & $: 3(1.331)$ \\
\hline 795 & 676.12 & 26.84 & 24.57 & 640 & 621.12 & $: 38.32$ & $3(1) .04$ \\
\hline 790 & 671.12 & 27.13 & $24.7 \%$ & 635 & 616.12 & 38. & 30.78 \\
\hline 785 & 766.12 & 27.42 & 24.85 & 630 & 611.12 & 39.2 .4 & $31.18: 3$ \\
\hline 780 & 761.12 & 27.71 & 25014 & (12:) & 606 & 39.71 & 31.28 \\
\hline $7 \%$ & 7.) 6.12 & 28.01 & 2.2 .20 & $(920)$ & 601.12 & 40.19 & $: 1.513$ \\
\hline ซชo & 751.12 & 28.31 & $25 .: 36$ & 615 & 596.12 & $41) .(17$ & $31.7 !)$ \\
\hline 76.5 & 746.12 & 28.69 & 25.53 & 610 & 591.12 & 41.16 & $3: .11 .5$ \\
\hline$\tau 60$ & 741.12 & 28.93 & 25.70 & $60 \%$ & 5S6. 12 & $41 .(i j)$ & 32.31 \\
\hline 755 & 730.12 & 29.25 & $2 \pi .87$ & $60)$ & 51.12 & 42.15 & 32.18 \\
\hline \%) & 731.12 & 29.58 & 26.04 & $59 \%$ & 576.12 & 42.66 & 32.85 \\
\hline 745 & 726.12 & 29.92 & 26.22 & 590 & 571.12 & $4: 3.18$ & $3: 3.13$ \\
\hline 740 & $\tau 21.12$ & 30.27 & 26.40 & 585 & 566.12 & 13.71 & 333.42 \\
\hline
\end{tabular}




\begin{tabular}{|c|c|c|c|c|c|c|c|}
\hline \multirow{2}{*}{ 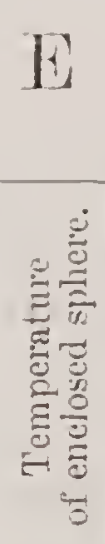 } & \multicolumn{7}{|c|}{ 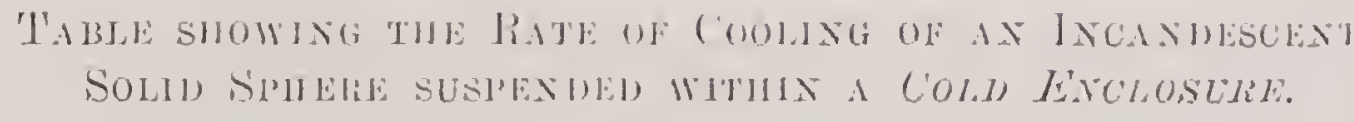 } \\
\hline & 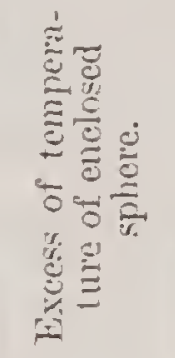 & 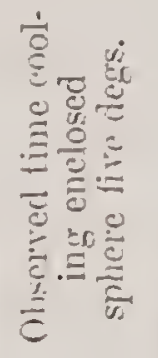 & 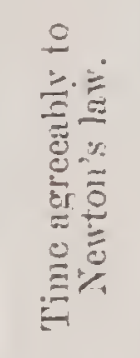 & 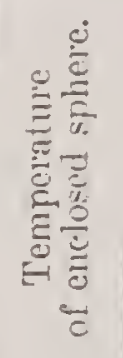 & 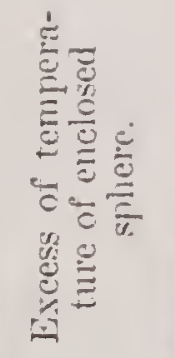 & 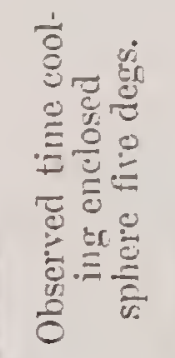 & 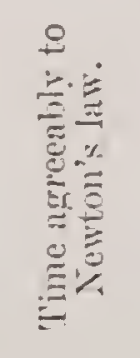 \\
\hline - vent & ${ }^{\circ}$ Cint. & Secs. & Secs. & - Cent. & - Cent. & $\sec \theta$ & Secs. \\
\hline . 80 & 561.12 & 44.25 & 33.71 & 425 & 406.12 & 71.19 & 46.18 \\
\hline .775 & 500.12 & 44.80 & 34.01. & 420 & 401.12 & 72.61 & 46.063 \\
\hline 570 & 651.12 & 45.37 & 34.31 & $41 \%$ & 396.12 & 74.08 & 47.20 \\
\hline $56 \%$ & 546.12 & 45.95 & 34.61 & 410 & 391.12 & 75.60 & 47.78 \\
\hline 560 & $5+1.12$ & 46.51 & 34.92 & 405 & 386.12 & 77.17 & 48.37 \\
\hline $65 \%$ & 536.12 & $47.1 \%$ & $3 \pi .24$ & 400 & 381.12 & 78.78 & 48.98 \\
\hline 50 & 531.12 & 47.78 & 35.56 & 39.5 & 376.12 & 80.44 & 49.60 \\
\hline $54 i$ & 596.12 & 48.41 & $3 \% .89$ & 390 & 371.12 & 82.14 & 50.24 \\
\hline 5) 10 & 521.12 & 49.00 & 36.22 & 355 & 366.12 & 83.89 & 50.90 \\
\hline $53 \%$ & .160 .12 & 49.72 & 36.50 & 380 & 361.12 & 85. 69 & 51.58 \\
\hline 530 & $\pi 11.12$ & 50.40 & 36.91 & 375 & 356.12 & 87.55 & 52.27 \\
\hline 5) 25 & $.5(1) .12$ & .7 .10 & 37.26 & 370 & 351.12 & 89.47 & 52.98 \\
\hline 520 & 501.12 & 51.82 & 37.62 & $36 \tilde{5}$ & 346.12 & 91.44 & 63.71 \\
\hline 515 & 490.12 & 52.56 & 37.90 & 360 & 341.12 & 93.47 & 54.46 \\
\hline 510 & 491.12 & 53.32 & 38.36 & 355 & 336.12 & 95.65 & 55.23 \\
\hline 505 & 486.12 & 54.11 & 38.74 & 350 & 331.12 & 97.69 & 56.02 \\
\hline 500 & 481.12 & 54.93 & 39.13 & 345 & 326.12 & 99.89 & 56.84 \\
\hline 495 & 470.12 & 55.78 & 39.53 & 340 & 321.12 & 102.15 & 57.68 \\
\hline 490 & 471.12 & 56.65 & 39.94 & 335 & 316.12 & 104.46 & 58.55 \\
\hline 485 & 466.12 & 57.55 & 40.35 & 330 & 311.12 & 106.83 & 59.45 \\
\hline 480 & 461.12 & 58.48 & 40.77 & 325 & 306.12 & 109.20 & 60.37 \\
\hline $47 \pi$ & 456.12 & 59.44 & 41.20 & 320 & 301.12 & 111.74 & 61.32 \\
\hline 470 & 451.12 & 60.44 & 41.64 & 315 & 296.12 & 114.28 & 62.30 \\
\hline 40.5 & 446.12 & 61.47 & 42.10 & 310 & 291.12 & 116.87 & 63.31 \\
\hline 460 & 441.12 & 62.54 & 42.56 & 305 & 286.12 & 119.52 & 04.30 \\
\hline $45 \%$ & 436.12 & 63.65 & $4: 3.03$ & 300 & 281.12 & 122.23 & (6). 44 \\
\hline 450 & 431.12 & 64.80 & 43.51 & 295 & 276.12 & 125.00 & 60.56 \\
\hline $44 \tilde{5}$ & 426.12 & 65. 99 & 44.00 & 290 & 271.12 & 127.83 & 67.72 \\
\hline 440 & 421.12 & $6 \% .22$ & 44.50 & 285 & 266.12 & 130.71 & 68.92 \\
\hline 495 & 416.12 & 68.50 & 45.01 & 280 & 261.12 & 133.65 & 70.52 \\
\hline 430 & 411.12 & 69.82 & 45.54 & 275 & 256.12 & & \\
\hline
\end{tabular}


СНАР. 11 .

tions. It will be seen that the time occupied in cooling the radiating sphere through a range of ten degrees forms dhe basis, the temperature being of comse deduced from the indi. antion of the thermometer f. The adrocates of Inlong amd Petit's doctrine will be surpuised to find by our tables that the incundescont sphere enclosed in a vacumm survoumded by a cooling medium maintained at a rery low temprature, requires upwards of twenty secombs to cool five degrees Contigrade, while agreeably to Dulongy's formula the stated reduction of intensity takes place during an interval ocenpying only a rery small fraction of one second. Again, onr tables show that the fall of temperature from $1,600^{\circ} \mathrm{F}$. to $500^{\circ} \mathrm{F}$. requires the considerable lapse of ninety-seren mimutes, a fatct 1 hich alone proves that the celebrated formula of Dulong is mossly erroneous.

We have before adrerted to the fact that physicists have supposed that the rate of cooling of a body approaching white heat cimnot be ascertained practically, because we possess no reliable instrument for measuring high temperatures. MII. Dulong and Petit, apparently impressed with this idea, con. fined their researches, as before stater, to temperatures below that of boiling mercury, imagining that by observing the rate of cooling up to a differential temperature of $240^{\circ} \mathrm{C}$. they would be enabled to establish a law which would deter. mine radiant energy for all intensities. Unfortunately, phy. sicists have accepted the result of those researches, Dulong's formula being now the guide which the student is taught to follow in calculating the energy of rmliant heat. Probably 
no doctrine in physics has occasioned such serious misconception as that propounded by MIM. Dulong and Petit. The advance of every branch of knowledge connected with radiant heat has been retarded by the adoption of their doctrine regarding its transmission. Anong other important matter's, the question relating to the temperature of the sun has be come seriously entangled by its adoption. It las led such eninent men as Pouillet to assume that the emission of heat at the surface of the sun is so rapid that the ascertained enormous development of 300,000 thermal units in a minute, on one square foot, may be accounted for by the accepted doctrine, even supposing the temperature of the surface of the photosphere to be only $1,461^{\circ}$ C. A glance at the preceding Table E, which is based on actual trial, shows the velocity of cooling to be so moderate at the high temperature of $890^{\circ} \mathrm{C}$, that the fall only amounts to $\frac{60.0}{22.18} \times(890-885)=13.5^{\circ} \mathrm{C}$. in one minute, instead of $1,876.6^{\circ} \mathrm{C}$. for the stated temperature, shown by Dulong and Petit's formula $Y^{+}=2.037$ (1.007 $7^{t}$ - 1). It is surprising that the true character of this palpably erroneous formula, so often applied by engineers and physicists, has never been subjected to practical investigation. A positive test might liave been applied in various ways, although not with that degree of exactness which is attainable by the means we have just described. The fallacy of the assumption, that an increase of a few hundred degrees of temperature suffices to augment the rate of cooling a thousand fold, becomes self-evident if we consider that an increased 
rate of cooling means a lloportionate increase of the (aiphlit. lity of communicating mechanical energy. P'ractical engineds who have observed the short time required to raise a masis of rex-hot metal to the melting point, ale fandiar with the fact that the heat impanted to the metal by the combustibles during the short interval necessaly to reach the point of lusion, from that of red heat, is wholly insufficient to commmonicaste the enormous amount of energeg assmed by those who atecept MII. Dulong and Petits formula. 'This practical mode of tent. ing the correctuess of the ancepted doctrinc demambs serions: reflection. Let us consider that brightred heat indicalls at temperature of $1,000^{\circ}$ C., while welding or white heal indi. cates $1,500^{\circ} \mathrm{C}$. Now, according to the formula $\mathrm{V}=2 .(1:) \mathrm{r}$

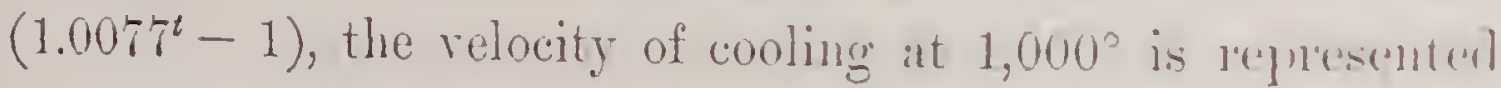
by a fall of temperature of one degree in the sluort time of $\frac{1}{4,356}$ of a minute, while the relocity of cooling at $1,500 \mathrm{C}$., assigned by the same formula, will be at the rate of one de. gree in the exceedingly brief period of $\frac{1}{202,710}$ of a minute; hence the energy imparted to the heated metal while its tenperature is being raised from 1,000 to $1,500^{\circ}$-viz., $500^{\circ} \mathrm{C}$. will be $\frac{202,710}{4,356}=46$ times greater than the energy impinted during the Tonyer period required to attain bright-red heat. Let us also consider that, owing to the diminished differential temperature between the burning combustible and the metal, the latter will absorb proportionably less heat from the former while attaining white heat than before red heat is reaclied; 
thus the fallacy of the formula becomes yet more apparent. We have allearly stated that the rate of cooling at high temperatures may be determined with perfect accuracy, by measuring the number of thermal mits which a certain amonnt of radiating surface derelops in a given time. It will be shown in Chapter XIII. that fused iron maintained at a tem. perature of $2,940^{\circ} \mathrm{F}$. above the surrounding air, develops $1,(1) 3$ thermal units per minute 11 pon an area of one square foot; the means employed to ascertain this fact being a calo. rimeter floating on the surfice of the fused metal, nearly in contact with the same. The illustration shown on Plate (6, Fig. fi, represents a rertical section of a calorineter for mea. suring the ratiant energy of incandescent metals. It is placed on the top of a block of cast iron bronght to white heat, in an air-furnace, the hottom of the instrument being nearly in contact with the top of the incandescent metal. The nature of the derice, and the mode of conducting the experiment, heing precisely the same as shown with great minuteness in Clliupter XIII., it will only be necessary to obserre, with reference to the apparently mprotected condition of the heater, that the initial temperature of the water contained in the same is equal to the atmospheric temperature, while the powerful matiation from the incandescent block, together with the inter. vention of the double casing, effectually prevents cooling by external currents of air. Again, the duration of the experi. ments being restricted to a few mimutes, the refrigerating in. Huence of the surrounding air will be practically inappreciable.

The result of numerous experiments condncted in order to 
ascertain the amonnt of ralliant energy developed at ran'ions differential temperitures from $1000^{\circ} \mathrm{F}$. to $2,900^{\circ} \mathrm{F}$, will he found by inspecting the amnexed 'Table F, which shows the number of thermal units dereloped in one minute by a ranti. ating surface of one square foot. The molinates of the curr. " $b$ (see diagrams Fig. $T$ and Fig. $S$ attalched to the illuatration Plate i) represent the radiant enerey developmed ly. the differential temperatures marked on the rertical base-line upon which the ordinates hive heen projected. It should he stated that the themal mits representerl hy the ordinales in Fig. I correspond with the energy developed by rating the temperature of a quantity of water weighing 1 1h. aroill. dupois $1^{\circ} \mathrm{F}$; while the unit. ("caloris") expunsoul ly" the ordinates in Fig. S correspond with the energy derolngent hy raising the temperature of 1 kilogranmme of Water I" Croti. gracle. The spaces between the ordinates Fing. $s$, of connrat, mark interrals of $100^{3}$ Centigrade, the spaces between the ordinates in Fig. 7 marking intervals of $100^{\circ}$ Falnenlucit. Referring to Table $\mathrm{F}$, it will be seen that the number of thermal units entered in the third colmmn is that developued luring one minute on an allea of one square forst; the rol. responding temperature of the radiating body being entered in the second columm. The fourth columm shows the incres. ment of dynanic energy for eath 100 increase of temprelat. ture, also expressed in thermal mits. The fifth colmmn ant tains the rate of increment, assuming the minimum anele?

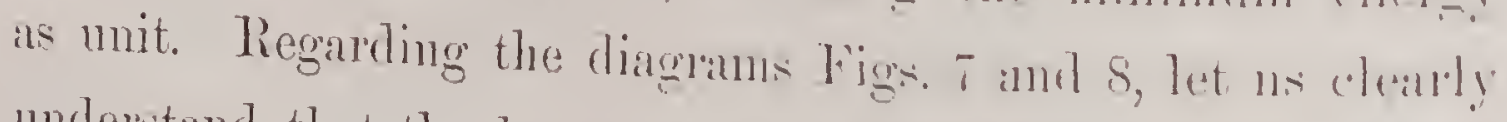
understand that the length of the ordinates of the curves a 


\begin{tabular}{|c|c|c|c|c|c|c|c|c|c|}
\hline \multirow{2}{*}{ 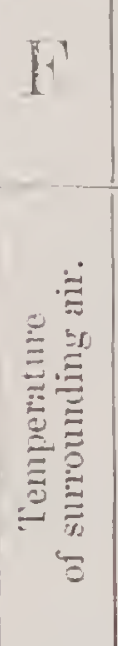 } & \multicolumn{9}{|c|}{ 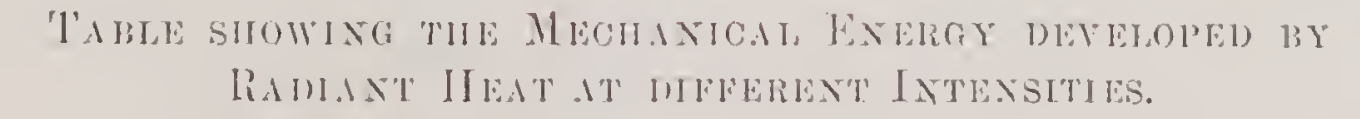 } \\
\hline & 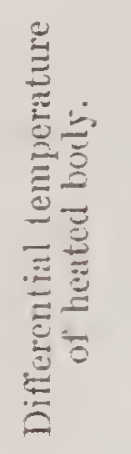 & 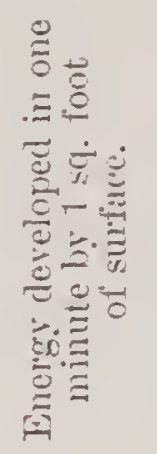 & 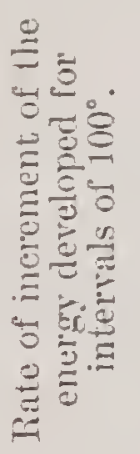 & 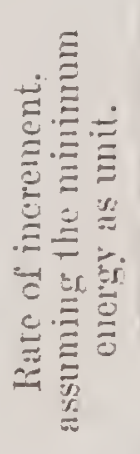 & 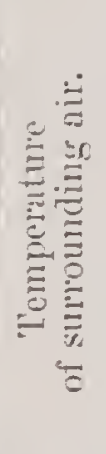 & 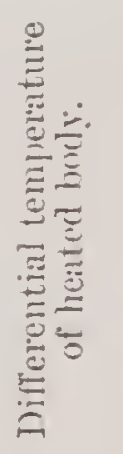 & 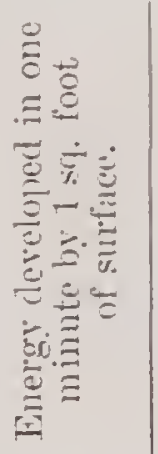 & 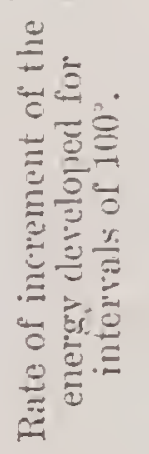 & 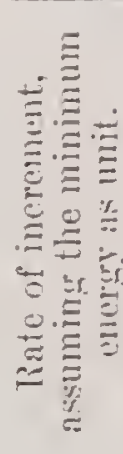 \\
\hline ofith. & - Fak. & $\begin{array}{l}\text { - Thermal } \\
\text { unite. }\end{array}$ & $\begin{array}{l}\text { Thermul } \\
\text { units. }\end{array}$ & Ritutio. & - Foth. & Fah. & $\begin{array}{c}\text { Thermal } \\
\text { units. }\end{array}$ & $\begin{array}{c}\text { Thermal } \\
\text { units. }\end{array}$ & Ratio. \\
\hline (ii) & 2900 & 980.2 & 81.7 & 12.38 & 60 & 1500 & 209.5 & 27.9 & 4.2 .2 \\
\hline (60) & 2800 & 898.5 & 77.2 & 11.70 & 60 & 1400 & 181.6 & 25.0 & 3.79 \\
\hline (6) & 2700 & 821.3 & $7 \% .8$ & 11.03 & 60 & 1300 & 150.6 & 22.3 & 3.38 \\
\hline (6) & 2600 & 745.5 & 68.5 & 10.38 & 6() & 1200 & 134.8 & 19.8 & $3.0(1)$ \\
\hline (6) & 2500 & 680.1 & 64.3 & 9.74 & 60 & 1700 & 114.5 & 17.5 & 2.65 \\
\hline (6) & 2400 & (i15). & 60.2 & 9.12 & 60 & 1000 & $9 \% .0$ & $1 \pi .4$ & 2.383 \\
\hline 60 & 2300 & 50.5. & 50.2 & 8.51 & 60 & 900 & 81.6 & 13.5 & 2.05 \\
\hline 60 & 2200 & 499.3 & 52.3 & 7.92 & 60 & 800 & 68.1 & 11.8 & $1.7 !$ \\
\hline 60 & 2100 & 447.0 & 48.5 & 7.35 & 60 & 700 & 56.3 & 10.3 & 1.56 \\
\hline 60 & 2000 & 398.6 & 44.8 & 6.89 & 60 & 600 & 46.0 & 9.1 & 1.38 \\
\hline 60) & 1900 & 353.7 & 41.2 & 6.24 & 60 & 500 & 36.9 & S.2 & 1.24 \\
\hline (6) & 1800 & 312.5 & 37.7 & 5.71 & 60 & 400 & 28.7 & $\% .6$ & 1.15 \\
\hline (ii) & 1700 & 274.8 & 34.3 & 5.20 & 60 & 300 & 21.1 & 7.3 & 1.10 \\
\hline (60) & 1600 & 240.5 & 31.0 & 4.70 & 60 & 200 & 13.8 & 7.2 & 1.09 \\
\hline & & & & & 60 & 100 & 0.6 & & \\
\hline \multicolumn{5}{|c|}{ - Centigrade. } & \multicolumn{5}{|c|}{ - Centigrade. } \\
\hline 1.) & $16(1) 0$ & 242.9 & 36.0 & 11.61 & 15 & 800 & 48.5 & 11.3 & 3.64 \\
\hline 1.) & 1500 & $2(1) 6.9$ & 39.1 & 10.35 & 15) & 800 & 37.2 & 9.3 & 3.610 \\
\hline 15) & 1400 & 174.8 & 28.8 & $9.2 !$ & 15 & 600 & 27.9 & 7.4 & 2.39 \\
\hline 15 & 1300 & 146.0 & 25.5 & $8.2 \%$ & $1 \%$ & 500 & 20.5 & 5.7 & 1.84 \\
\hline 15) & 1200 & 120.5 & 22.3 & 7.19 & 15 & 400 & 14.8 & 4.6 & 1.48 \\
\hline 15 & 1100 & 98.2 & 19.5 & $(0.29)$ & 15) & 300 & 10.2 & 3.7 & 1.19 \\
\hline 15) & 1000 & 78.7 & 16.4 & -1.29) & 1) & 200 & 6.5) & 3.4 & 1.09 \\
\hline 15 & 900 & 62.3 & 13.8 & $4.46^{\circ}$ & 15) & 100 & 3.1 & & \\
\hline
\end{tabular}


6 represent the number of thermal mits actmally tramsteremel from one square foot of radiating smeface to the Huid com. tained in the calorineter, during ane minute, the frompratinture of the radiator being that marked on the rertical line. It

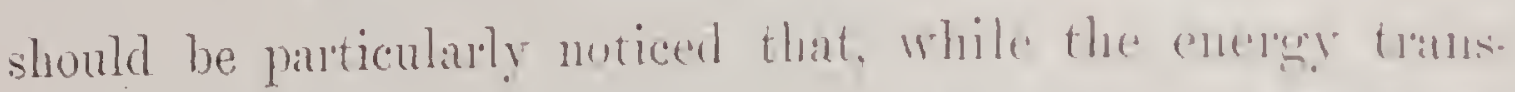

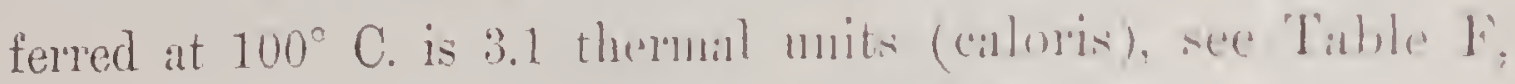

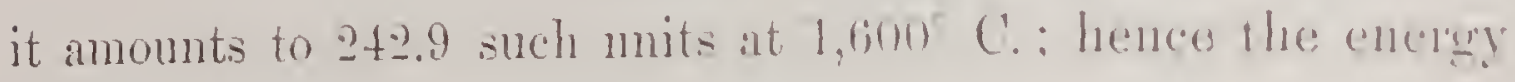
will be $\frac{2+2.9}{3.1}=78.3$ times greater al a differential tempe rature of $1,600^{\circ} \mathrm{C}$. than at $1000^{\circ} \mathrm{C}$. Newton's lat shom:

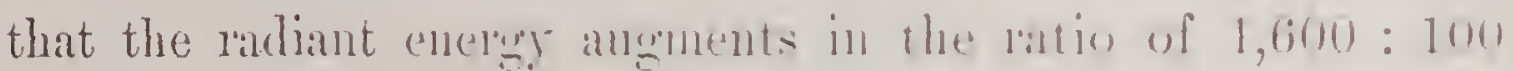
$=16: 1$. It will thus he seen that the alctual increase of energy is $\frac{T S .3}{16}=4.89$ times greatel thall Hant arigignul by

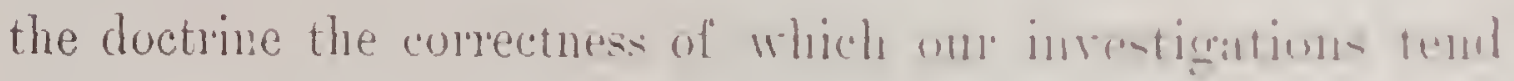

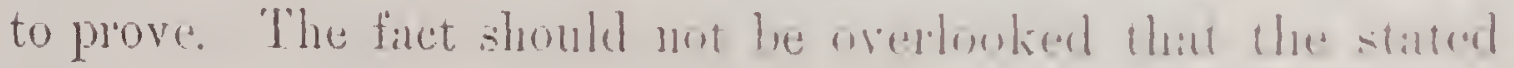
discrepancy refers to the maximmo intemsity of orombalterl fused cast iron just before the internal molecular andingennent is broken up and the metal dissipated. Besides, we have already pointed out that the expansion of 1netals is aceomplat. nied by molecular change within the mass, angunenting the energy of radiation. Nor shonld the fart be lost sight of that Newton's doctrine takes no congnizance of such molu. cular change or disturbance within the leated boly. 'The insignificance of the apparent error of the Yewtonian law referred to will be seen by a practical application of the rival theory of MMI. Dulong and Petit. Let us comprare the difference of energy pronluced at the extremss of $100^{\circ} \mathrm{C}$. 
and $1,500^{\circ} \mathrm{C}$. differential temperature established by their re. searches. According to the tables, accepted by Prof. Stewart and others, contained in the second part of Dulong and Petit's fanous work, "The Laws of Refrigeration," the rate of cool. ing at a differential temperature of $100^{\circ} \mathrm{C}$. is $2^{\circ} .30 \mathrm{C}$. in one ninute (the surrounding medium being maintained at the freezing point of water); while at a differential temperature of $240^{\circ} \mathrm{C}$. the rate is stated to be $10^{\circ} .69 \mathrm{C}$. Applying these rates to the formula of Dulong and Petit, it will be found that when the differential temperature is $1,500^{\circ} \mathrm{C}$. the fall will be $202,710^{\circ}$ C. in one minute. The radiant energy parted with at $1,500^{\circ} \mathrm{C}$. will accordingly be $\frac{202,710}{2.30}=88,135$ times greater than at $100^{\circ} \mathrm{C}$. But our tables and diagrams, based on actual trial, show that the radiant energy at $1,500^{\circ} \mathrm{C}$. is only $\frac{206.9}{3.1}=66.7$ times greater than at $100^{\circ} \mathrm{C}$. Hence the radiant energy at $1,500^{\circ}$ C., agreeably to Dulong and Petit's theory, will be $\frac{88,135}{66.7}=1,321$ times higher than that established by our elaborate practical investigation. 


\title{
CIIAPTER III.
}

\author{
INTENSITY OF SOLAR RAIIATION.
}

Ture illustration shown on Plate S repuerents a reertical section of an instrument constructed for asceertaining, hy at new and exact method, the intensity of solar radiation at the surfice of the earth, specially arranged for revolving colsere ratories. Sir John IEerschel's definition of the word wetimn. meter-" an instrument for measuring the intensity of lueat in the sun's rays" - warrants the adoption of that term.

The causes which modify the intensity of solar radiation are chiefly: the position of the earth in its orbit, the suris zenith distance-on which depends the depth of the atmosphere to be penetrated by the rays - and vapors in the atmosphere. The temperature of surrounding objects which radiate towards substances exposed to the sun's rays, and the heat abstracted from such substances by currents of air, present serious disturbing elements, rendering an accurate determination of the radiant intensity by ordinary thermometers practically impos. sible. It is hardly necessan'y to print ont that solar inten- 
sity cannot be satislactorily ascertaned by the old mothon of deducting the temperature of a themmometer in the shalle from that of another thermometer exposed to the smo. 'The investigations of Daniell relating to the sun's radiant heat, frequently refered to in works on meteorology, conducted in the latitude of London, where the depth of the atmosphere at noon, during the summer solstice, is 0.55 greater than on the ecliptic, merit serious consideration. The subjoined table contains the result of his observations on solar radiation throughout a day in the month of June.

A grance at this table shows that, according to the arlopted nethod of determining the intensity of solar radiation by ale. ducting the temperature indicated by a thermometer in the shade from the temperature attained in the sun, the radiant heat is considerably less before than after noon. 'The differential temperature, or solar intensity, at 9 s.M., accorting to this table, is $25^{\circ}$, while at 3 P.x., with an equal zenith distance and equal depth of atmospliere to pencetrate, the solar intensity is stated to be $62^{\circ}$, thus exhibiting the enormons difference of 27. An explanation of the canses of the extraordinary errors of Daniell's table is scarcely needer, but attention should be called to the gross imperfection of such a morle of determining solar radiation as that of noting the different indications of shaded and exposed themometers. During the early stages of my investigation relating to the mechanical properties of the sun's radiant heat, I adopted this mode of ascertaining the temperatme produced by solar raliation: but notwithstanding numerous expedients resurted to in order to prevent 


\begin{tabular}{|c|c|c|c|c|c|c|}
\hline \multirow{3}{*}{ 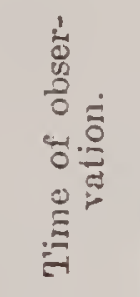 } & \multicolumn{4}{|c|}{ TEAIPERATURE, A.M. } & \multirow{2}{*}{\multicolumn{2}{|c|}{$\begin{array}{l}\text { Difrerential } \\
\text { temperature or solm } \\
\text { intensity. }\end{array}$}} \\
\hline & \multicolumn{2}{|c|}{ In the sinn. } & \multicolumn{2}{|c|}{ In the shade. } & & \\
\hline & - Fah. & - Cent. & - Fah. & - Cent. & ${ }^{\circ}$ Fuh. & 'Cent. \\
\hline 9.00 & 93 & 33.58 & 68 & 20.00 & 2.5 & 13.88 \\
\hline 9.30 & 103 & 39.44 & 69 & 20.55 & 34 & 18.89 \\
\hline 10.00 & 111 & $43.8 S$ & 70 & 21.11 & +1 & 20.79 \\
\hline 10.30 & 119 & 48.33 & 71 & 21.66 & 48 & ¿li.ii \\
\hline 11.00 & 124 & i) 1.11 & $\gamma 1$ & 21.66 & 53 & 29.4 .1 \\
\hline 11.30 & 125 & 51.66 & 72 & $2: 2.21$ & $0: 3$ & 29.4 .1 \\
\hline 12.00 & 129 & 53.58 & 73 & $2.2 .7 \pi$ & i) 6 & $: 31.11$ \\
\hline
\end{tabular}

\begin{tabular}{|c|c|c|c|c|c|c|}
\hline \multirow{3}{*}{ 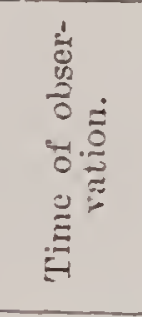 } & \multicolumn{4}{|c|}{ TEMPERATURE, P.M. } & \multirow{2}{*}{\multicolumn{2}{|c|}{$\begin{array}{c}\text { Diffurential } \\
\text { temprature or =olur } \\
\text { inten-ity. }\end{array}$}} \\
\hline & \multicolumn{2}{|c|}{ In the sun. } & \multicolumn{2}{|c|}{ In the shade. } & & \\
\hline & - $F a h$. & - Cent. & ${ }^{\circ}$ Fuh. & - Cent. & ${ }^{\circ} F u h$. & ren' \\
\hline 12.30 & 132 & 55.55 & 74 & 23.33 & 58 & 32.22 \\
\hline 1.00 & 141 & 60.55 & 74 & 23.33 & 67 & 37.22 \\
\hline 1.30 & 140 & 60.00 & 75 & 23.85 & 65 & 36.12 \\
\hline 2.00 & 143 & 61.66 & 75 & 23.88 & 68 & 37.78 \\
\hline 2.30 & 138 & 58.8s & 76 & 24.44 & 62 & 34.44 \\
\hline 3.00 & 138 & 58.88 & 76 & 24.44 & 62 & 34.44 \\
\hline 3.30 & 132 & 55.55 & 77 & 25.00 & $5 \tilde{5}$ & 30.55 \\
\hline 4.00 & 124 & 51.11 & 76 & 24.44 & 48 & 26.67 \\
\hline 4.30 & 123 & 50.55 & 77 & 25.00 & 46 & 25.55 \\
\hline 5.00 & 112 & 44.44 & 76 & 24.44 & 36 & 20.00 \\
\hline 5.30 & 106 & 41.11 & 75 & 23.88 & 31 & 17.23 \\
\hline 6.00 & 10() & 37.77 & 73 & 22.77 & 27 & 15.00 \\
\hline
\end{tabular}


the thermometers from being unduly influenced by the radiant heat of the air and surrounding objects, I failed to secure satisfactory results. The most important point-the controlling the inegular action of the surrounding air, which affects the exposed as well as the shaded thermometer-having foresented obstacles which no mechanical arrangement whatever could orercome, I adopted the method of wholly excluding the atmosphere. By this expedient the bulb of the thermo. meter within the instrument becomes surrounded by ether only; hence the energy transmitted by the sun's rays determines the temperature freed from atmospheric influence. It will be objected that the thermometer cannot be applied within a vacuum without the employment of some transparent covering, and that, consequently, the energy of the rays will suffer considerable loss before reaching the bulb. This objection is readily met by applying a thin lens of about 50 ins. focus, inserted at such a distance from the bulb that the gain effected by concentrating the rays will exactly balance the loss of calorific energy attending their passage throngh the lens. It is evident, however, that a plane crystal might be employed in place of the lens, provided its absorptive power were known. I have accordingly constructed an apparatus for measuring the loss of calorific energy attending the fassage of the sun's rays through plane crystals of adequate thickness to resist the atmospheric pressure when the air is withdrawn from the interior chamber of the instrument. It should be mentioned that many of the observations recorded in this work have been male with an actinometer provided 
with a plane crystal, the alsonptive powere of whilh ammonts

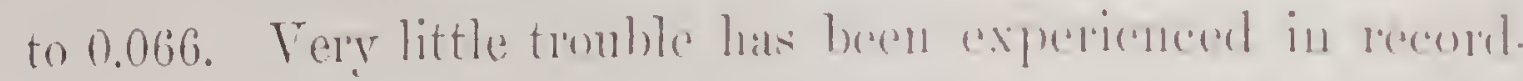
ing observations mate with this instrmment, the indicatcal dif. ferential temperatures having simply lues multiplied hy the coefficient 1.066 .

Careful inspection of our illustration, towethere with the foregoing explanations regrarding the nature of the lense and.

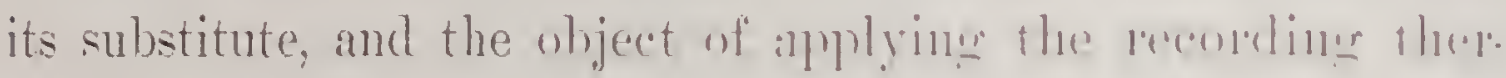
mometer within a racuum, render a mitmute description of the letail of the derice unnecessary. Like the solal calonimeter. Plate 10, barticularly describerl in Chapter V., the actime.

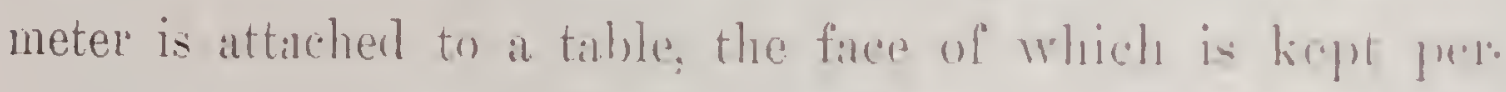

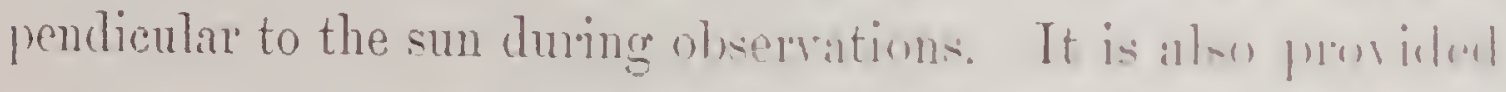
with a graduated are and stationary index, similan we throe applied to the solar calorimeter, hy me:tlls of which the suris zenitl distance may he ascertinined at every instant. The chimber contaning the bulb of the thermometer is 4.3 ins. in dianeter, plated with polished nickel and surrounded with a double casing, through which a current of witep is cirrulated by means precisely like those employed in the solitr calorimeter, the racuum being also produced in a sinular manner, and flexible tubes employed for commecting the instrument with the stationary pump. The cistern which sup. plies the circulating water is kept at a constant temprelialture of $60^{\circ} \mathrm{F}$, and, in order to secure perfect alcouracy, the thermometer employed for regulating this temperiture is so applied that the return current from the andimomelen to the cistern circulates romel its huib. A thin metallic sereen of 
ammular form, smpported hy forll columns, and plated with silver, protects the instrument from the suns ractiant heat. for the purpose of economizing the cooling medium requined to kiepl the cireulating water at the proper temperature. 'The opening in the screen corresponds with the size of the lens. The bulb of the themometer is 3 ins. in length, in order to expose a relatively large surface to the action of the solar rays; the proportion of heating surface to the contruts of the bull, being thus much greater than in ordinary thernometers. The upper half of the bull, is coated with lamp-black; the lower lualf being exposed to the action of the reflected ray from the bottom of the chamber, in such a mamner that the radiation of this lower bright half of the hull, is nentralized by reflected heat. Much pains has been bestower in order to attain this desirable object. Before making an ohservation witl the actinometer, the racuam gange should be inspected, and the water from the cistern be permitted to run freely through the casing for several minutes until the temperature of the return current and that indicated by the enclosed thermometer correspond. The ob. servatory being then turned to the sun, and the declination table on which the actinometer stands adjuster to the proper. angle, the corer orer the lens should be remored. The height of the mercurial colmmn of the enclosed thermometer will then, in due time, inclicate with absolute certainty the intensity of the sun's radiant heat, independent of atmospheric temperature and other disturbing causes which render the indications of solar intensity by common thermometer's mere 
approximations. It will be erident that, since the instral. ment is kept at a constant temperature of $60^{\circ}$, it continmally ladiates leat of that intensity townds the bull, of the end. closed thermometer; hence the zero of the thermonnetric scale of tho actinometer will mak $60^{\circ}$ alsore falluenlicit's zero. Obviously; the point reached hy the meremial columm of the enclosed themometel ahore the stated \%ere on exposule to the sun's lays can only be attained in rintue of the porrer of maided solar radiation. In support of this akson. tion it may be well to repeat the explanation al rouly griven, namely, that the bulb is surrounded by cother alume, fresol from all disturbing influences of ponklorous mattor, aml that

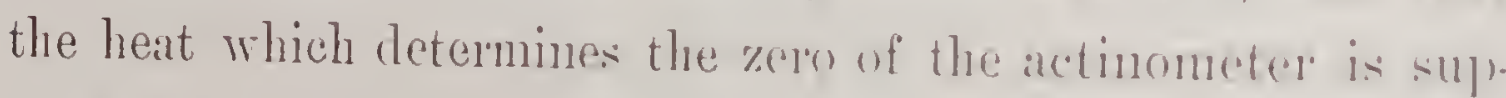
plied by radiation from the instrumesut itsolf. Tho impontant question of actual intensity with leferelice to the arlopion "absolute" zero will be diseussed in Chantel's I. . and XVI.; but it may be well to state in this place that the arotino. meter merely shows the thermometric interral of solar inter. sity on Fahrenheit's scale, without reference to the position of that interval on a scale which commences at the accepter "absolute zero." I regard this absolute \%ero, howerer, as an ignis-fatums, retreating as fast as we approach it.

It should be observed that all the actinometric observations contained in this work lave been made in lat. to deg. 42 min., thus only 17 deg. 12 min. from the tropic of Cancer. 'The depth of atmosphere so near the tropics being, at mid. summer, only 0.047 greater than on the ecliptic, while the sun's zenith distance on lat. 10 deg. 42 min. during the winter 
solstice is only 2 deg. 18 min. less than at the pole at mil. summer, I have been enabled to determine the maximum intensity of solar radiation for all latitudes from the equator to the pole. The diagram represented on Pl. ?, Fig. 1, show's the relations of atmospheric deptlı and solall intensity for each degree of zenith distance from the rertieal to the roth degree. A brief description will suftice to render this diagram readily understood. The ordinates between the curve $e$ a and the bise line ff ? exhibit the true proportions of the depth of the atmosphere penetrated by the rays from the rertical to $75 \mathrm{deg}$. zenith distance; while the ordinates of the curve o a indicate the relative intensity of the sun's radiant heat at the sumnner solstice for each degree of the sun's zenith distance from the rertical to 5 o deg. The straight line $b$ a is the tangent of the curres $e$ a and $c a$. It will be seen by closely eximnining these curres, and the ordinates resting on the base line $f^{\prime}$ o (comparing the same with the figures in the tables of this chapter), that the intensities of solar radiation vary ne:urly in the inverse ratio of the cube roots of the atmosplieric depth for all zenith distances not exceeding is deg. The ordinates between the irregular line $d d d$ and the base line $f y$ show the solar intensity for atch degree of zenith distance from 23 deg. to 75 deg., ascertained by actinometric observation during a day in the month of August when the sun was olscured by cirri of averige density. With reference to the solar engine this irregular line d d d possesses great interest, as it indicates the available solar energy, for mechanical purposes, during a day when the sun is partially obsenred. 


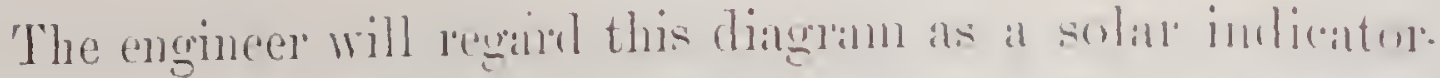

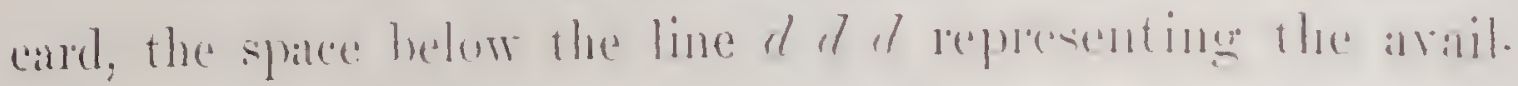
able powes, white the slate contained between that line and

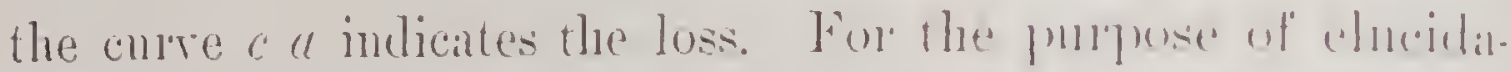

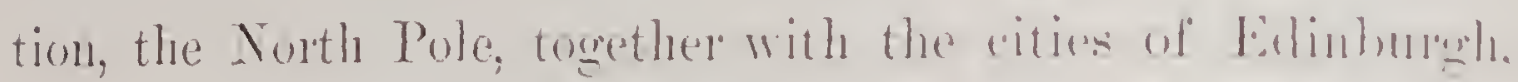

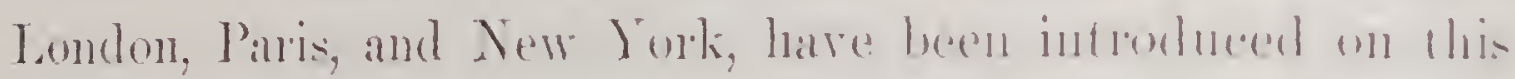

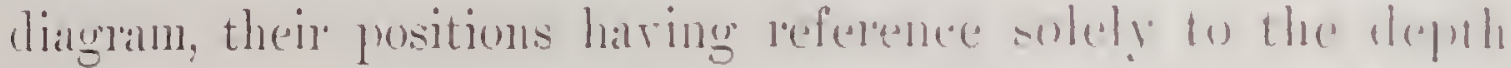
of atmosphere and solar intensity during the summer sol-tice. The amesed Tables $\mathrm{A}, \mathrm{B}$, and C shor the ledation depuld of atmosphere and maximum solan intensity at midsmmmer for each degree of the sun's zenith distance from the verticil w T5 deg.

Refering to the second part of the diagram, it will be

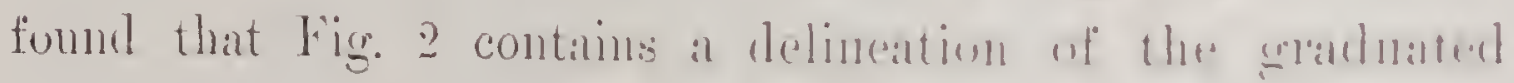
phate specially mentioned in Chapter V'. This plate in fur. nished with a morable radial index, to cmable the whorvele to ascertinn quickly the depth of atmosphere cormenombling with observed zenith distances. The graduated plate is cons. structed to a scale of 24 miles to the inch, the currature of the carth's surfice and the atmospheric bonmtaly (:mp). posed to extend 42 miles above the earth) being ancomat wy laid down aceording to the said seale. The rertieall hepth of the atmosplere, it will lie seen, has lxen dirided into 1001 equal parts, the same graduation having heen introduced on the movable index. Acerdingly, by plateme this index at angles corresponting with the obserred zentith distance, the intersection of its upper edge with the tor) line of the atmon. sphere will show the proportion of dialgential and rentitul 


\begin{tabular}{|c|c|c|c|c|c|c|}
\hline$\Lambda$ & \multicolumn{6}{|c|}{ 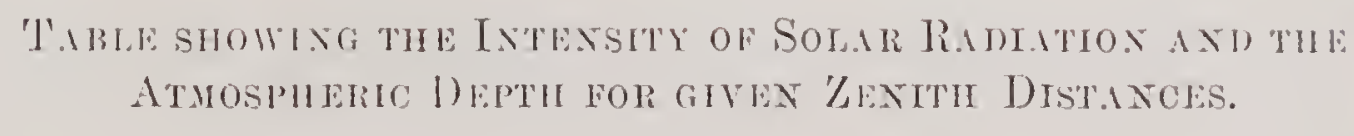 } \\
\hline \multirow{2}{*}{ 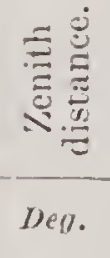 } & \multirow{2}{*}{$\frac{\begin{array}{c}\text { Atmospheric } \\
\text { depth. }\end{array}}{\text { Relative. }}$} & \multirow{2}{*}{$\begin{array}{c}\begin{array}{c}\text { Increment } \\
\text { of atmospheric } \\
\text { depth. }\end{array} \\
\text { Relative. }\end{array}$} & \multicolumn{2}{|c|}{ Maximum intensity. } & \multicolumn{2}{|c|}{$\begin{array}{l}\text { Observed intensity } \\
\text { during } \\
\text { a partially cloudy da. }\end{array}$} \\
\hline & & & ${ }^{\circ}$ Faht. & ${ }^{\circ}$ Cent. & ${ }^{\circ}$ Fith. & - Ce:ut. \\
\hline () & 1.000 & 0.000 & 67.20 & 37.33 & $\ldots$ & $\ldots$ \\
\hline 1 & 1.000 & 0.000 & $6 \% .19$ & 37.33 & $\ldots$ & $\ldots$ \\
\hline 2 & 1.000 & 0.000 & 67.18 & 37.32 & $\ldots$ & $\ldots$ \\
\hline 3 & 1.001 & 0.001 & $6 \% .16$ & 37.31 & $\ldots$ & $\ldots$ \\
\hline 4 & 1.002 & 0.002 & 67.14 & 37.30 & $\ldots$ & $\ldots$ \\
\hline 5 & 1.003 & 0.003 & $6 \% .11$ & 37.28 & $\ldots$ & $\ldots$ \\
\hline 6 & $1.00 \mathrm{~s}$ & $0.00 \%$ & 67.07 & 37.26 & $\ldots$ & $\ldots$ \\
\hline 7 & $1.00 \%$ & $0.00 \%$ & 67.02 & 37.24 & $\ldots$ & $\ldots$ \\
\hline S & 1.010 & 0.010 & 66.97 & 37.21 & $\ldots$ & $\ldots$ \\
\hline 9 & 1.013 & 0.013 & 60.91 & 37.17 & $\cdots$ & $\ldots$ \\
\hline 10 & 1.016 & 0.016 & 66.84 & $3 \% .13$ & $\ldots$ & $\ldots$ \\
\hline 11 & 1.019 & (0.(1)19 & $66.7 \%$ & 37.09 & $\ldots$ & $\ldots$ \\
\hline 12 & $1 .(12: 3$ & 0.023 & 66.69 & 37.05 & $\cdots$ & $\cdots$ \\
\hline 13 & 1.027 & 0.027 & 66.60 & 37.00 & $\ldots$ & $\ldots$ \\
\hline 14 & 1.0331 & 0.031 & 66.51 & 36.95 & $\ldots$ & $\ldots$ \\
\hline 15) & 1.0336 & (). $0: 36$ & 60.41 & 36.89 & $\ldots$ & ... .. \\
\hline 16 & 1.041 & (1).(1) 41 & $66.30)$ & 36.83 & $\ldots$ & $\ldots$ \\
\hline 17 & 1.046 & 0.046 & 66.19 & 36.77 & $\ldots$ & $\ldots$ \\
\hline 18 & 1.051 & (0.0.51 & $60.0 \%$ & 36.80 & $\ldots$ & $\ldots$ \\
\hline 19 & 1.0 .57 & (1).15.7 & 6.5 .94 & $36.6: 3$ & $\ldots$ & $\ldots$ \\
\hline 20 & 1.06:3 & $0.116: 3$ & 6.5.S() & 36.56 & $\ldots$ & $\ldots$ \\
\hline 21 & 1.070 & 0.070 & $6 \overline{5}) .66$ & $36.4 S$ & $\ldots$ & $\ldots$ \\
\hline $2: 2$ & 1.077 & 0.078 & $(0.5 .51$ & $36.4 \mathrm{C}$ & $\ldots$ & $\ldots$ \\
\hline $2: 3$ & 1.0855 & 0.08 .5 & 65.36 & 36.31 & .59 .5 & 33.05 \\
\hline 24 & $1.09: 3$ & $0.09: 3$ & $6 . \pi .20$ & 36.22 & 18.4 & 32.44 \\
\hline $2 \pi$ & 1.102 & 0.102 & 6.5 .03 & 36.13 & 58.7 & 30.04 \\
\hline
\end{tabular}




\begin{tabular}{|c|c|c|c|c|c|c|}
\hline B & \multicolumn{6}{|c|}{ 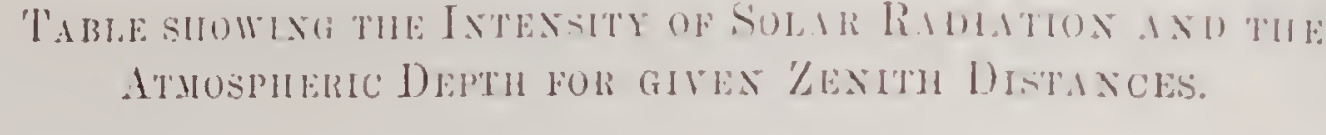 } \\
\hline 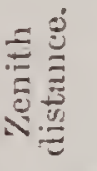 & $\begin{array}{l}\text { Atmospheric } \\
\text { depth. }\end{array}$ & $\begin{array}{l}\text { Increment } \\
\text { of atunospheric } \\
\text { depth. }\end{array}$ & Mrхіmи & ntensity. & Oberey partial & 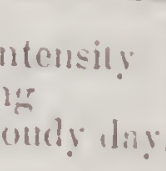 \\
\hline Deg. & Relative. & Pelative. & - Fath. & - Cont. & 'Filh. & - Cent. \\
\hline 26 & 1.111 & 0.111 & $6+.85$ & $: 36.11: 3$ & is. 4 & $: 3: 2.44$ \\
\hline 27 & 1.121 & 0.121 & 64.67 & 3.7 .93 & 57.5 & 31.95 \\
\hline 28 & 1.132 & $0.1: 32$ & 64.48 & 3.5 .80 & 57.7 & 32.01 .5 \\
\hline 29 & 1.141 & 0.141 & $(6+.2 !)$ & 36.72 & .78 .7 & 32.0 .5 \\
\hline 30 & 1.1 .12 & 0.152 & 04.18 & 3.5 .601 & 57.5 & 30.11 \\
\hline 31 & $1.16 t$ & 0.164 & 6.3.85 & $3 \%) .49$ & If(i.) & 31.61 \\
\hline 32 & 1.170 & 0.176 & fii). 66 & 35.360 & (16.) & $: 31.61$ \\
\hline 33 & 1.189 & 0.189 & (i3). $4: 3$ & 39.24 & .06 .7 & 31 . \\
\hline 34 & 1.2()$^{\circ}$ & 0.20 .3 & $(33.20)$ & 3i). 11 & 07.11 & $31.66 i$ \\
\hline 3\% & $1.21 \tau$ & 0.217 & (2).96 & 0.3 .95 & 56.8 & $31 . .1 .1$ \\
\hline 36 & 1.232 & 0.232 & 62.72 & 34.54 & ixi.t & 31.331 \\
\hline 37 & 1.248 & 0.248 & 62.47 & 34.80 & 56.2 & 31.22 \\
\hline 38 & $1.26 \%$ & 0.26 .5 & $(2.2 .21$ & 34.569 & $5 \pi .8$ & 31.00 \\
\hline 39 & $1.28: 3$ & 0.283 & 61.94 & 34.21 & 56.1 & 31.17 \\
\hline 40 & 1.302 & 0.302 & $61.6 \%$ & 34.26 & \%). 0 & 30.65 \\
\hline 41 & 1.322 & 0.322 & (i1.39) & $3+.11$ & 54.8 & 30.44 \\
\hline 42 & 1.342 & 0.342 & 61.10 & 33.95 & 54.8 & 30.4 .4 \\
\hline 43 & 1.363 & 0.363 & 60.81 & 333.78 & 54.8 & 30.501 \\
\hline 44 & 1.384 & 0.384 & 60.51 & 33.62 & 54.6 & .30 .34 \\
\hline 4) & 1.406 & 0.406 & 60.20 & 33.45 & 0.7 & $3(1.40$ \\
\hline 46 & 1.431 & 0.431 & 59.88 & $3: 3.27$ & 54.5 & 30.28 \\
\hline 47 & 1.4 .5 & 0.457 & 59.56 & 33.019 & 54.4 & $3(1.22)$ \\
\hline 48 & 1.485 & (0.4S5 & $59.2: 3$ & 39.91 & 53.4 & 29.60 \\
\hline 49 & 1.514 & 0.514 & 58.89 & 02.72 & $(i 3) .1$ & 29.41 \\
\hline 50 & 1.545 & 0.545 & 58.54 & 32.12 & (1)3.2 & 29.65 \\
\hline
\end{tabular}




\begin{tabular}{|c|c|c|c|c|c|c|}
\hline $\mathrm{C}$ & \multicolumn{6}{|c|}{ 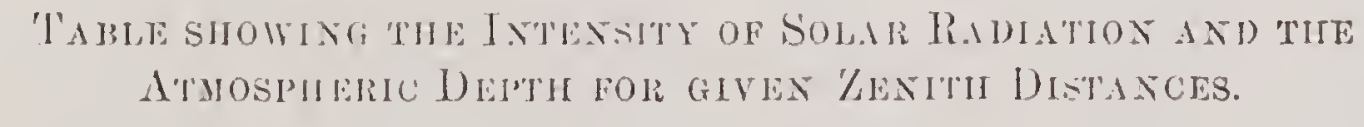 } \\
\hline \multirow{2}{*}{ 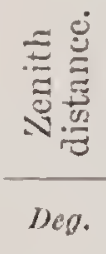 } & \multirow{2}{*}{$\begin{array}{c}\begin{array}{c}\text { Atmospheric } \\
\text { depth. }\end{array} \\
\text { Relatixe. }\end{array}$} & \multirow{2}{*}{$\begin{array}{c}\begin{array}{c}\text { Increment } \\
\text { of atmospheric } \\
\text { deptls. }\end{array} \\
\text { Relative. }\end{array}$} & \multicolumn{2}{|c|}{ Maximum intensity. } & \multicolumn{2}{|c|}{$\begin{array}{l}\text { Obscred intensity } \\
\text { during } \\
\text { a partially cloudy day. }\end{array}$} \\
\hline & & & Fah. & ${ }^{-}$Cont. & ${ }^{\circ} F u t h$. & - Cent. \\
\hline 51 & $1.67 \%$ & 0.577 & 58.18 & 32.82 & 50.7 & 28.16 \\
\hline 52 & 1.612 & 0.612 & 57.81 & 32.12 & 50.6 & 28.11 \\
\hline 53 & 1.648 & $0.64 \mathrm{~S}$ & 57.44 & 31.91 & 45.6 & $2 \% .44$ \\
\hline 54 & 1.686 & 0.686 & 57.05 & 31.70 & 45.4 & 25. 22 \\
\hline 5) & 1.726 & 0.726 & 56.66 & 31.48 & 44.6 & 24.77 \\
\hline 56 & 1.769 & 0.796 & 56.25 & 31.25 & 44.6 & 24.77 \\
\hline 57 & 1.815 & 0.815 & 55.82 & 31.02 & 47.0 & 26.11 \\
\hline is & $1.86 t$ & 0.564 & 55.39 & 30.77 & 48.0 & 26.66 \\
\hline 59 & 1.916 & 0.916 & 54.94 & 30.52 & 47.3 & $26.2 \%$ \\
\hline 60 & 1.970 & 0.970 & 54.47 & 30.26 & 47.4 & 26.32 \\
\hline 61 & 2.137 & 1.037 & 53.99 & 29.99 & 46.4 & 25.77 \\
\hline 62 & 2.098 & $1.09 \mathrm{~S}$ & 53.48 & 29.72 & 46.8 & 26.00 \\
\hline 63 & 2.164 & 1.164 & 52.96 & 29.42 & 46.8 & 26.00 \\
\hline 64 & 2.235 & $1.23 \tilde{0}$ & 52.41 & 29.12 & 46.4 & 25.77 \\
\hline 65 & 2.312 & 1.312 & $51.8 \overline{5}$ & 28.81 & 46.1 & 25.50 \\
\hline 66 & 2.398 & 1.398 & 51.26 & 28.48 & 45.0 & 25.00 \\
\hline 67 & 2.490 & 1.490 & 50.63 & 28.13 & 42.6 & 23.66 \\
\hline 68 & 2.591 & 1.591 & 49.96 & 27.76 & 43.1 & 23.94 \\
\hline 69 & 2.701 & 1.701 & 49.24 & 27.36 & 43.2 & 24.00 \\
\hline 70 & 2.821 & 1.821 & 48.43 & 26.93 & 42.8 & 23.77 \\
\hline 71 & 2.952 & 1.952 & 47.67 & 26.46 & 41.9 & 23.27 \\
\hline 72 & 3.097 & 2.097 & 46.72 & 25.96 & 40.4 & 22.44 \\
\hline 73 & $3.2 \%)$ & 2.255 & 45.72 & 25.40 & 33.5 & 18.61 \\
\hline 74 & 3.428 & 2.428 & 44.61 & 24.79 & 36.3 & 20.16 \\
\hline $7 \tilde{5}$ & 3.624 & 2.624 & 43.39 & 24.11 & 32.4 & 18.00 \\
\hline
\end{tabular}


atmosphoric deptle. The important relations of solan intere sity, zenth distance, atmospheric depth. and latitude, heimes exhibited by the diagram under considerations. lot us now consider the mode arlopted in constructimg the sinne.

The data indispensible in constructing the curve 11 , the ordinates of which represent the masimum solal inf(11-ity for given zenith distances when the canth is in aphelion, fint clatum our attention. It will be perceiverl, on reflection, that, moine to the valying intensity resultimg foum ehomge of distance he.

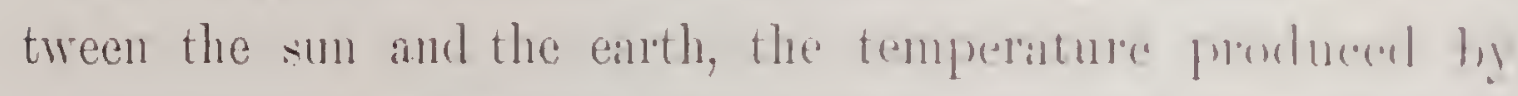
solar rarliation raries from day to day with the altereal gme

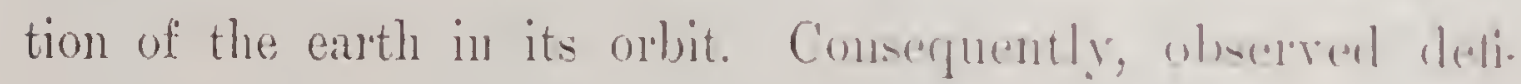
ciency of solar intensity at any griren zonith distance does not always fumish, as suplosod by celtain metromblegiste, al

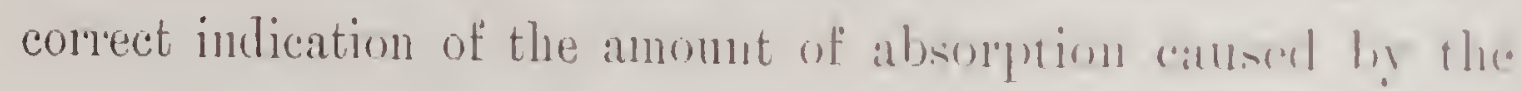
presence of rapor in the atmosphere. Ohwiomsly, the oherevel deficiency of intensity may result pintially from the eanthis proximity to the aphelion. It will be seen by reference to Chapter IV. that for equal zenith distance a diminution of temperature of $4^{\circ} .66 \mathrm{~F}$. takes place during the summer sol. stice, compared with the intensity of the ladliant heat at mid. winter. Consequently, if we omit to make a propor allowance for the difference of intensity resulting from the sun's distance at the time of observation, no satisfactory recold can be produced. It is hardly necessary to point out that, muless we establish some fixed position of the carth in its orbit, as a zero, it will be impossible to construct tables of varying solar intensity capable of being employed as a means of correction. 
I have accordingly adopted the aphetion as the controlling zero, all my tables relating to this subject having reference to maximum solur intensit!l when the curth is furthest from the sun. 'The reader will find the question of solar distance fully discussed in the next chapter.

Regarding the observations which lave furnished the data on which our diagram has been constructed and the amexed tables calculated, it will be necessary to state, for the information of those who are not familiar with the subject, that observations of maximum solar intensity should be continued luring a series of years. It sometimes happens that an entire season elapses without a single opportmity for a satisfactory observation presenting itself. Records of solar observations are therefore exceedingly irregular'; during some seasons reliable observations mily be made from day to day; then again a considerable period intervenes during which the work must be wholly suspended. Indeed, the difficulties inseparable from investigations of maximum solar energy can lardly be exaggerated. A complete record requires that the sun should be perfectly clear while we observe the temperature produced by the rays for each degree of the sun's zenith distance, upon each degree of latitude, for each day in the year. Now, observations continued during a century would not suffice to produce such a record; hence I have had recourse to the graphic method, projecting from a base line drawn on a large diagram ordinates representing the maximm intensity shown by each satisfactory observation. The position of the ordinates thus projected, it is scarcely necessary to observe, 
depends on the zenith distance under which the resprective observations are made, while their length will be deter. mined by the observed maximum temperature, to be marked on the diagram in accordance with at fixed scale. As the recorded investigations extend from the vertical to is degr. zenith distance, it will be evident that the base line shomld be divided into 50 equal parts, each division representing one degree of zenith distance. For each successful ohsertil. tion an ordinate will be projected at a position on the bise corresponding with the renith distance under which the sue. cessful observation has been made; the length of the ordi. nate being marked off according to the fixed scule nemtoned. It will be perceived, therefore, that, at the termination of al series of observations, the base line on the dingram, with its Tó equal divisions, representing degrees of \%enitl, distance, subdivided into minutes, will be studded with a mumber of perpendicular lines of unequal length, placed at irregular distances. In accordance with the rules of the graphic system, the terminations of the several irregularly-spaced perpendi. cular lines will then be connected by a curved line which, if uniform and nearly parabolic when completer, proves that the observations have been accurate. Should it, however, contain breaks, or should its curvature not be gradually increasing with increased zenith distance, in accordance with an ascending series, fresh observations must be made at \%enith distances embracing the defective portions. Again, it may happen that in connecting the terminations of the ordinates considerable gaps present themselves; in other words, that 
want of observation occurs for several succeeding degrees of zenith distance. These gaps must be filled by fresh observations, unless the completed parts of the curve on both sides of the gap, when extended over it, meet in such a manner as to produce a consistent curve. Our small diagram (Plate 9) has been copied from a large diagram constructed in accor. dance with the foregoing explanation of the plan adopted. The scale employed in laying down the observed tempera. tures, viz, marking off the length of the ordinates, being sufficiently large to admit of showing fractious of a degree of Fahrenheit, the temperatures entered in the Tables A, B, and $C$, for given zenith distances, will be found very precise. In view of the foregoing explanation of the procedure resorted to, the reader need not be reminded that the temperatures appearing in the tables have not all been determined by actual ohservation. Agreeably to the graphic system, several of these temperatures have been determined by measuring the height of the ordinates in the diagram. It needs no demonstration, however, to prove that intensities ascertained by measurement, in the manner pointed out, are as reliable as if ascertained directly by the actinometer, provided the curve be perfect which connects the termination of the ordinates obtained by actual observation. It should be stated that, during a period embracing many years, but few farorable opportunities lave been neglected of verifying the correctness of the preceding tables. No material discrepancies having been observed, future investigations are not likely to lead to any important modifications of these tables. 
Possibly observations conducted on the tible-lands of India might show somewhat higher intensitios for given \%enth dis. tances; but tables moditied agrceably to such ohservations would not be as useful for meteorological investigations conl. cerning the effects of solan intensity in Anericat and Europe as those here presented. It may be mentioned that it wats my original intention to extend the observations of \%nith dis. tance and sular intensity from the roth deg. to the horizon: but experience has shown that both the castern and western horizon, riewed from my present observatory; ares so seldom free from clouds and haze that too long a time wonld elapse. before the investigations of atmospheric ahsenption at wherme zenith distance conld be completed. It will be fomml. Lom. ever, on mature reflection, that the most impurtant motando. logical phenomena connected with solal heat alle confined within the rertical segment of 150 deg., which enturkes the result of my actinometric observations.

With reference to the maximum intensity of solar radia. tion on each legree of latitude, it will be erident that, since we possess an accurate knowledge of the relation of \%enth distance and temperature, we can readily determine the maxi. mum intensity for different latitudes during the summer sol. stice. For instance, we know, by referring to the precerling Table B, that, when the earth is in aphelion amul the zenith distance is 43 deg., the temperature producer by solan rati. ation is $60^{\circ} .81 \mathrm{~F}$; hence we know that this temperature marks maximum solar intensity on the Aretic Circle, the latter being 43 deg. from the eeliptic at the summer sol. 


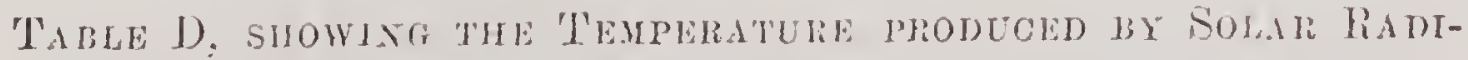

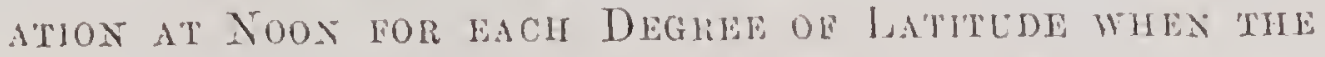
Fartir is is Aphlion. Northers Hemishere.

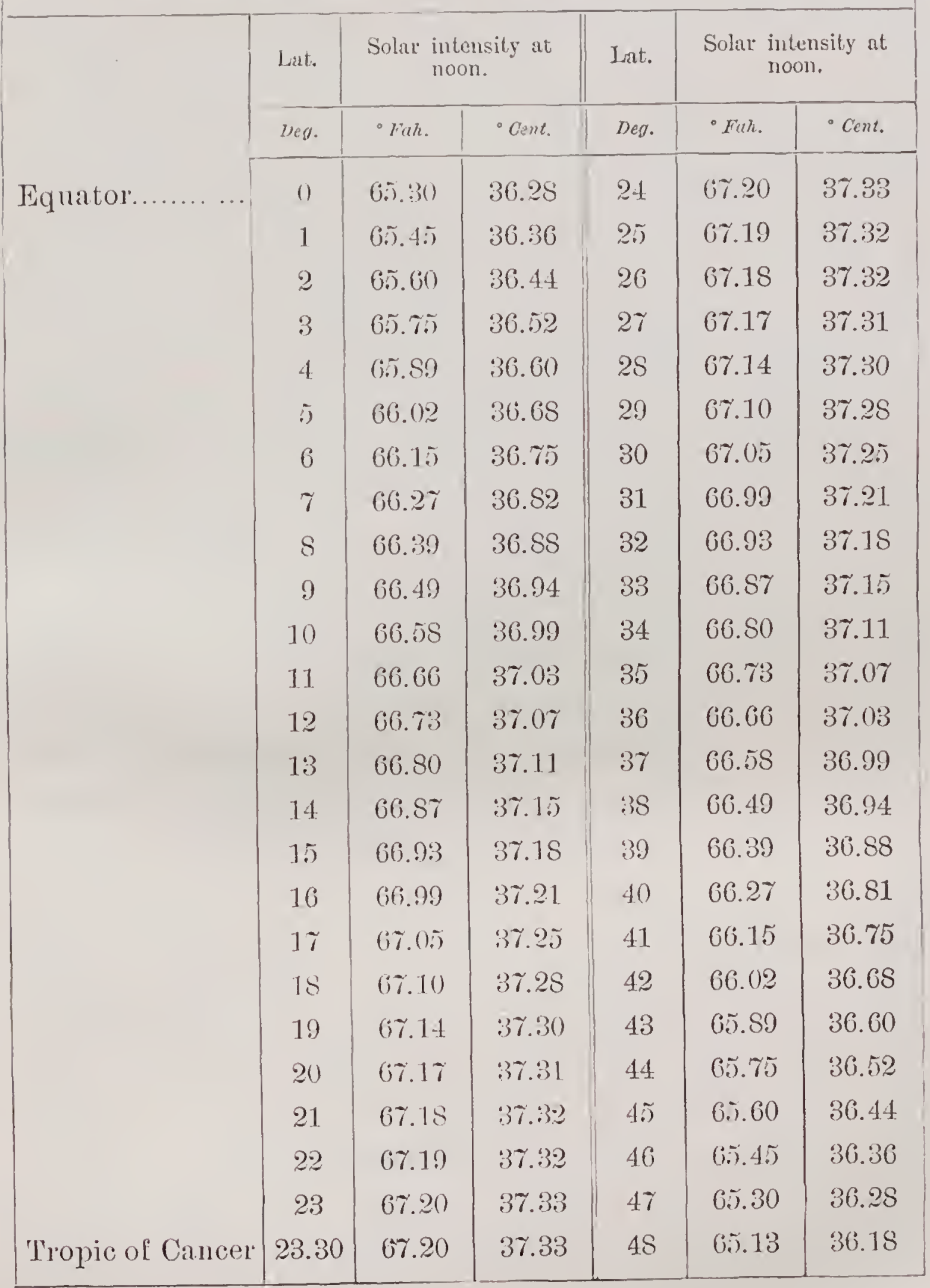




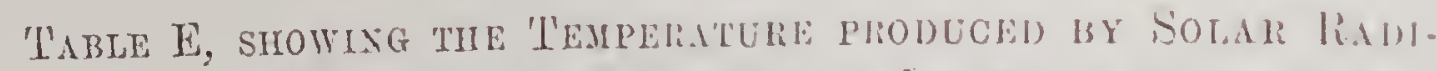

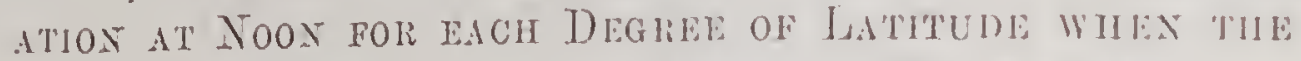

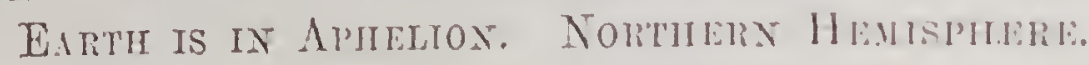

\begin{tabular}{|c|c|c|c|c|c|c|c|}
\hline \multirow{5}{*}{ Jat. } & \multicolumn{2}{|c|}{ Solar intensity at } & 1.at. & \multicolumn{2}{|c|}{ Sultr intensity ut } \\
nreon.
\end{tabular}


stice. Again, the Nortl Pole being 66 deg. 30 min. from the coliptic at the same time, we learn, by referring to 'Table C, that the maximum solar intensity at the said pole will be $50^{\circ} .95 \mathrm{~F}$, that being the temperature produced by solar radi. ation when the zenith distance is 66 deg. $30 \mathrm{~min}$.

The Tables D and $\mathrm{E}$ contain the maxinum solar intensities for all latitudes from the Equator to the North Pole, determined agreeably to the foregoing explanation. 'The difference of atmospheric density towards the pole calls for a trifling correction of the temperature entered in the table; but the data not being sufliciently well known, I have deemed it best to present the theoretical temperatures without correction.

As far as ascertained by means of the actinometer, there is an appreciable difference in the sun's energy for corresponding zenith distances early in the morning and late in the afternoon, which cannot be traced to any adequate phy. sical cause. I have accordingly attempted to explain the discrepancy on the ground that the orbital motion of the earth occasions a very considerable advance towards, and retreat from, the solal ware early A.M. and late P.n. 'The subject will be readily understood by reference to Fig. 3, which represents a section of the earth through the plane of the ecliptic, the line $d$ e indicating the orbit, and the straight arrow the earth's course, while the curved arrow shows the direction of rotation; $a b c$, etc., represent the sun's rays, the orbital velocity during a definite period being represented by $f g$ and $k l$. Let us assume that the latitude of the point $f$, on the earth's surface, is such that the prolongation of the 
ray a $h$ to of makes $h g$ three times longel than fo It will now be evident that the ray $a h$, which has been arrested at $h$, must, while the earth adrances from of to y, continue its course at a rate three times greater than the earth's orbital velocity, in order to reach y simmltaneously with f. Assuming the mean distance of the earth from the sun to be $91,430,000$ miles, the orbital relocity will be $96,120 \mathrm{ft}$ per secoml; hence the ray a $h$, to keep up with the retreating western quarter

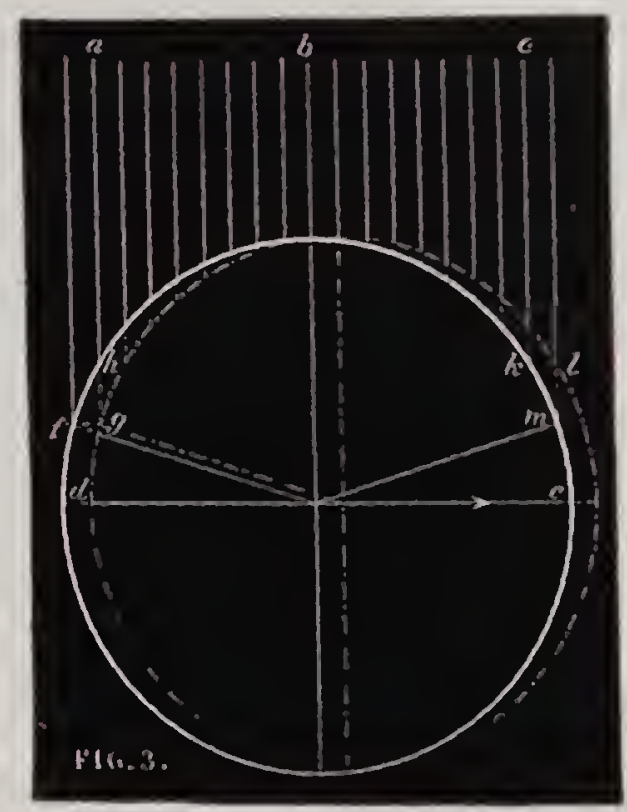

of the globe, must move at the rate of $288,360 \mathrm{ft}$. per second. The advancing eastern quarter obriously imparts a retrograde movement to the solar wave, consequently the lay $m l$ will, on grounds already set forth, be pushed towards the sun at the rate of $288,360 \mathrm{ft}$. per second. We have thus establisher a difference of adrancing and retreating velocity exceeding $600,000 \mathrm{ft}$. per second for the lower altitudes, which unquestionably interferes with the regularity of the solar wave, and thereby tends to disturb the uniformity of the intensity of the sun's radiant heat towards evening. Meteorologists will account 
for the ohserved riminution by pointing to the fact that during smoline-without which the actinometer cammot be usedthe atmosplere, in most localities, gradually becomes charged with rapor as the day advances; and that dust and other light dry particles are carried up into the atmosphere by the ascending heated current of air, thms olsstructing the sun's rays. These plausihle rasons lose their force if we consider' that, during the sasom most farorable for actinometric obserrations, the rapors are hedel fast within icy boundaries, and that the dust is bmied muler the snow.

'The extrandinary velocity of light-nearly 1,700 times wrober than the relocity shown by the foregoing demonstration-will he uresel as a reason wy the disturbance of the solar ware conld not he practically mplociable. This objection cammot be dermed ralid muless it can be shown that the dynanic energy imparted by solar heat is not partially the result of arresting the motion of the rays. The following farcts connected with the subject demand serious consideration. Owing to the orhital motion of the earth, the lens of a solar calorimeter, while exposed to the rallint heat, sweeps across the path of the sun's rays at the rate of $96,120 \mathrm{ft}$. per second: hence the fluid contained within the instrument receives the concrey of a countless number of rays following each other in an inconceivably rapid succession.

Ponillet, haring ascertined the number of thermal units imparted to the water in his proleliometer of 3.93 ins. diameter, imagined that he han measured only the eneroy of the rays contained in a pencil of 11.9 square inches section; 
whereas, in reality, he had, at the end of his experinent of five minutes' duration, subjected his instrument to the action of the entire number of rays contained in a passing pencil or sunbeam, the section of which we ascertain by multiplying the orbital advance of the earth during fire minutes, $28,836,000 \mathrm{ft}$., by the diameter of the pyrheliometer, $0.305 \mathrm{ft}$. 


\section{CHAPTER IV.}

\section{PERIODIC VARIATION OF 'THE INTENSITY OF SOLAR RADIATION.}

Trus preceding chapter has made the reader familiar with the construction of the actinometer, and with the leading results of the investigations conducted by means of that instrument, relating to the variations of temperature consequent on the sun's varying zenith distance. Let us now consider the variation of solar intensity consequent on the varying distance between the sum and the earth from day to day. Meteorologists, in recording the temperature produced by solar radiation, have hitherto taken no notice of the position of the earth in its orbit at the time of making their obser. vations. At the commencement of my investigation of the mechanical properties of solar heat, I committed the same oversight; but finding that the result of my observations frequently presented discrepancies that could not be accounted for on the ground of different zenith distance and presence of rapor in the atmosphere, I was led to examine systematically and very carefully the effect on solar intensity pro- 
duced by the rariation of the sun's distance from the earth. Sir John Herschel, in "Outlines of Astronomy;" says, regand. ing the effect of the sul's varying distance: "The angulan" relocity of the earth in its orlit is not miform, but valles. in the inverse ratio of the square of the sun's distance-that is, in the same precise ratio as lis heating fower. The momentary supply of heat, then, receired by the earth in every point of its orbit varies exactly as the monentary increase of its longitude; from which it obrionsly follows that equal amounts of heat are received from the sum in pasing orel equal angles round it, in whatever part of the cllipse those angles may be situated." $\Lambda$ s regurds the temperature leve. loper by the sun at different periods, the anthor of the "Out. lines of Astronomy" calculates that there is a difference of one-fifteenth; but, in judging of the effect of this difference on the temperature produced by solar radiation, he says: "We have to consider as our unit, not the number of degrees above a purely arbitrary \% point (such as the freczing point of water on the zero of Falnenheit's scale) on which a thermometer stands on a hot summer diy, as compared with a cold winter one, but the thermometric interval between the temperatures it indicates in the two cases, and that it wonld indicate did the sun not exist, which there is good reason to helicve would be at least as low as $239^{\circ}$ below aero of Falnenheit. Anil as a temperature of $100^{\circ} \mathrm{F}$. above zero is no uncommon one in a fail shade exposure under a sun nearly vertical, we have to take one-fifteenth of the sum of these intervals $\left(33 !^{\circ}\right)$, or $23^{\circ} \mathrm{F}$.

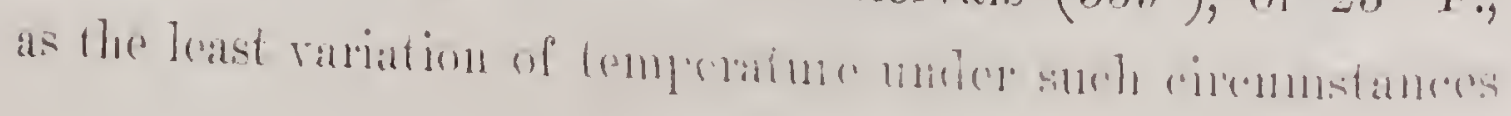


which can reasonably be attributed to the actual rariation of the sun's distance." Adopting the stated calculation, without reflecting on the erroneous grounds upon which it rests, I introduced corrections of the observed temperatures accord. ing to the supposed angmentation of radiant intensity, viz, $23^{\circ} \mathrm{F}$. when the earth is in peribelion. The application of these corrections proved that the discrepanteies in my records, before actrerted to, amounted to only one-fifth of that which, agreeably to sir John Iler'schel's theory, ought to have appeared. Fully comvinced, however, that the difference of solar intensity resulting from the rarbation of distance between the sun and the earth was the true carre of the irregularity and hreaks in the curve which I had constructed according to the olserved temperatures, I arailed myself of every farorable opportunity to ascertain the maximm intensity produced during the summer and winter solstices. It will be well to state, for the information of those who have not paid special attention to the subject, that mean results of observation are inadnissible in records intended to establish solar energy. The superior intensity ascertained at a single observation will set aside the result of previous observations continued for many years. It will be well also to correct the prevailing erroneous supposition that solar intensity cannot be ascer. tained during the summer montls, owing to vapor in the atmosphere. There are short intervals at all seasons when polar winds prevail, during which the sun is perfectly clear. Those who have paid close attention to this matter will say that they hate seene as hight a solat dise in August as in 
January. This fact has been repeatedly rerified by the indi. cations of my solar culorimeter, an unerring test, since it records the number of units of heat dereloped by the sun in a given time on a given area. Obriously the smallest increase of the absorptive power of the atmosphere will be detected by this method. It will be perceived from the foregoing remarks that the records of solar intensity connected with the solstices, kept during a series of years, possess m material interest regarding the question at issue-namely, the true maximum difference of intensity of solar radiation when the earth is in aphelion and in perihelion. The reades, there. fore, instear of being called upon to examine an extended record of observations, will simply have his attention directed to the fact that January $\%$, 18\%1, the earth being then, of course, very near perihelion, the temperature produced by solar radiation, indicated by the actinometer, reached 5\%.25 F. at noon; the zenith distance being 68 deg. $15 \mathrm{~min}$. Re. ferring to the table of temperatures for given zenith distances (Chap. III.), it will be seen that the temperature produced by solar radiation when the earth is in aphetion is $52^{\circ} .84 \mathrm{~F}$. at a zenith distance of 63 deg. $1.5 \mathrm{~min}$; consequently, an augmentation of solar intensity of $57.25-52.84=4^{\circ} .41 \mathrm{~F}$. takes place when the earth is in perihelion. The result of my actinometric observations, continued through a series of years, recorded in Chap. III., shows that when the earth is in aphelion the maximum solar intensity on the ecliptic is $6 r^{\circ} .20 \mathrm{~F}$. The law of inverse squares being true for spherical radiators and for ratiating circular discs subtending small angles, the 
stated intensity of solar radiation when the earth is in aphelion enables us to determine with absolute certainty what temperature will be produced when the earth is in perihelion. The ratio of the earth's distance from the sun at the two opposite points of the orbit, in aphelion and in perilhelinn, being 218.1 : 210.9, while the temperature produced by solar radiation during the summer solstice, as stated, is $67^{\circ} .2$ F., the radiant intensity during the winter solstice will be $\frac{218.1^{2} \times 67.2}{210.9^{2}}=71^{\circ} .86 \mathrm{~F}$. The temperature produced by solar' radiation at the surface of the earth will thus, agreeably to the laws which govern the transmission of radiant heat, be $71.86-67.20=4^{\circ} .66 \mathrm{~F}$. higher when the earth is nenrest the sun than when furthest from it. The actinometric obser. vation, Jan. 7 , 18 7 , having established a differential temperature of $4^{\circ} .41 \mathrm{~F}$, it will thus be seen that a discrepancy exists amounting to $0^{\circ} .25 \mathrm{~F}$. That is, the observed solar intensity, $57^{\circ} .25$, Jan. 5 , was $0^{\circ} .25$ less than the calculated intensity. $\Lambda$ closer agreement between connunted and observed increment of solar intensity consequent on the eccentricity of the earth's orbit could not reasonibly be expected. Besides, the record shows that, although the sun was exeeptionally clear on the day mentioned, there was a perecptible mist round the solar disc, indicating that the full radiant power' was not transmitted to the actinometer. In constructing the tables appended to this chapter I have, therefore, based my. calculations of dinmal variation of solar intensity on the dif. ferential temperature, $4^{\circ} .66 \mathrm{~F}$, determined by computations 
founded on the distance of the earth from the sun at the opposite points of the orbit. Referring to the tables, it will be seen that the maximum temperature produced by solir. radiation has been entered for each day thronghout the years: also the increment of solar intensity for each diay, comsequent on the varying distance of the sun. The princijal object of the tables being that of enathling the meteorologist to ascertain to what extent the result of his ofrerrations of solar radiation is influenced by the distance of the sun, it will be evident that some zero haring a fixed relation to the position of the earth in its orbit should be adopted, in order to render comparisons possible. Accordingly, the ap. pended tables have reference to the maximun temperature produced by solar radiation when the carth is in aphelion. The utility of adopting a fixed zero will be seen by the following explanation: Suppose that we find by observation, during bright sunshine, January 20, that, under a \%enith distance of 68 deg., the actinometer indicates $54^{\circ} .5 \mathrm{~F}$. Suppose, also, that our records of solar intensity during summer show that, June 15, the actinometer indicated $49^{\circ} .9 \mathrm{~F}$. at equal zenith distance-viz., 68 deg. Leaving the influence of solar distance out of sight, the inference would be that the diminished intensity of $54.5-49.9=4^{\circ} .6 \mathrm{~F}$, observed June 15 , was owing to the presence of vapor in the atmosphere. Secchi and others, who suppose that the absorptive power of the atmosphere called forth by rapor prevents the full development of solat rauliation at all times during summer, would not hesitate to ascribe the observed diminution of radiant intensity to that 
cause. But a glance at our tible at once discloses the true cause of the observed difference of solar intensity under equal zenith distance in January and in June. Consulting the table for Jamuary, and running the eye down the column headed "Increment," the temperature $4^{\circ} .6$ will be found opposite the date 20 th in the first column. Accordingly, the feebleness of solar radiation observed in the middle of June, instead of being caused by atmospheric absorption, is solely due to the increased distance of the earth from the sun. It should be observed that the assumed temperature of $49^{\circ} .9 \mathrm{~F}$., at a zenith distance of $68 \mathrm{deg}$. in the middle of June, is not imaginary, having frequently been observed during my investigations of solar energy. Again, temperatures exceeding $54^{\circ} \mathrm{F}$. have been observed during mid-winter at a zenith distance of $68 \mathrm{deg}$.

It will be proper to remind meteorologists accustomed to observe the intensity of solar radiation, hence familiar with the extraordinary discrepancy of observations made with ordi. nary "solar radiation thermometers," that the invariably consistent indications, and the freedom from conflicting results, in my actinometric observations of solar energy, are chiefly due to the fact that the bulb of the recording thermometer' is enclosed within an exhausted ressel, maintained at a constant temperature of $60^{\circ} \mathrm{F}$. during observations. Hence, whether the investigation be conducted in calms or high winds, or whether the thermometer marks $100^{\circ}$ in the shade or the temperature of the air be below zero, no material error is possible. This fact merits special consideration on the part of those who have questioned the possibility of determining 
practically to what degree the temperature produced by solar radiation is increased when the earth is in perihelion. And those who have alopted Herschel's conclusion, that " $23^{\circ} \mathrm{Fal}$. renheit is the least variation of temperature which can reasonably be attributed to the actual variation of the sun's distance," will do well to contrast the reasoning of the great astrononer with the reasoning which assigns $5^{\circ}$ Fahrenheit as the utmost increment of solar intensity in the southern hemisphere, consequent on the proximity of the luminary during our mis. winter.

Regarding the construction of the appended tables of solar intensity, the following explamation and recapitulation will suffice: Having determined the maximum solar intensity when the earth is in aphelion, in accordance witl the data furnished in Chilp. III., the maximum intensity in perihelion was determined by computation in the manner already pointed out. The result, as we have seen, has been fully corroborated by actinometric observation. The maximum increment of temperature produced by solar radiation when the earth is in perihelion having been fixed at $4^{\circ} .66 \mathrm{~F}$, the increment of tem. perature for each day throughout the year was determined by inverting the ratio of the square of the sun's distance from day to day.

We have already pointed out that investigations of solar intensity which do not take cognizance of the influence of the sun's distance are of no value. Obviously, the difference of temperature produced by solar radiation furnishes an infal. lible index of atmospheric absorption, provided we make due 
allowance for the sun's zenith distance and the position of the earth in its orlit at the time of making our observation. But. unless such allowance be made, the inference we draw from the indicated temperatures will prove wholly erroneous.

Respecting the mode of applying the tables, it will be evident, on reflection, that, if we desire to ascertain whether vapors are present in the atmosphere, the temperature contained in the column headed "Increment," for the day on which the observation is made, should be deducted from the temperature indicated by the actinometer. Suppose, for instance, that the indicated solar intensity, Aug. 26, is $\tilde{5} 8^{\circ} \mathrm{F}$. at a zenith distance of 40 deg. Deducting from $58^{\circ}$ the increment of temperature entered in the table for Aug. 26-viz., $0^{\circ} .96$-consequent on the diminished distance from the sun, we obtain $58-0.96=55^{\circ} .04$. Now, if we consult the table of temperatures for given zenith distance (see page 6.2 , Chap. III.), it will be found that the maximum solar temperature for a zenith distance of $40 \mathrm{deg}$. should be $61^{\circ} .6 \%$. Our obserration of $\Lambda \mathrm{ug}$. 26, therefore, shows that the rapors contained in the atmosphere have absorbed $61.67-57.04=4^{\circ} .63$ of the sun's radiant heat. The advantage of this positive mode of ascertaining the absorptive power-i.e., the presence of rapor in the atmosphere-meteorologists camnot fail to appreciate.

The close agrement between the computed and observed increment of the temperature produced by solar ratiation when the earth is in perihelion, before adverted to, calls for special notice in this place, since it prores the correctness of the actinometric observations recorded in Chap. III., on which our 
determination of the rarying intensity of the sun's radiant heat is based. It will be erident that, if our determination of maximum solar intensity when the earth is in aphelion (based solely on our observations) were incorrect, the infal. lible test of applying the law of inverse squares would at once expose the error. Now, this test has been applied; we have inverted the squares of the relative aphelion and peri. helion distance of the earth, and we find that in the latter position an increment of $4^{\circ} .66 \mathrm{~F}$. results from the proximity of the sun. Our observations show an increment of $4^{\circ} .41$ dif. ference $=0^{\circ} .25$ Fahrenheit. 
CHAP. IY. PERIODIC VARIATION OF SOLAR RADIATON.

\begin{tabular}{|c|c|c|c|c|c|c|c|c|}
\hline \multicolumn{9}{|c|}{ 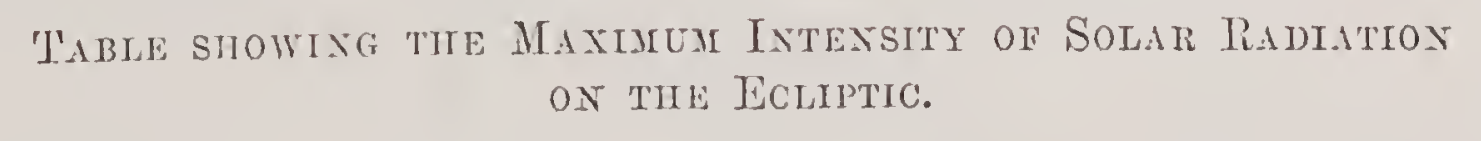 } \\
\hline \multirow{3}{*}{ 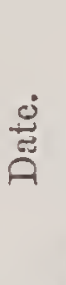 } & \multicolumn{4}{|c|}{ JANUARY. } & \multicolumn{4}{|c|}{ FEBRUARY. } \\
\hline & \multicolumn{2}{|c|}{ Maximum. } & \multicolumn{2}{|c|}{ Increment. } & \multicolumn{2}{|c|}{ Naximum. } & \multicolumn{2}{|c|}{ Inerement. } \\
\hline & ${ }^{\circ} F u k$ & - Cent. & ${ }^{\circ} F a h$. & ${ }^{\circ}$ Cent. & 'Fah. & - Cent. & ' Fuh. & ${ }^{\circ}$ Cent. \\
\hline 1 & $71.9 \pm$ & 39.97 & 4.66 & 2.59 & 71.59 & 39.77 & 4.31 & 2.39 \\
\hline 2 & 71.94 & 39.97 & 4.66 & 2.59 & 71.57 & 39.70 & 4.29 & 2.38 \\
\hline 3 & $\tau 1.01$ & 39.97 & 4.66 & 2.59 & 71.54 & 39.84 & 4.26 & 2.36 \\
\hline 4 & 71.93 & 39.97 & 4.6 .5 & 2.59 & 71.52 & 39.73 & 4.24 & 2.35 \\
\hline$\pi$ & 71.93 & 39.07 & 4.65 & 2.59 & 71.50 & 39.72 & 4.22 & 2.34 \\
\hline 6 & $\tau 1.92$ & 39.96 & 4.04 & 2.58 & 71.47 & $39 . \% 1$ & 4.19 & 2.33 \\
\hline 7 & 71.92 & 39.96 & 4.64 & 2.58 & 71.45 & 39.69 & 4.17 & 2.31 \\
\hline 8 & 71.91 & 39.0)$. & 4.03 & 2.67 & 71.42 & 39.68 & 4.14 & 2.30 \\
\hline 9 & $\% 1.91$ & 39.95 & 4.63 & 2.57 & 71.40 & 39.67 & 4.12 & 2.29 \\
\hline 10 & 71.90 & 39.94 & 4.62 & 2.56 & 71.38 & 39.65 & 4.10 & 2.27 \\
\hline 11 & 71.90 & 39.94 & 4.62 & 2.56 & 71.35 & 39.64 & 4.07 & 2.26 \\
\hline 12 & 71.89 & 39.93 & 4.61 & 2.55 & 71.32 & 39.62 & 4.04 & 2.24 \\
\hline 13 & $71.8 S$ & 39.93 & 4.60 & 2.55 & 71.29 & 39.60 & 4.01 & 2.22 \\
\hline 14 & 71.87 & 39.92 & 4.59 & 2.54 & 71.27 & 39.59 & 3.99 & 2.21 \\
\hline 15 & 71.86 & 39.92 & 4.58 & 2.)4 & $\gamma 1.24$ & 39.58 & 3.96 & 2.20 \\
\hline 16 & 71.85 & 39.91 & 4.57 & 2.53 & 71.20 & 39.56 & 3.92 & 2.18 \\
\hline 17 & 71.84 & 39.91 & 4.56 & 2.53 & $81.1 \%$ & 39.54 & 3.89 & 2.16 \\
\hline 18 & 71.82 & 39.90 & 4.54 & 2.52 & $\tau 1.14$ & 39.52 & 3.86 & 2.14 \\
\hline 19 & 71.81 & 39.90 & 4.53 & 2.52 & 71.11 & 39.50 & 3.83 & 2.12 \\
\hline 20 & 71.80 & 39.89 & 4.52 & 2.51 & 71.08 & 39.49 & 3.80 & 2.11 \\
\hline 21 & 71.78 & 39.SS & 4.50 & 2.50 & 71.05 & 39.47 & 3.77 & 2.09 \\
\hline 2.2 & 71.77 & 39.87 & 4.49 & 2.49 & 71.02 & $39.4 \%$ & 3.74 & 2.07 \\
\hline 23 & $\gamma 1 . \gamma 0$ & 39.87 & 4.48 & 2.48 & 70.98 & 39.43 & 3.8() & 2.05 \\
\hline 24 & 71.74 & 39.86 & 4.46 & 2.47 & 70.95 & 39.42 & 3.67 & 2.04 \\
\hline $2 \pi$ & $\pi 1.72$ & 39.84 & 4.44 & 2.46 & 70.92 & 39.40 & 3.64 & 2.02 \\
\hline 26 & 71.70 & 39.83 & 4.42 & 2.45 & 70.88 & 39.38 & 3.60 & 2.00 \\
\hline 27 & 71.68 & 39.82 & 4.40 & 2.44 & 70.85 & 39.36 & 3.58 & 1.98 \\
\hline 28 & 71.67 & 39.81 & 4.39 & 2.43 & 70.82 & 39.34 & 3.54 & 1.96 \\
\hline 29 & 71.65 & 39.80 & 4.37 & 2.42 & & & & \\
\hline 30 & 71.63 & 39.79 & 4.35 & 2.41 & & & & \\
\hline 31 & 71.61 & 39.78 & 4.33 & 2.40 & & & & \\
\hline
\end{tabular}




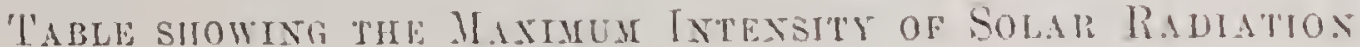
oN TII: EcLIPTIC.

\begin{tabular}{|c|c|c|c|c|c|c|c|c|}
\hline \multirow{3}{*}{ 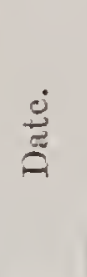 } & \multicolumn{4}{|c|}{ MARCH. } & \multicolumn{4}{|c|}{ APRIL. } \\
\hline & \multicolumn{2}{|c|}{ Mraximum. } & \multicolumn{2}{|c|}{ Increment. } & \multicolumn{2}{|c|}{ Maximum. } & \multicolumn{2}{|c|}{ Increment. } \\
\hline & ${ }^{\circ} F a h$. & ${ }^{\circ}$ Oent. & - Fah. & - Cent. & ${ }^{\circ} F a h$. & - rent. & - Futh. & - Cent. \\
\hline 1 & 70.79 & 39.33 & 3.51 & $1.9 . j$ & $(39) .60$ & 38.67 & $2.3 \%$ & 1.29 \\
\hline 2 & 80.75 & 39.81 & 3.47 & 1.93 & 69.56 & 38.64 & 2.38 & 1. 20 \\
\hline 3 & 80.72 & 39.29 & 3.44 & 1.91 & 09.42 & 38.62 & 2.24 & 1.24 \\
\hline 4 & 80.68 & 39.27 & 3.40 & 1.89 & 69.48 & 38.60 & $\therefore .20$ & 1.22 \\
\hline 5 & 70.05 & 39.25 & 3.37 & $1.8 \%$ & $(99 .+4$ & 38.08 & 2.11 & 1.20 \\
\hline 6 & 70.61 & 39.23 & 3.33 & 1.85 & 69.40 & 38.56 & 2.12 & 1.18 \\
\hline$\tau$ & 70.58 & 39.21 & 3.30 & 1.83 & 69.36 & 38.633 & 2.18 & $1.1 \%$ \\
\hline 8 & 70.54 & 39.19 & 3.26 & 1.81 & 69.32 & 38.11 & 2.04 & 1.18 \\
\hline 9 & $\tau(0.50$ & 39.17 & 8.22 & 1.79 & 69.28 & 38.49 & 2.00 & 1.11 \\
\hline 10 & 70.40 & 39.14 & 3.18 & 1.76 & 69.24 & 38.47 & 1.90 & 1.09 \\
\hline 11 & 7() .42 & 39.12 & 3.14 & 1.74 & 69.20 & 38.44 & 1.92 & $1.116^{\circ}$ \\
\hline 12 & 70.38 & 39.10 & 3.10 & 1.82 & 69.16 & 38.42 & 1.SS & 1.04 \\
\hline 13 & 70.35 & 39.08 & 3.07 & 1.70 & 69.13 & 38.40 & 1.85 & 1.02 \\
\hline 14 & 70.31 & 39.06 & 3.03 & $1.6 \mathrm{~s}$ & 69.09 & 38.38 & 1.81 & 1.00 \\
\hline $1 \tilde{~}$ & 70.27 & 39.04 & 2.99 & 1.66 & 69.05 & .38 .36 & $1.7 \%$ & 0.98 \\
\hline 16 & 70.23 & 39.02 & 2.95 & 1.64 & 69.01 & 38.34 & 1.73 & 0.96 \\
\hline 17 & 70.19 & 38.99 & 2.91 & 1.61 & $68.9 \%$ & 38.32 & 1.69 & 0.94 \\
\hline 1S & 70.15 & 38.97 & 2.87 & 1.69 & 68.93 & 38.29 & $1 .(65)$ & 0.91 \\
\hline 19 & 70.12 & $38.9 \%$ & 2.84 & $1.5 \%$ & 68.89 & 38.27 & 1.61 & 0.80 \\
\hline 20 & $70.0 S$ & 38.93 & 2.80 & 1.55 & 68.85 & $38.2 \overline{0}$ & $1.5 \gamma$ & 0.87 \\
\hline 21 & 70.04 & 38.91 & 2.76 & 1.58 & 68.S1 & 38.23 & 1.53 & $(1.85$ \\
\hline 22 & 70.00 & 38.89 & 2.72 & 1.51 & 68.78 & 38.21 & $1.50)$ & (1).8:3 \\
\hline 23 & 69.96 & $38.8 \%$ & 2.68 & 1.49 & 68.74 & 38.19 & 1.46 & 0.81 \\
\hline 24 & 69.92 & 38.84 & 2.64 & 1.46 & 68.70 & 38.17 & 1.42 & $0.79)$ \\
\hline 25) & 69.88 & 38.82 & 2.60 & 1.44 & 68.60 & 38.14 & 1.38 & 0.76 \\
\hline 20 & 69.84 & 38.80 & 2.56 & 1.42 & 68.63 & 38.12 & 1.35 & (1).74 \\
\hline 27 & 69.80 & 38.78 & 2.52 & 1.40 & 68.59 & 38.10 & 1.31 & 0.72 \\
\hline 28 & 69.76 & 38.75 & 2.48 & 1.37 & 6S.5\% & 38.18 & 1.27 & 0.70 \\
\hline 29 & 69.72 & 35.73 & 2.44 & 1.35 & 6S.52 & 38.06 & 1.24 & 0.68 \\
\hline 30 & 69.68 & 38.71 & 2.40 & 1.333 & 68.48 & $: 38.14 .4$ & 1.20 & 0.66 \\
\hline 31 & 69.64 & 38.69 & 2.36 & 1.31 & & & & \\
\hline
\end{tabular}




\begin{tabular}{|c|c|c|c|c|c|c|c|c|}
\hline \multicolumn{3}{|c|}{ 'TABLE SHOWIXG THE } & \multicolumn{3}{|c|}{$\begin{array}{l}\text { Maxinga IrThasity } \\
\text { ON The ECLPTIC. }\end{array}$} & F SoLd & \multicolumn{2}{|c|}{ RADIATION } \\
\hline \multirow{3}{*}{ 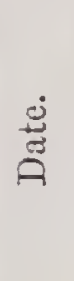 } & \multicolumn{4}{|c|}{ MUY. } & \multicolumn{4}{|c|}{ JUNE. } \\
\hline & \multicolumn{2}{|c|}{ Maximum. } & \multicolumn{2}{|c|}{ Increment. } & \multicolumn{2}{|c|}{ Maximum. } & \multicolumn{2}{|c|}{ Increment. } \\
\hline & - Fuh. & - Cent. & 'Fuh. & - Cent. & ${ }^{\circ} F \alpha h$. & - Cent. & ${ }^{\circ} F u h$. & ${ }^{\circ}$ Cent. \\
\hline 1 & 68.45 & 89.03 & 1.17 & 0.65 & 67.58 & 37.54 & 0.30 & 0.10 \\
\hline 2 & 68.41 & 38.01 & 1.13 & 0.63 & 67.56 & 37.53 & 0.28 & $0.1 \%$ \\
\hline 3 & 68.38 & 37.99 & 1.10 & 0.61 & 67.64 & 37.52 & 0.26 & 0.14 \\
\hline 4 & 68.35 & 37.97 & 1.07 & 0.59 & $6 \% .62$ & 37.51 & 0.24 & 0.13 \\
\hline 5 & (38.32 & 37.95 & 1.04 & 0.57 & $6 \% .51$ & 37.50 & 0.28 & 0.12 \\
\hline i & 68.28 & 37.93 & $1 .(0)$ & $0.5 \tilde{5}$ & $6 \% .49$ & 37.49 & 0.21 & 0.11 \\
\hline 7 & 68.25 & 37.92 & 0.97 & 0.54 & 67.47 & 37.48 & 0.19 & 0.10 \\
\hline 8 & 68.22 & 37.90 & 0.94 & 0.52 & $6 \% .46$ & $3 \% .48$ & 0.18 & 0.10 \\
\hline 9 & 68.19 & 37.88 & 0.91 & 0.50 & 67.44 & 37.47 & 0.16 & 0.09 \\
\hline 10 & 68.16 & 37.87 & 0.88 & 0.49 & $67.4: 3$ & 37.46 & (0. 15 & 0.08 \\
\hline 11 & 68.13 & 37.85 & 0.85 & 0.47 & 67.42 & 37.45 & 0.14 & 0.07 \\
\hline 12 & 68.10 & 37.83 & 0.82 & 0.45 & 67.40 & 37.44 & 0.12 & 0.06 \\
\hline 13 & 68.06 & $3 \% .81$ & 0.75 & 0.43 & 67.39 & 37.44 & 0.11 & 0.06 \\
\hline 14 & 68.03 & 37.79 & 0.75 & 0.41 & $6 \% .38$ & 37.43 & 0.10 & $0.0 \%$ \\
\hline 15 & 68.00 & 37.78 & 0.72 & 0.40 & 67.37 & 37.43 & 0.09 & 0.05 \\
\hline 16 & 67.97 & 37.76 & 0.69 & 0.38 & 68.360 & 37.42 & 0.08 & 0.04 \\
\hline 17 & $67.9 t$ & 37.74 & 0.66 & 0.36 & $67.35)$ & 37.42 & 0.07 & 0.04 \\
\hline 18 & 67.91 & 37.73 & $0.6: 3$ & 0.35 & 67.34 & 37.41 & 0.06 & 0.03 \\
\hline 19 & 67.89 & 37.72 & 0.61 & 0.34 & 67.333 & 37.40 & 0.05 & 0.02 \\
\hline 20 & 67.86 & 37.70 & 0.58 & 0.32 & 67.32 & 37.40 & 0.04 & 0.02 \\
\hline 21 & 67.84 & 37.69 & 0.56 & 0.31 & 67.32 & 37.40 & 0.04 & 0.02 \\
\hline 22 & 67.81 & 37.67 & 0.53 & 0.29 & 67.31 & 37.39 & 0.03 & 0.01 \\
\hline 23 & 67.79 & 37.66 & 0.51 & 0.28 & 67.30 & 37.39 & 0.02 & 0.01 \\
\hline 24 & 67.77 & 37.65 & 0.49 & 0.27 & 67.30 & 37.39 & 0.02 & 0.01 \\
\hline 25 & 67.75 & 37.64 & 0.47 & 0.26 & 67.29 & 37.38 & 0.01 & 0.00 \\
\hline 26 & 67.72 & 37.62 & 0.44 & 0.24 & 67.29 & 37.38 & 0.01 & 0.00 \\
\hline 27 & 67.70 & $3 \% .61$ & 0.42 & 0.23 & 67.28 & 37.38 & 0.00 & 0.110 \\
\hline 28 & 67.67 & 9ד. & 0.32 & 0.21 & 67.28 & $3 \% .38$ & 0.00 & 0.00 \\
\hline 29 & $67.6 \%$ & 37.58 & 0.37 & 0.20 & 67.28 & 37.38 & 0.00 & 0.00 \\
\hline 30 & 67.63 & 37.57 & 0.35 & 0.19 & 67.25 & 37.38 & 0.00 & 0.00 \\
\hline 31 & 67.60 & 37.55 & 0.32 & 0.17 & & & & \\
\hline
\end{tabular}




\begin{tabular}{|c|c|c|c|c|c|c|c|c|}
\hline \multicolumn{9}{|c|}{ 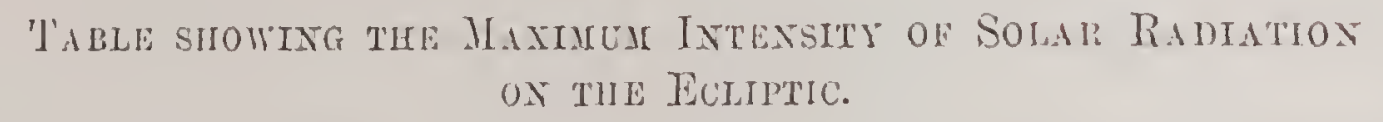 } \\
\hline \multirow{3}{*}{$\stackrel{\dot{s}}{\tilde{a}}$} & \multicolumn{4}{|c|}{ JULY. } & \multicolumn{4}{|c|}{ AUGUST: } \\
\hline & \multicolumn{2}{|c|}{ Maximum. } & \multicolumn{2}{|c|}{ Increment. } & \multicolumn{2}{|c|}{ Maximum. } & \multicolumn{2}{|c|}{ Increment. } \\
\hline & - Fal. & - Cent. & - Full. & - Cent. & - Full. & - Cent. & - Fah. & - Cent. \\
\hline 1 & 67.28 & 37.35 & 0.00 & 0.00 & $67.5 \mathrm{~S}$ & 37.64 & 0.30 & 0.16 \\
\hline 2 & 67.28 & 37.38 & 0.00 & 0.00 & 67.60 & $37.5 \%$ & 0.39 & $0.7 \%$ \\
\hline 3 & 67.28 & 37.38 & 0.00 & 0.00 & 67.63 & $3 \% .67$ & 0.3 .5 & 0.19 \\
\hline 4 & 67.28 & 37.35 & 0.00 & 0.00 & 67.65 & $37 . \mathrm{s}$ & 0.37 & 0.20 \\
\hline 5 & 67.28 & 37.38 & 0.00 & 0.00 & 67.67 & 37.59 & 0.39 & $(1.21$ \\
\hline 6 & 67.28 & $3 \% .38$ & 0.00 & 0.00 & 67.70 & $: 3 \% .61$ & $(1.42$ & 0.28 \\
\hline 7 & 67.29 & 37.35 & 0.01 & 0.00 & 67.72 & 37.62 & 0.44 & 0.24 \\
\hline S & 67.29 & 37.38 & 0.01 & 0.00 & $6 \% . \%$ & 37.64 & 1). 47 & 0.26 \\
\hline 9 & 67.30 & 37.39 & 0.02 & 0.01 & 67.77 & $37.6 \%$ & $0.4 !$ & 0.27 \\
\hline 10 & 67.30 & 37.39 & 0.02 & 0.01 & 67.79 & $3 \pi .645$ & 0.51 & 0.28 \\
\hline 11 & 67.31 & 37.39 & 0.03 & 0.01 & 67.81 & 37.67 & $0.5 \% 3$ & 0.29 \\
\hline 12 & 67.32 & 37.40 & 0.04 & 0.02 & 67.84 & 37.69 & 0.50 & 0.31 \\
\hline 13 & 67.32 & 37.40 & 0.04 & 0.02 & 67.86 & 37.70 & 0.58 & 0.32 \\
\hline 14 & 67.33 & 37.41 & $0.0 \tilde{5}$ & 0.03 & 67.89 & 37.72 & 0.61 & 0.34 \\
\hline 15 & 67.34 & 37.41 & 0.06 & 0.03 & 67.91 & 37.73 & $0.6: 3$ & 0.35 \\
\hline 16 & 67.35 & 37.42 & 0.07 & 0.04 & 67.94 & 37.74 & 0.66 & 0.36 \\
\hline 17 & 67.36 & 37.42 & 0.08 & 0.04 & 67.97 & 37.76 & 0.69 & 0.38 \\
\hline $1 \mathrm{~S}$ & 67.37 & 37.43 & 0.09 & 0.05 & 68.00 & 37.78 & 0.72 & 0.40 \\
\hline 19 & 67.38 & 37.43 & 0.10 & 0.05 & 68.03 & 37.79 & 0.75 & 0.41 \\
\hline 20 & 67.39 & 37.44 & 0.11 & 0.06 & 68.06 & $3 \% .81$ & 0.78 & 0.43 \\
\hline 21 & 67.40 & 37.44 & 0.12 & 0.06 & 68.10 & 37.83 & 0.82 & 0.45 \\
\hline 22 & 67.42 & 37.45 & 0.14 & 0.07 & 68.13 & 37.85 & 0.85 & 0.47 \\
\hline 23 & 67.43 & 37.46 & 0.15 & 0.08 & 68.16 & 37.87 & $0.8 S$ & 0.49 \\
\hline 24 & 67.44 & 37.47 & 0.16 & 0.09 & 68.19 & 37.88 & 0.91 & 0.50 \\
\hline 25 & 67.40 & 37.48 & $0.1 \mathrm{~s}$ & 0.10 & 68.22 & 37.90 & 0.94 & 0.52 \\
\hline 26 & 67.47 & 37.48 & 0.19 & 0.10 & 68.25 & 37.92 & 0.97 & 0.54 \\
\hline $2 \pi$ & 67.49 & 37.49 & 0.21 & 0.11 & 68.2S & 37.93 & 1.00 & 0.55 \\
\hline 28 & 67.61 & 37.50 & 0.23 & 0.12 & 68.32 & 37.95 & 1.04 & 0.57 \\
\hline 29 & 67.52 & 37.51 & 0.24 & 0.13 & 68.35 & 37.97 & 1.07 & 0.59 \\
\hline 30 & 67.54 & 37.52 & 0.26 & 0.14 & 68.38 & 37.99 & 1.10 & 0.61 \\
\hline 31 & 67.56 & 37.53 & 0.28 & 0.15 & 68.41 & 38.01 & 1.13 & 0.63 \\
\hline
\end{tabular}




\begin{tabular}{|c|c|c|c|c|c|c|c|c|}
\hline \multicolumn{3}{|c|}{ T'ABLE SHOWIXg TH } & \multicolumn{6}{|c|}{ 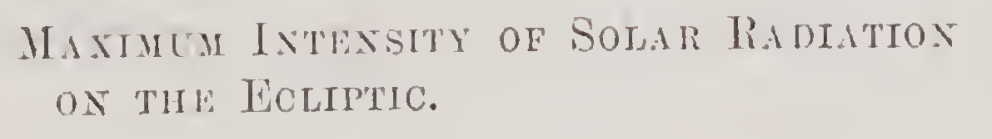 } \\
\hline \multirow{3}{*}{ 芯 } & \multicolumn{4}{|c|}{ SEPTEMBER. } & \multicolumn{4}{|c|}{ OCTOBER. } \\
\hline & \multicolumn{2}{|c|}{ Maximum. } & \multicolumn{2}{|c|}{ Increment. } & \multicolumn{2}{|c|}{ Maximum. } & \multicolumn{2}{|c|}{ Increment. } \\
\hline & ${ }^{\circ}$ Fuh. & - Cent. & "Futh. & - Cent. & - Fuh. & - Cent. & "Filh. & ${ }^{-}$Cent. \\
\hline 1 & 68.45 & $38.0: 3$ & 1.17 & 0.65 & 6.9 .60 & 38.67 & 2.32 & 1.29 \\
\hline 2 & 68.48 & 38.04 & 1.20 & 0. 66 & 69.64 & 38.69 & 2.36 & $1 .: 31$ \\
\hline 3 & 68.52 & 38.06 & 1.24 & 0.68 & 69.68 & 38.71 & 2.40 & 1.333 \\
\hline 4 & 68.55 & 38.08 & $1.2 \%$ & 0.70 & 69.72 & 38.73 & 2.44 & 1.35 \\
\hline i & $(68.59$ & 38.10 & 1.31 & 0.72 & 69.76 & 38.75 & 2.48 & 1.37 \\
\hline 6 & 68.633 & 38.12 & 1.35 & 0.74 & (69.S() & 38.78 & 2.52 & 1.40 \\
\hline i & 68.66 & 38.14 & 1.88 & 0.76 & 69.84 & 38.80 & 2.56 & 1.42 \\
\hline si & 68.70 & 38.1 & 1.42 & 0.79 & 69.SS & 38.82 & 2.60 & 1.44 \\
\hline$!$ & 63.74 & & 1.46 & 0.81 & 69.92 & 38.84 & 2.64 & 1.46 \\
\hline 10 & 6s. is & 38.21 & 1.50 & 0.83 & 69.96 & 38.87 & 2. is & $1.4 ! 9$ \\
\hline 11 & 68.81 & 38.23 & 1.53 & 0.85 & 80.00 & 38.89 & 2.72 & 1.51 \\
\hline 12 & 68.8. & 38.25 & $1.5 \%$ & $0.8 \%$ & 80.04 & 38.91 & 2.76 & $1.5 \% 3$ \\
\hline $1: 3$ & 65.89 & 38.27 & 1.61 & 0.89 & 70.08 & 38.93 & 2.80 & 1.5 .5 \\
\hline 14 & 68.93 & 38.29 & 1.6.i) & 0.91 & 70.12 & 38.95 & 2.84 & $1.5 \%$ \\
\hline 1.5 & 68.97 & 38.32 & 1.69 & 0.94 & 70.15 & 38.97 & 2.87 & 1.59 \\
\hline 16 & 69.01 & 35.34 & 1.73 & 0.96 & 70.19 & 38.99 & 2.91 & 1.61 \\
\hline $1 \%$ & 69.0 .5 & 38.36 & 1.87 & 0.98 & 70.23 & 39.02 & 2.95 & 1.64 \\
\hline 18 & 69.09 & 38.38 & 1.81 & 1.00 & 70.27 & 39.04 & 2.99 & 1.66 \\
\hline 1!) & 69.13 & $38 . \pm 0$ & 1.8 .5 & 1.02 & 70.31 & 39.06 & 3.03 & 1.68 \\
\hline 90 & 69.16 & & $1 . S S$ & 1.04 & 80.35 & $39.1) \mathrm{S}$ & 3.07 & 1.70 \\
\hline 21 & $(3 !) .20)$ & 38.44 & 1.92 & 1.06 & 80.38 & 39.10 & 3.10 & 1.72 \\
\hline $2 \%$ & 69.24 & $3 S .4 \%$ & 1.96 & 1.09 & 70.42 & 39.12 & 3.14 & 1.74 \\
\hline $2: 3$ & 60.28 & 38.49 & 2.00 & 1.11 & 80.46 & 39.14 & 3.18 & 1.70 \\
\hline 24 & 69.32 & 38.51 & 2.04 & $1.1: 3$ & $\gamma(0 . j)$ & 39.17 & 3.22 & 1.79 \\
\hline 25 & 69.36 & 38.53 & 2.08 & 1.15 & 80.54 & 39.19 & 3.26 & 1.81 \\
\hline 26 & 69.40 & 38.56 & 2.12 & 1.18 & 70.58 & 39.21 & 3.30 & 1.83 \\
\hline 27 & 69.44 & 38.58 & 2.16 & 1.20 & 80.61 & 39.23 & 3.33 & 1.85 \\
\hline 28 & $(39.45$ & 38.60 & 2.20 & 1.29 & 70.65 & 39.25 & 3.37 & 1.87 \\
\hline 29 & 69.52 & 38.62 & 2.24 & 1.24 & 70.68 & 39.27 & 3.40 & 1.89 \\
\hline 30 & 69.56 & 38.64 & 2.28 & 1.26 & 70.72 & 39.29 & 3.44 & 1.01 \\
\hline 31 & & $\ldots$ & $\ldots$ & $\ldots$ & 80.75 & 39.31 & $3.4 \pi$ & 1.93 \\
\hline
\end{tabular}




\begin{tabular}{|c|c|c|c|c|c|c|c|c|}
\hline \multicolumn{9}{|c|}{ 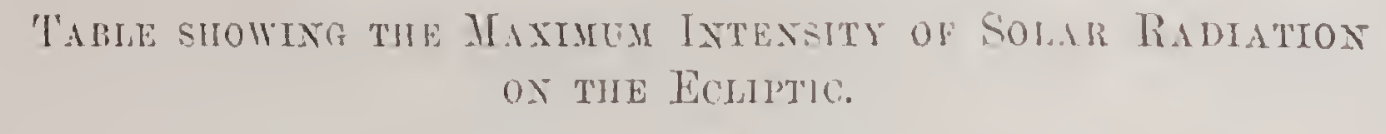 } \\
\hline \multirow{3}{*}{ 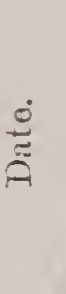 } & \multicolumn{4}{|c|}{ NOVEILBER. } & \multicolumn{4}{|c|}{ DECEMBER. } \\
\hline & \multicolumn{2}{|c|}{ Maximum. } & \multicolumn{2}{|c|}{ Increment. } & \multicolumn{2}{|c|}{ Maximum. } & \multicolumn{2}{|c|}{ Increment. } \\
\hline & 'Fah. & - Osint. & ${ }^{\circ}$ Fah. & - Cent. & ' $F u h$. & - Cent. & - Fuh. & - Cent. \\
\hline 1 & 70.79 & $39.3 \% 3$ & 3.51 & $1.9 j$ & 81.033 & 39.79 & $4.3 \%$ & 2.41 \\
\hline 2 & 70.82 & 39.34 & 3.34 & 1.96 & 71.65 & 39.80 & 4.37 & 2.42 \\
\hline$\because$ & $7(0.85$ & 99.36 & 3.57 & 1.98 & $71.6 \%$ & 39.81 & 4.39 & $\therefore 43$ \\
\hline 4 & 70.88 & 39.38 & 3.60 & 2.00 & 71.68 & $30.8 \%$ & 4.40 & 2.44 \\
\hline ). & 70.92 & 39.40 & 3.64 & 2.02 & 71.70 & 39.83 & 4.42 & 2.45 \\
\hline 6 & $80.0 \tilde{5}$ & 39.42 & $3.6 \%$ & 2.04 & 71.72 & 39.84 & 4.44 & $\because .40$ \\
\hline$\tau$ & 70.98 & $39.4: 3$ & 3.80 & 2.05 & 71.74 & 39.86 & 4.46 & 2.47 \\
\hline 8 & 71.02 & $39.4 \tilde{5}$ & 3.74 & 2.07 & 21.76 & 39.87 & 4.48 & 2.48 \\
\hline 9 & 71.05 & 39.47 & $3.6 \%$ & 2.09 & 71.77 & 39.87 & 4.49 & $2.4(9$ \\
\hline 10 & 71.08 & 39.49 & 3.80 & 2.11 & 71.88 & 39.88 & 4.50 & $\therefore 50$ \\
\hline 11. & 71.11 & 39.50 & 3.83 & 2.12 & $\tau 1.80$ & 39.89 & 4.52 & 2.51 \\
\hline 12 & 71.14 & 39.52 & 3.86 & 2.14 & 71.81 & 39.90 & 4.53 & 2.52 \\
\hline 13 & 71.17 & 39.54 & 3.89 & 2.16 & 71.82 & 39.90 & 4.54 & 2.12 \\
\hline 14 & 71.20 & 39.56 & 3.92 & 2.18 & 71.84 & 39.91 & 4.56 & 2.53 \\
\hline 15 & 71.24 & 30.58 & 3.96 & 2.20 & $\tau 1.8 \tilde{5}$ & 39.01 & 4.57 & 2.513 \\
\hline 16 & 71.27 & 39.59 & 3.99 & 2.21 & 71.86 & 39.52 & 4.68 & 2.54 \\
\hline 17 & 71.29 & 39.60 & 4.01 & 2.22 & 71.87 & 39.92 & 4.59 & 2.54 \\
\hline 18 & $\tau 1.32$ & 39.62 & 4.04 & 2.24 & $\tau 1.88$ & 39.93 & 4.60 & 2.55 \\
\hline 19 & 71.35 & 39.64 & 4.07 & 2.26 & 71.89 & 39.93 & 4.61 & 2.55 \\
\hline 20 & 71.38 & $39.6 \pi$ & 4.10 & 2.27 & 71.90 & 39.94 & 4.62 & 2.56 \\
\hline 21 & $\tau 1.40$ & 39.67 & 4.12 & 2.29 & 71.90 & 39.94 & 4.62 & 2.56 \\
\hline 22 & 71.42 & 39.68 & 4.14 & 2.30 & 81.91 & $39.9 \%$ & 4.63 & 2.57 \\
\hline 23 & $71.4 \tilde{j}$ & 39.69 & 4.17 & 2.31 & 71.21 & $39.9 \%$ & 4.63 & 2.57 \\
\hline 24 & 71.47 & 39.71 & 4.19 & 2.33 & ז1.92 & 39.96 & 4.64 & 2.58 \\
\hline 25 & 71.50 & 39.72 & 4.22 & 2.34 & 71.02 & 39.96 & 4.64 & 2.58 \\
\hline 26 & 71.62 & 39.73 & $4.2 \pm$ & 2.35 & 71.93 & 39.97 & 4.65 & 2.59 \\
\hline $2 \pi$ & 71.54 & 39.74 & 4.26 & 2.36 & 71.93 & 30.97 & 4.65 & 2.59 \\
\hline $2 S$ & 81.57 & 39.76 & 4.29 & 2.38 & 71.94 & 39.97 & $4.66 j$ & 2.59 \\
\hline 29 & 71.59 & 39.77 & 4.31 & 2.39 & 71.94 & 39.97 & 4.66 & 2.69 \\
\hline 30 & 71.61 & 39.78 & $4.33)$ & 2.40 & 81.04 & 39.97 & 4.66 & 2.59 \\
\hline 31 & $\cdots$ & $\ldots$ & $\ldots$ & $\ldots$ & 71.94 & 30.97 & 4.66 & 2.59 \\
\hline
\end{tabular}




\section{CHAPTER V.}

MECHANICAL ENERGY OF SOLAR RADIATION.

The mechanical energy developed by solar radiation cannot be accurately determined unless we possess means of ascertaining (1) the energy actually called forth by the sun's radiant heat at the surface of the earth, and (2) the energy lost during the passage of the rays through our atmosphere. The illustration shown on Plate 10 represents a solar calorimeter, an instrument constructed for measuring the energy actually developed near the earth's surface. An instrument for measuring the amount of radiant heat absorbed by the atmosphere, the actinometer, has been fully described in Chapter III. Evidently, if we possess reliable means of ascertaining the heat developed on a given area at the surface of the earth, and that lost by atmowpheric absorption, we can state positively what amount of dynamic energy is developed on a given area by solar radiation at the boundary of the terrestrial atmosphere. And since we know the true relation between the semi-diameter of the sun and the distance from the sun's centre 
to the earth, we can calculate the exilt regree of dispersion of the solar rays on reaching the atmospheric boundary. Are corlingly, we possess all the elements necessinly to compun. the amount of mechanical energy transmitted by radiation from a given area of the surface of the sum. Now; it will be found, on referring to Chat). VI., that the sun emits lieat of equal energy in all directions; hence we are enabled (1) estimate the total amount of mechanical power developed and transmitted by the smin as a motor:

Sir John Herschel and M. Punillet conceived the ideri. neally at the sime time, of meisming the energy of sulat radiation by exposing a given qunntity of water, prescuting a given area, to the sun's litys. Having ascertained the elevation of temperature of the water acquired in a griven time, and added the energy supposed to be lost by atmospheric absorption, together with the loss consequent on the dispersion of the rays, they computed the total dyramic energy developed by the sum. Herschel employed a small, stationary, open vessel, which he termed an actinometer; while Pouillet resorted to a close, movible vessel, the well-known "pyrheliometre." The simple instrmment devised by the great English astronomer, although very defective and incapable of furnishing exact data, demands particular notice, since it was employed in the first investigation of a practical nature intended to solve the important problem of solar energy. The result of the investigation of Herschel, it will be remembered, startled the world by the inconceivable magnitude of solar energy which it disclosed. 'The actinometer, agreeal)]. 
to the following lucid statement, furnished by the distingruished designer himself, consisted of "a light cylindrical ressel of timned iron, open at the top, $3 \frac{3}{4}$ inches in diameter and 2.4 inclies in depth, weighing 1,069 grains, nearly filled with water moderately darkened by a slight admixture of ink. This vessel was placed on a light wooden support, covered with cotton cloth, and touching it only in a narrow ring (to avoid the communication of heat by conduction), in the interior of an iron cylinder of much larger diameter, to protect it from wind and external radiation, the upper part of which was covered by an iron plate well protected from sunshine by several separate diaphrigms of paper laid lightly one over the other thereon. This plate had a circular aperture somewhat wider than that of the tin cylinder, and vertically over it, centre corresponding to centre. The mouth of the tin cylinder was covered with a circle of stiff paper, having an aperture exactly circular and concentric with the cylinder, so as to admit a vertical or nearly vertical sumbeam somewhat less in section than the ressel, and wholly incident on the surface of the contuind liquid. This cover also projected over the exterior of the cylinder on all sides, so as to prevent any lay from striking on its outside, even when the upper iron plate was remored from the exterior vessel. Lastly, to cut off effectually all lateral radiation from the region of sky near the sum, a paper diaphragm but very little more in aperture than the mouth of the tin cylinder was laid concentrically on the upper iron plate and its diaphragms. Plunged into the liquid, and resting on the bottom when not 
in use, was a circular plate of mica $3 \frac{1}{4}$ inches in diameter, attached to a light rod of reed 0.1 inch in diameter, for the purpose of completely stirring and mixing the strata of the liquid by one or two up and down movements. When thus prepared, the whole apparatus was placed in the sunshine at noon, or somewhat before, and so adjusted that, on the admission of sunlight, a ninrow ring of light surrounded concentrically the aperture in the diaphragm of the tin cylinder beneath, which was carefully watched during the progress of the experiment, and kept unaltered. These arrangements being made, the sun was shaded oft, the temperature of the liquid (after stirring by the mica plate) taken by an exceed. ingly delicate and sensitive thermometer by (richton, and again after a certain noted number of minutes. The shade being then removed, the sun was allowed to shine into the aperture on the liquid for ten minutes. During this expo. sure, the liquid was three times stirred by the mica plate, allowing five seconds for each stirring, and shading the aperture during that operation (which, of course, was not counted as part of the ten minutes' exposure). The temperature was now again taken, and, after remaining shaded again a certain noted number of minutes, finally once more. The mean of the minutely change of temperature, deduced from the shade observations, being obtained, was applied as a correction (in all cases a very small one) to the minutely elevation of temperature in the sun exposure; and thus the true effect of the sun was concluded."

The "pyrheliometre" having been described in nearly all 
recent works on solar energy, and accurately delineated in Pouillet's "F́léments de Physique" (Tome II., Paris, 1856), it will only be necessary to remind the reader that the ressel exposed to the sun, composed of polished silver, contains 100 grammes of water. 'The dianeter is 1 decimetre and the depth 15 millimetres, the top exposed to the sun's rays being coated with lamp-black. 'The radical defect of Pouillet's instrument is that it cannot be used during winter when the thermometer is below the freezing point, as warm water would have to be used, in which case the loss of heat by radiation and conrection would be so great as to render the task futile of accurately measuring the force of solar ratiation. This defect of Pouillet's method is the more serious as the heat of the sum is most intense during the winter solstice for given zenith distances, on account of the diminished distance between the sun and the earth, and because the sky is generally clearer on a cold winter's day than during the heat of summer when the air is charged with vapor.

The loss of heat by radiation, in the pyrheliometre; the loss of lieat by convection, accelerated by currents of air; the absence of adequate means for eirculating the fluid contained within the heater; the rude method of keeping the instrument perpendicular to the sun with the hand, not to mention the listurbing influence of respiration and the radiation from the operator's body, are self-evident defects. Nor can we pass unnoticed the want of any direct means of ascertaining the depth of the atmosphere through which the radiant heat passes at the moment of measuring its energy. I need scarcely 
point out that computations bised on latitude, date, and exact time are too complex and tedions for investigations in which the principal element, the depth of the atmosphere, is con tiulually changing.

It will be well to state that the solar calorimeter, aml all my instrments constructed for investigating the mechil. nical properties of solar heat, are attached to a ribrating table applied within a revolving observatory, supported on horizontal journals and provided with a declination movenent and a graduated arc. Consequently, the sun's zenith distance may at all times be ascertained by mere inspection, a very great conrenience in an investigation which at every instant is dependent on the clanging depth of the atmosphere through which the solar rays pass. As this depth bears a fixed relafion to the sun's zenith distance, it may of course be accurately letermined by noting the position of the fixed index on the graduated are; but, as alrealy pointed out, there is no time luring investigations of this kind for computations. I have, therefore, constructed a graduated scale provided with a mov. able radial index, which, by being brought to the division corresponding with the observed zenith distance, shows the depth of atmosphere (see diagram in Chap. III., Plate ()). It is proper to observe that, in constructing this scale, I have assumed the earth to be a perfect sphere of 3,956 miles radius. 'The error resulting from this assumption is, however, so trifling that the described graphic method of ascertaining the depth of the atmosphere may, without aplrecialsle crror', be employed for all latitudes. 'The solar colorincter consists of a double 
ressel, cylindrical at the bottom and conical at the top, an sin. lens being inserted at the wide end in the mamner shown ly the illustration. The interior is lined with polished silver, the space between the two ressels being closed at the top and bottom by means of perforated rings, as shown in the transverse section. The object of these perforations is that of distributing equally a current of water to be circulated throngh the space between the vessels. Nozzles are applied at the top and bottom of the external ressel, of suitable form to anmit of small flexible piper being attached. $\Lambda$ stop-cock with coupling-joint is applied at the bottom, communicating with the interior chamber of the calorimeter and connected with an air-pump, for exhansting the same. A cylindrical ressel, with closed ends, composed of polished silver, is secured in the lower part of the interior chamber, and provided with a conical nozrle at the top, through which a thermometer is inserted from without. Within the lower part of this cylindrical vessel a centrifugal paddle-wheel is applied, surrounded by a cylindrical casing divided into two compartments by a circular diaphragm. 'The lower compartment contains four radial wings, or paddles, the diaphragin being perforated in the centre. The said paddle-wheel revolves on a vertical axle, which passes through a stufting-box applied at the bottom of the surrounding ressels, the rotary motion being imparted by means of a pulley secured to the lower end of the axle. 'The operation of this wheel, designed to promote perfect circulation of the fluid within the cylindrical ressel when charged, is quite peculiar. It will be readily understood that the 
centrifugal action produced by the rotation of the paddles will draw in water downwards through the central perforation of the diaphragm, and force the same into the annulas space round the casing of the wheel; thus an upward current will be kept up through this aunular space uniform on all sides. The circulating water, after reaching the top of the heater, will then return, first entering the open end of the casing of the wheel, and ultimately the central perforation of the diaphragm. I have been thus particular in deceribing this system of promoting uniform circulation, becizuse a correct indication of the mean temperature of the water contained within the ressel subjected to the action of the concentrated rays, is the all-important condition on which depends the accuracy of the determination of the number of thermal units developed by the radiant heat. It only remains to be pointed out that the lens, which is so proportioned as to admit a sunbeam of $53.45 \mathrm{sq}$. ins. of section, is placed at such a distance from the heater that when the concentrated rays reach the upper end (coated with lamp-black) they are confined to an area of 3.35 sq. ins., viz., $\frac{1}{16}$ of the sectional area of the pencil of rays which enter's the lens.

It will be obvious that the concentration of the radiant heat on an area of only one-sixteenth of that of the section of the pencil of rays admitted to the instrument remores a very difficult disturbing element from the investigationnamely, the great amount of heat raliated by the blackened surface of the heater, which in the pyrheliometre is 16 times greater for a given amount of radiant lieat than in the solar 
calorimeter. But this is not all; while the extensive blackened surface of the former is exposed to currents of air, the disturbing effect of which can neither be controlled nor computed, error arising from convection is wholly removed from the latter, because the reduced blackined surface of the vessel exposed to the solar rays receives the concentrated radiant heat within a vacuum. The loss of heat at the bottom and sides of Pouillet's instrument, caused by convection and currents of air, is likewise wholly removed in the solar calorimeter by the expeclient of operating within a vacuum. It will be seen, therefore, that the loss from these causes has been wholly obri. ated in this instrument, while the loss occasioned by radiation from the blackened surface which receives the concentrated ladiant heat has been reducul to a mere fraction. It may be contended, however, that the loss by radiation of the heater against the interior surface of the calorimeter, although minute, is yet appreciable, and that some heat will be lost by conduction at the points where that vessel joins the surrounding chambers. Even these trifling sources of error, it will be seen presently, have been removed by the new method. A forcepump and a cistern containing water maintained at a constant temperature of $60^{\circ} \mathrm{F}$. are arranged near the calorimeter. By means of this pump and the flexible pipes before referred to, a constant current is kept up through the space between the internal and external casings of the instrument; hence the materials composing the latter may quickly be brought to the same temperature as the circulating water. The process of measuring the radiant energy is conducted in the following 
mamner: The thermoneter being withdram, the cylimblial ressel or heater is charged with distilled water of at tempes rature of ahout tis $\mathrm{F}$, after which the thermometer is anam inserted and the instrument exposed to the sum, the farlille. wheel being kept in motion. The indiantion of the thermu. meter must then be watcherl, and the time alcumately noted when the mereurial colnum malks $50^{\circ}$ on the sale, the obser. vation continuing until the themometer mallks $70^{\circ}$, at which point the time is again accurately moted. The experinent being then conclueled, the lens should be corered. The air. culating water being kept at a constant temperature of $6\left(0^{\circ}\right.$ F., it scarcely needs explanition that, during the alevation of the temperature of the water from $50^{\circ}$ to $60^{\circ}$, the instrument radiates tomards the heuter; and that, while the temperature rises from $60^{\circ}$ to $70^{\circ}$, the heater radiates toucurds the instrm. ment. In each case the amount of heat radiated and received is almost inappreciable, since the ressel contrining the water to be heated and the surrommling vessel are compuned of highly polished metil. The amounts of gain and loss of heat by comlurtion at the points where the heater is joinerl to the external ressel, if appreciable, evidently balanre each ofluel. in the same manner as the gain and loss by radliation.

The weight of distilled water at $60^{\circ}$ contained in the heater, and the weight and specific heat of the materials which compose its parts, being ascertaned, the number of thermal units necessary to elevate the temperature of the whole $20^{\circ} \mathrm{F}$. may be readily calculater. To this nust he added the percentage of calorific energy lost dming the pas. 
sage of the sun's rays through the lens. The sum will represent a permanent coeflicient for each particular instrument. Obviously, the indication of the solar calorimeter will not be less reliable during winter in a northern latitude, with the mercury at zero, than during summer within the tropics, when the thermometer marks $100^{\circ}$ in the shade. Nor must it be supposed that the same difficulty presents itself in ascertaining the loss of energy of the lays of heat as that involved in a determination of the retardation which rays of light suffer during their passage through a lens. In order to determine the former; we have only to compare the units of heat developed hy the direct action of a pencil of rays of a given section with the number of units developed by another pencil of equal section, acting during an equal interval and at the same time, through the lens the retarding influence of which we desire to ascertain.

The weight of water contained in the heater of the solar calorimeter employed during the investigations referred to in this work is $0.8125 \mathrm{lb}$. avoirdupois, the weight of the materials composing the heater, paddle-wheel, and other parts heing $0.29811 \%$. As the specific heat of these materials is 0.125 , it will he evident that $0.125 \times 0.298=0.03 \% 2$ lb. should he arlded to the weight of water contained in the lieater. Ac(o)dingly, the total weight will amount to $0.8125+0.03 \% 2$ $=0.8497 \mathrm{lb}$. The elevation of temperature in the heater being fixed at $20^{\circ} \mathrm{F}$, it will be seen that the dynamic energy developed during each experiment will amount to $20 \times 0.8+97$ $=16.99+$ thermal units, besides the energy absorbed by the 
lens, which, agreeably to actual trial, amounts to vely nearly 0.10. Consequently, $0.10 \times 16.994+16.994=18.6934$ there mal units represent a permanent coefficient of energy for the particular instrument referred to. Let us clearly understum that, at the conclusion of each experiment; whatever be the time occupied in attaining the stipulated $20^{\circ} \mathrm{F}$, the stater amount of energy, viz., 18.6934 thermal units, has been dere. loped. We are, therefore, enahled to detemine the amomnt of mechanical energy developed by solar radiation at the sur. face of the earth by observing the time occupied in attainingr the stipulated temperature, and then dividing the coneflicient of energy by the time thus olserved. But it will be per. ceived, on reflection, that, in order to solve the importint problem of solar emission, the following conditions must be fulfilled at the time of conducting the experiment: (1) The sun must be perfectly clear. (2) The position of the earth in the orbit must be known in order to enahle us to deter. mine the distance of the sun and the consequent dispersion of the rays during the observation. (3) The sun's zenith distance must be known, since the loss of radiant energy by absorption depends on the depth of atmosphere pene. trated by the rays. The second and third of these conditions are of course readily met; but the first condition can only be fulfilled by repeating the observations during a series of years whenever the sun is exceptionally deant. The writer feels confirlent that, by having alopted this system, the problem of solar emission has been satisfactorily solved. An account of the observations successively marle being devoid 
of interest, it will be sufficient to state that the olsserved maximum solar intensity occurred March 7, 1871, the sun being then so clear that the before-mentioned amount of 18.6934 thermal units was dereloped in 10 min. 0.5 sec., hence $\frac{18.6934}{10.00833}=1.8678$ units per minute. The sectional area of the pencil of rays entering the solar calorimeter was, as already stated, 0.37187 square foot. Consequently, if we reduce the foregoing elements to the usual standard-one square foot of area acted upon by the sun in one mimuteit will be found that, on the occasion referred to, an energy of 5.03 units of heat per minute was dereloped by a pencil of solar rays of 1 square foot section. The mean zenith distance during the experiment was 46 deg. 5 min., while the position of the earth in the orbit was such that the sun's rays suffered a dispersion of 45,400 to 1 . Referring to the table of temperatures for given zenith distances (see page 62 ), it will be found that the radiant intensity at $46 \mathrm{deg} .5 \mathrm{~min}$. zenith dis. tance is diminished in the ratio of $67^{\circ} .2: 59^{\circ} .85$. The energy developed by our calorimeter during the experiment was, of course, reduced in the same proportion. Introducing, then, the necessary correction for the stated loss caused by zenith distance-i.e, atmospheric absorption-the true energy developed by the radiation at the surface of the earth during the experiment was $\frac{67.20 \times 5.03}{59.85}=5.64$ units per minute. Referring to Chap. III., it will be found that the temperature produced by solar radiation at the boundary of the terrestrial 
atmosphere is 0.20 g greater than that develuped nean the sintface of the earth; in other words, the energy alsorthed ly. the atmosphere is to that tramsmitted to the enth as 0.207 : 0.793. Consequently; the energy dereloped by solar radialtion at the boundary of the atmosphere, Manch $i, 1571$, was $\frac{\tilde{0} .64}{0.793}=7.11$ thermal units on one square foot of surfice: while the dispersion of the rays on that day was in the ratio of 45,400 to 1 . It needs 110 demonstrition to prove that. aceording to this ratio of discrerion of the rals, the curery emamating from one square foot of the photosphere must heat 45,400 square feet of surface at the boundary of the terrestrial atmosphere. Our inrestigation having shown that solar radiation develops an energy of 7.11 units to the squalre foot on entering the terrestrial atmosphere, it follows that solar emission amounts to $45,400 \times 7.11=322,794$ thermal units in one minute for each square foot of the photosphere. In view of the completeness of the means adopted in measuring the energy developed, and the ample time which has been devoted to the determination of maximum intensity, it is not probable that future labors will change the result of our investigation. The continuous shrinking of the sun will produce a perceptible dimimution of the radiant energy trans. mitted to the earth in the course of a few hundred centuries, but the emissive energy for a given area of the sun will remain constant for millions of years, since the intensity developed by the falling mass will increase inversely as the square of its distance from the solar centre, thus balancing the dimi. 


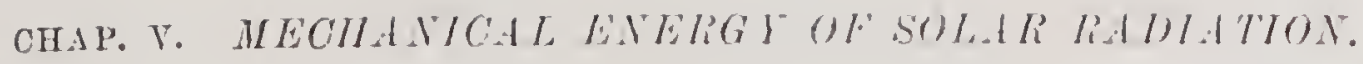

nution of energy consequent on the reduced fall of the mass.

The illustration shown 111 Pate 11 represents a rertical section of a portable solin calorimeter, in all essential features similar to the instrument ilescribed in the present chapter, the only material difference being that of employing a selfucting circulating wheel within the heater. Refering to the illustration, it will be seen that the instrument is placel on an ordinary table, a weight being suspended under the same for actuating the circulating wheel. The cylindrical chamber' which contains the heater moves on a hinge secured to a circular bed-plate proviled with cogs, turning round a rer. tical pirot fastened to the top of the table, the inclination being regulated by a tangential screw. A horizontal pinion, geared into the cogged bed-plate referred to, enables the operator to follow the diurnal notion, while the tangential screw (nables him to regulate the inclination of the lens with refe. rence to the sun's declination. Appropriate sights are applied to the front side of the cylindrical chanber, showing when its axis points towards the sun's centre, while a graduated fuadrant indicates the zenith distance at all times. It will be found, by inspecting the illustration, that the axle of the harrel actuated by the motive weight is connected by a train of cog-wheels to the shaft of the circulating wheel within the heater. The perfect regulurity of rotation imparted to this wheel, and the consequent pertectly uniform circulation kept up within the heater, dispenses with the necessity of exhansting the air from the cylindrical cliamber; on the fol. 
CHAP. T.

lowing grounds: The heat imparted by the air within the chamber during the first half of the experiment balances the heat absorbed during the second half. There is a lifference, but too small to cause an appreciable error. It may be men. tioned that the portable solar calorimeter thus described was originally constructed for ascertaining the dymanic energy developed by solar radiation on the plains of India and in Australia. 


\title{
CHAPTER VI.
}

\author{
'IHERMAL ENERGY 'TRANSMITTED 'T'O 'THE EAR'TH BY \\ RADIATION FROM DIFFEREN'T PARTS OF 'IHE \\ SOLAR SURFACE.
}

Perre Secchi, in the second edition of "Le Soleil," published at Paris, 18\%5, calls special attention to the result of his early investigations of the force of radiation emanating from different regions of the sun's surface, reiterating without modification his former opinions regarding the absorption of the radiant heat by the solar atmosphere. It will be well to bear in mind that the plan adopted by the Italian physicist in his original researches, on which his present opinion is based, was that of projecting the sun's image on a screen, and then, by means of thermopiles, measuring the tempera. ture at different points. The serious defects inseparable from this method of measuring the intensity of the radiant heat I need not point out, nor will it be necessary to urge that a correct determination of the energy transmitted calls for direct observation of the temperature produced by the rays projected towards the earth. Accordingly, on taking up that 
branch of my investigutions of radiant lieat which relates to the difference of intensity transmitted from difterent parts of the sun's surface, I adopted the methol of direct observation. The progress was slow at the beginuing, owing to the necessity of constructing an astronomical anparatus of unusual dimensions; but haring derised means which rendered the employment of any desirable focal length easy, the work has progressed rapidly. An instrument of 17.7 motres (5s fent) focal length, erected to conduct lnelininiry cxperinents, has proved so satisfactory that the construction of one of 30 metres focal length, which I supposed to he necrssaly, has been dis. pensed with. Considering that the appranent diameter of the sun at a distance of 17.7 metres from the observer's eye is 162.4 millimetres, even when the earth is in aphelion, the efficacy of the instrmment employed might have been anticipated. The nature of the device will be rearlily comprehender by the following explauation: Suppose a telescopic tube 1 \%. metres long, 1 metre in diameter, devoid of object-glass and lenses, and mounted equatorially, to be closed at both ends by metallic plates or diaphragms, at right angles to the tele. scopic axis; suppose the diaphragm at the upper end to be perforated with two circular apertures 200 millimetres in diameter, situated one above the other in the vertical line, 360 millimetres from centre to centre; and suppose a third circular perforation whose area is one-fifth of the apparent area of the solar disc-vi\%, 72.6 millimetres diameter-to be made on either side of the rertical line; suppose, lastly, that the diaphrigm which closes the lower end of the tube 
be perforated with three small apertures of millimetres in diameter, whose centres correspond exactly with the centres of the three lange perforations in the upper diaphragm. The tube being then directed towarls the sun, and actinometers applied below the three small apertures in the lower. diaphragm, it will be evident that two of these instruments will, after due exposure to a clear sun, indicate maximum solar intensity, say $35^{\circ} \mathrm{C}$, while the actinometer applied in line with the perforation whose area is one-fifth of the apparent area of the solar disc will indicate $\frac{3 \overline{5}}{\bar{J}}=7^{\circ} \mathrm{C}$, unless the central portion of the solar dise radiates more powerfully towards the earth than the rest, in which case a higher intensity than $7^{\circ} \mathrm{C}$. will be indicated by the actinometer referred to. It will be readily understood that the solar rays entering through the perforations at the upper end of the tube converge at the lower end and pass through the small perforations, causing maximum indication of the focal actinometers as stated. Now, suppose that a circular plate, the area of which is exactly four-fifths of the apparent area of the sunvi\%, 145.2 millimetres diameter-be inserted concentrically in either of the two large perforations of the diaphragm at the top of the telescopic tube. The apparent dianeter of the sum being, as before stated, 162.4 millimetres, it will be perceived that the inserted plate will only partially exclude the solar radiation, and that the rays from a zone $1^{\prime} 42^{\prime \prime}$ wide will pass outside the said plate, converging in the form of at hollow cone at the luwer end of the tube, and there enter' 
the respective actinometer. 'The indication of the latter wi]l then show the thermal energy transmitted by radiation from a zone whose mean width extends $t g^{\prime \prime}$ from the sun's border. It should be particularly observed that the three focal acti. nometers employed will be acted mpon simultanconsily by the converged rays, (1) from the entire area of the solar disc, (2) from a central region containing oue-fifth of the area, and (3) from a zone at the border containing also one-fiftl of the area of the solar disc. It is scarcely necessury in point out that an accurate comparison of the intersity of the ladiant heat emanating from the central purt and from the sun's border calls for simultaneons observaltion, in orter to aroid the errors resulting from change of zenith distamce ambl rariation of atmospheric absorption during the investigation. The great advantage of obtaining also a simultaneous indication of the intensity transmitted by radiation from the entire solar disc is self-evident, since this indication serres as an effectual check on the observed intensities cmanuting from the centre and from the border. The latter obrinusly must be less, while the former must be greater, for a given area, than the indication of the focal actinometer which receires the radiation of the entire solar disc.

The foregoing demonstration, based on hypothesis, having established the possibility of ascertaining by direct observa. tion the tenperature produced by the rays projected from certain parts of the solar surface, let us now examine the means actually employed. An observer on the 40 th deg. latitude, stationed on the north side of a building. 28 metres 
ligh, pointing east and west, can just see the sum pass the meridian, during the summer solstice, if he occupies a position about 8 metres from such building. Now; if an opaque screen, perforated by a circular opening 313 millimetres in cliameter, be placed on the top of the silposed building, the entire solar disc may be seen through the same, provided it faces the sun at right angles. But if the perforation in the said screen be 140 millimetres in dimeter, only one-fifth of the area of the solar disc will be seen. And if the screen be remored and a circular plate $2 S 0$ millimetres in diameter put in its place, the observer, ranging himself in line with the plate and the sun's centre, can see only a narrow border $1^{\prime} 42^{\prime \prime}$ of the solar disc. Obriously the screen placed on the top of the building might be perforated like the upper diaphragm of the supposed telescopic tube, and a plate resembling the lower diaphragm, secured by appropriate means near the ground, might be made to support the focal actinometers in such a manner that their axes pass through the centres of the perforations of the screen above the building. It is hardly necessary to state that the plate supporting the actinometers should be attached to some mechanism capable of imparting to it a parallactic movement, during the observation, corresponding with the sun's declination and the eartli's diurnal motion, and that some adequate mechanism should be employed for regulating the position of the perforated screen and adjusting the focal distance in accordance with the change of the subtended angle consequent on the varying distance from the sun. It will be evident that, since 
the first-named meehanism rests on the gromel, while the latter is secured to a massive building, fin greater straliness will be attained by our simple and compratively inexlensive device than by employing a teleseopic tube of the most perfect construction mounted equatorially.

With reference to the influence of diltraction, it shoult be stated that, before detemining the size of the sererms intended to shut out certuin parts of the solar disc during the investigation, the amount of inflection of the sunts lays wis carefully ascertained. Tro distinct methods were adopted: (1) measuring the additional amount of hont transmitted to the focal themometers in consequence of the inflection of the rays; (2) increasing the theoretical sime of the screens until the effect of inflection was orercome and the luninoms rays completely excluded. Reganding the first-naned methor of ascertaining the diftaction, it is important to mention that the temperature transmitted to the focal actinometers by the inflected radiation which passes outside of the theoreticully determined screens is not proportionate to the inflection ascer. tained by the process of enlargement referred to. This cir. cumstance at first rendered the investigation somewhat conplicated, but it soon became evident that the discrepancy was cansed by the comparatively small inflection of the invivile heat rays. It will be seen presently that the radiant heat which passes outside of the screens in consequence of diffriction is considerably less thin that which would be transmitted to the focal actinometers if the calorific lays were sulbjected to an amount of inflection corresponting with the enlargement 
of the screens beyond the theoretical dimensions necessary to exclucle the luminous raiys.

Let us first consider the method of ascertaining the inflection of the latys by measuring the arditionil amount of heat transmitted to the focal actinometers. Fig. 1 (see Plate 12) represents the solar disc, "being the fucal actinometer exposed to the converged rays, $a^{\prime} a^{\prime}$ representing an imaginary plane situated 17.5 metres from a, at which distance the section of the pencil of converging rays will be 162.4 millimetres in diameter, provided the earth is near aphelion. Fig. 2 also represents the solar disc, and $c$ the actinometer exposed to the converged rays; but a perforated screen $b^{\prime} b^{\prime}$ is interposed, the perforation being of such a size that only the rays projected by the central half of the solar dise (indicated by the (ircle 7, 7) pass through the same and reach the focal actinomoter. The screen $b^{\prime} b^{\prime}$ being situated 17.7 metres from $c$ when the earth is in the position before referred to, the said perforation must be 114.83 millimetres in diameter; in order that the lines $b a^{\prime} c$ may be straight. Fig. 3 likewise represents the solar disc, its area being divided into two concentric halves by the circle $d d$; but, in place of a perforated screen, an opraque circular screen $d^{\prime}$ is introduced at the same distance from the focal actinometer as in Fig. 2 ; consequently, the lines d. $y^{\prime} f$ will be straight. Now, if the actimometers a, c, and f be exposed to the converged solan rarliation simultancously and during an equal intervat of time, $c$ and f receiving the heat from one half of the solar disc (the former from the central and the latter from the surrounding half), the tempe- 
ratures of $c$ and $f$ added together should correspond exactly with the temperature transmitted from the entire solar disc to $a$. Observation, howerer, shows that the temperature of c and $f$ together is 0.091 greater than the temperature imparted to $a$. Hence an increase of temperatme of nearly one-elerenth is produced by the inflection of the calorific rays, one-half being the result of the bending of the rays within the perforation of the screen $b^{\prime} b^{\prime}$, the other half resulting from the bending outside of the screen $d$. 'The increment of tempe. rature being thus known, the degree of inflection may be easily determined by drawing a circle $a$ a round the circle $\checkmark 6$, covering an additional alea of $\frac{0.091}{2}=0.0455$; and by iuscribing a circle $y$ within $d$, covering an area of 0.0455 less than the area of $d d$. It will be perceived, on reflection, that $x \quad x^{\prime} \quad b$ represents the angle of inflection of the calorific rays within the perforation of the screen $b^{\prime} b^{\prime}$, and that $d y^{\prime} y$ represents the angle of inflection outside of the screen $d$. Demonstration shows that the former angle measures $14^{\prime \prime} .57$, while the latter measures $14^{\prime \prime} .86$, the mean being 14".71. Having thus determined the inflection resulting from invi. sible radiation, let us now ascertain the inflection of the luminous rays. As before stated, the apparent diameter of the sun at a distance of 17.7 metres from a given point is 162.4 millimetres when the luminary is furthest from the earth. Now, our investigation shows that a screen 167 milli. metres in diameter hardly suflices to exclude the Iuminous rays; hence their inflection amounts to $\frac{167-162.4}{2}=2.3$ 
millimetres in a length of 17.7 metres. Their angle of inflection will therefore be $26^{\prime \prime} .81$, against $14^{\prime \prime} .71$ for the dark rays. We have thus incidentally established the fact that the inflection of the luminous and calorific rays differ's nearly in the same proportion as the calorific energies of the invisible and risible portions of the solar spectrum.

The illustration on Plate 13 represents a top view (see Fig. 15) and a transrerse section (see Fig. 17) of the paral. lactic mechanism enployed in the investigation. The leading feature of the device is that of attaching three actinometers, $f$, $h$, and $\%$, to a plate which may be set at any desired inclination, and capable of being moved simultaneously at right angles to, and in a direction parallel with, the meridian. The mode of effecting this movement will be readily understood by the following description, reference being had to the illustration: $"$ is a screw, the threads of which are formed to a pitch of three-eighths of an inch, placed horizontally and at right angles to the meridian, the ends turning in bearings bolted to a substantial frame 6 b, supported by legs resting on a solid stone foundation. A radial arm $c$, the position of which is regulated by a graduated quadrant $c^{\prime}$, is fastened to the end of the screw $a$; the latter being by that means prevented from turning round? d $d$, arms connected by a cylindrical socket di, which slides freely back and forwards on the screw. The said socket is prevented from turning round the screw by the application of a square key a', fitted accurately into a rectangular longitudinal groore formed in the side of the screw. e e, plate sliding between 
appropriate guide-rods securen to the upper side of the arms d $d$, motion being imparted to this plate hy a micrometric screw $e^{\prime}$. The actinometers $t, \%$, and $h$ alle attached to at plate $k$ bolted to the top of $e e$. 'The sliding socket $d$ ' is moved along the main serew by a milled unt /, held against the end of the said socket by a forked pioce ? fistened to the arm $d$ and acting on a collar formed at the small comb of the milled nut. It searcely needs cxplanation hint, lu! turning this nut, the sliding socket d' may he made to move along the main screw in either direction, therehy infrating

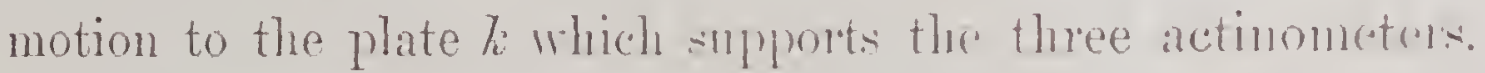
Nor will it be necessary to lemomstrute that, hy tmming the micrometric serew e', the said plate may he mored at right angles to the main screw ". Consequently, the mechanism thus described enables us to move the actinometers with great rogularity and precision across the meridian, and in a direction parallel with it. By means of a flexille tube m m, which connects the surrounding casings of the three actinometers, a stream of water is circulater through the Jatter during observations. An ordinary force-pump is employed for this purpose, attached to a capacious cistern containing water maintained at a constant temperature. 'The centres of the actinometers f and a are 160 centimetres apart, a colored glass $n$ being attached to the plate $k$ in a direct line with, and equidistant from, the stated centres. An eyepiece is applied to the colored glass m, below the plate $k$. The actinometers are provided with conical apertures on the ripper side, through which the thermometers are introduced 
when the instrument is in operation. In the illustration these apertures are closed by conical plugs provided with globular handles. Fig. 16 represents a square bar 1, to which three (ircular discs, composed of sheet brass, are attached by means of deep and thin arms, formed as shown by the drawing. The discs f' and " $f^{\prime}$ are placed 160 centimetres apart, from centre to centre, corresponding exactly with the distance between the axes of the actinometers $f$ and $g$; while the centre of the disc $\&$ corresponds with the centre of the eyepiece below the colored glass $n$. 'The square bar $r$ is held horizontally and at right angles to the meridian by a substantial bracket secured to the top of some building of adequate height; the angular position of the bar being such that it corresponds with the sun's \%enith distance. The frame 6 b, which supports the parallactic mechanism, rests on a level stone foundation, its distance from the building referred to depending on the season and the latitude of the place of observation. Assuming that the bar ", which supports the dises $f^{\prime}, s$, and $g^{\prime}$, has been correctly placed, and that the parallactic mechanism occupies a proper position on the ground, it will then be found that, when the sun passes the meridian, the disc $s$ will throw a small round shadow covering the colored glass $n$. Obviously, an operator lying on his back under the frame which supports the instrument, with his right hand turning the milled nut $l$, and his left hand turning the micrometric screw $e^{\prime}$, will be enabled to impart a simultaneous right-angular movement to the actinometers. Now, the diameter of the disc $s$ is such that, 
when brought in line with the sun and the eye-piece below $n$, only the extreme edge of the solar disc is seen through the colored glass. The operator, therefore, by careful mani. pulation, may readily keep the eye-piece and the disc s in line with the solar centre. My original design was that of actuating the parallactic mechanism by clock-work; but, warned by the frequent failures of astronomers to keep the sun accurately in focus even during the short period of an eclipse, I adopted the safer method of operating by hand. The distance between the centres of the discs $f^{\prime}$ and $g^{\prime}$ corresponding exactly with the distance between the axes of the actinometers $f$ and y, both being equidistant from the axis of the eye-piece, it will be evident that the centres of the discs $f^{\prime}$ and $g^{\prime}$ will always coincide with the axes of their respective actinometers directed towards the solar centre, provided the operator manipulates the instrument so carefully that the sun is kept accurately in focus; in other words, that no distortion is suffered to take place of the ammular face or narrow border of the sun seen through the colored glass. It hardly needs explanation that the actinometer $h$ is at all times exposed to the full energy of the converging rays from the sun.

As a detailed account of the result of the investigation would occupy ton much space, the leading points only will be prescnted. The observations have all been made at noon, the duration of the exposure to the sum having been limited to seven minntes, during which period the actinometer's are moved, by the parallactic mechanism, through a 
distance of about 55 centimetres, from west to east. The intensity of the radiant heat imparted to the actinometers has been recorded by the observers at the termination of the fourth, fifth, sixth, and seventh minute, the exact moment for reading off being indicated by a chronograph. The relative intensities transmitted by radiation from the centre and from the border of the solar disc first claim

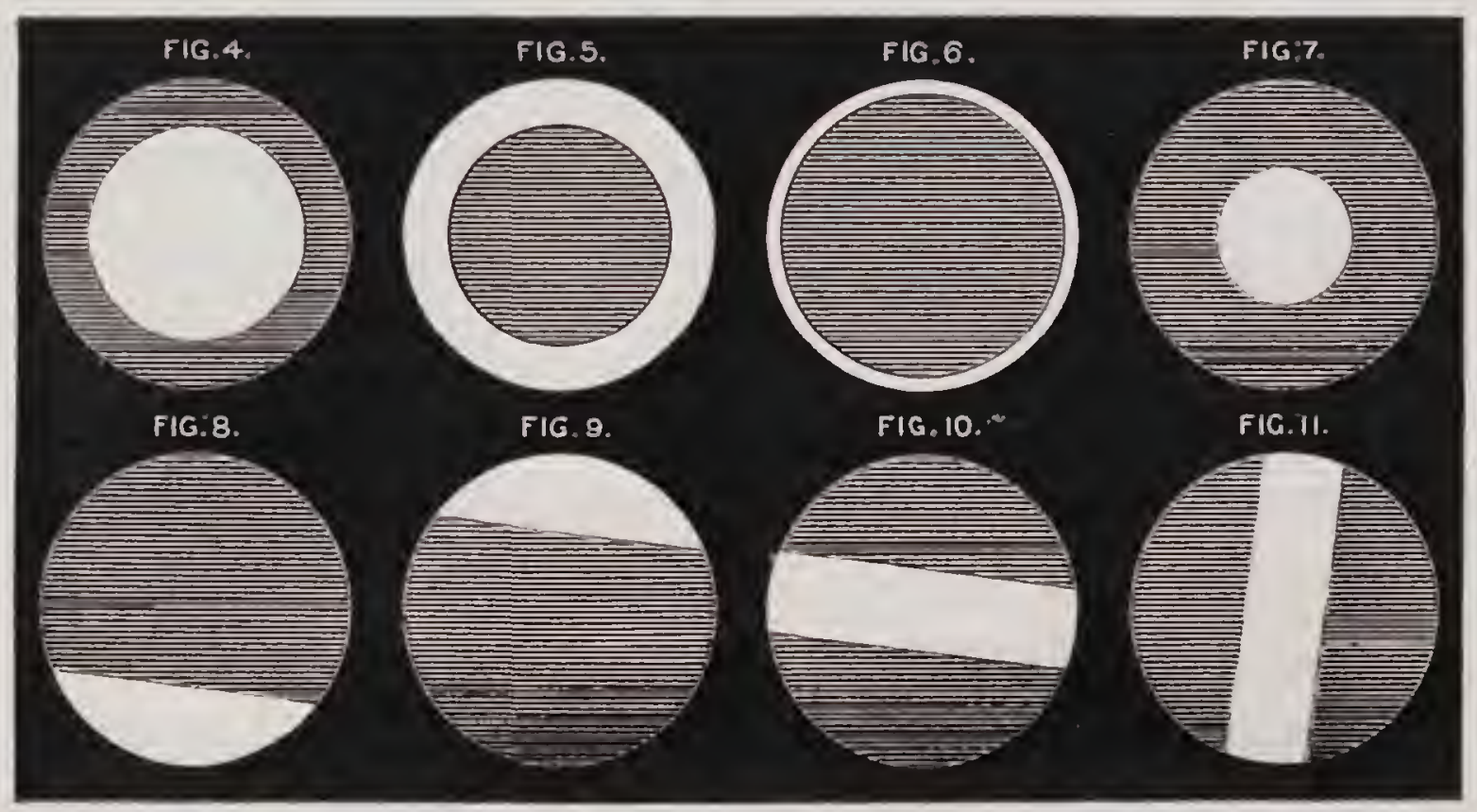

our attention. Figr 6 represents the solar disc covered by a circular screen 145.25 millimetres in diameter, excluding the rays excepting from a narrow zone, the mean width of which is situated $49^{\prime \prime}$ from the border of the photosphere. Fig. 7 shows a screen excluding the solar rays excepting from the central portion, the area of which is precisely equal to the area of the narrow zone in Fig. 6. The following table shows the intensities transmitted to the actinometers 
during an observation, August 25, 185, the rartiation from the solar disc being then excluted in the manner shown in Figs. 6 and 7 .

\begin{tabular}{|c|c|c|c|}
\hline 'Time. & $\begin{array}{l}\text { Central portion. } \\
\text { Cent. }\end{array}$ & $\begin{array}{l}\text { Border. } \\
\text { Cent. }\end{array}$ & Rate of difference \\
\hline $4^{\prime}$ & $3^{\circ} .28$ & $2^{\circ} .19$ & $\frac{2.19}{3.20}=0.667$ \\
\hline $5^{\prime}$ & $3^{\circ} .56$ & $20.3 \%$ & $\frac{2.35}{3.56}=0.665$ \\
\hline $6^{\prime}$ & $3^{\circ} .73$ & $2^{\circ} .49$ & $\frac{2.49}{3.73}=0.66 \pi$ \\
\hline $7^{\prime}$ & $3^{\circ} .88$ & $2^{\circ} .60$ & $\frac{2.60}{3.88}=0.669$ \\
\hline & & & Mean $=0.605$ \\
\hline
\end{tabular}

It should be particularly observed that this table records the result of four distinct observations; nor should it be over. looked that althongh the intensities vary greatly for each observation, in consequence of the continued exposure to the sun, yet the rates showing the difference of the intensity of the rays transmitted from the border; inserted in the last column, is practically the same for each observation, the dis. crepancy between the highest and the lowest rate being only 0.004. It should be mentioned that all my instruments for measuring radiant heat referred to in this work have been graduated to the Fahrenheit scale, which practically is more exact than the Centigrade, owing to its finer divisions. For the benefit of the majority of readers the observed temperatures have been reduced to Centigrade scale before being entered in our tables. Persons pratically acquainted with 
the difficulty of ascertaining the intensity of solar radiation will be surprised at the exactness and consistency of the indications of our instruments. This desirable exactness has been attained by surrounding the actinometer's with waterjackets, which communicate with each other by connecting pipes, through which a steady stream of water is circulater. By this expedient the chambers containing the bulbs of the several thermometers are maintained with critical nicety at equal temperature-an inexorable condition when the object is to determine differential temperature with great exactness. Apart from this, the chamber's which contain the bulbs of the thermometer's are air-tight, the radiant heat being admitted through a small aperture at the top of the chamber, covered by a thin crystal.

Referring to the preceding table, it will be seen that the intensity transmitted by radiation from the sun's border, represented in Fig. 6, is 0.667 of the intensity transmitted from the centril region represented in Fig. 7 , the area of each being precisely alike. From the stated intensity must be deducted. the heat imparted to the actinometer by the inflection of the calorific rays. The circumference of the perforation of the screen shown in Fig. 7 being exactly one-half of the circumference of the screen in Fig. 6, while the central region radiates more powerfully than the border, fully one-lialf of the inflected radiation from the border will be balanced by the inflected radiation emanating from the central region. Agreeably to the previous demonstration relating to Figs. 2 and 3 , it will be seen that the unbalanced inflection amounts to 
0.029 ; hence the radiation transmitted from the border zone will be $0.667-0.029=0.638$ of the intensity of ratiation transmitted from the central region. We hare thus shomm by a reliable method that the intensity of the ritys directed towards the earth from the border zone sufters a diminution of $1.000-0.638=0.362$ of the intensity of the ractiation emanating from the central region. But the mean depth of the solar atmosphere of the border zone, in the direction of the earth, is 2.551 greater than the vertical depth, whild the mean depth over the central region referred to is 011 ! 0.036 greater than the vertical depth of the solar atmosphere. It will be evident that if the law of retardation were known, the foregoing figures would enable us to determine the absorpl. tive power of the solar atmosphere. Concerning this law, it should be mentioned that in the first edition of "Le Soleil," page 264, the author assumes that the absorption of the calo. rific rays by the atmosphere "augments in proportion to the secant of the zenith distance"; in other words, as the depth of the atmosphere penetrated by the rays. Consequently, if this assumption be correct, the absorption by the solar atmo. sphere camnot exceed $\frac{0.362}{2.551-0.036}=0.144$ of the racliant heat emanating from the photosphere. It will be found, on referring to the revised edition of "Le Soleil," Vol. I., p. 212, that Pire Secchi makes the following statements regarding the absorptive power of the solar atmosphere: (1) "At the centre of the disc-that is to say, perpendicularly to the surface of the photosphere-the absorption arrests about $\frac{2}{3}$, 
ol, more exactly, $\frac{6 \%}{100}$, of the total force" (2) "The total action of the absorbing envelope on the hemisphere visible from the sum is so great that it allows only $1 \frac{12}{10}$ of the total ladiation to pass, the remainder, namely, is s. $^{8}$, being absorberl." It is unnecessary to criticise these figures presented by the Roman astronomer, as a cursory inspection of our table and dingrams is suflicient to show the fallacy of his computittions. Besides determining the absorptive power of the solar atmosphere, another important problem may be solved by accurately measuring the intensity of the radiation emanating from rarious parts of the disc-namely, that relating to the sun's emissive power in different directions. In order to decide this question, I have adopted the plan of measuring the energy of the radiant heat transmitted from zones crossing the solar disc at right angles, as shown in Figs. 10 and 11. Repeated observations having shown that the actinometers are equally affected by the radiation from these zones, each of which occupies an arc of 30 deg., containing one-third of the area of the disc, the inference is irresistible that the sun emits heat of equal intensity in all directions. It should be borne in mind that, agreably to our method, the radiations from these zones are observed simultaneouslya fict tending to prove that our conclusions cannot be erro. neous. The arangement exhibited in Figs. 10 and 11 hardly needs explnnation. Referring to Fig. 10, it will be seen that two segmental screens are employed excluding the radiant heat, excepting from the zone, which is parallel with the sum's equator. Similar screens are employed (see Fig. 11) 
for excluding the rays excepting from the zone parallel with the sun's polar axis. The curratures of the segmental screens, it should be observed, have been struck to a radius of ninety millimetres, in order to cut off effectually the inflected radi. ation from the sun's border. Obriously diffraction has not called for any correction of our observations relating to this part of the investigation, since the inflected radiation from the equatorial zone exactly balances the inflected radiation from the polar zone. As already stated, repeated observations show that the radiant energies transmitted to the actinometer's from the two zones are identical.

The observations relating to the temperature of the polar regions, represented in Figs. 8 and 9 , at first led to the supposition that the rays projected from the north pole of the sun transmit a perceptibly greater energy to the actinometer's than the rays from the opposite pole. Subsequent observations having positively established the fact that the polar and equatorial zones transmit equal intensities, it became evident that some other cause than difference of temperature within the polar regions influenced the actinometers. The only ralid reason that could be assigned in explanation of the anomaly being the considerable angle subtended, and the consequent difference of zenith distance of the opposite poles of the sun, my table of maximum solar intensity for given zenith distances (prepared from data collected during a series of years) was consulted, in order to ascertain the influence of zenith distance. The observations indicating a higher temperature at the north pole, it should be mentioned, had been made 
while the smin's zenith distance ranged between 32 degr. and 33 deg. at noon. Now, the table referred to shows that there is a difference of radiant intensity of $63^{\circ} .63-63^{\circ} .40=0^{\circ} .23$ $\mathrm{F}$. between the stated zenith distances. The mean angle sub. tended by the sun being fully thirty-two minutes, it will thus be seen that, owing to the absorptive power of the terrestrial atmosphere, the radiant intensities transmitted frm the oppo. site poles of the luminary differ considerably. The magni. tude of this difference, adequate to explain the discrepancy under consideration, need not excite surprise if we consider that thirty-two minutes of zenith distance involves an additional depth of more than half a mile of atmosphere to be penetrated by the rays projected towards the actinometer from the south pole of the sun. The foregoing facts show the necessity of taking the difference of zenith distance between the opposite poles into account in making exact observations of the sun's polar temperature, especially at the lower altitudes, where the secant of the zenith distance increases rapidly.

Regarding the calorific energy of the radiation emanating from the border of the sun, the following brief statement presents facts of considerable importance hitherto unknown. Several observations during the early part of the investigation pointed to the fact that increased energy is transmitted to the actinometers by radiation from the sun's border. Again, considerable irregularity was observed in the progressive dimimution of the force of radiation towards the circumference of the solar disc. It has already been shown that the radiation from the border zone, $1^{\prime} 42^{\prime \prime}$ wide, occupying one-fifth of the 
area of the solar disc, transmits 0.638 of the intensity trans. mitted from an equal area at the centre of the disc. Of course it will he supposed that the rate of the dimimution of intensity within the zone thus ascertanted is much greater near the border of the photosphere than at the mishlle of the zone. Such, however, is by no menns the calse, notwith. standing the assumption of physicists that the heat thamsmitted by radiation from the border is very feehle. In order to test

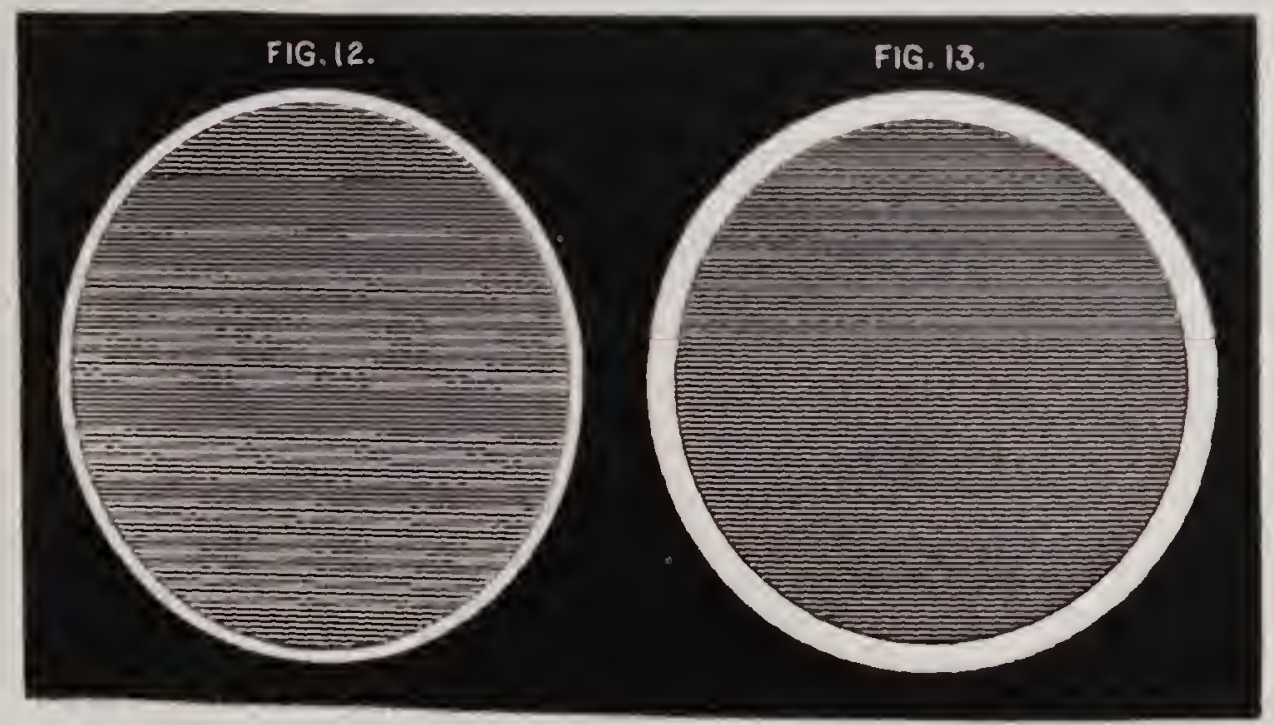

the truth of the indications referred to, showing considerahl. radiant energy at the border of the photosphere, a very carešlul investigation was made, Sept. 9, 1875, by means of screens excluting the rays from the solar disc, as shown in Figs. 12 and 13. The diameter of the screen represented in Fig. 1:, being 154.06 millimetres, covered ninetenths of the area of the disc; while the screen shown in Fig. 13, being 145.25 millimetres, covered four-fifths of the disc. It will be well to mention that the dimensions of the screens referred to 
correspond to the angle subtended by the sun when the earth is in aphelion. Accordingly; the distance between the actinometers and the screens was adjusted previous to the observation-that is, shortened-in order to compensate for the increase of the angle subtended by the sun. Agreeably to the stated dimensions of the screens, it will be found that the rone represented in Fig. 13 is $1^{\prime} 42^{\prime \prime}$, while the zone in Fig. 12 is $49^{\prime \prime} .6$. The mean width of the latter is consequently situated only $24^{\prime \prime} .3$ from the border of the photo. sphere.

The following table shows the intensities transmitted to the actinometers from the zones represented in Figs. 12 and 13 :

$\begin{array}{cccc}\text { Time. } & \begin{array}{c}\text { Zone, Fig. 13. } \\ \text { Cent. }\end{array} & \begin{array}{c}\text { Zone. Fir. 12. } \\ \text { Cent. }\end{array} & \begin{array}{c}\text { Rate of Difference. } \\ 4^{\prime}\end{array} \\ 2^{\circ} .011 & 1^{\circ} .333 & \frac{1.333}{2.011}=0.662 \\ 5^{\prime} & 2^{\circ} .248 & 1^{\circ} .471 & \frac{1.471}{2.248}=0.654 \\ 6^{\prime} & 2^{\circ} .425 & 1^{\circ} .583 & \frac{1.583}{2.425}=0.652 \\ & & & \\ 7^{\prime} & 2^{\circ} .485 & 1^{\circ} .666 & \frac{1.666}{2.485}=0.670 \\ & & & \text { Mean }=\overline{0.660}\end{array}$

The rate of difference inserted in the last column, it will be noticed, is not quite so consistent as in the table recording the observations made Aug. 25. The discrepancy is, howerer, not material, the difference between the lowest and the mean rate being 0.008 . It will be seen, on inspecting the registered intensities, that the border zone represented in Fig. 12, whose 
CHAP. VI.

area is only one-half of the area of the zone in Fig. 13, trans. mits 0.660 of the intensity of the latter. This, at first sight, indicates an extremely disproportionate transmission of heat from the narrow border zone; but it should be considered that the inflected radiation imparts relatively more heat to the actinometer exposed to the radiation from the narrow zone than from the wide zone. It will be readily understood that, since the inflection of the calorific rays is $14^{\prime \prime} .5$, the first-mentioned actinometer receives radiant heat from $14^{\prime \prime} .7+49^{\prime \prime} .6=64^{\prime \prime} .3$; while the actinometer exposen to the radiation from the wide zone receires heat from $1^{\prime}+2^{\prime \prime}+14^{\prime \prime} . \mathbf{T}$ $=116^{\prime \prime} . \%$. Consequently, the radiant heat emanating from the narrow zone will be $\frac{64^{\prime \prime} .3}{116^{\prime \prime} .7}=0.551$ of that transmitted from the wide zone, hence somewhat more than one-half. Our investigation therefore proves that the radiant heat transmitted from the narrow border zone represented in Fig. 12 is $0.660-0.501=0.109$ more intense than that transmitted from the zone represented in Fig. 13, although the mean distance of the latter is twice as far from the border of the photosphere as the mean distance of the former. The singular fact thus revealed can only be accomnted for by supposing that internal radiation is not incompatible with the constitution of the photosphere, and by adopting Lockyer's views expressed in the Senate House at Cambridge, 1871, that "the photosphere must be a something suspended in the solar atmosphere." Let a b, Fig. 14, represent a section of the "suspended" photosphere, and $d c, g f$, rays pro. 
jecterl towards the earth. Agreably to the conditions men. tioned, and in riew of the fact that the force of radiation from incandescent gases presenting equal areas raries nearly as their depth, we are warranted in concluding that, since the de'pth $d d^{\prime}$ is greater than $g g^{\prime}$, the radiant heat transmitted from the photosphere by the ray $d c$ will be greater than that tranmitted by the ray $g$ f. It should be obserred that the energy transmitted towards the earth by d o suffers a greater diminution than the energy transmitted by $g f f$ in consequence of the greater depth of the solar atmosphere penctrated. Hence the augmented energy established by our

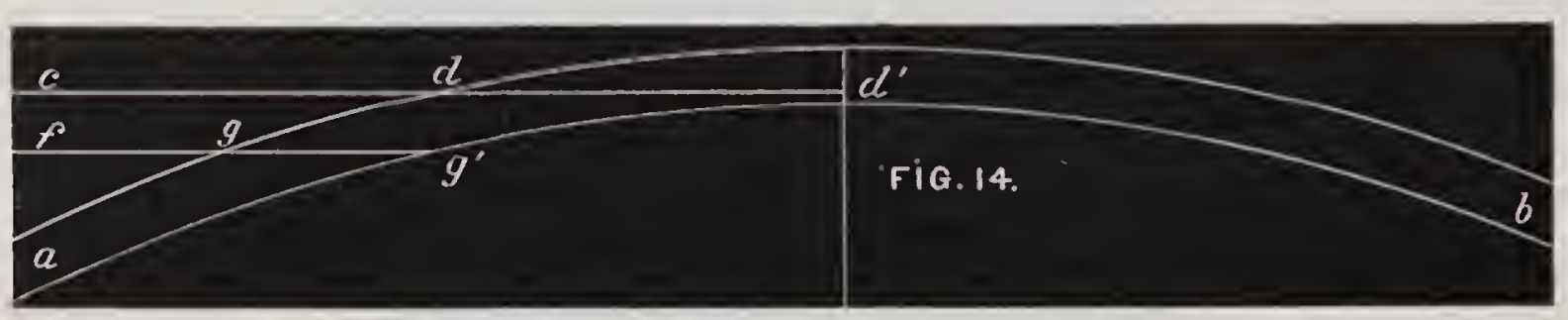

investigation does not show the full amount of the increase of radiant heat transmitted from the border of the sun.

Having thus briefly stated the result of my observations, it will be moper to mention that, before undertaking a sys. tematic investigation of the difference of thermal energy trans. mitted to the earth by radiation from different parts of the solar surface, I examined thoroughly the merits of Laplace's famous demonstration relating to the absorptive power of the sun's atmosphere, proving that only $\frac{1}{12}$ of the energy developed by the sun is transmitted to the earth. The demon. stration being based on the assumption that the sun's rays 
emit energy of equal intensity in all directions, my initiary step was that of testing practically the truth of that propu. sition. It has heen asserted that Laplace did not propound the singular doctrine involved in such a proposition; I therefore feel called upon, before proving its unsommlness, to quote the words employed by the celebrated mathemati. cian (see "Mécanique Céleste," 'Tom. IV. page 28t). Maring caller attention to the fact that any portion of the solar

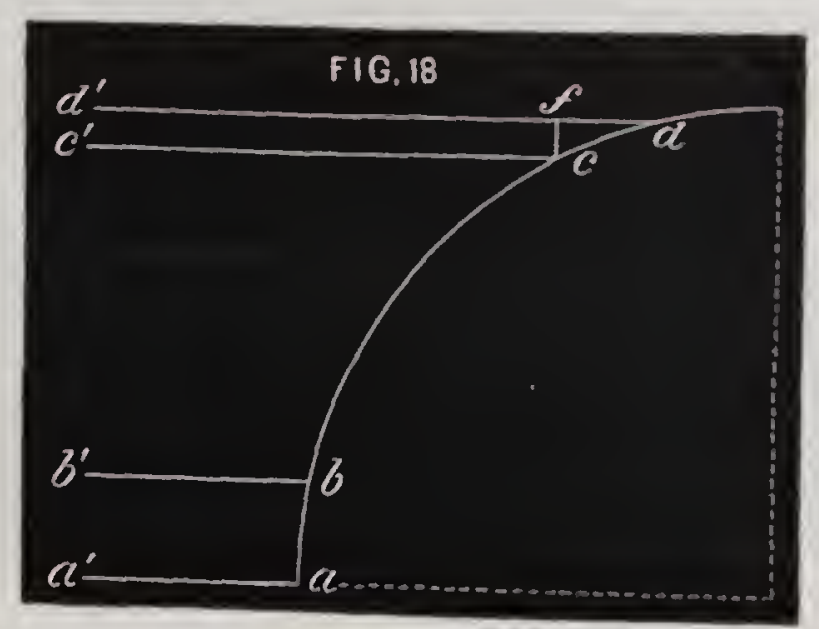

disc, as it approaches the limb, ought to appear more brit. liant because it is riewed under a less angle, Iaplace adrls: "Car il est naturel de penser que chaque point de la sur. face du soleil renvoie me lumière égale dans tous les sens." Let $a b a d$ in the above diagram, Fig. 18, represent part of the border of the sun, and $b a, c d$, small equal ares; $a a^{\prime}$, l. $l^{\prime}, c c^{\prime}, d d^{\prime}$, being parallel rays projected towards the earth. Laplace's theory asserts that, owing to the concentration of the rays, the radiation emanating from the portion $d$ a trans. mits greater intensity towards the earth than $b a$, in the pro. 
portion of $c d$ to $f^{\prime} c$. The proposition is thus stated in "Mécanique Céleste": "Call $\theta$ the arce of a great circle of the sun's surface, included between the luminous point and the centre of the smin's disc, the sun's radius being taken for unity; a very small portion, $a$, of the surface being removed to the distance $\theta$ from the centre of the disc, will appear to be reduced to the space a cos. $\theta$; the intensity of its light must therefore be increased in the ratio of unity to $\cos . \theta$."

In order to disprove the correctness of the stated demonstration, I have measured the relative thermal energy of rays projected in different directions from an incandescent metallic disc by the method minutely described in Chap. XI. The following brief description will, howerer, be necessary in this place, reference being had to the illustration adverted to in the said Chapter XI. (see Plate 21). Fig. 2 represents a section of a conical ressel covered by a morable semi-spherical top, the vessel being surrounded by a jacket through which water may be circulated. A rerolving disc a a, composen of cast iron, the back being semi-spherical and protected by fire-clay, is suspended across the top of the conical ressel, supported by horizontal journals attached at opposite sides. The angular position of the disc is regulated by a radial handle $b$, comnected to one of the journals, the exact inclination to the rertical line being ascertained by means of a graduated quadrant d. An instrument $c$, capable of indicating the intensity of the radiant heat transmitted by the incandescent disc, is applied at the bottom of the conical ressel. 'The movable corer' and its lining of fire-clay being removed, 
the cast-iron disc is heated in an andurnace to a trmurera. ture of $1,800^{\circ} \mathrm{F}$. It is then remored by appropriate tonges, and suspended orer the conical ressel, the lining and corel being quickly replaced. The temperature shown by the instru. ment at the bottom of the concul ressel, resulting from the action of the radiant heat of the clise, is then recorded fin every tenth degree of inclination. The investigation, it mily be briefly stated, shows that the temperature injurted hy radiation to the recording instrument is exartly as the simes of the angles of inclination of the dise. Hence, at all incli. nation of $10 \mathrm{deg}$. to the vertical line, the temperature innpurtul to the thermometer is scarcely $\frac{1}{6}$ of that implanterl when llw disc faces the thermometer at right angles; yot in hoth calnen an equal amount of surface of an equal degree of imeonter. cence is radiating towards the instrument. Laplace and his. followers have evidently orerlooked this important and somfewhat anomalous fact proving that rarliation emanating from leated bodies is incapable of exerting full enerey in more than one direction. Our practical experiments with thes revolving incandescent disc have thus fully demomstrated the truth of the proposition intended to be astablisher namely, that the rays emanating from incmulescent plines. do not transmit heat of equal intensity in all directions, the energy transmitted being, as stated, proportionate to the sines of their angle of inclination to the ratiating surfice.

The next step in the preliminary investigation was that of measuring the radiant energy transmitted in a given direc. tion by an incandescent solid metallic sphere. For this pur- 
pose I employed a double conical ressel similar to the one alleady described, the incandescent sphere being suspender orer the conical ressel in the manner minutely described in Chap. XII. A brief explanation will, however, be necessan'y here, reference being had to the diagram on Plate 2t, repre. senting four spheres, Figs. :3, 4, 5, and 6. Each sphere is divided into four zones, $A, B, C$, and D, ocenying unequal arcs, but containing equal conrex areas. Semi-spherical screens, composed of non-conducting substances, were applied below each sphere, provided with amular openings arranged as shown in the diagram. Through these ammular openings the radiant lieat from the incandescent zones D, C, B, and A was transmitted to the thermometer's $f^{\prime}, g, h$, and $h_{i}$ respectively. Père Secchi and other followers of Laplace will be surprised to learn that when the suspended sphere was maintained at a temperature of $1,800^{\circ} \mathrm{F}$, the radiation from the zone C, Fig. 4 , imparted a temperature of $27^{\circ} .49 \mathrm{~F}$. to the thermometer g; while the radiation from the zone A, Fig. 6, imparted only $6^{\circ} .19 \mathrm{~F}$. to the thermometer 7 . Let us bear in mind that the radiating surface $l m$ of the zone $A$ is equal to the radiating surface $p q$ of the zone $C$. The stated great difference of temperature produced by the radiation from zones of equal area furnishes additional proof that Laplace based his remarkible analysis on false premises. "The sun's disc ought to appear more brilliant towards the border because viewed under a less angle," we are told by the great analyst. The instituted practical tests, horrever, prove positively that the energy of the rays projected from the border of an incan- 
descent sphere is greatly diminished because viewed under a less angle from the point occupied by the recording thermo. meter.

The result of the experiment with the serolving incandescent disc shows that if the small arc $b$ a, in Fig. 18, be reduced until the field represented by l' $a^{\prime}$ becomes equal to the field represented by $c^{\prime} d$, the radiant energy trans. mitted through each of those fields will be alike; the reason being that the number of rays of diminished internsity passing through $c^{\prime} d^{\prime}$ will be as much greater than the number of rays of maximum intensity passing through $b^{\prime} a^{\prime}$ as $c \quad d$ is greater than the reduced $b a=f c$. It shonld be observer that $c d$ is so small that we may, without appreciable error; regard it as a straight line, and $f^{\prime} c$ as the sine of the angle c df. It follows from this demonstration that if the solar atmosphere exerted no retarding influence, the radiant heat transmitted towards the earth would be alike for equal areas of the solar disc; more correctly, for areas subtending equal angles, since the receding part of the solar surface is at a greater distance from the earth than the central part.

Encouraged by the results of the instituted practical tests showing the actual intensity transmitted by ladiant heat emauating from incindescent spheres and inclined discs, I devised the method before described, proving positively that the polar and equatorial regions of the solar disc transmit radiant heat of equal intensity to the earth, and that the sum emits heat of equal energy in all directions. Accepting Secehi's doctrine relating to the retardation suffered by calorific rays in passing 
through atmospheres-namely, that the diminution of energy is as the deptli penetrated by the rays-I have shown, by the easy calculation before presented, that the absorption by the solar atmosphere camnot exceed $\frac{144}{100}$ of the radiant energy emanating from the photosphere.

Concerning the plan resorted to by the Director of the Roman Observatory and others of investigating the sun's image instead of adopting the method of direct olservations, I will merely observe, in addition to what has already been stated, that the information contained in the several works of the Roman astronomer funnishes the best possible guide in judging of the efficacy of image-investigation. Let us select his account of the investigations conducted between the 19th and 23d of March, 1852. Having pointed out that in these experiments it was impossible to approach within a minute of the edge of the sun, and that during a later observation -date not mentioned-he had approached within a minute, the investigator observes: "But at this extreme limit, even making use of the most accurate means of observation, we find difficulties which it is impossible to overcome com. pletely." In addition to this emphatic expression regarding the difficulties encountered, the author adds: "Moreover, it is impossible to study the edge alone, for the unaroidable motions of the image do not admit of its being retained at exactly the same point of the pile; we have, therefore, been unable to push the exactness as far as we hoped, and we have discontinued the pursuit of these researches, although the results obtained are quite interesting." (See revised edi- 
tion of "Le Soleil," Vol. I. p. 20ir) It is needless to institute a comparison between a system of which its founder speaks so despondingly and one which enables us to push our inves. tigations to the extrene limit of the solar disc, admitting of entire zones being riewed at once, instearl of only small, isolated spots.

The foregoing demonstration, showing that the solar atmo. sphere absorbs 0.144 of the heat radiated, it should be remem. bered, is based on the assumption that the retardation is as the depth penetrated by the rays. In view of the fuct that projectile force diminishes inversely as the sculure of the depth of the medium penetrated, we are, of course, not com. pelled to accept the stated assumption. Adopting the dynamical law relating to projectile motion, referred to, it will be found that the retardation, instead of being 0.144, will be $\frac{0.362}{(2.551-0.036)^{2}}=0.057$. But even this apparently small amount of absorption of the radiant intensity cannot be satisfactorily accounted for, since the mechanical energy developed by the sum is at least 322,000 thermal units per minute upon an area of one square foot. Consequently, 322,000 × $0.057 \times 7 \tau_{2}=$ $14,169,288$ foot-pounds represent the mechanical equivalent of ros of the radiant energy emanating from each square foot of the photosphere. Owing to the high temperature and conse. quent lightness, no conceivahle work performed within the solar atmosphere can satisfactorily account for the disilppearl. ance, every minute, of such an amount of energy. It is therefore demonstrable that we have not underrated the ahsorptive
power. 


\section{CHAPTER VII.}

THE SOURCE OF SOLAR ENERGY.

Srr Wifiman Trrousox, in his celebrated paper on the Mechanical Energies of the Solar System, read before the Royal Society of Edinburghl, April, 1854, puts the question: "What is the source of mechanical energy, drawn upon by the sun, in emitting heat, to be dissipated in space?" Having very briefly examined the question, he adds: "We see, then, that all theories which have yet been proposed, as well as every conceivable theory, must be one or other; or a combination, of the following three: (1) That the sun is a heated body losing heat. (2) That the heat emitted from the sun is due to chemical action among materials originally belonging to the mass, or that the sun is a great fire. (3) That meteors falling into the sun give rise to the heat which he emits." The second and third of these suppositions having been disposed of by more recent investigations, let us confine our discussion to the first hypothesis, that the sun is a heated body losing heat, regarding which the eminent physicist renlarks: "In alluding to theories of solar heat in a former conmunication to the Royal Society I pointed out 
that the first hypothesis is quito mutumalle. In fact, it is remonstrable that, unless the sun be of matter inconcoivably more conductive for heat, and less rolatile, than any terres. trial meteoric matter we know, he womld becone dirk in two or three minutes, or dilys, or months, or yeans, at his mesent rate of ennsion, if he hat no sounce of energy io draw from but primitive heat. This assertion is founderl an the supposition that conduction is the only mons by which heat could reach the sun's surface from the interion: and perhaps reguires limitation. For it might he supposent thit, as the sun is no doubt a melten mass, the brightness of his surfice is constantly refreshed by incundescent fluir rushing from below to take the place of natter falling upun the surface after becoming somewhat cooled and consegucutly denser-a process which might go on for man! years with. un any sensible loss of brightness. If we consider, howerer; the whole ammlan enission at the present actual rate, we find, eren if the sun's themal capacity were as great as that of an equal mits of Watel; that his mean temperature would be lowered by about $3^{\circ}$ Cent. in two years." It would appear from this reasoning that Sir Trilliam Thomson had orerlooked Laplaces important nebulan then!y which leads to the conclusion that the sun's lueat is the result of con. densation caused by gravitation. Ofrimsly this condensation is progressing at the present time as fist as the mass cools, the proces being the sume now as millions of years ago, the heat generated by the condensation beconning gradually intensified in the inverse ratio of the rarlins of the contract. 
ing mass. Let ns consiler, howerer, that the matter com. posing this contracting mass suffer's a proportionate reduction of relocity; hence the emision of leat becomes constant for a given area of the solan smlface, motrithstanding the angmentation of intensity. But, while the emission from a given alrea is constant, the bulk of the cooling mass is continually diminishing. The important consequences of this diminution of bulk will be considered presently. Of conse? it will not be necessany to prove that the sm is continually becoming smaller, since all incandescent bodies shrink liaphilly if permitted to radiate freely, the rate being nearly proportional to the degree of incandescence. Onr task, therefore, will be confined to a simple demonstration showing that the emission of 322,000 thermal units per minute on each square foot of solar surface, established in Chapter V., is capable of being dereloped hy the contraction of the mass, in accordance with the nehular theory of Laplace. At first sight it would appear that no probable amount of contraction of the solar mass conkd develop, by gravitation towards the centre, an amount of mechanical energy of 322,000 $x$ TrD $=248,584,000$ foot-pomels per mimute for each square foot of the surface of the sun. Yet so rast is the amount of matter covered by the insigniticant anea of $1+t$ square inches of the solan smifice-in other words, such is the contents of a spherical pyramid the base of which is one square foot, and whose length is enual to the sun's radius-that a rery small amount of contranction suffices to develop, ly graritation towands the solar centre, the stated enormons mecha- 
nical energy. It will be readily milerstood that the energy developed by the shrinking of a spherical pyranid whose sides are sectors of the great circle of the sum will represent correctly the relative energy produced by the shminking of the entire solar mass. Hence, if we can determine the amount of longitudinal contraction of the supposed spherical pyramid requisite to produce, by gravitation towards the centre of the mass, a mechanical energy of $248,58,000$ foot-ponds per minute, we need not enter into any finther computation, since a corresponding contraction of the sun's radius will derelop for every square font of his surface a like energy.

Let I $K$ s, Fig. 1 (sec Plate 1t), represent the great circle of the sun, a $m$ a the spherical pyranid referred to, and Fig. 2 the said pyranid drawn to a larger scale, its axis being divided into ten equal parts. It is proposed to ascertain what extent of longitudinal contraction of the spherical pyramid a $m$ a is necessary to produce an anount of dynamic energy corresponding with that developed by the radiation from $1 \mathrm{sq}$. ft. of the solar surface in a giren time. The investigation will be facilitated and more readily comprehended if we compute the amount of energy developed by a definite contraction of the sun's radius, saly one foot. Let us, therefore, suppose that the surfice $a a^{\prime}$, the distance of which is $\frac{852,584}{2} \times 5,2 S 0=2,250,821,760$ ft. from $m$, has fallen through a space of one foot, the intermediate points l, c, d, etc., participating proportionably in the fall. Assuming that the solar mass remains lomogeneous during the contraction, it follows 
from Newton's demonstration ("Principia," Lib. I. Prop. LXXIII.) that, since a particle just within the circumference of the spliere at $a$ is ten times further from the centre $m$ than a particle at 7 , the former will be attracted towards $m$ with ten times greater force than the latter. It will be perceived, on reflection, that, for a giren movement towards the centre, the quantity of matter put in motion at a will be greater than at $l$, in the ratio of the squares of $a$ a', and $l$ 1, or 100:1. Hence, in accordance with the demonstration refered to, a given radial depth of the solar mass at a will exert a force towarls $m 10 \times 100=1,000$ times greater than an expal radial reptle at 7 . But in computing the dynamic energy dereloperl hy the shrinking of the sun, it must be borne in mind that a particke at a falls through a distance ten times greater than a particle at 7 . The length of the ordinates of the curve p t, Fig. 3, representing the ratio of dynamic enery dereloped at the respective distances from the sun's centre, has been calculated accordingly. A cursory eximnination of Fig. 2 can scancely fail to leal to the supposition that the mass composing the smaller sections of the spherical pyramicl near the centre of the sphere will be attracted by the larger mass composing the sections near the circunference. Newton has disposed of this question by a geometrical demonstration which, considering the form of the attrating mass, and the extreme complication arising from the varying direction and unequal magnitude of the attracting forces, may be regarded as one of the most elegant of his masterly demonstrations of important propositions 
and theorems. Unless it call be proved that a particle at P' is not attracted by any portion of the mass contanined within the external spherical superficies I $K$ s and the interior spllericil superficies $P$ p we must assume that the mass comporsing the sections near the base of the spherical pyramil will exert the disturbing attraction before allucled to. Hence our demonstration of the energy produced by the attraction of the matter within the sun, during shrinking, falls to the ground muless it can be shown that every particle compos. ing the spherical pyramid is in perfect repose as regands the attraction exerted by exterior particles. 'The great geometer" thus establishes that repose: "Let II I K I, he a splierical superficies and P a compusle placed within. 'Through P' lot there be drawn to this superficies the two lines H. K, I L, intersecting very small ares II I, K L; and because the triangles H P I, I, P K are homogeneous, those ancs will be proportional to the distances $\mathrm{H}$ P, I, P, and any particles at $\mathrm{H} I$ and $\mathrm{K} L$ of the spherical superficies, teminited by right lines passing through $P$, will be in duplicate ratio of those distances. Therefore the forces of these particles exerted upon the body $P$ are equal between themselves. For the forces are as the particles directly, and the squares of the distances inversely. And these two ratios compose the ratio of equality. The attractions, therefore, being marle equally. towards contrary parts, destroy each other; and, by a like rear soning, all the attractions through the whole spherical superficies are destroyed by contrany attractions. Therefore the borly P will not be any way impelled by those attractions." 
Sir Isaac Newton, in his demonstrations relating to spherical bodies, supposed these to be composed of an infinite number of spherical superficies, the thickness of which he thus defines: "By the superficies of which I here imagine the solids composed, I do not nean superficies purely mathematical, but orbs so extremely thin that their thickness is as nothing; that is, the eranescent orbs of which the spliere will at last consist when the number of the orbs is increased, and their thickness diminished without end."

Referring to Fig. 3, it should be particularly observed that the ordinates of the curre $p t$ to not inclicate the force exerted by mere attraction. As already stated, their length Jepresents the dynamic energy, developed at the indicated distances from the solar centre. Consequently, the energy actually developed by the shrinking of the mass is represented by the superficies o p t, while the rectangle o p ut represents the energy that would be called forth if the force exerted at every point of the axis of the spherical pyramid were the same as that exerted at $a a^{\prime}$. Having alrealy pointed out the manner of determining the length of the ordinates of the curve $p t$, it will suffice to state that their mean length is 0.20015 of $o p$; hence the superficies $o p t$ is 0.20015 of the superficies o $p u t$.

Let us now consider whether the want of homogeneity of the solar mass will materially affect the calculated amount of energy developed by the gravitating force during the sun's shrinking. Referring to the Miagram Fig. 3, it will be seen that the energy exerted by a given small amount of contraction 
at a section equidistant between $m$ and $a-v i \%$, at $f$ 'j-will be, as shown by the length of the ordinates, $\frac{625}{10,000}=\frac{1}{10}$ of that exerted by a like amount of contraction at $a a^{\prime}$; and that, since $m f$ is one-half of $m$ a, the energy developed by the contraction of the mass contained within the splerical pyramid $f$ m 5 amounts to mily $\frac{1}{3}$ of that dereloped by the contraction of the mass contrined in the spherical pyramisl a $m a^{\prime}$. Now, the rolume of the spherical pyramid $f m$.j represents that of a sphere the linncter of which is one-hilf of the sun, while the spherical prramid a $m$ a' represents the rolume of the entire solal mils.s. The energy resulting from gravitation during the contration of the central sphe rical mass $\mathrm{P} p$ being thus only $\frac{1}{3}$ of the energy resulting from gravitation during the contraction of the spherical mass I K S, it will be perceived that the degree of density of the matter near the sun's centre will not materially affect the result of our calculations founded on perfect homogeneity.

We may now proceed to ascertain the amount of dynamic energy produced by the assumed contraction of one foot of the axis of the spherical pyramid a $m a^{\prime}$. Having already demonstrated that the said energy will be 0.20015 of that produced by the gravitation of a homogeneous mass, the section of which is one square foot, extenting from $" \|^{\prime}$ to $m$, it only remains to deternine the weight of one cubic foot at the surface of the sun. The weight of the solill mass being $85.6 \mathrm{lbs}$. per cubic fot, while the surn's attraction is 27.2 times greater than terrestrial attraction, the weight of one cubic 
fort of the solall sulfiace will be $27.2 \times 8.5 .6=2,328.311 \mathrm{ls}$; multiplying this weight by the sun's randius, explessed in feet, we have $2,328.3 \times 2,2.50,821,000=5,240,586,000,000$, which product multiplied by 0.20015 shows that the gravitating energy of the matter contained in the spherical pyrand, exerted during a longitudinal contraction of one foot, annonts to 1,048,900,000,000 foot-pounds. Dividing this latter product by the ancertained solar enission of $2+8,58+, 000$ foot-pommls per minute, it will be seen that the nechunical energy pro. duced by the shrinking of one foot of the smins radius is sulficient to make good the power lost by solar emission during a period of $4,219.5$ minutes. If we then divide this quotient in the minutes in a year, 525,960, it will be found that a fill of $12+65$ feet of the solar surface per anmmun must tilke plalce in order to sustain the present emission of heat. At this rate of shrinking the diameter of the sun will be reduced Toto in the course of 1,805 years. It has already been observed that the intensity of the radiant heat will not diminish with the diminished size of the sun. On the contraly, for a given mea of the solur surface, the dynamic energy produced by a given rate of sluinking will be increased, since the mass remains the same, while the attraction is inversely propor. tional to the distance from the centre. But the rate will diminish with the contaction of the sphere; hence a shrinking of $\frac{1}{10}$ th of the suris diameter, instend of occupying 1,000 $\times 1,805=1,805,000$ years, will reguire somewhat more than 2,000,000 years. At the end of that period the gravitating energy will continue to develop, as at present, an amount 
of dynamic energe represented by $82.2,000$ thermal mits jer. minute for each superficial foot; hut the radiating surfice -i.e., the area of the solar disc-will latre diminished in the ratio of ilearly $10^{\prime \prime}$ to $9^{2}$.

The present maximum temperature pronlucer by solat ratiation on the ecliptic when the eanth is in apluclion being (j-.2 deg. (see Chap. III.), while the intrusity of radiant heat diminishes as the area of the radiating smlatee, it follows that at the end of $2,000,000$ yens from the present time the tro. pical solar intensity will be reduced to $\frac{!^{2} \times 67.2}{10^{2}}=54.4$ degr. Fahrenheit. The result of the elaborate investigations of solar intensity described in the preceding chapter fuses the correctness of the foregoring calculations based on the area of the solar disc, and disposes of the opinion held by some physi. cists that there is no established relation between the cliameter of the smu and the transmitted energy. It was found, during the investigation referred to, that, in shutting ont the ratiation from the external zones of the sum ancl exposing an actinometer to the rays emanating from a circular area at the centre measuring 380,000 miles in dianeter, the intensity of the radiant heat was resluced to one-thind of that transmitted to another actinometer exposed to the radiation from the entire solar disc. Can we dould, then, that the fut mole diminution of the diameter of the sun will cause a corre sponding diminution of the transmitted energy? Arlopting the sime morle of calculating the solar intensity for past agres as the foreguing calculation of future solar intensity, it will 
The fomm that the temperature produced by solat ratiation g, (n)0,000 year's ago (owing to the grreater dimeter of the sum at that period) must have been nealy $\frac{11^{2} \times 67.2}{10^{2}}=81$ deg. Fall. within the tropics. Concerning this great intensity of the radiant heat, and the consequent high atmospheric temesrature, we ane justified in assuming that increaser evalporation of the seat, and conresponding humidity of the atmosphere, mollified the apparenty destructire tenperature, calling forth the luxuriant flora which geology has male us acquanted with. The computed dininution of solar intensity, $67 \mathrm{deg}$. - 54 deg. $=13$ deg., luring the next 2,000,000 years, will be deemed extravagant by those who do not bear in mind that we must base our computation on the assmuntion that a continuous power will be exerted during the stated period capable of developing, as at present, the stupendous energy of 248 millions of footpounds in a single minute for each square foot of the surfice of a sphere whose diameter exceeds 850,000 miles. Persons speculating on the cause of solar energy will to well to consider that this inconceivable amount of work camnot be performed with a less expenditure than the motive energy developed by the fall of a mass equal to the mass contained in the sun. But a continuous development of such an amount of energy is obviously inpossible, since the dis. tance is limited through which the mass can fall. Now, the foregoing demonstration enables us to determine the said limit with sufficient exactness to prove that, although the efficiency of the great motor during the past may be measured by hun- 
CH.1. VII.

dreds of millions of years, its future efficiency will be of comparatively bricf duration.

Statements frequently made relating to the perminency of solar heat, based on the assertion that no diminution has been abserved dning historic times, have no woight in riew of nom Temonstration showing that a shrinking of $\frac{1}{10}$ of the sun's thilmeter can only reduce the intensity from s1 deg. to 6r.2 deg. difference $=13.8$ deag, in the comrse of tro millions of yeart. This perion heing 300 tines longer than "historic tines," it will be seen that the diminution of the temperature problucen by solar radiation has not exceeded $\frac{13.8}{500}=0.027$, or $\frac{1}{3}$ deg. Fall, since the erection of the Pyramids.

It will be proper to notice, before concluding our brief investigation of the source of solar energy, that the development of heat by the shrinking of the sm, howerer fully demonstrated, leares the inportant question manswered: How is the heat generaterl ly gravitation within the mass transmitted to the surface? If the matter within the sun is a perfect conductor of heat-a rery improbable supposition-that fact alone furnishes a sitisfactory answer. Tnuedfect conductivity, on the other hand, calls for other means of transmitting the energy from within to the sulface. What those means are presents a problem susceptible of positive demonstration. The application of coll at the surface of any heated gaseous fluid, or the reduction of temperature of such a fluid by radiation upwarls, invariably produces a ver. tical circulation within the heated miss, the particles cooled 
descending, in rirtue of their increased specific grarity. Eri. dently a number of particles descending one atter the other will produce a downward rertical current of greater specific grarity than the rest of the fluid. Xow, as this current, composed of comparatively cold and heary particles, descends, it displanes a corresponding bulk of leated fluid, which, since there is no moceupied space below, must rise to the surface. Descending and ascending currents of nearly uniform magnitude and velocity will thus be established in the heater fluid mass, provided no disturbing force be applied, causing agitation either at the surfice or within. It needs no proof to show that in case disturbing force be applied the regularity of the distribution of descending and ascending currents within the fluid ceases, and that the established rertical circulation, instead of being alike at all points, becomes dividerl into groups. Nor is it necessary that the disturbing force should be of great magnitude. Obriously a continued uniform distribution of the descending and ascending currents through the heated mass calls for perfect absence of disturbing influences of any kind. Now, within the sun the descending and ascending masses of heated matter are influenced by numerous disturbing causes. (1) The particles composing the descending currents, possessing the vis vicu lue to the angular velocity of the sun's surfice, gradually encounter the particles of less angular velocity composing the ascending colunns. Conflicting motions will thus be producer, resulting in an increased angular relocity of the interior of the solar mass; while (2) the particles of the 
ascending currents, which stant with al slow angular velo(ity; will be gratually impelled by the sumounting mass during their ascent; the energy thereby absorbed cansing a lagging of the entire solar matis towards the surface. Of course there is an exchange of angular vis vied between the descending and ascending currents, but obrionsly there will be a loss, proluctive of perceptible lagging at the sirk. face of the rotating mass. (3) The attraction of the plante tary masses will seriously disturb the rertical circulation ly alternately inpelling and retarding one or the other of the descenting and ascenting colmuns of heaterl matter, thus

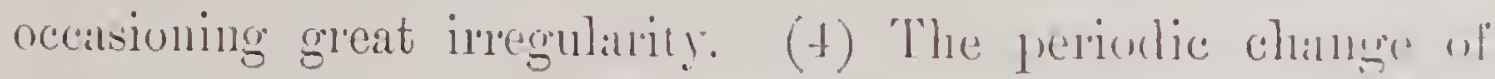
position of the centre of gravity of the aggregate planctary mass must necessarily froduce a perivelic maxinum and minimun disturbance of the descending and ascending currents within the solar mass. It will be erident that the frepuent near approach and consequent powerful attraction of Tenus greatly complicates the question of maximum disturbance. (j) The rotation of the sun, it should be particularly observed, tends to mollify the disturbing influence of flanctary attraction on the rertical circulation, since, owing to this rotation, the descending and ascending motion of the heated matter within the solar mass is successively reliered from maximum disturbing influence twice in twenty-five days. It may be shown that, but for this frepuent eheck, the power exercised by planetary attraction would ang. ment, and fatally derange the internal circulation indispensable to the regular performance of the functions assigned 
to the sum. ( $i$ ) It needs no explanation that a continuous disturbance and consequent cessition of cilculation at certain points of the solar surfare woukt produce permanent dark spots. Bearing in mind the emormous amount of the regular emission of heat demonstruterl in Chap. I. (322,000 thermal units per minute on a squale foot of the solar surface), it becomes evident that any considerable diminution of the supply of energy trom within, comsequent on delunged cilculation, will at once produce a great fall of temperatmpe at the surfince of the photosphere, and a conesponding dimimution of the temperature of the contignous solal atmosplere, accompanied hy a sudden condensation and down-1nsh orem the regions of nostructed cinculation. Considering the incroased reight of the condensed mattre put in motion hy the sun's powerful attraction, we can readily imagine that the photosphere, suspended orer the solar mass, as supposed by Lockyer; may be piereed by the descending colmm, and an opening formed, exposing that part of the solar mass which, for want of circulation and supply of heat from within, las lost intensity and radiant power. It should be olserver that, athomgh we hare no knowledge of the cumstitution of the photosphere, we may assert positively that its radiant power is derived from the molerlying solar mass, and that, therefore, any dimimution of energy of the latter, oceasioned by distmbed corenlation, will at once diminish the? temperature and ratiant power of that portion of the photospluere which is situated ahove the obstruction. ( $T$ ) The descending and ascending colmmns of heated matter between 
the solar centre and the poles. being acted mon almost at right angles by planetary attraction, remain at all times nearly undisturbed ; hence only a few dark spots, of small size, form in the polar regions.

Regarding the permanency of solar ratiation, the foregoing explanations show that the system of rentical circulation, upon which depends the efficiency of the sun ats a motor, maly become deranged. The consequence of this precintons feature of the scheme is self-erident, if we consicler that the present solar enission is depenulent on a given rate of contraction of the solar mass. Should that contratction lue checked by intermpted circulation, the development of heat will also be checked, and, consequently; the intensity of solat randiation become inadequate to sustain animal and regetable life, as now organized, on onr planet. Ilistory informs us that the luminary has at certain eporlss partially fariled to perform its functions. Herschel mentions, in his "Outlines of Astro. nomy," that "in the mmals of the year A.1). 536 the sun is said to have suffered a great diminution of light, which contimued fourteen months. From October A.D. 626 to the following June a defalcation of light to the extent of one-half is recorded; and in A.D. 1547, during three days, the sun is said to have been so dirrkened that stars were seen in the day-tine." Again, the gracial periorls, the ascertained abrupt termination and recurrence of which puzzles the geologist, point to periodical derangement of the solar mechanism in paist ages. 


\section{CHAPTER VTIT.}

RADIATING POWER AND DEPTII OF THE SOLAR

A'T'MOSHIIERE.

The illustration shown on Plate 15 represents an instrument constrncted for the purpose of ascertaning the radiant power of the solar atmosphere, and for meanming its depth, the leading feature of the levice being that of shutting out the rays from the photosphere huring the investigation. Eridently the expedient of shutting out the photusphere while examining the effect produced by the rays emanting from the solar enrelope calls for means by which the sum may be kept accurately in focus durmeg the preriod required to complete the observations. The main features of the instrument being clearly shown by the illustration, a hrief description will be sufficient to explain its detail. A parabolic reflector, applied for the purpose of concentrating the ralys of the solar atmosphere, is inserted in the carity of a conical dish of cast iron, secured to the tor of a table suspended on two horizontal journals, and revolving on a vertical axle. The latter, slightly taper, turns in a castiron socket, which is busherl 


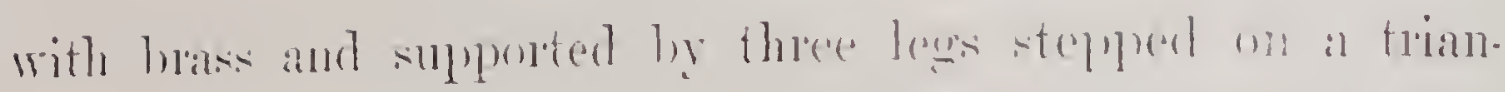

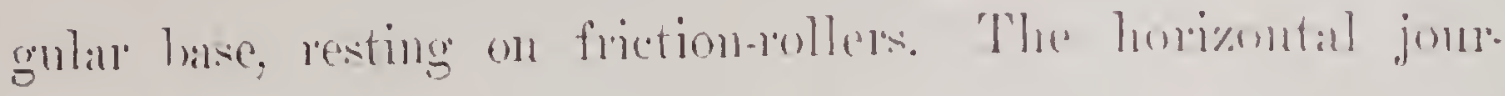

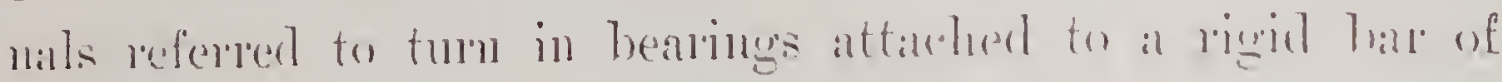

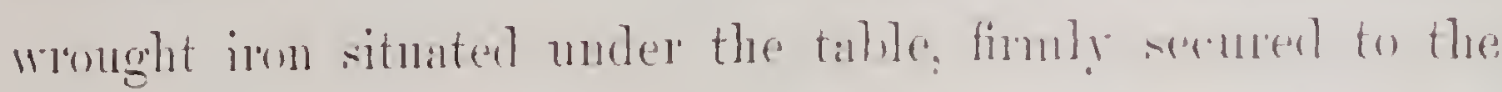

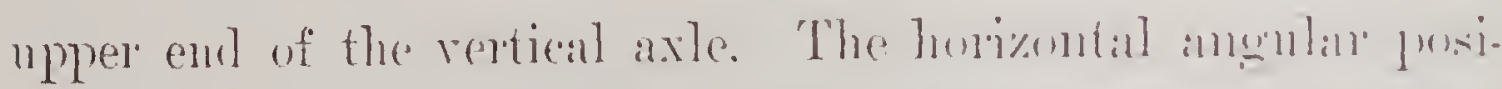

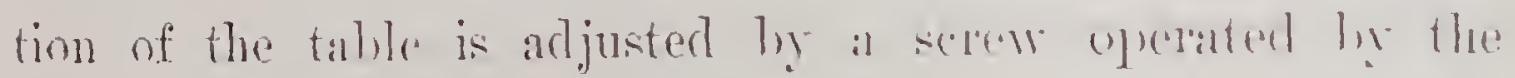
small lambluleel ", the inclination heing legulated hy an-

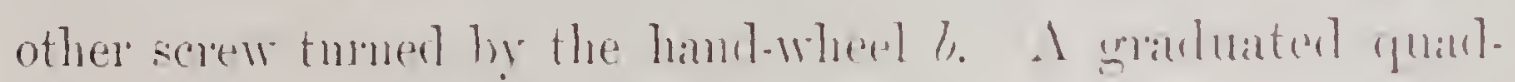
lant, $s$ is attacher to the emi of the table in molne to

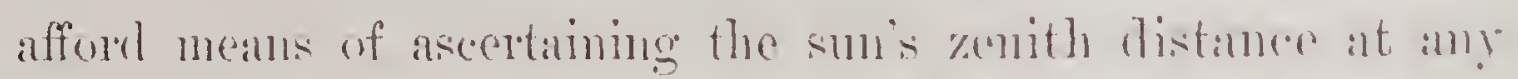
moment. The imlex t, which minks the regree of inclinit-

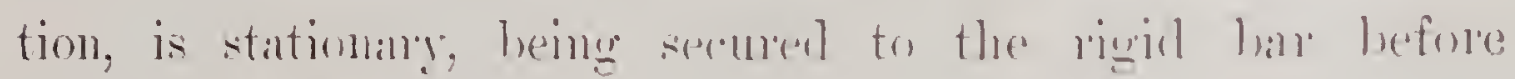
described. The lays from the photosplere ane shul wot hy a circular dise t, composed of sheet metal tmmerl to exact size, mol supported by three diagonial rods of steel. 'These

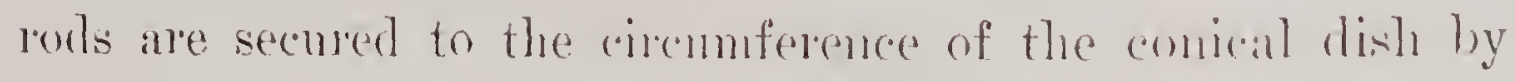
screws and adjustable muts in such a mannme that the centre of the dise $f^{2}$ may leatily le blought in a linect line with the axis of the reffector. The mechanism arlopted for arljust. ing the position of the tuble hy the lamel-wheds a and $b$ requires no explanation; but the hevice which emables the operator to ascertain when the axis of the reffector is pointed exactly towards the centre of the sun demamls particular notice. A shallow cylimbical box $/ 2$ providerl with a flat lid and open at the botton, excenting a minrow flange extent. ing round the circunference, is firmly hold by two colmmos secured to the top of the tilble. A comrex lens of 20 ins.

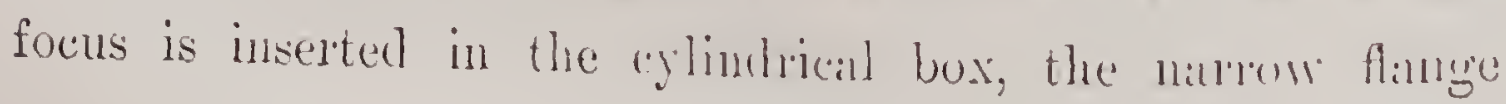


mentioned afforeling necessing sulpent. The lirl is perfo. raterl by two openings at right angles, 0.0.j in. wide, 2.5 ins. long, forming a cluss, the lens being so adjusted that its axis passes though the central proint of intersection of the cross. The face of the table heing turned at right angles to the sun, or nearly so, it will be evident that the rays parsing through the perforations and through the lens

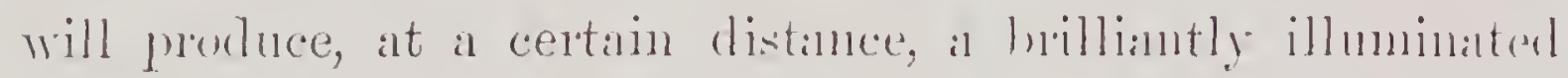
cross of small size and shanp ontline. A piece of irory, on which parallel lines are drawn intersecting falch other at right angles, is attached to the top of the table in such it pusition that the centre of intersection of the sild lines coincides with the axis of the lens. This axis hemer paralicl with the line passing through the centre of the disce $t$ and the focus of the reflector, it will be perceived that the olsrator, in directing the tilble, has anly to hring the illuminated cross within the intersecting farrallel lines on the piece of ivory. Ample practice has shown that by this arrangement an attentive person can easily keep the dise f'accurately in line with the focus of the reflector and the centre of the sun duling any desinble length of tinte. The alssence of any perceptible motion of the column of the focial thermometer employed during the experiments fumblas the lest rvidence that the suris rays have been effectually shut out by the intervening lise t, which, it should be renembered, is only lange enough to soressl the aprertire of the reflector from the rays projected hy the photonshere. It is worthy of observation that the lightness of the artopted mechanism 


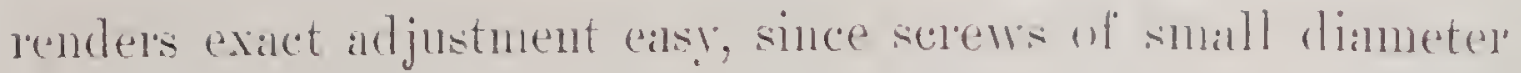
and fine pitch may be muployed. It is landly necessang to point out that the table represented ly ome illustration is admirably aldapted for actimometric observations, sinces, apant

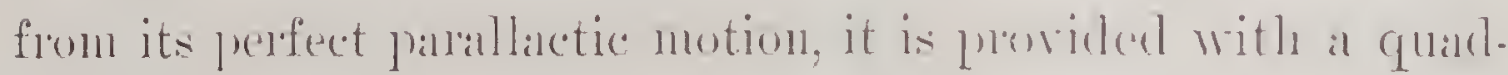
lant and index showing the sunis monith distance.

ligg. 2 see Plate 16) leplesents a ratical section of the parabolic reftector before arliented to, inserted in the cast.iron

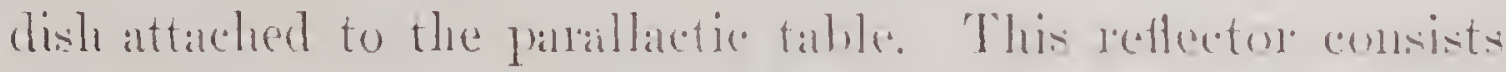
of a solid womghtiron ling lined with sillere on the insile, turned to exact form and highly polished. An ammlan plate

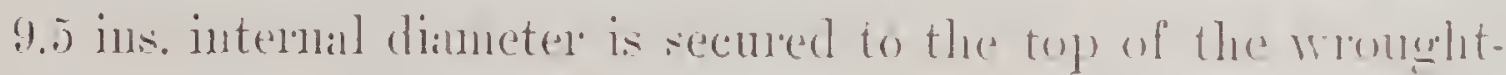
iron ring, in oreler to prevent eflectually all ra!s projected by the photosphere fiom reaching the reflector.

'The important question whether the solan envelope possesses an appreciable ladiant power, and whether the high temperatmes of the attemuated matter of whirh it is composed exereises any marked influence on the sun's radiant energy, maly mquestionahly be answered pratetically ly means of the instrument thus described. I have arecordingly comducted an investigation laked on the expedient of enencentrating the lotent.

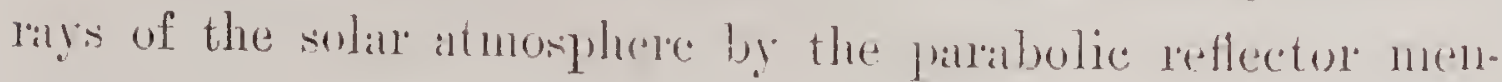

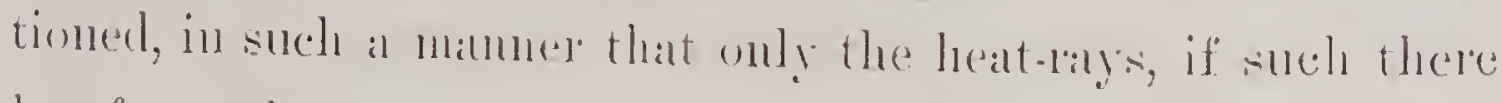

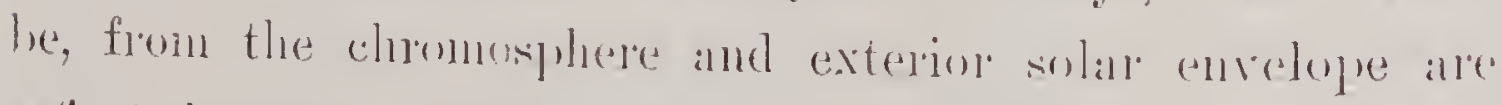
reffected, while the rigs from the photosplore alre effectually shut out. Fig. 1 shows the general allanlgenenent; "f"

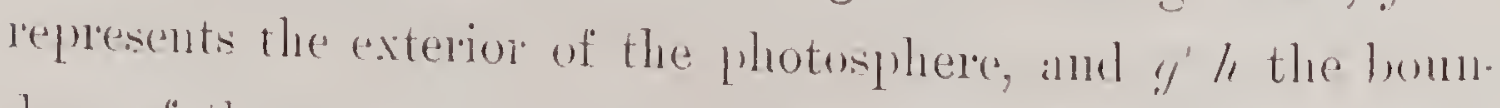

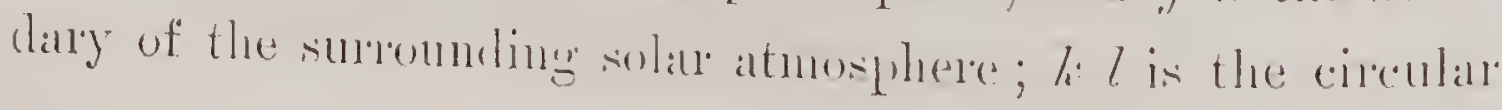


metallic disc, snpported above the parabolic rethector hefore describerl, and markerl fin the illustration on Plate 15 . This

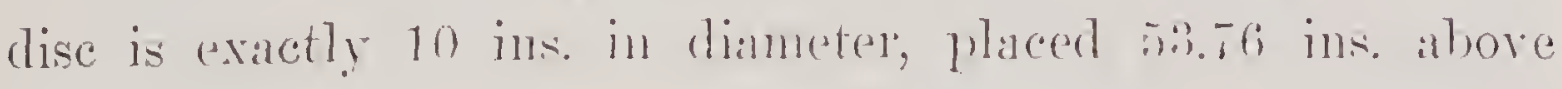
the base line "o; the hitter conciding with the top of the parabolic reflector. The stated distance hetween the disc and the top of the reflector obvions? ramies considerably with the seasons. Assming that the investigation takes place when the sun subtends an angle of 32 min. 1 sec., and making propere allowance for diffraction, the disc bit, if placed 53.76 incles from a $o$, will throw a shatow of fally 9.) ins. dianeter" hence, if $f$ " be 9.5 inches, oljects in the plane "o, platerel within of o, will be effecturlly shut out from the rals projected by the photospliere, while they will be fully exposed to the rays if a and h "emathating foun the chromosphere and outer stratis of the solas envelope. It is evident, therefore, that a parabolic reffector of propere size llated inmediately below of " will concentrate the ranliant heart, if any, trimsmitted by the rays of" $f^{\prime \prime}$ and $g^{\prime}$ /, and the intermediate lays. It has alleady been stated that an anmular plate 9.5 ins. internal diameter is secured to the top of the reflector to prevent effectually any rays projected by the photosphere from reaching the sime. The prolongation of the rays $f^{\prime} f^{\prime}-g^{\prime}$ a and $h n-a^{\prime}$ o are shown by dotted lines $f, g$ and $n$, o in Fig. 2; also the reflected rays directed tomards the bull, of the focal thermometer, manked respee. tively $f^{\prime \prime}, o^{\prime}$ and $y^{\prime}, n^{\prime}$.

The following brief acoont is teemed sufficient to explain the mode of conducting the investigation: Turning the reflec- 


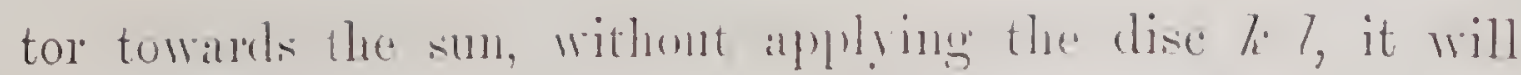
be fomed that a nallom zone of dar\%ling white light is produced on the black bulls of the focal themenometer pr the mercurial colmm commencing to rise the numbent the ray strike the roflerting surface. With a perfectly cleal sky, the (o)lumm has leeen found to reach 320 deg. Fall. in 3.5 sece.

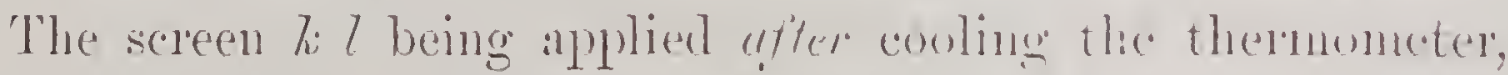
a zone of feehle gray light appeals on the hlack hull, neally as deep as the one protuced hy the rats from the photosphere, but situated somewhat lower. The columm of the

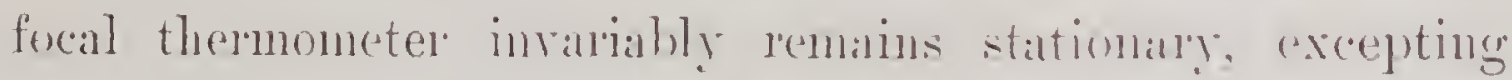
the oscillation which always takes place when at themonmeter is subjected to the influence of the conlents of arlo matroiabie in a place exposed to a powertiul sum. It is lioper to remark that, wring to the stater oscollation, it cannot be positively asserted that no loating whaterer has been produced by the refleretion and concentration of the rays which form the rene of gray light allierted to. But the recorded oscillations prove absolutely that the lieating does not exceed $0 . \tilde{5}$ deg. Fall.

Assuming that a temperature of $0 . \overline{5}$ deg. Falı. has actually been produced by the reflected concentrated heat enianating from the solar envelope, the following alculation will show that the energy therely establisher is too insigniticant to excreise any appreciable influence on the sunis radiant power. 'Theoretically, the temperature tramsmitterl to the bulb of the focal thermometer hy the reflection of the rays $f$ and 0 , Fig. 2 , is as the foreshortencel illmumated area of 
the reflector to the area of the \%onc of light produced on the bub. Obvionsly these areas bear nearly the same relation to each othere as the squares of $f^{\prime \prime}$ or o' to the square of the radius of the bull, $\%$. The length of $f^{\prime \prime}$ being 4.5 ins. while the ratius of the hull, is 0.125 in., calculation shows that the temprature tramsunted ly the ray of would be increased 1,456 times if the reflector did not albsorb any heat. Allowing that 0.7. of the heat is reftected, the allogmentation of intensity by concentration will annoment to 0.72 $\times 1,456=1,048$ times the temperatmre transmitted by the rays $f$ and $o$. The records of the sicillations of the morecurial columm during the experiments show; as stated, that the temperature resulting from concentration cannot exceed 0.5 deg.; hence the temperature tramsmitted by the rays enanating from the lieated matter of the solar enrelope will only amount to $\frac{0.5}{1,048}=0.00047 \mathrm{deg}$. Fah. The recorded observations having been made when the sun's zenith distance was 32 deg. 15 min., a correction for loss occusioned by atmospheric absorption amounting to 0.26 will, howerer, be necessary. This correction being made, it will be found that the heat actually tramsmitted by the rays from the solar envelope during the experiment referred to did not exceed 0.00059 deg. Fall.-a fact which completely disposes of Secchi's remarkable assmption that the ligh temperature of the photosphere is owing to the "rathation receired from all the transparent strata of the solar envelope" (see his letter to Vature, published June 1, 18i1). 
Haring thus positively established the fact that no appreclable heat is transmitted to the earth by the rauliant power of the solar atmosphere, and thereby disposed of Secchi's erroneous assumptions, and proved the unsoundness of the views entertained by other physicists that "the regions near. the sun augment the radiant energy tramsmitted by the luminary," let us now consider the probable weight and depth of the solar atmosphere. The inrestigation will be grently facilitated by instituting a comparison between the sun: envelope and the terrestrial atmospliere, and by adopting as a basis in our calculation the fact, established in Chap. X., that the temperature at the surface of the photosphere, and hence that of the contiguous solar atmosphere, exceeds 4,000,000 deg. Fah. The fallacy of Dulong and Petit's formula relating to the rate of cooling of incandescent matter at high temperatures, and its consequent inapplicability to the question of solar temperature, having been fully demonstrated in Chap. II., while our actinometric observations recorded in Chap. III. have established the intensity of solar radiation at the boundary of the terrestrial atmosphere, we possess, it should be borne in mind, the elements neces. sary to prove the correctness of the assumed high degree of solar temperature. As before stated, our investigation will be simplified by comparing the solar and terrestrial atmospheres; hence the following mode of solving the important problem: The increase of the volume of atmospheric air, under constant pressure, being directly proportional to the increment of temperature, while the coeflicient of expansion 
is 0.00203 deg. for 1 deg. of Finhrenheit, it will be found by calculation that 3,272,000 deg. Fiah. (that being the nuean temperature of the solar atmosphere) communicated to the terrestrial atmosphere would reduce its density to $w^{1}+3$ of the existing density. Aecordingly, if we assume that the leeight of our atmosphere is only 42 miles, the elevation of temperature mentioned would cause an expansion increasing its leight to $6,649 \times 42=259,006$ miles. This calculation, it should be observed, takes nu cognimance of the diminution of the eartli's attraction at great altitudes, which, if taken into acount, would consideratily increase the estimated height. Let us now suppose the atmosphere of the sun to be replaced by a medium similar to the terrestrial atmosphere raised to the teniperature of $3,272,000$ deg. Fah., and contaning the sime quantity of matter as the terrestrial atmosphere for corresponding area of the solar surface. Eridently the attraction of the sun's mass would, muler these conditions, augment the density and weight of the supposed atmosphere nearly in the ratio of $27.9: 1$; hence its height would be reduced to $\frac{279,006}{27.9}=10,000$ miles. But if the atmospliere thus increased in density by the sun's superior attraction consisted of a compound gas, principally hydrogen, say 1.4 times heavier than pure hydrogen (the specific weight of which is only $\frac{1}{14}$ of that of atmospheric air), the height would be $10 \times 10,000=100,000$ miles. The pres. sure exerted by this supposed atmosphere at the surface of the photosphere would obriously be $14.7 \times 27.9=410 \mathrm{lbs}$. 
per sq. in. nearly. It will be olserved that unr amputa. tions are based on a solar attraction of 27.9 , instcad of the recent estimate of 27.2. The foregoing calculations prove that, miless the depth greatly exceeds 100,000 miles, and unless it can be shown that the mean temperature is less than $3,272,000$ deg. Fah., the inportant conclusion must be accepted that the solar atmosphere contains an cxceedingly small quantity of matter. Now, the assmued mean temperature, 3,272,000 deg. Fah., so far from being too litgh, will be found to be unclerrated. It will be seen, on reference to Chap. X., that the temperature at the surface of the photo.

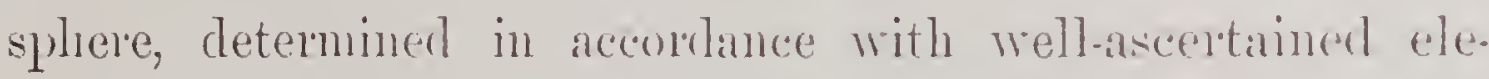
ments, somewhat exceeds f,035,000 deg. Fah. Conserpuntly; as the diminution of intensity caused by the dispersion of the rays is inversely as the convex area of the photosphere and that of the spliere formed by the boundary of the solan envelope-namely, as 1.52: 1-miner the supposition that the depth of the solar atmospliere is 100,000 miles, the temperature at the said boundary will be $\frac{4,035,000}{1.52}=2,654,000 \mathrm{deg}$. The true mean, therefore, will be $3,344,800$ deg., instead of $3,272,000$ deg. Fah.-a difference which leads irresistihly to the inference that either the sun's atmosphere is more than 100,000 miles in deptl, or it contrins less matter than the terrestrial atmosphere for corresponding area of the solar surface. The ratio of dinimution of the density of the gases composing the solar atmosphere at succeerling altitudes is represented by Fig. 3 , in which the length of the ordi- 
nates of the curve $a$ a $b$ shows the degree of temuity at definite points above the photosphere. 'This curve has been constructed agreeably to the theory that the densitios at different altitudes, or, whit amounts to the same, the weight of the masses incumbent at succeeding points, decreases in geometrical progression as the lieight above the base increases in arithmetical progression. The rertical line a $c$ hals been divided into t2 equal parts, in order to facilitate compritsons with the terrestrial atmosphere, supposen to be 42 miles deep, the relative density of which, at corresponding heights, is obriously as correctly represented by our diagram as that of the solar atmosphere. It is true that, owing to the greater height of the latter compared with the attractive force of the sun's mass, the upper strata of the terrestrial atmosplere will be relatively more powerfully attracted thin the upper strata of the rastly deeper solitr atmosphere. 'The ordinates of the curve a d b will therefore not represent the density quite correctly in both cases. The discrepancy, however', resulting from the relatively inferior attraction of the sun's mass at the boundary of its atmosphere will be very nearly neutralized by the increased density towards that boundary, consequent on the great reduction of temperature-fully 1,380,000 deg. Firh.-callsed by the dispersion of the solar lays before entering space. It maty be well to state that, in representing the relative height and pressure of the terrestrial atmosphere, a c in our diagram indicinter t2 miles, while $b$ a indicates a pressure of $14.7 \mathrm{lbs}$. per. sq. in.; and that, in representing the solar atmosphere, a c indicates 100,000 miles, and $b c$ 
410 lhs. per so. in. Beanging in mind the high temperature and the exceedingly small specific grarity of the matter composing the solar atmosphere, the extreme tenuity of the higher regions, indicated by the ordinates shown in the diar gran, will be readily comprehented. Calculation shows that towards the assumed boundary the density of the solar atmo-

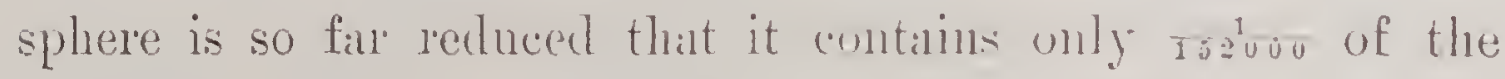
(11antity of matter contained in an equal rolume of atmosplere at the surfalce of the earth.

The dininution of intensity eonserpent on the increased depth of the sulat atmosphere through which the callorific rays pass, which are projected torards the earth from the receding surface of the photosplere, having been considered in Chap. TI., it will only be necessally to mention in this place that lig. $\frac{1}{x}$ represents the sun, and its atmosphere extending $\&$ of the semi-dianeter of the photospliere, $m h$, (: $y$, ete., being the rays projected towards the earth. 'The depth of the solar atmosphere at a distance of 19 of the radius from the centre of the luminary, it will be seen, amounts to only 2.0012 of that of the rerticial depth. It is handly necessary to observe that the radiant energy transmitted by the ray o d will be to the energy transnitted by $a b$ as the sine of the angle f $c a$ to minty.

The foregoing reasoning demonstrates that the solar atmosphere, owing to its enomous tenperatme, may reach a height of 100,000 miles and yet not contain more niatter on il gुiven area of the sun than the terrestrial atmosphere on an equal area. I hare endearored to rerify this important conclusion 
CHAP. III, RADITTAG LOIIER OF SOTAR ATHOSLHERE. 165

prictically, and for that purpose resorted to the experlient of (mlarging the disc f (see illustration on Plate 15) until the spectrum disappears which is formed on the focal thermometer by the concentration of the rays emanating from the sum's atmosphere. It shonid be stited that the original object of the instrument illustrated was merely that of ascertaining whether the incandescent matter contined in the solar atmo. sphere transmits radiant lieat of sufficient energy to artmit of thermonetric measurement. But the appearance of a spectrum on the bulb of the focal thermometer, after slutting out the rays from the photosphere, sugresterl the experlient of substituting for the themometer a small crlindrical stem of metal, couted with lammplinck, in order to ascertain with some degree of precision what amount of enlargennent of the disc $f$ is necessily to exclude the focal spectrum, as by that means the depth of the sun's atmosphere might be measured. The result of the observation proves that while a disc of 10 ins. diameter effectually shuts out the rays trom the photosphere, an enlargement of about 0.15 inch of the ratius of the disc is necessiny to exclude completely the observed spectrum from the focal stem. Now, the distance between the spectrum and the dise being 53.7 ins., it will be found by calculation that the stated enlargement of the disc corresponds with an angular distance of $9^{\prime} 45^{\prime \prime}$; Tence, assumbing the radius of the photospliere to be 426,000 miles, the depth of the meisurable part of the solar envelope camnot be less than 255,000 miles. 


\section{CHAPTER TX.}

'THE FEEBLENESS OF SOTAR RADIATION DEAIONSTRA'LED.

IT is a remarkiable fact that some of the most prominent scientists entertain wholly incorrect views reganding the sun's racliant intensity. Apparently, they are not aware that the temperature produced by uncided solar radiation is fully 300 deg. Fahrenheit below the freezing-point of water. Sir John Herschel, in discussing the increase of the intensity of solar radiation consequent on the reduced distance from the sun when the earth is in perihelion, presents the following views: "In estimating the effect of any additional fraction, as onefifteenth, of solar radiation on temperature (this fraction being determined by applying the law of inverse squares to the diminution of the sun's distance when the earth is in perihelion), we have to consider as our unit, not the number of degrees above a purely arbitrary zeropoint-such as the freezing. point of water or the zero of Fahrenheit's scale-on which a thermometer stands in a hot summer day, as compared with a cold winter one, but the thermometric interval between 
the temperature it indicates in the two cuses and that which it would indicate did the sun not cxist, which there is good reason to believe would be at least as low as $239^{\circ}$ below zero of Fahrenheit. And as a temperature of $100^{\circ}$ above zero is no uncommon one in a fair shate exposure under a sun nearly vertical, we have to take one-fifteenth of the sum of these intervals $\left(\frac{239+100}{15}\right)=23^{\circ}$ Fahrenheit, as the least variation of temperature under such circunstances which can reasonably be attributed to the actual vuriation of the sun's distance." It will be observed that the foregoing quotation has partially appeared in a preceding chapter, yet it could not be omitted in this place without rendering the demonstration incomplete. Considering that "absolute zero" (ascer. tained in the meantime) is $460^{\circ}$ below the zero of Fahrenleit instead of $239^{\circ}$, as supposed by Herschel, it will be seen that, according to his doctrine, the increase of temperature resulting from the sun's proximity when the earth is in perihetion should be $\frac{460+100}{15}=37^{\circ} \mathrm{F}$. Referring to Chap. IV., it will be found that solar intensity at the atmospheric boundary is $90^{\circ} .52 \mathrm{~F}$. during the winter solstice, and that the increase of the radiant intensity at that time, owing to the sun's proximity, is $t^{\circ} .66 \mathrm{~F}$., besiles the loss of energy, 0.207 , caused by atmospheric absorption, together $5^{\circ} .88 \mathrm{~F}$., instead of $37^{\circ} \mathrm{F}$. This extraordinary discrepancy is the result of Sir John Herschel's misapprehension of solar intensity. He supposes, as we have seen, that the energy required to raise the 
temperature fron absolute cold to Finhenheit is zero, achled to the energy necessaly to ralise the temperature from that zero to the point reached on the falneruheit scile, indicates the true intensity of the radiant leat; hence $460^{\circ}$, in aldition to the $90^{\circ} .72$ before mentioned, together 5j(r.7.2 F., instead of $90^{\circ} .52 \mathrm{~F}$. Referring agin to C'hap. IV., it will be fomm that the interssity of solar radiation when the earth is in

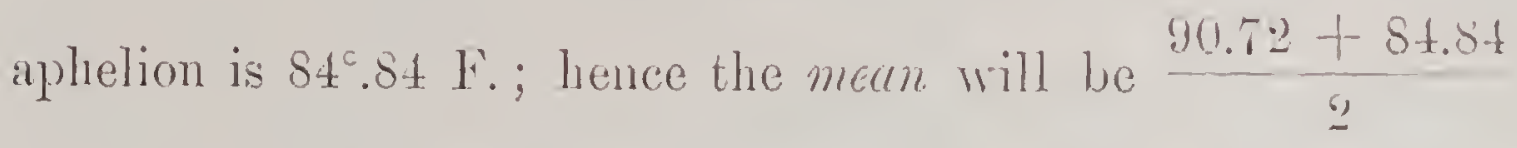
$=87^{\circ} .78 \mathrm{~F}$. Now, the mean distance of the carth from the sm's centre being $91,430,000$ miles, it will be pereered that solar intensity at that distance cammot exceed $8 r^{\circ} .48$ Fallrenheit. In order to show the practical result of this deterdmination of solan intensity, let us suppose that an an-thermoneter, surrounded by some permanent gas maintained at at temperature of $100^{\circ} \mathrm{F}$. above alsolute zero, be exposed to the sun, and that the side of the hulb exposed to the sun's rays is nearly flat, while the bate is semi-spherieal and effectually protected by non-conducting substances. It needs no demonstration to prove that the said themometer will indicate $100+87.78=187^{\circ} .78 \mathrm{~F}$. above absolute zero, or 4.2 $-187.78=304^{\circ} .22 \mathrm{~F}$. below the freezing-point of water; although exposed to the full energy of the sun's l'ays. Persons assigning a high temperature to the surface of the moon will do well to consider the important fact thus established. A moment's reflection will convince them that, but for the accumulation of heat effected by the intervention of the terrestrial atmosphere, water could not exist in a fluid state, 
and that eren the vertical rays of the sun within the tropics would not possess sufficient power to retain mercury in a fluid state.

It has been asserted by physicists that the differential temperature shown by thermometer's, howerer judiciously arranged, does not furnish a reliable indication of solar energy, on the ground that when the supposed maximum intensity has been reached the temperature of the bulb balances that of the solar heat, thus preventing further in. crement. 'The radiating power of the heated bulb, it is urged, remains undiminished, while the differential temperature between the same and the surrounding medium is at its maximum; consequently promoting maximum loss of energy by radiation. In order to test practically the merits of this plausible argument, and in order to determine the true intensity of solar radiation, I have constructed the instrument illustrated on Plate 17. The delineation represents a vertical section through the centre line of the instrument. 'The leading feature of the device is that of applying a hollow revolving sphere (composed of rery thin copper) within an exhausted cylindrical vessel. This revolving sphere, coated with lamp-black inside and outside, is exposed to the sun's rays admitted through a thin crystal covering the open end of the exhausted vessel, the diameter of the crystal being equal to that of the spliere. The exhausted cylindrical ressel, it will be seen by inspecting the illustration, is surrounded by an external casing, water of a given temperature being circulated through the interrening space. The sphere is caused 
to revolve by means of a small hand-wheel attiched to in hollow stem connected with the grhere; the said stem tmrning in an air-tight stuffug-box applied on the upper side of the exhansted vessel. A thermometer is inserted through the hollow stem, the bulb, coated with lamp-black, occulying a central position within the sphere. Obriously the thermometer participates in the rotary motion of the sphere when turned by the hand-wheel. The instrument is supported om columns secured to a table prorided with parallactic mosement for the purpose of pointing the axis of the exhauster cylindrical ressel torards the solar centre. The water circulated through the external casing of the instrunent is maintained at a constant temperature of $60^{\circ}$ F, a vacuum being kept up within the intermal ressel. As the thermometer does not fit air-tight in the hollow stem, it will be evident that the pressure of the air within the revolving splere will at all times balance the external atmospheric pressure. Let us now institute a comparison between the instrument described and the ordinar'y thermometer:

The convex area of the revolving sphere being four times greater than the area of its great circle, the latter being equal to the area of the pencil of rays admitted through the crystal, it will be evident that the refrigerating surface of the spltere is four times greater than the sectional area of the solar laty's which supply the radiant heat. Accordingly, if the surrounding cylindrical ressel be permitted to radiate freely towards the centre, the temperature retained by the revolving splicre thus exposed to cold radiation from all points will be only 
one-fourth of the temperature capable of being imparted by the pencil of rays to the face of a flat disc composed of some non-conducting substance. It may be stated, in further explanation of the foregoing demonstration, that, since the surrounding exhausted ressel is maintained at a constant temperature of $60^{\circ} \mathrm{F}$, it will radiate heat of that energy towards the sphere. An exchange will consequently take place which will prevent maximnm temperature being attained by the sphere unless the radiant energy transmitted by the solar rays entering the instrument be four times greater for equal area than the radiant energy of the heat-rays projected by the sphere towards the cold enclosure. It follows from this important foposition that the temperature acquired by the revolving sphere represents only one-founth of the intensity of the radiant energy actually passing through the crystal of the exhausted cylindrical ressel. It will be readily perceived that the temperature of the air within the revolving sphere correctly represents the temperature of the metal composing the same; also, that the metal itself, owing to its almost perfect conductivity, will become uniformly heated all orer. 'The inserted thermometer, therefore, will show the temperature of the revolving sphere sufficiently near for the object in view. As already demonstrated, only one-fourth of the radiant heat entering through the crystal is retained by the sphere; hence the thermometer will indicate only one-fourth of the actual intensity of the sun's rays. Accordingly, if we multiply the indication of the thermometer within the rerolv. ing sphere by $t$, we ascertain the true solar intensity, less the 
heat absorbed by the crystal covering the exhausted vessel. The result of careful observation has proved the soundness of the foregoing reasoning and demonstration. The conclud. ing investigation, instituted when the z'nith distance was 30 deg. 50 min., established the fact that while the standard acti. nometer indicated a solar intensity of $5 t^{\circ} .5 \mathrm{~F}$., the thermo. meter within the revolving sphere indicated a differential temperature of $13^{\circ} .3 \mathrm{~F}$. According to our theory, it should have indicated $\frac{\tilde{0} 4.57}{4}=13^{\circ} .64 \mathrm{~F}$, thus showing a deficiency of $0^{\circ} .34$. If, howerer, a correction be introdnced anding the proportion of heat absorbed by the crystal-riz, 0.066 - the stated deficiency of temperature will be more than balanced. This apparent inaccuracy is occasioned by the radiation of the crystal towards the sphere, and by the diminution of the radiating surface of the surrounding ressel at the point where the crystal is inserted. The last-mentioned source of error may be easily ascertained, as it depends on the solid angle formed by straight lines drawn from the circumference of the crystal to the centre of the sphere. 'The deficiency of radiating surfice ascertained by that process amounts to 0.012. Proper allowance having been made on account of these sources of error, it was found during the concluding investigation referred to that the temperature retined by the sphere exposed to the solar heat is exactly one-fourth of the temperature imparted and retained by the bulb of an actinometer simultaneously exposed to the sun. It is important to observe that the difference between the intensity 
of the radiant heat of the sun and the temperature of the metal composing the sphere was $54^{\circ} .57-13^{\circ} .64=40^{\circ} .93 \mathrm{~F}$. during the investigation; while the temperature of the bulb of the actinometer exposed to the sun, at the same time, balanced the intensity of the solar heat. This fact completely refutes the assertions of certain physicists before referred to. Regarding the actual intensity of solar radiation, no further demonstration is needed to show that the temperature indicated by the thermometer within the revolving splere, multiplied by 4 , deternines the true energy of the sun's radiant heat at the surfice of the eartli; not, howerer, including the energy lost by atmospheric alsorption. The close agreement between the indication furnished by the instrument thus examined and the indications of the actinometer described in Chap. III. proves, it is satisfactory to observe, the reliable character of the tables of solar temperature contained in that chapter constructed in accordance with our actinometric observations. It remains to be noticer that, before the conception of a dry revolving bulb, I constructed an instrument for determining solar intensity, in which a large star tionary bull, filled with water and provided with an internal rotating paddle-wheel, was employed. The illustration on Plate is represents a section through the rertical plane of that instrument. Before giving a description of the same, it will be well to present an outline of the reasoning which led to its construction.

Suppose a small spherical body of perfect conductivity and radiating power to be suspended within a large enclo- 
CHAP. IX.

sure provided with a perforation in the direction of the sun, of sufficient size to admit a pencil of rays of the sane diameter as the spherical body. Suppose, also, that the temperature of the said body is $64^{\circ} \mathrm{F}$. higher than the temperature of the enclosure and the air contained within the same. The convex area of a sphere being fum times greater than the area of its great circle, while the area of the great circle of the sphere which we have imigned corresponds exactly with the sectional area of the pencil of rays entering through the perforation of the enclosure, it will he evident that the supposed excess of temperature, 64t, camnot be maintained unless the radiant energy of the sun's rays be four times greater for corresponding area than the radiating energy of the sphere. It will also be evident that, if the assumed excess of temperature of the sphere gradually falls while exposed to the smin's rays, until it is reduced to $16^{\circ}$ above the temperature of the enclosure, then the intensity of the sun's rays cannot be more than $4 \times 16=64^{\circ}$. Bearing in mind that the section of the pencil of rays which transmits the energy is only 0.25 of the convex area of the radiating sphere which receives the heat and, in turn, radiates that heat towards the enclosure, we cannot question the correctness of the derluction that, assuming the rays to be parallel, the intensity of the radiant energy which enters through the perforation of the enclosure is four tines greater than the radiant energy which the sphere parts with. Again, the intensity of the radiant hent enamating from solid bodies being a correct index of dynamic energy, it will be pereeived 
that the energy transmitted to the enclosure by the radiating sphere at a differential temperature of $16^{\circ}$ will be exictly balanced by the energy transmitted by the pencil of ray's at $64^{\circ}$ entering through the perforation of the enclosure, the area of which is 0.25 of the convex area of the sphere.

The demonstration thus 1resented, it will be admitted, establishes the important fact that the temperature produced by solar radiation is four times higher than the differential temperature of a black spliere, composed of materials of presfect conductivity, exposed to the sun, and permitted to radiate freely towards an enclosure of a uniforne tenrerature.

Let us now examine the instrument before referred to, shown by our illustration, which represents a section through the central rertical plane: $k p$ is a spherical vessel composed of copper, charged with water and coated with lampblack on the outside, suspended within a spherical enclosure o. The latter is provided with a circular opening a b, to which a cylindrical trunk a $g$ is attached, the spherical enclosure as well as the trunk being coated with lamp-black on the inside, as shorn by the black tint in the illustration. A thermometer provided with a cylindrical bulb is inserted into the spherical vessel, and also a rotating paddle-wheel, operated by an axle passing through a water-tight stufting. box. A cylindrical ressel $r$, filled with water, smrounds the spherical enclosure and trunk, nozzles being applied at the top and bottom, to which flexible tubes are attached for circulating a current of cold water through the ressel. The instrument is mounted within a rerolving observatory; and 
attached to a tible tuming on horizontal journals, and prorided with appropriate mechanism, by mems of which it may be directed at right amgles to the sun. It will be evident that, if the axis of the eylindrical trunk a g be pointed accurately torards the centre of the sun, the sphere $k p$ will receive the whole radiant energy of the rays within the tangential lines $k f$ and $p y$, the sectional area of the pencil of rays, as before stated, being 0.25 of the convex area of the sphere. It will be evident also that, owing to the openingr a l, of the spherical enclosure, the sphere $k p$ will not be acted upon by the full amount of refrigeration that would be pro. duced by the radiation of a continuous enclosure. Agreeably to the theory of exchanges, the deficiency will, howerer, not be great, since the side $f$ a of the trunk $a g$ will radiate as powerfully towards the sphere as a portion of the splierical enclosure corresponding with the angular distance determined by the radial lines $a c$ and $f c$. But the convex surface of the segment $e d$, depending on the angle subtended by $f$ c and $g c$, will obriously be subjected to far less refrigeration than an equal surface on the opposite side of the sphere. Regarding the exact amount of deficient refirgeration conse. quent on the opening in the enclosure at $a b$ referred to, it will be perceived, on reflection, that the radiation of the enclosure towards the semi-spherical surface presented to the sun will be reduced in the exact proportion which the area e d bears to the entire convex area of the semi-sphere. It will be seen, therefore, that although the condition coupled with our proposition has not been fully complied with- 
namely, that the enclosure should be of great extent conpared with the size of the radiating sphere-yet the enclo. sure of our instrument and the comparatively lange opening at $a b$ will not materially affect the refrigerating influcnce to which the sphere is subjected. Besides, the known solil angle subtended by the radial lines $f(c$ and $g c$ enable us to calculate the amount of deficient radiating surface presented by the enclosure.

Sereral experiments liave been made simultaneously with this instrument and a standard actinometer, in order to ascer. tain the precise relation between the temperature transmitter by the sun's rays to the radiating sphere and to the actinometer. Both instruments have invariably been attached to the same parallactic table during the inrestigation; conse. quently the energy of the radiant heat transmitted to each has been precisely alike. Respecting the instituted tests, it will suffice to record the result of an experiment conducted at noon, October 20, 1871, the solar radiation on that day being of nearly average intensity, while the sun's zenith distance, 51 deg. 40 min., was also near an average. Observations made at equal intervals of 5 min., from 11 hours 55 min. s.x. to 12 hours 30 min., showed that the radiating. sphere of the instrument, the contents of which was effectually agitated by the internal paddle-wheel, attained a temperature of precisely $55^{\circ}$, while the enclosure was maintained at a constant temperature of $61^{\circ} .3$. Accordingly, an increase of temperature of $13^{\circ} .7$ above that of the enclosure was proluced by the solar radiation acting freely on the sphere, 
the actinometer, at the same time, indicating a temperature of $51^{\circ} .36$. Now, agreeably to our theory, the temperature of the sphere ought to have been only $\frac{51.36}{4}=12^{\circ} .84$, thus showing a discrepancy of $13.5-12.84=0^{\circ} .86 \mathrm{~F}$. It has already been explained that the sphere does not receive a full amonnt of refrigeration, in consequence of the opening in the enclosure necessary to admit the cylindrical trunk; hence the temperature of the sphere ought to exceed that which our theory has established. The observed difference, $0^{\circ} .86$, is, however, greater than it should be in accordance with the relative magnitude of the convex surface $e d$ and the area of the sphere. But, referring to the illustration, it will be seen that, at the point where the thermometer is inserted, a considerable area of the sphere is not subjected to any radiation from the enclosure, nor at the point where the axle of the paddle-wheel enters. Adding these areas to that of $e d$, calculation shows that the amount of cold radiation prevented from acting on the sphere accounts very nearly for the discrepancy of $0^{\circ} .86 \mathrm{~F}$. before referred to. We are, therefore, warranted in stating that the temperature indicated by the actinometer during the experiments has proved to be exactly four times higher than that indicated by the thermometer inserted in the sphere cxposed to the radiant power of the sun's rays and to the refrigerating influence of the enclosure. The soundness of our theory has thus been fully proved, and, consequently, additional evidence furnished of the correctness of the determination of 
solar intensity by means of the actinometer described in Chap. III. No further proof is reeded in support of the demonstration already presented, showing that the temperature produced by solar radiation, instead of being, as Sir Joln Herschel supposed, equal to the maximum shade temperature within the tropics added to the temperature of the Fahrenheit zero above absolute zero-viz, $100+460=560^{\circ}$ F.-scarcely reaches $88^{\circ} \mathrm{F}$. at a distance of $91,430,000$ miles from the solar centre.

Concerning the radiant heat which reaches the distant planets of the solar system, the stated discrepancy is of vital importance. Were it true that the intensity of the sun's l'adiant heat is $560^{\circ} \mathrm{F}$. at the distance mentioned, the rays on reaching Jupiter's atmosphere would be capable of developing a temperature of $\frac{560}{5.2^{2}}=20^{\circ} .7 \mathrm{~F}$. We can readily imagine that the atmosphere of the giant planet might, by some system of accumulation, raise this temperature to such a degree that organisms like those of the earth might be sustained. But can the insignificant temperature of $\frac{88}{5^{2}}=3^{\circ} .2 \mathrm{~F}$. transmitted to Jupiter's atmosphere be sufficiently elevated by the process of accumulation to sustain animate and regetable organizations resembling those of our planet? The stated low temperature need excite no surprise if we reflect on the fact that the sun, as seen from the boundary of the atmosphere of Jupiter, is no larger than an orange viewed at a distance of one hundred feet. As seen from Saturn, the size 
CHAP. IX.

of the sun is that of a musket-ball at a distance of fifty feet from the observer's eye; while the transmitted solar heat scarcely develops a temperature of $1^{\circ} \mathrm{F}$. where it enters Saturn's atmosphere. Speculations regarding the habitabi. lity of the distant planets are futile, in riew of the insuffi. cient radiant intensity of solar emission established by the actinometric observations recorded in this work, and by the adopted tests proving their reliability. 


\section{CHAPTER $X$.}

TEMPERAIURE OF THE SOLAR SURFACE.

'Tre illustration on Plate 19 represents an instrument for' ascertaining the temperature of the surface of the sun. At first sight it will appear futile to undertake the construction of an instrument capable of indicating temperature at a distance exceeding 90,000,000 miles; but in view of the fact that the sun has been weighed by an instrument consisting principally of four leaden balls less than one foot in diameter, the attempt cannot justly be deemed absurd. The reader will remember that in the celebrated Cavendish experiments, afterwards re. peated by Baily and others, the reight of the earth-on which the weight of the sun is based-was ascertained by measuring the attraction exerted by spheres of lead weighing 174 lbs. The delicate nature of the experiment may be inferred from the fact that the ascertained attractive force was found to be only $\frac{\text { th }}{4300}$ of a grain. The illustrated instrument, the solar pyrometer, by means of which the temperature of the sun has been measured, involves no such nicety. 
Before entering on a description of the solar pyrometer, it will be necessary to call attention to the demonstration in Chap. I., showing that the law relating to radiating spheres is also applicable to concave spherical radiator's, if the sub. stances exposed to their radiant heat be placed in their foci. The demonstration referred to also proves that the tempera. ture produced by the radiant heat transmitted by concave radiators of equal temperatures and curvature, at equal distances, is directly as their areas. Melloni and Leslie's experiments, conducted in the presence of the disturbing influences of atmospheric air, not being sufficiently accurate to warrant their being cited in support of the correctness of the stated relation between areas and temperatures, the construction of the pyrometer has been so modified as to enable us to prove, independently of the demonstrations in the preceding chapter referred to, that, under the stated conditions, the temperatures correspond exactly with the areas.

Our illustration represents a longitudinal section through the vertical plane, and a photographic perspective view of the pyrometer. It will be seen, by inspecting the longitudinal section, that the instrument is composed of four principal parts: (1) A heater consisting of a cylindrical vessel with spherical bottom and open top, supported by an ordinary stove, the firechamber of which it partially enters. Inlargements resembling truncated cones with concave spherical ends are formed near the middle of the heater. The latter is partially filled with water, as shown in the illustration. (2) A conical ressel, surrounded by a double casing, secured to the base of the 
large conical enlargement of the heater. (3) A cylindrical ressel secured to the small end of the enlargement, likewise surrounded by a double casing. (4) An ordinary stove, into which the lower end of the heater is inserted. 'The curvature of the spherical concavity at the base of the large conical enlargement of the leater is struck to a radius of 18 inches, its diameter being 10 inches, hence presenting an area of $\uparrow 8.84$ square inches. 'The opposite spherical concarity, the ridius of which is 9 ins. (its diameter being $\tilde{y}$ ins.) presents an area of $\frac{r 8.84}{4}=19.51$ square inches. Thermometers are applied at the foci of the spherical concarities, their stems being placed as shown in the illustration, in order that the bulbs may present unobstructed semispheres towards the radiators. It is hardly necessary to observe that thermometers intended to measure the intensity of radiant heat should be protected so that those parts of their bulbs which are not acted upon by the heat-rays emanating from the radiators may not lose their heat by radiation or convection. 'The cylindrical as well as the conical chamber of the pyrometer containing the thermometer's are connected by suitable tubes with an air-pump, by which the air is withdrawn; a current of water being circulated through the double casings when the instrument is in operation. With reference to the heater, it should be observed that, being open at the top, the water it contains will always be maintained at a constant temperature when the furnace is in action.

It may be briefly stated that the principle of the pyro. 
meter is that of ascertaining solar intensity by comparing the temperature transmitted by a concare spherical radiator of 10 ins. diameter to a themoneter placed at a distance of 18 ins. from its fice, with the temperatme produced by the radiant heat emanating from an incandescent sphere of \$32,584 miles in diameter; at a distance of $91,430,000$ miles. The radiant heat in both cases is transmitted through ether'; in the former to the surface of the bulb of the enclosed ther. moneter; in the latter to the boundary of the earth's atmo. sphere. The law which governs the transmission of radiant lieat through space is as absolute as the law of gravitation, whatever be the distance; hence it is indisputable that the solar pyrometer in which the radiant heat acts at a distance of 18 inches is as competent to determine the temperature of the sum as the Cavendish leaden spheres acting at a dis. tance of 8.85 inches to deternine lis weight. 'The chances, howerer, of an exact determination are greatly in faror of the pyrometer. In the first place, while the area of the concave radiator of the pyrometer is to the area of the great circle of the sun as $1: 2,871 \times 10^{16}$, the weight of the leaden ball employed in the Cavendish experiments is to the weight of the sun as $1: 2,367 \times 10^{25}$; thus showing a difference of $1: 824,500,000$ in faror of the pyrometer. Besides, the element of distance through which the radiant and the gravitating forces act is in favor of the pyrometer, in the ratio of 18 to 8.85 . But these considerations, however important on account of the greater difference of the magnitudes involved, may be considered unimportant in comparison with the direct. 
ness of the means by which the solar pyrometer solves the problem, contrasted with the indirectness, exceeding complication, and nicety inrolved in the Carendish experinents. In the solar pyroneter we only require a correct indication of the temperature of the radiating concave spherical surfate, and of the temperature transmitted to its focus; together with an accurate measurement of the distance of that focus, and of the area of the ratiating surface. These points being readily determined, while the relative distance and diameter of the sun and the temperature produced by solar radiation at the boundary of the terrestrial atmosphere are known, we may enter upon and carry out our computation without introducing a single correction. How different the Carendish experiment, with its numerous disturbing elements depending on barrometric and thermometric conditions and changes, influencing a gravitating force amounting to only ato of a grain! An accomnt of the almost insuperable difficulties which were surmounted in those remarkable experiments, which for ingenuity, care, and perseverance stand unequalled in the amnals of physics, would be out of place here; yet the foregoing brief allusion to experiments which satisfactorily determined the weight of the earth, and thereby the weight of the sun, has been deemed appropriate as a contrast. The directness, facility, and certainty of measuring solar temperature by the means we are now considering would scancely be alpreciated without calling to mind the method adopted for ascertaining the sun's weight.

Referring to the construction of the solar pyrometer and its 
apparently ponderous character, it will be well to bear in mind that the indispensable condition in this instrunent of maintaining a constant temperature of the complanatively dinge (onlcave spherical radiator is not easily fulfilled. Nothing shont of an open heater contaning a fiuid which readily eraporates, and the application of an excess of heating power, will effer. tually accomplish the object in view. Evidently the lus. occasioned by radiation camot be exactly made good by the most delicate mechanical contrivance; but by alplying an excess of heat in the furnace, the fluid which regulates the temperature of the radiator will be preventecl from falling below the boiling goint; and since the leater is open, the steam formed will carry off superfluous heat, and thus maintain the fluid at the desired uniform temperature. The exhausted chambers which contain the thermoneters nust of course be maintained at a constant tempelinture, the least fluctuation being fatal to accurate indication of the intensity of the heat trinsmitted by the radiators. In order, there. fore, to keep up the necessary constant temprerature during the investigation, a current of water lass been circulated through the double casings which surround the exhausted chambers. By this expedient, in connection with the perfectly uniform temperature maintained in the heater, it has been easy to ascertain with critical nicety the temperature produced by the radiant heat transmitted from the spherical radiator to its focus. Regarding the area and curvature of the radiators, accurate workmanship alone will insure what is requisite; lut the position of the thermoneter; the placing 
the hulb at the proper distance with reference to the focus, demands some consideration. Obvionsly it would not be corlect to place the centre of the bulb in the focus of the rarliator; as that would bring the face of a bulb of $\frac{1}{2}$ in. diameter $\frac{1}{4}$ in. in arlinuce of said focus; nor would it be proper to calry the hulb so far back that its face would intersect the focus. The focal distance being 18 ins., it will be fornd that placing the bulb halt way between these two positions will cause an error of fully 0.007 . Conflicting indication, it should be observed, is mirroidable, since erery part of the exposed half of the convex surface of the bulb cannot be equidistant from the face of the concare radiator; but this notwithstanding, there is a distance at which the indication of the thermometer will be precisely the same as if its entire contents were concentrater in the focus of the radiators. This position has heen practically determined.

'The hitherto accepted loctrine, that the intensity of radiant heat is directly as the area of the radiators, for equal distances, has been shown, in a previous chapter, to be fallacious, because the ladiant heat transmitted from the boundaries of plane radiators beconnes enfeebled by distance and the consequent dispersion of the heat-riys, in the ratio of the squares of the distance between the radiator and the recipient of the radiant heat. The solat pyrometer laving been constructed before I had satistactorily demonstrated that the intensity of the larliant heat transmitted from concave spherical surfaces is directly as the areas of such radiators, it was deemed necessary to establish the collectness 
of that assumption; hence the solar pyrometer has been modified as hefore mentioned. The lesser lauliator attached to the conionl entargement of the heater, and the cylimdrical chamber enclosing the same, were aconelingly alded to the instrument. It has alrearly leen stated that the area of the spherical radiator within the comical chamber is exactly four times greater than that of the opposite radiator, and that the radius of the currature of the latter is me-hatf of the rarlius of the former. 'The demonstration containsed in Cluap. I., before referred to, has established the fact that in concilve sphelical radiators puesenting equal aleas the ladliant loat transmitted is in the inverse ratio of the square of the distances if the substance exposed to the molinnt heat be placed in the focus of the radiator. It folluws from this demonstration that, for equal area, the intensity of the rarliant heat transmitted to the focus of the lesser radiatol will be four times greater than the intensity of the rarliant, heat transmitted to the focus of the large rarliator. But the area of the latter is exactly four times greater than the area of the former, while the thermometers in both chambers ale exposed to the radiation of surfaces heated by the same nedium, and therefore of precisely equal temperatures. At the same time these themometers radiate against suffuces mantained at a constant tempreature, by the reliable experlient of employing a powerful continuons current of water. Consequently, the enclosed themometers, although exposed to radliatom of different area, shomld indicate precisely equal temperatme. Actual trial having shomm that such is the case, the correct- 
ness of the foregoing assumption must be accepterl as fully established.

I will now briefly adrert to the result of an experiment marle with the solar prometer while the atmospheric pres. sure halanced 29.91 inches colnmm of mercury, the temperature of the water in the heater being then precisely 212. Apart from having thus insured a definite indication of heat applied to the concave radiator, the temperature of the current of cold water circulated through the casing surrounding the exhausted chambers did not fluctuate in the least during the experiment, the thermoneter inserted in the exit-pipe of the casings continuing to indicate steadily $48^{\circ} .1$ F. The circulation of cold water laving been kept up fully half an hour previous to the experiment, it is hardly necessary to state that, before the fire was applied in the furmace, the enclosed thermoneter, the surrounding chamber, the water contained in the heater, and the radiator all indicated $48^{\circ} .1$. The fuel in the furnace having been ignited, and the water in the heater brought to boiling-point, the temperature of the spherical radiator was observed to increase from $48^{\circ} .1$ to $212^{\circ}$, difference $=163^{\circ} .9$; the temperature of the focal thernometer at the same time rising from $48^{\circ} .1$ to $60^{\circ} .2$, difference $=12^{\circ} .2$.

It results, from previous demonstrations (see Chap. I.), that the temperature of spherical ridiators transmitting equal intensities to their foc are inversely as the square of the sines of half of the angles which they subtend-that is, the angles formed by the axis of the radiator and the heat-rays 
projected from the circunference to the focus. Consequently, as the spherical radliator of the solar pyrometer, the difleren. tial temperature of which is $163^{\circ} .9$, transmits to its focus an intensity of $12^{\circ} .2$, we are (nabled to calculate what temperature the sun must possess in order to transmit an intensity of $12^{\circ} .2$ to the boundary of our atmosphere. 'The mean angle subtended by the sun being 32 min. 1 sec. during the expe. riment, while that subtended by the radiator of the pyroneter was 32 deg. 15 min., it follows that the ratio of the square of the sines of half these angles will be $1: 3,56$ tit.7. Accord. ingly, the sun, in order to produce by its radiant heat a tenperature of $12^{\circ} .2$ at the houndary of the atmospliere of the earth, must possess a temperature $3,567.7$ times greater thatu that of the spherical radiator of the pyrometer. 'This latter' temperature being $163^{\circ} .9$, that of the sun camnot be less than $3,567.5 \times 163.9=584,546^{\circ}$ in order to transmit an intensity corresponding with a thermometric interval of $12^{\circ} .2$ on the Fallrenheit scale. But colar intensity at the boundary of our atmosphere, as shown by our actinometric observations (see Chap. III.), is $84^{\circ} .84$; hence $\frac{84.84}{12.2}=6.95$ tines greater than that transmitted by the radiator of the pyrometer to its focus. The temperature of the sun, therefore, cannot be less than $6.95 \times 584,740=4,063,984$ deg. Fall.

It will be recollected that the demonstration in a precerl. ing chapter established with as much certainty as any proposition in the "Principia" that the temperature produced by the radiant heat transmitted by a sphere of miform tempe. 
rature at the surfice is to the temperature of the sphere itself inversely as the square of the radius to the square of the distance from the centre to the point exposed to the radiant heat. The distance between the earth and the sun, at the summer solstice, being such that the angle subtended by the latter is 31 min. 32 secs., the ratio of distance and radius will be $218.1: 1$; hence the ratio of the squares, $47,565: 1$. Consequently, the temperature of the sum must be 47,567 times greater than the temperature produced by solar radiation at the boundary of the earth's atmosphere. That temperature being, as before stated, $84^{\circ} .84$, the sun's temperature camnot be less than $47,567 \times 84^{\circ} .84=4,035,584$ deg. Filh. 'Thus the previously demonstrated temperature of 4,063,984 deg. Fah., based on the indications of the solar pyrometer and the angles subtended by its radiator, differ's only 0.007 from the computations just presented. The methods by means of which these results have been reached differing entirely, both being based on sound physical and mathematical principles, we cannot doubt the correctness of the determination. Nor can it be questioned that the actual temperature of the surface of the sun, at the point of maxi. mum intensity, is still higher, since the rays in passing through the solar atmosphere suffer considerable loss of energy, as shown in Cliap. VI.

Let us now consider briefly the extraordinary diversity of views entertained by scientists regurding the temperature of the sun. In view of the fact that all practical datar necessary to solve the problem are known, it is surprising 
that any difference of opinion should exist on the subject. Zölner apparently rejects the positive eridence of high solar temperature fumished by the fact that the sun's rays, after having suffered dispersion in the ratio of 46,000 to 1 , and penetrated the terrestrial atmosphere, are calpable of developing a temperature of nearly $70^{\circ}$ F. on the ecliptic. It will be remembered that he published, some time ago, an elaborate demonstration, founded on the height of the solar prominences, showing that the sun's temperature does not exceed ro,000 C. Secchi, on the other hand, alsserted, in his original work on the sun, that, owing to the accession of energy received by radiation from the outer layers of the solar atmosphere, the temperature of the surface of the photosphere is fully 140 times greater than the temperature announced by Zöllner. Let us first notice the investigations of the Italian astronomer. In his work "Le Soleil," published at Paris, 1870 , he presents calculations showing that the temperature of the solur surface is at least $10,000,000^{\circ} \mathrm{C}$. Prof. Newcomb, in a review of the work referred to, jub. lished in Nature, showed that, if the temperature reached ten million degrees of Centigrade, as asserted by the author of "Le Soleil," the earth would speedily be converted into vapor. In answer to this objection, Pire Secehi urged, "that a body may have a very high temperature and yet radiate very little," contending "that a thermometer dipped inside the solar envelope in contact with the photosphere" would indicate the temperature mentioned. "This high temperature," he observes, "is really a virtual temperature, as it is 
the amount of radiation received from all the transparent stratal of the solar enrelope, and this body at the outer shell must certaninly be at a lower temperature." What information is intended to be conreyed by the statement that $10,000,000^{\circ} \mathrm{C}$. "is really a virtual temperature," on the gronnd that it is "the anrount of rarliation reverved from all the tramsparent strata outside of the photosphere," we can only conjecture.

Our denonstrations, based on the indication of the solar byroneter, have shown that the supposed thermometer, if hronght in contalet with the photusphere, camnot possibly indicate the enormons temperature of $10,000,000^{\circ}$ C. assumed by the Italian plysicist. The assertion that "a body may hive a rery high temperature and yet radiate but very little," were it correct with reference to the photosphere, does not affect the question. It is of 110 consequence whether the photosphere belongs to the class of active or sluggish incandescent ladiators inagined by the distinguished savent; the temperature of the radiant surfice, not its capacity to radiate more or less copiously, is the problem to be solved.

Very recently Père Secchi, much to the surprise of those who had accepted his estimate of solar temperature published in "Le Soleil," has changed his views completely. In an elaborate essay presented to the Acadeny of Sciences at Parlis he underrates the intensity of solin energy more than he formerly overestimated it. Apprehensive that a synopis would fail to grive at correct idea of the remalliblile demonstration 
by which the author of "Le Soleil" now reverses all his previous notions on the subject, and in order to furnish a complete exposition of the mitenable chanater of the hypo. thesis tending to discredit the result of my labors, I will present without abridgment the essential points of his communication to the French Academy, published in "Comptes Rendus," Tome LXXVIII., No. 11: "I)uring list sumner (1873) I made some experiments in order to determine the relation of the radiation of the sun to that of the electric light, in the hope of solving the question of solal tempera. ture. This souree of light was selected, becantse its inter1. sity differs the least from that of the sun. Hence I expect to lammonize the conflieting opinions regurding the law of radiation existing anong the followers of Newton and those of Dulong and Petit. In estimating the two radiations I have used the themohelionetre, the same alfratutus described in my work 'Le Soleil.' 'This instrument, in spite of the objections made to it [by the writer of this work], seens to me appropriate, particularly for determining mere differences, as in this case. Let $I_{8}$ and $I_{c}$ be the absolute intensities of the radiations of the sun and of the charcoal points; $\theta_{8}$ and $\theta_{c}$ the excess of temperature of the black thermometer above that of the surromoling medium, in the cases of the solar and the electrie radiations; a and o the apparent diancters of the radiating surfaces, viewed from the centre of the black thermo. meter, and we have $\frac{\theta_{8}}{\theta_{0}}=\frac{I_{s} \text { tang. }{ }^{2} \delta}{I_{c} \text { tang. }{ }^{*} \alpha}$ whence $I_{s}=I_{c} \frac{\theta_{s} \text { tang. }{ }^{2} \alpha}{\theta_{c} \text { tang. }{ }^{2} \delta}$. It is very difficult to determine pratcically the radiating 
surface of the charcoal points. The point is generally very brilliant, but beyond this the incandescence decreases rery rapidly; besides, the arce between them has a very different maliation. The hare tried to detemine the surface of the radiating parts of the charenal points by comparing their dimensions with those of glass tubes placed in their immediate vicinity, and estimating the distance at which a thin wire of platinum connencer to melt without touching them. We lave thus obtained an almost rectangulan surface, equal to that of a circle of 1 centimetre in diameter; besides, the radiation from the parts ontside of this linit was intercepted by diaphrams. The pile comsisted of bo elements (Bunsen) immersed in fresh nitric acil. The diameter of the elements was (1).12 and their hright (1).20). 'The electrodes were short and very thick; the current was so intense that the insulating plates of an appalatus of Foucault were fused almost immediately, and an inon wire of 1 millimetre in dialmeter and $2^{m} .50$ of lengtl was constantly kept at whiteheat." 'The author laving explained that these data are vague, proceeds: "Inaving placed the thermoheliometre at a level with the chanconl points and the black thermometer at a distance of $0 \mathrm{~m} .395$, I found after halt an hour a difference of $33^{\circ} .63$ hetween the temperature of the surroming merlium and the black themometer. During several days of July, about nom, I determined, with the same instrument, the temperature produced ly solar rantiation. I found a difference of $17^{\circ} .37$, allowing for \%enith distance. By substituting these amounts in the previous formula and calculating 
the diameters of and is according to the dimensions and distances of the radiating atmonphere, we have $\mathrm{I}_{8}=\mathrm{I}_{c} \times 336.468$,

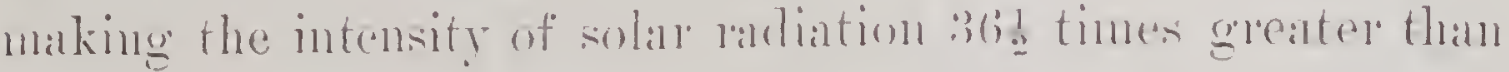
that of the charcoul points. This estinate, howeres, falls short of the actual temperature: for we know that the eor. rection for atmospheric alsorption is too small. Mr. Soret has found on the Mont Blanc $21^{\circ} .13$; at the upper limit of our atmosphere that anount would probibly lo about 25. These two amounts would give respectively: For 210.13: $\mathrm{I}_{8}$ $=\mathrm{I}_{c} \times 44.36 ;$ for $27^{5} .00: \mathrm{I}_{8}=\mathrm{I}_{c} \times 56.66$.

These results differ materially from those nhtained by other observers. Apprehending that some minkmon wanse in my electric light might produce an axessive aror'; I compared it with the light from a stearin candle. I found that it equalled 1,450 common cundles, showing the intensity of an ordinary good pile. In another series of experiments, instituted when the pile harl worked for some time, I found $\mathrm{I}_{s}=\mathrm{I}_{\mathrm{c}} \times 47.5$, which result differs very liftle from that obtained by alopting the temperature of $21^{\circ} .1: 3$ observed by Mr. Soret. Thus, if we accept this temperature of $21^{\circ} .1 \%$, which is incontestably below the real one, and supposing the temperature of the radiating surfice of the charcoal points to be $3,000^{\circ}$ - an amount by 110 means exagrerated, since that part of the platinum exposed to the heat was fused-and if we estimate rartiation as proportional to temperature, we obtain $198,7811^{\circ}$ as the potential temperature of the sum. This amount may be raised even to $169,981^{\circ}$, by atopting the temperature of $2 r^{\circ}$ produced by solar radiation." 
The result, then, of Pire Secchi's hatest researches shows that the potential temperature of the smo is $138,780^{\circ} \mathrm{C}$., which he thimks may be raised eren to $160,980^{\circ}$ C. Aceorlingly,

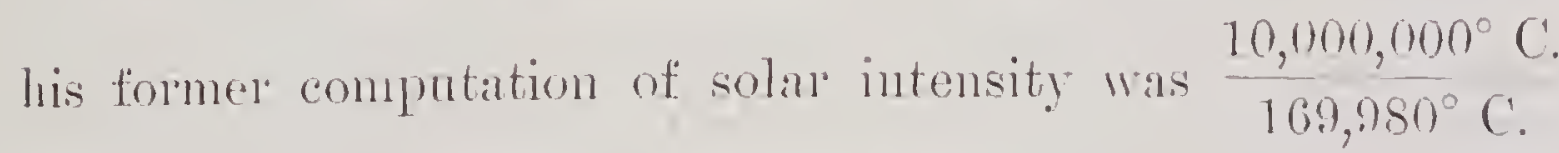
$=59$ times higher than his present. Referring to Chapl. XIII, it will be fomml that Ponillet, whose estimate of solan intensity at the boundary of the terestrial atmosphere is nearly irlentical with that which my actinometric olservat tions have estahlished, but who bases his computations on Dnlong and Petit's erroneons formula, arrives at the concusion that the temperature of the smm is from $1,461^{\circ}$ to $1,761^{\circ}$ C. (nean $=1,611^{\circ}$ C.) M. Ticaire, aropting, like Ponillet, Inulong's law, states, in his paper presented to the French Acardemy, that the temperature deduced from that law is hetween $1,400^{\circ}$ and $1,500^{\circ}$ C. Sainte-Claire-I)evills conchules his essay on solar temperature by the announcement that "solar temperature will not he found far removed from 2,500 to $2,800^{\circ}$ C." It is very important to observe that no difference of opinion exists reginding the rymamic energy developed by the sun. All physicists accept Pouillet's computation showing that each squane foot of the solar sul. face derelops about 300,000 thermal units per minute. It will be asked how Ponillet conld reconcile such an enormons derelopment of energy with the insignificant intensity represented by $1,611^{\circ} \mathrm{C}$. A satisfiletory answer will be found in Chapl. II. An examination of Mr. Boxe's table of temperatures in Chalp. XIII. will also suggest a satisfactory answer'. 'This table 
whose emissive power is not more than one fourth of that of iron at corresponding temperatures; hence it is reasonable to infer that solar radiation emanates from incandescent gitses.

The question of relative ladiant power of solids and galses having presented itself at the beginning of my investigations of radiant heat, I constructed the apparatus illustrated on Plate 20, in order to ascertain the temperature produced by the radiation of incandescent gases. The illustration represents two vertical sections of the apparatus (see Figs. 2 and :3) and a perspective view (see Fig. 1). Bufore cutering on it description, it will be proper to state that the device resortent to was intended to produce a colunn of incandescent gats of uniform density supplied with oxygen at every point within the bunning mass. This condition, it wats supposed, contel only be fulfilled by employing a centrifugal blower forcing a current of atmospheric air vertically upwards through at mass of easily-ignited combustibles, divided into small pieces, placed on a horizontal grate. Fig. 1 represents a conical fintnace, provided with a grate applied at the contracted lower portion, admitting of a free passage of the air between the bars at every point. A capacious chanber is formed under the grate, into which air is forced by an ordinary centrifugal hlower: The internal portion of the furnace is contracted towards the top, as shown at $/$ in Fig. 2, terminating with a squalre opening, over which is placed a square trunk a, corresponding exactly with the said opening. The furnace being charged with combustibles which readily ignite, it will be evident that a moderate speed of the blower will, 
soon after ignition, fill the squalle trunk with a dense flamo of perfectly uniform temperature throughout, contact with the exterior atmosphere being wholly prevented, while the air which supports the combustion is subdivided almost infinitely, and uniformly dispersed, through the mass of buming fuel. A chimney, the section of which is equal to that of the contracted part of the furnace, being applied above the square trunk, any tendency to pressure and accumulation in the same will be effectually prevented. A dense flame of mifom temperature having thus been obtained, its radiant power has been ascertained by the following device: A conical vessel $b$, open at the large end, surrounded with a water-jacket of cylindrical form, shown in Fig. 2, is secured to the square trunk, a circular opening c, shown in Fig. 3, being formed in the side of the latter, corresponding with the open end of the conical ressel. Referring to Fig. 2, it will be seen that a perforated diaphragn d (composed of polished silver) is introduced near the small end of the conical ressel. A thermometer is applied near the circular perforition of the diaphrigm, the bulb being placed exactly in the centre line of the ressel. An opening $f$, surrounded by a short conical tube, covered with a piece of mica, affords a view of the interior of the conical ressel. 'The waterjacket was supplied from the street-main, a constant stream being kept up during experiments. 'The application of a chimney of large diameter above the square flame-trunk, and the covering of the short conical tube with mica, as stated, in order to prevent currents of heated air or gas 
from circulating through the conical ressel, have contributed to secure the desired result-riz, a dise of flanne of uniform brightness, the color varying with the speed of the blower: It might be supposed that the high temperature of the flame would at once destroy the square trunk. Such, howerer; is not the case, the trumk being made of plateiron only $\frac{1}{15}$ in. thick, the radiation of which is so rapid that the gases composing the flame camnot communicate the heat as fast as it is carried off by extermal radiation. The top of the furnace at the point where the flame is concentrated and conducter into the square trunk, being cxposed to intense healt, is lined with fire-clay. It should be borne in mind that the apparatus is exposed to a high temperature only while the blower is in operation, the motion being stopped as soun as the internal thermometer reaches maximum indication.

It will be noticed by those who hare paid attention to the demonstration in Chap I. that, unless the radiant surface forms a spherical concavity; the focus of which coincides with the centre of the bulb of the recording themometer, the indication will not be exact. The flame-disc being cir. cular, this objection may be overcome by remoring the ther. mometer from the flame to such a distance that the mean length of the heat-riys directed to the bulb corresponds with the radius of a concave radiator of the same dianneter as the flame-disc. For the sake of ready comparison, the diameter of this disc and the focal distance of the recording thermometer have the same relative proportions as in our solar pyrometer: 
The result of the initiary experiments with the apparatus thus described prored that the temperature transmitted to the focal thermometer by the radiation of the flame-disc was relatively the same as in the solar pyrometer. It was inferred from this fact that the radiant power of a dense flame with active combustion kept up through its entire mass is the same, for equal temperatures, as the radiant power of metallic substances. Further investigation, however, disclosed the fact that this unexpected result was owing to the circumstance that the steam emanating from the burning fuel during the experiment had entered the conical ressel, and, reaching the bulb of the recording thermometer, elevated the temperature rery considerably. The presence of steam hal not been overlooked, but it was supposed that the rapid circulation of cold water through the jacket surrounding the conical chamber would produce instant condensation. It is much to be regretted that before the disturbing influence of the presence of steam in the chamber containing the focal thermometer had been dis. covered, the results of the initiary experiments had been published in sereral mechanical journals. The main feature of the apparatus is, however, not without merit, as probably no better method could be devised for producing a dense flame within which active combustion is being kept up at erery point. In combination with the thermoelectric pile, should a reliable mode of calibration hereafter be derisen, there is reason to suppose that the illustrated machine may prove very useful. In the meantime, I have 
instituted numerous experiments to ascertain the radiant power of flames as comprared with that of metallic sub. stances. The result in every instance proves the feebleness of the radiation of incandescent gases compared with incan. descent solid substances of equal temperature; but until the conclusion of the investigation, definite statements must be deferred.

Regarding the constitution of the solar surface, the temperature of which we are now considering, the relative feeble. ness of its emissive power compared with that of fused iron, shown by our investigations, leads irresistibly to the conclu. sion that we are dealing with an incindescent gas. The constitution of the solar surface, however, has nothing to do with its temperature. Rut, obviously, our endeavor to ascertain the constitution of the sun will prove futile until the temperature at its surface be first established. This will be readily admitted. Suppose that the temperature of the sun's surface is only $1,600^{\circ} \mathrm{C}$, as Ponillet tells us, and that the solar atmosphere extends to the moderate height of 100,000 miles above the photosphere. It may be shown, by an easy calculation, that the specific gravity of the gases near the solar surface would under these conditions, owing to the low temperature, the depth of the superincumbent mass, and the great attraction of the smin's mass, exceed that of fused iron. It will be evident, therefore, that, until the temperature of the surface shall have been established, investigations relating to the constitution of the interior mass and the sur. romnding atmosphere camnot lead to any safe conclusions. 
I now propose to show, by a demonstration which cannot be objected to, that the high temperature sitablished by the indications of the solar pyrometer really exists on the solar surface. Astronomers, while adnitting their inabi. lity to compute the degree of temperature imparted to the surface of the planets of our solar system, owing to the unknown properties of their atmospheres in retaining the heat received from the sun, have no hesitation in assigning the exact degree of solar intensity transmitter to the atmospheric bomulary of each planet, compared with that transmitted to the boundary of our atmospliere. Sir John Herschel, in treating of the planet Mercury, does not admit that any doubt exists as to the relative degree of solar intensity to which its atmosphere is subjected. The mean ladius of the orbit of this planet being to that of the earth as $38: 100$, he tells us that the temperature produced by the sun's rays on reaching the atmosphere of Mercury is nearly seven times greater than the temperature prorluced by solar radi. ation at the boundary of the terrestrial atmosphere. The following extract from the "Outlines of Astronomy" shows the confidence which Sir Joln Herschel places in the appli. cation of the lar of inverse squares to the determination of solar energy at given distinces: "The intensity of solar" lanliation is nearly seren times greater on Mercury than on Earth, and on Neptune noo times less; the proportion of the tro extremes being that of mpwats of $5,600: 1$. Let any one figure to limself the combition of our globe were the sun to be septupled, to say nothing of the greater 
ratio! or were it diminished to a serently, or to a 900 th! It is true that, owing to the remarkible difference between the properties of radiant heat as emitted from bodies of very exalted temperature as the sum, and as from such as we commonly term wam, it is rery possible that a dense atmosphere surrounding a planet, while allowing the excess of solar heat to its surface, may oppose a powerful obstacle to its escape, and that thus the feeble sumshine on a remote planet may be retained and accunnulated on its surface."

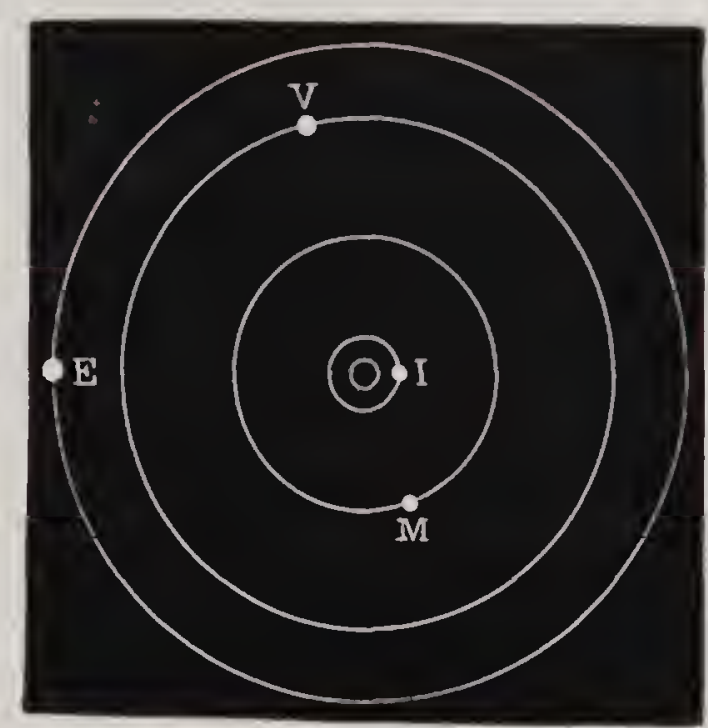

No doubt Pouillet would lave felt as little hesitation as Ierschel in determining by the application of the law of inverse squares the temperature produced by solar radiation on Mercury. Chapter I. contains an elaborate demonstration, proving the correctness of this law with reference to radiat. ing spheres uniformly heated at the surface.

The above diagram represents the orbits of the Earth, Venus, and Nercury, their relative mean distance from the sun being correctly drawn. The orbit of an imaginary body I, revolving at a distance of 10,000,000 miles from the solar 
centre, has also been introduced in the diagran, for the purpose of demonstrating that a body revolving round the sun at that distance would be exposen to a temperature greatly exceeding that which Pouillet assigns to the solar surface. Astronomers agreeing that the law of inverse squares lolds for all distances, whether it be that of Neptune, which is 30 times further from the sun than the earth, or that of Mercury, whose distance from the luminary is less than $\frac{1}{s 0}$ of that of Neptune, we are warranted in applying that law to the body I, shown in our diagram, supposed to revolve at a distance of ten millions of miles from the centre of the sun. Let us then calculate what degree of solar intensity this imaginary body will be subjected to. Our calculations, obviunsly, must be based on the temperature produced by solar radiation at the boundary of the earth's atmosphere; hence it will be necessary first to establish that temperature. Assuming that it will prore more satisfactory to persons having obtained their knowledge from standard physical works, I will leare out of sight the result of my own actinometric observations, and adopt those of Pouillet, the difference, besides, being quite unimportant. In his "Éléments de Physique," published at Paris, 1856, second rolume, this suvant states, with reference to the anount of heat given out by the sun: "In the vertical passage the atmosphere absorbs at least 0.21 of the incidental heat, and at most 0.27 , beyond which the sky ceases to be serene; I should add, however, that the 2sth of June, on which day the absorption was $0.2 \zeta$, a light white veil was perceptible in 
the sky." The observed and commonly accepted maximum solar intensity on the ecliptic being $65^{\circ}$ li., it will be found, by adding the loss of heat caused by atmospheric absorp). tion-viz., 0.21, assumed by Pouillet-that the mean temperature produced by solar radiation at the boundary of the atmosphere is fully $\delta 6^{\circ} \mathrm{F}$. The mean distance of the enth being in round numbers 92 millions of niles, while that of the imaginary body I is 10 millions of miles, from the sun, the solan intensity to which the latter would be exposed is to that tramsmitted to the boundary of the terrestrial atmo. sphere as $10^{2}: 92^{*}=1$ : 84.6. Pouillet's calculations, ancl common observations, llaring, as before stated, estiblished the intensity of the sun's rays on entering cur atmosphere to be nearly $86^{\circ} \mathrm{F}$., the foregoing analogy proves that the supposed borly I will be subjected to a radiant intensity of $86^{\circ} \times 84.6=7,275^{\circ} \mathrm{F}$. We liave thus shown by a methorl the correctness of which cannot be disproved that the radiant heat emanating from the sun (a boly the temperature of which, Ponillet informs us, is under $3,000^{\circ}$ F.) develops an intensity of $7,275^{\circ}$ Falnenheit at a distance of ten millions of miles. Well-iuformed persous will not dispute the correctness of the foregoing demonstration, nor ask further evidence of the erroneous character of Secchi's recent speculations or the fallacy of Zöllner's and Pouillet's computations assigning a low temperature to the solar surface. 


\title{
CHAPTER XI.
}

\author{
RADIATION FLON INCLNDESCEN'T PLANES.
}

Soms eminent scientists have supposed that the surface of an incandescent body projects rays of equal energy in all directions. Laplace, hiving full confidence in the correctness of this assumption, founded upon it the demonstration adverted to in a previous chapter, proving that the radiant energy which emanates from the receding surface of the sun possesses greater intensity than that emanating from the central regions of the luminary. But actual observation having shown that the radiant energy from the sun's border, so far from being more intense, is considerably less than from its centre, the persistent mathematician was driven to the alternative of proving that the retardation produced by the greater depth of the sun's atmosphere towards the limb neutralizes the assumed increase of intensity of the radiant heat. How satisfactorily the dexterous analyst proves the startling proposition will be found on referring to "Mécanique Céleste," Tome IV. 1P. $284-2 S 8$ : the result of his 
demonstration leading to the monstrous assumption that the solar atmosphere absorts $1 \frac{11}{12}$ of the entire conergy enanating from the radiant surface. Fridently Ealplace did not regind solar radiation as molecular action capable of heing converted into mechanical energy; or he would hatre perceived the inpossibility of 11 being absorbed by the solat atmo. splere. It is not intended to enter on a criticiom of the famous demonstration, but the question is so intimately connected with the subject under consideration that a reforence to the main points is called for', showing on what gromeds the conclusion was based that, but for the setandation prer. duced by the solar atmosphere, the radiant energy? of the luminary would be increased towards the border. If we andmit the correctness of Lalplace's assumption that the intensity of radiation increases with the obliquity of the radiant surface and the increased number of rays contaned in a given section, we must also admit that the radiant energy from the regions near the sun's border will be greatly enlanced. And since it has been found, by actual observation, that no increase of intensity takes place, the inference cammot be resister that the retaldation produced by the solar atmosphere actually neutralizes the increased intensity oecasioned by obliquity. Accortingly, the retartation maty be determined by calculating the increase of intensity corresponding with the obliquity and consequent crowring of the ralys. But this calculation, it is evident, will not show the full extent of retardation, since not only is there no increase, but a considerable diminution of intensity towandi the smu's 
border. Hence, the anomt of retarlation letemined agreeably to the doctrine that the radiant intensity is increased by the ollignity of the rays will be still further augmented. The reader will perceive, from this exposition, on what erroneous grounds Laplace's munciation is based, that "if the sun were stripped of its atmosplere, it would appear twelve times as luminous."

'The foregoing reference to doctrines promulgated nearly a century ago, when solar radiation was hut imperfectly understood, will be deemed inappropriate by those who do not bear in mind that the highest anthorities of the present time arlvocate similar doctrines. Referring to Chapter VI., it will be seen that Père Secchi, who has deroted more time to the investigation of the subject than any one else, presents calculations intended to prove that the retardation offered by the solar atmosphere to the passige of the rays is so great that only a fraction of the rarliant heat enters space. He sums up his inrestigation by the following positive statement: "1st. At the centre of the disc, perpendicularly to the surfice of the photosphere, the alsorption arrests about $\frac{2}{3}$, more exactly $\frac{63}{100}$, of the total energy. 2d. The total action of the alsorbing envelope of the visible hemisplere of the sun is so great that it allows only $\frac{12}{100}$ of the entire radiation to pass, the remainder-that is to say, $\frac{88}{100}$ - being absorbed." Persons accustomed to compare mechanical equivalents, esprecially those who possess practical knowlerlge of the amount of mechanical power developed by the radiant heat emitted by incandescent bodies at definite temperatures, 
positively reject all assumptions involving any considerable loss of radiant energy by absorption in a medium perpetually exposed to the radiator. Nor will the assertion that the radiant heat is converted into molecular motion within the solar envelope be accepted by any person comprehenting that the mechanical energy capable of heing developed hy the heat-rays projected from the photosphere must enter space less only the amount of actual work performed during the passage through that envelope. The investigations con. ducted by means of the solar calorimeter described in Chap. $V$. have shown that the dynamic energy developerl by the sun's rarliant heat on entering the earth's atmosphere amounts to 7.11 thermal units per minute upon an area of one square foot, while the dispersion of the rays is in the ratio of $1: 45,400$; hence, each square foot of the photosphere emits, as shown in the chapter referred to, 322,000 thermal units jer minute. Secchi says that only $\frac{1}{8}$ of the heat emitted passes through the sun's atmosphere. Accordingly, $7 \times 322,000=2,254,000$ thermal units per minute are absorbed. Now, the derelopment of one horse-power requires $\frac{33,000}{772}=42.7$ units per minute; hence the energy supposed to be absorbed represents a mechanical force, continually acting, amounting to $\frac{2,254,000}{42.7}=52,700$ horse-power for each square foot of the surface of the photosphere. Considering that the sum is surrounded by highly attenuated gases, containing a very small quantity of matter, Secchi's assumption that the stated enor- 
mous amount of energy is absorbed by the sun's atmosphere is utterly at variance with the laws of mechanics. 'The foregoing discussion has been deemed appropriate in this place, in order to cill attention to the importance of ascertaining the true energy of heat-rays projected from incandescent surfaces at acute angles. If we can prove by positive practical means that the assumption is false which asserts that radiators emit rays of equal energy in all directions, we destroy the foundation on which the theory rests which las led to the conclusion that only $\frac{1}{8}$ of the energy developed by the sun penetrates its atmosphere.

The illustration on Plate 21, referred to in Chapter VI., represents a rertical section and top view of an inverted conical ressel, the bottom of which is concave, the top being open and provided with a wide flange. A revolving semi-sphericul disc of cast iron, flat on the under side, is suspender on two transverse axles above the open end of the conical ressel, the axles turning in appropriate bearings resting on the top of the wide flange before mentioned. A lever handle is secured to one of the transverse axles, for the purpose of placing the disc at any desired angle, the degree of inclination being indicated by a graduated quad. rant applied as shown in the illustration. The conical ressel is surrounded by a jacket, a stream of water being circulated through the intervening space during experiments. The incandescent revolving disc is protected against loss of heat on the top by a non-conducting covering composed of fire-clay, so arranged that it may be quickly applied and removed. A 
semi-spherieal water-jacket is applied athore the rewolving dise, to protect the same from the disturbing influnence of currents of air. It will he found, on eximining the illustration, that the water-jacket referred to is placed on the top Hange of the conical ressel, without fastening; hence it mily be taken awar and replaced in a ferw seconds. The jacket surround. ing the conical ressel being maintained at a constant temperature by a current of water, the air in the lower part will also be maintained at a constant temureatme. Obrionsly; the leated air at the top camnot descend to the bottom; comse. yuent? the bulh of the recorting thermometer will be influenced only hy the rartiation of the surpunting vessed, and hy the radiant leat which the incandescent lise transmits. It is landly uscesary to mention that the lower halt of the lulb is protected by a non-conducting covering. In view of the foregoing explanation, it will be evillent that the measmement of the intensity of the radiant heat projected from the incandescent disc towards the bulh of the thermometer, at different angles of inclination, will be als reliable as if the air were exhansted from the conicil ressel. In either case, the temperature of the smrounding vessel which radiates towards the thermometer, being derlusted from the temperature indicated hy the same, shows the intensity of the radiant heat transmitted to the moll. It may he contended that the rpper part of the latter loses a small amomit of heat hy convection attending the presence of air within the ressel. Assunning that the loss of heat from that cause is appreciable, this loss will be proportiomate to the intensity 
of the heat transmitted during each experinent; honce it cannot affect the relative difference of intensity for dillerent degrees of inclination of the incandescent disc.

During experiments, the appalatus is placed near an ail. funace, hose being attached to the nozzles of the external casing for circulating at constant stream of water through the intervening space. 'The furnace having been charged with combustibles capable of producing a steady fire, and heated to the requisite degree, the disc is inserted. Having remaned in the funate until the color of the metal approaches bright orange, the disc is quickly withdriwn and placed orer the open conical ressel, supported by the axles shown in the top? view of the illustration.

Agreeatbly to the theory, the correctness of which we are going to disprove, the incandescent dise, placed at the inclination shown in the illustration, will transmit a higher tenperature to the thermometer than if it were placed at at greater angle to the rertical line; the reasons assigned for this assumption being that the same number of radiating points are presented by the disc, and the same number of rays of equal energy enitted in either position, while in the former they are more concentrated than in the latter. The stated assmuption involves the proposition that parallel rays projected at an acute angle, from a given number of radiating points, transmit greuter intensity than an equal number of parallel rays projected at a less acute angle to the radiant surfice. That this proposition, although untenable, is very plausible, will be seen by reference to Fig. I (see diagrim 
Plate 22). Let $a b$ represent the inclined radiant surface, and $a c b$ the several radiating points projecting heat-rays towards the spaces $d f$ and $k g$. The number of radiating points and the number of heatrays projected being alike in each case, while the space represented by $k g$ is only onethird of that represented by $d, f$, it must be admitted, if we assume all rays to possess equal energy, that the concentra. tion of heat within $k y$ is three times greater tham withim d. $f$. In other words, that a given area within $k g$ receives three times more heat than an equal area within $d . f$. This apparently correct view of the question, and its application to spheres, led Laplace astray in his demonstration concern. ing solar intensity. In the next chapter, which, as already stated, will be devoted to the consideration of radiant heat trinsmitted from incandescent spheres, the influence of the spherical form on radiant intensity will be fully considered. In the meantime, we must adnit that the demonstration con. tained in Fig. 1 is unanswerable under the stipulated condition that all heat-rays emitted by a radiator possess equal energy. Our task, therefore, will be to show, practically, that the stated condition is based upon false assumptions. Having alleady made ourselves acquainted with the apparitus constructed for this purpose, we may at once proceed to consider the results of the experiments which have been instituted. It will be evident that, owing to the high temperature of the revolving disc, it will cool very rapidly after being removed from the furnace and placed in position over the conical vessel, and that the recording thermometer, however sensitive, will 
require so long a time before reaching maximm inclication that only one inclination of the disc can be experinnented on at a time, thus rendering reheating indispensable for each change of angle. The number of changes of inclination during the investigation have, therefore, been limited to ten, beginning with 90 deg. and ending with 10 deg. inclination to the vertical line. It will be evident that the high temperature renders it practically impossible to impart exactly the sane degree of incandescence at each operation. I have, therefore, resorted to the expedient of maintaining the furnace at a miform temperature, and to expose the disc to the action of the heat during an equal interval of time for each opreration. This methou, though not precise, has conclusively sstablished the fact that the temperature transmitted to the thermometer by the radiant heat varies in the exact ratio of the sines of the mean of the angles formed by the face of the disc and a line drawn from its centre through the centre of the bulb. The result of an experiment made with great care will be found recorded by the diagram Fig. 5, in which the ordinates of the curve $a b$ represent the sines of the angles formed by the disc and the lines mentioned, the ordinates of the irregular line c a e representing the temperatme transmitted to the recording thermoneter: The figures inserted below the base line of g show the number of degrees of inclination corresponding with the sine represented by each ordinate, while the figures above the curve " b show the discrepancy between the calculated and the actual temperature transmitted to the thermometer. It will be found on inspec. 
tion that the mean difference of the actual and the calculated temperature above the curve is $1.94^{\circ}$, that below the same being $1.08^{\circ}$; hence the mean discrepancy is only $0.86^{\circ}$ Fah. Considering the difficulty of imparting an equal tem. perature at each operation during the experiments, this dis. crepancy between the calculated and the actual temperature transmitted by the radiation of the incandescent disc is unim. portant. Te are warranted, therefore, in adopting the conclusion that the temperatures vary exactly as the sines of the angles of inclination of the radiant surface. It has been deemed proper, in riew of the great importance of this conclusion, and in order to render the subject clearly understood, to introduce Figs. 4 and j) combined, showing the sereral angular positions of the incandescent disc during the investigation. Dotted lines, it will be seen, have been introduced, connecting these angular positions with the corresponding ordinates of the curve $a b$. A mere glance at the geometrical representation contained in Figs. 4 and 5 will show that the temperatures indicated by the ordinates of the curve a $b$ correspond exactly with the sines of the angles of incli. nation of the disc. Bearing in mind the facts thus established, let us agrain refer to Fig. 1 , in which the space $l: g$ is onethird of the space $d f$. We are now enabled to demonstrate that the heat transmitted to a given area within the former is only one-third of the heat transmitted to an equal area. within the latter. Laplace and his followers, assuming the reverse to be the case-viz, that the temperature within $k g$ will be three times higher than within $d f$-their estimate of 
the radiant intensity of inclined surfaces will obviously be too high in the inverse ratio of the sines of angles of inclination. The consequence of this grave mistake, with reference to the radiant power of incandescent spherical bodies, will be demonstrated in the next chapter, containing a record of the temperatures developed by the heat-rays projected in a given direction from different zones of a metallic sphere raised to a high degree of incandescence. 


\section{CHAPTTER XII.}

\section{RADIAIION FRON INCANDESCEN'T SPHERES.}

Time question whether equal areas at different points of the solar surface transmit equal energy towards the earth has engaged the attention of several cuninent scientists. It was mentioned in the previous chapter, on radiation from inclined incandescent planes, that the author of "Mícanique Céleste," finding by observation that equal areas of the sum do not tramsmit equal energies (the central portion transmitting, in opposition to his reasoning, much greater intensity than those near the border), explains the matter by showing that the solar atmosphere retards the passage of the rays, causing a great diminution of the energy of the radiant heat projected from the borter of the sun towark the earth. It but seldom happens that questions of a cosmical nature atmit of being decided by actual experiment, the present being one of the rare instances in which experimental tests maly be resorted to. Evidently, if the great retardation of energy towards the border, demonstrated by Laplace, is cansed solely by the olstruction encountered during the passage of the rays 
throngh the, atmosphere surrounding the sun, the receding surface of an incandescent spherical body not surrounded by a retarding medium will transmit the supposer intensified radiant heat undiminisher. The illustration on Plate 293 represents an apparatus by means of which it has been clearly demonstrater that, notwithstanding the absurce of a retarding medium round an incandescent sphere, the supposen increase of radiant energy resulting from the ohliquity of the heat-rays projected by the receding surface does not take place. The said illustration shows a rertical section and top view of a conical ressel surrounded by a water-jacket, and in other respects constructed as the apparatus described in the preceding chapter. The top flange of the conical ressel nuw under consideration is, however, provided with a groove, the bottom of which supports a solid sphere of cast iron, in the mamner shown in the illus. tration. Below the sphere are inserted two semi-cylindrical screens of different diameter, each composed of two thin plates of iron, the intervening space between these plates being filled with a fire-proof non-conducting substance. It will be seen, on carefully inspecting the illustration, that the externil screen is annular as well as seni-spherical, while the central screenl consists of a concave disc; hence an annulal opening is formed between each pair of screens. Supposing the cast-iron sphere to be heated before being placed in the position represented, it will be evident that the thermometer at the bottom of the conical ressel will only receive the radiant leat transmitted by the heat-rays projected towards 
the bulb through the amular opening formed between the two screens. It will be readily understood that, by employing screens of different proportions, zones containing equal. convex areas, but occupying different positions, may be made to radiate towards the thermometer, and that by this means the radiant intensity transmitted from any portion of the spherical surface may be ascertained. Consequently, we are enabled to test practically the truth of the assertion that, but for the intervention of the sun's atmosphere, the receding solar surface would, owing to the increased number of rays contained within a given section, transmit an increased radiant intensity towards the earth. It may be urged against our device that atmospheric air intervenes between the incandescent sphere and the recording thermometer. A moment's consideration, howerer, will show that the consequent retardation is practically inappreciable. It has been established in preceding chapters that the retardation sustained by the sun': rays in passing through our atmosphere amounts to 0.207 on the ecliptic, while solar intensity at the boundary of the terrestrial atmosphere is rery nearly $85^{\circ} \mathrm{F}$. Conse. quently, the loss of radiant heat hardly reaches $15=\mathrm{F}$. in passing through 28,800 feet of atmospheric air of maximum dewsity. The radiant heat of our experimental alluratus being transminted through a depth of only ? feet, the betark. ing influence of the ain interrening between the raliating spliere and the bulb of the recording thermometer will be only $\frac{2 \times 18^{\circ}}{28,500}=0.0012^{\circ} \mathrm{F}$. We may, therefore, without appre. 
ciable error, assume that no retarding medium surrounds the experimental incundescent splere. The principal features of our apparatus having thus been explained, and the method of solving the problem under consideration pointed out, we may now proceed to consider the result of the experiments which lave been instituted. In order to facilitate comprison, the lower half of the sphere visible from the centre of the bulb of the recording thermometer (see Fig. 6 in the diagram Plate 24) has been divided into four zones, A, B, C, and D, containing equal areas. It will be seen, on inspecting the arrangement of screens shown in the diagram, that no part of the surfice of the sphere excepting that contained within the parallel lines defining each zone is capable of radiating towards the thermometer, all the rest being shut out by the screens. Oh. viously, the latter can be so proportioned that the radiant heat from any part of the lower half of the sphere may be projected torvards the bulb. Figs. $3,4,5$, and 6 in the diagram show the arrangement of screens adopted in our experiments, by means of which the transmitted radiant power of each of the zones has been ascertained. The dimensions of the several screens have been determined hy drawing radial lines from the centre of the bulb of the thermometer to the points. where the termination of the rones intersect the circumference of the sphere. The subject will be most readily understood by referring to Fig. 4, which exhibits zone C. The screens being made to terminate where they meet the radial lines $p, q$ and $q, q$, it will be seen that an annular opening $p q$ is formed, permitting all heat-rays to 
pass which are projected from the zone $\mathrm{C}$ in the direction of the bulb of the thermometer. A similat arangement permits the radlint heat from rone $B$, in Fig. 5 , to act on the thermoneter: Referring to Fig. 3, it will be found that only one screen, perforited in the centre, is rernined to shut out the radiant heat from the three upper zones, C, B, and $A$; while in ligg. 6 the radiation from the three lower zones, D, C, and B, is shut out by a single central screen, the circunference of which is defined by the radial lines $m, k$. It should be borme in mind that, although the sereral screens are represented by single lines in the diagram, they are, as already explained, composed of double plates, a fire-proof non-conducting substance being inserted between the two, the object of which is self-evident.

Referring to the demonstration contained in the previous chapter relating to the dininution of energy of heat-rays nojected at an acute angle to the lindiant surface, it will be seen, on mere inspection, that the upper zones represented in our diagrann, though containing an equal area with the lowel \%ones, cannot possibly transmit the same temperature at the latter. The adrocates of the views expressed in "Mécanique Céleste" will learn with surprise that, notwithstanding the absence of an intervening retanding nedium, so great is the difference of energy communicated that, white the zone I), of the experimental incandescent sphere, transmits a temperature of $42^{\circ} .5$ to the thermoneter, the zone $A$ transmits only 4.7. 'The latter zone being further from the thermometer' than the former, a correction is, however, necessinly on alcount 
of the increased dispersion of the heat-rays before reaching the bulb. 'This correction being made, the true ratio of temperature transmitted by the zones $D$ and $\Lambda$ will be $42^{\circ} .50$ : 60.19. Consequently, the heat-rinys projected from the lower zone of the incindescent sphere towards the bulb of the thermometer transmit nearly seven times higher temperature than the heat-rays firom the upper zone. 'The amount of radiant surface being alike in each zone, while the temperature of the spluere is uniform throughout, it will be atmitted that our practical test his dearly demonstrated the feebleness of the heat-riys projected from the border of an incandescent sphere towards a given point. It is hardly necessary. to add that each zone has called for a separate experiment, rendering reheating of the sphere indispensable for each. 'The same expedient has, therefore, been resorted to, in order to insure an equal legree of temperature during each experi. ment, as in the case of the incandescent inclined disc described in the previous chapter. Of conrse, it has been found impracticahle to impart an equal temperature to the sphere at ench operation; but this difficulty has been satisfactorily orercome by establishing a mean, as in detemining the intensity of the radiant leat transmitted by the inclined disc referred to. Besiltes, the result has been checked by computing the degree of temperatme capbable of being transmitted to the recording thermometer by each zone, in accordance with the relation which the intensities bear to the angles formed by the radiating surface and the heat-rays projected towards the centre of the bulb. Before griving an account of our expe- 
riments, let us demonstrate theoretically what temperature each zone ought to communicate to the thernometer, in conformity with the fact established by the experiment recorded in the preceding chapter, that the intensity of the radiant heat transmitted by an incandescent disc is directly propor. tional to the sines of the angles formed by the projected heat-rays and the radiating surface. In order to simplify the demonstration, the several zones have been diviled into halves by dotted lines (see Fig. 7 ); radial lines being drawn to the thermometer at $z$ from the points of intersection of the dotted lines referred to and the circumference of the sphere. Tangential lines, $d t, c u, b x$, and "y, have also been drawn from the said points of intersection. It will be evident, on considering the properties of spherical \%ones, that the radial lines $d \approx, c \approx b \approx$, and $a \approx$ represent the mean direction of the heat-rays projected by each zone respectively towards $z$. Hence the sines of the angles $t d z, u c z, x b z$, and $y a z$ will determine the amount of radiant heat transmitted towards z by each of the zones D, C, B, and A. Calculation shows that if the sine of the angle $t a z$ be represented by unity, the sines of the other angles, in the order presented, will be $0.671,0.384$, and 0.121 , while the experiments which have been made show that the zone $D$ transmits a temperature of $42^{\circ} .50$ to the recording thermometer. Consequently, the zones C, B, and A ought to transmit respectively 28.50 , $16^{\circ} .31$, and $5^{\circ} .16$ to the thermometer at $\approx$. The accompany. ing table shows to what extent the actual temperatures transmitted by the incandescent sphere differ from the stated 
computed temperatures. It should be observed that no direct comparison can be based upon the temperatures entered in the fourth column, since the heat-rays projected by the several zones are subjected to different degrees of dispersion, owing to the unequal distance from the thermometer. Due allowance being made for the dispersion of the rays, in conformity with the elements furnished in Fig. 7 , the consequent angmentation of temperature has been added, and the corrected values entered in the fifth column of the table. The

\begin{tabular}{|c|c|c|c|c|c|}
\hline 1 & 2 & 3 & 4 & 5 & 6 \\
\hline \multirow{2}{*}{ 总 } & $\begin{array}{l}\text { Mean angle of } \\
\text { projection. }\end{array}$ & $\begin{array}{l}\text { Comparative } \\
\text { sine. }\end{array}$ & $\begin{array}{l}\text { Observed } \\
\text { temperature. }\end{array}$ & $\begin{array}{l}\text { Corrected } \\
\text { temperature. }\end{array}$ & $\begin{array}{c}\text { Computed } \\
\text { temperature. }\end{array}$ \\
\hline & Deg. Alin. & Froportion. & - Fah. & ${ }^{\circ} F a h$ & ${ }^{\circ}$ Fah. \\
\hline D & $58 \quad 0$ & 1.000 & 42.5 & 42.50 & 42.50 \\
\hline $\mathrm{C}$ & 3440 & 0.671 & 24.2 & 27.49 & 28.50 \\
\hline B & 190 & 0.384 & 10.1 & 12.82 & 16.31 \\
\hline A & 555 & 0.121 & 4.7 & 6.19 & 5.16 \\
\hline
\end{tabular}

computed temperatures will be found in the sixth column. It will be imagined, at first sight, that the figures entered in the table indicate a serious discrepancy between the observed and the computed temperature. That such is not the case will be found on referring to Fig. 8 , in which the ordinates of the regular curve $a b$ represent the computed temperatures, while the ordinates of the irregular curve $a$ a $c$ represent the observed temperatures. Obviously, the computed and the observed, energies transmitted by the radiation of the 
incandescent sphere are truly represented by the superficies contained betreen the base f $f$ and the curves "l and a $d$ c respectively. Calculation shows that these superficies are as 1.000 to 0.945 . Considering the small anount of this dis. crepancy, in connection with the difficulty of bringing the heated sphere to an equal degree of incandescence during each experment, we are warmed in asscrting that the instituted test has proved conclusive, and that the inacuracy of the doctrine promulgaterl in "Micanique Cúleste," regard. ing the radiant energy transmitted by the rays projected from the receding surface of an incandescent splere, has been fully demonstrated. 


\title{
CHAP'TER XIIT.
}

\author{
RADIATION FRON FUSED IRON.
}

Trie illustration on Plate 25 represents a calorimeter originally constructed to demonstrate practically the fallacy of the statements contained in certain papers read before the Acadeny of Sciences at Paris by Messis. Sainte-ClaireDeville and M. E. Vicaire. These physicists assert that the temperature of the solar surface does not exceed that produced by the combustion of organic substances. Their reasoning being based on the law of radiant heat established by Dulong and Petit, I instituted, soon after the publication of the paper's referred to, a series of experiments on a very large scale, in order to test thoroughly the correctness of that law with reference to radiation at high temperatures. The nature of these experiments will be seen by the following brief description: An inon ressel, lined with fireclay on the inside, was filled with fused cast-iron obtained from a cupola furnace in which the metal had been raised to a temperature exceeding $3,000^{\circ} \mathrm{F}$. by the process of over- 
heating. On the surface of this fused mass, the reight of which exceeded 7,000 pounds, the cullorimeter represented in the illustration was floated while registering the dynamic energy dereloped by the radiant heat of the metal. Sir Isaac Newton, whose sagacity perceived that radiation with reference to mechamies is simply trimsmission of energy, assumed that the quantity of heat lost or gained by a bouly in a given time is proportional to the difference betreen its temperature and that of the surrounding medium. Some eminent scientists, horever; accepting the conclusions and formula of Dulong and Petit (see Chap. II.), assert positively that the stated assumption is incorrect. The important fact appears to have been orerlooked that the inrestigations instituted by those experimentalists have in reality established only the degree of conductivity of the radiators employed, under certain conditions, but by no means their true radiant energy at high temperatures. Sainte-Claire-Deville and Mr. E. Vicaire, therefore, commit a serious mistake in assuming that the quantity of heat transmitted by the radiation of incan. descent bodies, at very high temperatures, has been determined by their celebrated countrymen. The fact maly properly be adverted to in this place that the relation between the time of cooling and the quantity of heat transmitted by radiation which Dulong and Petit established, nisled Ponillet regarding the temperature of the solar surface, which he computed at $1,461^{\circ}$ C., or at most $1,761^{\circ}$ C. It will be well to bear in mind that Ponillet had himself ascertained with considerable accuracy the temperature produced by solar radiation on the 
surface of the enrth, and also the retardation suftered during the passage of the rays through the terrestrial atmosphere. He was, therefore, able to demonstrate that the dynimic energy developed by solar heat amounts to nearly 300,000 thermal units per minute for each square foot of the surface of the sun. Considering the imperfect means employed by Pouillet, his "pyrheliometer," the near approach to exactness of his determination of solar energy is remankable.

Temperature being a true index of molecular and mechanical energy, conclusively established by the exact relation between the degree of heat and the expansive force of permanent gases under constant volume, it is surprising that Pouillet did not perceive that an intensity of $1,461^{\circ} \mathrm{C}$. Or $1,761^{\circ} \mathrm{C}$. could not possibly develop on a single square foot of surface the enormous energy represented by 300,000 thermal units per minute. M. Vicaire, adopting, like Pouillet, Dulong's formula, states in the paper presented to the French Acadeny that "an increase of $600^{\circ}$ is sufficient to increase the radiation a hundredfold," and that Pouillet has verified Dulong's law to more than $1,000^{\circ}$. "Supposing," he observes, "that beyond this temperature the law ceases to be true, it cannot be absolutely remote from the truth for the temperatures of from $1,400^{\circ}$ to $1,500^{\circ}$, which we deduce by adopting the law." Sainte-Claire-Deville concludes his essay on solar temperature thus: "In accordance with my first estimate, I believe that this temperature will not be found far removed from $2,500^{\circ}$ to $2,800^{\circ}$, the numbers which result from the experiments of M. Bunsen and those published long ago by 
M. Debray and myself." The French soientists then angree that the temperature of the surfice of the sun does not exceed the intensity produced by the combustion of organic substances, their gromuls for this assmuption being; als we lare seen, Dulong's formula relating to the rolocity of cool. ing at high temperatmes. But 1)ulong and Petit, alpart from the inperfections of the means which they alopterl, did not carry their investigations practically beyond the temperature of boiling mercury. It will be scen, on reference to Chilp). II., that their formula redatimg to ligh temueratures is mere theory, the moomdness of which the investigation now mules. consideration has established in the nost conclusire mamer by the insignificance of the radiant power doreloped by a mass of fused netal presenting an area of 900 superficial inches, 30 inches deep, riased to a temperature of $3,000^{\circ} \mathrm{F}$.

Before describing the instrunent employed in deternining the radiant encrgy developed by the stated unprecedentedly large mass, I deen it inportant to print out briefly the condition of the fluid metal iluring the experiments. Tn the first place, the temperature was sufficiently high to produce an intense white light, luminous rays of great brilliancy being emitted by the radiant sulfuce during the trial; (2) the bulk of the fused mass being adequate, the intensity of radiation was sustained without apreciable diminution during the time required for observation. The temperature being higher than that which the French investigators assign to the surfice of the sun, while the bulk, as stated, was suflicient to minintain the temperature of the fused mass, it mily reasoniably be 
asked why an area of one square foot of our experimental luminous radiator should not emit as much heat in a given time as an equal area of the solar surface, if the temperature of the latter be that assumed by Pouillet? It is hardly necessary to observe that an increase of the dimensions of the radiating mass of metal to any extent whatever could not angment the intensity or ald to the dynamic energy developed by a given area. It his been shown in prerious chapter's that, agreeably to Dulong's crroneous formula, the emissive power of a metallic radiator raised to a temperature of $3,000^{\circ} \mathrm{F}$. considerably exceeds Pouillet's estimate of solar emission.

Let us now briefly examine the illustrated calorimeter, constructed for ascertaining the mechanical energy developed by the radiation of a fused mass of cast-iron raised to the temperature of $3,000^{\circ} \mathrm{F}$. Fig. 1 represents a rertical section, and Fig. 2 a perspective view; $a$ is a cylindrical boiler, having a flat bottom, composed of thin sheet-iron $0.012 \mathrm{in}$. thick, coated with lamp-black. The rertical part of this boiler is surrouncled by a concentric casing $b$, the intervening space being filled with a fire-proof non-conducting substance. A horizontal wheel revolving on a vertical axle d, and provided with six radial paddles attached to a perforated disc c c, is applied within the boiler. An open cylindrical trunk $g$ is secured to the perforated disc which supports the paddles. The rertical axle passes through the top of the boiler, a conical pinion being secured to its npper termination. By means of a cog-wheel h, attached to the horizontal 
axle $k$, and geared into the conical pinion, lotary motion is communicated to the paddles. The centrifugal action of the latter will obriously cause a rapid and moniform circulation of the water contained in the boiler-indispensible to prevent the intense raliant heat of the fused metal from burning the bottom. The boiles and mechanism thus iescribed are secured to a raft 7 7, composed of fire-bricks floating on the top of the fluid metal. By this means it has been found practicable to keep, the hotton of the boiler at a given distance, very near the surface of the fused mass, while, by moving the raft from print to point during the observation, irregular heating, resulting from the reduction of temperature of the surface of the metal under the botton of the calorimeter, has been prevented. The radiant heat emant. ing from such a larce borly of fused metal being too intense to admit of the axle lo being turned directly by hami, an intervening shaft of considerable length, provined with a crank-handle at the outer end, has been employed for keep. ing up the rotation of the paddle-wheel during the trial. It is scarcely necessary to mention that the intervening shaft should be coupled to the gear-work by means of a "universal joint," to almit of the necessary movement of the laft from point to point on the surface of the liquid metal. 'The experiment, repeated several times, has been conducted in accordance with the following programme: 'The boiler being charged with pure water, the paddle-wheel should be turned at a moderate speed while observing the temperature of the fluid, the thermometer employed for this purpose being 
introduced through an opening $m$ at the top of the boiler: The temperature heing ascertaned, the calorimeter should be placed on the raft as quickly as possible, and the time noted. As soon as rapor is observed to escape through the opening at $m$, the instrument must he instantly remored, the time again noted, and the temperature of the water in the boiler ascertained: It will be well to keep the paddle-wheel in motion until the last observation has been concluded.

The temperature of the fused metal haring been as high during our experiments as that of the solar surface, accord. ing to the computation of Ponillet and his follower's, while the thin substance composing the bottum of the calorimeter has been brought alnost in contact with, and consequently received the whole energy transmitted by, the radiant surface, the reader will be anxious to learn what amount of dynamic energy has been developed by the radiation of the metal in a given time on a certain area. The desired infor. mation is contained in the following brief statement: Allow. ance being made for heat absorbed by the materials composing the paddle-wheel, etc., the instituted test shows that the temperature of a quantity of water weighing 10 lbs. avoirdupois has been elevated $121^{\circ}$ F. in 164 seconds (2.73 min.), the area exposed to the radiant heat being $63 \mathrm{sq}$. in. Hence a dymamic energy $\frac{10 \times 121}{2.73} \times \frac{144}{63}=1,013$ thermal units per min. has been developed by the radiation from 1 sq. ft. of the surface of the fused metal maintained at $3,000^{\circ} \mathrm{F}$, against 300,000 units developed by the rarliation of $1 \mathrm{sq}$. ft. of the solar sur- 
face, the temperature of which, angeeably to the calculations of the French physicists, is less than that of onr experimental radiator. Comment is mmecessin'y.

Some adrocates of Dulong and Petit's theory explain the enormous discreprancy which on investigation of the radiant porer of fused metal discloses, by showing that their law relates to the relocity of conling, and not to the amount of dynamic energy parted with. That Pouillet regards the law as referring to dymamic energy is evilent, or he would not have attempted to establish by computations based upon it that an energy represented by 300,000 thermal units conld be developed in one minute upon an area of me square foot by a body whose temperature is under 1,, $00^{\circ} \mathrm{C}$. Before concluding our discussion, let us consider how Dulong and Petit's law is regarded by practical engineers, who are more interested in its infallibility than students of natural philo. sophy. Mr. Box, in his "Practical Treatise on Heat," pub. lished 1868, says, with reference to Dulong and Petit's investigations, in which he evidently places full confidence: "Dulong has given rules which agree well with experiments up to a difference of temperature of $468^{\circ} \mathrm{F}$. This rule is a very difficult one to apply, but it may be put in such a form as to give a rulio by which calculation by the simple rule may be easily corrected. The rule thus becomes: $\frac{124.52 \times 1.007 \tau^{2} \times\left(1.00 \tau \tau^{t}-1\right)}{T}=\mathrm{R}^{\prime \prime}$, in which $t=$ the temperature of the absorbent, or recipient of radiant heat; $\mathrm{T}=$ the excess of temperature of the radiating boty in degrees 
Centigrade; and $R^{\prime \prime}=$ the ratio of loss of heat under the given temperatures." The author of the "Practical Treatise on Heat" then proceeds to construct a table of temperature and ratio of loss by cooling; but before presenting the same

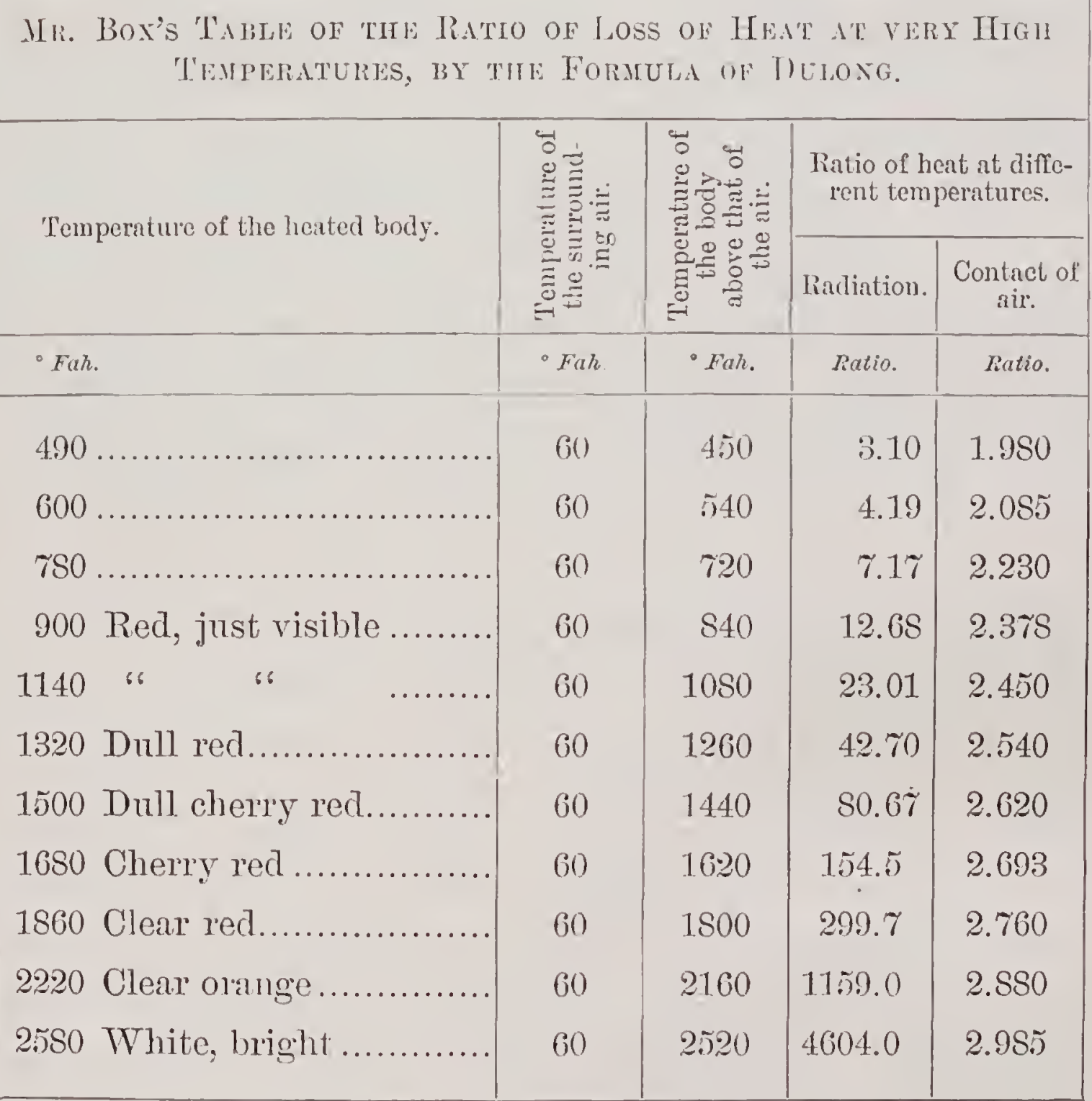

to his readers he prefixes the following observation: "This table shows that with a radiant body at a clear red-heat of $1,860^{\circ}$ the loss is about 300 ! times the amount due by the simple formula, and at a bright white-heat of 2,580 it rises 
to 4,604 !! times that amount." If any doubt existed on the subject, the author's emphatic exclamations furmish unques. tionable evidence that he is not aware of the fact that he is propagating a mischievous doctrine, and that he regards the stated extraordinary ratios as true measures of the amount of dynamic energy parted with at high temperatures.

'The fallacy of Dulong and Petit's formula relating to high temperatures having been conclusively demonstrated in Chilp. II., I have deemed it mnnecessary to examine the calculations based on that formula contained in the papers presented hy Messrs. Sainte-Claire-Deville and M. E. Vicaire to the Academy of Sciences at Paris, referred to at the commencement of this chapter. 


\section{CHAPTER XIV.}

RADIAN' HEA'T MEASURED BY THE THERMO-ELEC'IRIC MEIHOD.

MErmonr asserts, in "Lia Thermochrose," that the calorific energies imparted to a thermopile are as the ares through which the needle of the galvanometer sweeps, until the deflection exceeds 13 degrees. This assumption being at variance with the principles of dynamics, its correctness calls for a thorough investigation before it can be accepted. Intending originally to employ the thermo-electric method for ascertaining the difference of the radiant energy transmitted by the sun's rays from different portions of the solar disc, I carefully investigated the subject, and found, by experimental test, that Melloni's law is not correct. 'Theoretical demonstration pointed to the fact that, for deflections not exceeding 15 deg, the calorific energy imparted to the pile by radiant heat is rery nearly as the square root of the rersed sine of the angle of deflection from zero. It may be briefly stated that, having previously resorted to rarious 
expedients for testing roughly the reliability of the assump. tion that the energy is as the arc up to thirteen deg: deflec. tion-the result of the test in cach instance proving decidedly unfarorable to Melloni's doctrine-I undertook the construc. tion of a special apparatus for calibrating the gralvanometer applied to my thermopile. By means of this apparatus the energy developed for different deflections of the needle from zero to 35 deg. has been accurately determined. Before describing the new derice, it will be proper to examine

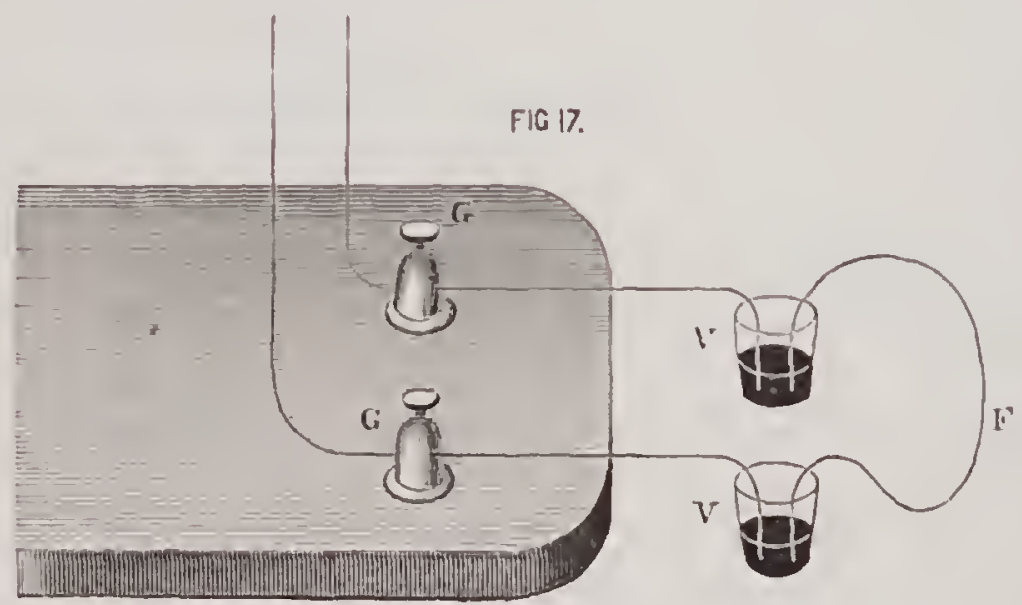

Melloni's method of calibrating galvanometers, described in the work referred to; especially since its supposed correct. ness has induced sereril eminent physicists to accept the assumption that the energies are as the ares swept by the needle from zero to 13 deg. Aeflection. "Two ressels V V (see Fig. 17) are lialf filled with quicksilver, and connected by two short wires, separately, with the terminations $G G$ of the galvanometer. The ressels and wires, arranged as shown, will not change the action of the instrument; the thermo-electric current between the pile and the galvano. 
meter being freely kept up as before. But if we establish a communication between the two ressels by means of the wire $\mathrm{F}$, a portion of the current will pass through this wire and then return to the pile. 'The quantity of circulating electricity in the galvanometer will then be diminished, while the deffection of the neelle will be reduced. Suppose that by this experlient we hare diminished the galvanometric deriation to one-fourth or one-fifth-vi\%, that the needle indicating $10 \mathrm{or} 12$ degrees, by the power of a constant sounce of heat located at a griven distance from the pile, recerles 2 or 3 degrees when part of the current is diverted by the outside wire. If we then canse the source of heat to act at various distances, and observe in each case the maximum deflection and the least deflection, we obtain the necessary data for determining the ratio between the deflection of the needle and the energy causing that deflection. To make the matter better understood, and to give at the same time an example of the manner of operating, let us take the numbers bearing on the application of the method to one of the thermo-multipliers. Let the outside circuit be interrupted, and the source of heat located at an adequate distance from the pile to deflect the needle not more than 5 degrees. The wire being then passed from $T$ to $V$, the needle falls to 1.5 ; the connection between the vessels being again interupted, and the source of heat placed near enongh t) produce the following deflections in succession: $5^{\circ}, 10^{\circ}, 15^{\circ}$, $20^{\circ}, 25^{\circ}, 30^{\circ}, 35^{\circ}, 40^{\circ}, 45^{\circ}$. Applying the same wire between $V$ and $V$ after each deflection, we obtain the following ener- 
gies : $1^{\circ} .5,3^{\circ}, 4^{\circ} .5,6^{\circ} .3,8^{\circ} .4,11^{\circ} .2,15^{\circ} .3,22^{\circ} .7,29^{\circ} .7$. Sup. posing the energy equal to unity which is necessary to cause the needle to describe ares corresponting with each of the first degrees of the galvanometer, we then have the number 5 as an expression of the cueroy corresponding to the initial observation. The other energies are rearlily ascertained by the relations: $1.5: 5=x=\frac{5}{15} a=3.338$, where a indicates the deflection when the outside cirenit is closed. Obrionsly, any diminished current is to the total current to which it corresponds as any other chinimished current to its corre. sponding total current. Hence, 5, 10, 15.2, 21, 28, and 37.3 are the energies corresponding to the deflections is, 10,15 , $20^{\circ}, 25^{\circ}$, and $30^{\circ}$. In this presentation it will be seen that the energies are nearly proportional to the ares 11 ) to about 15 degrees; but beyond this deflection the proprortionability is at an end, the discrepancy allgmenting with the ares." The energies at intermediate degrees, it is stated, are readily ascertained by calculation or by the graphic method, the latter being assumed to be sufficiently precise for the purpose. The accompanying table exhibits the corresponding deflections and energies deternined by Melloni in accordance with the foregoing demonstration :

The constructor of the table observes that no notice has been taken of deflections under 13 deg., since the energies within that deflection are, as he supposes, correctly repre. sented by the ares swept by the needle. It is hardly necessary to call attention to the unsatisfactory natme of the fore- 
going method of returning part of the electric current by the wire $F$, for the purpose of ascertaining the calorific energies imprated to the pile by the radiant heat emanating from the radiator. Unless we adopt some positive means of measuring the intensity of the heat to which the face of the pile is subjected at the instant of observing the deflection

\begin{tabular}{|c|c|c|c|c|c|}
\hline \multicolumn{6}{|c|}{ 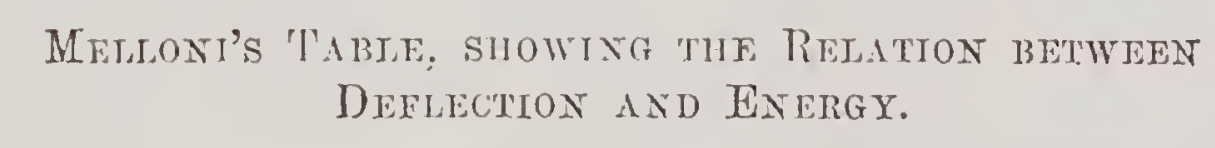 } \\
\hline 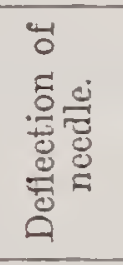 & 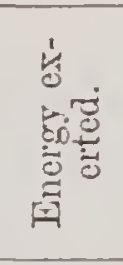 & 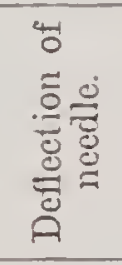 & 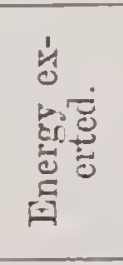 & 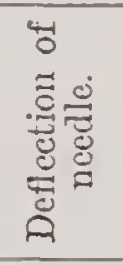 & 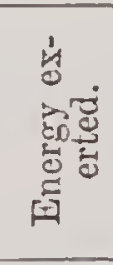 \\
\hline 13.0 & 13.0 & 19.0 & 19.8 & 25.0 & 28.0 \\
\hline 14.0 & 14.1 & 20.0 & 21.0 & 26.0 & 29.7 \\
\hline 15.0 & 15.2 & 21.0 & 22.3 & 27.0 & 31.5 \\
\hline 16.0 & 16.3 & 2200 & 23.5 & 28.0 & 33.4 \\
\hline 17.0 & 17.4 & 23.0 & 24.9 & 29.0 & 35.3 \\
\hline 18.0 & 18.6 & 24.0 & 26.4 & 30.0 & 37.3 \\
\hline
\end{tabular}

of the needle of the galvanometer, the relation of deflection and calorific energy cannot be accurately determined. Now, the demonstration contained in Chap. I. proves that the intensity of radiant heat transmitted through a given space by a circular radiator of known dianeter and temperature may be determined with positive accuracy. Accordingly, the methor of calibrating galvanoneters, which I am going to lay before the reader, is based on the stated demonstration proving that a correct knowledse of form, distance, anr? temperature of 
the radiator enables us to ascertain, with absolute precision, the degree of calorific energy imprirted to the thermu-electric pile during the investigation. The following brief descrip. tion of the apparatus represented by our illustration (see Pl. 26) will suffice to give a clent idea of the simne: t, table laving a longitudinal parallel groove, 6 ins. wide, 2 ins. deep, formed on the top. l, sliting wooden block, 12 ins. square, $1 \frac{1}{2}$ ins. thick, provided with a parallel projection below cor. responding with the groore in the table, and actmitting of the block sliding freely from end to end. A vertical pliate $s, 20$ ins. high, 12 ins. wide, is secured to the sliding loluck. p) repuresents a thermo-electric pile placed on the top of the table. The verticul plate s is perforated in the centre, for the purpose of supporting a cylindrical boiler r, 4 ins. in dianneter, provided with an open trunk on the top, through which a thermometer is inserted. The end of this boiler' pointing towads the pile is concave, while the opposite end is flat; a spinit-lanp being applied under the same, supported by the sliding bluck b. A scale, divided into 100 parts of one inch each, is attached to the side of the table, the zero of this scale coinciding with a perpendicular line drawn from the face of the thermo-electric pile $p$. The extreme point of the concavity of the boiler $\mu$ being in line with the front side of the plates, while the rero of the scale, as stated, is in line with the fiace of the pile, it will be seen that the distance thrungh which the radiant heat acts may be regulated by simply moving the sliding block to any desired division on the scale. 1 metallic screen $s^{\prime}$, 
20 ins. high, 12 ins. wide, plated with polished silver, is attached to the verticial plate s, in order to prevent the ratiant heat of the latter from acting on the thermo-electric pile. The metallic screen is provided with a central pertoration, 4 ins. in dianeter, the centre of which coincides with the prolongation of the axis of the cylindrical boiler. Regarding the temperature of the latter, it will be seen that, by applying the spinit-lamp, as already stated, the water may be kept constantly at the boiling point, since any excess of heat above that point will be carried off by the steam allowed to escape through the open trunk which contains the thermometer. Accordingly, the thermo-electric pile $p$ will at all times be subjected to a definite radliant intensity depending on its distance from the radiator $r$; while the graduated scale attached to the side of the table $t$ enables the experimenter to regulate that distance rapidly and accurately. In accordance with the law governing the transmission of leat, before referred to, the temperature imparted to the thermo. electric pile $p$ will bear the same relation to the differential temperature of the boiler as the square of the radius of the semi-spherical end of the latter bears to the square of the distance of the same from the face of the pile. Consequently, when the boiler is placed as shown in the illustration, the temperature transmitted by radiation may be ascertained by the following calculation: Assuming that the thermometer inserted through the open trunk at the top of the boiler indicates $212^{\circ} \mathrm{F}$, and that the tepmerature of the surround. ing air is $70^{\circ} \mathrm{F}$, the intensity of the radiant heat emanating 
from the woiler will be $212-70=142^{\circ} \mathrm{F}$. Now, as the position of the block $b$ is such that the concavity $r$ conincides with the juth division on the scale, the distance between the face of the pile and the ratiating surface will be 50 inches, while the radius of the concarity is 2 inches. The temperature inparted by the ratliation emanating from the boilel will, therefore, amount to $\frac{2^{2} \times 142}{50^{2}}=0^{\circ} .227 \mathrm{~F}$. The calorific energy transuitted by the radiator at all other distances may of course be determined by a similar prucess of computation. Having theoretically deternined the intensity of the radiant heat for each division on the scale, the existing relation between the doflection and the computed energy will be ascertained simply by observing the corresponding position of the needle of the galramoneter. Our task, howerer, is that of ascertaining the calorific energy corresponding with arcs not of varying length swept by the needle of the galvanometer, but arcs each neasuring $\frac{1}{36} 0$ of a circle commencing at the galvanometric zero. Evilently, ares and energies are not directly comparable; hence, we must ascertain, experimentally, what calorific energy corresponds with the first degree, or the first lialf degree, of deflection of the needle from zero. It has already been stated that the radiant energy enanating from the concave face of the boiler is $142^{\circ} \mathrm{F}$. when the temperature of the surrounding air is $70^{\circ} \mathrm{F}$. Hence, agrecably to the foregoing process of calculation, the temperature imparted to the pile when the boiler is placed at the extreme end of the scale-riz, 100 inches from the face of the pile 
-will be $\frac{2^{2} \times 142}{100^{2}}=0^{\circ} .057 \mathrm{~F}$. Now, such are the proportions of the illustraten apparatus that, when the differential fomperature of the boiler is $142^{\circ} \mathrm{F}$. and the concare face of the boiler coincides with the 100th division of the scale, the deflection of the neelle is 30 ' from zero. 'The foregoing demonstrations and reasoning being deemed sufliciently explatmatory, we may now consider the diagram attached to the illustration, Plate 26. The length of the ordinates of the curves $b f^{\prime}$ and $b$ d represcnt the relation between the encrgies imparted to the pile and the ares swept by the needle; the figures marked on the rertical base-line a c denoting the degrees of deflection from Eero. In other words, the ordinates of the curve $b$ d show the observed deflections for anch degree from zero, while the ortinates of the curve of show the dereloped energy. It will he seen, therefore, that the portions of the ordinates which are contained between the two curves represent the excess of developed energy above that of the observed deflection. Considering that the length of the ordinates of the curve $\delta$ of have been determined in accordance with the well-established laws goreming the tramsmission of radiant heat, while the length of the ordinates of the curve $b d$ is the result of actual observation, the correctness of the ascertained relation camnot be questioned. Consequently, a mere inspection of the diagram suffices to show the fallacy of Melloni's assmmption that, within a deflection of 13 degrees. the arc swept by the needle and the encrgy imparted to the pile correspond exactly. Obviously, by comparing the inter- 


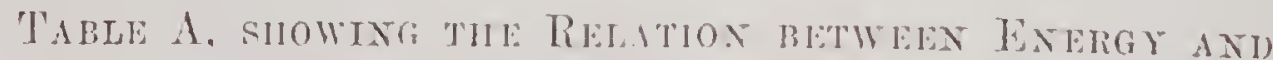

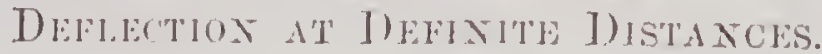

\begin{tabular}{|c|c|c|c|c|c|c|c|}
\hline 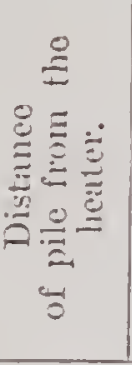 & 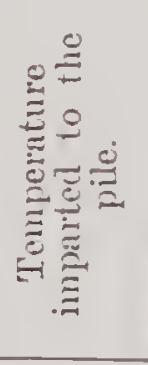 & 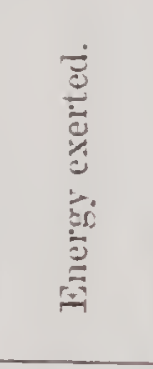 & 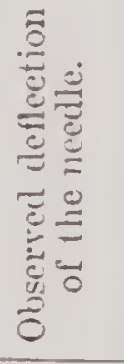 & 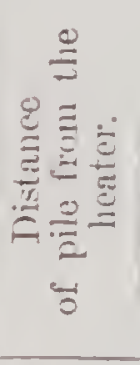 & 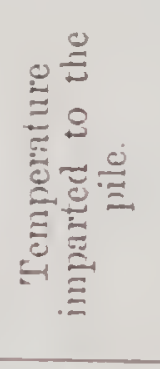 & 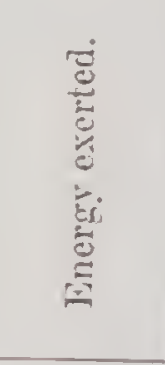 & 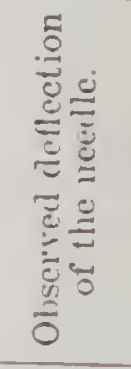 \\
\hline Inches. & ${ }^{\circ}$ Filh. & Relutire. & Deg. & Inches. & 'Filh. & Relative. & Deg. \\
\hline 100 & 0.057 & 0.50 & 0.50 & 34 & 0.491 & 4.31 & 3.80 \\
\hline $9 \tilde{5}$ & 0.063 & $0.5 \%$ & 0.60 & $3: 3$ & 0.521 & 4.58 & 4.00 \\
\hline 90 & 0.070 & 0.61 & 0.70 & $: 32$ & $(0.505$ & 4.87 & 4.30 \\
\hline 8.) & 0.078 & 0.68 & 0.80 & 31 & 0.591 & ธ. 19 & 4.60 \\
\hline So & $0.08 S$ & 0.77 & 0.90 & 30 & 0. $6: 31$ & 5.54 & 4.90 \\
\hline 7.) & 0.101 & 0.88 & 1.00 & 29 & (0.67i) & 5.92 & 5. 30 \\
\hline 71$)$ & 0.116 & 1.01 & 1.10 & 28 & 0.724 & 6.36 & 5.60 \\
\hline 65 & 0.1334 & 1.17 & 1.20 & 27 & 0.779 & 6.84 & 6.00 \\
\hline 60 & 0.158 & 1.38 & 1.40 & 26 & 0.840 & 7.37 & 6.40 \\
\hline $5 \tilde{5}$ & 0.188 & 1.64 & 1.60 & 25 & 0.909 & 7.98 & 6.90 \\
\hline ก) & 0.227 & 1.99 & 1.80 & 24 & 0.986 & 8.60 & 7.30 \\
\hline 49 & 0.236 & 2.07 & 1.90 & 23 & 1.073 & 9.42 & 8.00 \\
\hline 48 & 0.246 & 2.16 & 2.00 & 22 & 1.173 & 10.30 & 8.90 \\
\hline 47 & $0.25 \%$ & 2.26 & 2.10 & 21 & 1.2SS & 11.30 & 9.90 \\
\hline 46 & 0.268 & 2.35 & 2.20 & 20 & 1.420 & 12.46 & 10.90 \\
\hline $4 \overline{5}$ & $0.2 \mathrm{~S} 0$ & 2.40 & 2.30 & 19 & $1.57: 3$ & 13.80 & 12.00 \\
\hline 44 & $0.29: 3$ & $2.5 \pi$ & 2.40 & 18 & $1.7 \% 3$ & 15.38 & 13.10 \\
\hline 49 & 0.307 & 2.69 & 2.50 & $1 \%$ & $1.96 \%$ & 17.24 & 14.40 \\
\hline 42 & 0.322 & 2.82 & 2.60 & 16 & 2.219 & 19.46 & 16.30 \\
\hline 41 & 0.338 & 2.96 & 2.70 & $1 \pi$ & 2.525 & 22.14 & 18.50 \\
\hline 40 & $0.36 \tilde{9}$ & 3.11 & 2.90 & 14 & 2.8.8 & 25.42 & 20.40 \\
\hline 39 & 0.373 & 3.27 & 3.00 & 13 & 3.361 & 29.48 & 23.00 \\
\hline 38 & 0.3993 & 3.45 & 3.110 & 12 & 3.944 & $: 34.59$ & 25.90 \\
\hline $3 \%$ & $0.41 \%$ & 3.64 & 3.10 & 11 & $4.69 t$ & 41.18 & $2 !) .00$ \\
\hline 36 & 0.439 & $3.8 \%$ & 3.30 & 10 & 5.680 & 49.82 & 32.00 \\
\hline 35$)$ & 0.464 & 4.07 & 3.50 & 9 & 7.012 & 61.51 & $3 \% .00$ \\
\hline
\end{tabular}


rening space between the curves $b d$ and $b f$ on the 13 th ordinate, and the length of that ordinate between the base-line $a c$ and curve $b d$, we obtain a definite idea of the magnitude of the error inrolved in Melloni's doctrine that deflection and energy correspond until the position of the needle marks thirteen degrees from zero. It is important to observe that a scale, corresponding with the scale of inchos marked on the side of the table represented in the illustration, has been introduced parallel with the rertical base-line $a$ o in the diagram. This expedient enables us to make a direct comparison betreen the position of the concave radiator and the deflection of the needle of the galvanometer, marked on the rertical base-line $4 c$. It will be seen, for instance, that, when the deflection of the needle is 35 degrees, the radiator is placed 9 inches from the face of the pile.

Let us now consider briefly the mamer of conducting the experiments which have enabled us to construct the diagram referred to and the accompanying table $A$. The deffections of the needle of the galvanometer and the energies inparted by radiation to the pile beyond the 50th division being very small, the observations between that division and the termination of the scale have been confined to spaces of 5 incles each, as will be seen on reference to the table nentioned. But from the 50th to the 9th division the observations have been made for each inch. Accordingly, 41 distinct experiments were instituted while adrancing the boiler from the fiftieth to the ninth division of the scale attached to the side of the table. It is important to mention that, in order 
to allow the pile to cool effectually, the sliding block b, together with the boiler and sereens s and s', were remored into an adjoining loom, and the needle of the gallanometer brought to perfect rest at zero, for each obserration. It may be mentioned that the final investigation was carried out under rery farorable conditions, the tenuperatine of the surrounding air fluctuating so slightly that the differential tem. perature of the boiler did not vary one degree during the experiment. 'The mole of constructing 'T'able A, which exhibits the relation between energy and deflection at definite distances, will be readily understood. The distance butween the concare radiator and the face of the pile, it will be seen, has been entered in the first colmmn, while the tempe. rature transmitted to the pile by radiation has been entered in the second column. The determination of the temperature referred to is effected by the following simple arithnetical process: Multiply the square of the radius of the concare surfice $r$ by the difterential temperature of the boiler, and divide the prodnct by the square of the distance between the radiator and the pile; the quotient-entered in the second column of the table-expresses the intensity transmitter to the pile by the heat emanating from the radiator. For example, the intensity of the transmitted radiant heat, at a distance

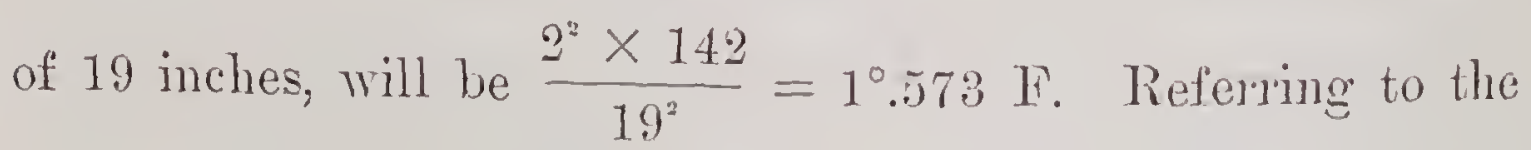
table, it will be found that the temperature thus ascertained is recorded in the second column, opposite the distance 19 entered in the first column. The mode of ascertaining the 
temperature transmitted by the radiator to the thermo-electric pile at each point of the scale being thus fully explained, let us now consider the relative amount of energy repre. sented by the temperature entered in the second column of our table. It has already been pointed out that the tempe. rature imparted to the pile by the radiant heat, and definite arcs-say degrees-swept by the needle of the galvanometer, are not comparable quantities; hence cannot be determined by calculation. We must therefore, as already pointed out, have recourse to the experimental process in ascertaining the relation of the temperature transmitted and the deflection of the needle when the radiator is at maximum distance from the thermo-electric pile. Repeated trials have shown that, when the radiator is placed at a distance of 100 inches from the face of the pile, the ratio between the deflection of the needle-measured by ares containing $\frac{1}{360}$ of a circle; and the temperature transmitted to the pile-measured by degrees of Fahrenheit, is as 0.50 to 0.57 . The energies inserted in the third column of the table have been determined in accordance with the stated relation of temperature and deflection of the needle of the galvanometer, while the deflections of the needle entered in the fourth column have been determined by observation. It will be seen, by inspecting the latter, that the energ! exceeds that indicated by the deflection of the needle, for all distances between the 55th division on the scale and the pile; the energy at that point being 1.64, while the defiection is only 1.60. Between the 100th and 60th divisions of the scale the observed deflec- 
tions, it will be noticed, are irregular, slightly exceeding the energies. This irregularity is occasioned by the sensitiveness of the instrument when the radiator is far from the pile. It only remains to call attention to Table $B$, exhibiting the final result of our elaborate inrestigation of the thermo-electric

\begin{tabular}{|c|c|c|c|c|c|}
\hline 'TABIE B & \multicolumn{3}{|c|}{$\begin{array}{l}\text { THE ReLation } \\
\text { AND Exergy. }\end{array}$} & \multicolumn{2}{|c|}{ DEFLECTIOS } \\
\hline $\begin{array}{l}\text { Deflection of } \\
\text { needle. }\end{array}$ & $\begin{array}{l}\text { Energy ex- } \\
\text { erted. }\end{array}$ & $\begin{array}{l}\text { Deflection of } \\
\text { necdle. }\end{array}$ & $\begin{array}{l}\text { Energy ex- } \\
\text { erted. }\end{array}$ & $\begin{array}{c}\text { Deflection of } \\
\text { needle. }\end{array}$ & $\begin{array}{l}\text { Energy ex- } \\
\text { erted. }\end{array}$ \\
\hline Deg. & Relative. & Deg. & relative. & Deg. & Relatice. \\
\hline 1 & 0.89 & 13 & 15.28 & 25 & 33.07 \\
\hline 2 & 2.17 & 14 & $16.5 \mathrm{~S}$ & 26 & 35.00 \\
\hline 3 & 3.38 & 15 & 17.90 & 27 & $3 \% .05$ \\
\hline 4 & 4.59 & 16 & 19.24 & 28 & 39.24 \\
\hline 5 & 5.77 & 17 & 20.60 & 29 & $41.5 \mathrm{~S}$ \\
\hline 6 & 6.86 & 18 & 21.98 & 30 & 44.20 \\
\hline 7 & 8.00 & 19 & 23.39 & 31 & 47.00 \\
\hline$S$ & 9.15 & 20 & 24.84 & 32 & 50.00 \\
\hline 9 & 10.33 & 21 & 26.34 & 33 & 53.30 \\
\hline 10 & 11.53 & 22 & 27.90 & 34 & 57.00 \\
\hline 11 & 12.75 & 23 & 29.53 & 35 & 61.23 \\
\hline 12 & 14.00 & 24 & 31.25 & & \\
\hline
\end{tabular}

method of measuring radiant heat. It will be seen, on carefully examining this table, that the deflection of the needle of the galvanometer at the termination of the first degree excects the energy transmitted by the radiator towards the thermoelectric pile in the ratio of 100 to 89 , difference $=0.11$; 
an unimportant irregularity already adverted to. Beyond 90' from zero the energy becomes greater than the deflection in a constantly increasing ratio as the ares swept by the needle angment. Accorlingly, when the needle has mored through an are of 13 degrees, the energy is greater than the deflection in the ratio of 15.28 to 13.00 , instead of being exactly balanced, as stated by Melloni. 


\section{CHAPTER XV.}

THE THERMOHELIOME'TER.

THe calculations presented by Pire Secchi in his work "Le Soleil," relative to the intensity of solar radiation and the temperature of the sun, being based on the indications of his thermolieliometer, I have carefully examined the pro. perties of this unique device, delineated on page 267 of the work referred to. The accompanying illustration (see Fig. 1) represents a longitudinal section of the same through the vertical plane. A B and C D are two concentric cylinders soldered one to the other; they form a kind of boiler, the annular space being filled with water or oil at any temperature. A thermometer $t$ passes through a tube, across the amnular space, to the axis of the cylinder; it receires the solar rays introduced through a diaphragm $m n$, the opening $o$ of which is rery little larger than the bulb of the thermometer. A thick glass $v$ closes the back part of the instrunent, and admits of ascertaining whether the thermometer is placed in a direct line with the pencil of rays. 'The interior cylinder 
and the thermometer $t$ are coated with lamp-black. A second thermoneter $t^{\prime}$ shows the temperature of the annular space, and consequently that of the enclosure. 'The whole appantus is mounted on a support having a parallactic morement, to facilitate following the dimnal motion of the sum. 'The alpraratus being exposed to the sun, it will be found, on observing the two thermoneters, that their difference of temperature incleases gradually, and that in a short time it ends by being constant.

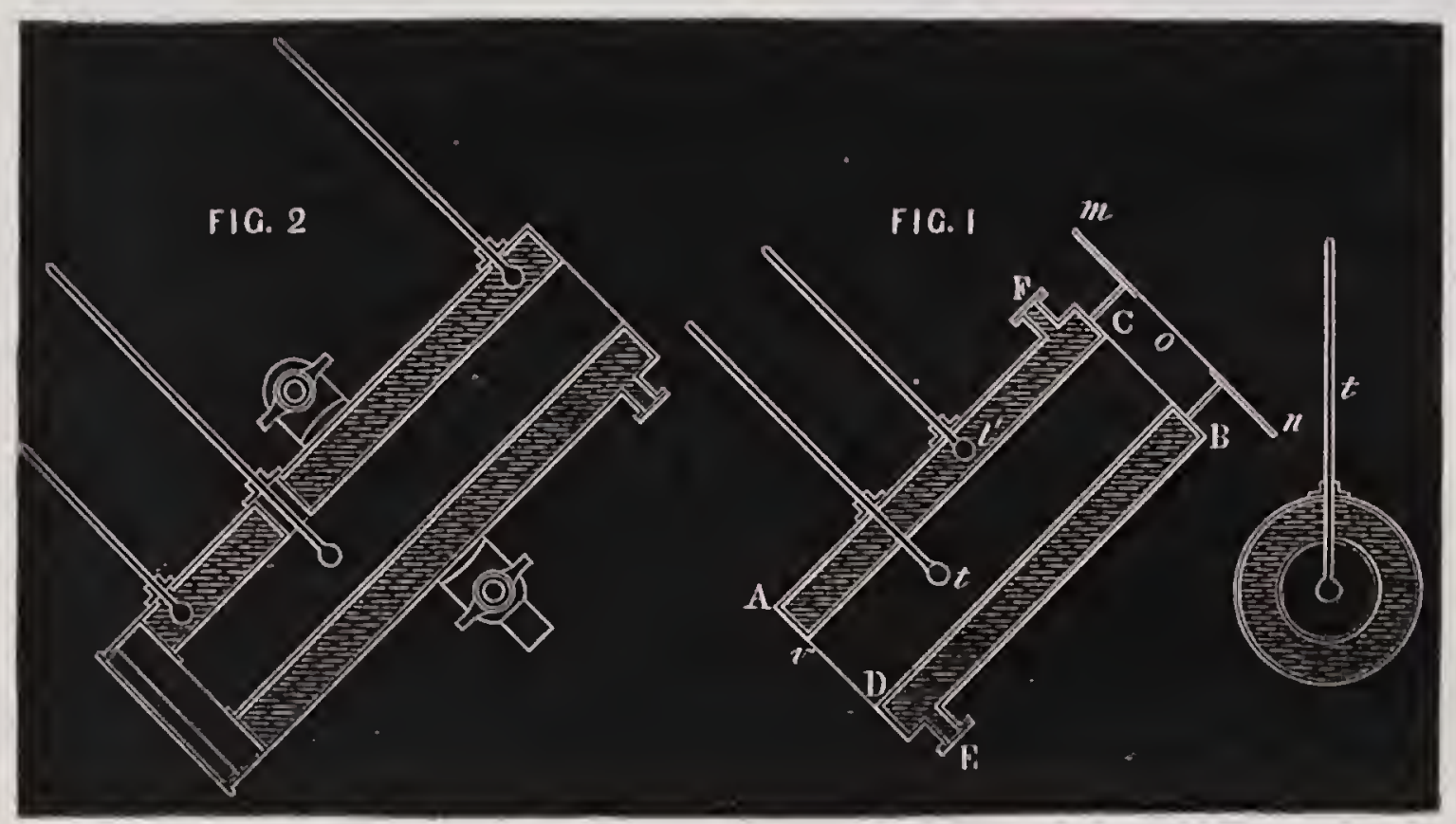

Before pointing out the peculiaritres of the contrivance thus described by Pìre Secchi, it will be instructive to examine his "solar intensity apparatus," manufactured by Casella, represented in Fig. 2. 'The manufacturer publishes the following statement regarding this instrument: "Two thermometers are here kept inmersed in a fluid at any temperature, and a third smromded hy the same conditions, but not immersed, is exposed to the rays of the sun. The 
increase of temperature thus obtained is found to be the same, irrespective of the temperature of the fluid which sur. rounds it." No one accuainted with the principles which gorem the transmission of heat within circulating fluids can fail to observe that the thermometers applied above the central tube will not furnish a reliable inclication of the temperature of the fluid below the sinne, nor of any portion of the contents of the anmular space townds the bottom. Apart from this defect, it will be percered that an upward current of atmospheric air will sweep the under side of the external cylinder, causing a reduction of temperature of the fluid confined in the lorrer half of the ammular space. Again, the heat radiated by the bulb of the thermometer exposed to the sun will elevate the temperature of the air within the central tube, and consequently produce an internal circulation tending to heat the upper part of the fluid contained in the ammular space. The effect of the irregular heating' and cooling thus adrerted to will be considered after an exanination of the result of some observations recorded in Tables A and $B$, which I conducted at different times during the month of September, 1871. In order to insure an accurate position, the instrument during these observations was mounted in a revolving observatory upon a table tuming on declination axes provided with appropriate mechanism and declination circle. An actinometer being attached to the same table, the true intensity of the radiant heat, as well as the sun's zenith distance, were recorded simultaneously with the indications of the Secchi instrument funished 


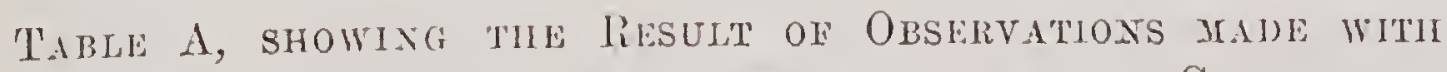
Secchl's 'T'hermohelioneter, mayuactured by Casella.

SEPTEMBER 2.

\begin{tabular}{|c|c|c|c|c|c|}
\hline \multirow{2}{*}{ 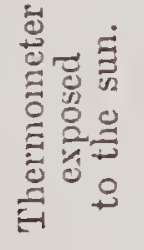 } & \multicolumn{3}{|c|}{ External casing. } & \multirow{2}{*}{ 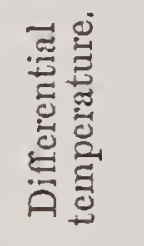 } & \multirow{2}{*}{ 总 } \\
\hline & $\begin{array}{c}\text { Upper } \\
\text { thermometer: }\end{array}$ & $\begin{array}{c}\text { Lower } \\
\text { thermometer. }\end{array}$ & Mean. & & \\
\hline${ }^{\circ} F a h$. & - Fah. & - $F a \hbar$. & - $F a \hbar$. & - Fah. & Deg. \\
\hline 83.5 & 76.0 & 70.0 & 73.0 & 10.5 & 33.0 \\
\hline 84.2 & 77.0 & 71.5 & 74.2 & 10.0 & \\
\hline S5. 5 & 79.0 & 74.2 & 76.6 & 8.8 & 32.50 \\
\hline 86.0 & 83.5 & 74.5 & 79.0 & 7.0 & \\
\hline 89.0 & 84.0 & 75.5 & 79.7 & 9.2 & 33.0 \\
\hline 90.5 & S5. 0 & 76.5 & 80.7 & 9.7 & \\
\hline 92.0 & 85.5 & 78.0 & 81.7 & 10.2 & 33.10 \\
\hline 93.0 & $S 6 . \tilde{5}$ & 79.0 & 82.7 & 10.2 & \\
\hline 94.0 & 87.8 & 80.0 & 83.9 & 10.1 & 33.21 \\
\hline 94.5 & 89.0 & 81.5 & S5̃.2 & 9.2 & \\
\hline 95.5 & 90.0 & S2.5 & 86.2 & 9.2 & 33.32 \\
\hline 96.5 & 90.5 & 83.5 & 87.0 & 9.5 & \\
\hline 98.0 & 91.5 & S4.5 & 88.0 & 10.0 & 33.44 \\
\hline 99.0 & 92.0 & 85.0 & SS.5 & 10.5 & \\
\hline 100.0 & 93.0 & 86.0 & S9.5 & 10.5 & 33.56 \\
\hline 101.0 & 93.5 & 86.5 & 90.0 & 11.0 & \\
\hline 101.5 & 94.0 & 87.0 & 90.5 & 11.0 & 34.8 \\
\hline 93.1 & 86.9 & 79.7 & 83.3 & 9.80 & 33.24 \\
\hline
\end{tabular}




\begin{tabular}{|c|c|c|c|c|c|}
\hline \multicolumn{6}{|c|}{ 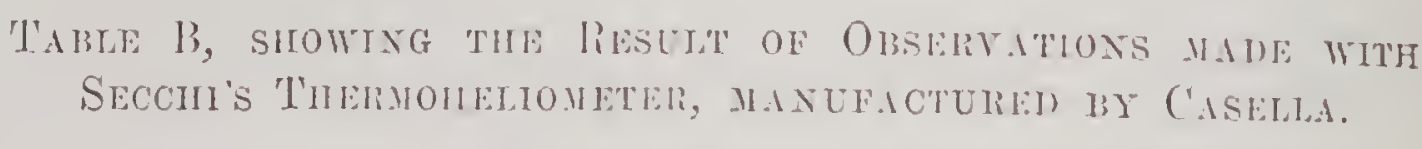 } \\
\hline \multicolumn{6}{|c|}{ SEPTLUBER 6.} \\
\hline \multirow{2}{*}{ 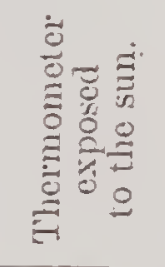 } & \multicolumn{3}{|c|}{ External casing. } & \multirow{2}{*}{ 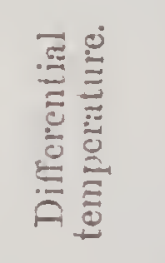 } & \multirow{2}{*}{ ב怘 } \\
\hline & $\begin{array}{c}\text { Upper } \\
\text { thermoneter. }\end{array}$ & $\begin{array}{c}\text { Lower } \\
\text { thermometer. }\end{array}$ & Мсан. & & \\
\hline 'Fah. & ${ }^{\circ} F a h$ & 'Fah. & 'Fah. & ' Futh. & $D i g$. \\
\hline 94.5 & SS.0 & $81 .)$. & 84.8 & 9.7 & 3.5 .66 \\
\hline 95.5 & SS.5 & S3.0 & 8.1 .7 & 0.7 & \\
\hline 96.5 & S9.5 & 84.5 & 87.0 & 9.5 & $3 . \% .41$ \\
\hline 97.5 & 90.0 & S.).0 & S\%.j & 10.0 & \\
\hline 98.0 & 90.0 & S.).0 & 87.5 & 10.5 & 3.5 .26 \\
\hline 98.5 & $90 . \tilde{5}$ & $8.5 . \tilde{5}$ & SS.0 & $1(1.5)$ & \\
\hline 99.0 & $90 . \tilde{5}$ & 8.5 .7 & SS. 1 & $1(1.9$ & 3.7 .11 \\
\hline 100.0 & 91.0 & 86.5 & 88.7 & 11.2 & \\
\hline 100.3 & 91.0 & Sั.0 & 89.0 & 11.3 & 34.56 \\
\hline 100.3 & 91.2 & 87.5 & 89.3 & 11.0 & \\
\hline 100.5 & 91.5 & SS.0 & 89.7 & $10 . \mathrm{S}$ & 34.41 \\
\hline 98.2 & 90.1 & 8.5 .3 & 87.7 & $10.4 \tilde{5}$ & 35.33 \\
\hline \multicolumn{6}{|c|}{ SEPTEMBER $2 \%}$. \\
\hline 78.5 & 64.0 & 64.0 & 64.0 & 14.5 & 44.0 \\
\hline 79.0 & 65.0 & 64.0 & $6+.5$ & 14.5 & \\
\hline 79.5 & 65.0 & 64.5 & 64.7 & 14.7 & 44.55 \\
\hline 79.5 & 63.0 & 65.0 & 64.0 & 15.5 & \\
\hline 79.5 & 61.0 & 65.0 & 64.5 & 150 & 45.51 \\
\hline 79.0 & 04.5 & 6.5 .0 & 64.7 & 14.2 & \\
\hline 79.0 & 64.5 & 6.5 .5 & 65.0 & 14.0 & $46.4 \mathrm{~S}$ \\
\hline 79.0 & 64.5 & 0.5 .5 & $6 \tilde{5} .0$ & 14.0 & \\
\hline ช9.0 & 65.0 & (6.). .5 & (6.). 2 & 13.8 & 47.46 \\
\hline 79.1 & 64.4 & 64.9 & 64.65 & 14.45 & 46.16 \\
\hline
\end{tabular}


by Casellat. Let us finst consider the tabulated observations of September 2, recorded at equal intervals of three minutes. The indication of the two thermometers immersed in the fluil contained in the amnular space first clains our attention, since the temperature of this fluid is the principal element in

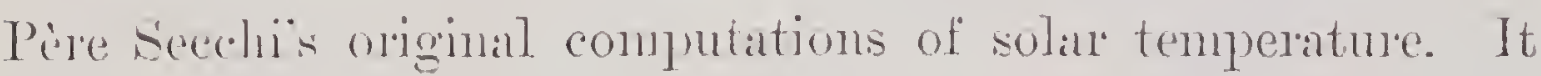
will be seen, on referring to the second and thind columns of the table, that, while the unper thermoneter indicates a mean temperature of $86^{\circ} .9$, the lower one shows only $59^{\circ} . \bar{x}$, difference $=r^{\circ} .4$. This great discrepancy of temperature at different points of the urper portions of the amular space at which, owing to the inclined position of the concentric tubes, something like uniformity ought to exist, suggests a still greater discrepancy of temperature at the under side fowards the lower temination of the tubes. In addition, therefore, to the observed irregularity of temperature at the "pper part, shown by the table, no indication whatever is furnished of the temperature of the fluid in the ammlar space below the central tube, nor towards the ternination at either side. Obrionsly, then, no accurate computation can be made of the degree of refrigeration to which the centual thermometer is exposed by the radiation from the cold blackened surface of the intermal tube, crery part of which, as we have seen, possesses a different temperature compared with the rest, consequently transmitting ladiant eneroy of different intensity. It will be found practically impossible, therefore, to determine the true differential temperature of the contents of the bulb exposed to the sun's 
rays and the fluid contained in the anmular space. Hence, the differential temperature entered in the table, the result of comparing the indications of the themometers, is mani. festly incorrect. It will be found, also, by reference to Table A, that, while the mean temperature imprated to the central thermometer by the sun's rays is $93^{\circ} .1$, the mean temperature of the fluid in the amnular space is $83^{\circ} .3$. Con. sequently, the intensity of solar radiation established by the instrument is only $93^{\circ} .1-83^{\circ} .3=9^{\circ} .80 \mathrm{~F}$. Now, the sum during the recorded experiment of September 2 was excep. tionally clear, the mean indication of the actinometer while the experiment lasted being $60^{\circ} .05$, thus showing that the energy developed was only $\frac{9.80}{60.05}=0.16$ of the true radiant intensity. The mean zenith distance, it may be mentioned, was only 33 deg. 24 min. during the experiment. Agree. ably to the table of temperatures (see Chap. III.), the maximum solar intensity for the stated zenith distance is $63^{\circ} .35$; thus we find that the sun, as stated, was exceptionally cleal while the trial took place, which resulted in dereloping the trifling intensity of $9^{\circ} .80 \mathrm{~F}$. The result of the experiments condricted September 6, recorded in Table B, it will be seen, was nearly the same as that just referred to, the moan temperature indicated by the thermometer exposed to the sun being $98^{\circ} .2$, while the mean of the two thermometers immersed in the fluid was $8 r^{\circ} .7$; hence the differential tenperature $98^{\circ} .2-8 r^{\circ} .5=10^{\circ} .45$. The mean temperature of solar radiation during the experiment, ascertained by the 
actinometer, was $59^{\circ} .75$, the zenith distance being 35 deg. 33 min. Consequently, the intensity indicated September 6 was only $\frac{1.0 .45}{59.55}=0.15$ of the true energy of the sun's radiant heat, against 0.16 during the previous experiment. It will be observed that the fluctuation of the differential tempera. ture was much greater Septenber 2 than during the succeeding experiment, owing, no doubt, to the influence of currents of air produced by a strong breeze on the first occasion, the revolving observatory being partially open on the side presented to the sun during observations.

With reference to the small differential temperature indicated by the Secchi instrument manufactured by Casella, it may be urged that it is not intended to show the true intensity of solar radiation on the earth's surface, but simply a means of determining solar temperature. Granted that such is the object, yet the extreme irregularity of the temperature of the fluid within the annular space shows that the instrument is unreliable-a fact established beyoud contradiction by an experiment instituted September $2 \uparrow$, on which occasion water of a uniform temperature was circulated through the annular space. This was effected by gradually charging the intervening space from the top, and carrying off the waste at the bottom, holes having been drilled in the external casing for that purpose. The result of this conclusive experiment is recorded at the foot of Table B. It will be found, on reference to the figures, that the mean difference of the two thermometers immersed in the fluid was only $64^{\circ} .9-$ 
$64^{\circ} .4=0.5^{\circ}$, while the mean differential temperature was anguented to $79^{\circ} .1-64^{\circ} .65=14^{\circ} .45$, agminst $9^{\circ} .80$ on the End of September, although the renth distance wats greater, and the solar intensity less; circunstances which ought to hare diminished the indicated intensity. It is needless to enter into any further discussion of the demerits of the instrument represented in Fig. 2. We may now retmin to the consideration of the revice relineater in Fig. 1, copied from "I se soleil." It will be seen that the material diflerence of construction is that of applying only one themon. meter for ascertaining the temperature of the fluid in the amnular space. Possibly this single thermoneter may indi. cate approximately the mean temperature of the nyper and lower portions of the fluid above the central tube; but it fumishes no indication of the temperature below; nor at either extrenity of the anmular space. The inalequacy of the means adopted for ascertaining the temperature of the internal surfice which radiates towards the bulb of the central themometer having thus been pointed ont, it will be well to consider whether the experlient of passing a stream of water of nearly uniform temperature through the annular space will insure trustworthy indication. In order to deter. mine this question, I have constructer two instruments, in strict accordance with the delineation in Fig. "1, excepting that in one of these the concentric cylinters are considerably enlarged, the anmular space, however, remaining unchanged. Experiments with the two instrunents prove that the enlargement does not materially infinence the indications, provided 
water of a uniform temperature be circulated through the anmular space. Thut these experinuents have demonstrited that the size of the bulb of the thermometer exposed to the

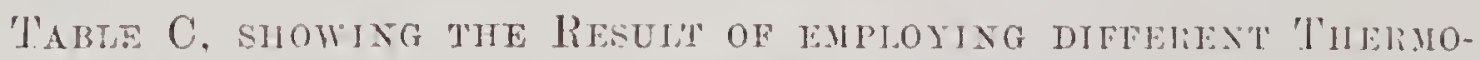
METERS, THE liUtBS OF WHCH ARE OE LXEQLA, DHAMTER.

\begin{tabular}{|c|c|c|c|c|c|c|c|}
\hline \multicolumn{8}{|c|}{ Iniameter of Bulb, 0.30 Tueh. } \\
\hline \multicolumn{3}{|c|}{ 11'-inch tube. } & \multirow{2}{*}{ 忢总 } & \multicolumn{3}{|c|}{ 3-inch tube. } & \multirow{2}{*}{ 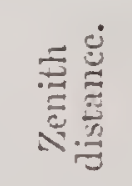 } \\
\hline Sun. & Fluid. & Dift. & & Sun. & Fluid. & Diff. & \\
\hline Pith. & Finti. & - Hah. & Deg. & - Fuh. & ${ }^{\circ} F u h$. & - Fith. & Deg. \\
\hline $7+0$ & (i). 0 & 14.0 & 50.32 & 77.5 & $(i 2.1$ & 15.4 & 49.51 \\
\hline 74.5 & 60.3 & 14.2 & 50.24 & 78.5 & $(i 2.3$ & 16.2 & $5(1.30$ \\
\hline 65.0 & 60.7 & 14.3 & 50.16 & 79.0 & 02.5 & 16.5 & 50.12 \\
\hline (5). & 61.0 & 14.4 & 50.08 & 79.0 & 63.0 & 16.0 & 50.21 \\
\hline $8(j .0$ & 61.0 & 15.0 & 50.01 & 79.0 & 0.3 .0 & 16.0 & 50.30 \\
\hline (i). 0 & 60.6 & 14.4 & 50.16 & 78.6 & 62.6 & 16.0 & 0.12 \\
\hline \multicolumn{8}{|c|}{ Diameter of Bull, 0.58 Inch. } \\
\hline S:3.6 & 62.6 & 21.0 & 49.54 & 79.2 & 60.1 & 19.1 & 50.332 \\
\hline 85.5 & 63.0 & 22.5 & 50.30 & 81.0 & 60.3 & 20.7 & 50.24 \\
\hline 86.4 & 63.4 & 23.0 & 50.12 & S2.5 & 60.7 & 21.8 & 50.16 \\
\hline$S 6 . \%$ & 63.5 & 23.2 & 50.21 & 82.7 & 60.7 & 22.0 & $50.0 \mathrm{~S}$ \\
\hline 87.7 & $6: 3.7$ & $2: 3.0$ & 50.30 & 83.0 & $6 i 1.0$ & $2: 0$ & 50.01 \\
\hline 8.7 .9 & 63.2 & 2.2 .5 & 50.12 & $81 . \%$ & 60.6 & 21.1 & 0.16 \\
\hline
\end{tabular}

smo cammot be changed without influencing the differential temperature most materially. This will be seen by reference to Table C, which records the result of experinents, 
with different thermometers, and tubes of different diameters, conducted October 17. As on previous occasions, the instruments, in order to insure accurate position, were attached to the declination table arranged within the revolving observa. tory. The bulbs of the thermometer's employed were very nearly spherical, their diameters being respectively 0.30 and 0.5s inch. The upper division of 'Table C, which records the experment with the small bulb exposed to the sum, estab. lishes, it will be seen, a differential temperature of $14^{\circ} .4$ for the instrument having the $1 \frac{1}{4}$. central tube, and $16^{\circ}$ for the one having the 3 -in. central tube. Referring to the lower division of the same table, it will be seen that, when the thermometer with the large bulb is exposed to the sum, the differential temperature reaches $22^{\circ} .5$ in the instrument containing the $1 \frac{1}{4}$-in central tube, and $21^{\circ} .1$ in the one having the 3-in. tube. We thus find that, by doubling the diameter of the bulb of the thermometer exposed to the sun, all other things remaining unchanged, an augmentation of the differential temperature amounting to nearly one-third takes place. 'This fact proves the existence of inherent defects fatal to the device delineated in Fig. 1, rendering the same wholly unreliable.

Agreeably to the doctrine of exchanges, the diameter of the bulb is an element of no moment, since the internal radiation towards the same-provided its temperature be uniform -depends solely on the temperature and angulan distances of the radiating points of the enclosure. Infillibility of the thermoheliometer has evidently been taken for granted on 
the strength of the somdness of this doctrine, as we find no allusion to the size of the bulb in M. Soret's account of his observations of solar intensity on Mont Blanc; nor does Mr. Waterston, who employed a similar instrument during his observations in India, advert to the dimensions of the bulb of the thermometer exposed to the sur. 'These physicists apparently overlook the fact that, while the entire convex area of the bulb is exposed to what may be considered the cold radiation from the enclosure, only one-half receives radiant heat from the sun. This circumstance would be unimportant if the heat thus received were instantly transmitted to every part; but the bulb and its contents are slow conductors, while the conducting power diminishes nearly in the inverse ratio of the square of the depth. Consequently, by increas. ing the diameter; the parts of the bulb opposite to the sun will receive considerably less heat relatively in a given time than if the dianeter be diminished. 


\title{
CHAPT'ER XVI.
}

\author{
BAROMETRIC ACITINOMETER.
}

THE bulb of the thermometer is charged with air; the intensity of the radiant heat deternined by the pressure in the bulb; the height of the meromial column indicates the pressure; a fixed graduated anc and morable index show the sun's zenith distance; the graduation of the scale of temperature effected without exposing the hulb to heat or cold; the sm's zenith distance and the intensity of the radiant heat observed simultaneously; the bulb, being placed withim a vacuum, is not exposed to the disturbing influence of atmo. spheric currents; the vessel surrounding the bulb maintained at a constant temperature; the atmospheric temperature does not affect the indication of radiant intensity; the quantity of matter contained in the bulb is excectingly small compared with the convex area exposed to the solan rays; suitable mechanism, operated by two small hand-wheels, enahles the observer to follow the dimmal motion and sun's declination: the instrument is portable. 
An accurate detemination of the intensity of solar heat calls for a thermometer capable of indicating the temperature produced by radiation after a very brief exposure to the radiant heat. It has been pointed ont in previous chapters that the sluggish action of an ordinary thermometer render's it wholly untit to meatsure the temperature proulneed by solar radiation at any griven zenith distance, since the diun'nal motion is so rapid that before an equilibriun cant be established between the heat recejved by the bulb and the heat ratiated ly the same, the zenith distance is materially changed. Consequently, the temperatmes indicated by common thermometers before noon are too low, while in the afternoon the indication is too high, for the zenith clistance at any given instant of time. In order to ascertain to what extent the ordinary thermometer is defective as a means of measuring the sun's radiant heat, consequent on the slow expansion of the contents of the bulb, I have conducted a series of experiments which show that a thermometer surounded by a ressel kept at a constant temperature and exposed to the radiation of a stearly gas-fime, requires from 20 to 25 minutes before the mercurial column becones stationary. Consequently, the rapid change of the sun's zenith distance, especially early in the morning and late in the afternoun, presents a difficulty which renders ordinary thermometers useless for measuring the intensity of solar heat at given renith distances. But a far greater defect inseparale from the ordinary form of thermometer remains to be noticed, namely: the section of the pencil of rays which imparts the radiant heat is less than the con- 
vex area of the bulb exposed to the sun. 'This circumstance presents a serious difficulty, calling for delicate counterating expedients (see Chap. III.), since although that half of the bulb which is turned away from the sun may be protected by a non-conducting substance, the other half on which the sun acts exposes a radiating surface twice as great as the sectional area of the acting pencil of rays, because the convex area of the bulb is four times greater than the area of its greatest section. It should be observed, howerer; that by cmploying a long bulb of cylindrical form, the inherent defect of the common thermometer thus pointed out may be miti. gated in the ratio of about 4 to 3 , since the plane which passes through the axis of a cylinder bears a greater pro. portion to its convex area than the area of the great circle of a sphere to its convex area. Some scientists contend that, agreeably to the law of exchanges, no actual loss of heat is sustained by the excess of radiating surface of the bulb orer the sectional area of the pencil of rays which imparts the radiant heat. A moment's consideration will dispose of this unsound doctrine. Admitting that by means of non-conduct. ing substances the half of the bulb opposite to the sun may be effectually protected against loss of heat by radiation, the other half which is turned towards the luminary will constitute a refrigerator as well as a heater. Now, the efficiency of refrigerator's and heater's is as their areas, all other things being alike; hence a spherical bulb of 0.8 in. diameter (the convex area of which is 2 square inches) presents a radiating surface exactly 1 square inch towards the sun, 
while the section of the pencil of solar rays which the bulb intercepts contrins only 0.5 square inch. The rays being thus distributed orer an area twice as great as their section, the mean intensity of the radiant heat imparted to the bulb will be diminished one-half. But, while the hemispherical surface of the bulb turned torards the sun is thus rendered ineflicient by the dispersion of the rays, its efficiency as a refrigerator, remaining unimpared, carries off the heat with full energy towards the surrounding cold medium. As our demonstration relates only to the defect consequent on the sectional area of the pencil of rays being less than the area which receives the solar heat, I have not noticed the serious loss caused by cold currents of air circulating round the exposed half of the bulb. The self-evident character of the foregoing explanation renders theoretical deductions, from the law of exchanges, unnecessary to establish the fact that ordiuary thermometers cannot furnish correct indications of the temperature produced by solar radiation.

Before entering on a detailed description of the instrument illustrated on Plate 27, it will be instructive to consider what proportion of the indicated temperature results from unaided solar heat when a substance surrounded by the atmosphere is exposed to the sun's rays; and whether the observed increment of temperature above that of the surrounding air occupies at fixed position on the thermometric scale, or whother it rises and falls with the increase and diminution of the atmospheric temperature. Suppose that we place a circular disc, composed of some black non- 
conducting substance, at the bottom of a very deep cylindrical ressel, kept at a uniform temperature, whose axis points towards the sun, and which is provided with an opening opposite the disc-the diameter of the dise and opening being alike. Suppose also that, by some aderuate device, a perfect racuum is kept up in the said ressel, and that the axis of the black cireular disc is directed tomarels the solar centre. I maintain that the temperature acouned by the surface of the supposed lisc-lass the temperature of the surrounding vessel-furnikles an accurate indication of the real intensity of the sun's ladiant heat. It will be percerved, on due reflection, that the differential temperature thus ascer. tained, which fumishes a true mensure of the ladinut intensity of solar heat, cannot occupy a fixed pusition on the thermometric scale. It jises and finlls by increase and dimi. nution of the temperature of the supposen surounding ressel. The investigations and observations refered to in Chap. III., conducted during a series of years, it should be borne in mind, have established the fact that during the summer solstice the differential temperature producerl by solar radia. tion, indicater by my actinometer, is fully $66^{\circ} \mathrm{F}$. in the latitude of New Jork, when the sky is perfectly clear and the renith distance 18 degrees. 'The question will be asked: Is there any linit to the rise and fall of the thermometric interval of $66^{\circ}$, consequent on changes of the temperature of the surrounding medium? As the leating points connected with this question have been fully discussed in Chap. IX., I will merely observe that the result of numerous obser. 
rations, and the trial of various expedients resorted to in order to determine the limit, shom that the morement is not limited. 'The extent of the fill, as far as ascertained, is so considerable that we must infer that, but for the intervention of our atmosphere and the accumulation of heat resulting from that intervention, the sun's maided radiant heat would not be sufticient to prevent the surface of the earth from falling several hundred degrees below the freering point of water. No reliable experinents hiove yet been instituted to ascertain the extent of the upward morement of the thermo. metric interval under discussion, when the solar rays are adnitted into an incandescent enclosure.

The following general description will enable the realer to form a colrect idtea of the nature of the barometric actino. meter. The lealing feature of the instrument is that of employing a bulb (see Plate 27, Fig. 1) composed of rery thin, hard plate-metal, changed with dry atmospheric air, in place of a bulb contaning some liquid sulstance. The lower part of this air-bulb is hemispherical, while the upper part, exposed to the surl, consists of a circular plate with a slight upward curvature, the extreme diameter being 2.55 inches. 'The hemispherical part of the bulb is plated with nickel on both sides, highly polished and thoroughly protected by a non-conducting external covering, while the top plate, ex. posed to the radiant heat, is conted with lamplolack on the ontside, the inside presenting a rough surfice. It will be evident from this description that the form of the bulb of the barometric actinometer fulfils the condition inseparable 
from devices intended to furmish accurate indication of the intensity of solar radiation-namely, that the area of the face which receives the radiant heat should not exceed the area of the section of the pencil of rays admitted to the instru. ment. The airbulb, as already stated, is placed near the bottom of an exhausted cylindrical ressel, 8 inches longr, 3 inches diameter, surrounded by a double casing through which water, kept at a constant temperature, is circulated. An ordinary force-pump is employed for this purpose, receiving its supply from a small portable cistern; the water thus circulated through the double casing being returned to the cistern by the action of the pump. The upper end of the cylindrical ressel is closed by a plate of glass 0.12 inch thick, forming an air-tight joint. 'The aperture in the ring which secures the glass to the cylinder is 2.75 ins. in diameter, corresponding exactly with that of the bulb. 'The exhausted vessel is held in position by a transrerse axle secured to its bottom (see Fig. 2), turning in appropriate bearings supported by columns resting on the circular bed-plate of the instrument. The transverse axle mentioned is provided with a central perforation which, by means of minute passages, communicates with the interior of the bulb, communicating also with a close mercurial cistern $f$ formed at the lower end of the barometric tube, as represented in the illustration. The height of the column in this baro. metric tube, it is scarcely necessary to observe, furnishes an exact index of the expansive force of the air within the bulb, and hence the intensity of the radiant heat to which it is sub. 
jected. It is important to observe, regarding the graduation of the scale of temperature, that the height of the mercurial column alone will not determine the length of the degrees. Certain obvious corrections must be made, especially on account of the loss of energy of the sun's radiant heat in passing through the crystal which covers the exhausted tube. This loss may be reatily ascertained by employing an apparatus by means of which the absorptive property of the crystil is tested before the scale of temperature is graduated. Refuring to the mechanism represented in the illustration, it will be seen that the inclination of the exhausted cylinder is regulated by a tangential screw a, while the adjustment called for by the earth's diurnal motion is effected by a small pinion $b$ actuating the cogged base-plate which supports the instrument. The mechanism thus described, together with a perforated sight $c$ and an index-plate $d$, enables the operator to direct the tube accurately towards the sum. The centre line of the index $g$ attached to the upper end of the exhausted chamber shows the zenith distance on the graduated quadrant at all times by mere inspection. It should be mentioned that, when the harometric actinometer is armed within a revolving observatory provided with a declination table, the mechanism just described for obtaining a parallactic movement is wholly dispensed with. Meteorologists irill do well to adopt such an instrument in all important observations, since its simultaneous indication of solar intensity and zenith distance enables them to determine the relative amount of rapor present in the 
atmosphere with a degree of precision probably unattainalyle by any other means. The sensitive nature of the instrument will be readily comprehended if we consider that while the surfice of the bulb, 2.55 ins. diameter, amounts to 5.93 square ins. (the section of the pencil of rays which imparts the ladiant heat contains also 5.93 superficial inches), the quan. tity of matter to be heated is only a small fraction of that contained in an ordinary thermometer whose bull is only 0.6 in. diameter. Besides, the latter bulb receives heat from a pencil of rays of only 0.28 square in section. Apart from this important difference in firror of the balronetric actinometer, the radiating surface of spherical bulls exposed to solar radiation, as alrealy stated, is twice as great at the section of the pencil of rays which imparts heat to the sime. 


\title{
CIAPTER, XVII.
}

\author{
CONDUC'IVIT'Y OF MERCURY.
}

I' was shown in Chapter XV. that the radiant intensity of the sun camnot be accurately ascertained by the thermoheliometer employed by Pire Secchi, owing, among other causes, to the imperfect conductivity of the mercury in the bulb exposed to the sun. Meteorologists are not generally aware of the fact that the conducting power of mercury is so imperfect as to affect materially the correctness of the indication of mercurial thermometers, Deschanel being quoted in support of the opinion that mercury is a very good conductor. Prof. Everett, in a recent translation of the works of the anthor mentioned, assumes that the conductivity of quicksilver in the bulb of a thermometer is the same as a ressel "with thin metallie sides containing water which is stired" (sce Prof: Everett's translation of "Deschanel's Natu. ral Philosophy," Part II., P. 245-38i). The subject is so intimately connected with the determination of solar temperature and solar energy that it has become necessary to 
settle the question by some reliable, practical test. I have accordingly constructed the apparatus illustrated on Plate 28, by means of which the relative conducting power of a column of copper and one of mercury has been ascertained with critical nicety. Before entering on a description, it will be instructire to point out that the heat communicisted to the bulb of a thermometer by solar radiation is tramsmitted to its contents chiefly by conrection; lience that the altitude
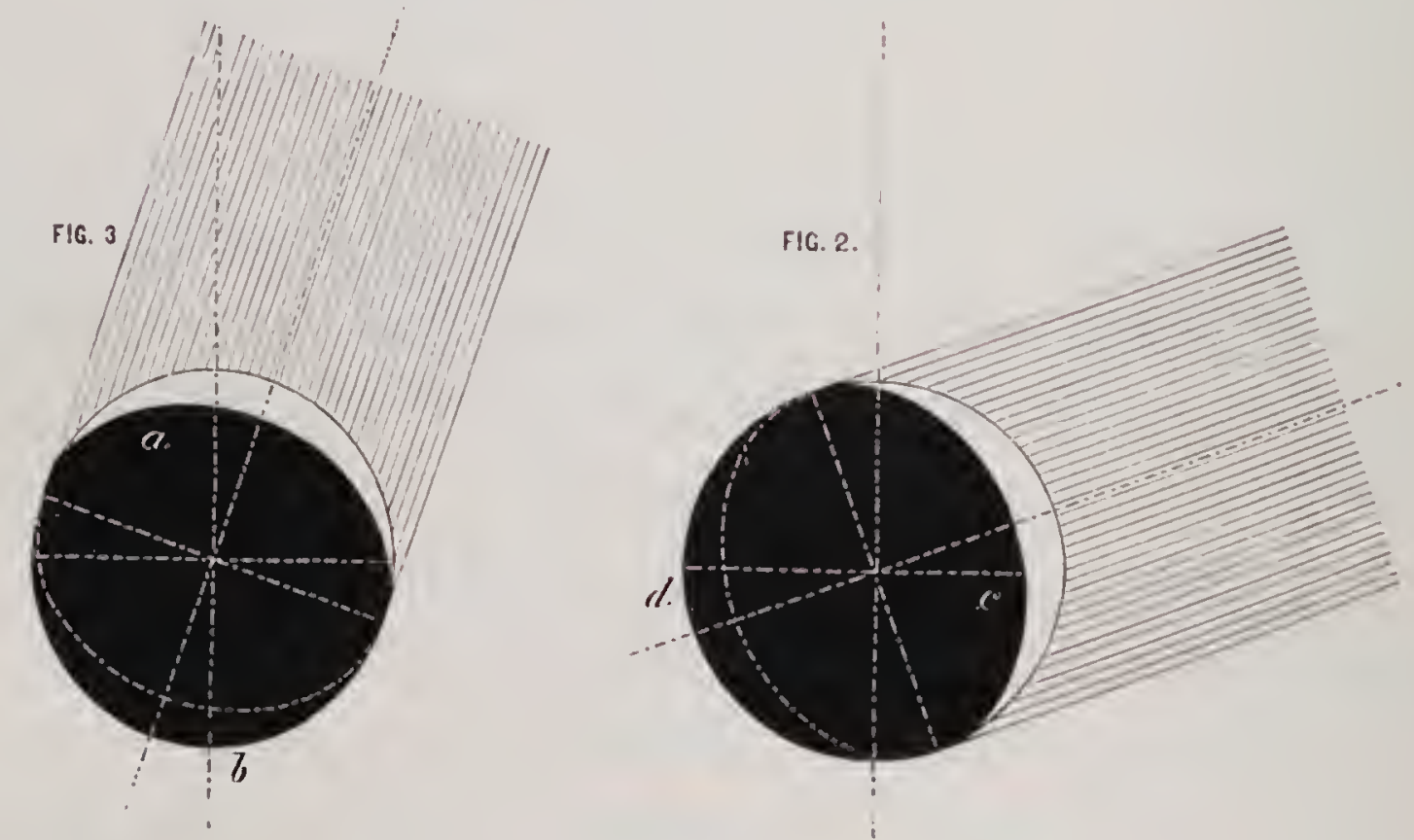

of the sun during the observation influences the accuracy of the indication. This will be reanlily comprehended. Fig. 2 represents the bulb of a thermometer exposed to the ralys when the sun's zenith distince is 65 deg.; Fig. 3 representing the bulb when the zenith distance is 18 deg. 23 min., the latter being the minimum at the observatory of the Roman College, where the thermoheliometer described in Chapter XV. has been long employed for the purpose of ascertaining 
the intensity of solar radiation. Referring to Fig. 2, it will be seen that the blank crescent $c$, whose varying thickness indicates rery nearly the relative amount of heat imparted at each point of the spherical surface presented towards the sun, ocenpies an almost rertical position. The mercury contained within the space indicated by the said crescent, haring its specific gravity reduced by the heat transmitted by the solar rays, will ascend; while the mercury on the opposite side, which retains its specific gravity, will descend; thus a circulation will be established by means of which the heat received from the sun will be gradually communicated to the entire mass of mercury in the bulb. But when the latter is exposed to the sun's rays under a zenith distance of about 18 deg., as shown in Fig. 3, the heated mass of mercury contained within the crescent a has so slight an inclination that scarcely any circulation takes place. Consequently, if it can be shown practically that mercury is incapable of transmitting heat from particle to particle with sufficient relocity, it will be evident that thermoncters and thermoheliometers with spherical bulbs are worthless as means of measuring maximum intensity of solar radiation. It will be perceived that if the bulb in Fin. 3 be surrounded by an enclosure, as in the thermolseliometer; the mercury contained within the space indicated by the crescent b will ratiate far less heat towards such enclosure than the mercury within the opposite heated crescent ". It will also be perceived that, by increas. ing the size of the bulb, the transmission of heat from $a$ to $b$ will be retarded unless the conductivity of mercury be per. 
fect. Hence the size of the bulb is an element affecting the accuracy of the indication-a circumstance fatal to the em. ployment of a spherical bulb in the thermoheliometer.

The nature of the illustrated apparatus constructed for the determination of the conductivity of mercury will be readily understood by the following description: Fig. 1, Plate 28, represents a longitudinal section through the rerti. cal plane. $a$ is a boiler, with a flat bottom and senicircular ends, supported on two columns fo and g, resting on the bottom of the cisterns $c$ and 7 . The column $f$ is composed of wrought copper plated with silver, highty polished. 'The column g consists of a cylindrical ressel of crlass open at the top, filled with mercury, and surromeled with a sorket h, composed of polished silver. The cisterns $c$ and $d$, sup. ported on non-conducting substances, are plated with polished silver, and provided with fumel-shaped openings at the top, through which thermometers are inserted. These cisterns, as well as the columns f and /, are surrounded with nonconducting coverings $p, p$ and $o, o$. A lamp b is applied between the cisterns for heating the water in the boiler. It is scarcely necessary to observe that the polisherl silver plat. ing of the copper colmmn, and the polisherl silver socket round the merculial columm, are intenderl to prevent loss of heat by radiation, while the coverings before mentioned are intended to prevent loss of heat by convection aftending atmospheric currents. The inside dimmeter of the cylindrical ressel $/ 2$ it should be noticed, is 0.5 in., conterponding exactly with the diameter of the copper colmmn fi, the top of which 
is on a level with that of the mercurial column. The lines li $l$ and $m$ an ane in the same horizontall plane, their distance below the upper ends of the columns ff and g being precisely 2 inclies.

The object of the apparatus being that of comparing the conductivity of merenry to that of some other metal, copper has been selected, is its conducting property is better known than that of any other: The leading feature of the arrangement will be comprehended by a mere glance at the illustrition. An equal amount of heat being applied to the top of each column, it is intended to show by the elevation of the temperature of the water in the cisterns $c$ and $d$ what relation exists between the conductivity of mercury and copper. Regarding the application of the heat, it will be evident that an equal amount must infallibly be imparted to each column if the lamp be sufficiently powerful to keep the water in a state of continuous ebullition. Obviously the heat from the lamp, if urged, will cause a rapid upward motion of the water in the middle of the boiler, and a correspondingly rapid descending current at each end. Accordingly, lateral currents, varying in velocity with the strength of the flume, applied under the boiler, will flow inwards over the upper ends of the columns $f$ and $g$.

Several experiments have been made under different barometric pressure and different atmospheric temperature, yet the results as regards the comparative conductivity of mercury and copper have proved to be very nearly alike in all. The accompanying tables record the result of the last trial, 


\begin{tabular}{|c|c|c|c|c|c|c|}
\hline \multicolumn{7}{|c|}{ 'Tabee J.-Coppla Coman. } \\
\hline$\stackrel{\stackrel{\Xi}{\Xi}}{\leftrightarrows}$ & 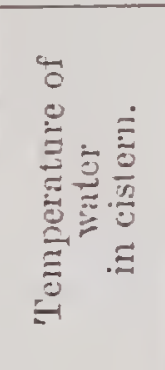 & 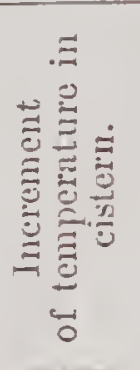 & 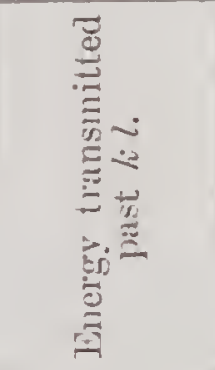 & 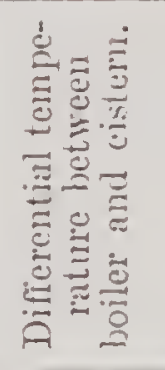 & 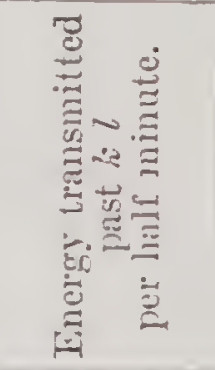 & 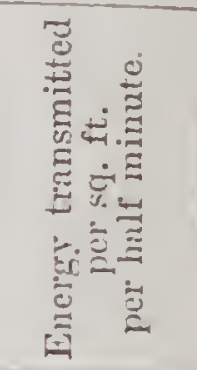 \\
\hline afin. & ${ }^{\circ}$ F'ah. & 'Fuh. & Therm. units. & Fah. & Therm. units. & Therm. units. \\
\hline & 73.50 & $\ldots$ & $\ldots$ & 138.50 & $\ldots$ & \\
\hline 0.5 & 7.15 & $1.6 j$ & $0.14: 3$ & 136.5 .5 & $0.14: 3$ & 104.873 \\
\hline 1.0 & $7 \% .2 \%$ & $3.7 \%$ & 0.326 & $13+.7 .5$ & $0.18: 3$ & 134.208 \\
\hline $1 . \overline{5}$ & SU.14 & 6.64 & $0.57 \%$ & $1: 31.80$ & (1).251 & $15+078$ \\
\hline 2.0 & S:3.81 & 10.34 & 0.898 & 128.10 & 0.321 & 235.41 .5 \\
\hline 2.5 & SS.1t & 14.61 & 1.272 & $1: 3.81)$ & 11.374 & $27+284$ \\
\hline 3.0 & $9: 2.81$ & 19.31 & 1.678 & 119.00 & 1.406 & 297.7 .52 \\
\hline $3 . \tilde{5}$ & $97.6 \%$ & 24.17 & 2.100 & $11+.2 .1$ & $0.4: 2$ & 309.486 \\
\hline 4.0 & 102.50 & 29.06 & 2.525 & 10.9 .44 & 0.42 .5 & 311.656 \\
\hline
\end{tabular}

\begin{tabular}{|c|c|c|c|c|c|c|}
\hline \multicolumn{7}{|c|}{ 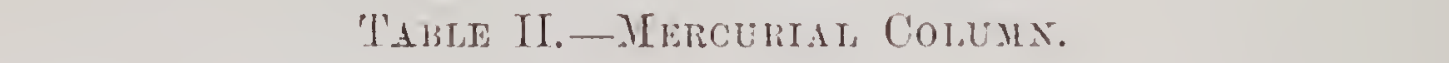 } \\
\hline$\stackrel{\varrho}{\triangleq}$ & 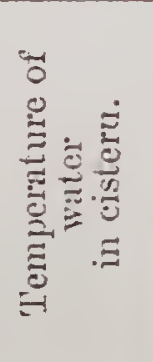 & 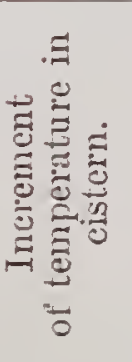 & 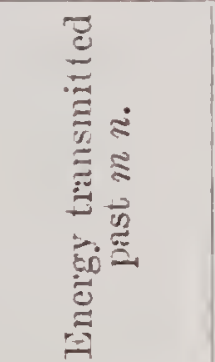 & 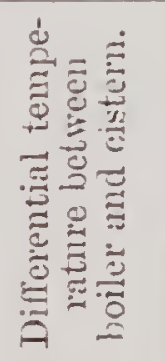 & 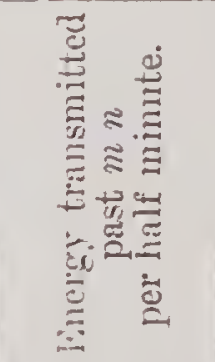 & 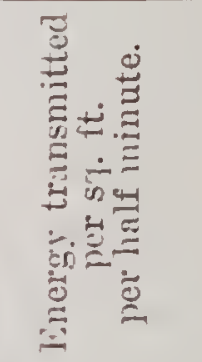 \\
\hline Min. & ${ }^{\circ} \mathrm{F} a h$. & - Fak. & Therm. units. & - Fath. & Therm. unite. & Therm. units. \\
\hline & 73.50 & ... & . & 138.50 & & \\
\hline $0 . \tilde{o}$ & 73.52 & 0.02 & 0.002 & 138.48 & 0.002 & .1 .460 \\
\hline 1.0 & 73.56 & 0.06 & $0.00 \tilde{\jmath}$ & 138.44 & 0.003 & 2.200 \\
\hline $1 . \tilde{5}$ & 73.64 & 0.14 & 0.012 & 138.36 & 0.007 & 5.133 \\
\hline 2.0 & 73.75 & 0.25 & 0.022 & 138.2 .5 & 0.010 & 7.334 \\
\hline $2 . \tilde{5}$ & 73.90 & 0.40 & $0.03 \tilde{5}$ & 138.10 & 0.013 & 9.534 \\
\hline 3.0 & 74.08 & 0.58 & 0.051 & 137.92 & 0.016 & 11.734 \\
\hline 3.5 & $74.2 S$ & 0.78 & 0.068 & 137.72 & 0.017 & 12.467 \\
\hline 4.0 & 74.50 & $1.00^{\circ}$ & 0.087 & 137.50 & 0.019 & 13.934 \\
\hline
\end{tabular}


CHAP. XVI.

conducted as carefully as practicable. The headings of the several columis explain so clearly the object of the tables that it will only be necessary to state that the energy inserted in the fourth column is the energy developed from the begimning of the experiment

Referring to Table I., it will be seen that at the termination of 4 minutes from the commencement of the experiment, the temperature of the water in the cistern $c$ had increased $29^{\circ} .06$, the differential temperature being then $212^{\circ}-102^{\circ} .56$ $=109^{\circ} .44 \mathrm{~F}$. During the same period an amount of dynamic energy represented by 2.525 thermal units had been transmitted past the line $7, l$, communicated to (1) the water in the cistern; (2) the part of the copper column immersed; (3) the metal composing the cistern; (4) the immersed part of the thermometer. But, while the entire energy transmitter past the line 7.2 during the 4 minutes thus amounted to 2.52.) units, the rate of transmission was actually 0.850 unit per minute at the termination of the fourth minute. This apparent discrepancy was caused by the heat absorbed by that part of the column which extends above the line $l: l$, the temperature at the commencement of the experiment being the same as that of the surrounding air, $73^{\circ} .50$. Referring to 'Table II., it will be seen that the energy transmitted through the mercurial column past the line $n n$, during 4 minutes, was only 0.087 unit against 2.525 units for the copper column, although the differential temperature of the water in the cistern $d$ was $135^{\circ} .50-109^{\circ} .44=28^{\circ} .06$ higher than in the cistern c. Accordingly, the conductivity of the 
copper composing the colmm th has proved to be $\frac{2.526}{0.085}=$ 29.06 times greater than the conductivity of the merenry of the column y, notwithstanding the higher differential temperature to which the latter was exposed. It will be observed that the glass, $0.02 \mathrm{in}$. thick, composing the glimilical ressel which contains the mereury, will eomluet some leat downward, tending to increase the temperature in the cisternd. This tentency, howerer, will be balancerl by the loss of heat occasioned by the radiation of the ylats cylinder, since the application of the polished silver socket and the nomconducting corering cannot wholly perent the refrigerating action of the smrounding ail. It is impromtant to obseree, regarding the loss of leat from the latter cause, that the cis. terns, previous to trial, are charged with water of the sann" temperature as the atmosphere. Now, comsidering that the increment of temperature in the cistern d does not arelage more than $0^{\circ}$.th above that of the atmosphere during the trial, it will be evident that the anount of error callsed by radiation will be quite inapreciable. We are therefore warranted in concluding that the conductivity of meren'y, determined by the increment of temperature in cistern $d$, and by the dynanic energy transmitted past the line $m \mathrm{n}$, camnot be fir from correct. It will be asker why columms of such small dianeter lave been employed. The principal object has been that of presenting a sectional area in the mereurial column !f corresponding as nearly as possible to the size of the bult of an orlinmy thermometer. The inves. 
tigation, then, has conchurely established the fact that mercury transmits heat from particle to particle too slowly to effect a sufficiently rapir indication of mercurial thermometers proviter with splerical bulbs; and that, when the heat is applied from above, the indicition of such thermoneters is wholly unreliable.

I subject of great interest presents itself in connection with the rate of transmission of energy exhibited in the sixth colnunn of Table $I$. It will be seen that, althongh the copper column of is only 0.5 in. in diameter $=0.19635 \mathrm{sq}$. in. section, the rate of transmission at the termination of the fourth minute is 0.850 unit por minute. Reducing this amonnt to the nsual stanclard of one square foot, it will be fonnd that the energy developer is $\frac{14 t}{0.19635} \times 0.850=623$ thermal units per minute for a sectional area of one square iont. It will be olserved that this extraordinary amount of energy (theoretically capable of exerting $\frac{623}{42.7}=14.5$ lorsepower) is called forth by the moderate differential temperature of $212^{\circ}-102^{\circ} .56=109^{\circ} .44 \mathrm{~F}$. Now, let us compare the stated enerey of 623 thermal mits per minute to that produced by the radiation of a metillic surface conted with lanp-black, and mantained at a temperature of $212^{\circ}$ within an enclesure of $102^{\circ}$. Actual trial shows that, muder these conditions, the radiant energy emanating from the face of a plate composed of copper, containing 144 sq. ins., scarcely reaches 6 thermal units per minute. Our experiment has 
therefore incidentally established the fact that, under the stated conditions, a plate of wrought copper 2 ins. in thick. ness is capable of transmitting by conduction from one side to the other, in a given time, an amomnt of mechanical energy more than one hundred times greater than the mechanical energy transmitted by the radiation of the same plate during an equal interval of time. 


\section{CHAPTER XVIII.}

INCANDESCEN'I CONCAVE SPHERICAL RADIATOR.

Ture illustration on Plate 29 represents an apparatus constructed for the purpose of proving the correctness of the indications furnished by the solin pyrometer described in Chapter X. Fig. 1 is a side elevation and Fig. 2 an end view of the apparatus. Objections have been raised against the solar pyrometer on account of the low temperature employed. It is contended that, unless the radiator is raised to the temperature of incandescence, emitting luminous rays, the radiant heat transmitted to the focus will not furnish an indication capable of determining the temperature of distant iricandescent bodies. The reader is aware that the idea of ascertaining the temperature of the sun by the indications of a surfice conted with lamp-black, maintained at only boiling heat, has been deemed absurd by certain physicists. Secchi, in a letter to Nature, says: "Very tew indeed will allow that which MLr. Ericsson takes for granted, that the radiating power of the solar materials may be com- 
pared to that of pure lamp-black, at he assumes." Numerous experiments, however, show that, relatively, there is no appre. ciable difference between the energy of the dark heit-riy's emanating from a metallic radiator of low temperature, pre. senting a thoroughly disintegrated or a blackened surface, and the energy of heat-rays aceompanied by a light emanat. ing from an incandescent metallic ristiator. The temperature transmitted by the radiant heat to the focus is, in each case, lirectly proportional to the temperature of the rarliant sur. face. An air thermometer placed in the foums of a concave spherical radiator composed of ice, and surrounted with very cold substances, say $100^{\circ}$ below \%ero, will furnish an indical. tion by which the temperature of distant incandescent bodies may be ascertinined with as mueh certainty as by employing a racliator heaterl to such a degree as to emit luminous rays. It scarcely needs explanation that my reason for constructing the solar pyrometer with a radiator kept at the low temperature of boiling water is that of admitting of operating within a racumn, besides rendering it possible to measure the temperatures with positive exactuess. No doubt the instrument could be so arranged that the metallic radiator might be maintained at a temperature comsilerahly above that of incandescence (Sir Hmmphry Dary, it will be remembered, fixed the temperature of incimlescence at 812 ); but we lack accurate means of measuring the intensity when metals alre brought to white heat or bright orange. Nor would anything be gained by resorting to a morle of cont struction involving both complication and uncertainty, since 
Jark heat-liy's, with reference to temperature, in no mammer differ from hoat-ray's atecompanied by light. As alrealy stated, no irregularity lias been observed by me in the fall of the temperature of an incinclescent rarliator, and that of the foral thermometer exposed to the radiant heat, while the color gradually changes from bright orange to black. On the contrary, the temperatures of the radiator, and the recipient of the radlant heat, continue to bear the same relation to each other during both cooling and heating. The times, compared with the increment or diminution of intensity, differ a little; but, as stated, the proportion between the temperature of the radiant surface and that transmitted to the focus continues as nearly uniform as practical test can show.

The radiator of the instrument represented by our illus. tration on Pl. 29 consists of a solid cylindrical block b, composed of cast iron, 10 ins. dianeter, 6 ins. long, placed horizontally on a perestal, the front end forming a spherical concavity a $b$ of of 18 ins. radius, precisely like the radiator of the solar pyrometer described in Chap. $X$. The under side of the cylindrical block is provided with a square projection corresponding with two gridile pieces on the top of the perlestal shown on Fig. 2 , intented to facilitate the operation of placing the block rapilly in a proper position ater having been heated in an au-furnace. I focal thermoneter d, simiJar to the one employed in the solar pyrometer, is secured to a bent arm attached to the front sile of the perlestal; the distance $b$ a between the centre of the butb and the liace 
a $b c$ of the concave spherical radiator being also precisely as in the solar pyrometer.

The accompanying table exhibits the result of a trial of the apparatus, conducted at a mechanical establishment in New York possessing air-furnaces well adapted for the inrestigation :

\begin{tabular}{|c|c|c|c|c|c|}
\hline \multirow{2}{*}{$\begin{array}{l}\text { Appearance of } \\
\text { radiator. }\end{array}$} & \multicolumn{2}{|c|}{ Temperature of radintor. } & \multirow{2}{*}{ 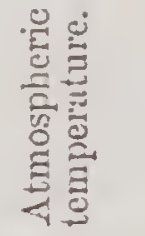 } & \multicolumn{2}{|c|}{$\begin{array}{l}\text { Temperature of focal } \\
\text { thermometer. }\end{array}$} \\
\hline & Actual. & Differential. & & Actual. & Differential. \\
\hline & ${ }^{\circ}$ Fuh. & - Fuh. & - Fah. & - Fah. & - Fah. \\
\hline Light orange... & 2190 & $21 t 9.3$ & 40.7 & 178 & $13 \% .3$ \\
\hline Deep olange.... & 2010 & 1969.3 & 40.7 & $17 \%$ & 132.3 \\
\hline Br't cherry red.. & $18: 30$ & 1759.3 & 40.7 & $160^{\circ}$ & $12 \div .3$ \\
\hline Full cherry red. & 1650 & 1609.5 & 40.5 & 156 & 115.5 \\
\hline Dull cherry red. & 1470 & 1429.8 & 40.2 & 144 & 103.8 \\
\hline Dull red heat... & 1290 & 1249.0 & 41.0 & 130 & $\$ 9.0$ \\
\hline Mean... & 1740 & 1699.37 & $40.6: 3$ & 157.83 & 117.2 \\
\hline
\end{tabular}

The following brief account of the manner of conducting the trial will show the simple nature of the investigation. The solid ladiator, before being placed on the pedestal, was heated in the air-furnace to very nearly white heat, and then, by means of tongs, quickly removed from the furnace and placed in the position shown by the illustration. The focal thermometer was then closely observed, its indication being recorded when the radiator had cooled so as to present a color of light orange. 'The indications during the succeding stages of brightness and color of the incandescent 
radiator were in like manner recorded. 'The temperature of the surrounding an was observed simultaneously with that of the focal thermoneter. The time which elipser between the first and last observation entered in the table was 29 minutes. It will be seen that the temperature transmitted by the rartiator to the focal thermometer was recorded at six different stages of incandescence, the color presented by the radiant surface determining the time for observation. The mean temperature of the ratiator during the experiment was $1,740^{\circ} \mathrm{F}$. Delucting the mean atmospheric temperature, $40^{\circ} .63 \mathrm{~F}$., the actual mean differential temperature of the radiant surface, the luminous heat rays of which acted on the focal thermometer, was $1,699^{\circ} .37$. The mean temperature transmitted to the focal thermometer exposed to the radiant heat being $157^{\circ} .83$, while the atmospheric temperature, as already stated, was $40^{\circ} .63$, we find that a temperature of $117^{\circ} .2$ was imparted to the focal thermometer by a radiant intensity of $1,699^{\circ} .37$. It will be recollecter that in the solar pyrometer a differential radiant intensity of $163^{\circ} .9$ transmitted a temperature of $12^{\circ} .2$ to the focal thermometer'; hence $\frac{12^{\circ} .2}{163.9}=0.074$ of the temperature of the radiator was transmitted to its focus, against $\frac{117.2}{1699.37}=0.069$ in the apparatus under consideration. Consequently, 0.074-0.069 $=0.005$ less heat, relatively, is transmitted by the incandescent radiator than by the comparatively cool radiator of the solar pyrometer. As this small discrepancy can readily be accounted for; the result of the instituted test fully estab- 
lishes the truth of the doctrine which forms the basis of the solal m rometer-manely, that the calonific energy of both dark and luminoms heat laysis is directly proportional to the temperature of the radiant surface. 'Tlue cimse of the dis. crepancy aldrerted to will be readily comprehemedel by the following explanation relating to the solar pyometer. The heat imparted by the radiant to the recipront surdice is transmitted througle ather alone; therefore neither the radi. ator nor the bulb of the focal thermometer are sirlijecter? to any loss by comrection: while the incamdercent concive landiator; as well as its focal thermometer, alle exposal to the refrigerating influence of the atmospheric are Ohrionsly the heated loulb of the thermometer will canse an mpard current of air; which, acting on its face, reduces is tempe. rature and indication, while the intense leat of the rarliatur tends to angment the said current. Igain, the rapirl suce cession of coll particles passing ored the intensely leated sunface of the latdiator will ineritably diminish the enewy of the radiant heat, since the molecular motion within the heated mass cannot instantly restore the loss to which the molecules at the surface are continually being subjected by the cold current. The diminution of rarliant energy from this cause, though not great, will be aploreciable, and, arlded to the loss of lieat, to which the bulb of the focal thermo. meter is subjected, satisfictorily accounts for the discrepancy adverted to; at the same time showing the necessity of carrying on investigations relating to ladiant heat witlin a racuum. 
Let us now calculate the temperature of the sun agreeably to the indications furnished by the incandescent moliaton. of the illustrated apparatus, withont reference to the inclications of the instrument, the reliability of which we are discussing. But in place of basing our calculations on the angle subtended by the sun from the earth, and the angle subtended by the concave spherical radiator from its focus, let us determine the solar temperature on the basis of areas and ristances alone. This mothorl will be more satisfactory to practical men than the one which takes no direct cognizance of areals and distances. Assuning the sun's diameter to he singst miles, the area of the great circle will be $15,912,929 \times 10^{12} \mathrm{sq}$. ft. The diameter of the spherical ratiator being 10 ins. and the rarlius is ins. its face presents $80.06 \mathrm{sq}$. ins. $=0.556 \mathrm{sq}$. ft. Accorlingly, the sun's area is $28,620,375 \times 10^{12}$ times greater thim the area of the concave face of the rarliator. The mean distance between the sun and the earth is 91,430,000 miles, or 482,750,400,000 ft.; the distance between the radiator and its focus is $1.5 \mathrm{ft}$. The ratiant heat of the sun, therefore, acts through a dis. tance 321,833,600,000 times greater than the ladiant heat. of the incandescent radiator. We have demonstrated in Chap. I. that the temperature transmitted to the foci of concare spherical ratiators of equal area is imersely as the square of their ladii; and we have shown that, owing to the great distance of the sun, every part of his face may, without material error in our computations, be considered as equidistant from the earth. Hence, if we square and inrelt 
the before-mentioned distances through which the landint heat acts, we ascertain that for equal intensity and cruml

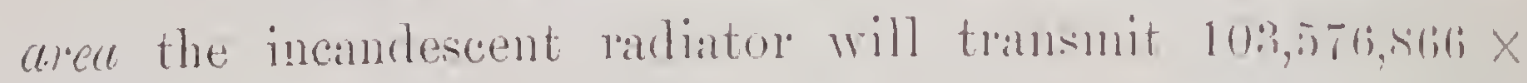
$10^{\text {is }}$ times higher temporature to its focus than that trans. mitted by the sun to the houndary of the eartlis atmosphere. But the area of the sum, at we larre stated, is $25,620,375 \mathrm{X}$ $10^{23}$ times greater than the area of the radiator; hence for equal intensity the radiant heat tramsmitterl to the foeus of the latter will be $\frac{103,576,866 \times 10^{13}}{28,620,377 \times 10^{15}}=3,618.99$ times greater than that transmitted by the sur. It will be rearlily seen, on reflection, that unless the temperature of the sun is 3,618.99 times greater than that of the incindescent radiator, it camnot transmit to the atmospheric bommlary the sane temperature as that transmitted by the ralliator to its foctis, viz, $117^{\circ} .2 \mathrm{~F}$. The temperature produced by solar radiation when the earth is in aphelion is, however, only $S t^{\circ} . S t$ at the said boundary; hence the sur's temperature need be only $\frac{3,618.99 \times 84.84}{117.2}=2,619.25$ times greater than that of the incandescent radiator $\left(1,699^{\circ} .37\right)$, in order to cause an elevation of $8 t^{\circ} .8 t$ on the Fahrenheit scule at the boundary of the eartl's atmosphere. Multiplying 1,699 .37 by 2,619.25, we find that the indication of the incandescent concave spherical radiator of our illustrated device proves the surn's temperature to be $4,451,924^{\circ} \mathrm{F}$. It will be seen, on referring to Chap. X., that the calculations based on the indications of the solar pyrometer prove the sun's temperature to be 
only $4,063,984^{\circ}$. 'The cause of this discrepancy of 0.087 has already been explained, viz, diminution of the radiant energy of the incandescent radiator, proatuced by currents of cold air sweeping over its face; together with the loss of heat to which the unprotected bulb of the focal thermometer is subjected by the refrigerating effect of the surrounding atmosphere. Making due allowances for these losses-inseparable from conducting the experiment in the presence of atmospheric influence-it will be found that the indications furnished by an incandescent concave spherical radiator assign very nearly the same temperature to the sum as the comparatively cold radiator of the solar pyrometer. 'The objection, then, urged against this instrument, that its temperalure is not high enough, cannot be maintained in view of the fact which we have established, that the intensity deduced from its indication is not affected by employing an incandescent radiator in place of one raised to merely boiling heat. 


\section{CHAPTER XIX.}

REELECTIVE POWER OE SILVER ANI) O'LHER METALS.

Draschantin informs ws that the reflection of calorific rays has been satisfactorily determined by the investigations of Melloni, Laprovostaye, and Desains, and that these physicists have practically ascertained the reflective power of polished silier and other metals. He states, also, that Laprorostaye and Desains have shown that, "contrary to what was previously supposed, the reflecting power varies according to the source of heat." "Thus," he adds, "the reflecting power of polished silver, which is 0.97 for lays from a Locatelli lamp, is only 0.92 for solar rays." It follows from this announcement that while the loss of radiant energy is only $1.00-$ $0.9 \mathrm{~T}=0.03$ when the rays emaniate from the lannp mentioned, it is $1.00-0.92=0.05$ when the lays from the sun are reffected. Accordingly, the loss of energy attending reflection will be nearly three times greater for solar heat than for antificial heat. That such a difference does not exist is known to all persons conversant with reflectors. Besiles, a 
moment's consideration of the properties of calorific rays suffices to show the untenable chanacter of the proposition, compelling us to reject Laynorostaye's and Desains's investi. fution as unreliable, although generally accepted by physicists. Moreover, the table of reflective power of rarious metals presented by Desclianel as the result of the celebrated investigation furnishes alditional evidence of its unreliable character. Let us select from Laprorostaye and Desains's tabular statement the relative reflecting capacity of silver and brass. 'The former' is represented to be 0.97 , while the latter is 0.93 ; consequently, the reflective powers of silver and brass are supposed to be in the ratio of $1.000: 978$, difference $=\frac{22}{1000}$. Manufacturers of reflector's practically acquainted with the subject are aware that silver possesses a far greater refiective power compared with brass than that indicated by the stated proportion.

'The leading feature of my solar engine being that of developing mechanical power by concentrating the sun's radiant heat, the efficacy of various metals for this purpose engaged my attention during the early stages of my labor's connected with utilizing solar energy for the production of motive power. 'Taking for granted the correctness of Laprorostaye's and Desains's statement of relative efficacy, I constructed reflectors composed solely of brass, in order to aroid the great cost of silver-plating. The difference of reflecting power agrecibly to the researches referred to being $\frac{22}{1000}$ 
in faror of silver, I simply enlinger the reflector's in that proportion, expecting to produce the same result as with silver-plated metals presenting $\frac{22}{1000}$ less area. It proved, howerer, on the first trial, that the reflective capability of brass is far inferior, and that the required temperature could not be produced by briss reflector's; the machine, consequently, failing to operate as designed. A thorough in. restigation capable of determining the true reflective power of various metals, therefore, became necessiry; but before commencing experiments, the method resorted to by Melloni, Laprorostaye, and Desains, referred to by Jeschanel, was carefully eximined. The said methor is thms described in his "Elementary 'Treatise on Natural Philosophy": "The substince under investigation is placed upon a circular plate, which is graduated round the circumference. 'The thermoelectric pile is curried by a horizontal bar which turns about a pillar supporting the circular plate. 'This bar is so al. justed as to make the reflected rays impinge upon the pile, the adjustment being made by the help of the divisions marked on the circular plate. In making an observation, the bar is first placed so as to coincide with the prolongation of the said principal bar, and the intensity of direct radiation is thus observed. The pile is then placed so as to receive the reflected rays, and the ratio of intensity thus obtained to the intensity of direct radiation is the measure of the reflecting power:" The accompanying sketch, Fig. 3 , represents a top view of the arrangement referred to in the 
above explanation. a represents a Locatelli lamp, $b$ the graduated circular plate on which is placed the polished reflecting substance $b$, and $c$ the thermo-electric pile. $d$ shows a cluster of parallel calorific rays projected from the lamp, through a perforation in the screen $f$, towards the polished substance $b$ '. 'The face of this polished substance heing placel at an angle of 45 deg. to the cour'se of the cluster of rays $d$, it will be ericlent that the rays will be deflected at the same angle; hence the cluster will be di-

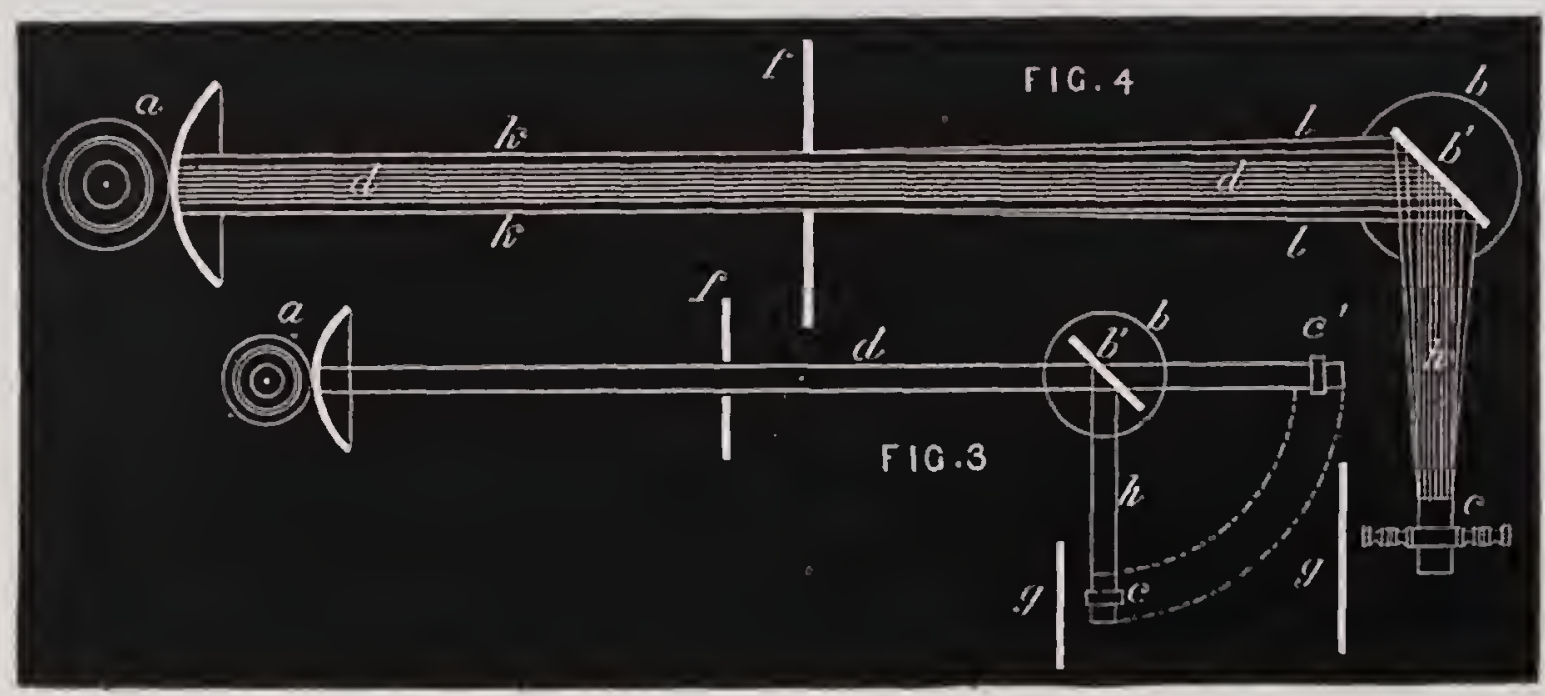

rected as shown by $h$, ultimately striking the face of the pile c. 'The latter', it should be mentioned, is protected against radiation from the lamp by a screen $\%$. The temperature imparted by the deflected radiant heat having been recorded, the pile is allowed to cool, and then placed in the position $c^{\prime}$, after which the polished substance $b^{\prime}$ is removed. As the radiant heat transmitted by the parallel rays $d$ emanating from the lamp will now act directly on the face of the pile, a higher temperature will obviously be produced than when the pile occupied the position c. The difference 
of temperature thus produced, we are told, indicates exactly the anount of loss of radiant intensity attending the reflec. tiun of the lays by the polished substance $b^{\prime}$. Lalprorrestaye and Desains, as before stated, fommd that the heat trans. mitted directly is to that reflected ats 1.000 to $0.97 s$, hence the loss of energy $=0.022$. The assumption of such perfect reflective power being palpably erroneous, let us examine cirrefully the adopted nethod in order to detect the cartse of the false deduction. Fig. 4 represents a top riew of Thilno. rostaye and Desains's arrangement, allearly describerl, hut drawn to a larger scale than in Fig. 3, similar letters of reference being employed in both figures. a a represents the cluster of calorific rilys transmitted by the limm to the polished substance $b^{\prime}$, and by it reflected, as shown hy $h$, towards the face of the pile c. It will be evident that the section of the reflected central cluster of calorific rays de. pents upon, and corresponds with, the face of the pile $c$, provided the perforation in the screen $f$ be sufticiently lingor. It will also be evident that the annular cluster $h_{2}$; the external diameter of which depends on the size of the prerforation of the screen $f$, will be projected towards the polished substance $b ;$. Owing to defraction, the stated annular cluster will expand to the size $l \quad l$ before reaching the substance $b^{\prime}$, and thus the rays become dispersed orer a considerable portion of the angular face of $b^{\prime}$. Consequently, the latter will become heated, and, since calurific lays rarliate in all directions, a certain amount of heat will be transmitted to the pile wholly independent of that propagated by 
the deflected centrial cluster of rays represented by 7 . But, after taking away the polished substance $b$, and moving the pile to the position $c^{\prime}$ (shown in Fig. 3 ), the pile will obvicusly receive heat only from the central cluster $d d$. Te have thus demonstrated that more heat will be imparted to the pile when placed in the position $c$ than when placed at $c^{\prime}$ in line with the cluster of rays $d$, since in the latter case the calorific energy due to the section of rays corresponding with the area of the face of the pile can alone be transmitted to the same. Apart from this cause of error; it should be ohserved that, assuming the distance $a b^{\prime}$, Fig. 3, to be three times greater than $b^{\prime} c^{\prime}$, the diverging radiation from the heated metal of the lamp will subject the substance $b^{\prime}$ to a greater increase of temperature than that to which the pile is subjected when at $c^{\prime}$, in the ratio of $4^{2}$ to $3^{2}$. 'The effect of this in causing undue transmission of heat to the pile, when placed at $c$, neers no explanation. Several other causes of error inseparable from Laprovostaye and Desains's method of determining the reflective porer of metals might be shown. Among these, the inaccuracy resulting from the uncertain power of the lamp in developing a uniform amount of heat during the experiments may be mentioned. In view of the foregoing, it is evident that the thermo-electric method is unfit to determine accurately the reflective porrer of different substances. And it may be denonstrated that, unless the various substances under examination be exposed simultaneously to a common source of heat, the relittive power of reflecting calorific rays possessed by the same 
cannot be ascertained with perfect accuracy by any method whatever'. 'The instrument illustrated on Pl. 30 has been constructed in accordance with the condition thus presented, the source of heat employed being solar radiation. The fol. lowing somewlat elaborate description and explanation have been deemed necessary to point out clearly its peculiar features. Fig. 1 represents a vertical section of the instrument and the table to which it is attached, the latter being pro. vided with parallactic mechanism by means of which its face is kept at right-angles to the sun during investigations. Fig. 2 shows a top riew of the instrument as seen from a point situnted in the prolongation of its axis, at right angles to the face of the table. $a$ a is a conical reflector composed of cast iron, the sides of which are accurately turned to an angle of $45^{\circ}$ to its axis, a flat bottom being attached provided with a central hub. An axle $d$ is firmly keyed in the said hub, extending both above and be. low the same. 'The lower part of the axle turns in a boss formed on opposite sides of a cross-piece o e, the latter being supported hy two columns bolted to the parallactic table. A hand-wheel $d$, secured to the axle $b$, enables the operator to turn the conical refiector during experiments. Four seg. mental heaters $f, g, h$, and $h$, precisely alike, composed of thin sheet metal, are secured to the botton of the reflector, at equal distance from the centre, with intervening spaces, as shown in the drawing; these spaces to be filled with some non-conducting substance. Fach heater is provided with a conical socket on the top, into which a perforated cork is in- 
serted for the purpose of supporting thermometers entering the fluid, as shown in the sectional representation. It is inportant to observe that, before being attached to the reflector, each heater should be filled with watel of a giren temperature and accurately weighed. In case of any difference of weight, small quantities of soft solder should be gradually applied, until the deficient weight is made good and the four charged heaters balance each other exactly. Regarding the construction of the reflector represented by the illus. tration, it remains to be stated that four segmental plates $f^{\prime}, g^{\prime}, l^{\prime}$, and $k^{\prime}$, composed respectively of silver', brass, nickel, and steel, precisely alike in size and form, should be sol. dered to the inside of the cone $n n$. The plates being thus secured to the conical surface, the reflector should be put before a rotating polishing machine, for the purpose of having an equal polish imparted to each plate.

Referring to Fig. 2, it will be seen that the polished seg. mental plates, the reflective power of which it is intended to measure, are attached opposite to the heaters. Thus the plate $f^{\prime}$, composed of silver, is placed exactly opposite to the heater $f$; the brass plate $g^{\prime}$ opposite to the heater $g$; the remaining plates $h^{\prime}$ and $l^{\prime}$, composed respectively of nickel and steel, being likewise placed opposite to their corresponding heaters $h$ and $h$.

Referring to the vertical section of the instrument shown in Fig. 1, supposed to be turned towards the sun, it will be seen that the solar rays $m$, $n$, indicated by dotted lines, are reflected by the polished segmental plates towards the seni. 
cincular faces of the heaters. The areas of the polished plates being alike, while the weight and areas of the heat. er's presented to the reflected solar lieat are also alike, it follows that if the reflective power of the sereral plates: does not rary, the thermometers inserted in the heaters will show an equal increase of temperature during equal intervals of time. But should the segmental plates not possess an equal power of reflecting the energy transmitted by the solar rays, the thermometer's will, after a brief exposure to the sun, indicate different temperatures. Obvionsly the dif. ferential temperature reached by each thermometer in the same time will furnish a true indication of the relative re. flective power of the several segmental plates, provider there are no disturbing causes affecting the heaters unequally. Before examining this important point, it will be proper to observe that the internal diameter of the conical reflector at $n n$ is 2.5 times greater than the external diameter of the heater's at $o \circ$; hence the radiant intensity transmitted to their faces will be 2.5 times greater than the direct radiant intensity conveyed by the rays $m n$. It should be particularly observed that while the effect of this concentration of heat will influence the four heaters alike, it greatly increases the sensitiveness of the instrument, since the thermometers will be subjected to a radiant energy ?.i) greater than that produced by the direct action of the sur's rays, less the loss occasioned by the imperfect reflective power of the segmental plates, together with the losses of heat caused by convection and radiation. It will be seen, 
on inspecting the rertical section in Fig. 1, that the Tower heater will be subjected to the cooling influence of the upward current of the air caused by the heat imparted by contact with the lower side of the heater. 'The upper' heater; on the other hind, will not be subjected to any appreciable loss of heat by convection, other than that which is shared by the lower heater. It is hardly necessary to point out that the conical reflector itself camnot be maintained at a miform temperature all over, owing to the powerful upward current of air mavoidable in a place exposed to the sun's rays. The apparently insuperable difficulties thus presented, and many others of ninor importance, are orercome by the simple expedient of causing the reflector to revolve during the investigation. The rotary motion is effected, as alleady stated, by means of the hand-wheel d, which is kept revolving at the rate of about six turns per minute while the heaters are being exposed to the reflected and concentrated solar heat. It needs no demonstration to prove that by this expedient all disturbing influences will affect the four heaters alike, thereby neutralizing the same as completely as if no disturbance existed. The nature of the device having been thus minutely described, let us now consider the mode of managing the same during the investigation. (1) Before turning the reflector towards the sum, bring the parallactic table to a horizontal position. (2) Remore the corks and thermometers, and fill the heaters with water of the same temperature as the atmosphere. (3) Replate the corks and thermometers, and bring the 
table to an inclined position corresponding with the sun's zenith distance. (4) In order to ensure a perfect mixture of the particles of water in the heaters, turn the reflector for about two minutes. (5) The rotation being then stop. ped, note carefully the indication of the thermometers, and keep a separate record for each heater and corresponding segmental plate. (6) The initial temperatures having been thus ascertained, and the parallactic table and reflector turned to the sun, the land-wheel should be kept in continuous motion, at the rate before mentioned, for a period of ten minutes. (7) At the expiration of the stated time the motion to be sufficiently reduced to admit of reading the thermometer's, two observer's being employed for that purpose. If the investigation be conducted at noon, during the winter season-the most farorable for accurate observa. tion-it will be well to continue the experiment for fifty minutes, the indications of the thermometers being noted at the termination of every other minute, after the expiration of the first ten minutes before adverted to. It might be sup. posed that an observation at the expiration of the 10th and joth minutes would suffice to ascertain the differential tessperature imparted by the reflected and concentrated rays to each heater; and that by the observed difference of indication the comparative reflective porer of the several seg. mental plates might be accurately letermined. But it will be perceived, on due consideration, that in casse of defects, such as imperceptible leaks or imperfect circulation, the re. corded temperature would lead to a filse determination of 
the comparative reflective properties. Numerous observaltions at definite intervals during the experiment will evidently serve as effectual checks. Of comse, if equal reflective porrer of the respective plates results from ach of these observations, then the accuracy of the determination may be reganded ats abolutely certain. Regarding the initial temperature? of the heaters, it will be perceived that if at starting the indications of all the thermometer's corresponded, the companison of the reffective power of the plates would be very simple; but experience has shown that a perfectly equal temperature at stanting is impracticable. Consequently, each plate, with its corresponding heater and thermometer, calls for a separate record.

It is wortly of notice that investigations intended to determine the lynanic energy of solar ratiation are rendered very difficult, becanse the heat acts on the upper part of any fluid intended to absorb it. Artificial neams must therefore be employer to caluse circulation, or mixture, of the particles within the miss exposed to the solar rays. The difficulty attending artificial cinculation, and the complicated character of the means neecsisary to promote a thorough mixtme of panticles when a fluid is heated from abore, has been shown in Chapter V. Nor can it be denied that, notwithstanding the elaborate character of those means, the ubject has been but partially attained. In the present instance, however, the circulation or mixture of heated and colder particles of the fluid within the heaters is alsolutely perfect; since, for each revolution of the reffector; the coller particles are trans. 
ferred from the bottom to the top of the ressel, and vice versa.

Before prescnting the result of our investigation of the comparative reflective power of silver and other metals, it will be necessary to explain the nature of the annexal tables. We have just stated that, owing to the impossibility of ensur. ing a uniform initial temperature, each of the four polisher plates attached to the inside of the conical reflector hals called for a separate record. The tables, accordingly, contain four distinct divisions, headed respectively silver, has, nickel, and steet; each division having a different intial temperature, rim, silver; $65^{\circ} .7$; brass, $66^{\circ} .1$; nickel, $65^{\circ} .4$; anct steel, $6.7 .1 \mathrm{~F}$. As the temperatures recorded in the table connmence at the termination of the tenth minute from starting, the miginal initial temperatures have not been entered, excepting that of the heater exposed to the solar rays reflected by the silver plate, which forms the standard of comparison. 'The headings of the several columns of the tables being sufticiently explanatory, it will only be necessary to point out the mole of determining the relative reflective power of the segmental plates. Let us select the nickel plate. Referring to the table, it will be found that, at the termination of the soth minute from starting, the thermometer inserted in the heater $/ h$ indicated $89^{\circ} .5$, while the initial temperature in that heater was $65^{\circ} .4$; hence an increase of $89.5-65.4=24^{\circ} .1$ during 30 minutes. During the same period the temperature of the heater $f$, sub. jected to the reflecterl solar rays from the silver plate $f^{\prime}$, it will be seen, by referring to the table, increased 96.4- -65.7 
CHAP. XIX. REFIECTIVE POWER OF POLISHED METALS. 307

\begin{tabular}{|c|c|c|c|c|c|c|}
\hline \multirow[b]{3}{*}{ 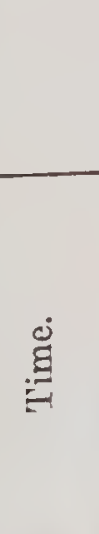 } & \multicolumn{6}{|c|}{$\begin{array}{l}\text { G The Reiative Reflectivis Powler of } \\
\text { Polished Metals. }\end{array}$} \\
\hline & \multicolumn{3}{|c|}{ SILVER. } & \multicolumn{3}{|c|}{ BRASS. } \\
\hline & 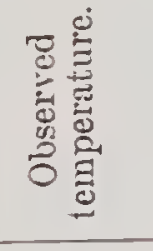 & 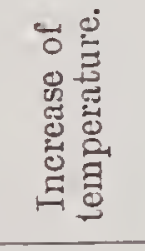 & 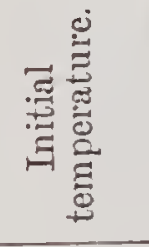 & 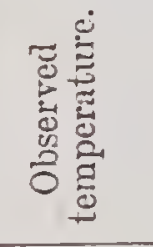 & 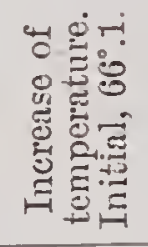 & 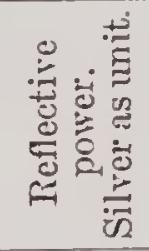 \\
\hline Min. & - Fah. & - Fah. & - Fah. & - Fah. & - $F a h$. & Ratio. \\
\hline 10 & 78.8 & 13.1 & 65.7 & 77.4 & 11.6 & 0.855 \\
\hline 12 & S0.9 & 15.2 & 65.7 & 79.5 & 13.4 & $0 . S S 1$ \\
\hline 14 & 83.1 & 17.4 & 65.7 & 81.5 & 15.4 & 0.SSẼ \\
\hline 16 & 85.0 & 19.3 & 65.7 & S3.2 & 17.1 & 0.885 \\
\hline 18 & 87.1 & 21.4 & 65.7 & S5.1 & 19.0 & $0.8 S 7$ \\
\hline 2() & S8.6 & 22.9 & 65.7 & 86.4 & 20.3 & $0.8 S 6$ \\
\hline 22 & 90.2 & 24.5 & 65.7 & 87.7 & 21.6 & $0 . S S 1$ \\
\hline 24 & 91.6 & 25.9 & 65.7 & 89.2 & 23.1 & 0.891 \\
\hline 26 & 93.3 & 27.6 & 65.7 & 90.8 & 23.7 & 0.858 \\
\hline 28 & 94.9 & 29.2 & 65.7 & 92.2 & 20.1 & 0.894 \\
\hline 30 & 96.4 & 30.7 & 65.7 & 93.5 & 27.4 & 0.892 \\
\hline 32 & 97.6 & 31.9 & 65.7 & 94.3 & 28.2 & 0.884 \\
\hline 34 & 98.4 & 32.7 & 65.7 & 95.4 & 29.3 & $0 . \$ 96$ \\
\hline 36 & 99.7 & 34.0 & 65.7 & 96.5 & 30.4 & 0.894 \\
\hline 38 & 100.8 & 35.1 & 65.7 & 97.3 & 31.2 & $0 . S S S$ \\
\hline 40 & 102.0 & 36.3 & 65.7 & 98.4 & 32.3 & $0.8 S 9$ \\
\hline 42 & 103.4 & 37.7 & 65.7 & 99.5 & 33.4 & 0.886 \\
\hline 44 & 104.0 & 38.3 & 6.5 .7 & 100.0 & 83.9 & 0.855 \\
\hline 46 & 104.7 & 39.0 & 65.7 & 100.5 & 34.4 & 0.882 \\
\hline $4 S$ & 105.3 & 39.6 & 65.7 & 100.9 & 34.8 & 0.575 \\
\hline \multirow[t]{2}{*}{50} & 105.9 & 40.2 & 65.7 & 101.4 & 35.3 & 0.578 \\
\hline & & & & & \multicolumn{2}{|c|}{ Mean $=0.855$} \\
\hline
\end{tabular}




\begin{tabular}{|c|c|c|c|c|c|c|}
\hline \multirow[b]{3}{*}{$\stackrel{\Xi}{ٍ}$} & BLE & ING. T & $\begin{array}{l}\text { RELATI } \\
\text { ISUED }\end{array}$ & $\begin{array}{l}\text { REFLA } \\
\text { PALS. }\end{array}$ & E & \\
\hline & \multicolumn{3}{|c|}{ NICIEL. } & \multicolumn{3}{|c|}{ STEEL. } \\
\hline & 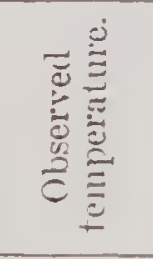 & $\begin{array}{l}0 \\
0 \\
0 \\
0\end{array}$ & 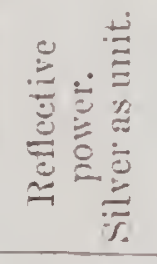 & 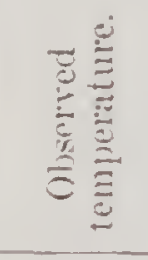 & 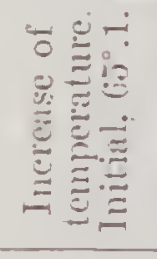 & 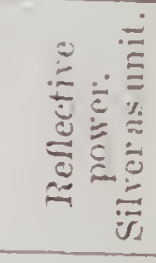 \\
\hline Min. & 'Fuk. & 'Fulk. & lintio. & - Fith. & Fiak. & liatio. \\
\hline 10 & $\pi.) . \tilde{5}$ & 10.1 & 0.781 & 74.1 & 9.11 & 0.687 \\
\hline 12 & $\tau \tau .2$ & 11.8 & 0.776 & 75.6 & 10.5 & 0.684 \\
\hline 14 & 78.8 & 13.4 & 0.77() & $7 \% .0$ & 11.9 & $0.68: 3$ \\
\hline 16 & 80.3 & 14.9 & $1) .792$ & 78.4 & $1: 3.3$ & 0.689 \\
\hline 18 & 82.0 & 16.6 & 0.776 & 79.9 & 14.8 & (1. 6991 \\
\hline 20 & 83.2 & 17.8 & 0.777 & 81.1 & $16.1)$ & 0.699 \\
\hline 22 & $84 . \tilde{5}$ & 19.1 & $0.789)$ & 82.3 & 17.2 & 0.702 \\
\hline 24 & $85 . \%$ & 20.3 & $0.78: 3$ & $8: 3.4$ & $18 .: 3$ & 0.706 \\
\hline 26 & 86.7 & 21.3 & $0.7 \%$ & 84.2 & 19.1 & 0.692 \\
\hline 28 & $8 \% .6$ & 22.2 & 0.760 & S5.9 & 20.8 & 0.712 \\
\hline 30 & 89.5 & 24.1 & 0.785 & $8 \% .1$ & 2.2 .11 & 0.716 \\
\hline 32 & 30.4 & 25.0 & 0.783 & $8 \% .7$ & 22.6 & 0.718 \\
\hline 34 & 91.4 & 26.0 & 0.795 & $8 S . \overline{5}$ & 23.4 & 0.715 \\
\hline 36 & 92.3 & 26.9 & 0.791 & 89.5 & 24.4 & 0.717 \\
\hline 38 & 93.2 & $2 \pi .8$ & 0.792 & 90.1 & $25 .(1$ & 0.712 \\
\hline 40 & 94.2 & $2 S .8$ & 0.793 & 91.0 & 2.5 .9 & $0.71: 3$ \\
\hline 42 & 95.3 & 29.9 & 0.7999 & 91.8 & 20.7 & 0.715 \\
\hline 44 & 0.7 & 30.3 & 0.791 & 92.5 & 27.4 & 0.715 \\
\hline 46 & 96.1 & 30.7 & 0.787 & 92.8 & 27.7 & 0.710 \\
\hline 48 & $9 \pi .0$ & 31.6 & 0.797 & 93.3 & 28.2 & 0.712 \\
\hline \multirow[t]{2}{*}{50} & 97.5 & 32.1 & 0.798 & 94.0 & 28.9 & 0.718 \\
\hline & & \multicolumn{2}{|c|}{ Mean $=0.786$} & & \multicolumn{2}{|c|}{ Mean $=0.709$} \\
\hline
\end{tabular}


$=30.5$. Consequently, the reflective power of silver is to that of nickel as $30^{\circ} .7$ to $24^{\circ} .1=1.000$ to 0.78 .5 . Now, it will be fomml, on inspecting the table, that the reflective power of nickel, tetermined by the mean of twenty-five distinct observations, is 0.786 against the stated 0.78.). This insignificant difference furnishes positive evidence of the reliable character of the investigation. 'The important question of comparative reflective power of siber, brass, nickel, and stort may therefore be reganded as permamently settled; while the reflective power of all other metals may be determined in like manner, by simply detaching the brass, nickel, and steel plates from the conical reflector and substituting other's in their places; the silver plates of conse, remaining as a standari of comparison. It has alleady been stated that, accorting to Iaprorostaye and Desanis's investigation, the reflective power of brass is to that of silver as 0.978 to 1.000 , difference $=0.022$, while onr exact methor of measuring the energy Inst by reflection shows that brass possesses a reflecting power of only $\frac{885}{1000}$ of that of silver, difference $1.000-0.885=0.115$ against 0.022 . Considering the preeision which distinguishes all Lapmorostaye and Desans's inrestigations, this extraordinary discrepancy proves indisputably that the exact loss of calnrific energer attending the reflection of radiant heat cannot be ascertaned by the thermo-electric method. 


\title{
CHAPTER XX.
}

\author{
RAPID-INDICAIION AC'IINOAE'TER.
}

Physicar observatories camnot be regarded as fully equip. ped unless provided with actinometers by means of which the intensity of solar radiation may be quickly ascertained, say in the course of one minute. The thermo-electric pile is of no arail for this purpose, from various reasons: (1) The temperature produced by solar radiation is too high to be correctly registered by the deflection of the galranometric needle; (2) The degree of actual temperature inferred from the arc describer by the reedle is mere guess-rork at the high temperature developed hy a vertical sun; (3) The disturbing effects of movable masses of iron, the presence of which ale marnilable; (4) The rotation of the observatory and consequent irregular change of the magnetic meridian.

The illustration on $\mathrm{Pl} .31$ rejresents a vertical section of an instrument constructed for the special purpose of ascer. taining the intensity of the rarliant heat after a very bricf exposure to the sun's rays. The leading feature of the de. 
vice is that of concentrating the rays before reaching the bulb of the thermometer employed to measure the intensity. It will be readily understood that by employing a lens of proper form the degree of concentration may be such that in the space of sixty seconds the mereurial column of the thermometer subjected to the concentrated rays will rise to the same height as the columm of another thermometer exposed to the direct influence of the sum's radiant heat during a period sufficient to produce maximum indication. Hence, assuming that a proper degree of concentration has been attained in the new instrument, its exposure to the sun during sixty seconds will obviously funish an indication of the intensity of the sun's rays as correctly as the actinometer described in Chap. III., whaterer be the zenith distance or other conditions at the time of making the observation. The concentration of the sun's rays, it shonld be observed, must take place within an exhausted vessel maintained at a constant temperature corresponding with that of the actinometer referred to. It is hardly necessary to point out that it would be impossible to determine theoretically the precise distance between the lens employed to concentrate the rays and the thermometer which receives the accumulated heat. 'The instrument should therefore be so constructed that the lens may be readily moved away from or towards the thermometer during observations. This property of the instrument under consideration may be regurded as another leading feature indispensable to render accurate adjustment practicable. Referring to the illustration, it will be seen 
that the exhamsted ressel anclosing the recording thermunetel' is surroumded by an extrmal casing, the forme of which, like the internil ressel, is eylindrical. The intervening spalce is filled with water maintained at a comstant temperature by a sinilan process of circulation as that anopted in the actinn. meter described in Chay. III. Complings for attaching the circulating tubes are applierl at the bottom and top of the external casing, as shown in the illustration. The inclination of the cylindrical ressel is regulated by a tangential screw working thomgh a nut turning in heanding attached to the side of the external vessel. By means of the gramluated quadrant represented in the illustration, the sun's \%enith distance may be ascertamed by nere inspection, at all times, during observations. A jommal anplied under the exhansted ressel coinciding with the centre of the gratuated quatrant, and turning in anpopriate bearings, supports the instrment. These bearings are secmed to the top of a rerticul column resting on a revolving circular plate, to which a small pinion is applien, as shown in the illustration. 'This pinion. intended to be operated by hand, works into cogs formed at the circumference of the circular hed-plate attached to the top of a substantial table. The tangential screw, it will he seen, is provided with a small hand-wheel at the lower end, enabling the operator to give any desired inclination to the instrument, while the sminl hand-wheel of the pinion, before referred to, enables him to follow the earth's diunnal motion. Let us now examine the mode of regulating the distance between the lens and the thermometer which is cmployed to 
show the intensity of the concentrated radiant heat. We have already pointed out that it is impossible to determine theoretically the said distance. Of course, it maly be calcu. lated approximately, but not sufficiently near to dispense with means admitting of a very considerable morement of the lens up and down during the process of adjustment. In order to meet this condition, the lens is inserted in a perforated piston fitting air-tight in the exhausted cylindrical ressel; the latter being bored out accurately like the barrel of an air-pump. The adjustment of the position of the lens, it will be seen by referring to the illustration, is effected by screws secured in the piston, the nuts employed for raising the same acting against substantial brackets bolted to the top fiange at the upper end of the exhauster cylinder. Conrenient means being thus arranged for raising or lowering the lens in the exhausted cylincler, it will be perceived on reflection that although the thermometer subjected to the action of the concentrated heat is graduated in the ordinary mamner, its indication may be made to correspond exactly with that of an actinometer exposed to the direct action of the sun's rays, provided the piston be placed correctly, viz., at such a distance that the energy of the converged rays under the lens be sufficient to raise the mercurial columm of the enclosed thermometer as high during an interval of sixty seconds as that of an actinometer exposed to the direct solar heat during a period sufficient to produce maximum indication. It will be admitted that but for the introduction of a morable lens it would be impracticable to construct an 
instrument furnishing maximmm indication of solar intensity during the exact interval of sint!l seconds. The experlient, however, of inserting the lens in a piston capable of heing placed at any desirable distance in orter to subject the lublt, of the enclosed thermometer to any requisite temperature, it will be perceived, remiler's that aljustment easy whirle is necessary to secure a given indication in a stipmlated time.

It has been pointel out in previous chapters that, owing to the rapid change of zenith distance, and the consequent variation of the repth of atmosphere penetrated by the suris rays, the indication of an actimoneter is too low during the forenom and too high in the aftermonn. It will be chrions, therefore, that the Tens-instmume under consideration should be adjusted when the sum passes the meridian, since the actinometer employed for comparison then indicites correctly the solar intensity at the moment of making the observation. The adjustment is effected in the following manner: Haring placed the lens-instrument by the side of the stantand acti. nometer selected for comparison, the casings or water-jackets of the two should be connected, by means of flexible tubes, in such a mamner that the ontlet pipe of the actinometer is made to communicate with the inlet pipe of the lens-instrument. Both instruments having been turned towarls the sun, and the usual connections to the cistern and hamrl-pumpl of the actinometer having been completer, the refrickerating current shoukl be circulated through the jackets until the actinometer. inticates maximum differential temperatme. In the mean. time, the operator attenrling to the circulation shonld screen 
the lens-instrument from the sun by a disc of pasteboard. A second operator, as soon as maximum temperature has been reached by the actinometer, starts the chronograph and calls time, the pasteboard screen being at once lowered. At the termination of sixty seconds, time is again called, and the protecting screen instantly raised. Iet us now suppose that the actinometer has continued to indicate a differential temperature of $56^{\circ}$ during the experiment, and that the themometer of the lens-instrument indicates only $j 2^{\circ}$ at the end of sixty seconds' exposure to the concentrated solar radiation. It needs no explanation to show that the observed difference of $56-52=4^{\circ}$ is owing to the want of adequate concentration, and that the discrepancy will be remedied simply. by moving the lens further from the enclosed thermoneter. This is effected by turning each of the nuts at the top of the exhausted cylinder, say once round, thereby increasing the distance. 'The chronograph should again be started, the screen removed, and the operation already described repeated as quickly as possible, and the result recorded. Should it now be found that the enclosed thermometer indicates $54^{\circ}$, another turn of the adjusting nuts should be given, and the operation repeated a third time. Due diligence being exercised by the operator's, the proper position of the lens may thus be determined before a change of the sun's zenith distance takes place sufficient to affect the indication of the standard actinoneter to an extent preventing accurate aljustment. In view of the fact that the form of the lens, and its distance from the thermometer which indicates the inten- 
sity of the concentrated radiation, may be approximately determined by calculation, it is evident that the lens might be stationary and the recording thermometer graduated by repeated exposure to the sum during intervals of 60 seconds, so as to correspond with the indication of a standard actino. meter. I have constructed small lens-actinometer's on this plan, useful for ordinary observations, but for physical obser. ratories and investigations requiring perfect accuracy the instrument having a movable lens, as represented by the illustration in Pl. 31, is far preferable. 


\section{CHAPTER XXI.}

SOLAR RADIA'IION AND DIATHERMANCY OF FLANES.

Tux readers of "Comptes Rendus" are aware that Pire Secchi addressed a letter to the Academy of Sciences at Paris (see "Comp. Rend.," tome lxxiv., pp. 26-30), containing a review of my communications to Nature, published July 13, October 5, and November 16, 1871, in which he questions the correctness of my published reports containing tabulated statements of the temperature produced by solar radiation. His reason for questioning the reliability of my tables appear's to rest on the supposition that my instruments do not furnish correct indications. "It is astonishing," he says, "that Mr. Ericsson should find with his instrument a higher stationary temperature in winter than in summer. This (even bearing in mind the greater proximity of the sur in winter) makes me think that there must be something rery singular in his apparatus, making all its indications deceptive. Even under the beautiful sky of Madrid has M. Rico y Sinobas found, in December, for the solar radiation, 12 div., 19 by his actinometer, and, in June, 25 div., 56." 
Père Secchi ought to have perceived "that there must be something very singular" in the actinometer employed by the Spanish physicist, or it conld not have indicated an intensity twice as high in June as in December: Obriously; a correct actinometer will indicate a ligher tenperature dining the winter solstice tham at midsummer for equal renith distance. The instrmment employed at Minlrid, if Secolni's figmes are (orrect, must therefore be fombled on utterly erroneons prin. ciples. In North America, in lat. to deg. 42 min. (the Jatitude of Madrid is 40 deg. 24 min.), solar intensity at nom during the latter part of June is $64^{\circ} .5$ when the sky is clear, while at noon during the litter pint of December the temperature under similar atmosplieric conditions reaches $57^{\circ} .70$. But observations made in the morning or evening during the month of June, at the hour when the sun's alti. tude is the same as at noon in Decenber, show that the intensity of the radiant heat in June is only $53^{\circ} .08$, agamst $57^{\circ} .49 \mathrm{I}$. in December. Actual observations lave thus established the fact that for corresponding aenith distance the temperature produced by the radiant heat when the earth has nearly reached perilielion, is $57^{\circ} .49-53^{\circ} .0 s=4^{\circ} .41$ higher than at milsmmmer. Referring to Chap). IV., it will be seen that, owing to the greater proxinity of the smm, the increase of absolute intensity of solar ladiation is $4.66 \mathrm{~F}$. dming the winter solstice. Pire Secchi will do well to eximine the subject more carefully, and make himself better acynainted with the character of the investigations which have led to an exact determination of the temperature produced by solar radiation. 
The readers of "Comptes Rendus" who have examined the review referred to, ignorant of the articles in Vuture, the contents of which Pire Secchi criticises, will be surprised to learn that I have not, as the reviewer asserts, questioned the power of rapor to diminish solar intensity. Having stated the result of numerous observations of the sun's ratiant power at corresponding zenith distance, and prover that the tempe. rature during midwinter is higher than at nidsummer, I made the folluwing remark in Nature, Nor. 16, 1581: "In the face of such facts it is idle to contend that the temperature lnoduced by solar radiation nuder corresponding zenith distance and a clear shy varies from any other cause than the varying distance between the sull and the earth." It is absurd to suppose that a person having deroted many years to the investigation of solar radiation should deny the retarding influence of rapor, since not one observation in a hundred indicates maximum solar intensity, owing to the presence of rapor in the atmosphere.

'The following brief description of the actinometer which Père Secchi supposed to be constructed on erroneous principles was inserted in ny reply to his criticism published in "Comptes Rendus," betore referred to, in hopes that, on learrring that there is mot anything "rely singulall" in my appatlatus, he woukl have seen fit to withllaw his statement questioning the colrectuess of my observations relating to solar intensity: "The principal part of the instrunent consists of an alr-tight cylindrical ressel, the axis of which is directed towards the sum, the upper end heing provided with 
a thin lens covering an aperture 3 ins. in diameter: The bulb and part of the stem of a mereurial thermometer is inserted through the uldere side, at right angles to the axis, a small arreump being applied for exhausting the air from the cylindrical ressel. The latter is surrounderl hy a cising through which water is circulaterl by means of an wrlinary force-pump and flexible tubes, comected with a cilpacions cistern containing water kept at a comstant temperature of $60^{\circ} \mathrm{F}$. The bulb of the thermometer' is cylindrical, 3 ins. long, its contents bearing a rely smill proportion to its convex area. The upper half is coated with lanmphlack, while the lower lialf of the bulb is effectually protrected against loss of lieat from undue radiation. 'The diminution of energy attending the passage of the sun's lays through the lens is made good by the concentration effected by its cur. rature; lience the true energy of the radiant heat trans. nitted will be shown by the expansion of the mercury in the hulb. 'The inclination of the latter, it should be ob. serverl, promotes a rapid upward current of the contents on the top sicle, and a corresponding downward current on the lower sile, thereby rentering the indication pronpt and trustworthy. The water in the surrounding casing being maintained at a constant temperature of $60^{\circ} \mathrm{F}$., it will be evident that the aero of the thermometric scale of the actino. meter must correspond with the line which mats $60^{\circ}$ on the Fahrenleit scale. It scarcely needs explanation that the height reacher by the mercurial. column after turning the instrument towards the sun will be due wholly to solar 
energy, since the ratiation of the exhausted ressel towards the bulb of the thermometer is only capable of raising the column to the actinometric zero ( $60^{\circ}$ Filnr.)"

'The readers of Nuture will remember that one of my articles reviewed by Père Sechi continins al demonstration accompanied by several diagrams, proving that the radiant heat emitted by the chromospliere and outwind strata of the solar envelope is inappreciable at the surface of the earth. It will be remembered, also, that the mole alopted in setthing the question whether the solar atmosphere is capable of emitting heat rays of appreciable energy was that of shutting out the rays from the photospliere and collecting those from the chromosphere and envelope, in the focus of a parrabolic reflector. Scarcely any heat being produced, notwithstand. ing the great concentration by the reflector, I prover the fallacy of Pere Secchi's remarkable assumption, that the high temperature at the surface of the photosphere is cansed by ratiution "received from all the tramsparent strata of the solar envelope." It is surprising that, notwithstanding the completeness and positive nature of my demonstration, no allusion whatever is made to the same in a review professing to scrutinize the subject critically. Tguoring the evidence furmished by actual trial in proof of the extreme feebleness of the radiating power, the reviewer proceeds to state "that the outward strata might be less hot, and that the effect. which we measure is the aggregate of the quantities of heat which are added, emanating from the rarious transparent stratal." How the outward colder strata cause an elevation 
of temperature by their radiation toward the solar surface is not explained, but reference is marte to the result of an ex. periment with three small flames in support of the assertion that the high temperature of $10,000,000^{\circ} \mathrm{C}$. assigned to the surface of the sun is owing to radiation receivel from all the transparent stratil surrounding the photosphere. "A very simple experinent," the reviewer states, "made at my request by P. Prorenzali, has shown that, if a heating of 2..) deg. can be oltained with one flame, with two flanes placed one before the other 4.5 deg. are obtainer; with three flanes, 5.4 deg:-a result easily foreseen, for everyborly knows that flames are transparent."

My practical demonstration establishing the feeblencss of the radiating power of the matter composing the solar enve. lope having received no consideration, while the reviewer, in support of his singular theory of solin temperature, points to the result of the rude experiment conducted by Pire Prorenzali, I have deemed it necessinly to show that the trans. parency of flames is too imperfect to warrant the inferences drawn.

'The illustration on Plate 32 represents an apparatus by means of which the exact degree of transparency of a series of flames has been ascertained.

Description: l, conical ressel, open at the top, the bottom communicating with a cylindrical chamber $f$ by a narrow pas. sage, the whole being enclosed in an exterior ressel c, charged with water kept at a constant temperature, precisely as in the actinometer. $\Lambda$ thermometer is applied near the bottom of 
the cylintrical chamber, the centre of the bulb coinciding with the prolongation of the axis of the conical ressel. A gas-pipe d, provided with a series of vertical burners, is firmly secrares to an inclined table in a position parallel to the axis of the conical ressel. 'The burner's are provided with caps in order to ardmit of any desimble number of jets being ignited at one time. When gas of ordinary pressure is admitted into the pipe $d$, the side view of the flame will be as indicated by the dotted lines at $m \cdot m$, the thickness of each flame being nearly $0.20 \mathrm{in.}$, while the width, shown by the dotted lines w. n, somewhat exceeds 3 ins. from point to point. It will be observed that the prolongation of the axis of the conical ressel upwards passes through the central portion of the flames at the point of maximum thickness and intensity. Supposing that the instrument (attached to a table provided with parallactic nechanism) is directed towards the sun, it will be evident that all the rays of a pencil, the section of which corresponds with that of the bulb of a thermometer, will pass through the flames before reaching" the said bulb. Now, the temperature of the flames at the point pierced by the solar rays is fully $2,000^{\circ} \mathrm{F}$, while the actual intensity of the rays does not exceed $60^{\circ}$. It is hardly necessary to observe that the illustrated device enables us to ascertain whether the solar rays thus entering at a difterential temperature $1,9 \pm 0^{\circ}$ lower than that of the incandescent gas have their intensity augmented or diminisher luring the passage through the heated medium. But before we can determine this question, it will be necessary to ascer- 
tain what temperature is communicated to the thermometer by the radiant eneroy of the flames alone. Accordingly; a series of experiments have been marle, the result of which is recorded in the amnexed table.

\begin{tabular}{|c|c|c|c|c|c|}
\hline \multicolumn{3}{|c|}{$\begin{array}{l}\text { The instrument turned away from } \\
\text { the sun. }\end{array}$} & \multicolumn{3}{|c|}{ The instrument directed towards the sun. } \\
\hline 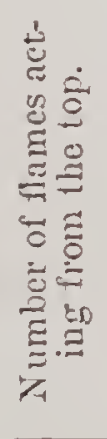 & 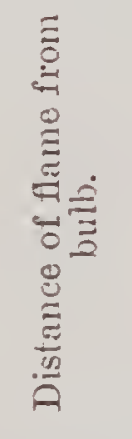 & 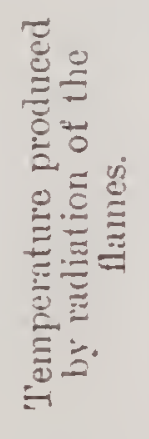 & 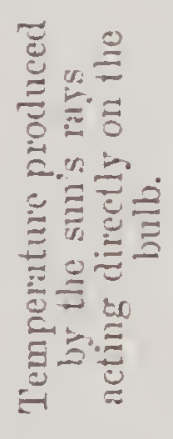 & 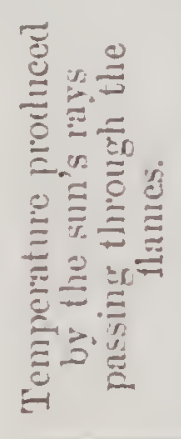 & 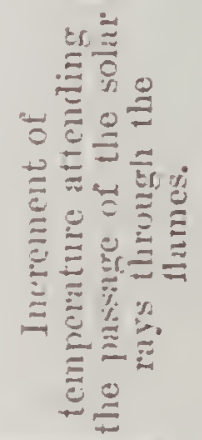 \\
\hline & Inches. & ${ }^{\circ} \mathrm{Fah}$. & 'Fah. & - lak. & ${ }^{\circ} \mathrm{Fah}$. \\
\hline 1 & 24.8 & 1.76 & 21.60 & 21.90 & 0.30 \\
\hline 2 & 23.5 & 2.88 & 21.61 & 22.20 & 0.59 \\
\hline 3 & 22.8 & 3.80 & 21.62 & 2.29 & 0.87 \\
\hline 4 & 21.8 & 4.58 & 21.63 & 22.75 & 1.12 \\
\hline 5 & 20.8 & 5.24 & 21.64 & 22.99 & 1.35 \\
\hline 6 & 19.8 & 5.84 & 21.65 & 23.32 & 1.57 \\
\hline 7 & 18.8 & 6.38 & 21.66 & 23.43 & $1.7 \%$ \\
\hline 8 & 17.8 & 6.91 & 21.67 & 23.63 & 1.96 \\
\hline 9 & 16.8 & 7.40 & 21.68 & 23.82 & 2.14 \\
\hline 10 & 15.8 & 7.90 & 21.69 & 24.00 & 2.31 \\
\hline
\end{tabular}

The nature of the investigation will be realily understood by the following explanation: The instrument being turned away from the sun and the upper flame $m$ ignited, while the external casing $c$ is kept at a constant temperature 
of $60^{\circ}$, the column of the thermometer at f slowly rises to 61.76. The ratiant heat, therefore, of a single flame produces a differential temperature of $61^{\circ} .76-60=1^{\circ} .76$. The second flane being ignited, the temperature rises to $62^{\circ} .88$, thus increasing the differential temperature to $2^{\circ} .85$. The ignition of the thind flame angments the differential temperature to $3^{\circ} .80$. The rentaning flames being ignited in regrtlan order downwards, their combined radiant energy elerates the temperature to $65^{\circ} .90$. Declucting the temperature of the enclosure $c\left(60^{\circ}\right)$, the trial shows that, although the single flame at the maximum distance from the bulb is capable of producing a differential tenperiature of $1^{\circ} .76$, the energy of the ten flames together produces only $7^{\circ} .90$. This fact furnishes conclusive evidence of the imperfect transparency of the flames. Assuming that the heat rays are capable of passing freely through the incaudescent medium, it will be perceived that the entire series of flames should produce a differential temperature of $1.56 \times 10=17^{\circ} .6$, showing a retardation of $17.6-7.9=9^{\circ} .7$. And if we take into account, the diminished distance of the lower flanes from the bulb of the thermometer, it will be found that the actual retardaltion greatly exceeds this computation. We have thus demonstrated that flimes are not transparent, as supposed hy Pire Secchi; consequently, the inferences drawn from the experiment to which the distimgisherl suvant refers in his letter to the French Academy of Sciences are wholly unwa!'rantable.

Having disposed of the question of transparency, and 
ascertained the degree of temperature communicated to the thermometer by the ratiant energy of the flames alone, let us now suppose that the instrument has been tumed foramds the sum. The temperature produced by the combined energy of solar radiation and the radiation of the flames, after direct. ing the instrument towards the luminary, will be found re. corded in the fifth colnum of the table. Dispensing with a detailed record of the energy transmitted for each flane separately, let us at once consider the effect produced by passing the sun's rays through the eutire series. It hats already been stated that the radiation of all the flames combined imparts a differential temperature of $7^{\circ} .90$ to the thermometer. By reference to the table, it will be seen that the temperature produced by the sm's rays is $21^{\circ} .69$ when the flames are extinguished. Consequently, the temperature produced after lighting the whole series onght to be 21.69 $+7.90=29^{\circ} .59$ instead of $24^{\circ} .00$, since solar lieat, under analogous conditions, is capable of increasing the temperature of substances, whatever be their previous intensity. Our experiment, therefore, furmishes adtitional evidence of the imperfect transparency of flames. But notwithstanding this want of transparency, it will be found on referring to the table that an angmentation of temperature of $24.00-21.69$ $=2^{\circ} .31$ takes phace while the comparatively cold solitr rays pass through the incandescent metium. 'This extramplinaly fact points to an increase of molecular energy within the incandescent gas, although its temperature is fully $1,900^{\circ}$ higher than the intensity of the sun's rays. 


\section{CHAPTER XXII.}

CONSTANOY OF ROTALION OF 'IHE EAR'TH INCONPAIIBLE WI'LH SOLAR INELUENOE.

LANLACE's demonstration, showing that the axial rotation of the earth is not affected by atmospheric currents and similar motions caused by solar heat, has been accepted by physicists as incontrovertible. The German mathematician, Dr. Mayer-celebrated for his demonstration establishing the equivalent of heat-says in a discourse on that branch of celestial mechanics which relates to the effect produced by contrary atmospheric currents: "The final result of the action of these opposed influences is, as regards the rotation of the earth, according to well-known mechanical principles $=0$; for these currents counteract each other, and therefore camnot exert the least influence on the axial rotation of the earth. This important conclusion was proved by Laplace." "The same," he adds, "holds good for every imaginable action which is caused by the radiant heat of the sun, or by the heat which reaches the surface from the earth's interior; 
whether the action be in the air, in the water, or on the land. The effect of every single motion prorluced hy these means on the rotation of the globe is exactly connensited by the effect of another motion in an opposite direction, so that the resultant of all these motions is, as far as axial rotation of the grlobe is concerned, $=0 . "$ I propose to show that this conlclusion is fallacious, and that the sun's radiant heat develops forces capable of diminisling perceptibly the earth's rotary velocity; and that unless the retarding influences of solun heat, the existence of which I am going to establish, are counteracted by some cosmical force of which we have no knowledge, the earth's rotary velocity will be consileribly reduced in the course of time.

There are two classes of force produced by solar heat, capable of retarding the axial rotation, diflering, howerel, entirely as regards ultimate results. The first class includes animate exertion, nechanical force produced by heat developed by the combustion of organic substances, and the resistances of abraded solid matter transferred from its original position by the waters of rivers flowing towards the equator. 'The forces thus enumerated, it will be shown, retand the rotary velocity of the globe in all cases when they remove weight to a greater distance from the axis of rotation, i.e., expand the circle of gyration, thereby diminishing the num. ber of revolutions performed in a given time. Obrionsly; the vis viva of the rotating mass will remain undiminished, as the centre of gyration is merely remored to a greater distance from the axis of rotation. Accordingly, the axial 
rotation, though checked, cin never be stopped by the class of retarding influences thus pointed out. 'The second class, however-which comprises the retardation produced by the atmospheric air during its course from the polar to the equatorial regions, and the retardation caused by the waters which flow towards the equator to restore the quantity lost by the powerful evaporation within the tropies-not only diminishes the rotary velocity, but, at the same time, deprives the earth of so great an amount of vis viva that the axial rotation must ultimately cease, unless some exterior conpensating force exists-a supposition at variance with the principles of mechanics.

Let us now briefly examine the nature of the retarding influences of the first-named class, which, as stated, are unattended by any loss of the earth's vis viva-namely, animate force and mechanical energy, resulting from the combustion of organic substances when expended in raising weight to remain permanently in an elevated position; and the retardation caused by solid matter carried towards the equator. Before entering on this examination, it will be instructive to test by some familiar illustration the correctness of Miryer's assumption, that "every imaginable action affecting the rotation of the globe is exactly compensated by the effect of another motion in an opposite direction." A great variety of instances might be mentioned in which the development of mechanical energy, productive of heat, counteracts the rotary motion of the earth, and deprives it permanently of a certain amount of vis viva. Suppose, for instance, a locomotive 
train weighing 400 toms to be started firon the western terminus of a railwaly rumning from west to cast. Suppose, also, that when this train has alequired a velocity of $50 \mathrm{ft}$. per second, it encounter's another sinilan train which is at rest. The result of such an concounter' in a dynamic print

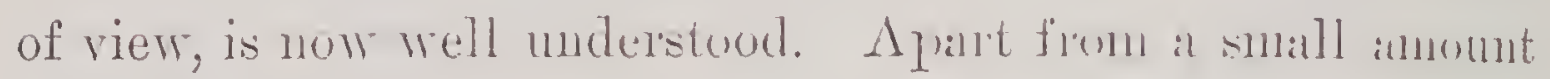
of energy absorbed in orereming the collesive fored between the particles composing the materials fractured by the cont-

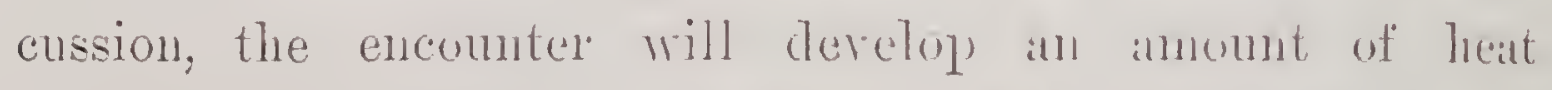
corresponding with the wis wien of the arrested train. It scarcely needs explanation that in putting the train in motion from the terminus eistward the rails-ic, the surfice of the earth-will, in conseguence of the adhesion between the wheels and the rail, be gushed westward; lience in a direction contrary to the earth's rotation. The amount of dynamic energy which the train thus inparts to the earth in an oplosite direction to that of rotation may be realily ascertained by multiplying the andested weight by the height necessiry to proluce a relocity of $50 \mathrm{ft}$. 1 er secont-mamely, $39 \mathrm{ft}$; hence $4(10 \times 2,240 \times 39=34,944,000$ foot-pomds. Deducting the small amomt of anerey which farours the eath rotation called forth ly the rolling friction and athesion of the wheels of the stationary train, during the short retrograde motion attending the concussion, it will he fomm that the earth loses an mount of vis viec of fully $3+, 000,000$ foot-pounds. The assumption of Dr. Mayer, hased on the theory of Laplace, that the resultant of all inaginable no. tions as regandes the earth's axial rotation is - 0 , hats thus 
been proved to be untenable. It is not intended to question Laplate's conclusion as regards the existence of a compensating effect; he was mistaken only as to its nature-a mistake, however, of paramount importance, as we have shown that the compensation tor the lost energy, in the case presented, is the generation of a certain amount of heat which, in less than three hours after the concussion, if the sky be clear, radiates into space, leaving the earth minus $34,000,000$ footpounds of vis viva. The important fact should not be overlooked that the retardation thus established is the result of solar energy stored in the combustibles of the locomotive furnace. Numerous instances of a similar nature might be mentioned in support of the assertion that the earth is subjected to retarding influences and loss of wis vive by mechanical motions on the enrth's surface which result in the production of heat radiated into space. But all these are insignificant compared with the stupendous amonnt of retardation caused by the conversion of mechanical energy into heat within the opposing atmospheric currents circulating betreen the equatorial and polar regions. In connection with this proposition, it will be proper to remark that om knowledge of the convertibility of mechanical energy and heat-in other' words, the convertibility of mechanical and molecular energy -has completely upset Lalplace's demonstration, on which. physicists have based their assumption, that the rotary velocity of the eartl camnot be aftected by the sun's radiant heat.

Let us now examine, separately, those forces producer by 
solar beat which tend to check the earth's rotary velocity by removing weight from the axis of rotation-i.e., expanding the circle of gyration-and those which occasion a diminution of the rate of axial rotation without disturbing the balance of the rotating mass. The first class: Animate or muscularl energy, and the force generater by heat from the combustion of organic matter, controlled by the human mind, both ressulting indirectly from the sun's radiant heat. That the land and intellect of men have caused a disturbance of the position of the earth's centre of gyration will be decmed a startling assertion, yet it cannot be controverted in view of the fol. lowing facts. The millions of tons of matter contanined in the Pyramids, remored to a greater distance from the axis of rotation by the muscular exertion of the ancient Egyptians, disturbed the prerious balance of the rotating mass, causing a tendency to check the earth's rotary velocity and to increase the length of day. Nor can it be questioned that if London had not been built, and if the building materials of Paris yet remained in the Catacoubs, the sun would rise earlier than it now does, though the difference would be small beyond computation. 'The aggregate of the weight remored from below, and piled above the crust of the globe by the liand of man, is, however, so great that figures are competent to express the extent of the consequent retardation of the axial rotation, while the divisions of our common instruments for measuring distance are sufficiently ninute to indicate the expansion of the earth's circle of gyration caused by the transfer of matter under consideration. A first-class modern 
city, for instance, contrins upwards of 100,000 houses; each house contains on an average 400 tons of mineral matter" hence the total weight of brick, earth, or stone remored from below the surface to a considerable height above the earth's surface exceeds 40,000,000 tons-al mere fraction comparest with the weight of the whole of human habitations and other structures raised above the surface of the earth chiefly by muscular effort. Let us add the weight of materials raised from mines to an increased distance from the axis of rotation, by animate exertion and by mechanical force controlled by intellect.

An element of greater importance, connected with the first class of retarding influences produced by the sun's radiant heat, next claims oul attention-namely, the solid and sedimentary matter detached by the abrasion of rain-water, and afterwards conveyed by the currents of rivers to a position nearer the equator; hence remored to a greater distance from the axis of rotation. 'The question whether any estimate can be made of the aggregate reight of matter, the original position of which is being changed during definite periods by the cause referred to, is by no means so diffieult to answer as might appear without due consideration. It is true, we do not know what quantity of water' or sediment is carried towards the equator by the sereral l'ivers; but we can compute with sufficient exactness the extent of the river basins. Accordingly, if we conld estab. lish a mean of discharge per square mile of some very extensive basin comprising all the varieties of climate and 
soil, the question could be satisfactorily answered. Fortu. nately, one of the longest rivers on the globe, the Missis. sippi, which drains the greatest extent of surface with but two important exceptions, has heen calcenly surveyed by a (orps of Topographical Engineers, ly orter of the Linited states Goremment. Not only las this great river been thus carefully exmined, but the hasin it drains comprises "very ralliety of soil and climate-its souree being anomg suows and lakes frozen during the greater prortion of the year, while the outlet is near the tropics. 'That the Miscissppi basin represents the average of the river systems of both hemispheres has been established hy the fact that, although the rain-ganges at its northern extrenity show only 18 ins. for twelve months, those of its sonthern boundany reach 66 ins., with every possible gradation of precipitation in the intermediate space. In adilition to this important circunstance, the basin covers 21 deg. of latitude and 35 deg. of longitude, or 1,460 miles by 1,730 miles; hence comprising an area greater than the entire European Continent west of the rivers Vistula and Pruth. It miry he conficlently as. sumed, therefore, that the Mississippi hasin represents the arerage discharge of water and sediment so nearly that calculations based thereon, applied to the river systems of both hemisplueres-excepting some of the northern Isiatic and Anerican rivers-will exhihit a general result differing but slightly from what would be established if each river had been examined.

The elaborate report of General Humplueys to the Bu- 
rean of Topographical Lugincers, Mashington, shows that the average quantity of earthy matter carried into the Cinlf of Mexico, partly suspended in the water and partly pusherl almog the bottom of the river by the current, anounts for each twelve months to 903,100 millions of pounds. This curmous weight of matter is contributed by numerous lange branches and upwards of 1,000 small tributilies. 'The mean distance of the streans along which the sedinent is cillnier in its connse to the sea exceeds 1,500 miles. The distance which determines the amount of force tending to check the carth's rotatim is, hmorer, considerably shorter.

The maps of the Mississippi River basin accompanying the report referred to show that its centre is situated 7 deg. 10 min. west of the month of the main river, and 11 deg. 12 min. north of the sance, in latitude $t 0$ deg. $15 \mathrm{~min}$. It will be found on inspecting the section of the earth (see Pl. 33) that, agreeably to the stated latitude, the centre of the Mississippi basin rotates in a circle of $15,784,782 \mathrm{ft}$. radius; lence its relocity round the axis of the globe is $1,147.90 \mathrm{ft}$. per second. The mouth of the river; it will be found on calculation, rotates in a circle of $18,246,102 \mathrm{tt}$. radius, with a circumferential velocity of $1,326.89 \mathrm{ft}^{\prime} \mathrm{l}^{\mathrm{r}}$ second. Comparing these relocities, it will be seen that an increased circumferential velocity of 178.49 -say $179-\mathrm{ft}$. per second is imparted to the water and to the sedimentary matter which it conveys during the course from the centre of the basin to the mouth of the river. As before stated, the annual discharge of earthy matter at the mouth 
of the liver is 903,100 millions of pounds. The centre of the basin-lat. 40 deg. 15 min.-being $2,461,320$ ft. wearer to the axis of rotation than the mouth of the river in lat. 29 deg. 0 min., it will be found that the increase of rotary relocity is $172 \mathrm{ft}$ per second, as already stated-a rate ac. quired by a fall of 500.6 ft. The elements are thus furnished for determining with exictness the amount of retardation attending the change of position of the abraded matter during its transfer from the basin to the mouth of the river. Multiplying 903,100 millions by 500.6, we ascertain that the counteracting force amounts to $452,000,000$, 000,000 foot-pounds amnually $=452 \times 10^{14}$ foot-pounds in a century. The earth's present vis viva being $18,575,361 \times$ $10^{22}$ foot-pounds (to be demonstrated hereafter'), it is easy to calculate that the retardation occasioned by the stated re. acting energy called forth by the sedimentary matter which is carried to the ocean by the Mississippi will amount to $\frac{36}{100000}$ of a second in a century. In view of this small frac. tion of time, it will be well to remind the reader that the retardation of the earth's rotary relocity, inferred from the apparent acceleration of the moon's mean motion, now generally admitted by astronomers, is somewhat under 12 seconds in a century. Insignificant as this retandation appears to be, it calls for a constant reacting force of 455,000,000,000 footpounds per second, as will be shown in the conrse of our juvestigation. Dividing this amount by the adopted standard. of a horse-power-viz., 550 foot-pounds per second-it will be found that a constant energy representerl by $827,000,000$ 
horse-power, exerted in a contrary direction to that of rota tion, is necessary to check the rotary motion to the extent mentioned-viz., $\frac{1^{2}}{560}=\frac{1}{82^{2}}$ of a revolution in the course of a century. Accordingly, 720,000 years, nearly, will elapse before one entire revolution shall have been lost, notwithstanding the existence of a constantly retarding force of 455,000 millions of foot-pounds per second. We can readily ascertain the aggregate of this force during the long period mentioned, if we multiply the same by the number of revo. lutions of the earth per anumm, and the number of seconds for ench revolution; thus, $455 \times 10^{9} \times 365.2+\times 86,400 \times$ $720,000=103,379,867 \times 10^{17}$ foot-pounds. By diriding this amount of energy in the earth's vis viva, $18,875,361 \times 10^{23}$ foot-pounds, we ascertain that the stated enormous retardition overcome in the course of 720,000 years amounts to unly $\frac{1}{18: 58}$ of the present rotary vis viva of our planet. Probably no other mode of presenting the subject could give so clear an idea of the rastness of the mechanical energy developed by the axial rotation of a sphere 8,000 miles in liameter, whose specific grarity is 21 times that of granite, revolving at a rate of one revolution in 24 hours. Let us bear in mind that the retardation produced by the sedimentary matter carried to the Gull of Mexico by the Mississippi, and the precipitation which canses the abrasion of the solid matter and the currents by which it is conveyed, are the direct results of the sun's radiant heat.

With reference to the tibles (see pages $342-353$ ), it should be stated that the amounts of the retarding force 
entered in the last two colnmms but one are based on the dat: furmished by the examinations of the great Western river-viz, that 1 1b. of solid matter and 1,350 1hs. of water per second wre carried to the sea for every to.0s sq. miles of basin. All other particulars necessary in compunting the retanding energy exerted by each river, seramaty for the two hemi. spheres, will be found in the tables. The morle arlopted in determining the area dramed he each river and tributmins will be reallily comprelenterl by the following explantion: The extent of the several livel hasins, los; in all in loth hemispheres, has been ascertained form the best maps oxtant; the boundaries of the hasin being determined by drawing a line on the maly, and diviling the territory equally between the source of each river and tributaries and those of adjoining basins. 'The boundarios being thus defined, the areas have been calculater in Finglish statute miles; the latitude and longitude of the centre of each bisin being determined at the same time. By supposing the earth to be at perfect splere 7,912.41 miles in diameter, according to Sil John Herschel's determination, the calculations have been rendered extremely simple. This will be seen by reference to the section of the eirth before referred to, which contains all the elements for computing the rotary velocity of the centres of the river basins and of the ontlets of the rivers. These velocities have been entered in the tables separately for each river basin; also the retardation, expressed in foot. pounds per second, cansed by the increase of rotary velocity during the transfer of the sedimentary matter from the cen- 
tre of the basin to the month of the river. The last column but one of the tables contains the result of computations of the anount of retardation occisioned by the rolume of water which conveys the sedinentary matter-a subject to be considered under a separate heal hereafter:

It should be observed that, owing to their trifling influence on the earth's rotation, and in order to save space, all the English and Scotch river basins whose sedinent is transferred in the direction of the equator latre been entered together in the tables; the rivers of Treland likerise. But in computing the loss or gain of energy, each river bisin has been calculated by itself, the amount of retardalfion entered being the result of the whole quantity of serliment transferred towards the equator by the sereral small basins referred to. Accordingly, the area which is entererl in the tible represents the total. The river basins of sweden and Norwaly, being very unmerous and unimportant, hare also, in some districts, been entered together in the tables like those of Great Britair. Finally, the narrowcoast districts, in both hemispheres, have been computed and inserter in the table in a similar manner.

The quantities of sedimentary matter discharged by the Indus, Ganges, and Brahmapootra, being known with tolerable accuracy from actual observation, have not been computed according to the standard furnished by the Mississippi, Which, as before stated, is $1 \mathrm{lb}$. of sediment per second for every 40.08 sr. miles of basin. Besides, local circumstances, such as the heated waters and profuse evalporation of the 
Bay of Bengal, and the porrerful condensation attenting the close ricinity of the Hinalaya Momntains, render the Ginges quite exceptional.

Respecting the African rivers, none of which have heen entered in the tables, it may be brielly stated that they hare no material influence on the carth's rotation, from the finct that the two principal rivers, the Nile and the Niger, flow in opposite directions-the former towards the pole and the latter towards the equator. There is, however, comsiderable difference of latitude, productive of an in. creased retarding influence of the Nile; but this cannot be far from balanced by the greater quantity of sedimentary matter brought down by the Niger'; as prored by its delta of 240 miles of coast. 'The general course of the other important rivers of Africa-the Senegal, Zambesi, and the Orange River-is so nearly parallel with the equator that they exercise no appreciable influence on the axial rotation of the earth.

Australia, being drained by rivers the courses of which are directed to all points of the compass, consequently exercising no appreciable influence as regards the earth's rotary motion, has likewise been excluded from the tables. It should be observed that the basin of the important river Croolwa and its tributaries (excepting the Callewatta) is almost on the same parallel with the moutl of the main river; hence scarcely any retarding force is produced, notwithstanding the great extent of basin drained by the Goolwa. 'The Amazon, which drains more than two mil- 
lions of square miles, strikingly illustrates the trifling influence on the earth's rotary velocity of rivers the centres of whose basins are nearly on the same parallel with their outlets, the enormous mass of solid matter carried to the ocean by this river-the greatest on the globe-exerting a retirding influence of only 70,000 foot-pounds per second.

The aggregate of solid matter removed from its original position by the river systems of both hemispheres, and carried towards the equator-consequently removed to a greater distance from the axis of rotation-exerts, as shown by the tables, a retarding influence of $39,894,658$ foot-pounds per second. If we multiply this amount by 86,400 seconds, we learn that for each revolution the earth has to orercome a retarding energy represented by $3,446, \$ 9 S, 451,200$ footpounds; but the effect of this retardation as regards tlie length of the century camnot be properly considered until we have investigated the second class of force before adverted to, viz, that force which destroys the earth's vis viva without disturbing the position of its centre of gyration. We hive, however, proceeded far enough with our investigation to show the fallacy of the accepted doctrine of compensation relative to the energies which affect the earth's rotary relocity. We have clearly shown that constancy of rotation of the earth is incompatible with solar influence. 


\begin{tabular}{|c|c|c|c|c|c|}
\hline $\begin{array}{r}\text { RIVERS FLOWING TOWARDS } \\
\text { HEMTS }\end{array}$ & $\begin{array}{l}\text { THE EQ } \\
\text { PH LERE. }\end{array}$ & ITOR. & EAST & KRS & \\
\hline & & Rive & ER BASI & & \\
\hline Name of River or District. & Area. & 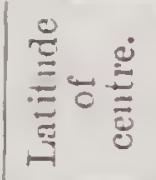 & $\begin{array}{l}\text { Tiast } \\
\text { of } \\
\text { outlet. }\end{array}$ & $\begin{array}{l}\text { West } \\
\text { of } \\
\text { outlet. }\end{array}$ & 焉 \\
\hline & Sq. Miles. & Deo. $x$ & $D \in\{1 .$. & Degl. .1 & $\begin{array}{l}\text { Feet per } \\
\text { secunul. }\end{array}$ \\
\hline Anadir.............. & 119,200 & $(6) 50$. & $\ldots$ & $1: 3 i$ & $(62 \cdot 2)$ \\
\hline N. W. coast Sea of hamtschatka & $12,00(1$ & (i) 12 & () 10 & $\ldots$ & 720 \\
\hline Penshima ................. & $50,1()(1$ & $6: 320$ & 1) 20 & .. & 6\&i \\
\hline IV. coast Sea of Okliotik. & $30.6(1)$ & 6200 & .. & () (1)i & $71: 3$ \\
\hline 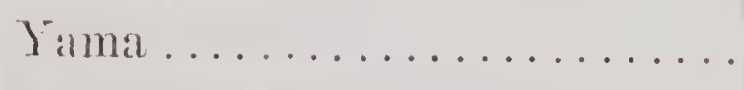 & $15,5)(0)$ & 6() 4.5 & $\cdots$ & 1. 30 & $7+2$ \\
\hline 'lawi and Kowa. & $1: 3,3(1)$ & (i) 25 & $\cdots$ & () 11) & Ti.11 \\
\hline Ochola ........ & $21, \tilde{5})(x)$ & (6) 48 & $\cdots$ & () 40 & $7+1$ \\
\hline Ud .... & $2 \pi, 400$ & 5.525 & $\cdots$ & 283 & $86 \%$ \\
\hline 'I'oumen . . . . . & 20,000 & 4320 & $\cdots$ & 015 & $1,10 i$ \\
\hline Yalon ............ & 21,200 & 41. 10 & 105 & $\ldots$ & 1,144 \\
\hline Sira M[uren ........ & 78,800 & 4240 & $\cdots$ & 106 & 1,117 \\
\hline Chanton..... & 29,800 & 4100 & $\ldots$ & $0: 30$ & 1,146 \\
\hline Pei-ho...... & $124,0(0)$ & 3840 & $\ldots$ & 245 & 1.186 \\
\hline Miı Kiang.... & $2 \pi), 400$ & 2620 & $\ldots$ & $11 \%$ & 1.362 \\
\hline Han Kiang. . . . & 26,200 & 2418 & 005 & $\ldots$ & 1,384 \\
\hline Trhe Kiang.... & 144,400 & 2410 & $\ldots$ & 350 & 1,386 \\
\hline IIoang Ho . . . . . . & 448,200 & 3650 & $\ldots$ & $10: 5$ & 1,216 \\
\hline 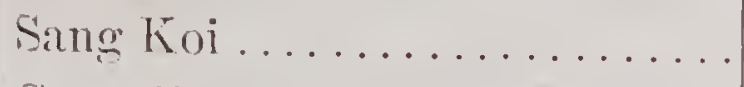 & 76,300 & 2240 & .. & 228 & 1.410 \\
\hline Coast Rivers, Gulf of Tonquin. & 26,000 & 2012 & $\cdots$ & 150 & 1,426 \\
\hline Henam Kong . . . . . . . . . . & 329,500 & 1638 & $\ldots$ & 315 & $1,45 \%$ \\
\hline Irawady . . . . . . & 205,000 & 2235 & $\ldots$ & 030 & $1,40: 3$ \\
\hline Brathmapootra ........... & 379,000 & 2912 & $10 \%$ & $\ldots$ & 1,326 \\
\hline Ganges above Ghazeponr.... & 187,100 & 2725 & $\ldots$ & 525 & 1,346 \\
\hline Ganges below Ghazeponr.... & 237.200 & 2730 & $\ldots$ & 512 & 1,347 \\
\hline
\end{tabular}




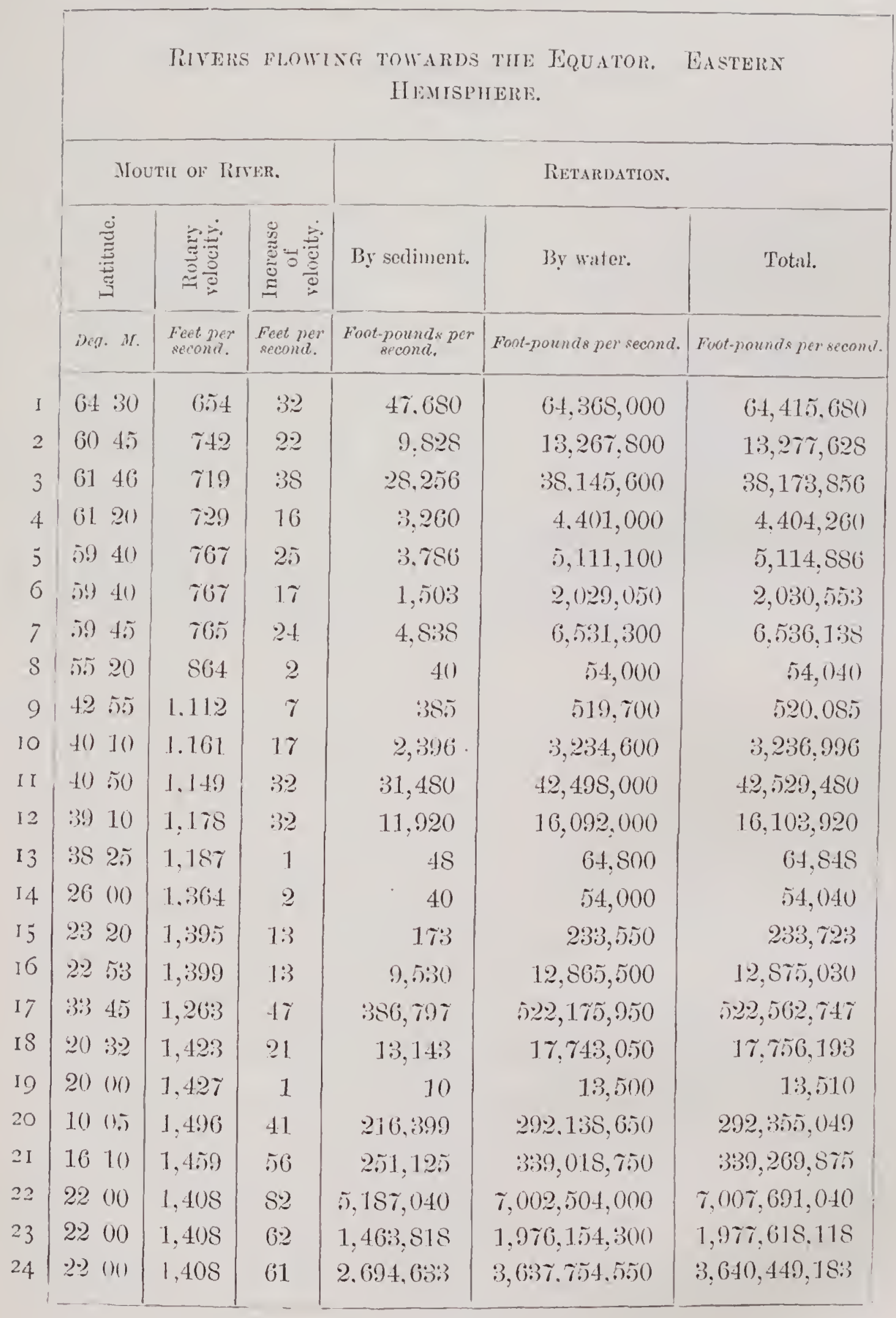




\begin{tabular}{|c|c|c|c|c|c|}
\hline \multicolumn{3}{|c|}{ 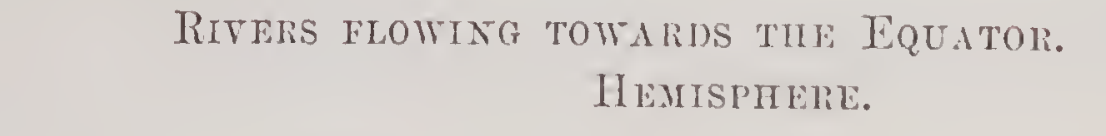 } & \multicolumn{3}{|c|}{ EASTERT } \\
\hline \multirow{3}{*}{ NaME of RtVER OR District. } & \multicolumn{5}{|c|}{ Tiner Basix. } \\
\hline & Aren. & 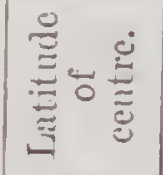 & $\begin{array}{c}\text { East } \\
\text { of } \\
\text { out let. }\end{array}$ & $\begin{array}{c}\text { West } \\
\text { of } \\
\text { outlet. }\end{array}$ & 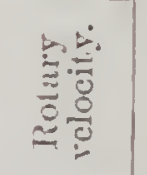 \\
\hline & Sq. Miles. & Deg. $1 \%$ & Deg. $Y$ & Deg. 1 . & $\begin{array}{l}\text { Feet per } \\
\text { recond? }\end{array}$ \\
\hline Khaladaing.......... & 27,400 & $211 \pi$ & .. & 020 & 1,416 \\
\hline Braming and Coyle.. & 31.000 & 2212 & ... & 126 & 1,406 \\
\hline Mahamuddy......... & 41,300 & 21012 & $\ldots$ & 35 & 1,418 \\
\hline N. TV. coast Bay of Bengal. & 24,000 & 1915 & .. & () $3: 2$ & 1.434 \\
\hline Godavery............... & 133,000 & $19: 35$ & $\cdots$ & 325 & 1,431 \\
\hline Kishna ............... & 104.900 & $16+5$ & $\ldots$ & $4: 3.5$ & $1,45 \%$ \\
\hline TV. coast Bay of Bengal. & 8,300 & 15) 45 & $\ldots$ & () 18 & 1,462 \\
\hline Penaur.............. & $1 \%, 900$ & 1445 & $\cdots$ & 130 & 1,469 \\
\hline Palar........ & 23,700 & 1252 & $\cdots$ & 120 & 1,481 \\
\hline Cilurery... & $2 \%, 000$ & 1145 & ... & 1533 & 1,487 \\
\hline I'apty....... & 23,600 & 2115 & 250 & $\ldots$ & 1,416 \\
\hline Nurbudda... & 21,600 & 2214 & $34 \pi$ & $\ldots$ & 1,406 \\
\hline Sukernully . & 29,700 & 2327 & 025 & $\ldots$ & 1,394 \\
\hline Jahu ....... & 48,300 & 2625 & 220 & ... & 1,360 \\
\hline Indus ...... & 346,300 & $33: 30$ & 520 & $\cdots$ & 1,267 \\
\hline Helmund ............ & 124,000 & $: 3242$ & 325 & ... & $1,27 \mathrm{~S}$ \\
\hline N. coast of Alabian Sea.... & 93,000 & $26: 30$ & 100 & $\ldots$ & 1,359 \\
\hline N. F. coast of Persian Gulf. & 66,000 & 2900 & 045 & $\ldots$ & 1,329 \\
\hline S. coast of Alabia......... & 96,000 & 15) 20 & $\ldots$ & 050 & $1,46 \pi$ \\
\hline Euphrates and Tigris. . & 282,100 & $35)$ & $\ldots$ & 435 & 1,243 \\
\hline Kour ............. & $9 \pi, 400$ & $305 \%$ & $\ldots$ & $3: 32$ & $1,16 \%$ \\
\hline Oumal. . & 120,300 & 5004 & 201 & $\ldots$ & 975 \\
\hline Don........... & 195,400 & 4856 & 148 & $\ldots$ & 998 \\
\hline Fmba district. . & 37,800 & 4750 & 300 & $\ldots$ & 1,020 \\
\hline
\end{tabular}




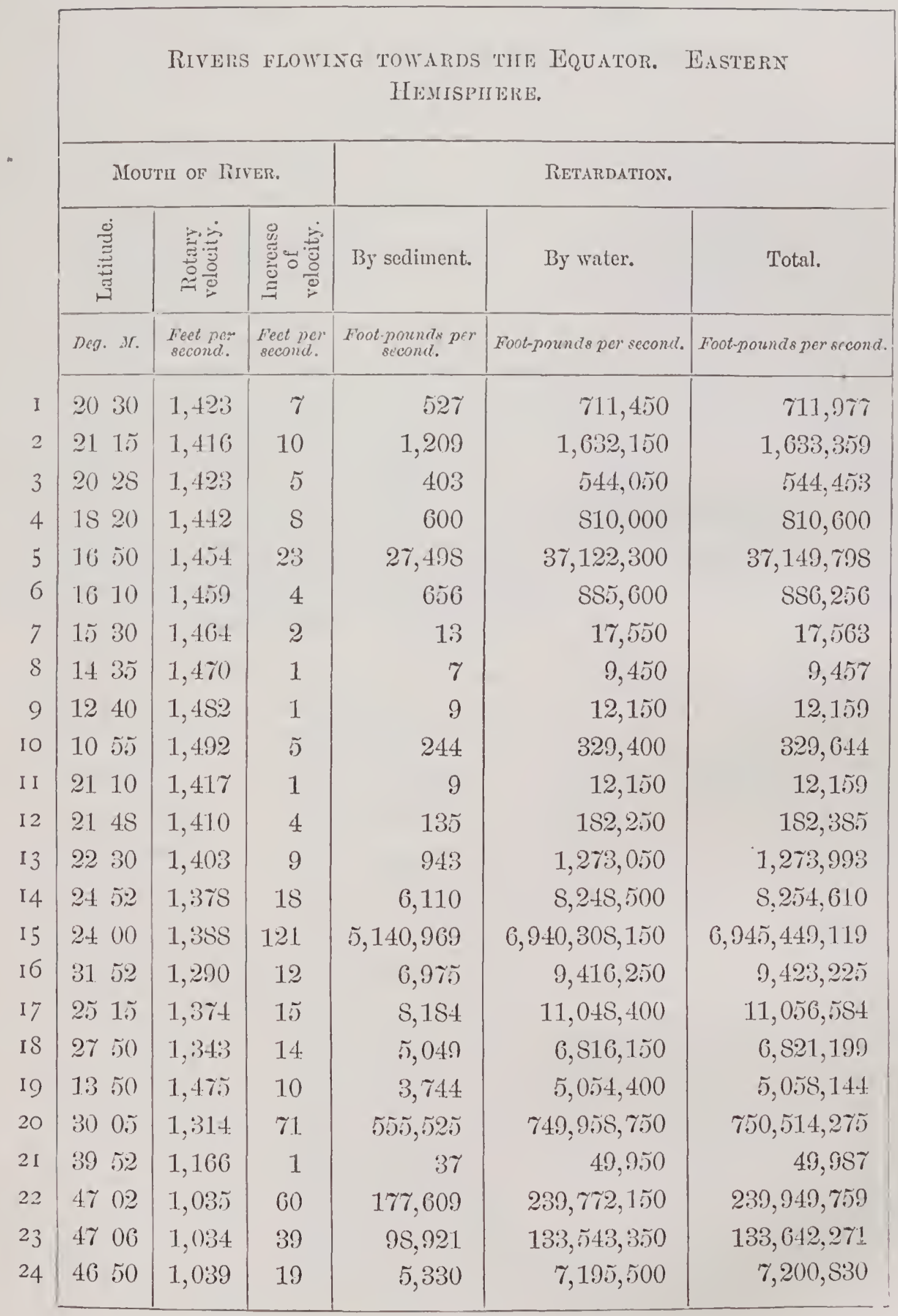


Rivers flowing towalios the Equator. Eastern HEMISPHIIE.

\begin{tabular}{|c|c|c|c|c|c|}
\hline \multirow{3}{*}{ Nase of Rrver or Distriot. } & \multicolumn{5}{|c|}{ River Basin. } \\
\hline & Area. & 苛 & $\begin{array}{c}\text { Enst } \\
\text { of } \\
\text { outlet. }\end{array}$ & $\begin{array}{l}\text { West } \\
\text { of } \\
\text { ourtlet. }\end{array}$ & 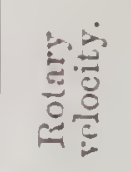 \\
\hline & Eq. Miles. & Des. $M$ & Deg. $M$ & Deg. $x$ & $\begin{array}{l}\text { Fiet per } \\
\text { secind. }\end{array}$ \\
\hline Tolga..... & $5 \% \%, 700$ & 5500 & $\ldots$ & 010 & 871 \\
\hline Kuban... & 34,600 & 4450 & 255 & $\ldots$ & $1,07 \%$ \\
\hline Rioni..... & 17,900 & 4238 & 050 & ... & 1,118 \\
\hline Syrian Mediterranean rivers.. & S, SOO & 3340 & 110 & $\cdots$ & 1,265 \\
\hline Jordan district............ & 12,400 & 3220 & $03 \tilde{3}$ & $\cdots$ & 1,280 \\
\hline Schoon .......... & 12,000 & 4740 & 015 & $\cdots$ & 1,023 \\
\hline Axon and otliers.... & 23,600 & 4732 & 200 & $\cdots$ & 1,026 \\
\hline Minder ............ & 9,900 & 4740 & 135 & $\cdots$ & 1,023 \\
\hline Sallabat..... & 8,300 & 4822 & 115 & $\ldots$ & 1,009 \\
\hline İnieper ............... & 181,000 & 5125 & $\cdots$ & 033 & 947 \\
\hline Bug and Indul.......... & 27,400 & 4905 & $\cdot \ldots$ & 121 & 995 \\
\hline Dneister...... & 30,500 & 4832 & $\ldots$ & $20 \mathrm{~s}$ & 1,006 \\
\hline Maritza ......... & 23,700 & 4200 & $\cdots$ & 022 & 1,129 \\
\hline Stroman .......... & 13,000 & 4128 & $\cdots$ & () 30 & $1,13 \mathrm{~S}$ \\
\hline Vardar...... & 12,300 & 4120 & $\cdots$ & 010 & 1,141 \\
\hline Drin .... & 9,500 & 4210 & 025 & $\cdots$ & 1,126 \\
\hline 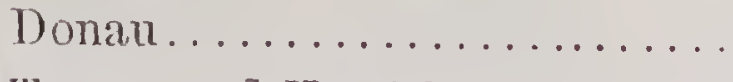 & 293,100 & 4625 & $\cdots$ & 950 & $1,04 \%$ \\
\hline Tornea and Kemi district. . & 41,700 & 6720 & $\cdots$ & 005 & $58 \tilde{5}$ \\
\hline Wester Botten.......... & 36,900 & 6550 & .. & 255 & 622 \\
\hline Wester Norrland......... & 26,200 & 6330 & ... & 158 & 678 \\
\hline River Dahl district........ & 20,300 & 6116 & .. & 200 & 730 \\
\hline Clara and Gotha Elv .... & 16,700 & 5940 & 145 & $\cdots$ & 767 \\
\hline Nïlar district............... & 9,400 & 5945 & $\ldots$ & 110 & 765 \\
\hline Eustern part of South Sweden. & 5,800 & 5655 & $\cdots$ & 100 & 829 \\
\hline
\end{tabular}




\begin{tabular}{|c|c|c|c|c|c|}
\hline \multicolumn{2}{|r|}{ Rivers } & \multicolumn{3}{|c|}{$\begin{array}{l}\text { FLOWTG TUWARDS THE EQUATOR. } \\
\text { MEMISPHERE. }\end{array}$} & EASTERA \\
\hline \multicolumn{3}{|c|}{ Mouth of River. } & \multicolumn{3}{|c|}{ Retardation. } \\
\hline & 窝 & 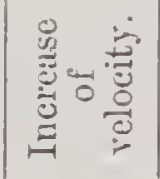 & By sediment. & By water. & Total. \\
\hline Deg. $x$ & $\begin{array}{l}\text { Fect per } \\
\text { second. }\end{array}$ & $\begin{array}{l}\text { Feet per } \\
\text { second. }\end{array}$ & $\begin{array}{l}\text { Foot-pounds per } \\
\text { second. }\end{array}$ & Foot-pounds per seconu. & Foot-pounds per second. \\
\hline 4610 & 1,052 & 181 & $7,137,026$ & $9,634,985,100$ & $9,642,122,126$ \\
\hline $4 \pm 42$ & $1,0 \mathrm{~S} 0$ & 3 & 121 & 163,350 & 163,471 \\
\hline 4215 & 1,124 & 6 & 251 & 338,850 & 339,101 \\
\hline 3322 & 1,268 & 3 & 30 & 40,500 & 40,530 \\
\hline $314 \mathrm{~S}$ & 1,290 & 5 & 121 & 163,350 & 163,471 \\
\hline $464 j$ & 1,041 & 18 & 1,518 & $2,049,300$ & $2,050,81 \mathrm{~S}$ \\
\hline 4040 & 1,042 & 16 & 2,360 & $3,186,000$ & $3,188,360$ \\
\hline 4730 & 1,026 & 3 & 35 & - 47,250 & 47,285 \\
\hline $4 S 1 S$ & 1,010 & 1 & 3 & 4,050 & 4,053 \\
\hline 4640 & 1,042 & 95 & $63 S, 115$ & $861,455,250$ & $\mathrm{~S} 62,093,365$ \\
\hline 4642 & 1,042 & 47 & 23,646 & $31,922,100$ & $31,945,746$ \\
\hline 4620 & 1,049 & 43 & 22,029 & $29,739,150$ & $29,761,179$ \\
\hline $404 \tilde{\jmath}$ & $1,14 \mathrm{~S}$ & 19 & 3,342 & $4,511,700$ & $4,515,042$ \\
\hline $405 \tilde{5}$ & $1,14 \mathrm{~S}$ & 10 & 507 & 684,450 & 684,057 \\
\hline 4032 & $1,1 \tilde{0} 4$ & 13 & $\mathrm{~S} 12$ & $1,096,200$ & $1,097,012$ \\
\hline 4140 & 1,135 & 9 & 302 & 407,700 & 408,002 \\
\hline 4515 & 1,069 & 22 & 55,396 & $74,784,600$ & $74,839,996$ \\
\hline 6552 & 621 & 36 & 21,111 & $28,499, \$ 50$ & $2 S, 520,961$ \\
\hline 6440 & 650 & $2 S$ & 11,301 & $15,256,350$ & $15,267,651$ \\
\hline 6220 & 705 & 27 & 7,460 & $10,071,000$ & $10,07 \mathrm{~S}, 460$ \\
\hline $60: 35$ & 750 & 20 & 3,172 & 4,2S?,200 & $4,285,372$ \\
\hline $574 S$ & SO9 & 42 & 11,506 & $15,533,100$ & $15,544,606$ \\
\hline 5925 & 773 & 8 & $23 \tilde{5}$ & 317,250 & $317,4 \mathrm{~S} 5$ \\
\hline 5615 & $\mathrm{~S} 44$ & 15 & 510 & $6 S S, 500$ & 689,010 \\
\hline
\end{tabular}




\begin{tabular}{|c|c|c|c|c|c|}
\hline \multicolumn{3}{|c|}{ 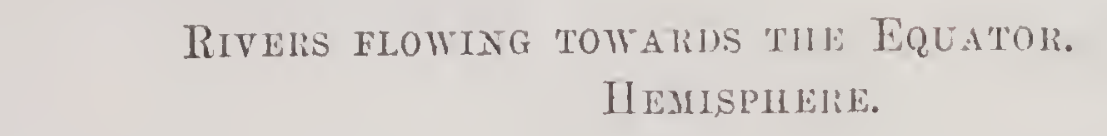 } & \multicolumn{3}{|c|}{ EASTERT } \\
\hline \multirow{3}{*}{ Name of River or District. } & \multicolumn{5}{|c|}{ River Basta. } \\
\hline & Area. & 总 & $\begin{array}{c}\text { East } \\
\text { of } \\
\text { outlet. }\end{array}$ & $\begin{array}{c}\text { West } \\
\text { of } \\
\text { outlet. }\end{array}$ & 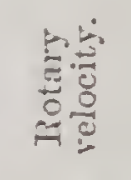 \\
\hline & Sq. sfiles. & Deg. $x$. & Dej. 15 . & Deg. 11 & $\begin{array}{l}\text { Fett per } \\
\text { second. }\end{array}$ \\
\hline Western part of South Sweden. & 6,600 & 5730 & 042 & $\ldots$ & 817 \\
\hline Glommen and Lauven district.. & 21,300 & 60 i2 & .. & () 04 & 740 \\
\hline Sonthern part of Norway...... & 9,500 & 5918 & $\ldots$ & 015 & 776 \\
\hline F. coast of Adriatic........... & 17,200 & 4350 & 020 & $\ldots$ & 1,096 \\
\hline Gull of 'laranto and Ionian Sea. & 7,500 & 4000 & $\cdots$ & $02 \pi$ & 1,164 \\
\hline Western part of South Italy... & 11,900 & 4115 & 030 & $\ldots$ & 1,142 \\
\hline 'liber..................... & 7,200 & 4242 & 017 & .. & 1,116 \\
\hline Arno and $W$. coast Central Italy & 8,900 & 4325 & 032 & $\ldots$ & 1,103 \\
\hline Etsch district.............. & 12,000 & 4615 & $\ldots$ & 034 & 1,050 \\
\hline Po............. & $2 S, 100$ & 4525 & $\ldots$ & 310 & 1,065 \\
\hline Rhone........... & 38,000 & 4542 & 041 & $\ldots$ & 1,061 \\
\hline 'Ter and Slobregat.... & 11,200 & 4245 & $\ldots$ & 025 & 1,115 \\
\hline Ebro .............. & 33,200 & 4206 & ... & 220 & 1,127 \\
\hline Guadalaviar...... & 8,900 & 4010 & ... & 054 & 1,161 \\
\hline Jucar......... & 8,100 & 3915 & ... & 115 & 1,176 \\
\hline Segura ............. & 8,200 & 3810 & $\ldots$ & 120 & 1,194 \\
\hline Guadalquiver........ & 20,000 & 3740 & 202 & $\cdots$ & 1,202 \\
\hline Guadiana..... & 25,700 & 3825 & 200 & $\ldots$ & 1,190 \\
\hline Caldoa......... & 7,100 & 3748 & 020 & $\cdots$ & 1,200 \\
\hline 'Tigus .... & 28,900 & 4000 & 350 & .. & 1,164 \\
\hline Dnero...... & 38,700 & 4130 & 305 & $\cdots$ & 1.139 \\
\hline Minlio ............. & 10,600 & 4241 & 1.15 & $\cdots$ & 1,117 \\
\hline Rivers of Great Britain.... & 46,015 & $\ldots$ & $\ldots$ & $\cdots$ & $\cdots$ \\
\hline Rivers of Ireland........ & 16,224 & & & .. & ... \\
\hline
\end{tabular}




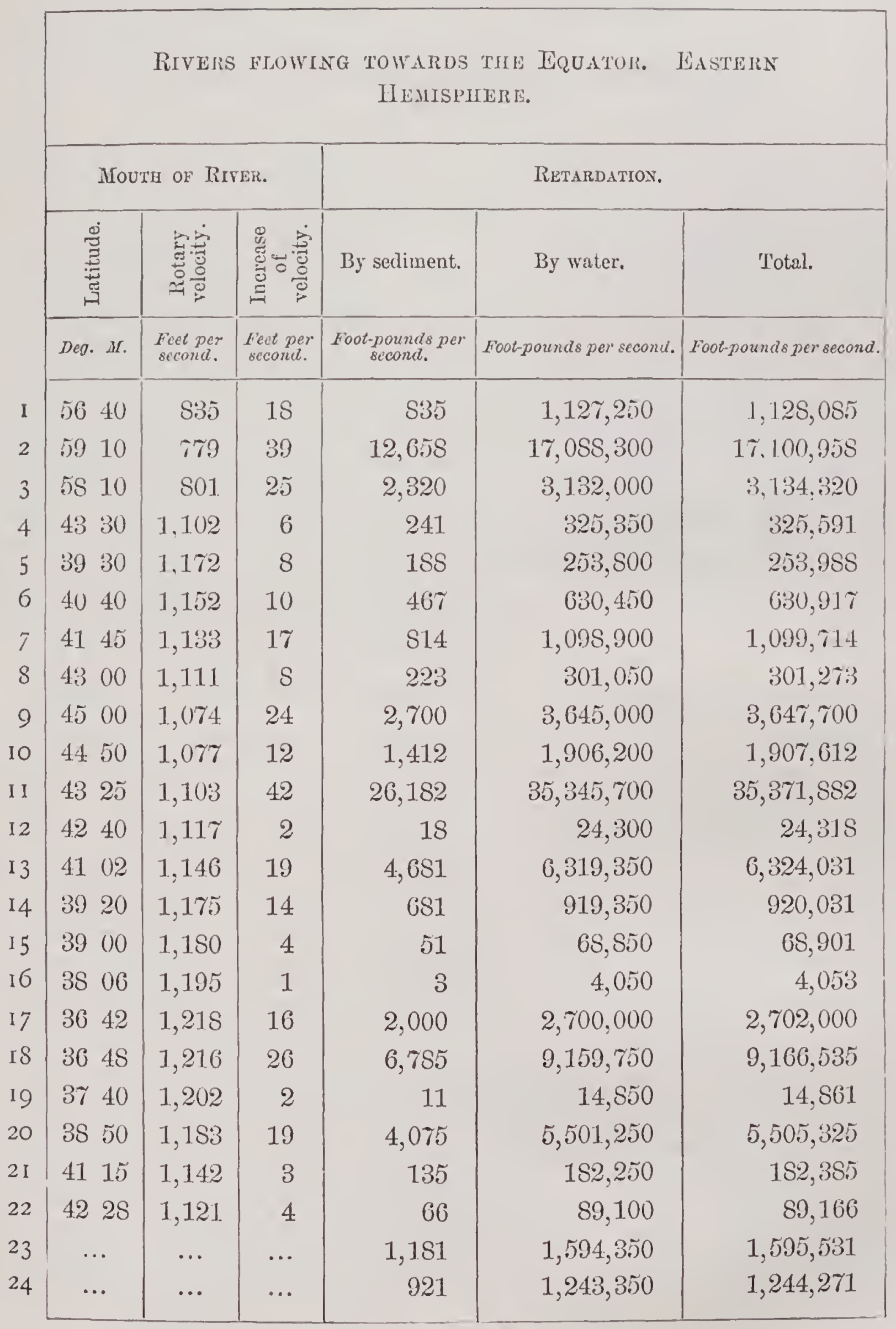




\begin{tabular}{|c|c|c|c|c|c|}
\hline \multicolumn{3}{|c|}{$\begin{array}{c}\text { RIVERS FLOWING TOWARIS THE EQUATOR. } \\
\text { HEMISPHERE. }\end{array}$} & \multicolumn{3}{|c|}{ WESTEIN } \\
\hline \multirow{3}{*}{ NAire of Rifer or District. } & \multicolumn{5}{|c|}{ Rrver Basin. } \\
\hline & Area. & 总 & $\begin{array}{c}\text { East } \\
\text { of } \\
\text { outlet. }\end{array}$ & $\begin{array}{c}\text { West } \\
\text { of } \\
\text { outlet. }\end{array}$ & 总 \\
\hline & sq. Milks. & Deg. $x$. & Deg. $Y$. & Deg. $y$ & $\begin{array}{l}\text { Fett per } \\
\text { second. }\end{array}$ \\
\hline Bastard, Pentecost....... & 33,000 & 5050 & $\cdots$ & 005 & 959 \\
\hline Saguenay ........... & 27,800 & 4902 & $\cdots$ & 245 & 996 \\
\hline St. John, Penobscot...... & 34,400 & 4640 & $\cdots$ & 100 & 1,042 \\
\hline Kenmebec, Androscoggin, Saco & 13,000 & 4445 & $\cdots$ & 020 & 1,0 is \\
\hline Merrimack... & 7,100 & 4320 & $\ldots$ & 038 & 1,105 \\
\hline Connecticut........ & 10,800 & 4320 & 002 & .. & $1,10 \tilde{5}$ \\
\hline Hudson, Housatonic...... & 16,000 & 4230 & 004 & $\cdots$ & 1,120 \\
\hline Delaware ............ & 11,500 & 4100 & 003 & $\cdots$ & 1,146 \\
\hline Susquehanna............. & 27,200 & 4114 & $\cdots$ & 052 & 1,142 \\
\hline Potomac, Rappahannock.... & 16,000 & 3900 & $\cdots$ & 115 & 1,180 \\
\hline James .................. & 13,100 & 3732 & .. & 1. 32 & 1,204 \\
\hline Roanoke, Tar............. & 18,800 & 3636 & $\cdots$ & 140 & 1,220 \\
\hline Santee, Nense. ......... & 44,100 & 3440 & $\cdots$ & 125 & 1,249 \\
\hline Savannah and others... & 51,200 & 3251 & $\cdots$ & $10 \tilde{5}$ & 1,276 \\
\hline Alabama district... & 128,700 & 3130 & 025 & .. & 1,295 \\
\hline Mississippi ............. & $1,244,000$ & 4055 & $\cdots$ & 710 & 1,148 \\
\hline Colorado, Brazos, 'lrinidad .. & 191,200 & 3112 & $\cdots$ & 150 & 1,300 \\
\hline Rio del Norte............. & 215,500 & 2950 & $\ldots$ & 640 & 1,318 \\
\hline 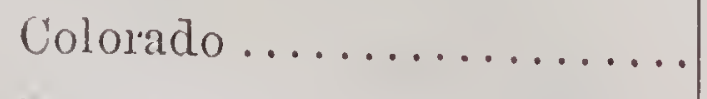 & 267,000 & 3604 & 106 & $\cdots$ & 1,228 \\
\hline E. coast Gulf of California.. & 140,000 & 2806 & 110 & $\cdots$ & 1,340 \\
\hline
\end{tabular}




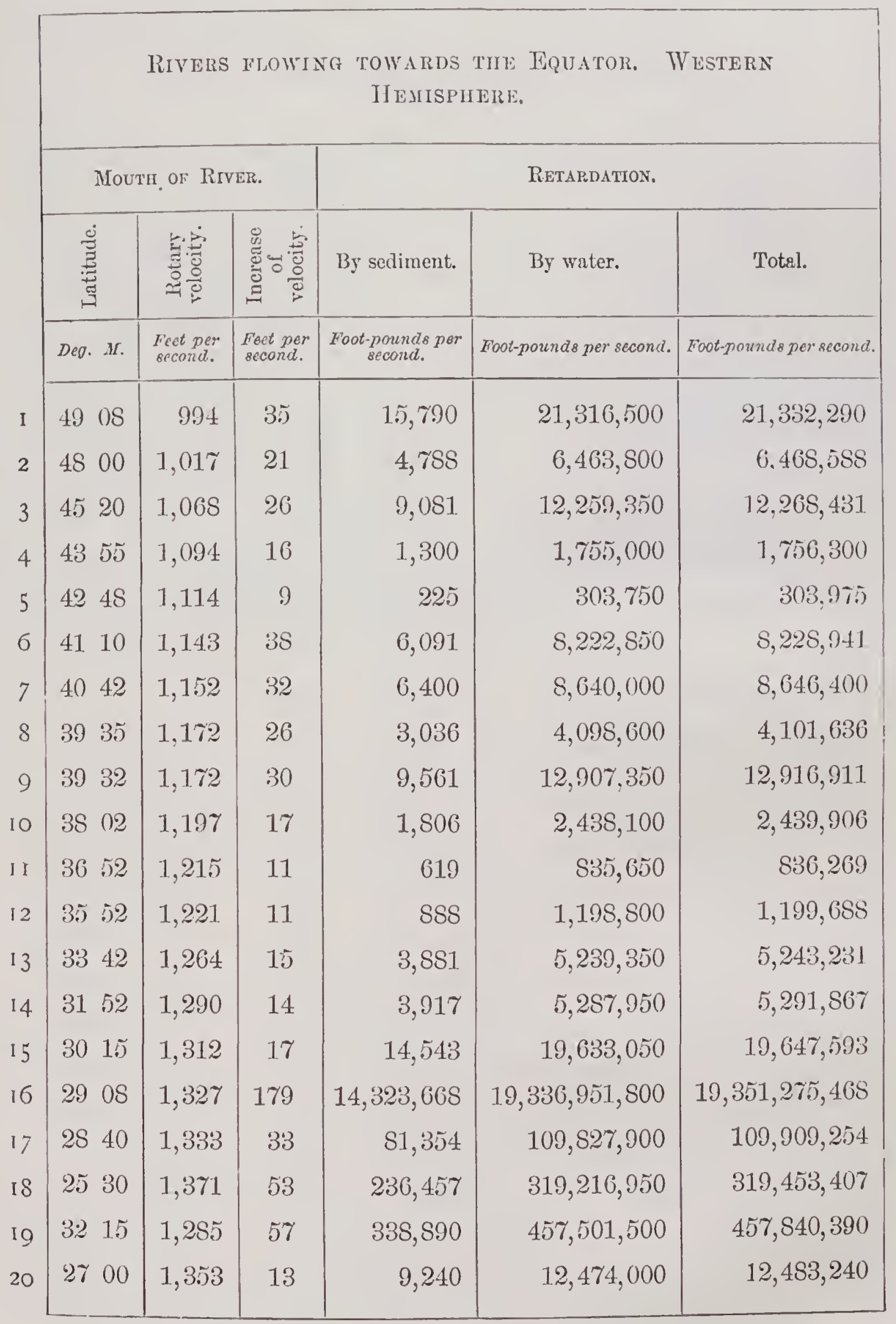




\begin{tabular}{|c|c|c|c|c|c|}
\hline \multicolumn{3}{|c|}{$\begin{array}{c}\text { RIVERS FloWING TOWARDS THE EQUATOR. } \\
\text { HEMISPHLLE. }\end{array}$} & \multicolumn{3}{|c|}{ WESTERT } \\
\hline \multirow{3}{*}{ NASTE of River or District. } & \multicolumn{5}{|c|}{ RTVER BasLy. } \\
\hline & Aren. & 总 & $\begin{array}{l}\text { Fast } \\
\text { of } \\
\text { outlet. }\end{array}$ & $\begin{array}{c}\text { West } \\
\text { of } \\
\text { outlet. }\end{array}$ & 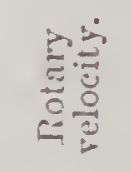 \\
\hline & sq. Mfiles. & Deo..$x$ & Deg. $U$. & Deg. $n$ & $\begin{array}{l}\text { Fetet per } \\
\text { second. }\end{array}$ \\
\hline Kalamath and 'Isashtl....... & 42,900 & 4200 & 1.15 & $\cdots$ & 1,129 \\
\hline Columbia........ & 283,400 & 45.2 & 702 & $\ldots$ & 1,0 ) \\
\hline Frazer....... & 138,300 & 5128 & .. & 040 & 946 \\
\hline Simpson and Frances district. & $5,3,600$ & 5640 & 200 & $\cdots$ & 83\% \\
\hline Atna or Copper............ & 34,900 & 6212 & 005 & .. & 708 \\
\hline Bolsas, Yopez, Verde... & 71,500 & 1800 & $00 \%$ & .. & 1,445 \\
\hline Sirano district ....... & 24,700 & 1400 & 010 & $\ldots$ & 1,474 \\
\hline San Juan de Nicaragua...... & 23,700 & 1200 & .. & 120 & 1,486 \\
\hline Sacramento ......... & 33,000 & 4000 & .. & 008 & 1,164 \\
\hline Paraliyba and Grande....... & 37,600 & 640 & $\ldots$ & 150 & 1,509 \\
\hline Ciara, Croayhu......... & 33,700 & 508 & $\ldots$ & 005 & 1,513 \\
\hline Jaguaribe........... & 19,900 & 550 & $\cdots$ & 030 & 1,511 \\
\hline Belmonte and Doce dist.. & 114,400 & 1725 & $\cdots$ & 148 & 1,449 \\
\hline Parahyba (South). & $3 \tilde{)}, 800$ & 2200 & ... & 212 & $1,40 \mathrm{~S}$ \\
\hline San Francisco... & 247,600 & 1400 & ... & 700 & $1,47 \pi$ \\
\hline Paranahyba ......... & $15 \%, 300$ & $S 05$ & $\ldots$ & 230 & 1,504 \\
\hline Maranha and Itaqieura..... & 59,600 & .) 00 & ... & () 40 & 1,613 \\
\hline Gurupy and 'Turyassu...... & 49,000 & 320 & ... & 100 & 1,516 \\
\hline 'T'ocantins .... & 376,000 & 1010 & $\ldots$ & 100 & 1,495 \\
\hline Amazon ... & $2,236,000$ & 620 & $\ldots$ & 1250 & 1,510 \\
\hline
\end{tabular}




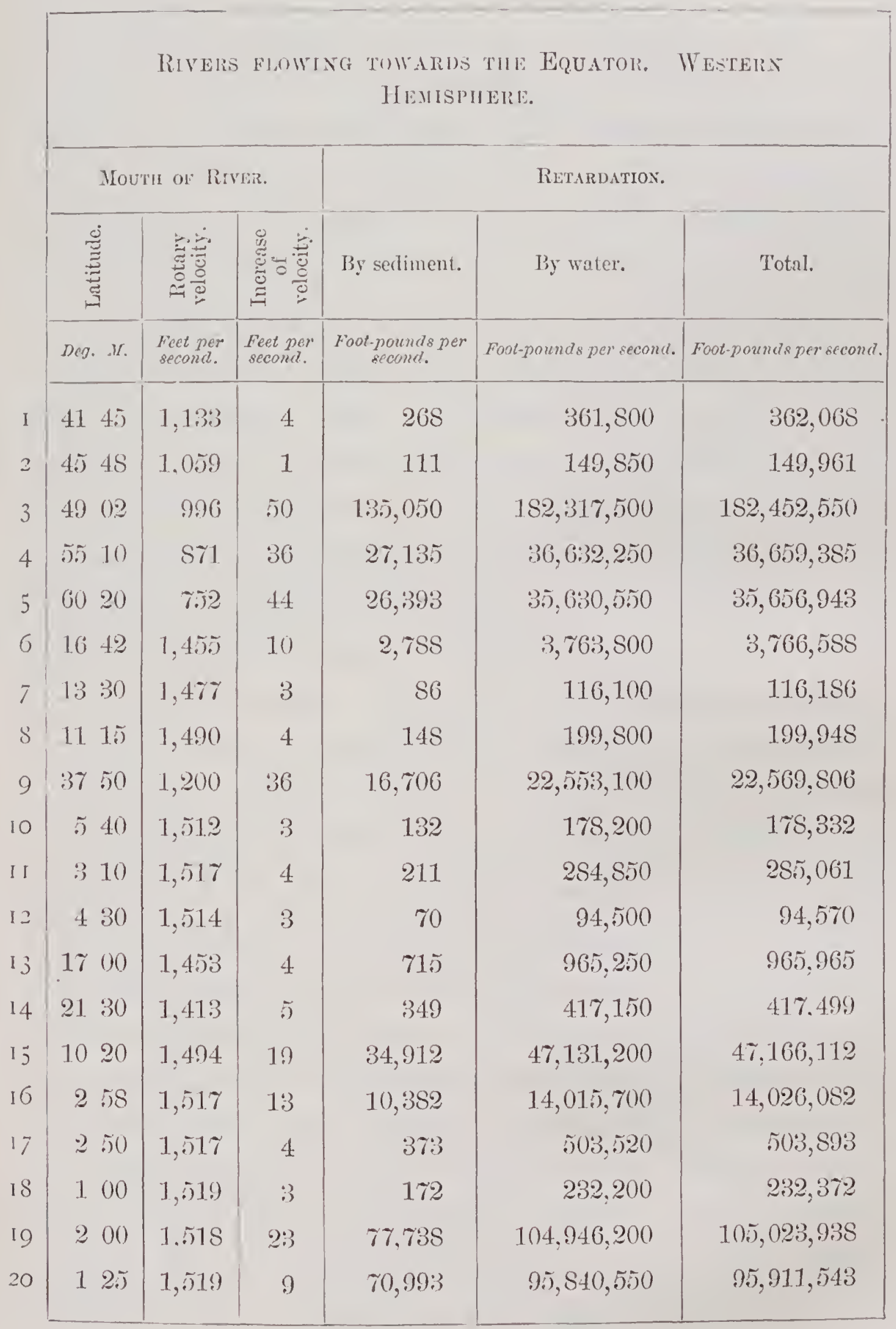


The tast column of the preceding tables contains the amount of retaldation callsed by the waters of rireds Howing towatris the equator. L'he computation of the restarling

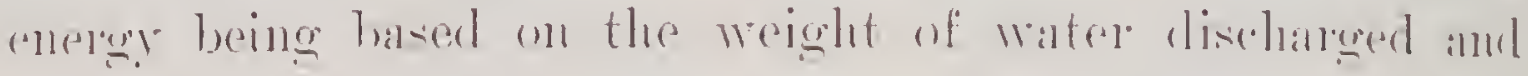

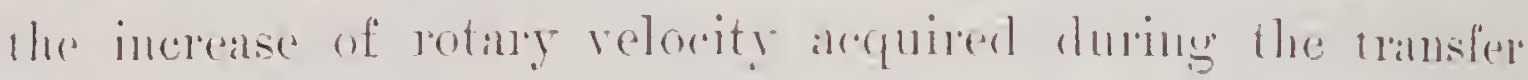

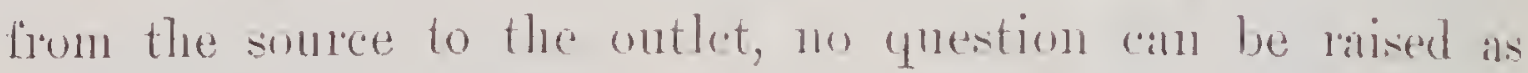
to the existence of the retarmation entered in the tables: but whether compenating energies are called forth hy the return. ing rapors before the condensation takes placer which results in the precipitation on the river basins, domands calreful consideration. Dr. Maryer, in his discomse previnsty adrerted to, positively asserts that, agreeably to the drommotral. tion of Taplace, based on alsstract mechanical principles, the compensating energy corresponds in erery instance with the amount of retardation to which the rotary motion of the globe may be suljected. Admitting this conclusion to he correct, we must assume the arlequacy of the eapors which rise within the tropics to restore, during their transfer to the temperate and polar regions, the Joss of ris riva occasioned hy the comdensed witer which, in the form of rivers, flows towarks the equaters. Obriousty, such restoration of energy could only he effected by friction or pressure of the vapors against projections on the earth's surface directly, or through the intervention of particles of the atmospheric air put in motion by the rapers. The Astronomereroyal of Sweden, in an elaborate demonstration presented to the Royal Academy of Sciences at Stockholum, in refutation of my assertion that solar influence is capable of diminshing 
perceptibly the rotary velocity of the earth, thus states the case: "The globe and its atmospluere constitute a combined systen in notion, in which no part can by any outside caluse be disturbed in its relative position without the motion of the entire systen being thereby infintuced. Consequently, a body of air which, for instance, is carried firom the direction of the equator towads either of the poles unust, by degrees, positively part with the excess of rotary vis viec which it possessed at the commencement of the motion, compared with the rotary relocity of the regrion to which it has been transferred, and must innart the entire surplus to the earth undininished, the rotation of which must consequently he accelerated by this current of air; and, conversely, a current of air of contriry direction, or from either of the poles towards the equator, must produce retardation. To diflerence can exist in this respect between a current of water and a curent of air." 'The Swedish astronomer, like Ianlace, thus puts the whole question in a nutshell, asserting that air and water, water and air, maty circulate in any manner whatever between the equator and the poles, and between the poles and the equator, without influencing the axial rotation of the globe. It is very true that the enuth, with its rivers and atmosphere, constitute a "combined system in motion"; but we must not lose sight of the import. ant fact that an outsile energy-the smin's radiant heat-is being continually exerted, which interferes with the motions within that combined system. Accordingly, no alloment can prove the conlectness of the statement laid before the 
Royal Academy of Sciences at Stockholm shert of al peri. tive denonstration showing that particles of ralpor corresponding in weight with the wated dischanterl ly some river-sily the Mississippi-are capable of impanting by friction agininst the earth's surfice, directly or through the agency of the atmospliere, a rotary foree exactly balancing the retarding correy which we have establisherl.

The allocates of the theory of compensation, while almitting that they cannot furnish any practical evilence of the truth of their doctrine, assert that the sulject is not susceptible of experimental test. It would, imleerl, be a fruitless task to mudertake the construction of anemoneteris, or similar instruments, slowing that the pressure and friction of the farticles of the returning rapor; exerter directly or through atmospheric intervention against the surface of the Miscissippi river basin, from west to east, are capable of compensating the cstablished retardation of $19,336,000,000$ footpounds per second.

The admitted impossibility of proving by direct measure. ment the existence of compensating force has suggested the resort to some indirect method. I have accordingly constructed an instrument which practically demonstrates the truth of the following proposition, on which the solution of the problem unquestionably depends: 'The retarding influence produced by currents of water, confined within channels which convey a given reight in a given time, from the pole to the equator of a rotating sphere, camnot be compensated

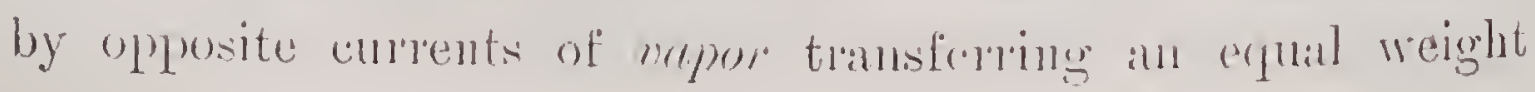


CHAY. XXII.

in equal time wer the surface of the said sphere from its equator to its pole.

The illustration on Plate 34 represents the instrument adverted to; but before entering on a description, it will be well to define alearly the problem intended to be solved by experimental demonstration. The rotary relocity of the surfirce of the earth, for instance, on the foth parallel is 1,07t ft. per second, that of the equator $1,519 \mathrm{ft}$ per second; lence the water of a river flowing from lat. 45 deg. to the equator will have its velocity round the axis of the earth incleased $1,519-1,07 t=445$ tt. per second. It needs 110 demonstration to show that the expenditure of energy necessary to produce this increase of rotary velocity will cause the earth to lotate at a diminished late; the amomnt of retarding force being readily ascertained by multiplying the weight of watel tramsferred by the height necessary to generate a velocity of $4 t 5 \mathrm{ft}$. per second, vir., $3,094 \mathrm{ft}$. Consequently, each pound of water transferred fiom lat. 45 deg. to the equator demands the expenditure of a dymanic energy of $3,09 t$ foot-pounds. 'The question now plesents itself, whether a pouml of water evaporated on the equator, and retmrned in the form of rapor to lat. 45 deg., cam, during the return movement, impart a rotary enelgy of 3,094 footpounds to the earth. Of conlse the vapor, on leaving the equator, possesses a lotaly velocity of $1, \tilde{y} 19$ ft. per second, while the surface of the earth in lat. t5 deg. rotates, as before stated, at a rate of only 1,07t ft. per second. It will be evident, therelore, that huring the return morement the 
vapol, by contact with the earth, will have its lotary relocity

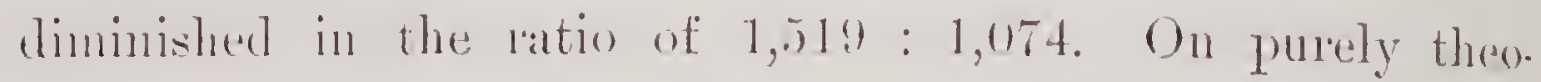
retical comsiderations, it must be admited that this contant, hy which the returnimg gonud of vapor has its rotaly relo. city diminished tty ft. pel second, will restore to the anth the whole of the enery which was previously expended in angmenting the speed of the pound of water from 1,07t to 1,j19 ft. per second during its transfer from lat. Aj deg. to the equator. But practice shows that rotaly nution cannot be imparted to eylindrical or spherical boties, homerer. lough theil surface may be, by enlents of ail or steanl, with. out givent loss of mechanical energy. Convelsely, curlents of air or steam camnot be producel by the action of similan lotating bodies without a corresponding loss of mechanical energy.

Practical engineers fannliar with these facts fully aplure. eiate the difliculty of instituting experinesuts intended to determine exactly what anount of force is expented in caus. ing rotary motion by currents, and what anomnt of force is developed by emrents produced by rotating bollies, as suyposed. The illustrated dynamic register, Plate 34, obviates this diflicult companison between energy expented and developed, by the simple expedient of applying heat and cold in such a manner that the returdimg influence of a eurrent of water flowing from the pole to the equator acts simultaneously with the acceleratim! influence of an oplosite current of vapor, transferring equal weight in equal time, from the equator towards the pole. 'The detail of the in- 
strument will be understood by the following description: Fig. I. shows a section of a hollow sphere 6.25 ins. diat. meter, composed of very thin brass partially filled with is light non-conducting substance, male to revolve on its reltical axis; the upper half being covererl with a light semispherical casing, extenting a short distance helow the horizontal central plane of the sphere. A cylindrical cistern, provided with a flat cover, is attached to the top of the remi-spherical casing. The morle of supporting the lower pivot on which the sphere turns, as also the axle at the top, will be seen by reference to the drawing. Rotary motion is inparter to the sphere hy a horizontal toother rack (see top view, Fig. II.) working into the teeth of a wheel at. tached to the rertical axle; the motive power consisting of a weight suspended by a light cord passing over a pulley and secrured to the rack. A circular gatspipe, provided with a series of burners, surrounds the sphere some distance below its centre. Referring to Fig. II, it will be seen that the guide-pieces which support the horizontal rack, and through which it slides, act as stops which regulate the extent of the movement. It should be particularly noticed that the anangement is such that when the nuotion is rhecked by the righthand stop the last $\operatorname{cog}$ of the rack his just slipped out of the cog-wheel, thus allowing the sphere to turn freely. The extent of motion of the rack is $0.186 \mathrm{ft}$, and the weight exactly 2 1bs. It will be seen, therefore, that the motive force is $0.186 \times 2=0.372$ footpound, or $2 \times 7,000 \times 0.186=2,604$ foot-grains. Deduct. 
ing the loss by friction-64 frot-grains-the effective motive porrer will be 2,5 to foot-grains. The axis of the splere being exactly rertical, there is obvionsly no friction whit. ever at the upper bearing after the shipping of the last cong of the rack, while the lower pirot presents a mere point of hardened steel to the step under it; hence the orercoming the atmospheric resistance against the outside of the sphere and the cistern may be considered as the only work to be performed by the stated arailable motive power of 2,540 foot-grains. It only remains to be noticer that when the spluere is to be put in motion the rack is geared into the cog-wheel and brought up against the left-hand stop, als represented in the drawing, the check-lever (Fig. TY.) being at the same time placed in the position shown by the lotted lines. The moment for starting, inclicated by the chronometer, having arrived, the check-lever is brought to the horizontal position as quickly as possible, in order to prevent dragging at the monent of liberating the toothed rack. As shown by the illustration, a small quantity of water is confined within the surrounding casing of the sphere, thus forming an aqueous belt round its equator; the polar cistern being filled with water.

'The object of the instrument having been clearly set forth, it scarcely needs explanation that the derice is intended to show that when the lieat of the galsflimes is applied to the aqueous belt, causing evaporation, while condensation is effected by the cold water in the polar cistern, the motive energy $(2,540$ foot-grains $)$ will be incapable of 
turning the sphere as fist and as long as when heat and refrigeration are not applied. This assumption, it will be perceived, is in direct opposition to the views held by the Astronomer Royal at Stockholm and other followers of Larplace, who contend that "no difference can exist" as regunds the effect on the axial rotation of the globe between currents of water and currents of aëriform matter transferring equal weight in equal time.

The mode of conducting the experiment with the dynamic register will be readily understood by the following explanation: 'The polar cistern is charged with boiling water, and the garflames applied for a few minutes until the water round the equator is brought near boiling heat. The gas is then shut off, and the toothed rack geared and afterwards locked by the check-lever. The chronometer being then carefully observed, the check-lever should be quickly pushed down when the hand marks exact time. The motive weight, being thus liberated, puts the sphere in motion through the intervention of the rack and cog-wheel, the time elapsing between the commencement of the morement and the slipping of the last tooth of the rack occupying about one second. The observation of the chronometer should continue, in order to ascertain the exact time when the sphere is brought to rest. In the meantime, the number of turns must be accurately counted. The first experiment being concluded, the sphere is again put in motion, as before, without changing the water in the polar cistern or applying the gasflumes, the object of employing heat before starting being 
merely that of expanding the where to proper dincmasons. The experiment having been repeater six times, the mean of time occupied and number of turns performen, resulting from the expended energy of 2,5 to foutgrinin, sloukl be determined with the utmost precision. 'The procedne will then be changed: the polall cistern will be challged with cold water, and the gansflames applied and kept huming. The sphere, monter these altered comblitims, is agnin started, but not until boiling temperature in the explatorial belt lais heen altaned and evalporition commeneed. The experiment, as before, will be repeated six times, and the mean of time and the number of turns ascertained.

'The law of compensation relating to solar influence on the axial rotation of the earth, expomeder by I)r. Malyer, is evidently strictly alplicable to the dymanic register, since the equatorial helt of the rotating spliere is being continually heated, while the polan regrion is being exposed to continuous refrigeration, vilpor being thus formed at the equator, and currents produced which comtente on reaching the cold semi-spherical covering orel the pole. 'The water thus formed, divided into small streanns, flens inate on the sul. face of the splyere to the equator, where it is andin converted into rapor' hence a continued circulation of oplusite antrents of rapor and water will be kept up. It should be particularly observed that the vapor in its lasioge tomints the pole not only acts against the surface of the spliere, but also against the inside of the semi-spherical covering. thereby affording a double chance of innarting motion to 
the rotating mass. But this notwithstanding, the experiments have shown that the returlining energy of the condensed water flowing in smill streans from the pole to the equator on the surfice of the sphere, greatly exceeds the accelerating enery inpurted by the excess of rotary relocity of the rapor in its conse towarls the pole, and the consequent friction of its particles against the surfaces of the sphere and the semi-spherical casing. Agreeably to Int. Mayer's conclusions, founded on the theory of Laplace, the opposite currents which result from high temperature on the equator; ant the refrigeration over the temperate zone and the poles, cammot affect the axial rotation of the globe. "The effect of erery single motion by these means on the rotation of the globe," he says, "is exactly compensated by the effect of another motion in an opposite direction." Nor can the Swetish Astronomer, as we have seen, perceive any difference between currents of water and currents of aëriform matter. In direct opposition to the conclusions of these physicists, our experiments prove that, although the weight transferred from the pole to the equator of the sphere of the dynamic register is precisely the same as the weight which is transferred in the opposite direction, the contact and friction of the particles of rapor against the surfaces of the convex and concive splueses is incapable of restoring the loss of vis viva consequent on imprating rotary motion to the particles of water transferred from the pole to the equator:

Too much space would be occupied by a detailed ac- 
comt of the experiments which lave been made with the dynamic register; hence only the most important facts bear. ing directly on the question will be presenter. 'The number of turns of the rotating sphere prentuest hy the motive force of 2,5t0 footgrains has been 660.5 , occuly ing 10 min. 37 sec., the barometer at the time indicating 29.8, the tem. perature of the surromoling atmosphere being $62^{\circ} \mathrm{r}$. 'The mean of the force expented for each turn will therefore amount to $\frac{2,540}{660.5}=3.84$ foot-grains. It will be asked, in view of this insignificant motive power, chiefly expended in orercoming the atmospheric resistance against the rotating sphere and cistern, how the excess of retarding energ! of the condensed water flowing over the surface of the sphere, from the pole to the equator, can possibly be measured. The answer is that we need not consider the amomt of energy developed by the motive weight; we merely count the number of turns and note the time required to bring the sphere to a state of rest from the moment of starting, the gas-flames being liept huming and the refrigerating medium retained in the polar cistern during the observations. Then, removing the cooling medium and replacing the same with boiling rater, we again put the sphere in motion, count the number of turns, and note the time. The result of this change of procedure will be, as shown by our experiments, that the sphere will run much longer and perform a greater number of turns-a startling firct, since the motive encrgy of 2,540 foot-grains has not been increased. To practical 
minds the explanation will at once suggest itself, that because there is an expenditure of heut while condensation is kept "1, which ceases when the refrigerating medium is withdrawn, some arditional work is being performed while the cold medimm remains at the pole. Now, what is the nature of this work? Evidently the condensed water, while flowing from the pole to the equator, has its rotary speed successively increased corresponding with that of the surface of the sphere; hence work must be performed while refrigeration is kept up at the pole. Satisfactory as this explanation appears, it is net by the cardinal objection that, since force cannot he ammihilated, the opposite current of vapor, which simultancously transfers an equal weight from the equator to the pole of the rotating spliere, must, by friction or contact of some kind, positively return the whole of the mechanical energy expended in augmenting the rotary velocity of the particles of water moving in a contrary direction. This notwithstanding, we must accept the fuct proved by the dynanic register, that a certain amount of mechanical energy disappears when the rotating sphere is subjected to the action of differential temperatures. There was a time when we conld not account for such disappearance of energy, but-thanks to the Jabors of Joule and Mayer-the mechanical theory of heat las thrown light on the subject. The theoretical dectuctions of Laplace hare lost their potency. We no longer confine ourselves to the balance and rule in measuring the result of expended force. Joule and Mayer have taught us to comsult also the ther- 
mometer during our investigations. Theming in mind, then, what the new theory of heat teaches, the disappearance of mechanical energy doning the experiments with the dymamic register ceases to be a purzle. Close investigution shows that the heat resulting form the andested motion of the cir.

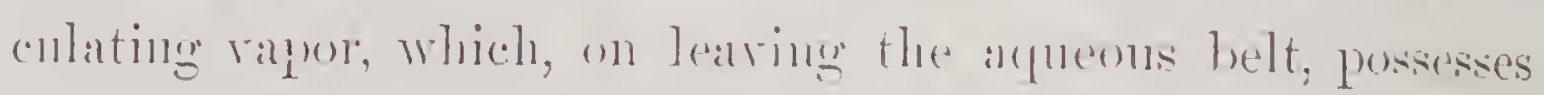
a rotary velocity equal with that of the circunfurence of the spliere, romesents very nearly an cyuvalent of the observed loss of entergy, the difterentere hering mante up by leat generated by the particles of the circulating rapor as they successively inpinge aganinst the minute forojections of the surface of the convex and concave splueses. Obrionsly, the heat thus generater is carried off hy the cold semi. shlierical casing surromeling the spluere of the dynanic register, precisely as heat proluced by analogous motions within the terrestrial atmospliere is carried off by ralliation into space. In either case the heat lost is an equivalent of the mechanical energy abstrated from the rotating sphere.

Illustrations and descriptions have heen frepared explanatory of important modifications of the lynamice rewister delineated on Pl. 3t, adopter in order to control the irregular resistance of the atmosplieric air against the rotating shere, maroilable in employing gats-flanes for hating the equatorlial helt; hut the subject having aldeally ocempres tro munch space, I now propose to state only the result of the experiments which have been made with the molified instrument, the dimensions of which, it should be olserved, have been considerably increased, the motive "power, however, 
remaining muchanged. It is scarcely necessary to rentark that a complete demonstration and record of an investigat tion of this complicated nature would present an array of figmes inadnissible in this work. The riaglann on P'l. 35) lras, therefore, been devised to dispense with linnles; the relitions of time, velocity, and resistance being presented in such a manner that, among otlier facts, the anount uf mechanical energy which disalpears during the experiment may be ancertained by mere inspertion. Hor the purpose of saring space and facilitating direct comparisun, this diagram has,

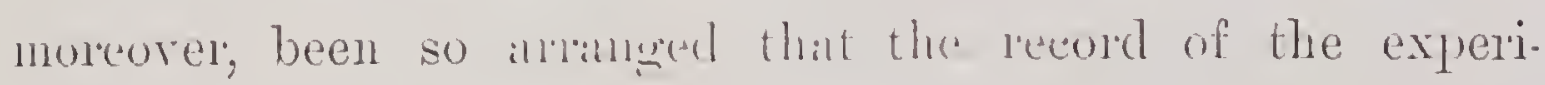
ments in which heat and refrigeration have been employed is plated on the sinue base-line with the record of the experiments in which difference of temperature was presented. The divisions on the base-line a 6 mark the time of rotation, the lalge spaces indicating minutes and the smaller divisions 10 sec. each. The length of the ordinates of the curre $c b$ resting on the base-line represents the number of turus performed in a given time when the rotit. ing sphere is not subjecterl to the action of heat and refrigeration; while the length of the orlinates of the curve $d$ e represents the number of turns when heat and cold are being "pplied. It will be readily perceiver that, for instance, the ordinate between 1 and the curve c b represents the number of turns per minute at the commencement of the second minute, while the ordinate 2 represents the number of turns per minute at the commencement of the third minute, and so on for all the other ordinates. 
The permanent firction of the instrument-i.e., the friction of the pirot on which the sphere turns-being practically inappreciable, it will be evident that the resistance opposing the rotation will vary in the ratio of the square of the relocities. Hence, as the respective ordinates between the curves $c b$ and $d$ e and the base-line represent the velocitics, it will only be necessary to square these ordinates in order to determine the exact amount of resistance to the periods indicated by the dirisions on the base. Accordingly, the ordinates mentioned have been prolonged in the ratio of their squares, the curres $f t$ and $g e$ being the result of this pru. longation. Obriously, the lengths of the ordinates of these curves resting on the line a $b^{\prime}$ represent accurately the anomt of resistance opposed to the rotation of the sphere at the times indicated by their intersection with that line. The rate of velocity-i.e., the number of turns per minute performed by the sphere at the commencement and at the termination of each minute-will be found by referring to the fignres marked on the rertical lines $f a$ and $b$ b. Thus, for instance, the rate of velocity at the termination of the second minute is 75.4 turns when refrigeration is not applied, while the rate is 68.0 when the cooling medium is applien at the pole. As might be expected from the irregular nature of the external resistance opposed to the rotating miss, the curves $f b$ and $g$ e do not correspond with any of the conic sections. The available motive power of 2,540 foot-grains expended during the experiment is represented by the superficies $f$ a b, the energy ineloped being represented 
by the superficies g a e. Assuming the former to be 1.000, the latter; as shown by our diagram, will be 0.763, difference $=0.237$; hence the amount of lost energy is $0.237 \times$ $2,540=601.98$ foot-grains. Now, if the weight of water which is condensed at the pole and returned to the equator, multiplied by the lieight necessary to generate the rotary velocity acquired during the transit, should amount to 601.98 foot-grains, the fact will be established that the current of rapor has not, during its passage from the equator to the pole, restored any of the energy abstracted from the sphere by the current of water flowing in the contrary direction. The quantity of water condensed and returned to the equatorial belt being readily ascertained by observing the increment of temperature of the contents of the polar cistern, it is easy to show that the energy abstracted from the rotating mass by the water thus transferred from the pole to the equator corresponds so nearly with the differential mechanical energy represented by the superficies $f g e b$, that the compensation resulting from the tangential force exerted by the particles of the currents of vapor against the surfice of the sphere of the dynamic register is inappreciable; precisely as we find that the compensating tangential force of the currents of vapor which sweep over the basin of the Mississippi from west to east (neutralized by the currents which pass from east to west) is an inappreciable fraction of the retarding energy of 19,336,000,000 foot-pounds per second, exerted by the water which the Mississippi carries in the direction of the equator. 
Having thus analyzed the opposing energies called forth by the waters flowing towarls the equator, and of the returning vapors, the condensation of which replenishes the river hasins. we may now enter on a conputation of the agorengate anount of the retarting energy; and the conseruent diminution of the rotary relocity; of the earth, callsed by the rivers enmmerated in the preceding table. 'The total of the retarding force entered in the column next the last, it will he foumd, anmonnts to $53,857,788,300$ foot-pounds per sec., which sum, multiplied by 86,400 sec., shows that the earth has to orereome a resistance of $4,653,313 \times 10^{\circ}$ foot-pounds during rach revolution. Mrultip] ying this resistance by $36,52+2$ days, we ascertain that the retarding energy of the water transferesed in the direction of the equator by the entire Southern river systems of both hemisplieres amounts to $16,995,760,069 \times 10^{10}$ foot. pounds in a century. Now, in order to deternine the diminution of rotary relocity consequent on this counteracting energs, it will be indispensable to compute the earth's rotary vis riva. The elements necessary in this computation are: rolume, time of rerolution, specific gravity, and the position of the centre of gyration of the rotating mass. The two first-named elements are known with desimble accuracy; the third element, specific gravity, has been ascertained witl tolerable accuracy; but the position of the centre of gyation, which depends on the internal temperatme of the globe and the disposition of its constituent parts, has not yet been determined. Physicists assume that the density of the globe increases towards the centre in arithmetical progression; but 
this assumption is not sustained by sound reasoning. Our space not arlunitting of discussing this complicated question at lengrtl, let us merely consider the leating fact, that, at at distance of only $\frac{1}{20}$ of the earth's radius $=1,04 t, 400 \mathrm{ft}$. firom the surface, the weight of a superincumbent mass of fused granite will exceed 900,000 1bs. to the sq. in. $=60,000$ atmospheres. Under this pressure the weight of air will be 70 times that of water, and 3.5 times that of the heaviest metals. Gold, at the point of fusion, is $T$ times hearier than fused granite, while neither of these solids loses more than $\frac{3}{100}$ of specific gravity at melting heat-a fact which proves conclusively that high temperature of metals and numerals is not incompatible with great density. Hence fused granite, in the earth's interior, may be many times heavier than the cold mineral at the surfice. Unless, therefore, we are prepared to dispute the assumption that fused granite, under a pressure of 900,000 lls. to the sq. in., will have its specific gravity doubled-involving a density less than one-third of fused gold not subjected to compression-we must aduit that the specific gravity of the earth at the depth of $\frac{20}{10}$ the radius is so great that, if the density, as physicists have assumed, increases in aritlmetical progression towards the centre, our planet would be many times heavier than it is. We are compelled, therefore, to reject the accepted theory, mole apecially as the stated enormons pressure consequent on superincumbent weight takes place at only $\frac{1}{2 \pi}$ of the eartlis radius below the surface.

In accordance with the foregoing reasoning, our compu- 
tation of the earth's rotary vis viva will be based on the assumption that the mass is homogeneons. It is true that the specific gravity at the surface is somewhat less than me-half that of the entire mass; but we have shown thit at a depth of $s^{1}$ of the ratius from the surface the rensity is so great that if it continued to angment in arithmetical progression, the specific grarity of the globe womld fall exceed that which has been determined by careful investigation. Nor should we lose sight of the important fact that the temperature corresponding with the compression produced by the superincumbent weight is so great that the component parts of the central mass may be as light as pumice. notwithstanding the enormous external pressure. Conse. quently, it may be satisfactorily demonstrated that the earth's circle of gyration extends considerably beyonl, in place of being within, that of a homogeneous sphere, agree. ably to the accepted theory of augmented density towards the centre. In our computations, howerer, we will assume that the circle of gyration is that corresponding with homo. geneity, which, in accordance with the property of spheres, is 0.6325 of the great circle. Sir John Herschel's deternination shows that the mean diameter of the earth, considered as a perfect splere, is $7,912.41$ statute miles, or $41,775,524 \mathrm{ft}$; hence, if we assume the specific gravity to be 5.5, we call readily calculate that the weight is $1,308,605 \times 10^{10}$ lhs. Nultiplying the equatoria] relocity-1,519.07 ft. per second --by 0.6325 , we ascertain that the mean rotary velocity of the entire mass of the earth is $960.81 \mathrm{ft}$. per second-a rate 
acquired by a fall of $14,424 \mathrm{ft}$. 'The earth's rotary vis viva will accordingly amount to $14,42+\times 1,308,608 \times 10^{10}=$ $18,875,361 \times 10^{22}$ footpounds. The mind being utterly incapable of conceiving this stupendous energy without comparison with mechanical energies of less magnitude, let us ascertain to what extent it will be diminished by the retardation exhibited in the tables previously presented namely, $16,995,760,069 \times 10^{10}$ foot-pounds, exerted in the course of a century by the southern river systems of both hemispheres. Dividing the stated retarding energy in the earth's vis viva, thus: $\frac{18,575,361 \times 10^{22}}{16,995,760,069 \times 10^{10}}$, we find that, notwithstanding the enormous amount of retardation exerted in a century, only $\frac{1100^{1} \overline{0} 000}{10}$ of the rotary energy of the earth will be destroyed in that time. And if we multiply the fraction thus presented by 10,000, we learn that at the end of 1,000,000 years the rotary energy of the earth will be only $\frac{1}{11060}$ less than at present! By no other comparison, probably, than the one we have instituted could we clearly comprehend the magnitude of $18,875,361 \times 10^{23}$ footpounds of mechanical energy.

Let us now calculate the effect of the tabulated resistance on the earth's rotary relocity with reference to time. The retardation observed by astronomers being; as before stated, about 12 sec. in a century, our object will be to ascertain how far this retardation may be attributed to the counteracting energy under consideration. Multiplying, then, the number of seconds in a century, $3,155,673,600$, by the 
retarding energy of $5 ., 855,780,300$ foot-pounds per second, entered in the table, we establish the fact before adverted to, that the total retardation is $7\left(6,995,5600,069 \times 10^{10}\right.$ foot. pounds in one century. Dividing this retardition in the vis.

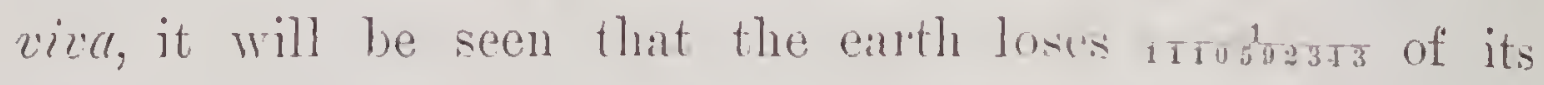
rotary energy in the course of 100 years; but in calculating the time corresponding with this loss, we have to consider that the relocities are as the square root of the forces, and that conserquently the rotary relocity will not be resluced as rapidly as the rotary energy. Evidently, if the diminution of energy and velocity corresponded exinctly, the retardation of the enth's rotary motion during one century womld be $\frac{3,155,673,600}{1,110,592,343}=2.8414$ sec. But, in accordance with the laws of motion referred to, the diminution of velocity during the century will be in the ratio of the square roots of the earth's vis viva at the beginning and at the termination of that perior. Now, this ratio being readily computed, as we know the anount of energy lost in one century, while the time in seconds is also known, we are entbler to show, hy an easy calculation, that the eanth suffers it retardation of 1.42071 sec. Adding the retardation occasioned by the tabulated sedinentary matter $=0.00105$ sec., ascertained in the mamner explained, the total retariation of the eantlis rotany relocity in a century, at the present epoch, will be 1.42176 sec. The vastness of the rotary vis viren of the earth having alreally heen discussed, it will not be necessary to offer any explanations with reference to the insignificance of the stated 
retardation in compraison with the magnitude of the counteracting enerey exerted by the water and sediment of the entire river system presenterl in our tables.

We have now to consider the influence on the earth's rotary energy exercised by rivers, the course of which is in the direction of the poles. Evidently river water romning from the equator will have its motion round the axis of rotation continually diminished as it reaches the morthern parallels; hence rotary energy will be imparted to the earth by all rivers flowing towards the poles. At first sight, it will be imagined that the energy thus inparted will neutralize the retarding force exerted by the waters transferred towards the equator. Certain physical causes, howerer, prevent the imparted energy from restoring any of the enrth's lost vis vimu. 'The subject will he most readily comprehend. ed by an exannination of the nature of the mentralizing force exerted by the following great rivers, namely, the Lena, Yenesei, Obi, and Mackenrie, which fumish the principal amount of Water discharged into the Arctic Ocean. These rivers drain an area of $3,840,000 \mathrm{sq}$. miles, the latitude of the centre of their hasins and their outlets being rery nearly in the same parallel. The mean of the former is 59 deg. 30 min., that of the latter 69 deg. 56 min. Accordingly, the mean circumferential relocity of ontlet is $421.1 \mathrm{~s} \mathrm{ft}$. per second, while that of the centre of hasin is $750.95 \mathrm{ft}$ per second. It will be scen, therefore, that a diminution of rotary velocity of $750.95-521.18=249.5 \%$, say $250 \mathrm{ft}$. per secont, takes place during the transfer of the water from the centre 
of the basins of these river's to their outlets. Now, a relocity of $250 \mathrm{ft}$. per second is produced by a fill of $976.5 \mathrm{ft}$., hence each pound of water discharged into the Arctic Ocean by the beforenamed rivers will impart a mechanical energy of 96.5 footpounds. A purt from this powerful neutralizing force of a given weight, the quantity of water transferred is so great, owing to the vast extent of the bisins, that, notwith. standing the moderate precipitation in high latitules, the rotary energy imparted to the earth will balance the retarda. tion of the 136 rivers entered in our tables. It scarcely requires explanation that the stated enormous force exerted by the water transferred by the great northern river's is owing to the rapid diminution of rotary velocity in alpunching the pole; a single degree of latitude at the point where, for instance, the river Lena discharges into the Arctic Sea having a greater fall than ten degrees have within the tropies. It would be waste of time, howerer, to compute the exact amount of energy imparted to the earth by the Arctic rivers, as will be seen by the following examination of the subject. Unquestionably, if the supposed pound of water, on entering the Arctic Ocean, at once evaporates and ascends into the atmosphere, we must achuit that an inpulse of 976.5 footpounds has been imparted to the earth by its trinsfer from the centre of the river basin; but if it should be found that, in place of evaporating on entering the cold polar sea, the pound of water commences a retrograde motion towards the equator through Behring's Straits or through the wide chammel between Norway and Greenland; and if we should find, also, 
that when it crosses the 59 deg. 30 min. parallel (the same as that of the centre of the river basin) it has not yet been converted into rapor, we must then admit that the whole of the energy imparted to the earth by the approach towarts the axis of rotation, during the original transfer to the polar sea, has been completely neutralized by the retardation consequent on the retreat from the axis of rotation during the southerly course to the last-mentioned latitude. Following our pound of water during the continuation of the motion towards the equator, we may discorer that it has not changed its form into vapor, even when reaching latitude 47 deg. 45 min., at which point the circumferential velocity is exactly $250 \mathrm{ft}$. per second greater than that of the centre of the basin from whence the motion proceeded. In that case, not only has the imparted energy been nentralized, but a retarda. tion of 976.5 foot-pounds has been called forth by the pound of water, the course of which may possibly continue until it mixes with the warm water within the tropics. Let us gruard against confounding the movement of the water discharged into the Arctic Sea by the northern rivers with the currents produced by the combined influence of lumar attraction, winds, differential oceanic temperature, and solar attraction. It has long been recognized that the water poured into the Arctic Sea by the great Asiatic rivers is the result of condensation of vapors raised by the sun within or near the tropics. A corresponding amount of water must, therefore, be returned from the polar sea, or its surface would be elevated, and that of the tropical seas suffer a proportionate 
depression. The reader camnot fail to perceive the important bearing of these facts on the question of retarkation of the earth's rotary velocity.

The result of the experiments with the dynamic register proves that the rotary motion possessed by the rapors on learing the equatorial seas may be almost entirely destroyed by being converted into heat during their course towards the basins of the northern rivers; hence imparting no perceptible tangential force to the earth. Accorlingly, the return to the tropical seas of the water which is continually being dis. charged by the northern rivers into the polar seas will, on account of the increased relocity round the axis of rotation imparted during the southern course, subject the earth to an amount of retardation far exceeding that protuced by rivers flowing towards the equator. It may be asked, under these circumstances, why the latter rivers have been tabulated and their inferior retarding energy calculated. The river's flowing in the direction of the poles have been examined, tabulated, and their counteracting energy calculated; but the question of attendant retardation of rotaly relocity camnot properly be entertained until certain other counteracting influences shall have been cxamined. The publication of the table containing the southern rivers has been recmed neces. sary as a point diappui facilitating demonstrations intended to establish the fact that, independently of the counteracting force of the tidal wave (hitherto greatly overestimated), the retarding energy called forth by the evaporation within the tropics, and the consequent condensation and precipitation 
in the temperate zones, fully account for the retardation of the earth's rotary relocity - 12 seconds in a century-inferred from the apparent acceleration of the moon's mean motion.

The fact being well known, through Enropean and American publications, that the results attained by the employment of the instruments described in the foregoing chapters rank among the most important scientific achievements of the latter part of the first century of the American Republic, I expected that the Centennial Commissioners would invite me to display those instruments during the Exhibition, and consequently caused the same to be repolished and arranged for the great occasion. It is proper to state that, although not wanted by the Commissioners, the time spent in preparing the collection for exhibition has not been wasted, since it is my intention to present the same to the Smithsonian Institution, after the completion of certain investigations. 


\title{
CHAPTER XXIII.
}

\author{
DIS'IANCE INS'TRUMEN'I,*
}

FOR MEASURING DISTANCES AT SEA. (SEE PLATE 36.)

This instrument is principally intended for the use of the naval oflicer in measuring the distance of an enemy's ship, to enable him to elevate his guns with precision. Modern naval tactics being principally based on distant firing, an accurate knowledge of the object to be aimed at becomes indispensable. Any device for obtaining it based on any process of calculation is evidently out of the question, considering that a single minute will bring two approaching vessels, moving at a rate of ten knots, full a quarter of a mile nearer each other. In firing beyond point-blank range, therefore, seconds are precious in determining the elevation of the guns. Accordingly, nothing will answer short of an instrument which, by a single observation and the reading off at sight, tells the distance. 'T'he instrument under' consideration meets these somewhat severe conditions perfectly,

* This instrument formed part of the original equipment of the steamship Princeton. 
as will be seen by the following explanation. An observer stationed on the maintop or cross-tree of a ship, looking at a ressel-say a mile off-will pereeive that his line of vision, directed to the horizon, passes over the point marked by the water-line of the hull, and he will also perceive that, as the ressel approaches, that point appen's to sink lower and lower below the line directed to the horizon; in other words, the angle formed by that line and the line directed to the water-line of the approaching ressel continually increases. On the other hand, if the ressel recedes, it will be found gradually to diminish. Now, the observer's eye (see the plate before referred to) being placed at a definite lieight above the level of the sea, and his line of vision directed to the horizon being the tangent of the earth's currature passing through the definite point $a$, it follows that the angles $h a c$ and $g a c$, respectively, will determine the distance of $h$ and $g$ from $b$, when rertical to $a$. Now, the earth's curvature is constant, the height of a above the level of the sea is known, and the angles $h$ a $c$, etc., may be readily measured by reflector's and the graduated arc. But there is no time for mathematical computation.

The Distance Instrument, it will be seen by the following description, performs the required computation with unerring certainty whilst the obserrer measures the angle, and it exhibits the result the instant he has performed his part. Every one familiar with nautical instruments will, by an attentive inspection of the drawing, readily understand its principle and operation; a rery brief description will there. 
fore suflice. $A$ is an ordinary reflector, as werl in cuudrants; B, the object-glass, and $\mathrm{C}$, the sight hy which the angles h "le, etc., are measured; D, a spindle, to the end of which the reflector is firmly attached ; E, lever for turning said spindle; F, sliding-nut male to more freely up and down in a slot at the lower end of lexer E; G, thmmbserew working in the slidingrnut; II, pinion on sald screm; wolling into cogs cut in the circumference of a gratuated index-phate J; K, socket sliding on the main stem of the instrument and supporting the frame and centre of the revolving index-plate. Before noticing the operation of the instruncent, it will be necessary to point ont the manner of grarluating the index-plate. Considering the extent of the print-blank range of naral ordnance, it is evident that no distance under 400 yards need be measured: supposing, therefore, that $h$ is 400 yards dis. tant from b, it will be seen that the operation or range of the instrument will be linited to the angle $h$ a c, which thus determines the extent of movement or vibration of the lever E. This movement again determines the pitch of the thumb. screw ant the relative diameter of the pinion, it being evident that the extreme vibration of lever $\mathrm{E}$ should not produce more than one revolution of the index-plate. Any convenient-sized index-plate being selected, a scale graduated into feet or yards is then constructed, corresponding to the circumference of the plate; the mode of dividing the scale being as follows: In the first place, a base-line of 100 feet (represented by $a b$ in the diagram) is supposed, and the tangent a c determined accordingly. The known curve $b$ d c 
is then dirided into spaces $h \mathscr{g}, \mathscr{g}, \mathrm{f}, \mathrm{f} e$, etc., of 10 yards each, commencing at a point, $h, 400$ yards from $b$. The sines of the angles 7 a c g g a c, etc., are next calculated and marked on the before-mentioned scale, and from thence ultimately transferred to the curved scale on the index-plate. The following directions for using the instrument are dermed sutitcient: Turn the thumbscrew until the line marked "horizon" is placed directly under the fixed index. Then adjust the object-glass by means of the set screw M, so that the real and reflected horizons come in a line. This adjustment being' made, the instrument is ready for use, and need not be readjusted unless disturbed. The process of measuring the clistance consists simply in turning the thumbscrew G until the reflected water-line of the object observed is brought in a line with the real horizon seen through the object-glass. The point on the scale of the index-plate placed directly under the fixed index shows the distance desired. It must be conceded, on theoretical considerations, that if the baseline be previously known and the instrument made to correspond thereto, the measurement cannot fail to be accurate; but such is the matme of this base-line that it camnot be previously known; accordingly, the base-scale $I$ las been introduced, by which the instrmment mily at all times be made to conform to the variable height of the base. It is evident that an increase of altitude would render the scale of the index-plate too short, and, on the other hand, too long if the altitude be diminished. It is also erident that by sliding the index-plate up, the effect of which 
will be to shorten the lever $\mathrm{E}$, any dimimution of the base may be compensated for, and the index-plate remain very nearly correct. The sliding the index down would in like manner compensate for any incrense of the base. On mathematical considerations, it is obvions, however, that this mode of compensating for variations of the base cannot be carried rery far. Index-plates of different graduations will, therefore, be employed to suit the height of the masts of different classes of ressels, and the base-scale only resorted to for compensation to meet irregularities occasioned by altered draught of water, consequent on diminution of ammu. nition, stores, etc. it first sight, it rould appear that the base employed in this instrument is not sufficiently definite or accurate; on due consideration, however; it will be found to be fully as definite as required.

In the first place, the height of the maintop, cross-tree, or other point of a ship above the bottom of the keel may be ascertained to an inch, and, when once known, may be recorded, as well as tomage, Jength, beam, etc. Secondly; the draught of water amidships is always known to a careful commander, within two inches or less. 'The dlaught of water', being deducted from the lieight above the keel, establishes the altitude above the water-line. The height of the observer's eye-ordinarily five feet six inches-being next added, determines the base within an inch or two. So far, then, the accuracy is all that can he desired for practical purposes. The effect of the rolling of the ship, which at sea always takes place to some extent, next demands attention. 
It would be an extreme case to suppose the observer tossed through an arc of 20 feet whilst taking an observation-riz, 10 feet on each side of the rertical line. On calculation, it will be found that such oscillation would only produce a depression of six incles at the lowest point. Finally, the rising and falling of the ship leserves to be noticed. The vertical movement of the midship body, being at all times surprisingly small, will be found quite unimportant at times when the Distance Instrument is likely to be wanted. Again, as each observation only requires a few seconds, it may be frequently repeated. It is proper to add that an error of 6 inches in a base of 100 feet, and which will not ordinarily occur, only catuses an error of distance of nine rards in a mile. 


\title{
CHAPTER XXIV.
}

\author{
THE STEAM FIRE-ENGINE.
}

(SEE PLATE 37.)

THE Mechanics' Institute of New York oflered its great gold medal, in January, 1840, as a prize for the best plan of a sterm fire-engine. Having several years previously de. signed such machines in England, among which may be mentioned the steam fire-engine employed during the mem. orable fire at the Argyle Rooms in Isondon, in 1830 (the first time fire had ever been extinguished by the mechanical power called forth by fire), I had no difficulty in producing plans complying with the conditions of the Mechanics' Institute in a mamer warranting the award of the prize offered.

The following deseription-reference being had to the illustration on Pl. 37-shows the detail of the steam fireengine thus accepted by the Mechanics' Institute of New York. A, double-acting force-pump, composed of gun-metal, 
firmly secured to the carriage-frame by four strong brackets cast on its sides; $a$ a, suction-ralres; $a^{\prime} a^{\prime}$, suction-passages leading to the cylinder; $a^{\prime \prime}$, chamber containing the suctionvalves, to which chamber are connected suction-pipes $a^{\prime \prime \prime} a^{\prime \prime \prime}$, the hose being attached to the latter by screw-couplings in the usual mamer, and closed by the ordinary screw-cap. The delivery-ralres and passages at the top of the forcepump are similar to the suction-ralves and passages mentioned. B, the ail-ressel, composed of copper, its form being spherical; $\zeta$ b, delivery-pipes, to which the hose is attached. When only one jet is required, the opposite pipe may be closed by a screrr-cap, ats usual. The piston of the forcepump is provided with double leather packing, the pistonrod being made of copper. C, boiler, constructed on the principle of the ordinary locomotive boiler, containing an ulequate number of tubes of suitable diameter. The top of the steam-chamber and the horizontal part of the boiler is covered with wood as usual, in order to prevent loss of heat by radiation. c, fire-door'; c', ash-pan; $c^{\prime \prime}$, box attached to end of boiler, enclosing the exit of the tubes. The hot air from the tubes entering this box is passed off through a smoke-pipe $c^{\prime \prime \prime}$, the exit of which makes a half-spinal turn round the air-ressel, as shown in the illustration. c'"', iron brackets, riveted to the boiler and supported by the carriageframe. $c^{6}$, a wrought-iron brace, bolted to the carriage-frame, for supporting the horizontal part of the boiler. E, vertical pipe attached to the top of the stean-chamber; containing a conical steam-valve $e$, and also the safety-valve $e^{\prime} ; e^{\prime \prime}$, 
regulating screw and handle, connected to the stamm-ralve, for admitting or shutting ofl the steam; $e^{\prime \prime \prime}$, induction-pipe for convering the steam from the boiler. F, double-acting working cylinder, providerl with stemm-passages and slideralle of the usual construction; it is fimly securerl to the carriage-frame by means of brackets, in the same mamer as the force-punp. If, eduction-pipe, for carrying off the stem to the atmosphere; $f^{\prime}$, piston, provided with netallic packing on Barton's plan; $f^{\prime \prime}$, piston-rod of sterel, attached to the piston-rod of the force-pump by means of the cross-head $G$, composed of wrought iron; both piston-pods heing inserted into the said cross-head and secured by keys. \% tappet-rod, attached to the cross-hent, for moring the slicle. valve of the steam-cylinder by means of the nuts $g$ ' $g$ '. 'The latter may be placed at any desirable position on the tappetrod, to ensure a regular action of the valve. $\Lambda$ short axle of wrought iron, turning in hearings attached to the cover of the steam-cylinder, operates the steam-valve by appro. priate levers acted upon alternately by the nuts $g^{\prime} y^{\prime}$. I, feed-pump for supplying the boiler, provided with spindlevalves on the ordinary plan, its suction-pipe communicating with the valve-chamber of the force-punn), the feed-water heing carried into the horizontal pint of the hoiler. i, plunger of the force-pump, composed of gun-metal or copper, attached to the cross-hearl G.

Before proceeding with the description, it will be necessilly to state that, although the efficiency of the "steam-blast" was well ascertained at the time, the prevailing opinion that, 
in common with the loconotive engine, red-hot sparks would emanate from a stean fire-engine, and prove dangerous among honses in a close-buitt city, I wats compelled to resort to the employment of a blowing appanatus for generating the necessarily large quantity of steinn indispensable to render. the machine efticient.

J, blowing appratratus, consisting of a square wooken box, with panelled silles, in which a thin stgune piston $j$ is applied, leather packing being employed to make atrotight joints. $y^{\prime}$, circular lubes through the sides for arluniting atmospheric air into the box, these holes being covered on the inside hy pieces of teather or Indiarubber cloth acting as valves. ${ }^{\prime \prime}$, similar loles throm the top of the box for passing off the air, at rach stroke of the piston, into the receiver or regulator $K$, which is provider with a movable top h. 'The latter is composed of wood, joined by leather' to the upper part of the box, a thin shect of lead being attached thereto, in order to keep up a certain pressure of air in the regulator. F', chamel male of sheet-iron, attached to the blowing apparatus, communicating freely with the regulator K. To the sairl channel is connected a conductingpipe, maked by dotted lines in the longitudinal section of the engine, for conreying the arir from the receiver into the

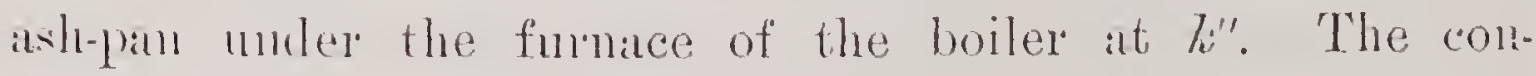
ducting-pipe, it shonld he observed, passes along the inside of the canriage-frame on either side.

L L, parallel iron rods, to which the piston of the blow. ing apparatus is attached. These rods work though gaide- 
brasses 7. 7, and may be attached to the cross-hearl fr by keys at $l^{\prime} Z^{\prime}$. 'The holes at the end of the said cross-hearl anduitting these rods are sufficiently large to allow a free morement whenever it is desirable to work the blowing apparatus independently of the engine. M, spindle of wrought irom, placer transversely, turning in bearings fixed under the carriageframe. To this spindle are fixed two crank-levers $m m$, which, by means of two connectingrods m' $m$ ', give motion to the rods L L attacher to the piston of the blowing appa. ratus.

$\mathrm{N}$, crank-lever secured to the end of spintle M, which, by means of a comnecting rod applied to a crank-pin, fixed in the hub of the carriage-wheel, on the outside, will communicate motion to the blowing apparatus whenever the carriage is in motion. By this simple expedient a powerful combustion will be kept up in the boiler furmace while the engine is on its way to the place of conflagration. By detaching the comecting-lod referred to, and applying a hand. lever to $\mathrm{N}$, the hlowing apparatus may be operated by manual labor: The carriage-frame should be marle of oak, plated with iron all over the outside; the top plate to hare small recesses, as shown in the drawing. The lock of the carriage, axles, and springs to be marle as usual, only differing by laving the large springs suspended below the axle. The carriage-wheels to be constructed on the suspension prin. ciple; spokes and outside of rim to be made of wrought iron, rery light. 


\section{CHAPTER XXV.}

THE STEAM-SHIP PRINCETON.

(SEE PLATES 38, 39, AND 40.)

In the sixty-sixth year of the American Republic-1842 -the first steam ship-of-war provided with a submerged propeller and steam machinery located below water-line was built at Philadelphia. Complete success attended this undertaking, as will be seen from the following extract from a speech delivered in the Senate of the United States by Senator Mallory, of Florida, May 14, 1858:

"In 1839 Congress authorized the construction of three war-ships. In 1840 the Secretary of the Nary, in obedience to that law, ordered two to be constructer. 'There were two plans at that time. The question of whether steam conld or could not be successfully applied to war-ressels had not then been solved; the fear of danger from ignition by fire prevailed in the minds of all naval men, and the problem was to be solved. Its solution was demanded by every naral 
power on earth. One of the ofticers of our nary, Captain William ITunter, subnitted a plan by which wheels were to be inserted in the bilge of the ressel on each side-sul. merged wheels. Ericsson had demonstrated his plan to be feasible, practicable, and just, already. 'This was no experiment in the Princeton. The experinent had been made at great cost by Captain Ericsson. . . . The Secretary of the Nary, in authorizing the construction of these two res. sels, directed one to be constructed on Hunter's plan-not model, as the Senator from Michigan says; the nodel was not in question at all; our models were as grood then as they are now; but the point was the application of steam to naval purpuses. One was to be built on Ericsson's plan, and one on Hunter's plan. Hunter's plan proved a total failure; Ericsson's plan laid the foundation of the present steam nurine. She was the first war propeller ever built on the face of the earth. In the Princeton he brought forwart not only his propeller inventer by Inimself, but a great many appliances appurtenant to steam navigation which hare since been used in our service.

"Now, to show the estimate in which this ship was held, I will mention that the American Institute, hearing of it, sent a committee to investigate the condition and success of what they deemed an experiment. I will not read the whole report of the committee of the American Institute. My purpose here is to show the value of Captain Ericsson's services to our country. The committee conclude by saying, after' summing up the speed of thinteen knots: 
"In conclusion, your committee beg leave to present the Princeton as every way worthy of the highest honor's of this Institute. She is a sublime conception, must successfully realized, an eftort of genius skilfully exeeuted, a grand, unique combination, honorable to the country as creditable to all engaged upon her.'

"This is signed by ten members of the Institute. Further to illustrate: Captain Stockton, in 1S44, after describing the ship, her guns and her armanent, says everything lumman language can to extol her in the eyes of the American people. As I said, the Princeton is the foundation of our present steam nulline. It is the foundation of the stean marine of the whole world. She created miversal surprise wherever she was seen. She revolutionized naral ressels; and hereafter, in manitine war, those who send sailing vessels to sea send them but to be captured."

The following extract fronl, the work on "Naval and Mail Steamers," published 1853 by Charles B. Stumt, Enyineerin-Chief of the United States Nary, furnishes some important particular's relating to the Princeton:

"This ressel was designed by, and constructed under the superintendence of, Cantain John Lricsson, of New Iork.

HIUILL.

Length on deck, . . . . . $16 \pm$ feet.

Length between perpendiculars, . . 156 "

Extreme beam on deck, . . . 30 " 6 inches.

Depth of lower liold to berth-deck, . 11 "

Depth from berth to spar-deck, . . $\quad$ i " 6 " 
Total depth of ressel, . . . 21 feet 6 inches.

Measurement burthen, . . . 673 tons.

Launching weight of hull, . . 418 "

Displacement at $16 \frac{1}{2}$ feet draught, . 954 “

Displacement at 18 feet draught, 1,046 "

Immersed midship section at $16 \frac{1}{2}$ feet draught, $3 \pm 6$ square ft. " " " 18 " $18 \quad 390$ "

Draught of water at deepest loud, with 200 tons of coal on bourd, . . . 19 feet 4 inches. Draught of water with 100 tons of coal in, after-bunkers and provisions, and water for the crew, half ont, $\quad$ aft, $1 \delta_{\frac{1}{4}}$ " Mean draught of water with half coal out, and all other weights full, . . . 17 feet.

"The peculiarity of model consisted in a very flat floor amidships, with great sharpness forward and excessive lean. ness aft, the run being remarkably fine, with a great extent of dead-wood terminating in a stern-post of the musual thickness of twenty-six inches at the centre of the propellershaft, but tapering above and below. This dead-rood and stern-post was pierced by a hole thirteen inches diameter for the passage of the propeller-shaft. 'The stern, measuring from a perpendicular from the aft end of the spar-deck, orerhung the sterm-post fifteen and one-half feet, and depending from it was a false stern-post, leaving a space of six feet, fore and aft, between it and the true sterm-post. The propeller (fourteen feet in diameter, composed of bronze, with six propellerblates, pitch thirty-five feet) was placed within this space. 
The false stern-post, or rudder-post, was composed of a wrought-iron bar, covered with half-inch-thick copper plate; it was attached at top by brass flanges to a strong oak linee, securely bolted to the counter of the ressel; the lower part of it was attached by similar flanges to a solid oak timber placed as a continuation of the keel beyond the true stern. post; this timber was fourteen inches deep, and securely bolted to the keel and dead-wood. The metallic false sternpost was five and three-eighths inches broad athwart ship, and two feet long fore and aft; the forward part was brought to an acute angle to diminish its resistance to the water, while its after-part was square to receire the attachment of the rudder. The rudder was also composite in its construction, being formed of a wrought-iron frame, the interstices of which were filled in with pieces of five-inch-thick pine plank, the whole cased over with a copper plate three-sixteenths of an incli thick. 'The thickness of the rudder athwart ship was the same as that of the false stern-post, viz., fire and threeeighths inches.

\section{ENGINTS.}

"The semi-cylinder engine of the Princeton is unquestion. ably the most remarkable modification of the steam-engine that has ever been carried into successful practice. A vibrating piston of a rectangular form moving in a semi-cylinder is an old mechanical device. Mr. Watt, in his celebrated patent, embraced this plan for transmitting the motive force of steam to machinery. Since his time several engineers have attempted to build engines on this plan, but without success. 
In common with Mr. Watt, they have adopted the single semi-cylinder with packing against the piston-shaft. Eriesson's plan differs materially from these various attempts, he larving introduced double or compound semi-cylinders of different diameters, with double pistons placed in opposite direc. tions on the piston-shaft, both being acted unon by the stem at the same time, their differential force being the effective motive power of the engine. The combination of two sur h double semi-cylinders, arranged so as to transmit their prower in directions nearly rectangular to a crank-pin common tu both, also contributes to the complete success of this singular. engine.

"By reference to the plate, it will be seen that the upper" semi-cylinder, which contains the reacting piston, is twenty inches in dianeter, the lower or working semi-cylinder being serenty-two inches diameter, both ninety-six inches long in the clear. The radius of the reacting piston, being deducted from that of the working piston, leaving twenty-six inches effective width of piston, with its centre of pressure placed $10+13=23$ inches from the centre of the pistons shaft. The active piston area will thus be $26 \times 96=2,516$ superficial inches, moring at a mean distance of twenty-three inches from the centre through an ance of ninety degrees.

"On close examination this engine will he found to possess many peculiar properties, some of which merit particular notice. The vibration of the working piston will be found to correspond nearly to the beat of the perdulum, and thus, unlike the ordinary engine, the return morement of the piston 
at each termination of the stroke is materially assisted by the force of gravity. An undue accmunlation of condensed water on the piston, so difficult to carry off in the ordinary engine, presents no inconvenience here, as the inclined porition of the piston allows the comblemed water to How grathally down into the steann-passages hefore the piston reachess the termination of the stroke. The ontward tendency of the packings, induced by centrifugal force, assists materially in forming tight joints, the main facking being hald out by the force of grarity. The lateral yielding of the piston-shaft, cansed by the prissure of the stean on opening the inletvalve, tends to give alditional tightness to the packings, the pistons being forced into reduced radial linits by the yielding alluled to. The crank-lever's attalched to the piston-shafts being baced nearly in the same position with the main pistons, it will be found that the arank-joumals of those shafts are relieved from pressure, on principles analogous to the relieving of water-wheel journals, by transmitting the power at some point near the centre of pressure. The increase of force inparted to the crank-pin at each half-turn of the main crank, owing to the angular position of the piston-rod crankis, and hilpening; as it does, when the former presents short leverage, is a marked feature of this engine.

"The small angnlar movenrent (ninety degrees) of the main piston also deserves attention. A greater motion, while it would angment the power of any given-sized cylnuler, would canse undue strain on all the principal bearings, as the force of the piston obviously increases in the inverse 
ratio of the sines of the angles of the priston-kluft cranks, with reference to the position of the connceting-men. I rery morlerate increase of dianceter nakes up the loss conscounent on the short anc through which the piston vilmates. Tery deep cylinder-corers, giving great strength to resist the up. ward pressure of the steam, ma! also be named ats an advalntage resulting from the short vilnation.

"As an instrument of producing, hy direct menns; the high speed requisite for screw-propellers, this emgine com. mends itself to the engineer. In its fitness for suren-resmits it seems to fulfil every condition. 'The very limited number of working parts, and the small antount of matter to he kept in motion, are self-erident alvinutages, best mulerstuod by reference to the plate. It is important to notice that the piston-shaft journals are supported by bearings placed out. side of the heads of the semi-cylinders, and that the brasses almit of adjustment in erery direction; the exact position of the centre of the pistom-shafts, with relation to the centre of the semi-cylinders, being indicated by an extermal index, enabling the engineer at all times to keep the shaft in line.

"The main packing is rendered accessible by lifting up one of the corers and removing the nearest side-plate forming the packing-groove. The upper packing becomes acces. sible by lifting up the centre-piece which forms the upper semi-cylinder. It may be stated with regard to the patekings, that the Princeton, after having served during the war with Mexico, was despatched on a cruise to the Mcditerranean without requiring new packings." 
CIIAT. XIV.

Mr. J. O. Sargent, in a lecture on "Steam Navigation and the Arts of Naral Warfare," delivered before the Boston Lyceum in 1St4, stated with reference to the motive power of the Princeton: "The next peculiarity to be noticed in the Princeton is the absence of the ordinary tall smoke-pipe employed to produce the draught for keeping up combustion in the furnaces of the boiler's. The smoke-pipe has hitherto formed a serious objection to a steamer as a ship-of-war; for the moment it is carried away the efficiency of the engines ceases from want of steam. The draught in the boiler's of the Princeton is promoted by means of blowers plateed in the bottom of the vessel, and is quite independent of the height of the smoke-pipe, which is only carried about five feet abore the deck of the ship. If this inconsiderable projection should becone partially deranged by a shot, the draught kept up by the blowers will continue as efficient as before.

"It is not out of place here to observe that Ericsson was the first to apply to marine engines centrifugal blowers, now so common in this country in all boilers using anthracite coal. In the year 1831 he applied such a blower, worked by a separate small steam-engine, to the steann-packet Corsain, of one hundred and twenty lorse-power, plying between Livelpool and Belfast." 


\section{CHAPTER XXVI.}

TWELVE-INCH WROUGH'I-IRON GUN AND CARRIAE.

(SEE PLATE 41.)

Trif question has frequently been asked, When was wrought-iron ordnance first introduced on board ships-of-war? When was breeching first dispenserl with and wrought-iron carriages introduced? The hearling on the plate referred to gives an answer to these queries.

Captain Robert F. Stockton, of the United States Nary, on visiting England-1839-for the purpose of witnessing the trial of a small screw-steamer (the first iron ressel to cross the Atlantic) built for him by Messis. Laird, to my design, consulted me regarding the possibility of constructing naral ordnance of wrought iron. Being an adrocate of that material, I readily met the wishes of Captain Stockton, and at once prepared drawings of a gun of 12-inch calibre. 'The Mersey Iron-TVorks, near Liverpool, being willing to enter into a contract with Captain Stockton, received forthwith 
an order from that enterprising and spirited officer to build the gun at his expense. Experienced commodores at the time protested loudly against the proposition to mount "the monster gun" on board a ressel so lightly built as the Princeton, insisting that, among other difficulties, the breech. ing would tear her upper works to pieces. It was urged by the opponents of my new system that the handling of such guns at sea would prove impossible, the constructing carriages of sufficient strength being pointed out as impracticable; while the imprudence on the part of the Nary Department of entrusting such matter's to mere engineering skill was severely criticised. In spite of remonstrances, however, Captain Stockton's influence with the Government prevailed. In the meantime the problen of handling the 12-inch gun received due attention. Calculations of the dynamic equivalent of the recoil convinced me that a moderate resistance, if contiuuons and uniform, would suffice to bring the piece to rest in less space than that required by breeching. Friction, being the simplest means of obtaining a continuous resistance, was accordingly resorted to. 'The method adopted will be readily comprehended by reference to the illustration already referred to, which represents a side elevation, top view, and end riews of the grum, carriage, and slide, mounted on board the Princeton in 1843. Two pieces of timber of semi-circular section, placed a few inches apart, slightly taper towards the front end of the shide, are secured to the latter in such a manner as to admit of some vertical motion. A broad hoop of plate-iron, attached to the car- 
riage, clasps the two timbers. An axle provided with a cam in the middle, operated by a lever, is placed across the fromt end of the slide passing through the spatce between the frimtion timbers. Obriously, these timbors will be pushed apart with considerable force if the transverse axle be turned so as to place the cam in a rertical position. The friction be. tween the hoop and the timber's produced by the pressure of the cam, it is scarcely necessary to observe, will be greatly enhanced during the recoil of the gum, in consequence of the increasing rertical depth of the timbers towals the rear' end of the slide. The transverse axle being tumed so as to place the cam in a horizontal position, permitting the friction timbers to approach each other, will of course at once relieve the friction. The monitor gun-carriages, constructed, like the Princton's, on the plan of checking the recoil by friction, differed as regards the mode of clasping the friction-timbers, a screw being employed to produce the requisite compression in place of the transverse axle and its cam. But in constructing gun-carriages for the celebrated thinty Spanish gumboats, and in all recent carriages, I have returned to the plan of employing a cam for setting up and relieving the friction, whereby, as in the case of the Princeton car. liage, the operation becomes almost instantaneous.

The 12-in. wrought-iron glin of the Princeton, as stated, was manufactured at the Mersey Tron-Works, of the very best materials, it has been asserted; but, on being tested in this country, it proved too weak. I therefore resorted to the expedient of hooping the breech of the piece up to the 
trumnion-band; the hoops being made of the best quality of American wrought-iron put on in two tiers, shrunk one over the other in such a manner as to break joint. 'This cxpedient proved entirely successful, the gun having stoor all tests to which it lias been subjected. It was a solid castiron shot from this 12-in. gun which in 1842 pierced a woughtiron target $4 \frac{1}{2}$ ins. thick, up to that period considered proof against naval ordnance.

The United States Government haring been the first to introluce heary wrought-iron ordnance for maval purposes, why does it not continue to build guns of that material? European artillerists repeatedly put this question. Probably the answer will be found in the fact that, although having in the meantime successfully constructed rifled wroughtiron ortnance of considerable size, the first essay at building heavy guns for naval purposes proved most disastrous. Inmediately after the trial of the gun referred to, manufactured in England, a 12-in. smooth-bore, of much heavier metal, was forged at Hamersley Forge, bored and turned in New York, and considered at the time to be a remarkable specimen of good workmanship. It was at once mounted on board the Princeton, by the side of its slender companion, upon a similar carriage. Much confidence was placed in the strength of this magnificent gun on account of the supposed superior quality of American iron. It stood the proof-charge and some preli. minary tests, but, on heing fired on a festive occasion while the ship was at Washington, the admired piece burst, with the sad result recorder in the naval ammals of the time. 


\section{OHAPTER XXVII.}

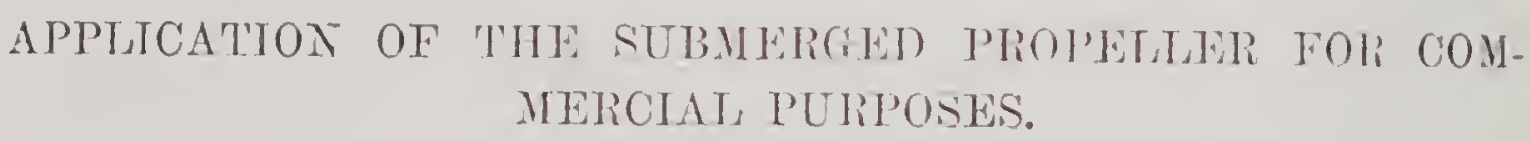

Durixg the construction of the Princeton numerous pro. peller-vessels were built for arying freight on the rivers and inland waters of the country, the machinery at first being built in New York, Philadelphia, and Osweggo. The line of propeller-steamers between Philaclelphia and Baltimore, which seriously interfered with the freight triflic of the Philadel. phia and Baltimore Railloar, merits special mention.

The amnexed table of propeller-vessels built up to Decem. ber, 1845, prepared by Lieutenant Johnson, of the Swedish Navy, in pursuance of order's from his Government, shows the extraordinary rapidity of the arloption of the propeller for commercial purposes.

The Engineer, in laying the table referred to before its readers, May 11, 1866, observes:

"The fate of mechanical inventions is much like that of 
the seed in the parable. The invention must fall on a pro. per soil, and be nurtured by favorable circumstances of time and place, in order to hloom into success. The application of the steam-engine to navigation was of greater necessity to the large extent of the rivers and lakes of the States than with ourselves; and Fulton did right to take his marine engine back to his own conntry. For similar reasons the screw-propeller worked its way into use there much quicker than with ourselres. 'This fact is very erident from the table furnished to Mr. Wooderoft by Captain Ericsson, prepared by Lieutenant Johnson, of the Swedish Nary, in 1843. Early in the following year (1S4t) a very large addition was made to the steam fleet prorided with Ericsson's pro. peller both on the inland waters of America and on the ocean. Of the latter may be mentioned the bark Edith and the steamships McKim, Marmora, and Massachusetts. The last ressel was subsequently purchased by the United States Government. It became the flag-ship of General Scott at the landing of Verin Cruz, which resulterl in the conquest of Mexico. It is worthy of notice that Ericsson applied his propeller to upwards of sixty ressels in America before any other form of propeller was adopted or a single attempt made at evading lis patent. Nor is it less worthy of remark that the adaptation of his propeller proved a great commercial success from the stant, many of the original ressels being now, after fifteen years of service, in good working condi. tion." 


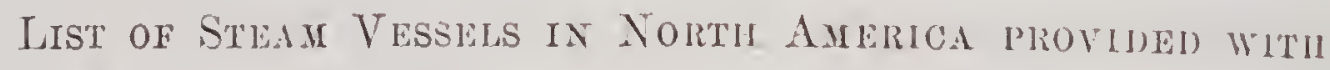
Firicsson's Sereir-Propelen up to Deckmber, 1943.

\begin{tabular}{|c|c|c|}
\hline Names of the ressels. & Destination. & 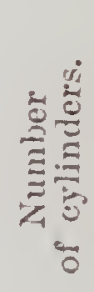 \\
\hline Robert I'. Stockton. & Delaware and Schuylkill...... & 2 \\
\hline Tandalia... & Oswergo to Chicago.......... & 2 \\
\hline Clarion..... & New York to Havana......... & 1 \\
\hline Baron 'Toranto...... & Rideau Canal and St. Litwrence. & 1 \\
\hline Royal Barge... & Rideau Canal and St. Lawrence. & 2 \\
\hline Propeller... & Rideau Canal and St. Lawrence. & 1 \\
\hline Ericsson ..... & Rideau Canal and St. Lawence. & 1 \\
\hline Ironside. & Philadelphia to Albany....... & 1 \\
\hline Anthracite. . & Philadelphia to Albany...... & 1 \\
\hline Black Diamond. & Philadelphia to Hartford ...... & 1 \\
\hline Vulcan .... & Pliviadelphia to Hartford..... & 1 \\
\hline Pioneer....... & Erie Canal. ................ & 1 \\
\hline Oswegro.... & Oswego to Chicago........... & 2 \\
\hline Chicago...... & Oswego to Chicago....... & 2 \\
\hline Cumberland.......... & Philadelphia to Baltimore..... & 2 \\
\hline Eiricsson. ......... & Philadelphia to Baltimore.... & 2 \\
\hline Pilot . & New York to Canada ......... & 1 \\
\hline Pliœnix............ & New York to Canada......... & 1 \\
\hline Governor McDowell..... & James River Canal to Virginia. & 1 \\
\hline Jefferson (Reveme Cutter) & Lake Erie. . . . . . . . . . . . . . . & 1 \\
\hline Legarée................. & Delaware River.......... & 1 \\
\hline
\end{tabular}


OHAP. XxVII, SCREW PROPITLSTON AND COMALTCE.

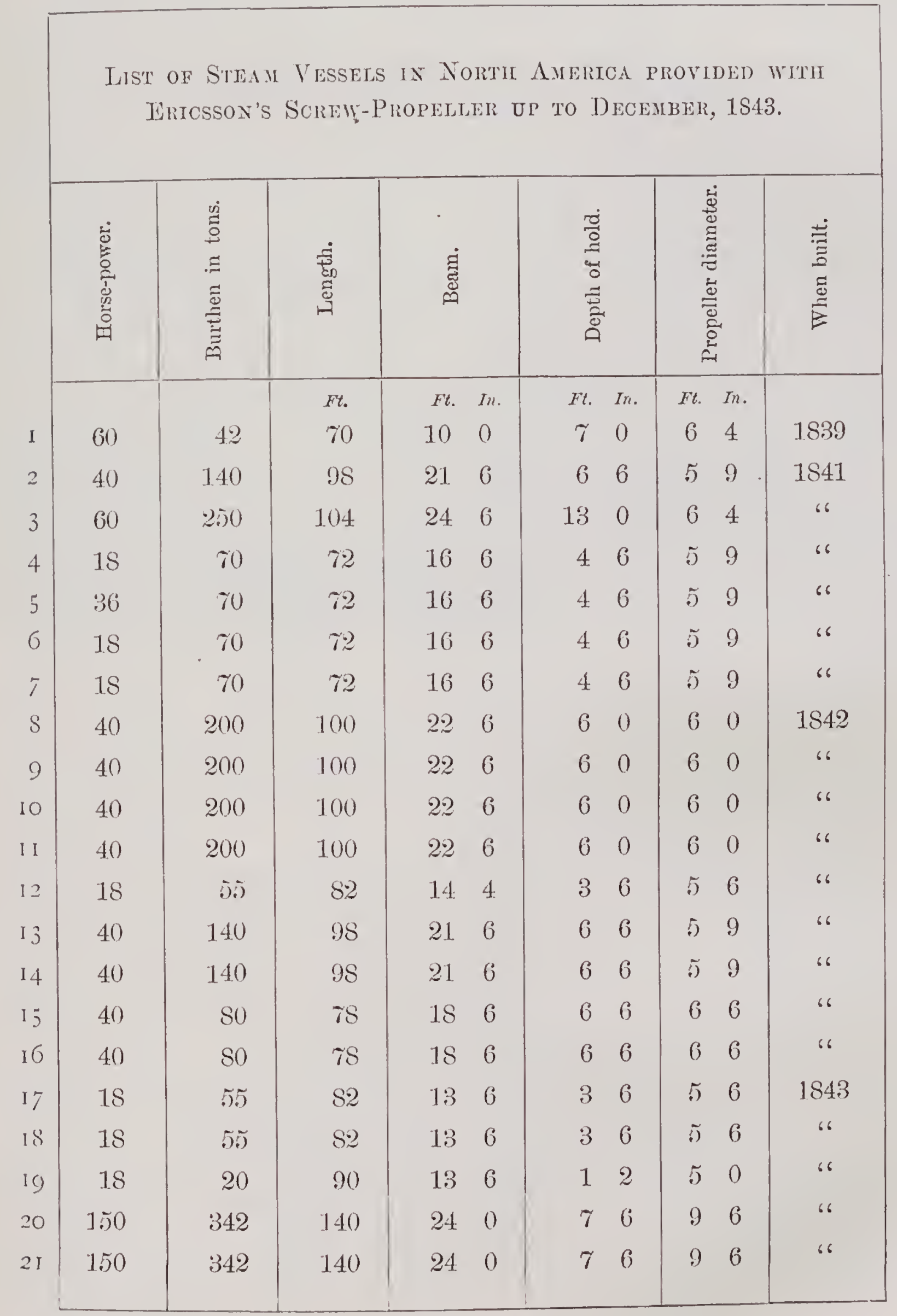




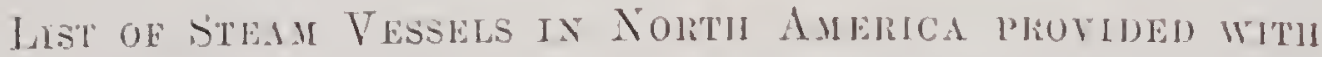

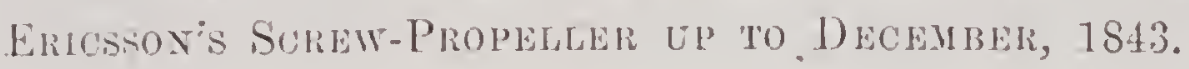

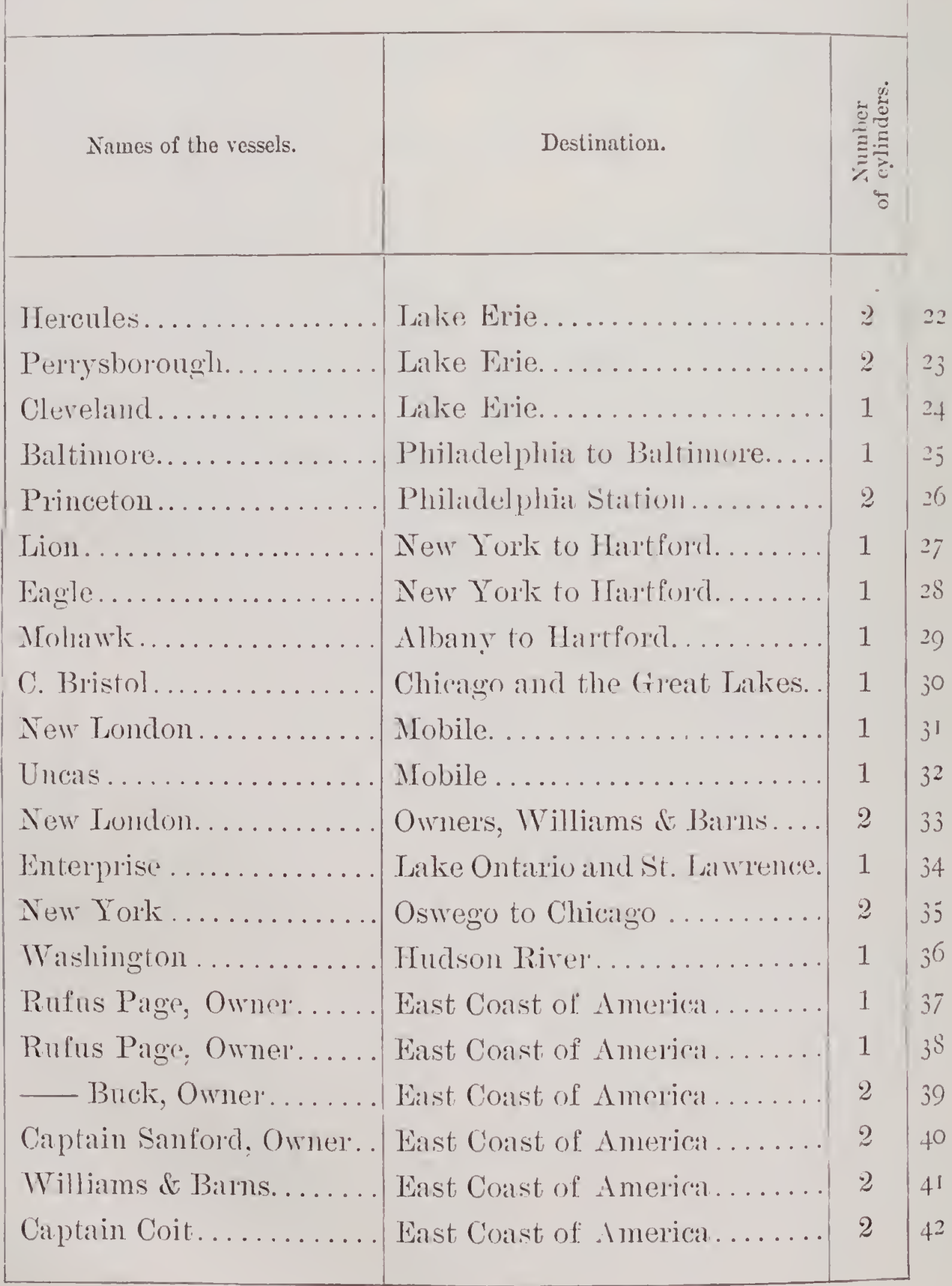


CHAP. XXVIJ. SCREW PROPULSION AND COMMERCE.

List of Stena Vessels in North America provided witu

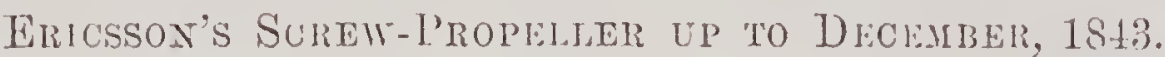

\begin{tabular}{|c|c|c|c|c|c|c|}
\hline 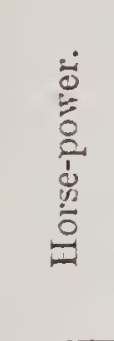 & 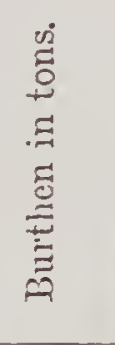 & 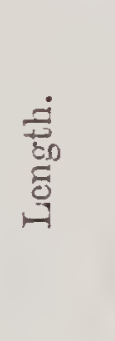 & ⿷匚⿱艹 & 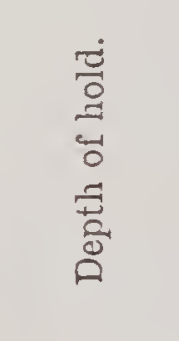 & 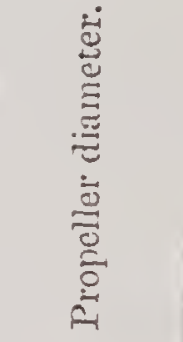 & 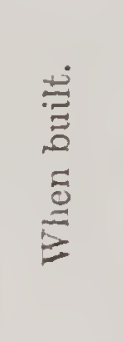 \\
\hline 50 & 250 & $\begin{array}{l}\text { Ft. } \\
\ldots\end{array}$ & $\begin{array}{c}\text { Ft. In } \\
\ldots\end{array}$ & $\begin{array}{cl}\text { Ft. } & \text { In. } \\
S & 0\end{array}$ & $\begin{array}{cl}\text { Ft. } & \text { In. } \\
6 & 0\end{array}$ & 1843 \\
\hline 50 & 250 & $\ldots$ & $\ldots$ & S 0 & $6 \quad 0$ & 66 \\
\hline 60 & 280 & $\ldots$ & $\ldots$ & 80 & 610 & 66 \\
\hline 50 & 127 & $7 \mathrm{~S}$ & 196 & 66 & 72 & 66 \\
\hline 400 & 672 & 164 & $30 \quad 0$ & 176 & 140 & 66 \\
\hline 50 & 172 & 115 & 236 & 60 & 610 & 66 \\
\hline 50 & 172 & $11 \tilde{5}$ & $2: 36$ & 60 & 610 & 66 \\
\hline 50 & $1 \% 2$ & 125 & 220 & 60 & 70 & 6 \\
\hline 60 & 300 & $\ldots$ & $26 \quad 0$ & $\$ 0$ & 74 & 66 \\
\hline 50 & 172 & 12.5 & 200 & 60 & $\tau 0$ & 66 \\
\hline 50 & 172 & $12 \pi$ & 220 & 60 & 70 & 66 \\
\hline 50 & 172 & 125 & 220 & $6 \quad 6$ & $\gamma 0$ & 66 \\
\hline 20 & 80 & $\ldots$ & $\ldots$ & $\ldots$ & 50 & 6 \\
\hline 50 & 140 & 98 & 216 & 66 & 59 & 66 \\
\hline 60 & 170 & $10: 3$ & $26 \quad 0$ & 76 & 74 & 66 \\
\hline 50 & 172 & 115 & 236 & 60 & 610 & 66 \\
\hline .50 & 172 & 115 & $23 \quad 6$ & 60 & 610 & 66 \\
\hline $5 \tilde{5}$ & 172 & 125 & $22 \quad 0$ & 60 & 70 & 66 \\
\hline 55 & 172 & 125 & $22 \quad 0$ & 60 & 70 & 66 \\
\hline $5 \tilde{5}$ & 172 & 125 & 220 & 60 & 70 & 66 \\
\hline 55 & 172 & 125 & 220 & 60 & 70 & 66 \\
\hline
\end{tabular}




\title{
CHAPTER XXVITI.
}

\author{
IRON-CTAD STEAI BATTERY, WITI REVOLVING CUPOLA, \\ SUBMTT'TED TO FIPEROR NAPOLRON III.
}

(ILLUSTRATION, SHE PLATL 42.)

The illustration referred to is a fac-simile of a drawing forwarded to the French Emperor at Paris, September 26, 185t, accompanied by an elaborate description and demon. stration of the utility of the battery.*

'The following extracts from the description of the new system of naval attack, formarded as stated, funishes a correct idea of its nature:

'The present system of long range is abortive. 1st, because large or heary bodies camnot be projected to a great distance;

* The Emperor promptly acknowledged the receipt of these doeuments through Gen. Fare, whose letter commences with the following flattering sentence:

"L'Empereur a examiné lui-mêne arec le plus grund soin le nourean sýstème d'attarue navale que rous lui avez communiquí.

"S. M. me charge d'aroir l'houneur de rous informer qu'clle a trouvé ros idíes très-ingénieuses et dignes du nome célèbre de leur autemr." 
2dly, because accurate aim at long range becomes absolutely impossible in practice. 'The recent trial of the Lancaster gun, when subjected to the unavoidable oscillation of a small vessel, may be cited as proof. Short range, "close quarters," will remove both difliculties, as it admits of large and heary projectiles being employed, and because it ensures accurate aim. Besides these advantages, a near approach to the enemy renders attack under water practicable. 'These facts establish the following propusitions: 1st, a complete system of naval atuch demands a solf-moving ressel capable of passing within range of guns of forts, and of moving at pleasure in defiance of the fire of broadsides. 2dly, with a ressel of such properties, a complete offensive system further requires adequate means of throwing projectiles of large size with absolute precision at short ranges, either point-blank or at very great elevation; the means of projecting shells (movable torpedoes) under water at short distances being also indispensable. 3dly. These conditions being fulfilled, the system yet demands a projectile that will infallibly explode at the instant of contact.

Accordingly, the writer has directed his experiments and labors to the solution of the following problens: I. A selfmoving shot-proof ressel. II. An instrument capable of projecting very large shells at slow velocities, but rery accurately, in accordance with previously-determined rate. III. A shell not subject to any rotation in the direction of its course, and so contrived as to explode with infallible certainty at the instant of contact. IV. A shell (torpedo) 
capable of being projected under water; and certain to ex. plode hy contact, together with an instrument for projecting such a shell from the vessel at a certain depth below the water-line.

The nature of the practical solution of the abore prob. lems will be readily comprehended by referring to the illus. trations (see Plate 42). A brief extract of the document forwarded to the Emperor will therefore suffice.

The vasser to be composed entirely of iron. The mid. ship section is triangular, with a broad, hollow keel, loated with about 200 tons of cast-iron blucks to balance the heavy upper works. The ends of the ressel are moderately sharp. 'The deck, made of plate inon, is curved hoth longitudinally and transversely, the curvature being 5 feet: it is mante to project $s$ feet orer the rudder and propeller. The entire deck is covered with a lining of sheet iron 3 inches thick, with an opening in the centre 16 feet diancter: Over this opening is placed a semi-globular turret of plate iron 6 inches thick, revolving on a vertical column by mans of stean-power and appropriate genr-work. The ressel is propelled by a powerful stean-engine and screw-propeller. Air for the combustion in the boilers and for ventilation within the ressel is supplied by a large self-acting centrifugal blower, the fresh air being drawn in through numerous small holes in the turret. 'The products of combustion in the boilers and the impure air from the vessel are forced out through conductors leading to a cluster of small holes in the deck and turret. Surrounding objects are viewed through 
small perforations at appropriate places. Reflecting telescopes, capable of being protruded or withdrawn at pleasure, also afford a distinct view of surrounding objects. The rudderstock passes through a water-tight stufing-box, so as to admit of the helm being worked within the ressel. Shot striking the deck are deflected, whilst shell exploding on it will prove harmless.

Tubs for projecting the shells to be made of cast iron or brass, 20 inches bore, 2 inches thick, and 10 feet long. It is open at one end, the other end being closed by a door moving on hinges provided with a cross-bar and setscrew, in order to be quickly opened and afterwards firmly secured. The shell is inserted through this door, and projected by the direct action of steam admitted from the boiler of the ressel through a large opening at the breech. The induction-valve is made with a double face of large areas, and moved by mechanism of instantaneous action, susceptible of accurate regration in regard to opening. One tube of the above description is placed on a level on the platform of the rerolving turret. Two similar tubes are placed in the body of the ressel, at a fixed inclination of 22 deg., revolving on vertical pivots. These tubes are supplied with steam through the centre of their vertical pirots, the admission of steam being regulated as before described.

The plan of throwing shells of several hundred pounds by the direct power of steam of ordinary pressure, demands special notice. Without reference to the result of actual trial, a brief investigation of the theory on which the plan 
is based will show that shells of enormous size may be projected with uncring precision.

T'me Shetr, composed of cast iron, is formed ats delineated." A groove is made round the circunference at right angles to the axis, into which an india-rubber ring is inserted to form a stean-tight joint when the shell is put into the tube. In order effectually to prevent rotation in the line of flight, a tail in the form of a cross, composed of thin plateriron, is attached to the shell. Opposite to this tail a cavity is formed, into which a cylindrical liammer is inserted. A pereussion-wafer is placed under the hammer; which, being always in advance of the shell, is struck at the instant of contact, infallibly causing an explosion.

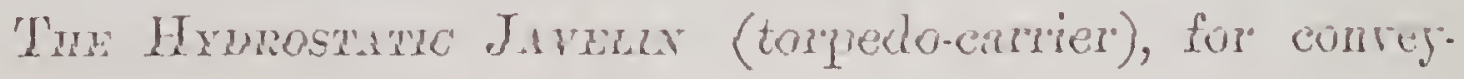
ing the shell (torpedo) under water, consists of a cylindrical block of light wood, 16 inches cliameter, 10 fect long. It one ent of this block a 16-inch shell is attached, charged with powder, and furuished with a percussion-hammer, als above describer. The other end of the block is pointed and londed at the under-side sufficient to balance the instrument perfectly. The displacement being 1,000 pounds, the weight of the whole is made to correspond accurately, in order to ensure perfect suspension in the water. 'The javelin (torpedo. carrier), when required, is passed through the ressel's bow or side by means of a short tube, as slown by the drawing, the water from the sea being kept out luring the insertion

* Unfortunately, the copies of this and other delincations referred to have been lost. henca cannot be presenterl in this work. 
by the obvious means of a slide-valve. 'The jarelin (torpedocarrier) is projected-pushed out-by means of a rod attached to the piston of a steam-cylinder of 18 inches diameter, 3 feet stroke. A force of 10,000 pounds acting through 3 feet is more than suflicient to propel the javelin 200 feet, at an average velocity of 12 feet per second. The javelin (torpedocarrier) is readily kept at any particular depth during its progress by a simple application of the hydrostatic pressure on a tail or rudder acting in the horizontal plane. 'The load inserted at the tail end of the javelin (torpedo-conductor) to balance the shell (torpedo) being applied at the bottom, the instrument cannot turn in the water.

\section{CONCLUDING REMARKS.}

This new system of naval attack will place an entire fleet of sailing vessels, during calms and light winds, at the mercy of a single craft. "Boarding" as a means of defence will be impracticable, since the turret gums, which turn like the spokes in a wheel, commanding every point of the compass at once, may keep oft and destroy any number of boats by firing slugs and combustibles. The loading at the breech and the dispensing with sponging ensures a rapidity in the lischarge of missiles quite irresistible in an attempt at boarding. A fleet at anchor might be fired and put in a sinking condition before being able to get under way.

Of what arail rould be the "steam gularl-ships" if attacked on the new system? Alin! for the "woorten walls" that formerly "ruled the wares." The long-range Lancaster gun would scarcely hit the revolving iron turret once in 
six hours, and then, six chanees to one, its shot or shell mould be detlected hy the ramping angles of the fire of the impregnahle globe. When ultimately stuck at right angles, the globe, which weighs npwarks of fo toms, will be less affected by the slock than a lieary anvil hy the blom of a hammer. Consequently, a cast-iron shot would crumble to pieces, whilst an expluting shell would strew the arched deck with liamless fragment:

Dnming contest the resolving tmiet shomld be kept in motion, the portholes being tumel away from the oppoment except at the moment of discharge, whichl, howeror, shombl be mate during full rotation, as the lateral aim in chose quarters requires but little precinions.*

* Captain Coles, of the British Niry, having claimed princity of invention, the following statement was published in various nantionl and mechanical jommals (186i2):

"Anscromty of Captain Coles's Ciam - Caprain Coles states, in "lelter to the Times of Aprit j, 1S62, that his experience in the Baltic and I3lack Sens, in 18jis, sugrgested to him the idea of building impresnable vessels, and that, towarls the latter part of that year. he had 'a rongh molel made by the carpenter of the Stromboli, and that he proposed to protect the grms hy a stationimy shiek or cupola. Captain Coles, it appears, net with un encourngemenit from the Ailmiralty. and therefore consulted IIr. Brmel. the celebrated engineer, who warmly cmbrared the plan. 'Ile did more,' says Captain Coles in his letter to the Timos: 'he assisted me in my calculations, and gave me the aid of his draughtsmen.' Captain Coles further states that, notwithstanding official neglect, he persevered, and in March, 1859. produced drawings of a 'shick fitted with turn-tables.' Lastly, in December, 18lio, Captain Coles published in PBlackerod's Vagnzine drawings of his 'grun-shich and revolsing platform, the platform being turned by manual power only." 


\section{CHAPTER XXIX.}

SUREACE-CONDENSER, OPERATED BY INDEPENDEN'T STEAM-

POWER.

(SEE PLA'TE 43.)

TuE following is an exact copy of the description accompanying the patent granted by the United States (1849) for the independent-action condenser illustrated on the plate referred to:

Fig. 1 is a longitudinal vertical section; Fig. 2, a crosssection of the condenser taken at the line ( $\mathrm{X} \mathrm{X}$ ) of Fig. 1; and Fig. 3, a cross-section of the pumping part of the apparatus and the auxiliary engine by which it is operated. The same letters indicate like parts in all the figures.

The object of my invention is to condense the steam without admixture with the condensing-water, that the water produced by the condensation may be carried back to the boiler, to prevent the evil consequences arising from the use of water that contains in solution or suspension mineral or 
other solid matter, and to condense the stenum which escapes from the safety-ralve, and also for the production of fresh water for any other use.

In my fresh-water apparatus $I$ use a tubular condenser', through the tubes of which the steam passes, and is com. densed by the cooling influence of a current of cold water taken from the outside of the resiel ol ship, and made to pass outside of the tubes; and to this end the finst part of my invention consists in combining the condenser of at stamengine for the propelling of a ship or resed with a jumly which receives the condensing water from outside the ship or other ressel, and causes it to pass through the condenser; the said pump being operated, inespective of the engine that pro. pels the ressel, by means of an auxiliary engine, whereby the amount of condensation can be regulated independently of the working of the engine that propels the ressel. The second part of my invention consists in connecting the condenser with the boiler or boiler's, or any part thereof, in addition to its or their comection with the exhanst of the engine, when the pump which carries the condensing water through the condenser is operated by an auxiliary engine, by means of which double connection not only is the steam that escapes from the safety-ralve contensed to be carried back to the boiler, but the boiler or boilers may be used to distil and produce fresh water for any purpose desired when the engine is not employed for propelling the vessel. And the last part of my invention consists in connecting the tubes of the condenser with the cylinder or outer case thereof by comnecting 
one ol both of the diaphragms to which the ends of the tubes are secured with the outer cylinder or case by means of a ring and flange, or the equivalent thereof, so that the said ring or flange may bend to adapt itsolf to the merpual contraction and expansion of the tubes and cylinder or outer case of the condenser.

In the drawings on Plate 43 (a) represents a horizontal cylinter, within which are arranged a series of small parrallel tubes (b). One ent of the said tubes is secured, in the usual way or any other desired and appropriate manner, to a diaphragn (c), which las a turned flange through which rivets or bolts (d) pass to secure it to the cylinder (a), and within such distance of the head as to leave a sufficient space betreen it and the hear (e) of the cylinder for two chambers $\left(f^{\prime}\right)$ and (g), these two chambers being separated hy a horizontal diaphragm or partition (h). The other ends of the tubes are in like mimner secured to another diaphragm (i) at the other ent, which said diaphragm, instead of being bolted directly to the end of the cylinder in the usual way, is bolted to a ring (j) near its outer periphery, the inner periphery thereof theing provided with a tmod flange bolterl to the end of the cylinder'; hut, instend of this, the end of the cylinder may be matle with a flange corresponding in size and form with this ring, and the diaphragm bolted to its onter periphery. The sairl ring or flange should be shighty conical, w bent, that the diaphragm miny be at some distance from the end of the eylinder, that it may move in and ont to arlapt itself to the unedual contraction and ex- 
pansion of the tubes and cylinder by reason of the passage of the steam through the tubes and the rater for the condensation through the cylinder. A chamber (ki) is formed at this end of the cyliniler by means of a head (b) secured to the diaphragm by means of a double-flanged ring $(m)$ and screw-bolts, that it may be remored to give access to the tubes.

The upper chamber ( $f$ ), at the end of the cylinder first described, communicates, by means of a pipe (n), in any de. sired manner with the exhaust-pipe of the engine, and, by another pipe $\left(n^{\prime}\right)$, also with the escape-pipe of the boiler, and these comnections should be governed by appropriate cocks or valves, so that either can be opened or closed at pleasure. Either of these comections bing opered, the steam passes into the chamber $(f)$, thence through the range of tubes abore the diaphragm or partition $(h)$ to the chamber (k) at the other end, and thence back through the lower range of tubes to the lower chamber (g), which communicates by means of the pipe (o) with the air-pump and supply-pumps of the engine, or, this comnection being closel, by means of a pipe $\left(o^{\prime}\right)$ with any desired recipient with which the pipe $\left(o^{\prime}\right)$ may communicate. The direction of the passage of steam, and the water produced by its condensa. tion, through the tubes, is indicated by the dotted arrows.

The steam, in passing through the tubes, is condenserl by the cooling influence of a constant current of cold water which passes outside of the tubes, and which travels in a direction the reverse of the current of steam, as indicated 
by the white arrows, so that the steam as it parts with its caloric is constantly approaching a cooler medium.

The water for the condensation is forced into the cylinder (a), near the diaphragm (c), through a pipe ( $p)$, and passes around the lower half of the series of tubes until it strikes the other diaphragm (i); thence it passes up around the end of a horizontal position-plate (q) on the same plate (h), which plate (q) extends from the diaphragm $(c)$ to within a short distance of the other diaphragm (i), and from this the water passes around all the upper half of the tubes to the first, where it escapes at the top through a pipe (r) that discharges through the side of the ressel abore the water-line.

The water from the condensation is impelled through the condenser by a rotating pump, the case (s) of which is provided with a tangential pipe $(t)$ at the lower part connected with the part $(p)$ by the condenser: And this case is also provided with another pipe (16) which extends from the centre thereof, to and through the side of the ressel, and so far down as to be always below the water-line, that the water may flow through it to the inside of the pump-case. To the centre of this case is adapted the shaft (v), the journals of which rum in appropriate boxes $(w w)$ in the cise, and provided with stuffing-boxes to prevent the escape of water; and on this shaft is a hub $(x)$, with four arms or vanes (y) accurately fitted to the case, and yet to rotate without touching it. By the rotation of these arms or vanes the water is drawn in near the centre, and by centrifugal 
force camied out through the tangential pipe $(t)$ to and through the comblemser. And the required rotation of the pump is given by an engine ( $a^{\prime}$ ) seculed to the casing of the rotary pump as represented in the drawings and the

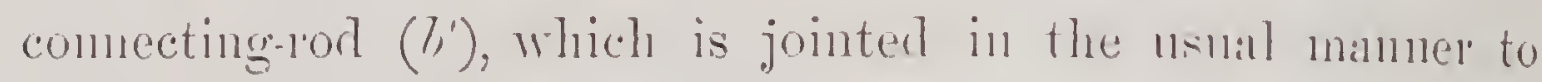
the cross-hear ( $\left.c^{\prime}\right)$, takes hold of a cramk ( $d^{\prime}$ ) on the shaft of the pump, the said shaft being, in the manial numner, pro. vided with an eccentric (e') for working the valless of the engine ( $\left.u^{\prime}\right)$, which are not represented, als they mily be on any of the known plans. The water-suplyly pund, which receives the witer from ontside the ressel, and which is for that purpose helow the water-line, is proviterl with a valve $\left(f^{\prime}\right)$, the stem $\left(g^{\prime}\right)$ of which passes through stufting-hoxes. and has a hamdle $\left(h^{\prime}\right)$ by means of which the pipe can be closed at pleasure when it becomes necessary to give access to the inside of the pump.

From the foregning it will be seen that, by means of the auxiliary engine which operates the punu, a constant current of cold water is carried through the condenser independently of the working of the propelling engine of the ressel, and, as al necessary consequence, the more the propelling engine labor's, by reason of heat winds or rough water, the more perfect will be the condensation and the vacumn thereby produced, thus increasing the power of the propelling engine when the power is most needed; whereats if the current of cold water were depentent on the working of the propelling engine, the sum of the mass of water passing throngh the condenser would be exactly in proportion to the motion of 
the engine, and therefore the condensation and racum would be decreased in the ratio of the decreased motion of the propelling engine.

It will also be seen that, by reason of the working of the pump which impels the water for the condensation by means of an axiliary engine, and the double connection of the condenser with the waste-pipe of the boiler or boilers, and with the exhaust of the propelling-engine, whenever the safety-ralve is opened, the steam issung therefrom, insteal of being wasted, will be carried through the condenser and condensed, to be returned to the boiler, thus aroiding the necessity of a separate supply of water to make up for the waste by the escape of steam from the safety-valve; and that when the propelling-engine is at rest the condenser can be used for the distillation and production of fresh water for any desired purpose on board ship, for the condenser is thus, when desired, rendered entirely independent of the propelling-engine.

By passing the current of steam in a direction the reverse of the current of condensing-water, the greatest amount of caloric is extracted with the least amount of water.

The condensing-water in its passage through the condenser' never reaches the point of evaporation, and therefore mineral and other matter held in solution will not be deposited to encrust the apparatus; and by ensuring a constant and rapid current of water around the tubes the danger of unequal contraction and expansion is reduced to the smallest amount, and so small as to prevent all injurious effects by the mode 
above described of comnecting one of the diaphragms, to which one end of the tubes is attached, with the cylinder by means of the conical or bent ring or flange.

Although I have described the use of a rotary pump, operated by a reciprocating engine, for impelling the con. densing-water through the condenser, I do not wish to confine myself to the use of either a rotary pump or a re. ciprocating engine for this purpose, as a rotary engine may be substituted for the reciprocating, and a reciprocating pump for the rotary; but I have described and represented this arrangement as the one which I have successfully es. sayed and deem the best. 


\title{
CHAPTER XXX.
}

\author{
I'HE CALORIC ENGINE. \\ IPPLICATION OF HEATED ALR AS A MOTOL. \\ (SEE PLATES 44 AND 45.)
}

ExGmbers are aware that I built a caloric engine in London, 1833, operated by heated atmospheric air; Faraday, Ure, and Lindner taking great interest in the same in consequence of its being based on the principle of returning, at each stroke of the working piston, the heat not converterl into mechanicil rork during the previous stroke. After my arrival in this country, 1839, I prosecuted the plan and built several caloric engines in succession, all of which promised ultimate success. At each step the dinemsions were enlarg. el, until I produced an experimentil engine, in 1851, having two working cylinders of seventy-two inches diancter, two feet stroke, and two compressing cylinders of fifty-eight inches diameter (see illustrations on Plates $4 t$ and 45 ). 'The leading feature of this large caloric engine was that of circulating 
the heated air, as it passed off from the working cylinder, through a series of wire discs containing an aggregate of 13,520,000 meshes for each working cylinder. The cold air in entering the engine was admitted through the meshes of the heated discs, taking up nearly the whole of the heat previously imparted by the exhaust air in its passage through the meshes, on its way to the atmospliere.

\section{DESCRIPTION OF THE ILLUSTRATIONS RERERRED TO.*}

Fig. 1 represents a transverse section, and Fig. 2 a longi. tudinal section of the engine.

$a$, air-receiver. $b \quad b$, supply-cylinder. $\quad e^{\prime}$, self-acting valve for letting air into, and $e^{\prime \prime}$ selfacting valve for letting air out of, the same. $c$, supply-piston; $c^{\prime}$, piston-rod of the same, connected to the working-beam of the engine. d d, working-cylinder; $d^{\prime} d^{\prime}$, holes at the junction of the two cylinders, through which the atmospheric air passes in and out freely: e e, working-piston; $d^{\prime \prime} d^{\prime \prime}$, rods connecting the two pistons together. $e^{\prime \prime \prime}$, air-tight vessel, suspended below the working. piston, filled with clay and charcoal to prevent transmission of heat from below. $f f f$, regenerator: $f^{\prime}$, discs of wire-net, placed vertically in the regenerator-hox. g, ralve, worked by the engine, for admitting air into the regenerator and working-cylinder; $h$, valve for letting air out of the same. $i i$, pipe, open to the atmosphere, for carrying oft the air after having passed through the engine; $k$, fire-place.

The operation of the engine is briefly as follows: A slow 
fire being liept up at $z_{2}$ for about two hours, until the various parts contained within the brick-work shall liave become moderately heated, the air-receiver is charged by means of a hand-pump. As soon as the internal pressure shall have reached about six pounds to the square inchinvariably effected in less than two minutes-the hand-pump is stopped, and the valve $g$ opened by a starting lever, as in steam-engines; the compressed air from the receiver, thus admitted under the valve $g$, rushes through the partially heated wires $f^{\prime \prime}$ into the working-cylinder, forcing its piston e upwards, as also the supply-piston c, by means of the connecting-rods $d^{\prime \prime} d^{\prime \prime}$. 'The atmospheric air contained in the upper part of cylinder $b$ will, by this upward morement of the supply-piston, be forced through the valve $e^{\prime \prime}$ into the air-receiver. When the working-piston has reached threefourths of the full stroke, the valve g is closed by the engine; and when the piston has arrived at the full up-stroke, the valve $h$ is opened. A free communication with the atmosphere being thereby established by means of the open pipe $i$, the air under the working-piston passes oft, and, orving to the removal of pressure under the working-piston, it will instantly begin to descend by its own weight.

The heated air from under the workingr-piston, in passing off through the wires $f^{\prime}$, gives out its caloric to the same so effectually that, on reaching the thermometer $m$, the temperature never exceeds that of the entering air at $l$ by more than $30^{\circ}$; on the other hand, the cold air from the receiver, in circulating through the meshes of wires in its 
passage to the working cylinder, becomes so effectually lieated that, on passing ", its temperature is invaribly. increased to upwards of $450^{\circ}$ when the machine is in full operation.

It is evident that during the descent of the supply-piston "the outlet valve e" remains clused hy the pussure from the receiver, whilst the inlet vilve e is kept open by suction, and hence that a fresh quantity of atmospheric alir enters the supply-cylinder at cacle lown-stroke of its piston, and by the nl-stroke is forced into the receiver. There being two supply-eylinflers of altermating action, a constant supply of fresh air into the recerver is obtained for feeding the working-erlinders.

It need hardly be stated that the smaller quantity ob. tained by the supply.cylinder suflices to fill the larger capacity of the working-cynder, in consequence of the in. crease of rolume attencling the increase of temperature; nor need it be stater that an equal amount of force is exerted by the up-and-itown movement, as there are two pairs of cylinders attached at opposite ends of a common working. beam.

The foregoing description being deemed suflicient to explain the mechanical operation of the engine, the result of its prolonged trial may now be consilfered ; hut, before doing so, it will be well to state some particulars in relation to the regenerator. The regenerator measures 26 inches in height and width intermally; each disc of wire contains 676 superficial inches, and the net has 10 meshes to the inch: each 
superficial inch, therefore, contains 100 meshes, which, multiplied by 676, grives 67,600 meshes in each disc; 200 discs being employer, it follows thist eileh regenerator contains $13,520,000$ meshes; and, consequently, if we consider that there are as many small spaces between the dises as there are meshes, we shall find that the ain within the regenerator is distributed in 27,000,000 minute cells. Theory clearly indicates that, owing to the small calpacity for heat of atmospheric air (that beneficial property which the Great Mechanician gives to it as a fit medium for animated uxm beings to live in), and in consequence, also, of the almost infinite subdirision anong the rires, the temperature of the circulating atr, in passing through the regenerator of the caloric engine, nust be greatly changed. Practice has fully realized all that theory predicted, for the temperatures at $x$ and z have never raried during the trials less tham $350^{\circ}$, when the engine has been in full operation; indeed, it has heen found impossible to obtain a differential temperature of less magnitule, with suflicient fires in the furruaces.

The reason is erident: the cold air from the receiver is half the time playing upon the wire dises at $x$, whilst the heuted air from the working-eylinder is playing during the other lalf on the wire dises at $z ;$ as no heated air can reach the former withont passing tinnong the regenerator, and ats no cold air ean reach the discs at $\approx$ before likewise pasing all the wires, it follows that the wablishing an equilibrium of temperature becomes impossible. The great numher of discs, their isolated character, and the before-named 
distribution of the air in such a vast number of minute cells, readily explain the surprising fall and increase of temperature of the opposite curents passing the regenerator, and which constitutes the grand feature of the caloric engine, effecting, as it does, such an extrandinary saring of fuel by rendering the catoric not converted into mechanical work active over and over again.

In further explanation of the wonderful efticiency of the regenerator; it may be stated that each dise contains 1,1 10 feet of wire in length, and eatch regentrator 228,000 feet, or $41 \frac{1}{2}$ miles, of wire; the superficial measmenent of which is 2,014 square feet, which is equal to the entire surliace of four steam-boiler's forty feet long and four leet dianeter; and yet the regenerator displaying that anount of heating surface is only two feet cube, less than ing of the bulk of said boilers!

In regard to loss of heat, the result of ample trial has been that at no time has the temperature of the escaping air at $m$ exceeded that of the entering air at $l$ by more than $30^{\circ}$. As this differential temperature exlibits the positive loss of heat, it becomes important to ascertain its amount in pounds of coal: the area of the supply-piston is 2,626 square inches, and its stroke two feet; hence $366^{4}$ cubic feet of atmospheric air is supplied for each stroke, and therefore at 30 strokes 1,092 cubic feet, and for both cylinters 2,184 cubic feet per minute $=131,040$ cubic feet per homr. 'The weight of atmospheric air is nearly $13 \frac{1}{2}$ cubic feet to the pound, and hence it will be seen that 9,706 pounds of air 
pass through the engine every hour. We know that one pound of coal will raise the temperature of 10 pounds of water $1,100^{\circ}$, while the specific heat of water is to that of the air as 26:100; hence it will be seen that $38_{10}^{\frac{4}{10}}$ pounds of air will be elevated in temperature $1,100^{\circ}$ with one pound of coal. Now, the observed loss of heat in the engine being $30^{\circ}$, the fact will be established that the loss will amount to one pound of coal for every 1,408 pounds of air passed through the engine, which, on 9,706 pounds, proves the actual loss of heat in both regenerator's to be only $6 \frac{3}{10}$ pomds of coal per hour. A pressure of 1.3 pounds being sustained in the receiver, exerting 60 horse-power with an actual waste of only 6.8 pounds per hour, it will be found that two ounces of coal per hour per horse-power is the quantity of fuel absolutely wasted in the process of transfer. 'The actual consumption of the engine is, howerer, nearly 40 pounds per hour, which is thus proved by the foregoing to be chiefly carried off by radiation of heat. On a large scale much of that radiation will be prevented. As the machine stands, an indicated horse-power is produced by a consumption of less than 11 ounees to the horse-power per hour.

The following particulars are of considerable practical importance:

1st. The valres $g$ and 7 are not subjected to heat, the caloric being taken up by the wires before reaching the ralves.

2d. The temperature of the packing of the working-pistous does not exceed boiling heat at any time, proving the efficicy of the heat-intercepter $e^{\prime \prime \prime}$. 
3d. As only a slow radiating fire is needed, it las been found that common whitewash, applied to the under side of the leater, remains for sereral weeks, proving conclusively that the effect of the heat is quite harmless.

4th. A hole of half an inch diameter, kept open for several hours, in the valve-chest, unter the inlet-ralye $y$, does not sensibly affect the pressure in the receirer a, so abundant is the supply of air. This fact has surprised all practical men who hare ritnessed the operation of the en. gine. It proves completely that the machine need not be perfectly air-tight, as supposed by many.

5th. After putting a moderate quantity of fuel into the furnace, it has been found that the engine works with full power for three hours without fresh feed, and, after remor. ing the fires entirely, it has frequently worked for one hour.

The regularity of action and perfect working of every part of this experimental engine, and, above all, its apparent great economy of fuel, induced some enterprising merchants of New York, in the latter part of 1851 , to accept my pro. position to construct a ship for navigating the ncean propelled by paddle-wheels actuated by the caloric engine. 'This wor't was commenced forthwith, and pushed with snch rigor that within nine months from commencing the construction of the machinery, and within seven months from laying the keel, the paddle-wheels of the caloric ship Ericsson turned romend at the dock! In view of the fact that the engines consisted of four working-cylinders of 168 inches diameter, 6 feet stroke, and four air.compressing cylinclers of 13 inches dia- 
meter, 6 feet stroke, it may be claimed that, in point of magnitude and rapidity of construction, the motive machinery of the caloric ship stands mivalled in the amnals of marine engineering. It may be added that the principal engineer's of New York all expressed the opinion that a better specimen of workmanship than that presented by the huge engines of the caloric ship had not been produced by our artisans up to that time.

'The following data, published in Appletons' Mechanics' Magazine, will interest the professional reader:

\section{DLMENSIONS OF 'THE' ERICSSON.}

Length on deck, . . . . . . . 260 feet

Length of keel, . . . . . . . 250"

Breadth of beam, . . . . . . . 40 "

Depth of hold, . . . . . . . 27 " . .

Draught of water on trial-trip, . . . . 17 "

Diameter of wheels, . . . . . . 32 "

Length of bucket, . . . . . . . $10 \frac{1}{2}$ "

Breadth of bucket, . . . . 20 ins.

Dip of wheel (supposed about), . . . 2 feet.

ENGINES.

Number of working-cylinders or single-acting air-engines,

4

Diameter,

168 inches.

Area of piston, . . . . $22167.07 \mathrm{sq}$. in.

Stroke, . . . . . 6 feet. 
Portion of stroke from commencement at which air is "cut off" (about), . . $\frac{63}{100}$

Cubical contents of each working-cylinder, 1596024 cub). in. Cubical contents of $\frac{63}{100}$ of working-cylinder, 995495 " Number of supply-cylinders or single-acting pumps,

Diameter; 13 inches.

Area of piston or plunger, - 14741 sq. ill.

Stroke, necessarily, .

(i) feet.

Cabical contents of each pump, 1061352 cub. in.

Number of regenerator's, 4

Number of discs of iron-wire netting in each regenerator,

Height of each disc, 6 feet. Width,

Size of wire, 4 "

Ratio of area of openings in the netting to total area of disc,

Total area of opening of "air-way" through each disc, $\frac{6 \times 4}{2}=$. . . . . . $12 \mathrm{sq} . \mathrm{ft}$.

Greatest or total heat of air in workingcylinder above atmosphere, $38.4^{\circ} \mathrm{F}$. Ileat of issuing air abore atmosphere, . $30^{\circ} \mathrm{F}$, Pressure necessary to move the engine,

Coal consumed in the four furmaces per diy, 6 tons. Maximum coal possible to consume in the four furnaces per day, 
Number of smoke-pipes, . . . . . 2

Number of air-pipes, . . . . . . 2

Height of each smoke mol air pipe above deck, 12 feet.

Diameter " " " "

Amount of air passing through the four cylin. der's per hour, . . . . . . 5 to to tons.

Depth of working-piston, or thickness, . 6 feet.

Thickness of cylinder-bottom, . . . . $1 \frac{1}{2}$ inches.

Distance of grate from bottom of cylinder, . $\quad 5$ feet.

Ordinary pressure of the engine per sq. inch, 12 lbs.

Actual pressure on the second trial-trip, Jalluary 11, • . . . . . . . . 8 "

Number of revolutions under pressure of S lbs. on trial trip, . . . . .

Number of revolutions expected with 12 ]bs. pressure, · • • • • · ·

Miles per hour obtained on trial-trip, January 11, allowing for ticle, etc., . .

Miles per hour expected with 12 lbs. pressure,

Number of meshes in each dise, . . .

Temperature in working-cylinder, $60^{\circ}+384^{\circ}=$

Common temperature of the atmosphere (usual assumption), . . . . . . . $60^{\circ}$

Specific heat of air-watel being 1000, . $\quad 2669$

Common pressure of air per square inch =

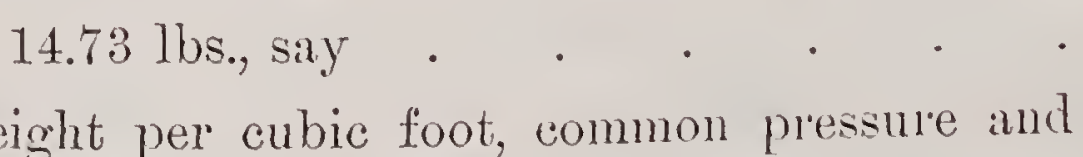
temperature $=.075291+1 \mathrm{hs}$, saly . . 
Density of air, temperature remaining constant, is directly as the pressure.

Weight per cubic foot, at 12 lbs. pressure: conmon temperature,

Expansion of air at $32^{\circ}$ for each degree add. ed, according to Rudberg, . . . . $s^{\frac{1}{4} 3}$

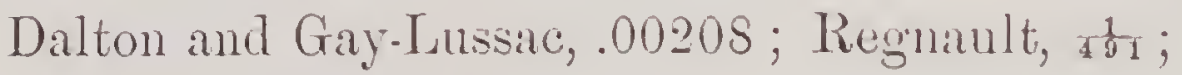
common estimate, . . . . . . 4 4bo Expansion of air at $60^{\circ}$, for the $384^{\circ}$ alded, $\frac{384}{5118}$ Density of air at $\left(60^{\circ}+384^{\circ}=\right) 444^{\circ}$, com. pared with air at $60^{\circ}$, as . . . $\frac{508}{508+384}$ to 1

Weight of a cubic foot at 12 lbs. pressure,

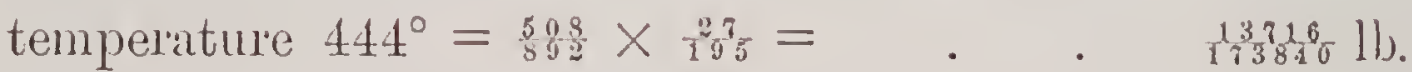

Weight of 995495 cubic inches at 12 lhs. pressure, temperature $444^{\circ}=295495 \times \frac{13796}{178}=$ 46 lbs.

Therefore, air passed through each cylinder each stroke, . . . . . 46 "

Weight of 1061352 cubic inches, at common temperature and pressure $=\frac{1081352}{178^{2}} \times \frac{1}{13}=$ 'Therefore, air passed each pump each stroke, $47.153 \mathrm{lbs}$.

Allowance made for clearance, leakige, etc., per stroke, $47-46=$. . . . .

Units of heat required to raise 4.7 lbs. air $384^{\circ}$ $=47 \times 384 \times .2669=. \quad$. . . 4817 units.

Units of heat retained by the 47 lbs. on escalping $=47 \times 30 \times .2669=$. . . 370 " Units of heat transferred each stroke, . . 4441" 
Absolute theoretical consumption of heat per stroke, per cylinder, . . . . . 376 units.

Mean pressure, per square inch, on workingpiston, allowing for continued addition of heat while expanding, initial pressure being 13 lbs., about . . . . . . . . 10.8 lbs.

Nean force acting upon working piston, $10.8 \times$ $22167=$. $. \quad . \quad . \quad . \quad 239403.6$.

Mean resistance per square inch to supply piston, commencing with 0 and increasing to 12 lbs., at which pressure it continues to end of stroke.

[The mean resistance in compressing an elastic fluid may be found by reversing the ordinary calculation on expansive working. The hyp. $\log$. of $\frac{15}{2}$ is .588] $1.588 \times 12 \times \frac{15}{2}=$ $10.55 \mathrm{lbs}$.

Mean resistance against supply-piston $10.55 \times$

$$
14741=\text {. } . \quad . \quad . \quad . \quad .155598 \text {. }
$$

Balance tending to move the engine, 239403

$$
-155598=\text {. . . . . . . } 83805 \text { “ }
$$

Units of porver theoretically obtainable per stroke $=83805 \times 6=$. . . . 502830 units.

Units of power theoretically obtainable from each unit of heat, . . . . . 1337 "

The ship after completion made a successful trip from New York to Waslington and back during the winter season; but the average speed at sea proving insufficient for com. 
mercial purposes, the owners, with regret, acceded to my proposition to remove the costly machinery, although it had proved perfect as a mechanical combination. 'The resources of modern engineering hiving been exhausted in producing the motors of the caloric ship, the important question has for ever been set at rest: Can heated air as a mechanical motor compete on a large scale with steam? The commercial world is indebted to American enterprise-to New York enterprise-for having settled a question of such vital inportance. 'The marine engineer has thus been encouraged to renew his efforts to perfect the stean-engine, without fear of rivalry from a motor depending on the dilatation of atmospheric air by heat.

'The engines of the caloric ship being an exact counterpart of the experimental engine of 18.51, excepting dimensions, a description has been deemed superfuous. It may be men. tioned, however, that the pair of engines in the caloric ship actuated a single crank in the middle of the paddleshaft by connecting-rods working at right angles on a common crank-pin, as in all my marine engines. 


\title{
CHAPTER XXXI.
}

\author{
CALORIC ENGINE FOR DOMESIIC PURPOSES.
}

(SEE PLATE 46.)

Although the caloric engine has proved inapplicable to navigation, it has been found to be of very great utility as a domestic motor, and for all purposes demanding a small amount of motive power.

The following interesting article from the New York Tribune of May 5, 1860, shows how rapilly the caloric engine was adopted after its adaptation to domestic purposes:

\section{"THE NEW MOTOR.}

"It is some eighty-six years since $M_{1}$. Boulton, at the great steam-engine works of Soho, made use of the memorable expression to Boswell: 'I sell here, sir', what all the world desires to have-Powen.' The mechanical world has been occupied from that time to the present with this problem of power, and mechanical ingenuity has tasked and exhausted 
itself with eftorts to construct a machine that should prove an efficient auxiliary or rival of the stean-engine. And it is most extraordinary that, notwithstanding the amount of inventive genius and science that has been expended in this special field of labor, literally nothing had been accomplished of any practical imprortance till Ericsson proluced the caloric engine, in the particular form and with the peculiar derices which distinguish it from all the engines actuated by heat, that have been built at such an enormous expense of time and money.

"Motive engines of a moderate or even of a small power play a very important part in the economy of humim life. The frightful horrors of the slave-trade; the scarcely less frightful horrors of the traftic in Coolies; nay, the haggard features and jaded limbs that, in our great cities more espe. cially, speak so distinctly of over-wrought human labor, and cry out so emphatically for relief-all these demonstrate that a compact, manageable, safe, and economical motor, adequate to the work of a single slave or Cooly, or overtasked white man or white woman, would do more to mitigate the suffering and diminish the drudgery of mankind than any other conceivable invention. After all the enormons accumulations of steam-power, water-power, wind-power, and horsepower, and their vast achierements, by how much the larger amount of power exercised in the world is the aggregate result of individual force applied to the thousands of little things that occupy the human fimnily in the daily rontine of living! Combine these forces, and what a stupendous whole 
they exhibit! Make an avalable motur that shall be of one-man power, and what a result is obtained! Make a motor perfectly safe, easily kept in order, requiring no water, and consuming but little fuel, of the power of at single horse, to what an extent the aggregate result is augmented, and what an importance in human affirirs such a machine assumes!

"If Ericsson's caloric engine, then, clamed to be nothing" but such a motor, it would be a subject well deserving the most earnest and serious investigation; but the proof is accumulated, of a nature that compels belief and defies contradiction, which demonstrates the existence in this engine of a power entirely sufficient for all but a very few of the thousand uses for which power is required.

"It is not material to our purpose to indulge in any retrospective review of Ericsson's labors. It is well known that this grand invention has occupied thirty years of his life, during which he has built many engines of the largest size and uncounted experimental engines of smaller power.

"We have seen an oflicial statement in relation to an engine put up about a year since to supply the locomotives at the South Groton Station, on the Fitchburg Railroad. From April, 1859, to April, 1860, this engine pumped 1,600,000 gallons of water, at an expense to the company for fuel and oil of $\$ 25$, and for an 'engineer' $\$ 25$, and las not cost one cent for alteration or repairs.

"A result more important, in view of the number of engines employed, is exhibited on the New York Central Railioad, on the line of which there are now some twenty 
of these engines in daily use. Mr. Chauncey Vibbard, the Superintendent of that road, reports, over his official signature, after several months' experience with a number of these engines, that they perform an 'increstible' amount of labor' 'for the small quantity of fuel consmmerl.' One of them, he says, for 96 of a cent per hour, does the work formerly done by four men at an expense of $\$ 25$ each per month. Another, of the same size, at the Savamnah Station, at an ex. pense of eleven cents a day, does the work of five men who received \$125 a month. Other engines have been erected on several other railroads for pumping purposes with the same farorable result.

"The second application of the caloric engine was to the driving of printing presses. The fust trial of the engine for this purpose was made in the office of the IIartford Times; the first that was entirely succersful was made in the office of T. W. Strong, No. 98 Nassau Street, in this city. The next engine built was set up in the office of Messr's. French \& Whent, No. 18 Ann Street, and the third in the office of $\mathrm{Mr}$. C. C. Shelley, a job-printer in Barclay Street. The result has been the adoption of the engine in numerous job-ofices in every part of the country. There are now no less than forty daily papers in the United States printed by Ericsson's engines, most of them of 24-inch, but three or four of 12 and 18 inch cylinder's. One of the most recent testimonials to its value is from the proprietor of the Savannah Evening Express, who states that he regards it as the most perfect and economical motive power erer applied." 
Several thousand caloric engines were subsequently constructed in this country and in Europe; but steam-engineers, finding by the extraordinary demand for caloric engines that very moderate power was a great desideratum, have perfected the steam-motor until it almost rivals the caloric engine in safety and adaptability; consequently, the demand for caloric engines has been greatly diminished of late. Yet this motor can never be superseded by the steam-engine, since it requires no water, besides being alosolutely safe from explosion. 'There are immunerable localities in which an arlequate quantity of Water camnot be obtained, but where the necessities of civilized life call for mechanical motor's; hence the caloric engine may be regarded as an institution inseparable from cirilization. It should be stated that the caloric engine has been found to furnish the only reliable motive power for operating the fog signals on our consts. 'The following statement, presented to the Light-House Board, sets forth very clearly the advantages of the air motor for the purpose mentioned:

With reference to the important question whether steam is a proper motive power for actuating the mechanism connected with fog-signals, I beg to express the opinion that unless a safer motor can be found than the steam-enginemore particularly a high-pressure steam-engine--the great practical benefit which you expect from the contemplated system of fog-signals will never be realized. My reason for expressing this opinion will be found in the following brief summary: 1. A high-pressure steam-boiler, even when supplied with pure, fresh water, is an apparatus which demands 
the constant attention of an experienced person. Considering that any neglect in keeping ny the foed in the boiler will inevitably result in an explosion, it is highly impurdent and scarcely lommane to put such an instrument in the hands of a lighthouse keeper. Let us reflect on the well-known fact that when a boiler fomms even the practised engineer is sometimes at a loss to determine the lieight of water within. 2. Apart from the difficulty and danger thus alluded to, another circumstance presents itself connected with the em. ployment of steam, which is practically insuperable, viz, that brackish or salt water must le resorted to in most localities. Accordingly, unless a certain quantity of the salt water is regularly drawn ofl and replaced by water less impregnated with saline matter, the hoiler will, at best, be rendered useless by the deposit formed. In most cases the first warning to the unskilful light-house keeper will probably be the explosion of the boiler.

In connection with this most important matter, I cannot omit adverting to the fact that the employment of salt water for land engines attended by skilful engineers has been found so impracticable that means of procuring fresh water-in many cases at very great cost-have been deemed indispensable. It is only in the steam-ship, where the most competent engineers are employed, provided with salinometers and other instruments, that it has been fouml practicable to employ salt water. But even in the steam-ship salt feed hals been dispensed with by employing the surface-condenser as the only certain means of saving the boilers from incrustation. 
3. During cold weather, another serious difficulty will be encountered if yon employ seam, which calls for the application of costly and complicated contrivances. Unless the boiler is constantly under steam, it must be kept in some place adequately heited by stores to prevent pmins, pipes, and coeks from freezing. Not only this, the cistern itself, which is to supply the boiler, will, on onr inclement coast, freeze muless warmed by some means. I need searcely remind you that, in many localities, the entire snpply of water will wholly fail during continued cold, dry weather. In fine, the disadrantages of steam for any greneral system of fogsignals are so numerous and formidable as to render the very proposition to employ that agent an absurdity.

Having thus briefy disposed of the question of employing stean as the motive power for actuating the machinery of your proposed fog-signals, I have now to state that long practice has shown that the expansive force of heated atmospheric air furnishes a reliable dr:" motor wholly independent of atmospheric temperatnre. 'The alvantages of such a motor, more especially as it requires no partieular kind of fuel, are so obvious that I will not detain you by enumerating the sime. Suflice it to saly that it enables you to locate your fog-signal on the dry, barren rock ats well als on the moist, sandy beacli; and that its efficiency is not atfected by the most intense cold, and that, so fin from deminding a heating appanatus during the inclement season, the light. house keeper will find it a very desirable aceessory in wanming his quarters. Above all, while it thus attds to his 
comfort, it carries no danger with it. The worst that can happen is that the machine will stop for want of fuel, or that its speed will slacken for want of nil being applied to the bearings. The caloric engine is now so well known that I need not enter on a description of its construction. It will be necessary, howerer, to adrert to the fact that the caloric engine is more bulky and of greater weight than the steam-engine, and that its cost is some 50 per cent. greater. These disadrantages, howerer; as regards the application to fog-signals, become triffing, in view of the hefore-named ad. vantages. Indeed, in many places the cost of procuring a suitable supply of water will be far greater than the difter. ence of price of engine-learing out of sight the impossi. bility of procuring suitable water in many cases.

The leading features of the domestic caloric engine will be seen by reference to Plate 46 , representing a longitudinal section through the central vertical plane. Professor Bar. nard having very thoroughly examined one of these engines at the Paris Exhibition, 186t, I propose to present a copy of his report:

"In its present form the Ericsson engine fails to present to the observer a combination at first view easily intelligible. It eren seems to be characterized by a certain amount of complication, which might suggest greater liability to derangement than ought to belong to a prime mover. $\Lambda$ closer examination, nevertheless, will show that the mechanism itself is in fact very simple, and that it is only the rather puzaling consecution of movements which confuses. 
"Before referring to the figure of this engine, which is given in the illustration on the plate mentioned, the following general explanation of the mechanical principles of its construction will be understood. Let it be supposed that a piston mores air-tight in a cylinder which is closed at both ends. Call one end of the cylinder $A$, and the other $B$. Call the piston also $C$. In the end $A$ let there be a valve opening inward, and in the end $B$ a second valve opening outward. These two valres open, then, in absolute direction, the same way. Let the piston C, furthermore, have a valve opening in this common direction. Then, if the piston $\mathrm{C}$ more toward $B$, its own valve will naturally close, and that of $B$ will open, because the morement tends to compress the air between $B$ and $C$. Also the valve $A$ will open at the same time, because the movement tends to rarefy the air between $A$ and $B$. Thus, in this movement, continued to the end of the cylinder, all the air on the side toward $B$ may be expelled; but at the same time the cylinder will be filled on the other side toward $A$, by the influx of air from without. If the piston $\mathrm{C}$ now reverse its motion, both the valves $\Lambda$ and $B$ will be closed, because the movement will tend to rarefy the air on the side of $B$, and to condense it on the side of $A$. But its own ralve will be opened by the joint effect of these causes, so that the air will pass freely through the piston, and, if the motion contimues, will ultimately be all transferred to the side of $B$. This operation may go on indefinitely.

"Now, if, on the side of A, the cylinder is closed by a 
second piston (which we may still call $A$ ), and not by a fixed calp, both pistons being movable, the silme succession of occurrences will take place, only modified hy the move. ments which may be given to $A$. If $\mathrm{C}$ and $\mathrm{A}$ both move in the direction of $A$, both their valves will open, and ail from the exterior of the cylinder will pass through both into the space between $B$ and $C$. If they both move towarl $B$, but $C$ faster than $A$, then air will enter on the side of $A$, and flow out on the side of $B$, the valve $C$ only reman. ing closed. If both move towand $A$, but $A$ faster than $C$, air will still enter the space between $\mathrm{C}$ and $A$, while, in less quantity, it is passing through $\mathrm{C}$ into the space between $\mathrm{C}$ and $\mathrm{B}$.

"Let now the piston A be supposed to occupy a position, say, one-third adranced down the cylinder, the piston $\mathrm{C}$ being further adranced still, and let the ralve of $B$ be secured by a strong spring pressing upon it, so that it callnot be opened without the application of some considerable force; and in these circumstinces let the cylinder, and consequently the air contained in it, be heated. The clasticity of the confined air, being increased by heat, will close the valve in $A$, and that piston will be moved in the direction of $A$, until, by the enlargement of rolume, the clasticity shirl] be reduced to equality with that of the external air. If the heat be uniform throughout all the mass of confined air, the valve in $\mathrm{C}$ will be equilly pressed on both sides. Under these circumstances, the piston $\mathrm{C}$ could be moved toward $A$, if there were any means of acting upon it, the 
air passing through the valve toward $B$. But if an attempt were made to move the piston itself toward $B$, it would encounter resistance, because its own ralve would be closed by the movement, and the valve of $B$ is supposed to be forcibly held down. Since now the external piston must more in the direction $\Lambda$, it is only necessary that it should be properly connecter with a machine, in order that the force exerted by the heated and expanding air may be turned to some practical account.

"If, again, at the end of the movement the air conld be immediately cooled without being discharged, the heat could be again applied and the effort repeated. But this not being practicable, the heated air may be allowed to escape by relieving the valve $B$ of the pressure of the spring which confines it, and by causing the piston $\mathrm{C}$ to descend to the extremity $\mathrm{B}$ of the cylinder. This morement of $\mathrm{C}$ not only drives out the hot air, but it draws in through $A$ a fresh supply of cold air ; and if A descends simultaneously to the position originally supposed-i.e., one-third adranced toward $\mathrm{B}$-there will be a body of air filling the other two-thirds of the cylinder at the common temperature, ready to be acted on anew by heat.

"In this statement is embraced the general minciple of the Ericsson engine. What remains is to explain the mechanical contrivances by which the morements of the pistons are governed, and to describe the heating apparatus which is employed to effect the prompt dilatation of the air. Inasmuch as the piston which we have called $\mathrm{C}$ is shut up in 
second piston (which we may still call $d$ ), and not by a fixed calp, both pistons being movable, the sime succession of occurrences will take place, only morlified hy the move. ments which may be given to 1 . If $C$ and $\Lambda$ both move in the direction of $A$, both their ralres will open, and air from the exterior of the cylinler will pass through both into the space between $\mathrm{B}$ and $\mathrm{C}$. If they both move toward B, but C faster than A, then air will enter on the side of $A$, and flow ont on the side of $B$, the valve $C$ only remain. ing closed. If both move towarl $A$, but A faster than $C$, air will still enter the space hetween $C$ and $\Lambda$, while, in less quantity, it is passing through $\mathrm{C}$ into the space between $C$ and $B$.

"Let now the piston A be supposed to necupy a posi. tion, say, one-third advanced down the cylinder, the piston C being further adranced still, and let the valve of $I 3$ be secured by a strong spring pressing upon it, so that it carr. not be opened without the application of some considerable force; and in these cireumstances let the cylinder, and consequently the ain continined in it, be heated. The elas. ticity of the confined air, being increased by heat, will close the ralve in $A$, and that piston will be mover in the direc. tion of $A$, until, by the enlargement of rolume, the elasticity sha!l be reduced to equality with that of the external air. If the heat be uniform thronghout all the mass of confined air, the valve in $\mathrm{C}$ will be equally pressed on both sides. Under these circumstances, the piston $\mathrm{C}$ could be moved toward $A$, if there were any means of acting upon it, the 
ain passing through the valve toward $B$. But if an attempt were made to move the piston itself toward $B$, it would encounter resistance, because its own valre would be closed by the morement, and the ralve of $B$ is supposed to be forcibly held down. Since now the external piston must more in the direction $A$, it is only necessary that it should be properly connecter with a machine, in order that the force exerted by the heated and expanding air may be turned to some practical account.

"If, again, at the end of the movement the air could be immediately cooled without being discharged, the heat could be again applied and the effort repeated. But this not being practicable, the heated air mily be allowed to escape by relieving the valve $B$ of the pressure of the spring which confines it, and by causing the piston $\mathrm{C}$ to descend to the extremity $\mathrm{B}$ of the cylinder. This movement of $\mathrm{C}$ not only drives out the hot air, but it draws in through $A$ a fresh supply of cold air; and if $\mathrm{A}$ descends simultaneously to the position originally supposed-i.e., one-third advanced toward B-there will be a body of air filling the other two-thirds of the cylinder at the common temperature, ready to be acted on anew by heat.

"In this statement is embraced the general principle of the Ericsson engine. What remains is to explain the mechanical contrivances by which the morements of the pistons are governed, and to describe the heating apparatus which is employed to effect the prompt dilatation of the air. Inasmuch as the piston which we have called $\mathrm{C}$ is shut up in 
the cylinder behind $A$, it is necessary that the rols which give it motion should pass through A. They do so, being packed by means of stufing-boxes to prevent leakage; and are comnected at their external extremities with oscillating lever's turning on a fixed centre of motion at their extrenities, and kept in motion by the engine. 'The rod of the external piston A, which is the driving-piston, is also con. nected with an upright oscillating lever, tuming on an axis of motion at its lower extrenity, and calrying at its "puer a horizontal connecting-rod, which acts on the crank of the main shaft of the engine. It would be simples to comnect the piston directly with this crank; but if that mode of comnection were adopted, the stroke of the piston wonkl have to take place in both directions, forward and back, in equal times. 'This condition is not favorable to the action of the machine; and inequality in this respect is still more important in the case of the supply-piston. The peculiar ingernuity of this machine is in fact manifested most signally at this point. By means of the systems of lever's interposer between the pistons and the main shaft, provision is marle for the perfect miformity of the revolution of the shaft, while the pistons, on the other liand, are accelerated and retarded in such a manner as to fulfil the condition that the aspiration of the charge of air should occupy the minimum of time. The oscillating lever's which connect with the piston-rods of the supply-piston are kept in oscillation by crank-motion from the main shaft, and in their oscillations they displace the inner prston, encountering no resistance but friction. In 
consequence of the un-uniform and unequal velocities of the two pistons, and their intentional adjustment, so that they do not begin and end their conse together, the distance between them varies in a manner which is quite important: first, to the aspiration of the charge; and secondly, to the effectual exposure of the aspired air to the action of the fulnace.

"It is of course of the highest importance that the positions of the cranks on the main shaft, and those of the axes of motion of the oscillating lever's, should be so related to each other as to produce a rapid separation of the two pistons at the beginning of the negatire stroke; because this is the time when the aspiration of the charge must take place. During this time, the inner piston, gaining on the onter, will not only draw in the fresh charge, but it will expel the exhausted one; the escape-ralve being lifted for the purpose and kept raised during all the period of aspiration by means of a cam. When the pistons are at the maximum distance from each other, the aspiration is ended. From this time until the lalf rerolution is complete, the confined air undergoes compression, and the morement is maintuined by the fly-wheel. In the second half revolution the driving-piston is urged by the elasticity of the air which is cxalted both by compression and by heat.

"The leating is accomplished as follows: The funtuce is within the cylinter, at the end which we have called $B$, where the cylinder is prolonged to receive it. It is of iron, and is cylindrical also, a small ammlar space only inter- 
vening between its walls and those of the cylinder. This space is open to the interior, but is closed at the extreme end; so that it forms, in fict, a portion of the proper air. chamber. To the supply-piston $\mathrm{C}$ is attached by its crown a sheet-iron cylindrical bell, which entors the annular space just spoken of without touching the walls of the furnace or those of the surrounding cylinder. The ralve in $\mathrm{C}$ opens above the crown of this bell; but any air which comes through the valve from the side of A can only reach the interior by passing down the anmulan space between the bell and the cylinder wall, and returning up the ammlar space between the bell and the wall of the furnace. In making this pas. sage, it will be exposed in a very thin sheet to the action of the furnace heat, a very large proportion of the molecules being brought into direct contact with the heated iron.

"That we may understand how this movement of the air" is made forcibly necessary, we need only consider the relative movements of the pistons during the period of a com. plete revolution. At the beginning of the negative stroke, or of the movement of $A$ in the direction of $B$, the supply. piston takes the lead, air enter's through the valve of $A$, and the aspiration is soon complete. 'The distance between the two pistons, which determines the amount of aspination, is now of course at its maximum. A next begins to gain on C, but both movements have still for a short time the same (negative) direction. The space occupied by the air is gradually reduced; or, in other words, the air undergoes compression. The piston $\mathrm{C}$ reaches the linit of its course 
sooner than A. It begins to more in the positive direction, while the motion of $\mathrm{A}$ is still negative. The valve in $\mathrm{C}$ is opened by the pressure, the air passes through, and, haring no other chamel, descends the annular space ontside of the bell, and returns by the ammular space inside the bell, becoming heated, as above described, in its progress. Presently after this displacement commences, the piston $A$ also reaches its limit of movement, and the direction of its motion becones positive. But $\mathrm{C}$ mores the fister of the two, so that the displacement continues throughout the greater part of the positive stroke. A little betore the end, the distance between the two pistons becomes minimum, and they are then nearly in contact. When the revolution is quite complete, this dis. tance is slightly increased. Just before this time C will have recommenced its negative movement, while $A$ continues still to be moving in the positive direction.

"The relative movements here described will be more advantageously compared by presenting them in tabular form, which we are enabled to do by the help of the determinations made by Mr. Mastaing, of Paris, upon the Ericsson engine, which was made the subject of experiment in 1861 at the Conservatoire des Arts et Métiers, by Mr. Tresca, sub-linector of that institution. In the first column of this talble are placed the angular positions of the driving-crank on the main shaft at different periods of the revolution; putting zero to represent the position of the crank when the piston $A$ is about to commence its negative stroke. The second column gives the direction of motion of the driving-piston, 
and its motion relative to that of the other: and the third column gives the same particulars in regard to the supply. piston. The last colmmn gives the rariation of distance taking place between the two pistons at the several points indicated in the table.

\begin{tabular}{|c|c|c|c|}
\hline $\begin{array}{c}\text { Angular posi- } \\
\text { tion of the } \\
\text { crank. }\end{array}$ & \multicolumn{2}{|c|}{ Relative motion of the pistons. } & \multirow{2}{*}{$\begin{array}{l}\text { Distance } \\
\text { between the } \\
\text { pistous. }\end{array}$} \\
\hline Degs. & Driving-piston. & Supply-piston. & \\
\hline 0 to 70 & Negative, losing. & Negative, gaining. & Increasing. \\
\hline 70 & Negative, equal. & Negative, equal. & Maximum. \\
\hline 70 to 120 & Negative, grajning. & Negatire, losing. & Decrialing. \\
\hline 120 & Negative, gaining. & limit of conse. . & Decrentising. \\
\hline 120 to 170 & Negative, contrar! & Positive, contrary & 1)ecreasing. \\
\hline 170 & Limit of conise... & l'nsitire, gainingr. & T)ecreasing. \\
\hline 170 to 310 & Positive, losing.. . & Positive, gining. & 1)ecreasing. \\
\hline 310 & Positive, losing... & Positive, gaining. & Minimum. \\
\hline 310 to 340 & Positive, gaining. & Positive, losing... & Increasing. \\
\hline 340 & Positive, gaining. & Limit of course... & lncreasing. \\
\hline 340 to 360 & Positive, contraly. & Negative, contrary & Increasing. \\
\hline
\end{tabular}

"It will be seen that the negative stroke is completed in less than half a revolution for either piston, while the positive stroke requires more; also, that this inequality is considerably greater for the supply-piston than for the drivingpiston. In the case of the driving-piston the inequality is as 170 to 190 dog.; in that of the supply.pistom, as 160 to 200 deg. These inequalities, which could not exist if the connection between the main shaft and the pistons were made directly; as in the stean-engine, are the effect of the interme- 
diate system of levers, and are intentionally produced. The increase of distance between the pistons from 310 deg. to the end of the rerolution is not an and vantage, but it is not a great increase, the total distance anounting finally only to about the onesixth part of the maximum separation, and re. ceiring the principal accession to its amount between 350 and 360 deg. $\Lambda \mathrm{s}$, after the second reversal of the morement of the supply-piston, the effective power of the engine is neces. sarily paralyzed, the escape valve is opened at 344 deg. by the action of the can above spoken of, and the aspiration commences before the revolution is quite complete. The ralve is closed again at 69 deg., just as the aspiration is beeoming. maximum.

"Inasmuch as the eftective power of this engine is negative or zero from 344 deg. onwaid to 170 deg., or through a little more than half a revolution, it is necessary that the machine should be provided with a heavy fly-wheel to maintain the movement during these intervals. The fly-wheel is made to act also as a sort of counterweight, as well as by means of its moment of rotation, the side of the wheel which is descending during the period of paralysis being made consider. ably heavier than the other. A companion engine, to act positively during the inaction of the first, would render such an expedient unnecessary; but, unfortunately, the bulk is considerable relatively to the power, and it would, in general, be a disudvintage to double it.

"The engines of Fricson are largely in use in the United States, but as yet they have not been constructed of any 
considerable power. As a general rule, they fall within three or four horse-power as an onter limit, though it is believed that there have been made some exceeling this limit. On account of their safety and convenience they have been regarded with faror; amil it has been clamed for them as an additional recommendation that they are economical. Such dir not appear to be the fact in the case of the particular engine which ras the subject of the experiments of Mr. Tresca above referred to. In this machine, which was of two horse-power, the result of rery cardul trial showed a consumption of 1.13 kilograms (about nine pounds) of coal per horse-power per hour.* In comparison with steam, this cannot be called a large econony. The consumption of a good steam-engine ought not to exceed, per horse-power per hour, two kilograms at the outside. One and a half ought to suffice.

"It may be observed, in conclusion, that Ericsson makes no attempt to carry the temperature in this engine to a rery high point. The mean maximum temperature in the experiments at the Conservatoire did not exceed $270^{\circ}$ Filnenheit, though doubtless portions of the air received a greater de. gree of heat than this. 'The expansion of rolume was further' determined to be but as $1: 1.48$ - that is to say, about fifty per cent. of the original bulk.

* There is not a single instance on record in the United States in which the consumption has exceeled four pounds of anthracite conl an hour per horse-power. It should be observed, howcrer, that by forcing the combustion by an excess of fuel, put into the furnace under an imperfect draught, the consumption may bo more than doubled. 
"The general description here given will be made more intelligible by reference to the figures of the engine given in Plate 46.

"Of the two pistons shown at $\mathrm{A}$ and $\mathrm{F}$, the first, $\mathrm{A}$, is the driving-piston, and the second the supply-piston, which in the foregoing explanation we have called $\mathrm{C}$. In $\mathrm{A}$ is seen a valve marked $a$.

"At $B$ is an axis of motion, the office of which is to communicate movement to the piston $A$, by means of a crank $o$, a comnecting rod $p$, a second crank $q$, and another rod $r$.

"In the piston $F$ the valve of communication is shown at $f$. The solid portion $\mathrm{F}^{\prime}$ is filled with plaster, or other badlyconducting substance, while $F^{\prime \prime}$ marks the bell-shaped prolongation which extends into the annular space surrounding the furnace. When, by the approach of the piston $F$ to the piston $A$, the space between these two pistons is reduced, there is no escape for the air between them but that which is afforded by the ammular cavities between this bell and the external wall of the machine $f^{\prime}$, on the one hand, and the wall of the furnace itself on the other. The air passes first along the outer space to the mouth of the bell, and returns through the imner, forming a thin stratmm in immediate contact with the lot wall of the furnace.

"Another axis of motion is shown at C, of which it is the office to communicate morement to the supply-piston $F$, through the crank $o$, the connecting rod $s$, and the cranks $t$ and $u$, which last two are fixed to the arbor $C$, at a fixed angle to eath other of seven degrees. 
"The escape-valre is placed at 1), and kept in position liy the spring d. A cam D', acting on this ralve through the lever D", opens it just before the driving piston commences its descent at the end of the positive stroke.

"The furnace is enclosed in the iron box $G$, the gratebars being shown at \% G' indicates plates of iron designed to protect the walls of the furnace.

"In order to ming the two pistons into a favorable posi. tion for starting; the fly-wheel is turned on its axis; and, for the purpose of facilitating this operation, the arbor $\mathrm{K}$ is introduced, which enables the attendint to act on the fly by neans of the clicks matked $h_{i}$, and the notches $h_{i}$.

"The furnace-toor I is mate double to reduce loss hy radi. ation. The walls of the furnace are similarly protected by means of a double envelope.

"The products of combustion esciple from the furuace through the flues h, protected by fire-brick, and are carried oft by the chimney II."

The caloric engine thus desclihed was patented 1858, the Rumford medal being arrarded in $1862 \mathrm{for}$ its sucessful practical application.

The following andress by lonfesson Horsforit, on present. ing the medal, cannot properly be onitter in this work:

"At the time the rote of the American Acarlem! of Arts and Sciences conferring npon you the Rumford Pre. minm was passed, I hat the honor to be Chamman of the Rumford Committee, and, you will remember, signified my wish to relieve myself of the trust imposed npon ne; but, 
as this formal act and the simple ceremony appropriate to it have been postponed in consequence of the pressure of the war, in which you, sir, have borne so consplicuous a part, the custody of the vote and medal has been continued rith ine to the present time.

"I have the honor now to place in your hands a certified copy of the rote passed by the Academy at its annual meeting, June 10, 1862. It is as follows:

"Voted, That the Rumford Premium be awarded to Joln Ericsson, for his improrements in the management of heat, particularly as shorn in his caloric engine of IS5S.'

"In now landing to you the gold and silver medals which hare been prepared in accordance with the statutes of the Academy, I beg to congratulate you upon the honors you have won through a life of research and experiment, deroted to the promotion of the prosperity and well-being of mankind, in the field contemplated by the illustrious founder of the Rumford Prenium." *

* A patent was grmuted Inne 15, 1869, to a German engineer, for a machine actuated by heated air, identical in principle and mechanical combination with my caloric engine of 185 , the only difference being that. like the solar engine delineated

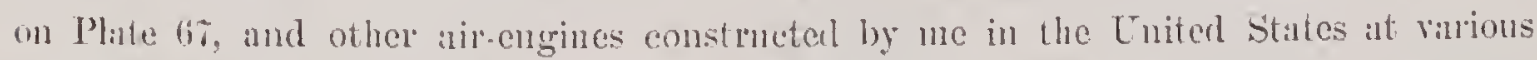
times-as far lack as 1843-the patented engine nses the same air orer and orer. The patent refered to also embraces a supposed novel plan of applying a waterchamber round the open end of the eylinder for eooling the same. Now, the leading

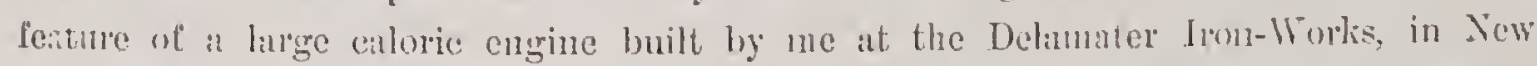
York. 18.ti, was that of cooling the open end of the cylinder ly such a waterchiminer. The patental engine, therefore, is a flagrmt plagiarism on devices alleady curried into practice. 


\section{CHAPTER XXXII.}

THE MONITOR SYSTEM OF IRON-CLADS.

(SEF PIATES 47 AND 48.)

THE monitor system is thus noticed in J. Scott Russell's great work on Naval Architecture:

"It is a creation altogether original, peculiarly American, admirably adapted to the special purpose which gare it birth. Like most American inventions, use has been allowed to dictate terms of construction, and purpose, not prejudice, has been allowed to rule invention.

"The ruling conditions of construction for the inventor" of the American fleet were these: the vessels must be perfectly shot-proof, they must fight in shallow water, they must be able to endure a heavy sea, and pass through it, if not fight in it.

"The American iron-clad navy is a child of these conditions. Minimum draught of water means minimum extent of surface, protected by ar'mor'; perfect protection means 
thickness to resist the heaviest shot, and protection for the whole length of the ship; it also means perfect protection to guns and gumners. Had they added what our legislator's exact-that the ports shall lie in the ship's side, nine feet above the water-the problem might at once have become impossible and absurd; but they wanted the work done as it could be done, and allowed the conditions of success to rule the methods of construction.

"The conditions of success in the given circumstances were these: that you should not require the sides of the ship to rise much above the water's edge; that you should not require more protection to the guns than wonld contain guns and gumners; that you should be content with as many guns as the ship could carry, and no more.

"To do the work, therefore, the full thickness of armor" required to keep ont the enemy's shot was taken, but the ship was made to rise a fer inches above water, and no more; and so a narrow strip of thick armor, all along the upper edge of the ship's side, gave her complete protection. Thus the least quantity of thickest armor did most work in protecting the ship, engines, boiler's, and magazine. Next, to protect the guns, a small circular fortress, shield, or torer meircled a couple of grums, and, if four guns were to be carried, two such turets carried the almament and contained the grunners. 'Thus, again, weight of armor was spared to the utmost, and so both ship and anmanent were completely protected.

"But the consequences of these conditions are such as 
we, at least for seilgoing ships, would reluctantly accept. The low ship's side will, in a sea-way, allow the sea to sweep orer the ship, and the wares, not the sailors, will have possession of the deck. The American accepts the conditions, removes the sailors from the leck, allows the sear to have its way, and drives his ressel thromgh, not orer, the sea to her fighting destination, ly steam, abandoning sails. The American also checrfully accepts the small romed turret as protection for grms and men; and pirots them an a central turn-table in the middle of his ship, rasing his port high enough to be out of the water, and then fighting his gun through an aperture little larger than its muzle.

"By thus frankly accepting the conditions he could not control, the American did his work and built his fleet. It is beyond doubt that the American Momitor class, with two turrets in each ship, and two guns in each turret, is a kind of ressel that can he made fast, shot-proof and sea-proof. It may be uncomfortahle, but it can be made secure. The sea may possess its deck, but in the air, above the sea, the American raises a platform on the level of the top of his turets, which he calls his huricane deck, whence he can look down with indifference at the wares fruitlessly forming and breaking themselves on the abamtoned deck helom. IIis ressel, tou, has the arliantage, as lue thinks it, of nut rolling with the wares; so that he can take his aim steadily and throw his shot surely. Thus, if he ahomenos much that we value, he secures what he values more.

"I think I have reason to know that the Anerican turet 
ships, of the larget class, with two turrets and four goms, are successful ressels-successful beyond the measure of our English estimate of their success. Like so many American inventions, they are sererely subject to the conditions of use, and successful by the rigidity and precision with which they fit the end and fulfil the purpose which was their aim.

"Plate $t i$ contanins side elevation, deck plans, and crosssection of the original Anerican Monitor of Captain Ericsson -the first turret ship that distinguished herself in action, laring to engage with her single turret and pair of guns a large broadside ship of much heavier tommage and armament, which she thoroughly defented.

"Captain Fricsson, the builder of the Monitor, has long been distinguished equally in England and America. He was known as the builder and designer of one of the most remarkable engines, in the original competition, preliminary to the opening of the Liverpool and Manchester Railroal; he was afterwards distinguished in the introduction of the screw-propeller in steam navigation; and he has crowned his career by the successful construction of the class of turret ships, which appear to have been taken up with avidity, and prosecuted with energy, by the American Govermment; and during the coure of their sull civil will the 'monitor's' appear' to have rendered to the Federal side very important services. The design of these ressels has about it all the charactelistics of American audacity. Every conventionality of the ship has been despised and discarded: in the sailor's sense of the word, there is nothing 'ship)-shape' ahout this original 
Monitor; everything is musual. She has neither keel, nor bilges, nor bulwarks. She is rery nearly a London brilge, covered by a great lorizontal platform of timber, projecting beyond her deck, and descending below the water-line. This great upper platform in no way conforms to the shape of the under-ship which carries it; it is obriously meant to shelter the rudder and the stern from every attempt to damage them by collision. At the bow the entire hull is equally mrotected by the overhanging platform of the deck, and the whole upper works of the ship are covered with thick iron armor on both sides, and the wooden deck is pro. tected by iron plates. The rudder is a balanced rudder; and the ship is propelled by a single screw; the boilers are the double-tier boilers, of the ordinary construction, with four sets of flues. It will be noticed that the arrangenents of the turret are very different from Captain Coles's arrangements. The whole turret is on the upper deck, exposed to shot; it is not carried on a revolving set of rollers, but is pivoted on the centre, which seems to carly most of its weight by means of an iron trussing, from which it is, as it were, suspended, and it slides on a smooth netal plate lying on the deck. The turret is worked by a small pair of doukey engines, working on tooth gear, and the ports are covered by hanging blocks. Like our tur'et," the Monitor shield has two guns worked parallel to each other on slides. The man-

* The English, in abandoning the cupola of Coles, and copying the monitor turret, also adopted the term turret. For some time, however, the English 11 aval architects adhered to the roord cupola; lut in a short while the phrase cupoli was dropped, hence "turret ship" in place of "cupola ship," 
ner in which these turrets were afterwards improved and matured by experience is shown in Plate 49, and it is certain that Captain Ericsson rendered great service to his country by inventing at once, and successfully introducing, a class of ressels peculiarly suited to action in their inland water's and shallow navigations; and when we consider the extreme rapidity which attended the execution of the project, we must say that the original Monitor was a remarkable success, and that she was a type of an entirely new class of warship."

The origin of the name "monitor" calls for an explanation in this place. 'The Nary Department at Washington having, shortly before the launch, requested me to suggest an appropriate name for the impregnable tureted steambattery, I addressed a letter to the Assistant Secretary of the Navy, saying: "The impregnable and aggressive character of this structure will admonish the leaders of the Souther'n Rebellion that the batteries on the banks of their river's will no longer present barrier's to the entrance of the Union forces.

"The iron-clad intruder will thus prove a severe monitor" to those leaders. But there are other leaders who will also be startled and admonished by the booming of the gums from the impregnable iron turret. 'Downing Street' will hardly view with indifference this last 'Tankee notion,' this monitor. 'To the Lords of the Admiralty the new craft will be a monitor, suggesting doubts as to the propriety of completing those four steel ships at three and a half millions apiece. 
"On these and many similar grounds I propose to name the new battery Monitor:"

It will be recollected that this letter was regarded in England as possessing political significance, setral members of Parliment having called for its reating in the ITouse of Commons when the news of the result of the battle between the Monitor and the Mrrmimarli alprearest in the Times. Unquestionably, the alvent of the Honitor materially comm. teracted the pressure which the French linnerom homght to bear on the British Ministry at the time, in faror of the Southern States.

John Bomme, the greatest anthority on maval engineering of our time, in a critical examination of the monitor system published in London, 1866, olserves:

"The confidence of the Anericans in the shot-pronf quali. ties of their monitors is manifested hy many of the incidents of the late Rebellion, one of Which is that Captain Trorden, of the monitor Montumi, attarcked and destroyed the Con-

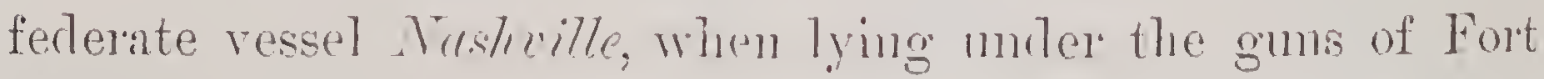
McAllister, in Georgia; and, althongh the fort was all the time pouring a fire upon the monitor from its heariest guns, the monitor took no notice of it, hut proceeded without interuption to the destruction of her antagenist. Another new feature in naval war is that, in the attack on fort Fisher, the fire of the rest of the fleet was directed againt the fort over the monitors; and although shot filling short and shells prematurely exploding contd not be prevented in such an cugrgement, the monitors, it was felt, were able to 
encounter such risks with impunity. The monitor's, during two year's of active service, in all weather's, on a hostile and stormy coast-sometimes watching for blockale-rumers in Cuba, sometimes engaged in the Gulf of Mexico, and often at sea in heary gales-were, on an arerage, each twenty-five times in action: being a larger amomnt of service than that of any ressels recorded in history. Shot could not damage them; storms could not swamp them; and at the end of the war they were as effective as at the heginning. The following extract from a report of Admiral Dahlgren will show something of the kind of service in which some of the monitors rere employed during three months in the summer of 1863 , and the number of shots they fired and with impunity receired:

\begin{tabular}{|c|c|c|c|c|c|c|}
\hline \multirow{2}{*}{ Name of Aronitor: } & \multicolumn{2}{|c|}{ No. of shots fired. } & \multirow{2}{*}{ Hits. } & \multirow{2}{*}{$\begin{array}{l}\text { Hits, } \\
\text { April \%, } \\
1863 .\end{array}$} & \multirow{2}{*}{$\begin{array}{l}\text { IIits at } \\
\text { Ogecchec. }\end{array}$} & \multirow{2}{*}{$\begin{array}{l}\text { Total hits } \\
\text { received } \\
\text { from } \\
\text { the encmy. }\end{array}$} \\
\hline & 10-inch. & 11-inch. & & & & \\
\hline Catskill.... & 138 & 425 & 86 & 20 & $\ldots$ & 106 \\
\hline Montauk... & 301 & 478 & 154 & 14 & 46 & 214 \\
\hline Lehigh . & 41 & $2 S$ & 36 & $\ldots$ & $\ldots$ & 36 \\
\hline Passaic. . & 119 & $10 \%$ & 90 & 35 & 9 & 134 \\
\hline Nahant... & 180 & 276 & 69 & 36 & .. & $10 \tilde{5}$ \\
\hline Patapsco. & $17 \mathrm{~S}$ & 230 & 96 & 47 & 1 & 144 \\
\hline TYecharken & 264 & 6333 & 134 & 53 & .. & $1 \mathrm{S \gamma}$ \\
\hline \multirow[t]{2}{*}{ Nantucket. } & 44 & $1 \tilde{6}$ & 63 & 51 & .. & 104 \\
\hline & $1,25.5$ & 2,332 & 718 & 256 & 56 & 1,030 \\
\hline
\end{tabular}

Mr. Bomrne also presents the following extracts from the 
reports of Captain John Rodgers, of the monitor Wechawken, to the Secretary of the American Navy:

(1) June 20, 1863.

"The opinion formed then confirmed my anticipations, that a hull rising but little abore the surfice of the water' (in this case only 16 inches), and haring a central elevation, as in the monitors, is the shiape to form a good sea-boat; and I am convinced that on this idea all successful iron-clads must be built. 'This form reduces the surfice to be plated to a minimum, and puts the part haring the necessirly elevation abore the sea for fighting goms where it can be carried without inconvenience, and in the Wechawhen is easily carried. With us, I think, safety is solely a question of strength.

"I had relied upon former experience to correct any faulty motion which I might discorer in a sea-way, by shifting or reducing weights. I abandoned, however, the idea of improve. ment. As I watched the action of the ressel it was perfect." (2) July 22, 1863.

"On Thursday night, when off Chincotengue Shoals, we had a severe gale from east-northeast, with a very heavy sea, made confused and dangerous by the proxinity of the land. The waves I measured after the storm abated. I found them 23 feet high. They were certainly 7 feet higher in the midst of the storm.

"During the heaviest of the gale I stood upon the turret and admired the behavior of the vessel. She rose and fell to the waves, and I concluded then that the monitor form had great sca-going qualities. If leaks were prevented, no 
hurricanc could injure her. I presume in two days we shall be ready for any service, as we need no repairs, and only some little fittings."

"It may be adted," says Mr. Bourne, "that, on the occasion of the heary gale which occurred just before the attack on Fort Fisher, the monitors were the only vessels of the fleet which were able to ride it out without dragging their anchors; and on the occasion of a common steamer having been sent to escort a monitor, before confidence had yet been established in the seaworthiness of that class of ressel, the stemer, hav. ing broken down in a heary sea, was taken in tow by the monitor, and was carried by her safely into port."

Mr. Bourne, in proof of the comfort and healthiness of the monitor's, likewise presents the following extract from at report of the Secretary of the United States Nary to Congress :

"It is gratifying to know that an examination of the sick reports, covering a period of orer thirty months, shows that so far from being unhealthy, there was less sickness on board the monitor vessels than in the same number of wooden ships with an equal number of men, and in similarly exposed positions. The exemption from sickness in the iron-clads is in some instances reminkable. There were on board the Sangus, from Norember 25, 1864, to April 1, 1865, a period of over four months, but four cases of sickness (excluding accidental injuries), and of these two were diseases from which the patients had suffered for year's. In the Montank, for a period of one hundred and sixty-five days prior to May 
29,1865 , there was but one case of disease on board. Other vessels exhibit equally remarkable results, and the conclu. sion is reached that $n 0$ wouten ressels in any squadron throughout the world cam show an equal immunity from disease. The facts and tables presented are worthy of care. ful study."

'The following rote of thanks was passed by the Thirty. seventh Congress, March 28, 1862 :

"Resolved, by the Senate and ITomse of Represcntatives of the United States of America in Congress assembled, 'That it is fit and preper that a pullic acknowledgment be made to Captain John Ericsom for the enterprise, skill, energy, and forecast displayed by him in the construction of his iron-elat boat, the Monitor, which, moler gallant and able management, came so opportunely to the rescue of our fleet in Hamptom Roads and, perchance, of all our coast defences near, and arrested the work of destruction then being successfully prosecuted by the enemy with their iron-chal steamer, seemingly irresistible by any other power at our command; and that the thanks of Congress are herehy presented to lim for the great service which he has thus rendered to the country."

It will be proper to mention, also, that several iron-ship huilders, in conjunction with the proprietor's of some of the most inportant manine-engine establishments on the Athutic coast, in token of their appreciation, honored me by present. ing a model of the Momitor, weighing upwards of fourteen pounds, manufactured of pure gold. 


\section{CHAPTER XXXIII.}

\section{'THE MONITOR 'IURREI' AND 'LHE CENIENNIAL EXHIBI'LION.}

(SEE PLAIE 49.)

THe imperfect character of the monitor turret exhibited in Fairmonnt Park has been noticed with surprise by professional visitors. In view of the important results attained by the adoption of this structure during the war, it camnot be denied that a painted wooden representative is unwortly of the occasion. Nor need it be urged that some turret bearing the marks of actual conflict onght to have been transfered to the Exhibition. Experts are aware that, owing to the laminated character of these turrets, they may readily be taken down, and the plates transported and put up at any required distance from the ressel. Besides, it may be shown that this process would have been less expensive than erecting a complete representative turret and mechinism. Regarding the armament applied within the rooden turret, 
naval artillerists from abroad, who expected to have had an opportunity of examining the detail of the friction-gear peculiar to the monitor armament, have been greatly dis. appointed to find that, instead of the carriages on which the guns were mounted during the war, an experimental steam-carriage devised by an engineer from St. Louis, after the war, has been placed in the representative turret. In consequence of this misleading procedure on the part of the authorities, of exchding the carriages which had been used, the majority of visitors have naturally inagined that the monitor g'uns, during the war, were mounted on the experi. mental carriage referred to." It should be mentioned that the plan of checking the recoil of our gruns by friction has not been superseded in the nawy, and that friction gun. carriages are at present being constructed for the Nary Department under my patents.

THE PIIOT-TIOUSE.

The pilot-house-wheel-house-of the monitors, and the steering-gear which it contains (see Plate 49), forming the most important features of the system, their exclusion from the turet at the Centenuial Exhibition must be regarded as an untoward circumstance. It cannot be supposed that the officer charged with the duty of putting up the representative turret would incur the responsibility of excluding with. out authority that part of the system which most interests

* Ny carriage, operated by a circular compressor, exhibited in the wooden turret, was applied in the Dunderborg, but not in the monitors during the war. 
the professional risitor. 'The comnty is aware that Adminal Porter's report to the Secretary of the Nary; published while the preparations for the Centemnial Exhibition were in progress, contained a recommendation to abolish the pilothouse of the monitor turrets. Pussibly this recommendation, condeminatory of my invention, led to the exclusion of the steering machinery and the massive pilothouse from the representative turret in Farmount Park. I do not propose to investigate the canse which has led to the exhibition of ny invention in a mutilated state, but I feel called upon to show that the removal of the pilot-house from the turrets recommended by Admiral Porter is highly improper and incompatible with the monitor system.

Well-informed naval officers are aware that Worden failed to sink the Merrimack at Hampton Roads because he could not personally control the firing and at the same time direct the steering of his vessel from a point enabling lim to observe properly the movement of his antagonist. This fact was well understood by the authorities at Washington, the Assistant Secretary of the Navy having himself witnessed the battle and the ineffectual firing. I was accordingly requested by the Nary Department, shortly after the conflict, to derise sone neans of steering from the turet. The despateh convering this request contained sereral inportant suggestions, and closed with the following sentence: "The placing the wheel-house on the turret would double the formiclable character of the ressel." Considering what hap. pened at Hampton Roads, more might have been said; for 
had the Monitor been provider with a wher-house on the top of the turret, Worden, instead of discontinumg the action almost blinded, would have forced the Merrimerk to surrender as readily als Rodgers conpelled the commander of the boasted impregnable Atlanke to hanl down the Comfederate flag by being emabled personally to direct the stecr. ing and the firing while watching from the elevalent turret wheel-house of the monitor Hecherblien the morements of his opponent. Again, it was from the turet wheel-huse of the monitor Monkule that the here of Irmpton Ronds detected the Nashville, and by a few filteen-inch shells, tired under his own supervision, burnt the Conferterate resed and cargo. It was reserver for the $\Lambda$ dumiral of the Xiry to discover that the arrangement which conbles the commander of a monitor to direct the firing and the steering from an elerated position abose the turret, aftording an all-around view, is a great mistake, although it has proved so efficaciuns in actual conflict. It was reserved for him also to find out "that the placing of the pilothouse on the top of the monitor" turret shows a lack of ingenuity"-a discorery apparently resulting from reflections connected with the fact mentioned in his report, "that this is the most exposed point in the vessel, and is liable to be swept away by the first heary shot that strikes." The Admiral appear's to have forgotten that the fleet of monitors at Charleston, commanded by Dihlgren, engaged the Confederate batteries some twenty times, at easy range, and yet the pilot-houses were not "swept away." The section of the turret and wheel-house (pilot-liouse) 
of a monitor of the Passaic class (shown on Plate 49) represents the structure precisely as built, excepting that the turret wall, in order to protect the base of the wheel-house in accordance with my original plan, should be carried two feet above the turret roof. As the wheel-house and steering gear must remain stationary while the turret revolves, it will be perceived that the plan presents a mechanical prob. lem of no ordinary character. 'This is understood by persons possessing correct mechanical knowledge, who have studied the arrangement, and know that it successfully passed the severe ordeal to which it was subjected during the war.

With reference to the original plan of extending the turret wall above the roof, it will be proper to mention that the managers of the plate-mills employed to manufacture the turret plating luring the war refused to furnish plates of nore than nine fect in length. Not only did they positively decline to roll plates of an additional length of six inches, but they liniterl the thickness to fifteen-sixteenths of an inch, owing to their inability to manufactnre plating above a given weight. Those who criticise the strength of the armor of the monitor's will do well to bear this in mind. A careful inspection of our illustration, representing a section of the turret of the Passaic class of monitors, at once disposes of the erroneous assertion that the pilot-house, the internal diameter of which is only six feet, may be "swept away." No target practice has yet shown that a cylinder of such small diameter, composed of solid iron eighteen inclies thick (of course it might be made thicker), can be 
penetrater. At the same time, the inertia of such a cylinder, owing to its weight, is so great that a basering of rery morlerate section attached to the turret roof will effectually prevent dislodgment muder the impact of shot.

In riew of the foregoing, it would lie waste of time to discuss the merits of the Ainiral's recommendation to the Secretary of the Nary, "to place the steering alp paratus below, with a smatl portion of the deck above it ratsed and hearily platerl, with apertures to lonk througgh." But his reference to lack of strength calls for some notice. In reply; I will simply observe that by sulstituting solid for Janinated armor; the original Womitro; "if in existence to-lary," wonld

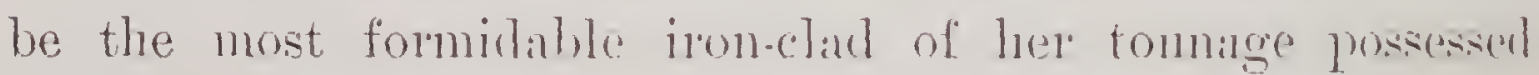
by any naral power. Of course it must be attributed to inadvertency that Alluirial Porter lias not, in his repurt, reminded the Secretary of the Nary that the laminated armor of the turrets of the entire monitor fieet ought to be at once substituted by solicl plating.

Naval constructors and engineers will find by examining our ilinstrations that, excepting the omission to place the pilothouse on the top of the turret, the original Momitor was a perfect fighting machine; and that not a single essential improvement has heen added in bulling the sulsequent monitor iron-elaks. It will also be found that the propeller was better protected in the origginal Momitor, and that the anchor was handled with greater facility and more perfect protection to the crew, than in the recent turret ressels. Moreorer, it is susceptible of positive demonstration that a 
ressel built precisely like the first Monitor, provided with a turret wheel-house and armor of alequate thickness, would present the most perfect ressel for harbor defence hitherto produced - whether for carrying heary orduance or for handling movable torpedoes employed against an attacking fleet.

It will be observed by those who have studied the matter that Adminal Porter's statement, at the commencenent of his report, is materially modified by a subsequent paragraph, strongly recommending the overhang of the Monitor, "which," the report states, "prevented the hull being penetrated if the ressel was struck by a rant." The Achiral further observes: "The value of this contrivance was shown in the contest at Ifampton Roads, where the Merrimack rammed the Monitor, merely turning the latter hilf round, and doing no damage whaterer." It will be seen, by the illustrition (Pl. 47) representing a transverse section of the original Ionitor, that a collision like that between the from, Dule and the Vanguard, which sent the latter to the bottom, would not be productive of greater danger than that cansed by the Merrimacli's lamming, since, owing to the orerhang and inclined sides, the Iron Duke's spur could not reach the Monitor's hull. 


\title{
CHAP'TER XXXIV.
}

\author{
'THE MONITOR LNOINE. \\ (SEF PLATES 50 AND 51, RLPRESENTIXG A TOP VTEW AND SIDE \\ ELEVATION.)
}

Ture Engineer of April 20, 1866, contains the following discussion relating to the engines employed in the monitor iron-clards, accompanied by a brief description of the mechanical combination of these motors:

"The common feature of all Ericsson's screw-propeller' engines, however otherwise different in arrangenent and principle, consists in what he himself las described as 'bringing the power of two engines to bear at right angles on a common crank-pin'-a feature alrealy noticeable in the engines built by him in 1839, at Liverpool, for the Robert I. Stockton. This rery ressel, tried on the Thames so many years ago, is stated to be, even now, not only the most powerful tug of her class on the river Delaware, but also the fastest. Her engines consist of two stean-cylinders, 
placed diagonally, with cross-heads and side-rods connected to a common crank-pin on the propeller-shaft. In the Eilith and Massachusetts Ericsson modified his diagonal form of engine by laying the cylinder's against the ship's side, under the deck, bottom 11, with the piston and comnecting-lods working downwards, but still connected to a common crankpin on the propeller-shaft. A combryman of Ericsson, Captain Carlsund, copied this arrangenent, applied it in a number of Swedish vessels, exhibited it at the Paris Exhibition, and, with the usual perspicuity of Universal Exhibition juries, was rewarded for this exhibit by the great gold medal.

"While still adhering to the feature of bringing the power of two cylinders on to a common crank-pin, the present form of marine engine adopted by Captain Ericsson may be looked rpon as an outgrowth of the peculiar engine, with semicylinders, which he first applied to the United States steam. frigate Princeton. Excellent illustrations of this engine appeared some years ago in a work called 'Imperial Cyclopredia of Machinery'; but as Captain Ericsson has himself observed, in a letter to Mr. Wooderoft, the description began by erroneously stating that "Watt has described a similar" arrangement in one of his earlier patents.' 'This is so far a mistake, as Thatt-according to a practice lie adopted, under the then state of the law, of inserting as many ideas as possible into his patents-merely described the bare idea of a piston vibrating within a semi-cylinder. As Captain Ericsson states, 'the Princeton's engine consists of componnd or double semi-cylinder engines, of different diameter's, with 
pistons attaled to the common axte in opposite directions, beth pistons being acted upon by the steam at the sanne line, their differential force constituting the effective motive power:' 'The writer of the description of the engines of the Princeton in the 'Cyelopectial' while allowing that 'this species of engine is rery compact,' and that it 'almits of being placed entirely below the water-line; as also that, "although rery many other arrangenents have heen since brought out in this country, it is still a preeminently sale. cesful engine,' yet olserves that 'the friction is, of course, more than in miny oblhers, inismuch as it is found practi. cally impossible to obtain the porrer of stean with so little friction in any form of chamber as a true cylincler.' 'To these objections Captain Eriesson replies: 'In the first place, the alsence of pressure on the main jourmal of the pistonshaft is not understood by those who ale not cognizint of the fitet that a straight line drawn from the crank-pin to the opposite jourmal of the shaft passes thromgh the centre of gravity of the piston.' 'Then, again, 'the weight of the piston, instead of scraping the bottom of the cylinder, is suspended in the jommals, and there produces but a very small amount of friction.'

"Nor have critics recognized the fact that during the passage of the crank-pin of the propeller-shate through the lower part of the alc of vibration, it is nearly relieved from pressure by the opposing action of the connecting-rod-one pushing while the other is pulling. Tarstly, the absence of the great friction produced by the diagonal thrust of the 
short comnecting-1od against the guides of ordinary propeller engines also forms an important item of saving peculiar to the semi-cylinder engine.'

"The weak point in this very ingenious engine is undoubtedly the piston. 'The ends, for instance, must wear' unequally and at a rate increasing with the radius of any given point from the centre of ribration." Ericsson is too grood a mechanic to shut his eyes to this fact; and accordingly, when, in 1859, the United States Nary Department submitted the problem of the best screw-propeller engine for solution by the engineer's of America, he presented a plan of an engine similar to that of the Princeton in all essential features, with the exception of the introluction of full cylinders insteal of semi-cylinders. Since that period the greatest success in America has accompanied this last form of stean-engine; it has been almost universally applied to the hater ressels of war of the States, and also in the mercantile nary of that country. There is not a single Anerican monitor without an engine of this kind, and all the Swedish monitors are engined on the same plan. It has been patented by the inventor, and the accompanying plans and descriptions are preprared from information sent by Captain Ericsson limself to Mr: Woorlcroft (see Plates 50 and 51). He has also sent a beautiful model of it, which

* In refutation of this objection, I have to state that the steamship Princeton, after serving in the Gulf during the Mexiean Wur, was sent to the Mediterrancan without repairing her pistons, the end-pectings on cxamination proving to be in jorfect order. 
may be seen in the Patent Office Museum at South Ken. sinģton.

"The several direct-acting screw-propeller engines hither. to constructed,' says Captain Ericsson, 'are all more or less objectionable in the following particulars, vi\%: the lorizontal engines occupy too much space transversely in the ressel to admit of being placed in the run; the vertical cugines pass through decks, and project so fir above the water-line as to be useless for war purposes; and all approvend dunble. cylinder engines operate on cranks placed at right angles to each other, which involves a series of bearings, much fric. tion, and liability to derangement from the shafts getting out of line. In addition to these imperfections, the extreme shortness of the cranks, with the attendant great friction on the crink-pins and journals, to say nothing of the heary diagonal thrust of the connecting-rods, are serious defects in the direct-acting screw propeller engines in common use.' In Captain Ericsson's present form of screw-engine the two cylinders of a double engine are arranged in such a manner that their base or bottom ranges with a plane passing through the axis of the propeller-shaft, or nearly so, in combination with a certain arrangement of rock-shafts, crankarms, and connecting-rods, for imparting notion from the pistons to the shaft, whereby he is enahler, first, to bring the cylinders nearer to the propeller-shaft, and hence to economize space and construct the frame of the engine of great strength and compactness; secondly, to aroid the diagonal thrist and friction of the slides, mavoidable when 
the connecting-rod is attached directly to the cross-head; thirdly, to operate the comnecting-rods nearly at right angles to each other, which admits of the production of a continuous motion with a single crank on the propeller-shatt, and with a single crank-pin common to both engines; fourthly, to employ a crank on the propeller-shaft much longer than half the length of stroke of the piston, thereby diminishing the heary pressure on crank-pins and on journals, which has hitherto caused so much trouble by the orerheating of the bearings, and at the same time diminishing the strain on the engine-frame."

DESCRIPIION OF ILIUUSTRATIONS ON PIATES 50 AND 51.

The general eharacter of the Monitor engine will be readily comprehended by a referenee to $\mathrm{Pl}$. 50, represent. ing a ground.plan, and Pl. 51, the side elevation, viewed from the bow of the vessel. The crank on the propellershaft and the main connecting-rods, being hidden by the steam-cy]inders, are shown by dotted lines in the side elevation. The two eylinders are placed end to end transversely in the vessel, trunks or hollow piston-rods being cast on the pistons, as shown by the sectional plan on page 487, projecting outwards towards the side of the ressel. These trunks are sufficiently large to permit the vibration of links connecting the pistons and short vibrating levers attacher to the forward end of the horizontal rock. shafts. Referring to the top view of the engine, it will be seen that vibrating levers of greater length are attached to 
the aft end of the rock-shatts. 'These lever's are compled to the common crank-pin on the propeller-shaft, the comnectingr. rods acting nearly at right angles to each other. By this arrangement the throw of the crank may be matle much longer than in ordinary directacting engines; conseguently; the strain on the crank-jommal of the propeller-shaft will he correspondingly reduced. A prokongation of the crank-shalt forward-of small dianeter-calries the eceentries which ac. tuate the steam-ralres, while a prolongation of onc of the rock-shafts towards the stern operates an air-pump common to both steam-eylinders. The hotton of the eylindirs, or the division between them, is formed as shmm ly the sec. tional plan of the cylinders before referred to.

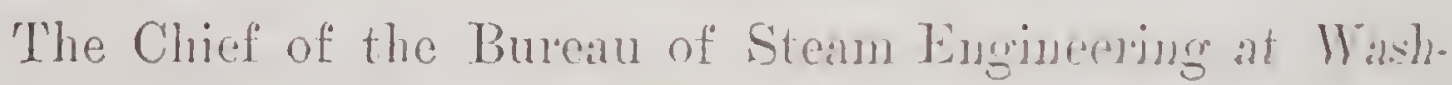
ington, Nr: B. F. Isherwood, having criticised the principle of the Monitor engine, I published the following reply in the Engineer of June 8, 1860:

"Referring to Mr. Tsherwood's 'Experinental Rescarches on Steam-Engineering; I find it stated, at pange $3 \pm 0$, that the cost of the horse-power in the engines of the Momitor, when cutting off at 0.425 of the stroke of the pistom from the commencement, is 27.7 per cent. more than in the U.S. padtle-wheel steamer' Michigan. 'Great as this excess ap. pears,' says Mrr. Isherwood, 'it is no more than what the conditions fully warant us to expect, and should be decisive against the use of such a type of engine. Mr. Isher. wood accounts for this great loss of power in the following manner: "From the description of the Monitor engine, it 
will be perceived that two cylinders occupy the same barrel, the separation being made by a simple partition of cast iron in the centre. Further, that during a large portion of the time the boiler-steam occupies one end of the cylinder, while the adjacent end of the other cylinder is open to the condenser. 'There is, consequently, one end of one cylinder' maintained at the temperature of the boiler-steam, while the adjacent cnd of the other cylinder, separated only by a cast-iron partition, is exposed to the temperature of the condenser. This arrangement, immaterial as it appear's-and is in a mechanieal point of view-powerfully affects the economical result by its great influence on the cylinder-condensation. To appreciate it, it is only necessary to imagine the piston of the starboard engine, for example, to be near the outboard end of its stroke, in which case nearly the whole of the cylinder of that engine will be filled with steam. At this moment the piston of the port engine is near the centre of its stroke, and about one-half of the port cylinder adjacent to the starboard cylinder will be open to the condenser and exposed to its refrigerating infunence; consequently, the boiler-steam in the starboard cylinder has been exposed for about one-half of the stroke of its piston to this refrigerating influence from the port cylinder, transmitted through the iron partition of the two cylinders, which, as their diameter is great in proportion to the stroke of their piston, forms a large proportion of the surface in contact with the steam. Nor does the evil end here; for', as the sides of both cylinders are the same piece of iron-those of the one 
being merely an extension of those of the other-the conduction of heat is very rapid from one cylinder to the other, and the heat imparted by the steam to the sides of the starboard cylinder quickly passes along by conduction to the sides of the port cylinder, whose interior is in communica. tion with the condenser, and whose exterior is exposed to the atmosphere. The inevitable result, it is manifest, must be a largely-increased steam-condensation in cylinders of this type of engine over that in the cylinders of the usual type-how much larger, is a question which experinent alone can answer. 'There is still to be added to the already-deseribed peculiar causes of steam-condensation in cylinders of the Monitor type of engine that of the hall-trunk, the effect of which is, for a given capacity of cylinder, to increase both the interior and exterior cylinder surfaces; while the thin, unprotected metal of the half-trunk-one side of which is always in contact with the atmosphere, while the other side is, too, for half the time, and not only in contact with, but in rapid movement through, it-makes it a regenerator of maximum power.'

"Before analyzing this extruordinary reasoning, let us examine closely the section of the cylinter in the amexed diagram.

"It will be seen that, although the two cylinder's are combined in one casting, each has a separate bottom, with a considerable space between the two; also that the heat to be transmitted through the metal of the cylnder, as Mr. Isherwood states, must travel a distance of 6 ins. from $a$ to 
$b$, or from $b$ to $a$, in less than half a second, in order to produce the baneful effect pointed out by the author of 'Experimental Researches.' It will not be necessary to demonstrate that heat cannot be tramsmitted through 6 ins. of metal in half a second, and it would be an insult to the intelligence of your readers to detain them by disproving Mr. Isherwood's assertion that a considerable amount of the motive force is lost by thus transmitting heat back and forwards through the substance of the cylinder.

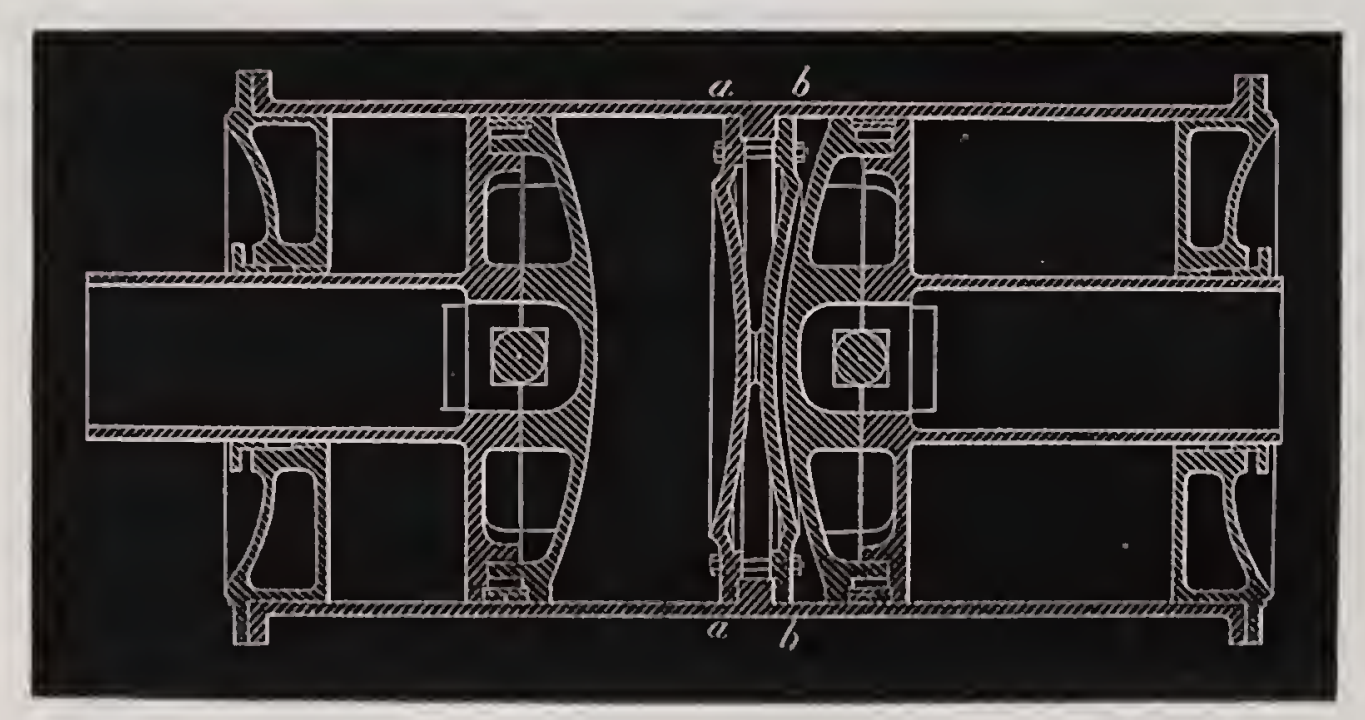

"With regard to the supposed rapid transmission of heat through the 'iron partition of the two cylinders', you will find on referring to the section that no transmission of heat can take place, since the two bottoms are separated by a stationary body of air or rapor. In the ordinary cylinderbottom, the outside of the metal acquires, during regular working of the engine, a permanent temperature, attended by a constant loss of heat rarliated inte, and continually ab- 
sorbed by, the atmosphere. In the case of the botton-plates of the Monitor's cylinder, a permanent temperature is also acquired, but there is no loss of heat by ratiation after the intervening small body of air or vapor hats attained maximum temperature. It may be truly said that the Monitur engine, with its cylinder's combined in one casting, fumishes the only instance in which no heat is lost by radiation through the cylinder bottom. Iraving thus disposed of the alsurd notion that a rast quantity of hat is transmitted from cylinder to cylinder, we now come to the question of increased internal cylinder surface consequent on the apulication of the trunk. Mr. Isherwood treats this question as one of such great importance that I have taken the trouble to ascertain the exact amount of increase. Area of 40-inch cylincler, 1,256 square inches; area of $13 \frac{1}{2}$-inch trunk, 143 squarc inches. Deducting from this 20 square inches for a 5 -in. piston-rod, which the ordinary engine would require, wo have a difference of 123 square inches occupied by the trunk. But the trunk only aftects the outboard end of the cylinder; and hence the mean area taken up is only $61 \frac{1}{2}$ square inches. To make up for this loss of area, the diameter of the cylinder, it will be found by calculation, lats only to be increased 鼔 of an inch. I should be trifling with the patience of your readers were I to enter on a calculation to show the anount of loss attending such small increase of the diameter of the cylinder. Only one more point, mred by Mr. Isherwood against the Monitor engine in explanation of the asserted 27 rer cont. loss of motive force, remains to be 
considered, viz., the effect of the trunk, which he calls a 'refrigerator of maximum power.' Mr. Isherwood derotes so much time to the theoretical consideration of the steam. engine that I can well understand that he has no time left for practice; otherwise I should feel surprised at his ignorance of the fact that the great difficulty with trunk engines is that of keeping the packing steam-tight without causing orerheating. Experience shows that the best that can be done in practice is to prevent the trunk from exceeding the initial temperature of the steam; and hence tlie trunk, in place of being a 'refrigerator of maximum power', is actually a super-heater.

"It will be asked by what process did Mr. Isherwood ascertain the amount of the assumed loss of power for which he accounts by this extraordinary reasoning? He placed, according to his statement in 'Experimental Researches,' a tank on a wharf, to which the Monitor was made fast. From this tank he supplied the boiler's of the vessel by means of temporary feed-pipes. Steam having been raised, the engines were started and kept in motion for seventy-two hour's in succession. Indicator-cards were taken every hour, by means of which the mean indicated horse-power exerted by the engines was ascertained. This was compared with the quantity of water measured into the tank and supposed to have been converted into steam. The utmost precision was practised; the water run into the tank was ascertained to the third decimal of a pound; the barometer and direction of the wind carefully noted. The difference between the indi- 
cated power and that which ought to have been produced according to the quantity of water used, supposed to have been converted into steam, was set down as "loss occasioned by cylinder-condensation.' I observe that Mr. Isherwoorlis tables and calculations make no allowince for condensition in the steampipes and rille-chests. Loss by leaks through the pistons, vilves, and glands; leaks and waste of witer and sterm in the boilers-all these sources of loss alpyeal to be ignored by the experimentalist, and every pound of water measured into the tanks is debited to the enginc. A balance is then struek by deducting the indicated horse-porer; and the difference put down as 'loss ciused hy eylinder-conden. sation.' I abstain from criticising this rongh and unsatisfac. tory mode of deciding the nice point of cylinder-condensation; but I cannot omit adverting to the fact that, while the pressure in the boilers, during the trial of seventy-two hours, wats kept at 17 lbs. above the atmosphere, the pressure admitted into the cylinders was only 13 lbs. abore the atmosphere. The tables show that, in order to maintain this low working-pres. sure in the engines, the throttle-valse was set permanently at an opening of four square inches. In view of the magni. tude of the engine-two double-acting cylinders of 40 ins. diameter-the admitting the steam through a single opening of such small area was certainly a most singular expedient. Had the object of the trial been to exhibit a minimum indicated horse-power; a more effective expedient could not hare been devised. As the mean area of the piston, according to the tables, was 1,155 square inches about three hundred 
times greater than the area of the throttle-valve-the speed of the pistons being at the same time upwards of 2.5 feet per second, some irlea may be formed of the amount of dynamic force exerted and heat extinguished in passing the steam from the boilers to the engines. Yet this waste of force was ignored by the experimentalist, and the indicated piston-power alone was set against the water measured into the tank.

"Apart from these facts, the most critical examination of the sectional plan of the cylinders of the Monitor befores referred to (see page $4 S t$ ) fails to discover any error of construction productive of cylinder-condensation to a greater extent than in the screw-engines of the most celebrated maker's." 


\title{
CHAPTER XXXV.
}

\author{
'I'HE MONITOR DIC'TATOR.
}

(SEE PLATES 52, 53, 54, AND 55.)

The Dictator is the most powerful and efficient fighting. ship possessed by the United States. Like the Monadnock class of monitors, she is also a good cruising ressel. The hull, engines, turret, and gun-carriages of this ship were de. signed and furnished by the writer, under a contract with the United States Navy Department, 1862. Her length on deck is $314 \mathrm{ft}$, the overhang aft being $31 \mathrm{ft}$, and the forward overhang $13 \mathrm{ft}$., leaving a length of $270 \mathrm{ft}$. between perpendicular's (see side elevation, Pl. 52). Her breadth over the sides is $41 \mathrm{ft}$. 8 ins., and her total beam $50 \mathrm{ft}$, whilst her draught is $20 \mathrm{ft}$, the sides midships projecting only $1 \mathrm{ft}$. 6 ins. above the water-line. The sides are protected at and near the water-line by 11 ins. of wrought irour this thickness consisting of inner bars 5 ins. thick, and six plates each $1 \mathrm{in}$. thick (see transverse section, Pl. 53). The plates are placed upon massive timber backing, as shown 
by the illustration on the plate referred to. Her tomnage is 3,000 tons.

The engines of the Dictator (see illustrations on Plates 53 and 54) are 4,500 indicated horse-power, consisting of a pair of rertical cylinders 100 ins. in diameter; with a stroke of $t \mathrm{ft}$. The pistons have small trunks on their upper side, and are connected by links with the ends of curred horizontal arms attached to the forvard end of rock. shafts placed outside the cylinders slightly above the latter. Straight arms nearly vertical are attached to the after-ends of the rock-shafts. These arms are coupled by means of diagonal comnecting-rods to a common crank-pin fixed near the circunference of a fly-wheel upon the screw-shaft. The engines drive a propeller 21 ft. 6 ins. in diameter, provided with four blades set at a pitch of $34 \mathrm{ft}$. 'The propeller' weighs 39,000 lbs., and its shaft 36 tons. The engines are supplied with steam by six boilers having altogether 56 furnaces; the total grate-surface is $1,12 \mathrm{~S}$ square feet, and the heating surface over 32,000 square feet. The coal-bunkers accommodate 600 tons of coal.

The Dictator has a single revolving turret, essentially the sime as that delineated on Plate 49 ; it is $24 \mathrm{ft}$. in diameter inside, by 9 ft. high, and contains two fifteen-inch guns. The sides of the turet are built up of two separate concentric cylinders, composed of plates 1 inch thick firmly riveted together, a space of fire inclies being formed betreen the said cylinders. This space is filled with segmental wrought. iron slabs 5 ins. thick and 12 ins. broad; hence the total 
thickness of the turret wall is 1 lt, in ins. The turret has a hell-mouthed top formed of irom plates $\frac{1}{2}$ in. thick, curred outwarks, as shown on l'late i2, for the purpose of throw. ing off the water which, Juring heary weather, is dashed up the silles of the turet. Aromd the bell-mouthed top mentioned is anderl a rooden srating provided with a hand-rail, and appropriate stanchions for supporting an andring. The grating referred to forms at convenient baleony for promenade. Orer the centre of the turet is placed the pilothouse, which is $8 \mathrm{ft}$. in dianeter in the inside, and $7 \mathrm{ft}$. high, its sirles being fomed of twelve thicknesses of 1-in. plates. This structure is supported by a strong cross beam which rests upon a collar formed on a strong contral wroughtejon shaft passing down through the turret; this shaft being stationary, the turret rerolving round it. Except. ing the bell-nouthed plate-iron extension at the top, the Dictator turret is constructed precisely as the turrets of the Passcic class of monitors delineated on Plate 49. Referring to this delineation, it will be seen that the weight of the turret wall is suspended by diagnonal rods in such a mamer that the entire weight of the turret and armament, as well as the pilothouse, is sustained by the stationary central shaft. The latter rests on a casting bolted to the transverse bulkhearls of the ship, as shown in Plate 47 . The pitothouse is provided with sight-holes placed at a convenient height, and, like the central shaft, is stationary. The diagonal rods before referred to, it should be observed, are furnished with screw-ends and nuts, in order to admit of their being tightened 
in calse the turret wall should sag. The cross-beam before mentioned, which extends across the top of the turet, supports rafters carrying iron bars $t$ ins. deep by 3 ins. wille, and 21 ins. apart, these bars being covered with perforated phates 1 in. thick. The base of the turret wall rests on at flat ring composed of bronze, the under-side of which is accurately faced. It is supported by another flat ring faced on the top and secured to the deck. By this means a watertight joint is formed between the base of the turret wall and the deck. It is obvious that considerable power wonk be required to cause the tmret to revolve if its weight rested on the rings described. Accordingly, a taper key is inserted under the stationary central shaft, by which the weight of the turret and appendages maly be raised so als to rest wholly on the shatt. During the war this key was invariably tightened before going into action, hence the turrets revolvel with perfect freedom while the gumers pointed the pieces. A circular chamel is formed in the deck near the inside of the turret, in order to carry oft water that mily leak under the base. It is conducted to the bilge by small scupper-pipes. The machinery for turuing the turet consists of a pair of donkey-engines, which work gearing connected with a large cog-wheel secnred by strong lugs to the under-side of the gunstides, which are in their turn firmly attached to the sides of the turret. It should be observed that all the turning gear is below the deck-line. The floor of the pilot-house consists of a wooden grating fitted with hinged hatches, through which the captain and 
steersman enter from the turet. 'The steering-wheel is contained in the pilot-house, and its motion is transferred, by gearing and by a rack sliding in a groove formed in the central shaft, to a pinion fixed upon the axle of the steering barrel below. From this birrel chains extend to the rudter, which is of the balanced kind. The ressel is strengthened beneath the turret by transverse and longitudinal bulkiheads.

The gun-carriages are run out upon their slicles by means of winch-handles moring whech-work geared into racks, the fliction-gear being lightened as soon as the ficces are full ont, and of course relieved inmediately after the recoil. Each gou has a radial ball placed above it, upon which runs a wheel supporting a block and tackle, provided with a small dished platform upon which the shot is placed. By this contrivance the shot can be rapidly raised from the shot-locker to the muzzle of the gun.

In the Dictator the air required for ventilation and for supplying the boiler-furmaces is drawn in by several large fan-blowers, partly through the top of the turet and partly through shot-proof trunks carried high above the decks, as shown in the side-elevation, Plate 52. The russel is provided with a spacious plattorm or promenade deck, placed at nearly the same height as the top of the turet (see plate referred to). This deck is supported on rertical iron stanchions, the ship's boats being suspended below the same. The cabins are lighted by means of bull'seyes fitted into brass frames let into the deck, these frames being replaced by solid wrought-iron covers when the ship is going into action. 
'The Engineer, in an article published 1866, states with reference to the Dictator:

"It may be laid down as a general axiom that when the introduction of fresh elements into any mechanical problem has effected a revolution in its first conditions, originality is at great advantage over hesitating and long-pondering judgment. 'Though without the adrantages which our great command over iron in large masses has given in the modern substitution of iron for wood in naval warfare, the Americans have certainly shown much originality and boldness in their designs for war-ships. A good deal of this is due to Captain Ericsson-an original thinker and constructor, whose very oliginality would have led him to be distrusted in this conservative country. Broally stating the matter, it may be said that in France and in England we have pretty much confined ourselves to bolting massive iron slabs, with an intermediate packing, to the skins of our iron ressels of war; but Ericsson has taken a much more comprehensive view of the capabilities of engineering in its application to the etermal war-problem of doing as much damage as pos. sible to your adver'sary with as little as possible harm to yourself." 


\section{CHAPTER XXXVI.}

'LHE MONITOR 'IURREL' ANTD 'IHF CASEMA'L'.

(

As opportunity of instituting a direct comparison between the monitor turet and the fixed casemate was furmished by the completion of the Turkish armol-clad ressel Mlloyini Zuffer, launched on the Thames in June, 1869. The building and arming of this iron-clad being the result of the joint efforts of Sir Willian Armstrong, Samula, and Ravenhill, we have a guarantee that whatever merits the fixed casemate system possesses have been fairly developed in this attempt to supersede the monitor:

It cannot fail to be noticed, on careful cxamination of the illustrations on the plate referred to, that the planning of the casemate of the Moyini Lafjer shows much thought and elaboration; also that the complication which characterizes its form is evidence that the planner. was dealing with a difficult subject. Nor can the attentive observer fail to 
see at a glance how imperfectly the disarlvantages attending the elongation and immobility of the battery-viz, the linited horizontal range of the guns-have been overcome by the combination of curvature and angles resorted to by the constructor of this substitute for the monitor tur'et.

Our illustrations, besides representing a top riew of the Moyini Zuffer, accurately drawn to scale, also represent a top view of a monitor provided with two turrets of the same diameter as those of the Pussair class - viz, 21 feet internally. 'The length of the Turkish vessel is 230 feet, with 35 feet 6 inches beam. The monitor, for the sake of exact comparison, has the same limensions; but the thickness of its armor is greater than that of the former, and so proportioned that the weight of armol of both vessels is alike. 'The freeboarl of the Moyini Zuffer, as in all iron-clads built by English engineers, is several times higher than that of the monitor, and consequently deeper armor below water must be applied to aftord protection, increased rolling being the ineritable result of high freeboard. Referring to the bat. teries, it will be seen that the circumference of the fixed battery is greater than that of the two turrets in the ratio of 25 to 15 .

The English mechanical journals, in describing the Moyini Zaffer, point with apparent satisfaction to the circumstance that this casemate ship, which is intender for the defence of the Bosporus, has armor-plates "generally six inches in thickness, the whole of the battery (backed with wood) being cased with j-inch plates." 'The battery, though pierced 
for eight guns, will only carry four of Armstrong's 12-ton rifles. 'The intention being to transfer the pieces from one side of the battery to the other during action, it is evident that Sir William has reached the limit of weight. The difficulty of changing sides with the rapidity called fol during contest witl screw-propelled assailints needs no explanation. But the constructor of the monitor turret, which, as onr illustration shows, commands 3 th leg. of the horizon, is not hampered by considerations of weight of metal, a 2-ton gun, or even one weighing forty-eight tons, being pointed als readily by turning the turret as the lightest field-piece. Accordingly, the monitor which our illustration represents is mounter with four 24-ton guns.

Making proper allowance for the greater area of side. armor and battery-plating of the Moyini Znffer, it will be found that our double-turreted monitor will, on the same draught of water, support 10-inch thick side-armor, 15-inch thick turret-plating, and carry four 24-ton guns. 'The greater security-we might say the impreguability-thus attained by the monitor form is, however, only a part of the advantage of this system orer that which is represented by the Turkish iron-clad-the latest endearor of some naral constructor's to demonstrate that the conflict at Hampton Roads was not, after all, so decisive as supposed.

Impregnability and calibre, although very important, by no means decide the superiority of armored rasels; horizontal range is in many cases of equal importance. A monitor hull provided with a fixed battery may be made as impreg- 
nable as a complete monitor, but at least two-thirds of the guns of such a ressel will be ineffective in battle. Samuda, evidently, was fully aware of the impotency of his artillery, owing to limited lorizontal range, when he adopted the complicated form of the battery of the Moyini Zaffer.

Let us now consider in detail this question of horizontal range, and inspect closely the extent of ranges marked on our illustration for each gum separately. The ranges obtainer by the fixed battery of Samuda's construction first claim our attention. To aroid confusion, the ports have been let. teres $a, b, c$, and $d$, the first letter denoting the forward port of the battery, and also the muzzle of the piece belonging thereto. Beginning with the first-mentioned port, it will be seen that each gun respectively ranges over a field of 96,98 , 98 , and 92 deg. Referring to the monitor, it will be seen that ench of the four guns sweeps a field of 170 deg. It should be observed that the ranges marked on the ilhustration have reference only to the starboard side of the line of keel.

It will be proper, before assigning a numerical value to the efficiency of each of the systems under consideration, to remember that the real porrer of naval artillery is determined by multiplying the weight of shot by the horizontal range, the position of the ressel remaining constant. Modern target practice having demonstrated that a 2t-ton gun is capable of throwing a projectile of 600 pounds with adequate force, and that a 12-ton gun is about the proper size for 300-pound projectiles, we are enabled, by applying the rule before men- 
tioned, to determine with exactness the relative efficiency of the monitor turret and the fixed battery or casemate. The power of the forward gum a of the casemate will accordingly be represented by $300 \times 96=28,800$. In like mamer, by multiplying the weight of the projectiles of the remaining three guns by their respective ranges in legrees, we obtain at sum total of 115,200 . Applying the same mode of com. putation to the monitor-riz., multiplying $600 \times 170 \times 4$ we establish the important fact that the actual efliciency of the monitor is to that of the casemate vessel as tos to 115. Apart from this superionity as regards the artillery of the monitor over that of the 'Turkish iron-chat, the arnor of both battery and hull of the latter is wholly insufficient to compete with the former. The interence, therefore, is obvious and irresistible that the monitor represented by our illus. tration could reallily destroy Samuda's casemate ressel. But it is not my intention to prove the rorthlessness of the Moyini Zaffer as a war vessel, the object of discussing the subject being simply that of instituting a comparison between the two systems represented by the illustrations on Plate j6.

It merits special attention that, apart from the limited horizontal range of all the gums of the Moyini Zaffer, only one of the fon-riz, a-can be pointed forward parallel with the ship's course; and that $c$, the only other gun capalle of firing ahead, cannot point nearer than 11 deg. of the line of keel. At a distance of a mile ahearl, there is, consequently, a field of 1,20 feet which an asialant may occupy, exposed to only one 12-ton gun. Chased by an enemy, the Turkish 
CHAP. XXXV. THE HOATTOR TURRET AND THE CASEMATE. 003

war-ship, with the Samuda-Almstrong battery, will be equally impotent; the gom marked d being her only defensive weapon. It will be found, on inspection, that the piece marked $b$, like that mirked $c$, cannot be pointed nearer than 11 deg. of the line of keel.

Let us now turn to the monitor. It will be seen that four 2t-ton guns, two forward and two aft, fire in a direct line with the keel; there being no sife position, as in the carse of the fixed battery, for the enemy's vessel to occupy. The entire fiek, riewed from stem to stern, as the plan shors, is swept by all the guns of the monitur. Bearing in mind that these powerful guns are protected by 15 -inch thickness of iron, which, if applied in two thicknesses, is proof against any artillery yet produced, while the 12-ton gans of the Simular-Armstrong battery alle protected by armor which a 7-inch rifle will pierce through and through, the argunnent in favor of the monitor turet becomes overwhelning.

It will be asked, in view of these incontrovertible fauts, why do constructor's adrocate the fixed battery? I know of no other reason than the assumption that the joint between the rotating turret and the deck cannot be mide secure. English engineers, relying on the accounts of the performances of the monitors published by the enemies of the Union during the war, apparently do not take the trouble to investigate the matter'; while American experts who have written about turrets appear to be ignorant of the leading facts comnected with the turret system.

For instance, Mr. Eads, in a report to the Nary Depart- 
ment, informs the Secretary that "the band round the base of the turret on the Dictator weighs over 20,000 pounds," and points out how much better this great weight of iron might be applied for other purposes. Now, this turret has no band round its base, nor was it ever intended to have one. Mrr. E. also tells the Secretary that any downward swelling of the plating, produced by the impact of projec. tiles striking low, will stop the rotation of the turret by friction under its base. This assertion proves ignorance of the fact that the Dictutor turret rests wholly on the four inner cour'ses of plating (which cannot be swelled), and that the intermediate wrought slabs and outer plating (together 11 inches in thickness) do not reach the deck, and therefore can, by no possibility, cause the predicted stoppage. Again, the apprehensions expressed in several reports, with reference to the base of the pilot-house in comnection with the rotation of the turret, prove that another very important circumstance has been overlooked-viz., that the turret projects consider. ably above said base, thereby effectually protecting it. 


\title{
CHAPTER XXXVII.
}

\author{
CARRIAGES FOR HEAVY ORDNANCE.
}

(SEE PLA'TE 57.)

The Engineer, in discussing the subject of gun-carriages (in 1868), salys: "Americans mount their big guns in turets, and liance has no peculiarly big guns to mount. In the matter of carriages, as in almost everything else connected with recent improvements in ordnance, England must be content to act as schoolmistress to the rest of the world." This assertion is preposterous, in view of the fact that Eng. land had not mounted a single heavy gun on shipboard at the time when we had a large fleet of iron-clads armed with 11 and 15 inch guns. Not only that: we had effectually used those gums in numerous engigements, and fully estab. lished the reliable character of our system of mounting the same, before English artillerists believed it possible to dispense with bxeeching. But our contest was watched by attentive eyes, and hence our success did not long remalin 
a secret. An enterprising English captain speedily pro. cured drawings of the Monitor gun-carriages and their fric. tion-gear. How filithfully he copied our systen the reater will see by comparing the sereral devices for producing friction represented on Plate 57. Sil William Armstrong, too, becoming convinced that the Moniton friction-gear was the best for checking the recoil of naral ordnance of heary calibre, also followed our lead. An amusing contest anrose between Sir William and the enterprising naval oflicer al. luderl to, whose indignation knew no bounds on finding that the great gunmaker had adopted the same plan as him. self for checking the recoil. But Mr. Soott Russell having in the meantime published accurate drawings of the Mromitm gon-carriages and friction-grear; Sir Willian was in a position to silence the complaints of his rival by sinply point. ing to Plate No. 139 of Scott Russell's great work on naral architecture.

By referring to the illustration mentioned, the reader will see at a glance that Captain Scott's friction-grear is iden. tical with that applied to the gun-carriages of the American iron-elad fleet. The principle is very peculiar, and inrolves the apparent pararlox of obtaining increased friction to any desirable extent withont adding to the force amployer. A lnief explanation will show how this singular lesult is effected. A series of rertical plates are secured to the lower part of the gun-carriage in such a manner as to admit of a slight transverse movement. These plates slide freely between longitudinal friction-timbers, or planks composen of 
hard wood, which in broadside vessels are attached to the "slides," and in the monitor's secured to the base of the turrets. It will be readily understood that, by applying lateril force to the two ontsicle vertical plates from with. out, friction will be established between all the plates and the intervening planks; and it will be evident that the amount of friction between the surfaces in contact will depend on the force thus applied, wholly independent of their number. Thus, by merely doubling the number of plates and planks, the friction will be doubled without calling for the application of any additional force. It rarely happens in mechanical contrivances that the effect to be produced is so completely independent of the force applied as in this instance. The practical advantage of obtaining requisite friction without employing great manual power is obvious; and that it is fully appreciated may be inferred from the alacrity with which the system has been copied in Europe.

The difficulty of hantling the modern monster guns on board ship in bad weather, which at one time was deemed impracticable by experiencerl sailors, ramished with the introduction of my multiplex friction apparatus thus briefly described. The reader will observe how closely even the detail of the original has been followed by the plagianists; the mode of producing the lateral pressure, for instance, has been carefully copied by Captain Scott. He employs the transverse screw and reptical levers by which the outside friction-plates are forced inwards, precisely as in the Monitor carriages. Sir William Arnstrong also employs the trans. 
verse screw and rertical levers, but he divides the screw in the middle-an ill-comsidered modification, as it calls for the application of foree on both sides of the carriage, increases the friction, and tends to pull the sides together. Sir Wil. liam Armstrong also introduces the modification of employing iron bans in place of the wooden friction-planks-a most objectionable expedient, as the needed friction is greatly diminished by presenting metal agalinst metal. Moreorer, the friction becomes so irregular as to baftle any attempt at systematic tightening with reference to the chimge of powder employed, rendering accillents inevitahle. It is evilent that if the metallic plates are kept dry, abrasion follows, and that their surfaces are liahle to cut and stick. If oiled, the least excess of Inbrication will resluce the friction to such an extent as to permit the gun to recoil withont check, as experience Anring experimental practice has shown. Apart from these objections, the want of that indispensable elas. ticity which the wooden friction-plank affords is fatul to Sir William Armstrong's substitution of metal for wook.

With such facts before it, the Engineer tells its readers that, in the matter of curriages and other improvenuents commected with naval ordnance, England must be content to act as "schoolmistress" to the rest of the workl.

Alas for the schoolunistress! She has heen endearoling to teach the world for a long time that our system of naral defence was all wrong, mutil at last she has discosered that her hoasted broadside iron-clads, on which millions have been spent, are hopelessly vulnerable. 
The leading jomrnal of England, February 12, 1868, trankly admits that "the final blow" has been given to the "already tottering theory of broadside iron-clads," and artds: "Why do we obstinately refuse to build small iron-clad, singleturret ressels, with low freeboard, and one or two guns of the heariest calibre? The American and Russian officers who have actually tried them report with enthusiasm of their sea-going properties." It wonld have been well for the "schoolnistress" if she harl not listened to the advice which prejudiced naval constructors have persistently tendered; it might have spared the naval administration of England the severe censure called forth at the time for haring neglected to adopt the monitor system. "It seems to us," says the Times of the date before mentioned, "that the Admiralty have in nothing so neglected their duty as in failing to provide us with a large supply of these formidable little ressels."

Cin the Engineer, moreover, point to a single invention connected with our turret iron-clads, naval ordnance, or guncarriages which has originated in England? Those best acquanted with the matter know that every mechanical device relating to the system which so successfully vindicated itself during the late war was contrived on this side of the Atlantic-a success the more renarkable since the exigency of the time did not atmit of previons experiments, everything heing despatcher directly from the foundry and work. shop to the scene of conflict. 


\section{CHAPTER XXXVIII.}

PIVOT-CARRIAGES OE' IHE 'IHIR'YY SPANISH GUNBOATS.

(SEL PIATE 58.)

THe gum-carriages and slides constructed for the Spanish gunboats present two inportant features which distinguish the same from other pirot systems-riz, the slide is made to rotate round a permanent central fighting-bolt secured in the middle of the deck near the bow; consequently, as the bulwarks of the Spanish gumboats are low enough to admit of firing en barbette, a horizontal range of $240 \mathrm{leg}$. is ob. tained.

The other important feature of the new system is that of enabling the gunner to apply and relieve the compressor instantaneously.

Naval artillerists are well aware of the advantage of rotating slides, but, owing to the circumstance that such an arrangement unaroidably carries the fighting bolt in the rear of the trumion when the gun is run out, such slides have been deemed impracticable. Evidently, if the fighting-loolt 
be placed far in the rear of the trumion, the slide will be lifted upwards with great violence at the instant of discharge. This apparently insuperable difficulty is completely overcome in the arrangement now under consideration, by the expedient of rasing the circular ring on which the slide turns about one inch above the deck. By this expedient an efficient abutment will be obtained for restraining the longitudinal movement of the slicle in all positions. A plate at. tached to the front transom of the slide, as represented by the illustration on Plate 58, extending down as far as the bottom of the ring, thus takes the place of the ordinary fighting-bolt. The central pirot, round which the slide rerolves, fits so loosely in the socket of the cross-plate that the whole force of the recoil is received by the descending transom-plate and the edge of the deck-ring. The latter is sustained by a circular platform of boards 1 in. thick, secured to the leck, and flush with the top of the ring. 'The front transom and outside circumference of the deck-ring being in adrance of the centre of the trumnion of the gun when run out, the force of the recoil, in place of lifting, will evidently tend to depress, the slide. Ample experience in working the slides of the Spanish gumboats has fully demonstrated this fact, and established the superiority of the rotating slide in point of easy handling as well as extensive lateral range.

It will be evident on reflection that a very slight modification will adapt the rotating slide thus described to broalside firing. Such a modification was made in Decenber, 1869, 
and the slide thus moritied, together with its carriage, was 1)esented to the Ordnance Burean for trial. A 100-pounder Parrott rifle-gun having been mounted on the carriage, Conmander E. Simpsom was ordered by the Chief of the Bureau to conduct the trial on board the U. S. steaner Tallapoosen, during a run from New Tork to Washington. Commander simpson's repent of this trial and his description of the new arangement are so lucid that I adopt the same in preference to any description I conld pen:

"The carriage consists of a slide and top-carriage, constructed of wrought irom. The slide is composed of two rails, with four bolts comnecting them at intervals of two feet. The hemrters consist each of two plates of half-inch iron, between which are placed the rollers for lateral train. They are each strengthened by two castings placed between the plates near the rails, those at the rear end being continued up nine inches above the rails, to which are secured the buffers of india-1ubber, designed to receive the recoil when the carriage is permitted to recoil the whole length of the slide.

"The middle of the slicle rests on a rail on the deck - Alesigned to support it at that point, and on which it slides when training.

"The slicle has one transom half way of its length riveted to the inner sides of the rails, and on a plane six inches below their upper surface.

"To an angle-iron turned up from the rear of the transon, and rising to the level of the rails, is bolted the rear 
end of the friction-bur, six inches wide and one and a quarter inches thick, which is continned horizontally to the formin! heurter, where it is bolted to a casting, after passing which it inclines downwards gradually to the pivot, where it is secured to the pivot-bolt through a hole in its end.

"A composition rack is bolted on the inside of the right rail, the teeth extending above the level of the rails.

"The carriage rests on four roller's front and rear, the former of 18 inches dianeter; the latter of 7 inches. 'To the inner face of the right forward roller is bolted a working-wheel of composition, with its cogs gearing below into the rack on the slide, while above it gears into a pinion on a shaft which has its bearings in the brackets of the carriage. A crank is attached to the end of this shaft on the right side of the carriage, and by it the carriage is run in and out on the slide. This shaft has a longitudinal motion, which allows the pinion to be geared or ungeared at pleasure. It is always desirable to ungear before firing, in order to prevent motion of the crank, which might prove dangerous to the gun's crew.

"A conveniently-arranged clutch holds the shaft in either position.

"The carriage has one transom, from the forward part of which project two arms, one-third the width of the transom apart, extending to a length of 20 inches, and terminating in eyes, through which the compression-shaft passes, which has bearings in the lower part of the brackets and well forward of the forward axle of the carriage. 
"Under the friction-bar is a clannp 1 t inches long and 6 and 10 inches wide, which himbs against the muler face of the bar: The compression is protuced through the ec. centric motion of a third piece resting on the uper clamp, a side-elevation of which represents a half-cirche, and which is fitted orer the compression-shatt. This eceentric piece is connected with the friction-clanps by two iron strips, with muts screwed on the fower ends of them. It will be pere ceived that the friction-clamps occups a position in the centre line of the carriage and between the enrls of the two arms projecting from the trinsom. The friction-chanps are lined with hand wood, which forms the sulfinces lind. ing on the friction-bar. The complession-shaft las its beald. ings on the brackets of the carriage, and projects fin enongh ontsille the left bracket to receive a long lever which is shipped on its end, and which has a rertical motion, linited by the adjustment of the screw-nuts on the ends of the iron straps which connect the friction-clamps. This lever is held in position hy a rack on the outside of the left bracket when the required compression is attained. A steel spring at the lower end of the lever binds it against the bracket, and a very convenient eccentric andangement at the handle of the lever enables this pressure to be overcome when desiring to move the lever:"

Having prefixed this very clear and precise description to his report, Commander Simpson proceeds: "During the firing thus tabulated, the rumning-ont geal was but seldom userl, the carriage being allowed to move obedient to the 
roll of the ressel, and its motion was found to be perfectly under the control of one man at the compression-lever, who could check it at any point. 'The compression being found to work well in deliberate fire, thirty rounds were fired to test the point whether rapid fire would callse the heating of the friction-har: The thirty rounds consumed nearly thirty minutes in firing, at the end of which time the temperature of the hal was shightly raised, but in no way interfered with a continunes of firing. Very rapid firing may be slone with this carriage; the time consumed in firing the thirty romils above mentioned was in consequence of the crew not being accustomed to gun-exercise.

"The most pominent adrantage-in fact, the essential characteristic of this carriage is its system of compression, which is complete and instantaneous.

"The compression in use with our pivot-guns and with our turretguns involves the use of a serew, which requires time to work; the suhstitute provided in this carriage is a simple motion in a rertical plane of a lever, which is instantaneous in action, and quite as effective in its result.

"The tardiness of action in the compression of our turretguns may often cause lesitancy in casting them loose in a seaway, when, with a more speedy means of compression, they might be made of service. The show and imperfect action of the compressor's fitted to our pirotguns renders necessary eccentric rollers to the axles, so that the carriage may be let down on the slide, to increase, by the increased surfice in contact, the friction that the compressors do not supply. 
"The system of compression now under consideration arl. mits of keeping the carriage always on its rollers, thus simplifying the mechanism of the carriage, and dispensing with the lever's which are now necessiry to bring the rollers in and out of action. The four men now deroted to this duty could be dispensed with.

"During the experiments here recorded the carriage has fulfilled the advantages claimed for it by its inventor, and, unless subsequent experiments or the experience of actual service should develop defects not now apparent, its claim for preference over any carriages now in use in the mavy must be allowed.

"During the firing, the shortest distance at which the

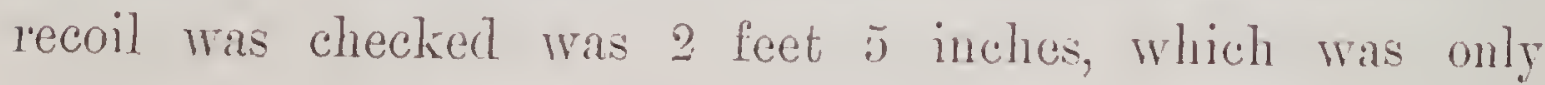
half the recoil that would be required in service so as to have the gun in position for loading. If less recoil were required at any time, it can be obtained by a change in the adjustment of the screw-nuts on the strap binding the friction-clamp." *

* It will be proper to notice that the new system has proved so suecessful in practice that the Spanish Government, in addition to the thirty carringes and slides mounted on board of the new gunboats, have recently ordered several sets of similur carriages and slides for other ressels. 


\title{
CHAPTER XXXIX.
}

\author{
RO'IART GUN-CARRIAGE AND 'TRANSIT PJA'TFORM. \\ APPILED TO THE SPANTSH GUNBOAT TORNADO.*
}

(SEE PLATE 59.)

TH: illustration on the plate referred to represents a new system of transferring the battery from side to side, without resorting to the complicated method of pivoting practised in our vessels of war. In addition to the advantage of rapidly transferring the guns from side to side, an all-round fire is also secured by this system, as will be seen by the following description :

The leading feature of the device is that of placing the gun-carriage and its rotary slide on a circular platform, supported on four cylindrical rollers (partially shown at $f f$ ) provided with flanges like those of the wheels of railway

* It will be remembered that in $18 \%$ i this gunboat, after a spirited chase, captured the American steaner Virginu, having on board a company of "Cuban patriots" and war material intended for the Cuban insurgents. The capture of this ressel, it will also be remembered, very nearly led to a war between the United States atnd Spain. 
carriages. These rollers, the axles of whing turn in appropriate bearings moler the platform, move on two flat parallel bronze rails, $l$ and $m$, secured to the deck at right angles to the line of keel. One of these rails, $m$, is provinted with cogs on the ontside, thus forming a tootherl ritck. I small horizontal cog-whed under the plitform is geared into the said rack, and actuated by a set of corg-whecls arranged as in ordinary lifting-jacks. The gean is put in motion by a rertical spindle haring a hams-wheel attacherl to its upper end, the lower ent being made to fit a sumare sockert, ", formed in the axle of the actuating pinion of the gatal. It is harlly necessiry to observe that after haring transfered the platform to the desired position, the vortical spindle should be lifted out of its socket and remover, in meler mot to interfere with the free rotation of the stide. It maty be mentioned that in ardition to the gen referrer to, suitahle ryeholts are applied to almit of employing nolinary tackle in transerring the platform from sicle to side. Maving been rolled into position on the fighting side of the vessel-say starboard-the platform must, of course, be secured by fwo fighting-bolts. One of these is seen at h, the second of the pair heing concealed by the slide. On rolling the platform to port, after having remover the fighting-holts, the latter will be inserted throngh the lonttholes of the lugs g on the opposite site of the platform. It slomkl be olsorved that in housing the gun the fighting-holts will occuly diagonal meitions-1)lates, as shown at $k$, being inserted in the deck accordingly. 
It was pointed out in the previons chinpter that if the force of the recoil were bromglit to bear on the central pirnt round which the shide revolves, the latter wonld be lifted up violently; or seriously jurred at the instant of discharging the gun, sinee the rertical line, passing through the centre of the trunnion, is far in atrance of the central pirot when the gun is rolled ont. To prevent such lifting or jarring, a rely effective expedient has been resorted to-riz, that of attaching a hracket $d$ at the forward end of the slide, extending about two inches below its base, and beanling firmly against the circumference $p$ of the platform. It will be readily seen that if the bracket referred to, which acts as a hook, be placel at a proper distance, while the pirot round which the slite turns fits loosely in its socket, the force of the recoil will be received wholly by the edge ${ }^{\prime}$ of the platform, at the point where the bracket d bears. 'The professional reader cannot fail to perceive the advalntage of transferring the strain from the central pirot in rear of the trumnion to a point in advance of the same. Obriously, the practieal result will be that of causing the carriage and slide to bear down against the platform, insteal of being violently jarred or lifted up, as it would be if the force of the recoil were brought to bear on the central pirot. Regarting the proper position of the fighting-holts for securing the platform during firing, it will be evident that if inserted at $h$, as shown (for the sake of rearly explanation) in the illustration, the platform woukl be lifted or jarred at the moment of discharging the gun; while by inserting the fight- 
ing-bolt at g the tendency will be to depress the platform, thereby securing perfect repose throughout the entire struc. ture.

The gun-carliage itself having been minutely described in Chap. XXXVIII, it will only be necessary to observe that the friction-bar c, which in the carriage referred to was made of iron, has been made of bronze in all the recent carriages constructed under my patents. It was found in practice that the application of oil or grease to this bar, indispensable to prevent its corrosion, considerably diminished the friction-a circumstance of no importance if the dimi. nution had been constant in annount; but the lubricating medium, rarying in quantity, obviously causes irregularity in the intensity of the required friction. Bronze being now substituted for iron, renders the application of grease unnecessary; hence the friction between the wooken lining of the clamp $b$ and the bar c becomes uniform. Accordingly, by pushing the hand-lerer a to a given notch of the circular tooth-rack s, it has been found that the length of the recoil may be regulated with remarkable accuracy. 


\section{CHAPTER XL.}

GUN-CARRIAGE FOR COAST DEFENCE.

(SEE PLATE 60.)

Engineering of March 20, 1872, published the following article, headed "Coast Defence":

"The problem of how best to defend our coasts has of late attracted so much attention that the illustration which we publish, representing a gun-carriage forming part of a new system of coast defence planned by Captain Ericsson, will possess special interest. The gun is mounted behind an inclined movable shield of solid plate iron, $4 \mathrm{ft}$. high above the parapet, so arranged that the muzile is unmasked at the moment of firing, the shield aftording protection against projectiles striking above the parapet. It is asserted that this plan is more efficient than that of Moncrieff; but, as it is not our intention at present to institute a comparison between the rival systems, we proceed at once to describe the illustrated carriage (see Plate 60). The recoil is checked by 
friction produced by clamping two longitudinal bars secured in the middle of the slide, the compression being effucted by a transverse axle, on the principle adopted in the Princeton carriage. The longitudinal bars, however, are composed of bronze in place of wood. 'The friction-clamp (a longitudinal section of which, through the rertical plane, will be found represented in the accompanying delincation is firmly attached to the front of the carriage. The faces of the friction-bars

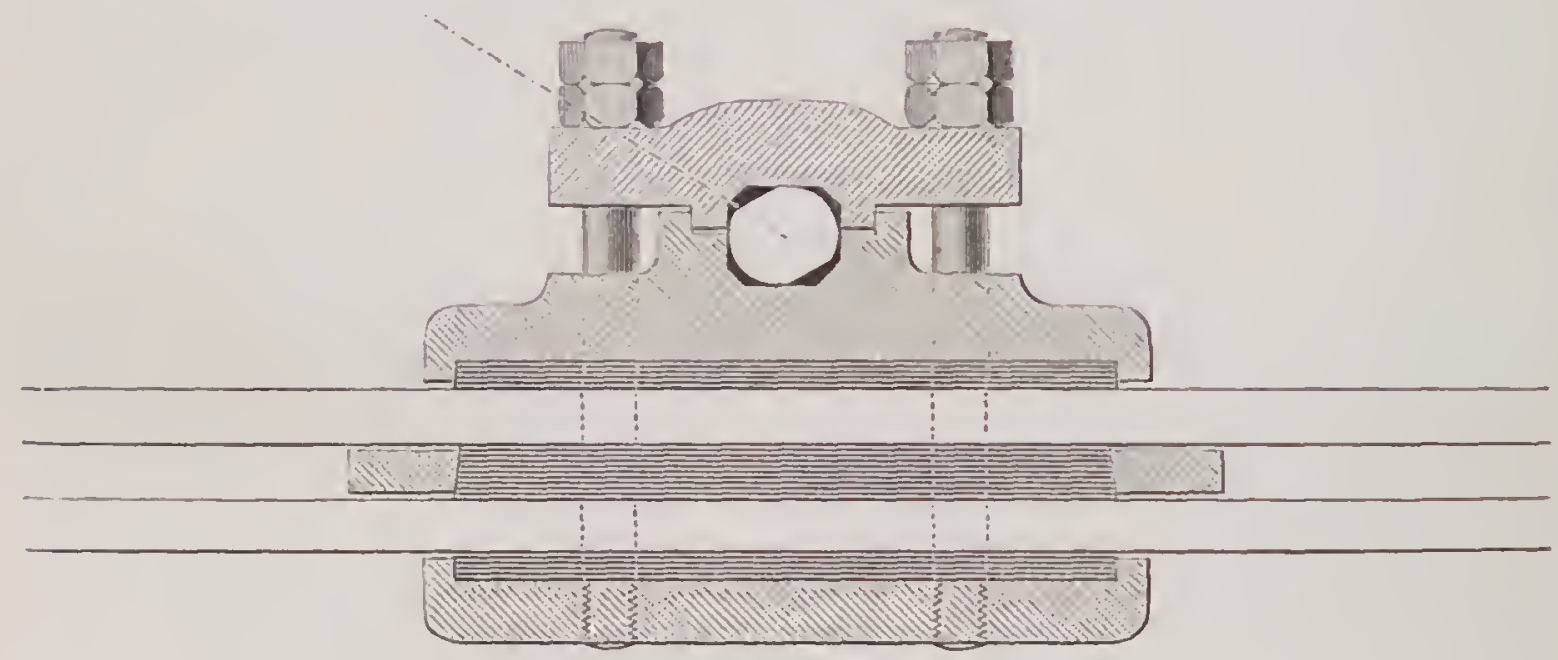

being smooth and true, and the wooden linings of the clamp accurately fitted, it will be perceived that a very slight movement of the upper and lower parts towards each other, after contact with the bars, will at once cause friction, provided that the set-nuts of the clamp-cap have been properly tight. ened. In order to comprehend correctly this peculiar system of compression, let us suppose that the clamp, as well as the bolts which hold the same together, are perfectly rigid, and that the transverse axle is flattened so as to make it but slightly oval. 'Tuming the latter through an arce of 90 deg. 
will, under these conditions, obviously produce an enormons pressure. It has been objected that, if the axle is but slightly oval, the wear of the wooden linings and the faces of the friction-bars will soon destroy the efficacy of the compression. To meet this objection the constructor has placed the clamp conveniently in front of the carriage, in order that the set-nuts may readily be screwed down whenever required. Practice, it appears, has shown that the wear is insignificant with friction-bar's composed of bronze. Iron bar's, on the other hand, owing to corrosion and consequent abrasion, tend to cut the wooden lining nuless grease be applied-an expedient inadmissible, as it greatly diminishes the desired adhesion, besides rendering the same very irregular. It will be seen in the illustration on Plate 60 that the hand-lerer by means of which the compression is applied or relieved is held in position by a segment (provided with notches) attached to the side of the carriage; while a spring secured to the end of the transverse axle presses against the outside of the lever, thereby preventing the same from leaving the notches during the recoil of the gim.

"Captain Ericsson's plan of employing a series of frictionbar's one above the otler, or placed side by side, as in the monitors, appropriately termed the 'multiplex system,' copied by Captain Scott, Sir Willian Armstrong, and other's, involves a paradox which merits special notice-viz, that without employing additional force, any amount of friction may be produced. It will be evident on reflection that whatever number of bars be employed, the friction between the firce 
of each and the face of the clamp will depend solely on the pressure applied. Hence, if four bars, presenting eight surfaces, be employed, the retarding force opposing the recoil of the gun will be quadruple that of one bar presenting two surfaces. With reference to rmning out the gun, the following explanation will suffice: 'The forward trucks, situ. ated somewhat in adrance of the trumion, are keyed to an axle supported by bearings in the side frames of the carriage. A cog-wheel is attached to the said axle, into which a small pinion, operated by an ordinary crank-handle, is geared.

"Before adverting to the mechanism of the slide, it will be well to observe that light gear of small multiplying porer will answer for training, since the movement is always in the horizontal plane. It will be noticed that the exterior segment is provided with a projecting rack in the middle -an expedient which overcomes the difficulty so frequent? experienced on the old plan of employing separate racks, that settlement of the segment on which the rollers run occasions binding between the cogs of the driving pinion and those of the rack. It is scarcely necessury to remark that the rollers applied on the opposite sides of the toothed projection of the exterior segrment tum freely on the axle to which the drivingrinion and the vertical conical wheel are attached. The action of the small conical pinion geared into the wheel mentioned, operater by means of the hori. zontal hand-wheel, requires no explanation." 


\section{CHAPTER XLI.}

'THE 'IHIR'TY SPANISH GUNBOATS AND THEIR ENGINES.

(SEF PLATE 61.)

Tre material aid which the Cuban insurrection derived from outside sources compelled the Spanish Government in 1869 to build a fleet of swift gumboats to form a cordon round the island as the only means of preventing blockaderumners from conveying men and warlike stores to the insurgents. Admiral Malcampo, naval commander in Cuba, was accordingly instructed by his Government to procure the needed vessels in the United States. The Admiral succeeded in carrying out his instructions with extraordinary promptness, as will be seen from the following concise statement, copied from the Army and Navy Joumal of November 20, 1869 :

"The annals of naval construction probably furnish no instance of greater diligence than that displayed in the production of the thirty Spanish gunboats now floating on the 
Hudson. The planning laving been entrusted to Captain Ericsson, the contract for building the fleet was entered into with the Delamater Iron- Works, in this city, on the $3 \mathrm{~d}$ of May, 1869. On the 19th of May the first keel was laid, and on the $23 d$ of Tune the first vessel was lannched from Pouillon's ship-yard-thirty-four working days after laying the keel. September 3-just four months from the signing of the contract, and three months and sixteen days alfter lay. ing the first keel-the last vessel of this fleet was lannched, at which time fifteen of the vessels previously launched had engines and boilers on board!

"The Spanish gumboats are sea-going twin-screw vessels, 10 - fect long on the water-line, 22 feet (i inches extreme beam, 8 feet depth of hold, and draw 4 feet 11 inches when fully equipped for service, with coal, ston's, and anmmunition for 100 rounds on board. The lines at the bow are somewhat full, in order to sustain a heary bow gun, the breadth of the deck being carried well forward for the purpose of facilitating the manipulation of this gun, of which we will speak presently. The run is rery clean, the lines being deemed faultless for a twin-screw vessel. The construction of the hull presents two novelties worthy of special mention. The apparently insoluble character of the problem-a grmhoat of this class drawing only 59 inches of water when fully equipped for service-compelled the designer to dispense with the keel. Shiphuilder's, it appears, at first objected to this innovation, but now admit that these gunboats may take ground with far less risk of straining and leaking than 
ordinary light-draught ressels with their weak keels. The other novelty alluded to is the cutting down the rail and substituting a low, heary timber bulwark at the bow, provided with substantial water-ways and lined with sheet-iron to admit of firing the gum en barbette.

"In addition to their ample steam-power, the Spanish gunboats carry full anount of canvas, being schooner-rigged, with yard and square-sail on the foremast. Wire-rigging having been adopted, and the masts and smoke-pipe raked more than usual, the appearance of these twin-screw ressels is peculiarly light and sancy. Considering their great number, swiftness, light dranght, and the lung lange of their gums, it is wident that the Spaniards will be enabled for the future to prevent effectually incursions on the Cuban coast.

"As might be expected, the steam mactinemy of these novel war-ressels presunts features of special interest (see illustration on Plate 61). It has frequently been urged as an objection against the twin-screw system that the double set of engines, four steam-cylinder's, with duplicates of all their working parts, called for in this system, render the whole too complicated and heary for small ressels; preventing at the sane time the application of surfuce-condensation. The designer has overcome these objections by introducing a surface-condenser which, while it performs the function of condensing the steam to be returned to the boiler in the form of fresh water, serves as the principal support of the engines, disponsing entirely with the usual frame-work. Be- 
sides this expedient, each pair of cylinders have their slide frames for guiding the movenent of the piston-rods cast in one piece. Altogether, the combination is such that the total weight and the space occupied by these novel twin-screw engines do not exceed the ordinary single-screw engines of equal power: Several improvements connected with the working-gear have also been introduced. 'The outer bearings of the propeller-shafts, always difficult to regulate and keep in arder on the trin-screw system, are self-adjusting, and accommolate themselves to every change of the direction of the shafts. This is effected by their being spherical externally, and resting in corresponding cavities in the stern braces or hangers. 'The 'spring-bearings,' for supporting the middle of the shafts, are also arranged on a similar selfadjusting principle. The thrust-bearing, which receives the pressure of the propeller, is a peculiar construction, the arrangement being such that the bearing surfaces remain in perfect contact, however much the shaft may be out of line. The reversing-genr, likewise, is quite peculiar, insuring conplete control orer the novement of the two propellers under all circumstances. It is claimed that these engines are the lightest and most eompact yet constructed tor twin-screw vessels.

"The internal arrangements and fittings show thorough knowledge and experience on the part of the superintending officer. Our friends on the Baltic, who pride themselves on knowing more about gunboats than other nations, will be astonished when they learn how the Spaniards fit out such 
CHAP. XILI.

vessels. Indeed, the equipment more resembles that of a yacht than that needed for a plain gumboat. We camnot aftord space for a specification, and therefore proceed to notice only that which is essential. The coal-bunkers are placed on each side of the boiler, extending equally forward and aft of the centre of displacenent of the vessel, in order to preserve perfect trim, whether the bunkers are full or empty. The magazine, located in the centre of the ressel between the engine-room and the officer's' quarters aft, is lined with lead on the inside, with the unusual precaution of having the outside protected by sheet-iron. There are three distinct modes of flooding this magazine-viz., from the sea, by a powerful hand-pump, and by the donkey-engine pump. In addition to the ordinary water-tanks, a 'freshwater maker' of ample capacity is provided, in which the condensation of the steam is effected by the current of searwater which passes through the surface-condenser; the fresh water being drawn off through a bent pipe on deck. A combined capstan and windlass of novel construction, suffciently low to fire over, is bolted to the deck over the chain-locker at the bow, the combination being such that the capstan may be used alone, or one or both anchors raised at the same time.

"Respecting the armament, the following brief notice must suffice for the present: It consists of a 100-pound riflegum placed at the bow-a Parrott rifle-but a very different weapon from that represented by the photographed fragments which embellish so many pages of General Gillmore's 
famous book. Briefly, it is an improved Parrott 100-pound rifle, with wrought-iron hoops round the chimber, carried to within thee inches of the trumnion, the chase being increased to correspond with the increased strength attained ly the extension of the re-enforce. The severe ordeal through which the improved gun has passed during recent trials at Cold Spring, conducted by the Spanish officer's, promises so well that no doubt this improved Parrott gun has a future.

"Of Captain Ericssun's new gun-carriage-on which the improved gun is mounted-one of the leading features of the Spanish gumboats, we have space for only a cursoly no. tice. It will be inferred from what has already been stated that the intention is to fire over the bow and in line with the keel. For this purpose, and in order to command a wide horizontal range, a circular platfor'm of rood, surrounded by a brass ring of 12 feet 6 inches diameter, is bolted to the deck at the bow. The gun-slide, composed of wrought iron, provided with friction-rollers at both ends, rotates round is pivot secured to the deck, in the centre of the said brass ring. The carriage is made of light wrought-iron plates and angle-iron, riveted together in such a manner as to ensure great strength longitudinally as well as transversely." (See illustration of gun-carriage on Plate 59.)

Having described the internal arrangements of the Spanish gumboats somewhat minutely, the Army and Navy Joumal concludes its notice of these ressels by saying:

"A fleet of thirty war-vessels precisely alike being by no means an ordinary sight, a visit to Delamater's works on 
the Hudson where the saucy-looking craft are now stationed, ten abreast, cannot fail to be very interesting to naval men. It is a significant fact that this great display of offensive and defensive force is the result of the efforts of a single estab. lishment, directed by individual skill. Evidence more conclusive could not be furnished that the progress of the country and its resources are equal to any future emergency." 


\section{CHAPTER XLII.}

\section{A NEW SYSTEM OF NAVAL ATIACK.}

(SEE PIATTI; 62.)

A meavy body of regular form, whose density is greater than that of atmospheric air, moving laterally through the atmosphere, is inexorably under the influence of the earth's attraction, and therefore describes a foreshortened parabolic curve during its flight; while a submerged body, the weight of which is equal to the weight of the water it displaces, is not affected by the earth's attraction; and that consequently, if put in motion under the surface of a quiescent fluid of unli. mited extent, such a borly will continue to more in a straight line until the motive energy which propels it becomes less than the resisting force of the surrounding medium.

In virtue of the first part of this general proposition, a heary body may be projected in such a manner that the termination of its trajectory shall make any desirable angle, less than to deg., with the horizontal line, independently of the length of the chord of the trajectory. In other words, 
the body may be projected at variable distances over water, and yet strike its surface at any desirable angle. 'This important result is effected simply by varying the relative proportion between elevation and strength of charge. The second part of the stated general proposition is of equal importance. It points to the fact that the trajectory may be extended in a straight line under water, to any desirable distance, irrespective of the speed of the submerged projectile. Accordingly, a shot may be projected from one vessel towards another within moderate ranges in such a manner that it shall dip into the water at a considerable distance from, or close to, the vessel assailed, independently of the distance between the two vessels. Also, that the shot may be projected at such an angle that the prolongation of its trajectory in a straight line, after contact with the water, shall strike the hull of the vessel assailed at any desirable depth below the surface.

That a certain relation between charge and elevation enables us to project a spherical shot in such a manner as to strike the water at any desirable distance from an oppo. nent's vessel, at angles within 45 deg., needs no further' demonstration. Hence, if the trajectory be such that its extension in a straight line from the point of contact with the water leads to the hull of the ressel assailed, the latter will be hit-on condition, however, that the shot is not di. verted from its course on entering the water, and provided its vis viva be sufticient to overcome the resistance encomtered during its passage through the water. These indis- 
pensable conditions, especially the first-namer, which apluarently cannot be complied with, show the rifticulty of hitting a ressel below the water.line. Ant if we suppose that the projectile is not spherical, another serious difficulty presents itself: An elongated body will not bend to the curvature of the trajectory during the flight through the air, but retain during its course the same inclination as the gun from which it has been projecterl hence it will fall nearly flat on the surface of the water when striking.

Agreeably to our general proposition, a regular body, weighing as much as the water it displaces, is independent of the earth's attraction; but there is another force which, notwithstanding the absence of any gravitating tendency, will canse a hody of regular form moving under water to deviate from a straight line and rise to the surface. A cone moving in the direction of its apex and in the line of its axis horizontally, or on an incline, will, owing to the inertia and the nearly incompressible nature of water, more readily displace the column which rests upon and depresses its upper half than the column from below with its lifting tendency. Consequently, the course of the conical body will be diverted from the straight line upwards, describing a curve nearly elliptical, and quite surden, if the speed he great. A cylinder with semi-spllerical ends will, from the same cause, ascend to the surface if moved in the line of its axis; while a cylinder with flat ends will take a downward course, gradnally increasing its inclination, until at last the axis assumes a vertical position. Obviously, the lower 
part of the forward flat end encounters a greater resistance than the upper part; lience the lower half of the transterse section of the cylinder suffers an excess of retardation, which occasions the downward course described.

The question whether the apparently insuperable difficulties thus pointed out can be overcome by mechanical expedients, has occupied my attention for a long time; and numerous experiments have been made to test the efficacy of certain forms suggested by theoretical considerations. These forms being correct, the direction of the projectile duning its flight through the air will be parallel with the trajectory, and on entering the water it will not be diverted, but continue to move under the surface with the same incli. nation it had on coming in contact with the dense medium.

The illustrations on Plate 62 present the main features of the system under consideration so distinctly that it will be superfluous to enter on a general explanation of the nature of the scheme. It should be stated, however, that the elongated projectile is charged with dynamite or gumcotton, and provided with a percussion-lock at the forward end, which explodes the charge by contact. It may be mentioned that numerous plans have been suggested during the last few years for projecting solid shot under water, for the purpose of sinking ships. In several instances these plans have been carried into practice, with the invariable result that the resistance of the water has been found so great, even at short distances, that an ordinary wooden hull has proved to be impenetrable. The plan now under conside. 
ration bear's no resemblance to these projects, since the force of the projectile on reaching its destination need only be sufficient to actuate the trigger which causes the ignition of the explosive charge.

Apart from the theoretical considerations relating to the course of elongated projectiles under water; the practical question of motive prower to propel the same claims our attention. It is hardly necessary to state that the force relied upon is the vis vive possessed by the projectile on coming in contact with the water. Before estimating this force, it will be proper to call attention to the fact that the new system, to be successful, does not call for attack at a great distance, provided the ressel from which the missile is projected has greater speed than the opponent, and at the same time adequate protection against his artillery. Hence the destruction of the vessel assailed would be as certain if the distance of $500 \mathrm{ft}$. were the limit as if a range of $5,000 \mathrm{ft}$. better suited the new system. It will be inforred from this explanation that, although there is no special limit within ordinary ranges, the plan is to attack at distances not much exceeding 500 feet, unless the sea be very smooth.

The vis viva of a projectile $15 \mathrm{in}$. in diameter, of such a length that it displaces 500 llus. of water, may be readily estimated if we suppose the charge of powder in the gun to be so regulated that the speed on entering the water will be $400 \mathrm{ft}$. per second, necessary to furnish sufficient motive power; thus $\frac{400^{2}}{64}=2500 \times 500=1,250,000 \mathrm{ft}$.lbs. A cylin- 
drical body, 15 in. in dianeter, with semi-spherical ends, moring at a rate of $100 \mathrm{ft}$. per second under water, requires a constant motive force of somewhat less than $1,500 \mathrm{lbs}$. Assuming, then, that the projectile passes through $150 \mathrm{ft}$. of water-the mean distance represented by the diagramwe have a lesistance of $150 \times 1500=225,000 \mathrm{ft} .-1 \mathrm{bs}$. to overcome. The motive force, it will thus be seen, is more than five times greater than the resistance; consequently, $n o$ doubt can be raised as to the adequacy of the motive power furmished by the vis viva of the projectile. It should be observed that the resistance is very great at first, and that the speed diminishes in a very rapid ratio; but it would be futile to present a formula expressing the ratio of speed and resistance, since the form of the bouly (withheld for obvious reasons) is the chief element in the calculation. Let us bear in mind that, while the resistance against a blunt body is exceedingly great, one provided with a sharp point readily enters the water; even at the rate of $400 \mathrm{ft}$. per second.

With reference to the gun, it should be mentioned that the very low speed of the projectile, and the consequent small charge of powder needed, render heavy metal unnecessary. Besides, slow-burning cake-powder, contanined in cellular cartridges, will be employed, in order to check rapid ignition, and in order to sustain a mitorm pressure during the discharge. By reference to our illustration, it will be seen that the guns are loated from below, and for that purpose so arlanged ats to admit of being depressed 60 deg. 
Gun-carriages are dispensed with, the trumions being sus. pended by adjustuble pentulum-links secured unter the turretroof. The recoil is checked by buffer's attached to the turet wall in rear of the breaclu.

It is proper to stute that the method of loarling gons from below deck, as shown in our illustration, was planuen by me, and drawings of the same exhilited in Xow York several years before it was claimed by certain American engineers as their invention.

Respecting the salcey of the charge in the shell from ignition during the dischlarge, it should be observerl that recent improvements in torpedo pratetice effectually prevent such accidents. With reference to the culibre, it is evident that this system of attack calls for dimensions that will armit a projectile of sufficient capacity to contain a charge which, by its explosion, will destroy a firstectass ship of wall built on the cellular plan. Nothing short of 15-in. callibre will answer for this purpose. Thle Anerican and Swedish 15-in. gums are admirably calculated for the purpose, although they are unnecessarily lieary.

European savants, especially certain Swedish naral artillerists, who have criticised my adroeacy of the 15-in. gums, will understand, on looking into hlis matter, why I lialve persisted in adrising the Scandinarians to carry this large calibre in their monitor turets as the most effective weapon against their powerful neighbors. Assuredly the Danes will have no cause to fear the Prussian Köning Wilhelm or Friedrich der Grosse, should their ports be defended ly 
vessels amed with guns, by means of which sereral hundred pounds of dynamite or gun-cotton conld be exploded under the hulls of the intruders.

The important question of hitting the intended object will be best answered by a careful examination of the illus. tration, which cimmot fail to convince experts that, in mode. late weather, the proposed projectile may be made to dip at the proper distance from the opponent's vessel. 'The different parabolic curves marked on the delineations on Plate 62 clearly show that no great accuracy is called for, and that the projectile may dip at various distances from the vessel ascailed, and yet strike the hull. It should be observed that the rertical scale is different from that of the horizontal, in order unt to place the ressels too firr apart for the limited size of the plate; consequently, the trajectory shown is considerably foreshortened.

The turret represented on the illustration, in which the light 15-in. shell-guns are momted, is composed of wrought. iron plates of great thickness, the size of the structure being sufficient to accommodate the two pieces, suspended, as alleady stated, by pendulum-links secured under the roof. A massive central shaft of wrought iron supports the turret, on the plan adopted in the monitors. The ressel designed to arry the battery is a mere inon lull, crammed with motive power, in order to ensure high speed. The midship section is triangular and the bow raking, as shown by the illustration. The overhanging sides and deck are heavily armored. 


\section{CHAPTER XLIII.}

SUBICARINE WAREARE-THE WOVABLE 'IORPEI)O.

(SEL: PIAATL 63.)

IT was stated as a general proposition, in the preceding chapter, that a heary body, of regular form, projected lite. raliy through the air, commences to fall from the instant of leaving the muzzle of the gun, describing during its pro. gress a parabolic curve considerably foreshortened owing to atmospheric resistance. But a borly of regular form, pro. jected under the surface of water or other fluid, in a horizontal or inclined direction, will move in a straight line, provided its specific gravity be equal to that of the fluit. In other words, a heary horly moving through the atmosplere is under the influence of the gravitating force of the earth; while a submerged borly, the weight of which is equal to its displacement, is not affected by gravitation. If put in motion under the surface of a quiescent fiud of unlimited extent, such a body will continue to move in a straight line 
until the motive energy which propels it hecomes lesis than the resisting force of the surrounding medium.

Starting with these cardinal propositions, I entered, some thinty years ago, on the task of solving the problem of submarine attack-viz, the propelling or projecting below the surface of the water of an elongated boly containing explo. sive substances to be ignited when reaching some point uncle the bottom or bilge of an opponent's ressel. The best method of carrying out the itca is that of projecting the elongated body by means of a tube or chlumber with parallel sides applied near the bottom of the aggressive vessel. Snch a method I proposed to the Emperor of France in the month of September, 1854, as mentioned in Chirp. XXVIII.

At close quanter's the stated plan of attack will unques. tionably be found very effective-indeed, inliallible; but, unless the opponent's ressel can be approached very near, it will prove abortive. Obviously, if the projectile be pushed out in any direction not parallel with the line of keel while the agroressive vessel is in motion, a side resistance will be offered by the stationary water of the sea, which will divert the comse of the missile the instant it is deprived of the guiding power of the tube from which it is ejecter. Cnrrents will, from the same canse, change the intended course. It need scarcely be observed that, in atdition to the difficulty of controlling the direction of the projectile, the force imparted to the same, whether steam or compressed air, will be insufticient to propel it to any consilerable distance. In order to meet these serious practical objections-viz, that 
the projectile camot be propelled far emongh, and that its comse cannot be controllerl-I hare resorted to a derice by which any lesimble amount of propulsive force may be im. parted, inespective of the distance traversed, and by which the comse of the missile is maler perfect control during its progrese to the intended point. Pensoms of a mechanieal tmrn of minl in alunst erery comntry have for al long time been engaged in contriving torperloes to he propelled moler water by independent motive ponter of vintous kinds, for the purpose of blowing up ressels. The Austrian torpeito, urged through the water by moms of compressed alld, mily be clissed as one of this mumerous tribe, the reported ter. rible nature of which has from time to time frightened naval comstructors, and ambed some munedhanical sailors who have witnessed the trials, and fouml that the mysterims boly actually can move muler water. Proper investigation of the subject, however; exposes imperfections of the Anstrian torperlo which render its final success problematical.

It should be borne in mind that atmusploredic all com. pressed, so as to exert a pressure of 300 1hs. to the so. in. weighs nealy 2 lhs. to the culic ft. Consequently, the amount of motive force which the torperlo is capalle of containing will be fomml wholly insufticient for its effective mopulsion mulese an impraticable or, at any late, dangerous presure be employed, accompanied hy great weight, serionsly interfering with busyancy, while the want of means for direct. ing the torlerlo to the desired print puesents an insuperable objection. As before stated, I lave contrived a torpedo 
('HAY'. XILII.

that may be propelled with any requisite anount of force, inespective of distance, the comse of which is muler perfect control, notwithstanding curdents, and which nily be directed with perfect certainty to an object in motion. In contradistinction to the tern projectile, applierl to the structure of 185t, which was propelled alone by its vis viva on leaving the guiling-tube, I propose to apply the term torpeclo to the contrivance now to be considered.

It shoukd be observed that some attempts to propel bodies under water lave been successful as regards main. taining a giren depth. The self-evident derice of applying af fin or horizontal rudder, operated by a piston or elastic bag actuated by hydrostatic pressure, has suggested itself to inventors. It will be readily perceived that an increalse or dinninution of draught, attended as it is with a con're. sponding variation of pressure, may be made subservient in changing the inclination, thereby establishing a tendency of the horizontal rudder either to elevate or depress the torpedo luring its forward notion. 'Thus, by a proper adjustment and application of the hychostatic pressure, the torpedo may be made to move at any lesirable depth below the surface of the sea. Nor has any difficulty been experienced as regards the instrument of propulsion in the experinents mate since the introduction of the screw propeller: But the difficulty of procuring the requisite amount of motive force for actuating the propeller, and the absence of means for directing the torpedo, have in each instance defeated the object in view. 
Before proceeding to consider the important question of griting the torperto, I will now briefly describe my method of obtaning the requined power for actuating the popellers. $\Lambda$ reel, of suitalnle diameter, revolving on al horizontal axle, is applied near the chamber from which the torpedo is ejecterl, one ent of the axle being supported by a suitalle bearing, while the other enters an all-ressel through a stuffing-hos. The end thus inserted in the an-vessel is perforated longiturinally for a short distance, and provided with an opening in the side at the point where the perforation teminates. A tubular rope, the bore of which is about one inch in diameter, composed of hemp and rulcanired rubber; is comected with this opening, and then coiled anomnd the reel a certain nnmber of times, and, lastly, connected with the rear end of the torperto. The air-vessel into which the perforited axle of the reel enters, being charged with compressed air (by means of force-pumps worked by stean. power), it will be readily understood that the compressed air will pass through the axle, then through the sereral coils of tubular rope wound round the reel, and ultimately reach the rear end of the torpedo, where the rope is attached to the engine which actuates the propeller's. Accordingly, the propulsion of the torpedo may be regulated by simply opening or closing the aperture of the perforated shatt within the air ressel. The rotation of the reel, consequent on the omwar morement of the torpedo, obvionsly cimmot interrupt the passige of the compressed air through the corils of the tubular rope; lence the sulply of motive force will continne 
undiminished during the onward movement. The tubular rope being about one inch diameter in the bore, it will be found by calculation that a quantity of compressed air; suflicient to develop any desirable amount of power, way be transmitted through it during the progress of the torpedo, whether far oft or near the aggressive ressel. The arrangement thus described being sufficiently simple to be comprehended without entering into detail, it will only be necessury to state that the tubulan rope, after leaving the reel under the deck, is made to descend through a vertical tube into the torpedo chamber; in order to prevent an entrance of water at the point where the rope passes out. Also, that two propellers are employed, revolving in opposite directions round a common centre-indispensable to prevent the torpedo itself from rotating when subjected to the powerful torsion produced by a single propeller actuated by the motive force which may be transmitted through a tubular rope of one-inch bore.

I will now proceed to describe my method of guiding the torpedo, premising that the external easing which contains the mechanism and explosive compound is heavier at the bottom than at the top, in order to preserve a vertical position, and that, in addition to the horizontal rudder's for' regulating the inmersion, the torpedo is provided with a vertical balance-rudier for directing the lateral course. 'The reel having a mean circunference of $10 \mathrm{ft}$., it will be seen that the tubular rope need only be eoiled round it 100 times to admit of attack at a distance of $1,000 \mathrm{ft}$., probably 
far enough, since the position of the angressive ressel which carries the torpedo maly be changed at all times with de. sirable rapidity.

The apparently absurd monusition to direct and clange the course of the torperlo at will, on hoard of the aggressive ressel, without external aid, is solved hy the folloning simple

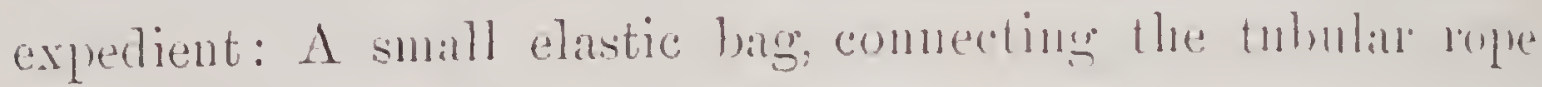
with the intuetion-pipe of the rotary angine, is attalched to the side of the tiller of the torpertis halancerpulder. As the compressed air during its palssigge to the motor must pass through the elastic bagg, the latter will expand and contract with everg change of intermal pressure; and, ats such change will depend on the flimblty of compunesed air almitted into the tubular rope, the expansion and contanction of the bag is eridently muter perfect control. Now; the power of this hag, or the porrer of a loakled pistom in an open cylinder, to resist internal pressure, nuty he so pro. portioned that when maximum pressure is andmitted the swelling of the bag, or the motion of the pistom, will cause the tiller to move about 20 deg. to port; and when the pressure is reduced 25 per cent, the accomplanying contrace tion of the bag, or corresponding motion of the loaded piston in the open cylinder, will more the tiller 20 degr. to staboard. 'Thus, hy admitting more or less compressed ail into the tubular rope, thereby ehanging the dimensions of the bag or moving the piston referrer to, the tiller will as. sume any desimble angle within 20 deg. on either side of the torpedo's centre line. 
According? $y$, the direction of the torpedo will be as completely under the control of the hand which admits the compressed air to the tubular rope as if an intelligent directing power resided within the torpedo itself. Probably no greater mechanical feat than this can be instanced. The position of the torpecto is indicated by a circular disc, four inches in dianeter, attached to the upper end of a perpendicular steel wire, or mast, secmed to the top of the torpedo. 'The said disc is painted sea-green on the forward side and white on the opposite side. It need scarcely be observed that the explosion of the torpedo will sever the connection with the tubular rope, which thus may be hauled in by turning the reel. Shonld the intended object not be reached, the adnission of compresserl air to the tubular rope will be slut off, and the torpedo hauled in, or sent out on a new errand.

The scope of the derice thus described is, of course, more limited than the scope of the method illustrated on Pl. 62; yet, harl the Italians possessed it, the result at Lissa would unquestionalhly have been reversed. No harbor can be entered which is protected by it; nor would any anomnt of vigilance save vessols from destruction if approaching an enemy's coast lefended by it.

With reference to the reel on which the tubular rope is coiler, it will be well to mention that it may be applied within the torpedo itself; in which case the tubular rope, insteal of being towed, will be paid out during the onward notion towards the object intended to be struck.

The illustrutions on Pl. 63, Figs. 1 and 2, represent top 
view and side eleration of the actuating steam-engine, ar. compressing pump, air-ressel, and reel; while Figs. 3 and 4 show the side eleration and top view of the torpedo. It may be briefly mentioned that the torpedo this represented, after having been tested during a series of trials in open water, has been furchased by the Kary Department at Wash. ington. Negotiations are now pending for the purchase of the invention by the United States Gorermment, on conditions of secrecy, as in the case of the Austrian torpedo; hence detailed information respecting the internal mechanism can. not be presented in this work. 


\title{
CHAPTER XLIV.
}

\author{
TRANSMISSION OF MEOHANICAL POIFER BY COM- \\ PRESSED AIR.
}

(SEL PIATES 64 AND 65.)

Professor Barmard, in his admirable report of the Paris Universal Exposition, observes "that, next in importance to the creation of a new motive porrer, may be placed any material improvement in the methods of making arailable the powers which we have. Nature often furnishes us with such powers in abundance in situations where they cannot be conveniently converted to use. 'The positions of waterfalls are determined by geographical accidents. 'These do not ahays conspire with the causes which promote the growth of towns and development of industries. If it were possible to transfer the immense forces which are thus unprofitably expending themselves to points where there are hands to direct them, and materials on which to employ them, they might he productive of incalculable wealth, and of immeasurable benefit to mankind." 
The foregoing riews, so well expressul, are quite cor. rect; but there is another power rumming to waste which the engineer; ere long, will be alller npon to utilize-vi\%, the porrer of the tides. Ahearly a prominent association has been formed in France for erecting tidal motors on a very large scale. Thus, while engineering skill has nemly exhansted itself in endeavors to improve the stemm-engine, a new field opens, boundless in extent, which will demand far greater abilities than those catled for within the narow bounds hitherto limiting the energies of the mechanical engi. neer. The grand scheme of utilizing the matural fores now running to waste divides itself into two distinct branches: 1st. The requisite mechanisun for recoiving the force exerted by nature. 2d. The means for trinsmiting that force to desirable localities. It is the latter branch which I propose to discuss. But, before entering on the subject, it will be proper to point out that it is not the matural forces alone which the engineer is caller upon to devise meams for trans. mitting. Indeed, with our present abundant supply of conl, the transmission of force developed hy steam will be most fre. quently called for ; since the stemm-engine, however portable in its character, cannot be alplited in all places where power is required. The experience of liate yenrs has shown that the substitution of mechanical power for mamual labor in driving tumnels and for mining operations has reduced the cost and greatly increased the amomnt of rork done in a given time. But the presence of steam in tumnels and in the galleries of mines is wholly inatmissible; lrence small 
motive engines, operaten ly compressed air, have been introluced for operating the rock-drills and other cutting tooks. Not only has the work by these neans been greatly ancelerated, but the escape of the exhaust air from the motors his in a material degree tended to purify the atmosphere within the mines, rentering the work healthful which formerly proved destructive to the miners.

The fint question which presents itself in treating of the transmission of force by conpressed an is the size of the tube necessary to convey a certain amount of energy in a given time-pressure and velocity being the elements which determine the question. Fortunately, we are not without practical clatar on the subject, the engineer's of the Mont Cenis tunnel having, some tine ago, thoroughly investigated it. The result of their labor's his been recorded in the Report of the Uniter States Commissioner's at the Paris Universal Expusition of 1867. The Commissioners state that, at the date of the report on the progress of the work in the tunnel during the year 1863, the operation was earried on at a distance of nearly two thousand metres from the reservoirs of compressed air, and that nine borers were in operation with a force of two and a half horse-power each. The tube conveying the air was rery nearly eight inches in dianceter, the air being under a pressure of six atmospheres, and its relocity in the tube three feet per second. The transmission of the power under these very farorable conditions was attended with no sensible loss, the pressure not being perceptibly less at the working extremity of the tube when all 
the perforations were in operation than when the uachinery wats entirely at rest.

The Report of the Commissioners fumishes a very full account of the result of the experiments conducted at Corsica, in 1837, by order of the Italian Govermment, on the resistance of tubes to the flow of air through them. These experiments were made previously to the commencement of the rork on the tumnel, the employment of compressed atmo. spheric air as a motive power to actuate the boring apparatus being at the time considered a doubtful cxperlient." The Re. port states that it was the aim of the invertigation not only to ascertain the alsolute loss of force attenling the trans. mission of air through tubes of certain dimensions at certain relocities, but also to determine what are the lnos which govern the resistance when the velocities of the air and the diameter of the tube are raried. The fullowing conclusions were deduced from the experiments: 1. The resistance is directly as the length of the tube. 2. It is directly as the square of the relocity of flow. 3. It is inversely as the diameter of the tube.

The fact before adverted to - that in the actual working of the machines in the tumncl no perceptible loss of power was experienced at a distance of two thousand metres from the reservoirs-must be attributed to the wint of delicacy of the manometer or pressure-gatuge employed. Although insignificant at moderate distances and low relocities, the experiments at Corsica prored that the loss becomes serious when the velocity and distance ane considerably increased 
since, agreeably to the law before cited, the resistance varies as the square of the velocity. Consequently, when the velo. city is six times greater than the moderate rate of six feet, or thirty-six feet per second, the resistance will be thirty-six times greater, the power dereloped increasing in the ratio of the volume of air delivered-viz, six times. It will be perceired, therefore, that while the leugth and dianeter of a tube remain unaltered, and while the absolute resistance opposed to the flow of a current of air through it varies as the square of the velocity, the relative resistance is only as the simple velocity. It follows from the foregoing facts that the power of compressed air varies as the product of its pressure and its volume; hence, when the pressure is constant, as the rolume simply. But the rolume delivered varies as the velocity multiplied by the square of the dia. meter of the tube. Now, as the resistance is inversely as the diameter, and the rolume directly as the square of the diameter when the velocity remains constant, it follows also that under a given pressure and velocity the relative resistance (namely, the resistance divided by the power) will rary inversely as the cube of the diameter. Obviously, therefore, by enlarging the diameter of the tube, we may increase the power transmitted, and at the same time diminish both the absolute and relative resistance. In conclusion, I strongly recommend engineer's who may be called upon to transmit mechanical power by compressed air not to aim at economy by employing tubes of small diameter.

Haring thus disposed of the first branch of the subject 
under consideration, let ns now consicter the mechanism needed to compress the air to be tramsmitted. At first sight the solution of the problen appears to be rery simple, but due refiection at once suggests to the practical nind mumerous dificulties. Considerations of weight, space, and first cost, of course, demand the adoption of a double-anting compressing-ylinder; hence the practicalbility of employing double action is the rery first question that presents itself. Now, in double-acting cylinders both ends must be closed, consequently lubrication of the compressing piston must he effected from without. Supposing that means for effecting such lubrication have been devised (by no means easy), will the packing of the piston be preserved and abrasion pre. vented? In answering this question, we nust bear in mind that even at moderate pressure the compression of the air generates a degree of heat which precludes the employment of oil, as it quickly dries up and ultimately burns. Wrater, if continually replenished, so as to make grood the loss caused by the formation of steam, may answer for a short time. The dust drawn into the cylinder from the surrounding atmo. sphere will, however, mix with the water, and soon form a paste, resembling mud, on the piston, productive of friction and abrasion of the cylinder incompatible with the functions of a piston. The objectionalile plan of compresing air by rising and falling columus of water I to not propose to discuss in this place.

The illustrations on Plate 64 represent a perspective view, while Plate 65 shows a longitudinal section of a machine 
for compressing air, in which the difficulties before referred to have been effectually orercome; the leading features being that the compressing cylinters, open at the top, are immersed in a cistern through which a continuous circulation is kept up by a current of water which flows over the compressing pistons before entering the cistern. A glance at the sectional drawing on Plate 65 will give a clear idea of the nature of the device and the mode of operation, which may be thus briefly describer: A small pipe communicating with a reservoir or other supply of water is applied behind the machine, provided with a branch for each compressing cylinder. 'These brancl-pipes are bent downwards vertically in such a manner that a stream of water flowing through each will fall on the top of the compressing piston, near its circumference. The compressing-cylinder's, as already stated, are suspended within a water-cistern, and supported by their upper flanges, which rest on the top of the cistern. Referring to the perspective view of the machine, shown on Plate 64, it will be seen that the water-cistern forms a pedestal supporting the side frames on which the pillowblocks of the crank-journal rest. It will also be seen that the side frames form slides which guide the cross-head of the piston-rods. A band-wheel, provided with a very heary lim, to be driven by steam or other motive power, is attached to the crank-shaft between the pillow-hlocks formed at the top of the side frames. It scarcely needs explanation that the object of making the rim of the band. wheel very heary is that of equilizing the irregular resistance 
offered by the compressing-pistons. The inlet-valves which supply the atmospheric air to be compressed are inserted in the pistons, while the outlet-valves are placer at the bottom of the cylinler, the ralve-chambers of the latter communi. cating directly with an air-conductor which leads to an ordi. nary air-reservoir. Referring again to the sectional repre. sentation of the machine, it will he seen that the sides of the compressing-cylinter are perforiter near the top, the position of these perforations heing such that when the piston reaches the full up-stroke its upper face will not quite reach the under side of the perforations. It will be readily understood that by this arangement a certain body of water will always remain on the top of the piston, white at the same time the perforations effectually prevent an orerfow within the cylinder. The comectingrod is rery short compared with the length of throw of the crank; hence the piston will remain for a considerable interval of time near the top of the cylinder; during which time the necessary discharge of the water lodger on the top of the piston takes place. 'To prevent undue accumulation of water' in the cistern, an overflow-pipe is introduced at the side, as shown in the sectional illustration. It should be particularly noticed that the air, while undergoing compression in the cylinder, is completely surrounded by metallic surfaces cooled by the circulating water. But this is not all. During the reciprocating action of the piston, the body of water lodged on its top washes the inside of the cylincler both during the upward and downward morement. Now, the speed of the piston 
is fully one hundred and fifty feet per minute; hence an internal refrigeration is established far more efficient than the external circulation. The metal composing the cylinder, it will thus be seen, is actually conled on both sides, a very remarkable and almost paradoxical achievement. Again, it will be perceived that the circulating cold water continually washes the top of the piston before entering the cistern. Accordingly, the entire quantity of water required for cooling during the compression passes orel the piston at the initial low temperature, thereby subjecting the part of the machine that most needs cooling to the greatest amount of refrigeration. As regards lubrication, it is self-evident that no conceivable plan can be more efficient than that of actually washing the inside of the cylinder with the lubricating medium, both during the up and down movement of the piston.

Regarding the utility of cooling the compressed air, it needs no demonstration to show that refrigeration after the air has left the compressing-cylinder, recommended by some engineer's, is not only useless, but tends to reduce the efilciency of the compressed air as a motive agent. Obviously, if the air during its transmission from the compressor to the motor intended to be actuated loses in temperature, it also loses in bulk. On the other hauc, refrigeration withim. the cylinder during the down-stroke is useful, as it tends to check the swelling of the volume of air under the piston callsed by the heat generated by compression, consequently diminishing the necessary motive power. 


\section{CHAPTER XLV.}

SUN POWER-'THE SOLAR ENGINE.

(SEE PIATLS 66 AND 67.)

Tru: illustration on Plate 66 derives its chief interest from the fact that it represents the first motor actuated by the direct agency of the sun's rarliant heat. It was constructed at New York, 1870, and intended as a present to the French Academy of Sciences. Apart from being a motor, this engine was designed to operate as a meter for registering the volume of steam generated by the concentrated heat of a pencil of solar rays of a given section. Regarded as a steam-meter, it proved inpmetant, as it rerified the results of previous experiments and previous calculations, based on the number of thermal units developed by the evaporation of a certain weight of water in a given time. Engineers will not fail to notice the unusual proportions of the working parts, nor will they fail to appreciate the object in riew, that of reducing the friction to a minimum-an indispens- 
able condition in a meter. 'The entire mechanism being' shown with perfect distinctness in the perspective view of the engine on the plate referred to, it is only necessary to mention that the square pedestal which supports the steamcylinder ( $1 \frac{1}{2}$ ins. in diameter), the beam-centre, and the crank-shaft, conceals a surface-condenser.

Under a clear sun the engine performed its functions with perfect uniformity, at a relocity of 240 revolutions per minute. It consumed, at the stated rate, only part of the steam furnished by a solar steam-generator, temporarily employed, belonging to an engine of greater dimensions then in the course of construction. With reference to ascertaining correctly the amount of mechanical power dereloped by the concentrated ladiant heat applied to this engine, experts need scarcely be reminderl that, by dispensing with a racuum, the atmospheric resistance and back pressure exerted against the piston furnish elements for measuring, with critical nicety, the dynamic force transmitted by pencils of solar rays of definite sections.

Drawings and descriptions of the mechanism by which the sun's radiant heat has been concentrated in my experimental engines will not be presented in this work, nor will the form of the stemm-generator which receives the concentrated heat he delineated or described. Experienced professional men will appreciate the motive-riz, that of preventing enterprising persons from procuring patents for modifications. With reference to the course thus adopted, it will be proper to mention that I have in sereral instances, 
notably in the case of the screw-propeller and the caloric engine, been prevented from perfecting my inrention in consequence of conflicting privileges having in the meantime been grianted to others.

Regarding the solar engine, it may be well to state that I shall not apply for any patent rights, excepting for the purpose of protecting the community, and that it is my intention to derote sufficient time and means to ensure its completion. Hence my anxiety to guand against legal ob. structions being interposed before perfection of detail shall have been measurably attained. In the meantime, let us hope that no exclusive privilege will be granted tending to throw obstacles in the way of an unrestricted manuficture and introduction of the solar engine in countries where a continuously clear sky warrants its adoption, especially in Upper Egypt and on the coast of Peru.

The experiments instituted show that the mechanism which I have adopted for concentrating the sum's radiant heat abstracts, on an average, Juring nine hours a day, for all latitudes between the equator and 45 deg., fully 3.5 units of heat per minute for each square foot of areal presented perpendicularly to the sun's rays. A unit of heat being equivalent to 752 foot-pommls, it will be perceived that, theoretically, a dynamic energy of 2,702 foot-pounds is transmitted by the radiant heat, per minute, for each square foot; hence, 270,200 footpounds for an alea of 10 feet square. If we divide this sum by the arlopted standard, 33,000 , we ascertain that 100 square feet of surface ex- 
posed to the solar rays develop continuously S.2 horsepower during nine hours a day, within the linits of latitule before mentioned. But engineers are well aware that the whole dynanic energy of heat camnot be ntilized in puactice by any engine or mechanical combination whatever, nor at all alphorehed; leence I have assmed, in order not to oremate the capability of the new system, that a solill engine of one horse-power demands the concentration of solar heat from an area of 10 feet square. On this basis, I will show presently that those regions of the earth which suffer from an excess of solar lieat will ultinately derive benefits resulting from an mulinited command of motive power which will, to a great extent, compensite for disillvantages hitherto supposed not to be comberbalinced by any good. But before estiunating the magnitude of mechanical power which we maly prorluce by availing oulselves of the fuel contained in thist great storehouse fiom whence it may be obtanied free of cost and transportation, let us comsider the leading feature of the device resorterl to, especially that by which I have succeeded in alugmenting the comparatively low temperature developed by direct solar radiation sufficiently for the production of useful work.

The solar engine, when steam is enployed as the medium for transmitting the rationt energy, is composed of three distinct parts-the engine, the stean-generator, and the nechamism by means of which the inadequate energy of the sun's rays adverted to is increased to such a degree that the resulting temperature will exceed that corresponding with 
the stemn-pressule necesin! in an eflicient engine. 'The motor itself, when the acting medimm moler consideration is cmployed, lesembles in all exrential points a molem stann.

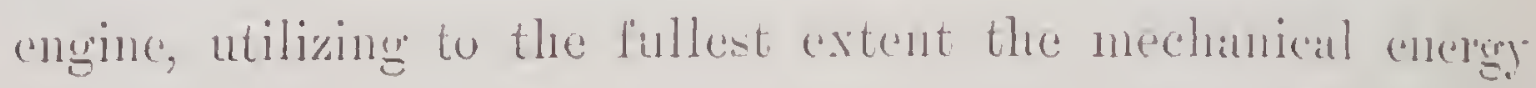
of the steam ialmitted to the wolling-ylinder. lint when atmospheric air is empioyed as the modiun for lramsmitting the solat energy to the motor: an cutinely dilledent combinat

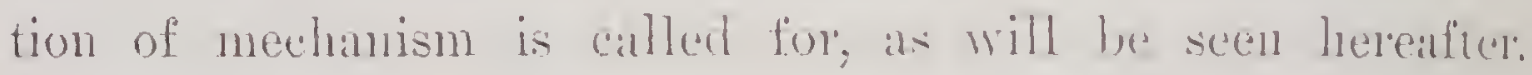

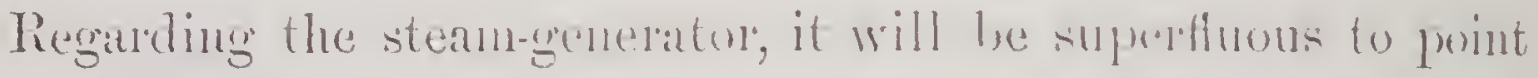
out the alvantages resulting from its not heing exposed to

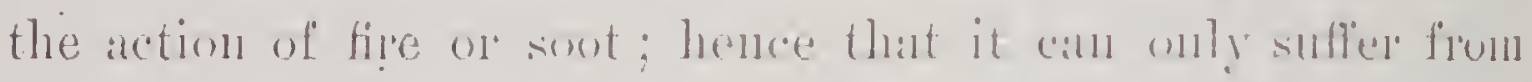
the stom action of ordinaly oxidation. As the motom itsolf

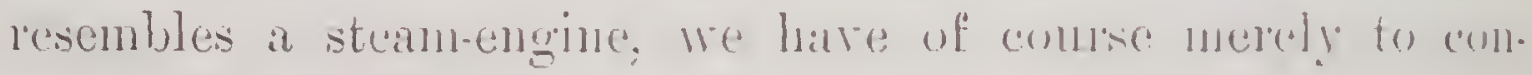
sider the nature of the mechannisin by means of which the solar heat is concentrated and the temperatme raised ahore that of the water in the steam-generator. Regarding this mechanisn-vi\%, the concentration apparatus-it has been asked, Is it costly? Is it leavy and lunliy, so as to rendele transportation diflicult? And, finally, the question lats fre. quently been put, Is it liable to derangenent and expensive to keep in order? 'The cost is moderate. The woight is small; indeed, lightness is the most notable peculianity of the concentration apparatus. As to bulk, it may be observed that this apparatus is composed of small parts learlily put together. With reference to inmbility, nho falct need only: be pointed out that certain metals, howerer thin, if kept dry, may be exposed to the smin's jays during an indefinite length of time without alprectable deterioration: hence, 
unlike the furmaces of stean-boilers, which soon become unserviceable, the concentration apparatus, as it consists of thin metallic plates, composer of durable materials, camot be damaged by the nere action of the sun's rays. Another question has been askerl, Whether the solar engine will answer as well on a linge as it does on a small scale? The following reply disposes of this pregnant query: It is not necessury, nor intended, to enlarge considerably the size of the apparatus by means of which the comparatively feeble intensity of the sun's rays hils been successfully concentrated, and the temperature sufliciently elevated to generate steam for actuating the solur engine. The maximum size adopted hias been alequate to utilize the radiant heat of a pencil of lays (sunbeam) of 35 square feet section. The employment of an increased number of such structures will, therefore, in most cases be resorted to when greater power is wanted, as we increase the number of hands when we desire to perform all aditional amount of work. 'The motor itself-viz., the steam-cylinder and the working parts-will obvionsly be proportioned, as at present, in accordance with the pressure of steam employed and the work to be done.

It should be clearly understood that I do not recommend the erection of solar engines in places where there is not steady sunshine, until proper means shall have been devised for storing up the radiant, energy in such a manner that regular power may be obtained from irregular solar rauliation. Experienced engineers need not be told that formidalsle difficulties present themselves iu storing up mechanical energy 
of any kind: yet when coal can no longer be obtained, necessity, ingennity, and increased experience will find mans of orercoming nbstaleles which now appear insmrmomutable.

Before considering further the nature and calpalilities of my solar engine, it will be furpere to notice the result of the labors of Professor. Mourhot of Tours, formerly of the Lycée of Alengon, who claims to hatre anticipated me in employing solar heat tor the morluction of nutive porres: Tonchot bases his chim on some experiments, male in 1866, intended to show that by the aceumulation of leat which takes place when a blackener surface is surrounded by glass bells, stean may be groncrated for actuating machinery. Sir John Herschel, it is well known, elitborated the old idea of concentrating solar radiation, and conducted at series of experiments at Cape Tomn, in 18:38, showing that not only was it possible to produce boiling heat by accumulating solar lieat as described, but he suc. ceeded in elevating the temperature sufliciently for roasting meat. Some time previous to 1870, Nouchot mide a small model engine, a mere toy, actuated by stean gyenerated on the plan of accumulation by glatss bells; but finding the lieat insufficient, he added a polished metallic reflector: The increase of temperature resulting from this expedient rendered his steam-generator more effective, and it wis found that under fivorable cireumstances suflicient steam conld be produced to actuate his small model. 'The Conseil-Génćral of Indre-et-Loire having subsequently provided Professor Monchot with necessiry means, he jut np a stean- 
generator at Tons's in 1872 , which he deens a perfect machine, its action being based on the results of his previous experiments. 'The accompanying diagram, Fig. 1, represents a rer. tical section of the said steam-generator, thus described by M. L. Simonin in Revue des Denx Mondes:

"The traveller who visits the library of 'Tours sees in the court-yand in front a strange-looking appanatus. Inngrine

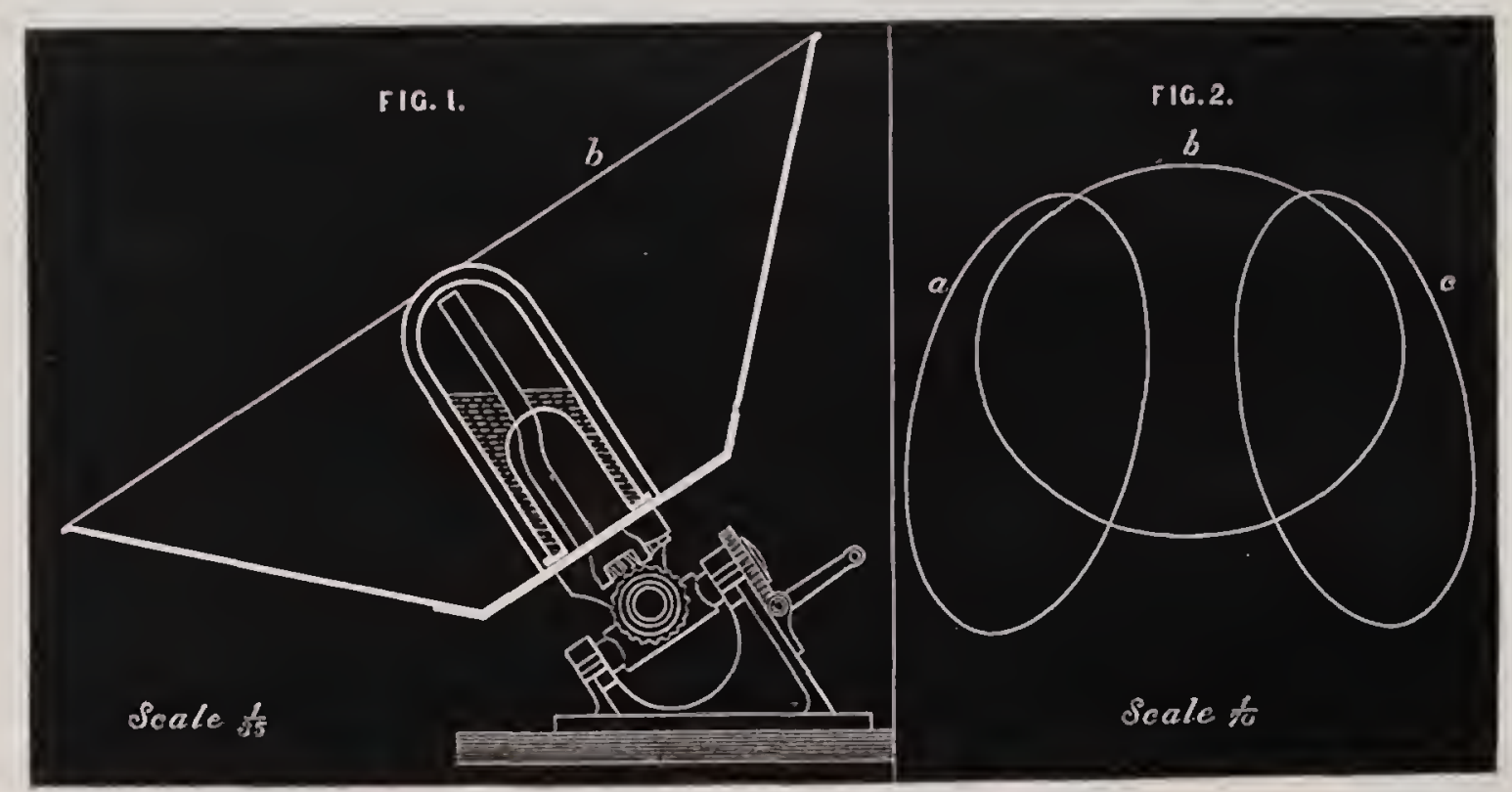

an immense truncated cone, a mammotl lamp-sliade, with its concavity directed skywart. 'I'his apparatus is of copper, coated on the inside with very thin silver-leaf. On the small base of the truncated cone rests a copper cylinder; blackened on the outside, its rertical axis being identical with that of the cone. This cylinder, surlounded as it were by a great collar, temminates above in a hemispherical cal), so that it looki likr an enommous thimble, and is covered with a bell-glass of the same shape.

"This curious apparatus is nothing else hut a solal" receiver, 
or, in other works, a boiler, in which water is made to boil hy the heatrays of the smll. This stean-generator is designed to raise water to the hriling point and beyond by means of the solar rals, which are thrown mon the cylinder by the silvered inmer smlface of the conical reflector. 'The boiler receives water up to two-thirls of its capacity through a feed-pipe. A glass tube and a steam-gange communicating with the inside of the grenerator, and attached to the untsids of the reflector, indicite both the level of the water and the pressure of the stcan. Finally, there is a silfety-ralve to let off the steam when the pressure is greater than desired. Thus the engine ofters all desinble safety, and may be pro. vided with all the accessories of a steam-lmiler.

"The reficctor, which is the main portion of the generator, has a diameter of 2.60 metres at its large, and one metre at its small, bake, and is eighty centimetres in height, giving fom square metres of reftecting surface, or of insolation. The interior walls are lined with bumished silver, because that metal is the best reffector of the heat-rays; still, brass with a light coating of silver would also serve the purpose. The inclination of the walls of the apparatus to its axis mensures 45 reg. Fien the ancients were aware that this is the best form for this kind of metallic mirors with linear focus, inasmuch as the incillent rays parrallol to the axis ane reflected perpemeliculanly to the same, and thus give a forus of maxi. munn intensily.

"The boiler is of copper', which of all the common metals is the best conductor of heat; it is blackened on the out- 
CHAP. XLV.

side, because black possesses the property of absorbing all the heat-rays, just as white reflects them; and it is enclosed in a glass envelope, glass being the most diathermanous of all bollies - that is to say, the most permeable by the rays of luminous heat. Glass further pussesses the property of resist. ing the exit of these same rays after they liave been trans. formed into dark ray's on the blackened surface of the boiler. None of these applications of physical laws present iny novelty; people reduced them to practice instinctively, as it were, before men of science conld assign the reasons. Here the ants of cookery and of gandening, and the pro. cesses for walming our looms, did not wait for the experiments of the physicist. Sallssure himself started from these data in his researches; but the inventor needed the discoveries of modern physics, in order to give to these applications a rigorous formulit.

"The boiler proper of the Tour's solar engine consists of two concentric bells of copper, the larger one, which alone is visible, having the same height ats the minror-i.e., eighty centimetres-and the smaller or inner one fifty centimetres; their respective diameters are twenty-eight and twenty-two centimetres. The thickness of the metal is only three millimetres. The feed-water lies between the two envelopes, forming an annular envelope three centimetres in thickness. Thus the volume of liquid is twenty litres, and the steamchamber has a capacity of ten litres. The inner envelope is empty. Into it pass the steam-pipe and the feed-pipe of the boiler. 'To the steanrpipe are attached the gratuge and 
the safety-ralve. 'The bell-ghass corering the boiler' is eighty. five centimetres liggh, forty centinetres in dianceter and five millimetres in thickness. There is everywhere a space of five centimetres between its walls and those of the boiler, and this space is filled with a layer of rery hot alls.

"The calth, owing to its diurnil ant anmulal revolution, does not occupy the same position with regilld to the suln at all hours of the day, or in all seasons of the year. This being the case, the generitur is so contrived ats to revolve 15 deg., or one twenty-fourth of its circunference, homily around an axis parallel to the eallh's axis-i.e, so its to follow the apparent diurnal motion of the sun, and to incline gradnally on its axis in proportion to the solan acclination. Hence the intensity of the utilized leat is alwilys nearly the same, whaterer the hour of the day or the season of the year, inasmuch as the apparatus is always so arranged as to reflect with the least possible loss all the rays emitter by the sum. 'This domble motion of the generator' is effected by a very simple contrivance."

The foregoing description of the Solal Steam-Generitor" of Mouchot is so lucid that it requires no explanation. Mr: Simonin, however; erroneously sujposes that the power developed by the apparatus is nearly the same at all homs of the day, the fiut being that the energy developed by the concentrated solill heat varies with the depth of atmosphere penetrated by the rays. The latter eviklently depends on the sun's zenith listance; hence at Paris, where the maximun solar intensity during the stmmmer solstice is $65^{\circ} .0$ 
Fah. at noon (see diagrann on Plate 9), it scallecly reaches $52^{\circ} .0 \mathrm{~F}$. at five o'clock in the altermoon, owing to the increased \%onith distance, and consequent increase of the depth of atmosplicre to be penetrated by the smin's rays. Obviously, the eftiviency of the solan genelatol will be diminished in the sanne latio as the stated intensities. Mr. Sinnonin states that on some occasions, when the sun has been exceptionally cleall, the solar generator at 'Tours has evaporated fire litres of water per hour, which lie assumes equivalent to half a horse-power: 'The reflector' producing' this result-a truncated conte-being 2.6 netres (s feet 6 inches) in dianeter, it will be found that in order to double the reflective aleat necessally to generate steam for an engine of one horse-power, a trunciater cone of 8.6 metres (11 feet 9 inches) aperture will be refuired. Practical engineers are aware that an inverted conical boly whose base is nearly 12 feet in diameter, swinging round an inclined axle at least 60 deg. on cach side of the vertical line, presents a structure so formidable, even if comnterpoised, that it would not be prudent to increase its size. Aceorlingly, one hundred of Monchot's solar generators would be needed to furmish stean for an (nngine of 100 horse-al very moderate power, if enployed for manufacturing of other industrial purposes. Refering to the diagrinn on page stis, Fig. 2, representing al bird'seje view of the aperture of the conical reflector at 'Tours in three difterent positions-riz., a in the morning, l, at mid. lay, and c during the afternoon-it will be seen that each instrument, owing to the necessary change of position, de- 
mands a front space of nearly twenty feet. If placel side by side, the conical solar generators required for an engine of 100 horse-power would therefore ocenpy a front of 2,000 feet from east to west. If arranged in four lines, with suf. ficient space north and south to prevent interference, a distance of 500 feet by 200 feet would be requiret.

Now, let us consider that the scheme calls for 100 separate boilers, to be continually fed with water; the height of which can only be known by the indication of outside gangus, while the steam from the scattered boiler's must be comreyed by a series of flexible tubes to the motive engine. The hundred ghass bells cinn, no loubt, be lusted and kept clean with moderate exertion; but the hundred silver-plitenl reflectors, which Mr. Simonin says must be exposed to the vicissitndes of the atmosphere, camnot be kept bright without herculean labor, since silver tarnishes in a few hours. In riew of the foregoing statement, which embraces only the chief difticulties attending Mouchot's system, the most singuine might well despair of rendering sum-porrer available for practical purposes.

The Professor of the Lycée of Alençon, in claiming to have anticipated me, has done so ignorant of the fiact that sun-power has been the study of my whole professional life -a life the early part of which was chiefly deroted to the production of a cheaper motive power tham steam. The industrious scientist, if he had been correctly informed on the subject, would no doubt have perceived the adrantages $\mathrm{l}^{\prime \prime-}$ sulting from such antecedents, with reference to a successful lractical solution of the problem of utilizing solar heat. 
On grounds already fully explained, minute plans of my new system of rendering sun-power arailable for mechanical purposes will not be presented in this work. The occasion, however, demands that I should present an outline of the concentration apparatus before referred to. It consists of a series of polished parabolic troughs, in combination with a system of metallic tubes charged with water under pressure, exposed to the influence of converging solar rays, the augmented molecular action produced by the concentration being transferred to a central receiver, from which the accumulated energy is communicated to a single motor. 'Thus the mechanical power' developed by concentrated solar heat is imparted to the solar stean-tugine without the intervention of a multitude of boiler's, glass bells, galuges, feeders, etc. Mroreuver, the concentration apparatus, unlike the instrument of Monchot, requires no parallactic motion, nor does its management call for any knowledge of the sun's declination from day to day. Its position is regulated by simply turning a handle, until a certain index coincides with a certain bright line produced by the reflection of the sun's rays.

Plate 67 represents a perspective view of a solar engine, in which the concentrated energy of the sun's rays is communicated to the motor by means of heated atmospheric air, instend of being communicated by water heated nnder pressure and expanded into steam. A glance at the illustration shows that the upper end of the working-cylinder is heated by the sun's rays reflected by a curved mirror. It will be seen by careful eximination that the solar rays converge at 
a point beyond the axis of the reflector; hence that the form of the latter is not parabolic, but composen of an irregular curre. The object is that of spreading the converging latys over a greater longth of the cylinder than possible with the divergence which would result from en. ploying a reflector of true prabolic currature. It will be

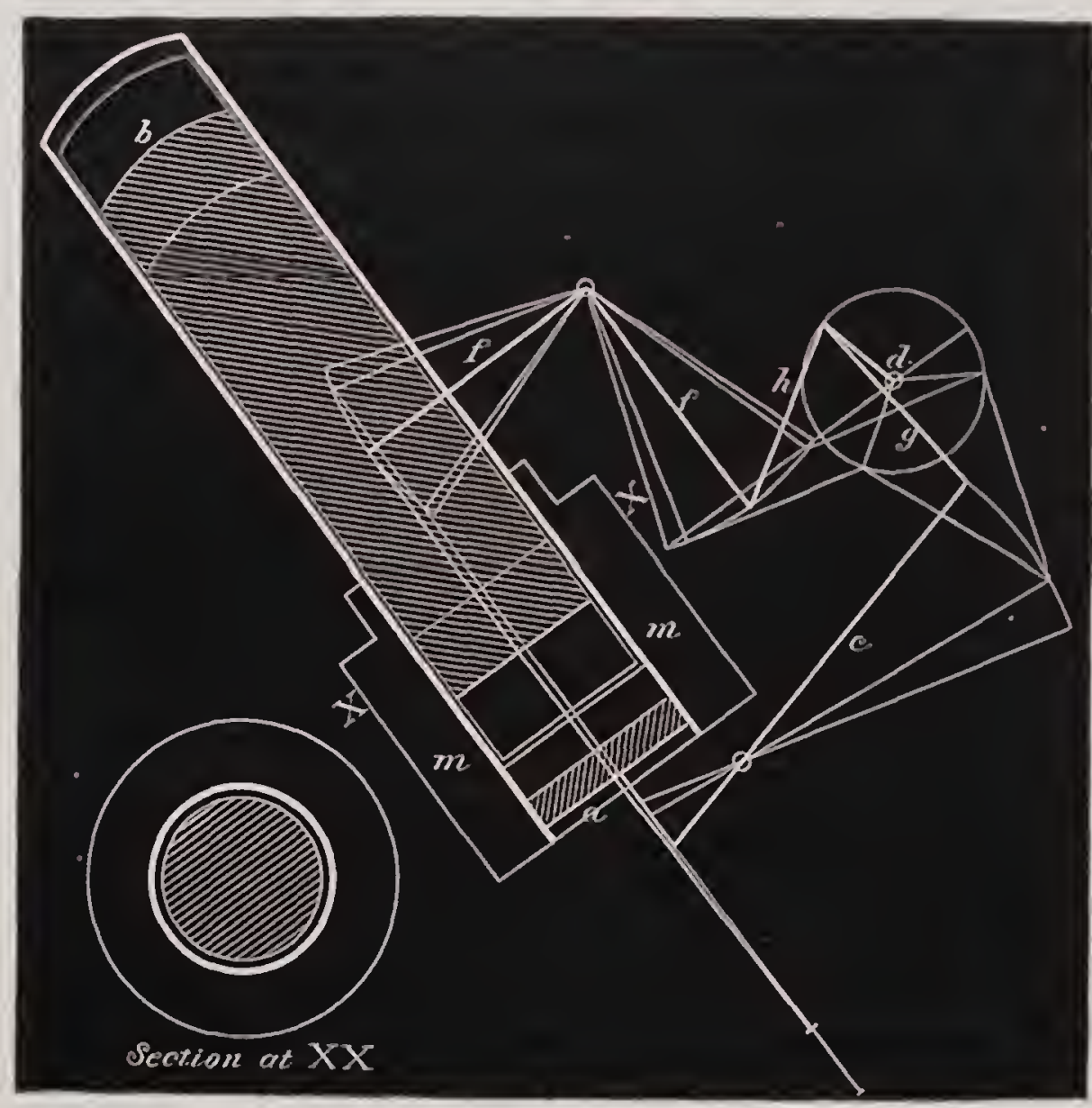

perceived on inspection that the upper and of the cylinder will be subjected to a concentration of heat many times greater thim the concentration at the luwer ent. Referring to the accompanying diagram representing a vertical section of the machine, it will be seen that the working-cylinder; open at the lower end, contains two pistons, a working. pistion a and an exchange-piston b. The working piston is 
comnected with the crank-shaft d by the bean o and the connecting-rod \%. The exchange-piston b is connected with the crank-shaft by the bell-crank ff and connecting-rod $h$. An annular space is forment romel the exchange-piston, admitting of a free passigge of the air from end to end of the cylinder Anring the motion of this piston. It will be readily understood that chring the downand motion of the exchange-piston the colet air from the lower end of the cylinder will be trinsferred to the upper end, heated by the concentrated solar rays; hence intemal pressure will be moluced tending to force the working-piston down. By a careful examination of the combination of the sereral working pints, it will be earsily comprehended how the workingpiston is actuated ly the confined air, heated and cooled alternately by the peculiar motion of the exchange-piston. It will be evident that the large surface presented by the outside of the exchinge-piston, and insile of the cylinder, will canse a rapid change of tempernture of the air while cirrulating from end to end of the latter. The npper end of the eylinter being heated by the concentrated solar lays, the cohl air from the lower end will, during its transfer to the upper end caused by the fownwat motion of the exchange-piston, become heated and expanded; while during the npward motion of the silit piston the air, in being transfrred to the lower end of the cylinder, becomes cooled and contrateted. It will be found on due considerattion that the exchangerpiston thus performs the oflice of a regenerator. The angine, therefore, is capable of operating 
for a considerable time by exposing the upper end of the cylinder to the reflected solar heat during a few minutes at starting. By continuous exposure to the concentrated solan' rays, the engine performs fully 400 turns per minute. It should be observed that concentrated solar radiation supplies heat with such extraordinary rapidity that the apparently insufficient amount of heating surface presenter by the cylinder lias proved adequate, notwithstanding the great speed of the engine. It only remains to be stated that the borly on m represents a radiator carrying off the heat which is not taken up by the circulating air during the notion of the exchange-piston. Of course, the amount of heat carried off by the radiator furnishes a nearly correct measure of the solan energy not converted into mechanical work. Engineers need not be reminded that the form of the solar engine thus described is applicable only for purposes requiring moderate power. In the largest class of solar engines actuated by atmospheric air, in which the radiator is incapable of ab. stracting the superfluous heat, I employ valves, and take in fresh air at each stroke of the machine, precisely as in the caloric engine delineated on Plate 46.

Having thus cursorily examined the construction of the solar engine actuated by the intervention of atmospheric air, and briefly adverted to the steam solar engine and the mode adopted in concentrating the molecular motion imparted by solar radiation, and also pointed ont the nature of the expedient resorted to in transferring the said concentrated molecular motion to mechanical motors, let us now 
consider the stupendous amount of the energy at our command.

It has already been stated that the result of repeated experiments with the concentration apparatus shows that it abstracts on an average, luring nine hours a day; for all latitudes between the equator and 45 deg., fully 3.5 units of heat per minute for each square foot of area presented perpendicularly to the sun's rays. Theoretically, this inticates the development of an energy equal to 8.2 horsepower for an area of 100 square feet. On grounds before explained, our calculations of the capabilities of sun power to actuate machinery will, however, be based on one horsepower developed for 100 square feet exposed to solar radialtion. The isolated districts of the earth's surface suffering from an excess of solar heat being very numerous, our space only admits of a grlance at the sumburnt continents.

There is a rainless region extending from the northwest coast of Africa to Mongolia, 9,000 miles in length and nearly 1,000 miles wide. Besides the North African deserts, this region includes the southern coast of the Mediterranean east of the Gulf of Cabes, Upper Egypt, the eastern and part of the western coast of the Red Sea, part of Syria, the eastern part of the countries watered by the Euphrates and Tigris, Eastern Arabia, the greater part of Persia, the extreme western part of China, Tibet, and, lastly, Mongolia. In the western hemisphere, Lower California, the table-land of Mexico and Guatemala, and the west coast of South America, for a distance of more than 2,000 miles, suffer from continuous intense radiant heat. 
Computations of the solar encery wasted on the rast areas thus specified wonld present an inconceivably great anount of dymanic force. Let us, therefore, merely esti. mate the mechanical power that would result from utilizing the solar heat on a strip of lamel at single mile in width, alonge the rainles: western const of Americia: the southerne const of the Merliterranean before alluted to: both sides of the allurial plan of the Nile in Upper Esypt; both sirles of the Euphrates am 'Tigris for a distance of ton miles above the Persim Gulf; ant, finally at strip one mile wile along the rainless portions of the shores of the Red seib belone pointed out. The aggregate length of these strips of hand, selecterl on accomet of heing acossihte hy water communication, farl exceeds 8,000 miles. Llopting the staterl length and al wittl of one mile as a basis for computation, it will be secu that this very nurrow belt cover's 22:3,000 millions of square feet. Dividing the latter anom by the area of 100 square feet necessary to profluce one horse-power, we learn that 22,300,000 solar engines, talch of 100 horse-power, could be kept in constant operation, nine hours a day, by utilizing only that heat which is now wasted on the assmmed small fraction of land extending along sone of the water-fronts of the sumbunt regions of the earth. Due consideration camnot fail to comvince us that the rapid exhanstion of the European coalfields will soon cause great changes with reference to international relations, in firror of those comm. tries which are in possession of continuous sun-power. Upper Egypt, for instance, will, in the course of a few cent- 
turies, derive signal advantage and attain a high political position on account of her perpetual sunshine and the consequent command of minlinited motive force. The time will come when Europe must stop her mills for want of coal. Upper ligypt, then, with her never-ceasing sun-power, will invite the European manufacturer to remore his machinery and erect his mills on the firm ground along the sides of the alluvial plain of the Nile, where an amount of motive power maly be obtained many times greater than that now employed by all the mambiactories of Europe. 





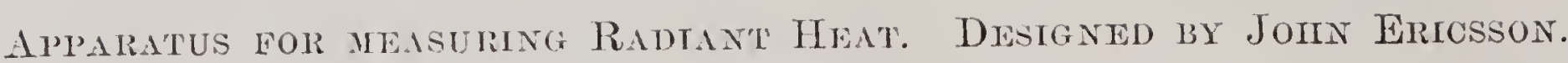

Construeted AT New York, 1873.

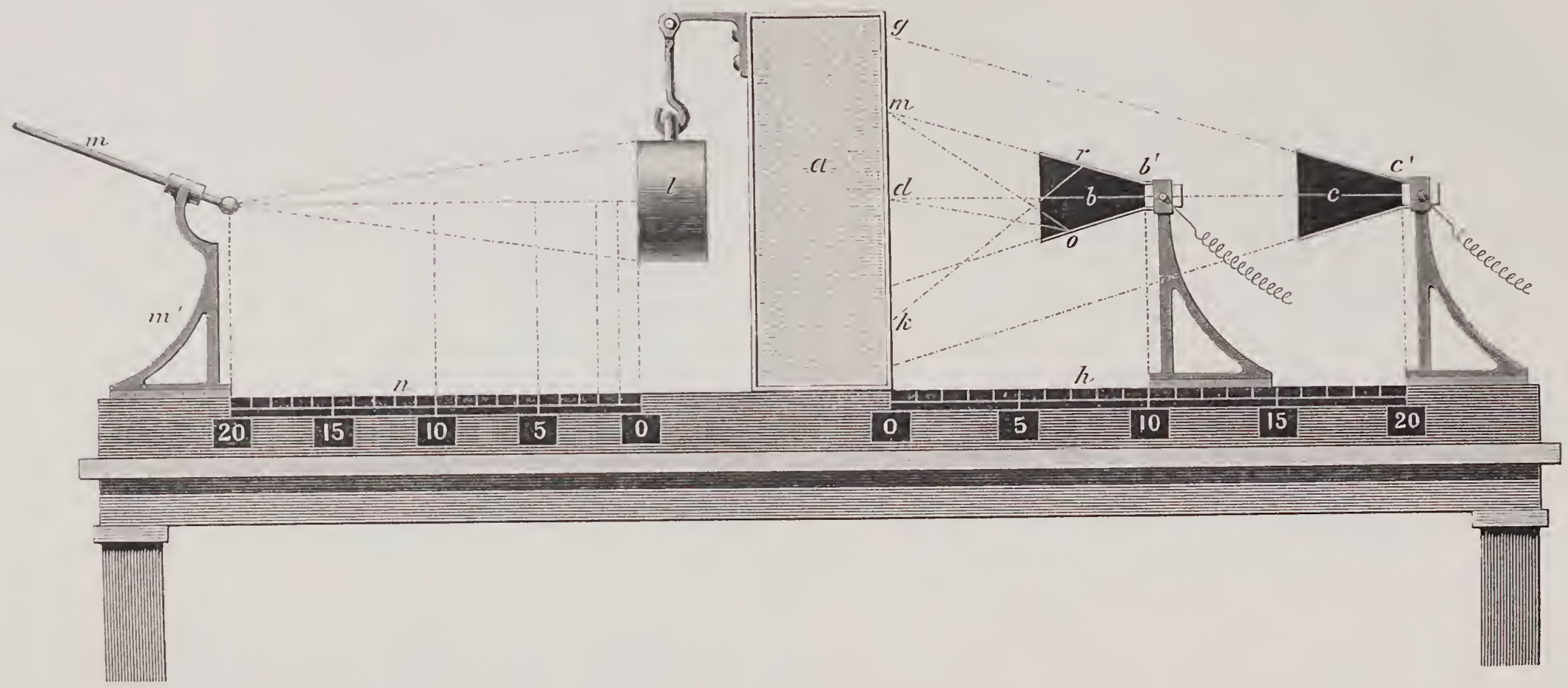


INSTRUMENT FOR MEASURLAG THE INTENSITY OF RADIATION FroM Exchosid Coxcave Raditors.

Designed m Toin Ericsgon. Manufactured at New York, 1873.

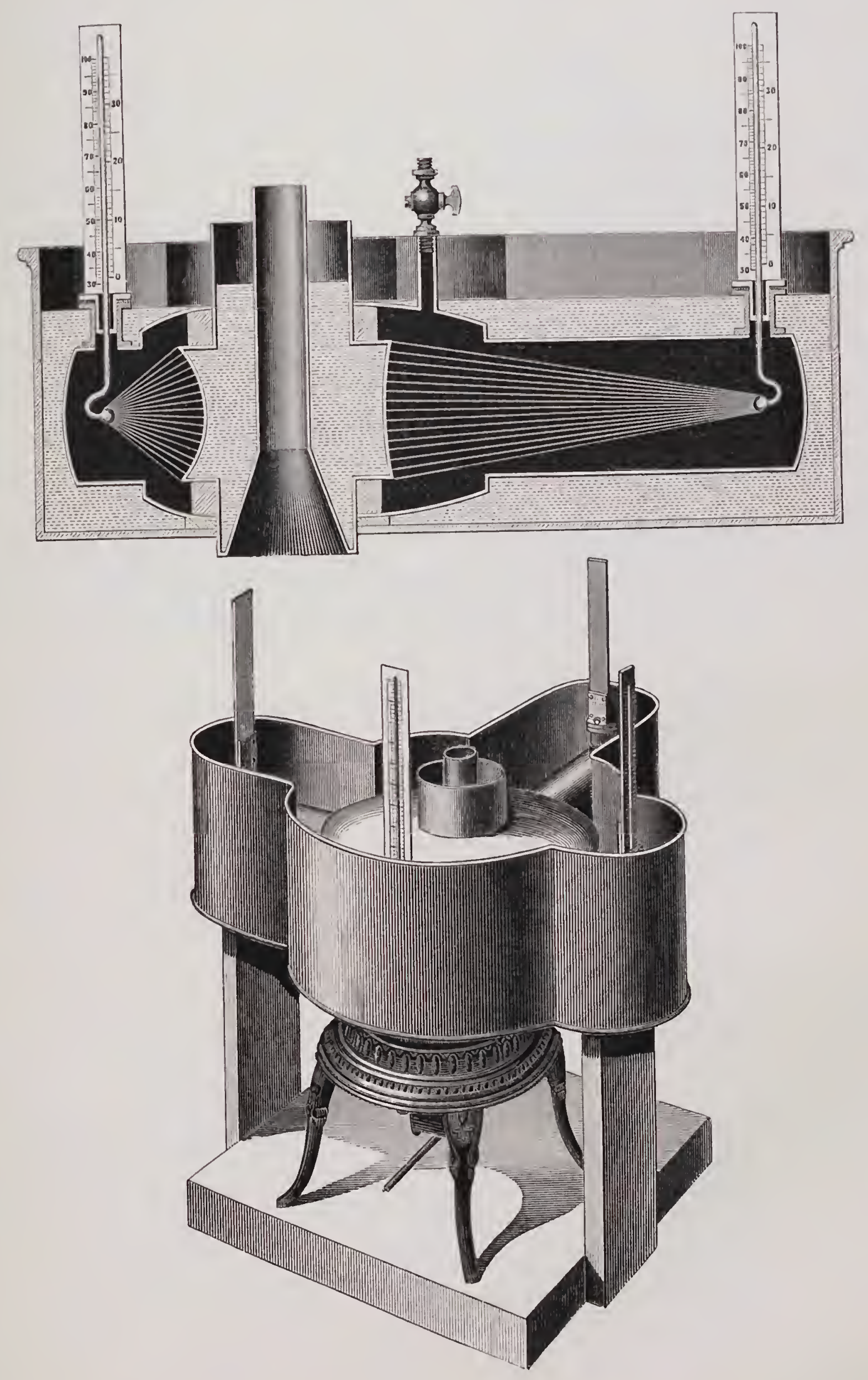





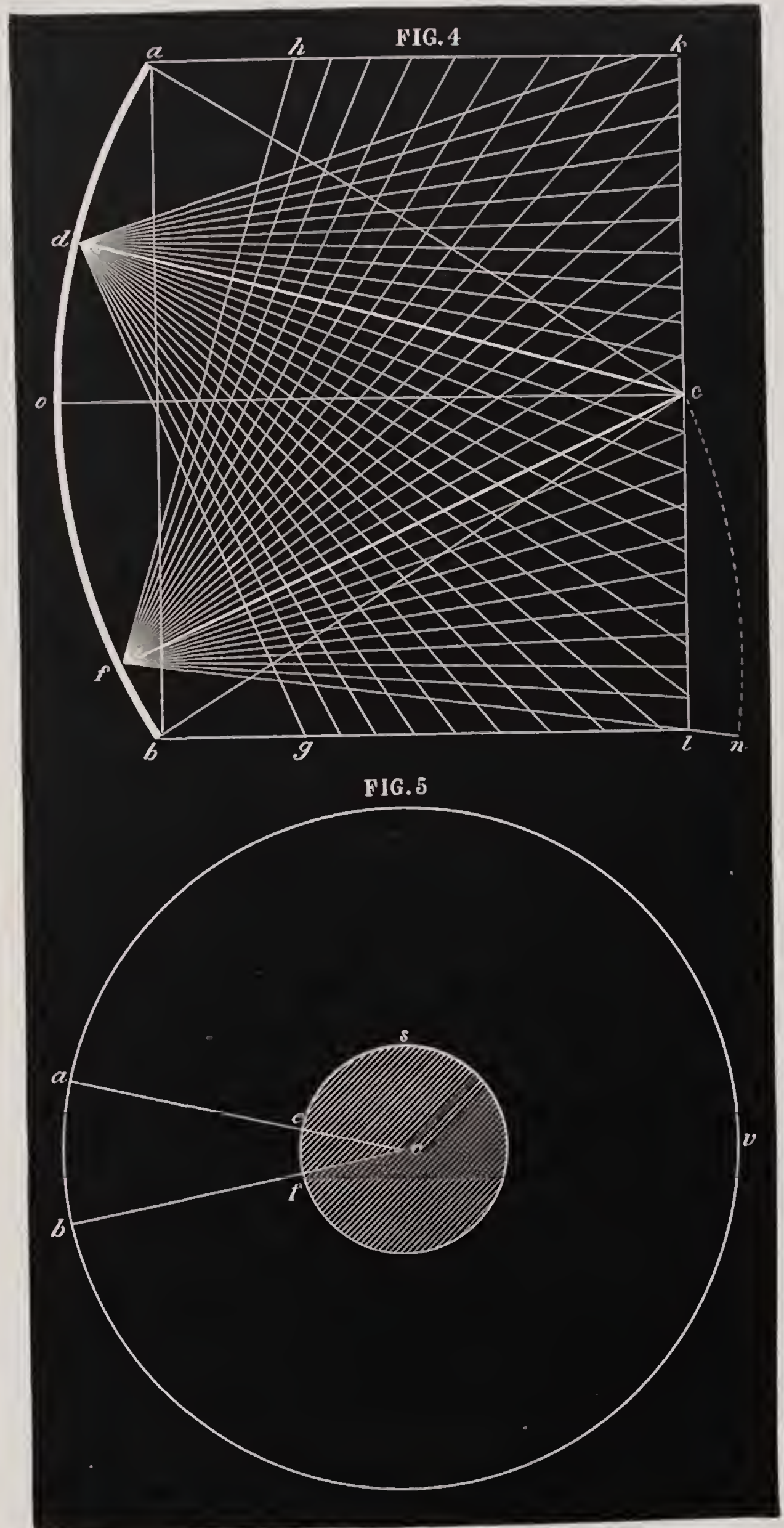





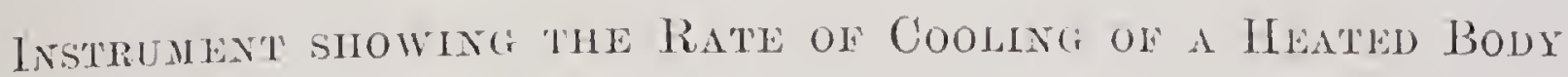

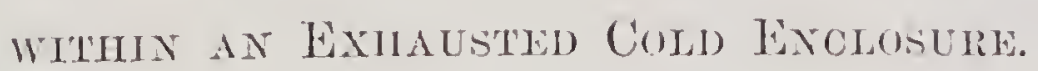

Designed by John Ericsson. Manufactured at New York, 18 id.

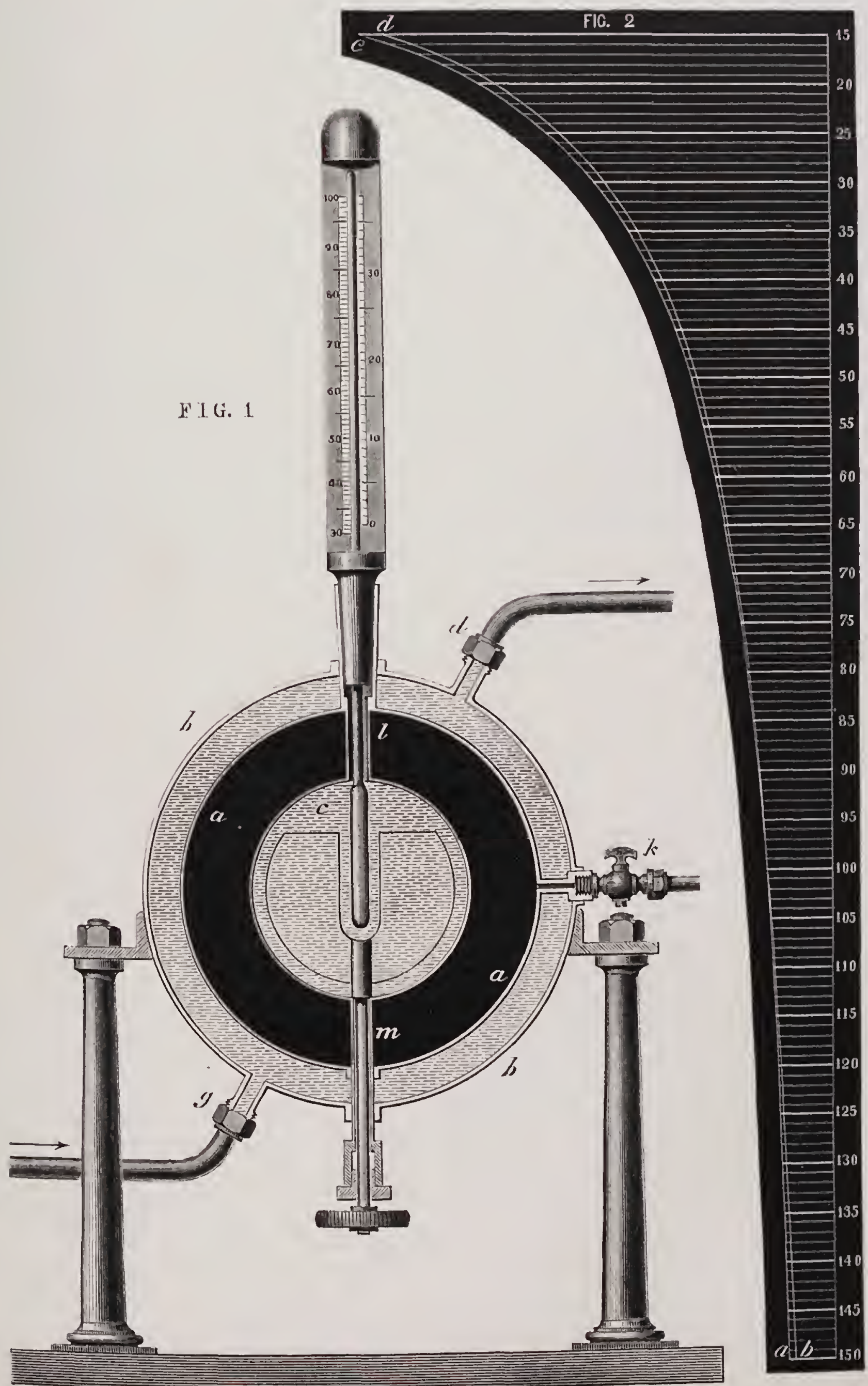



Ixstrunext show tag tife Rate of Heatixg of a Cold Body

WITHN AN ExHAusted HeATED ENClosuri.

Designed hi John Ericsson. Mandfactured at New York, 18 ia.

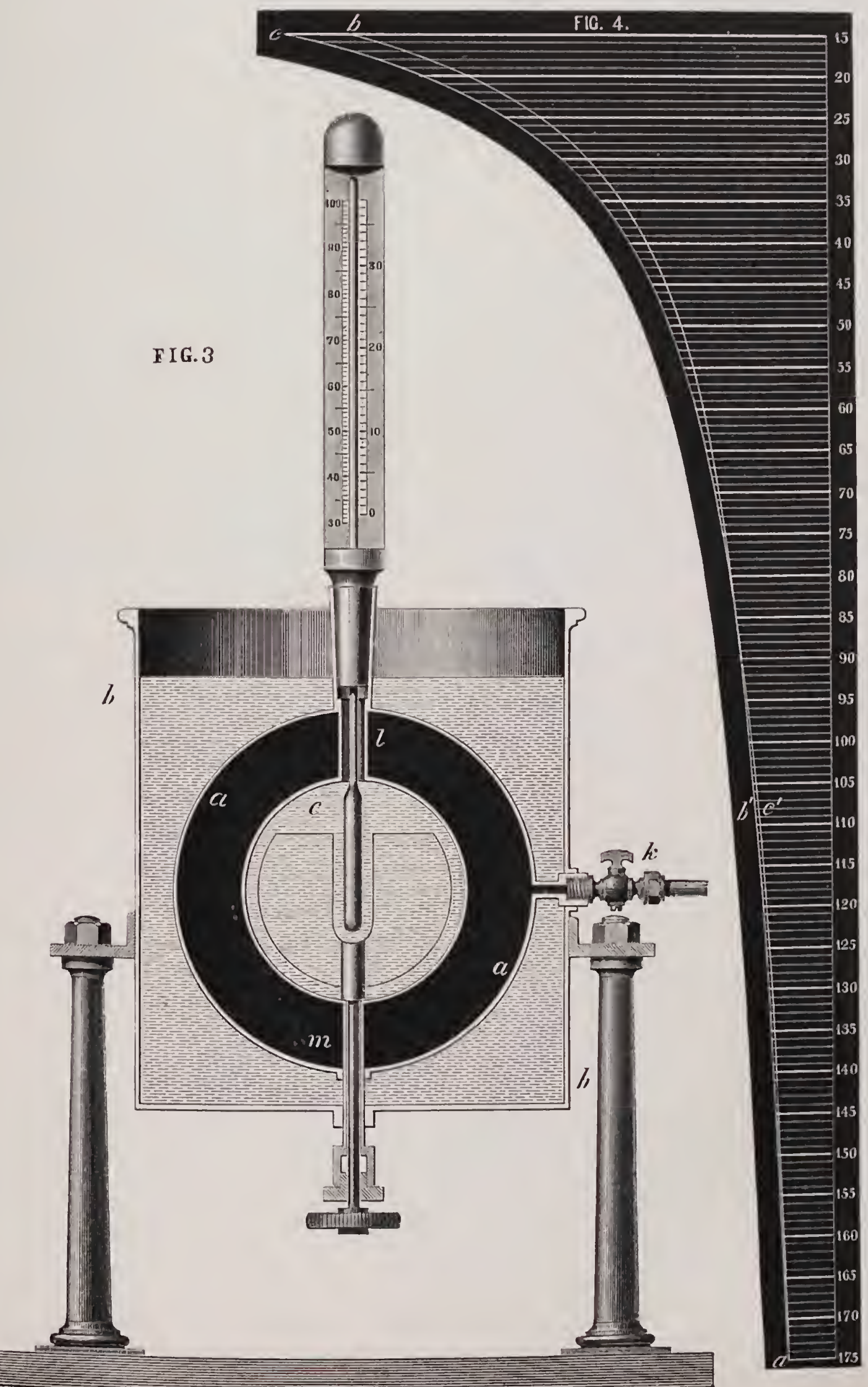

FLATE 5. SEE CHAL. II. 

Instruneste showhe tire Rate of Cooming of an Incandescent Spmere witme aN Eximusted Coln Exclosure.

Destgned m . Tome Emosson. Manufactured at New Tork, 184.
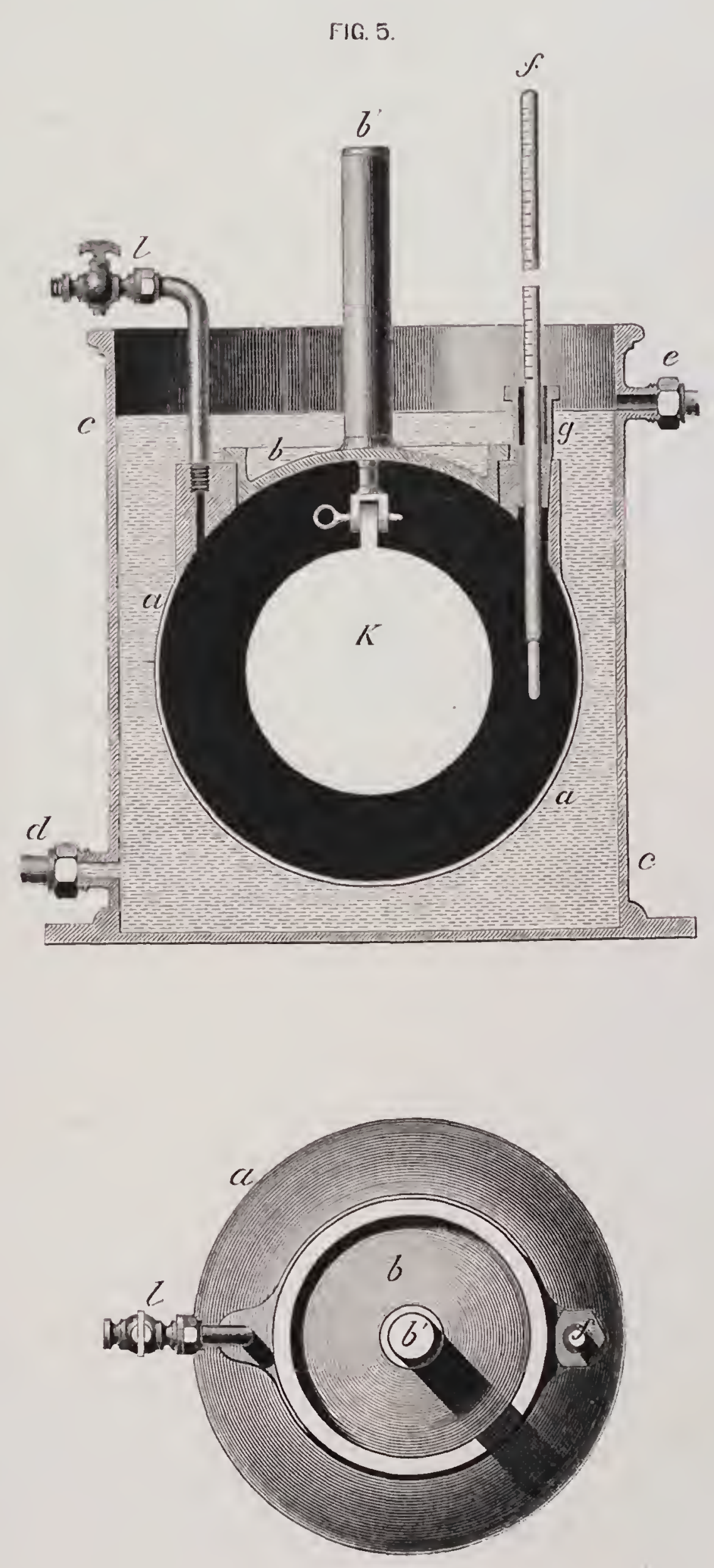



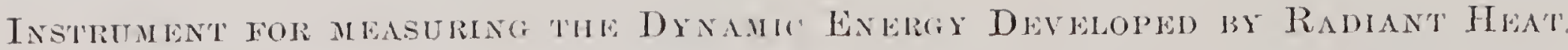

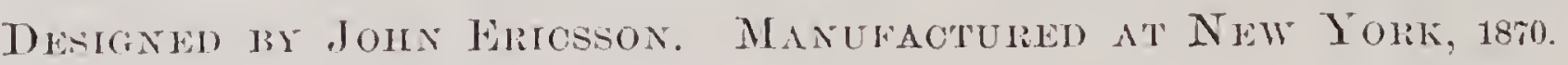

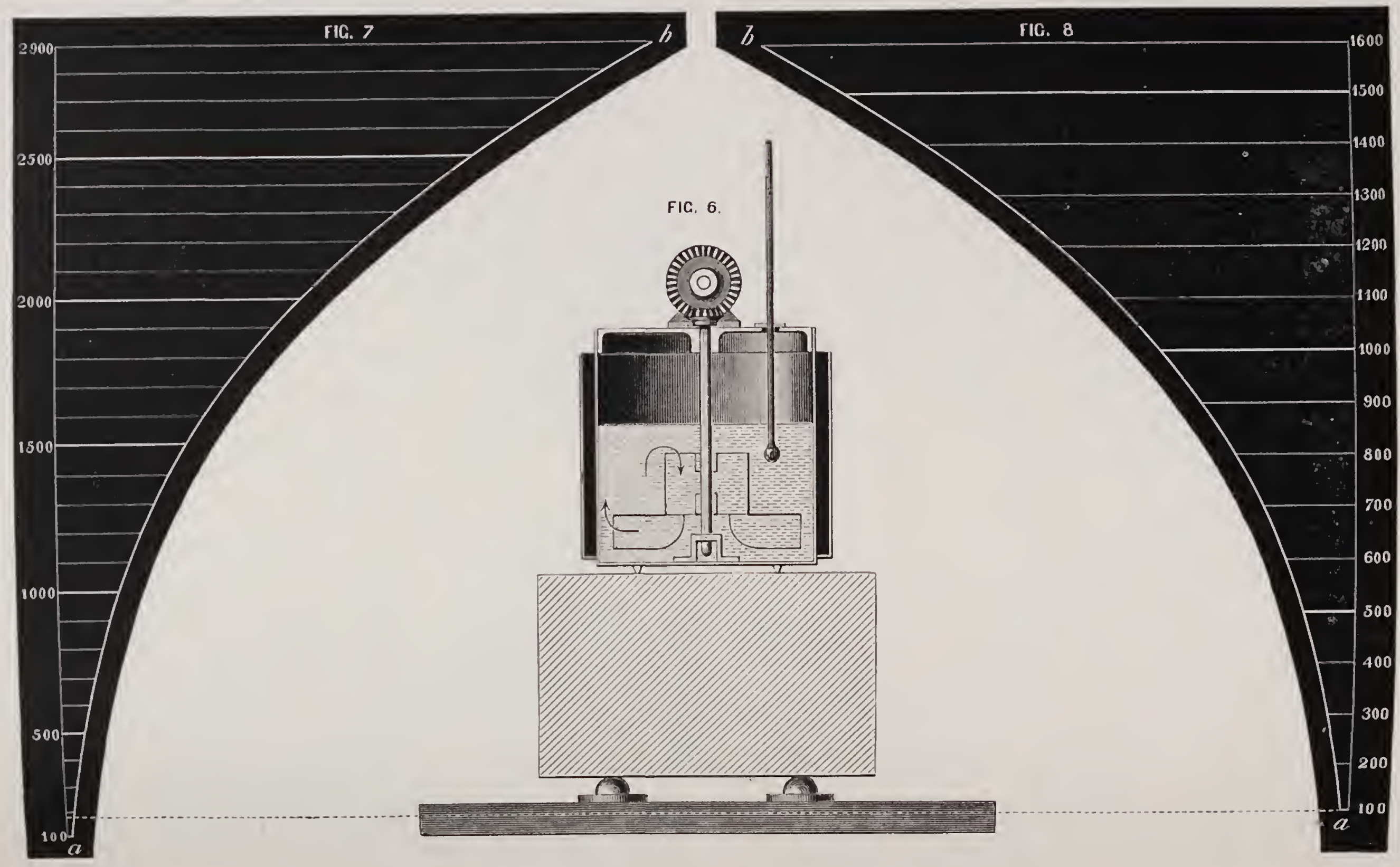




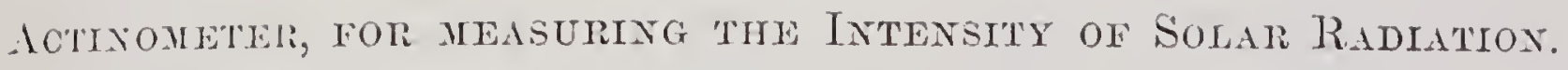

Designed 3r Jomn Ericsson. Manufacteren at New Tork, $18 \pi 0$.

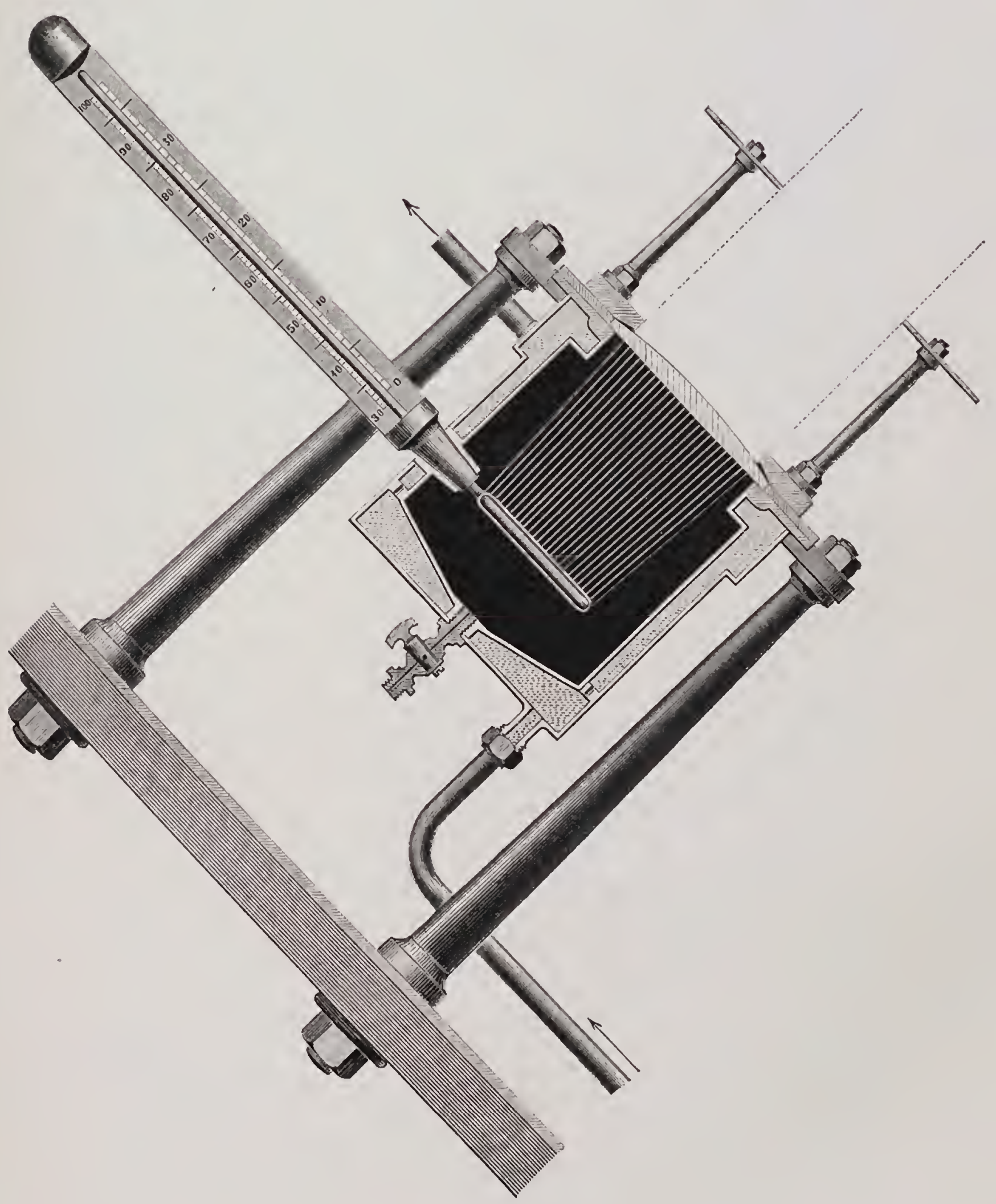

PrATES. SEE CHAP. III. 



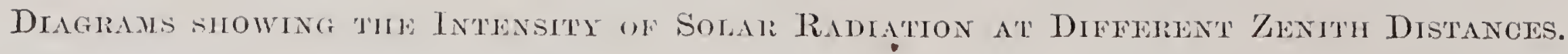

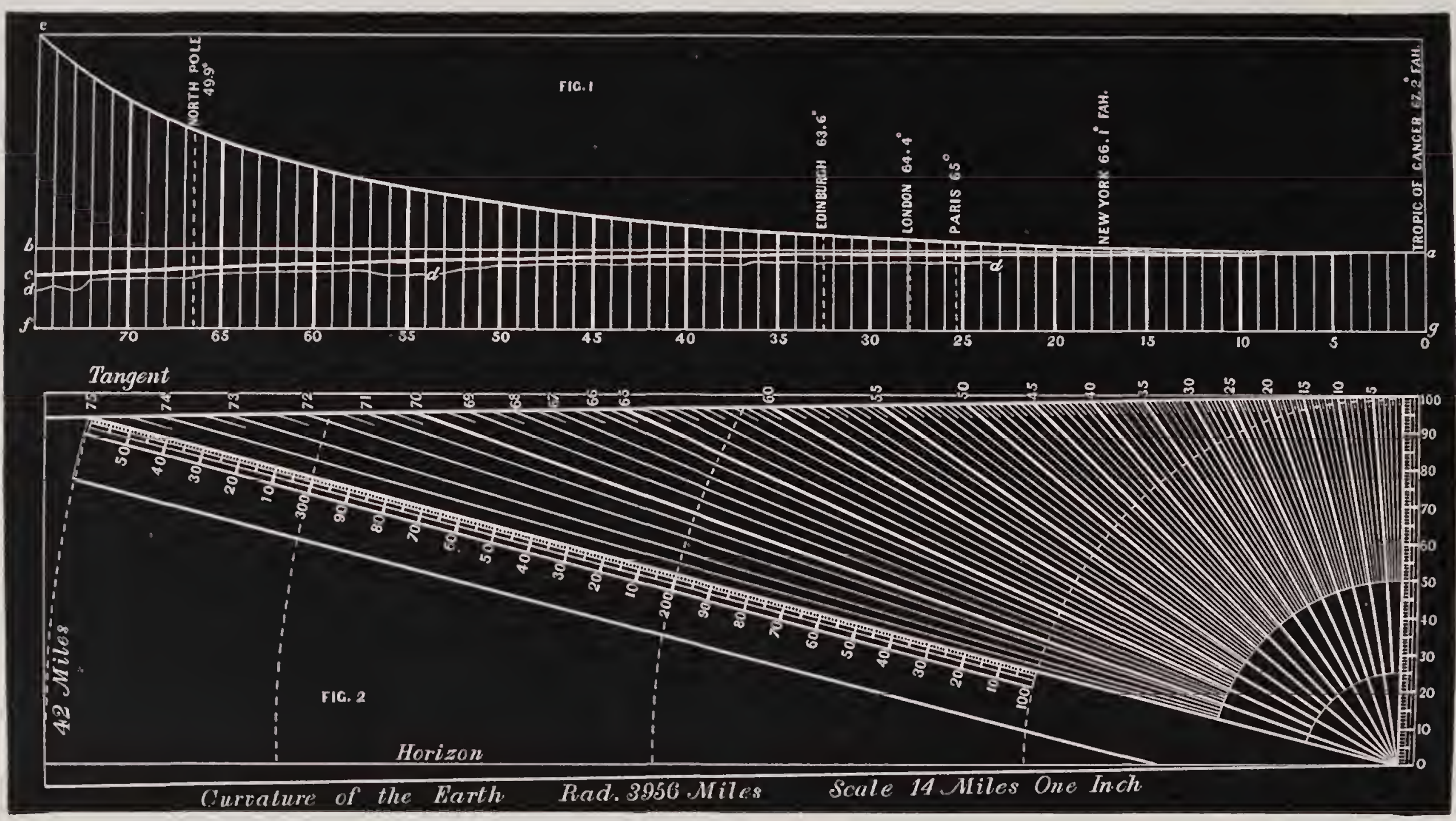





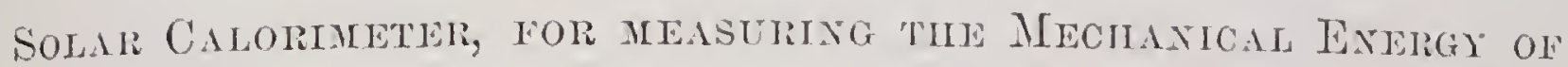

Solar Radation. Designed by Jomn Ericssox.

Manufactured a't New Yolk, 1870.

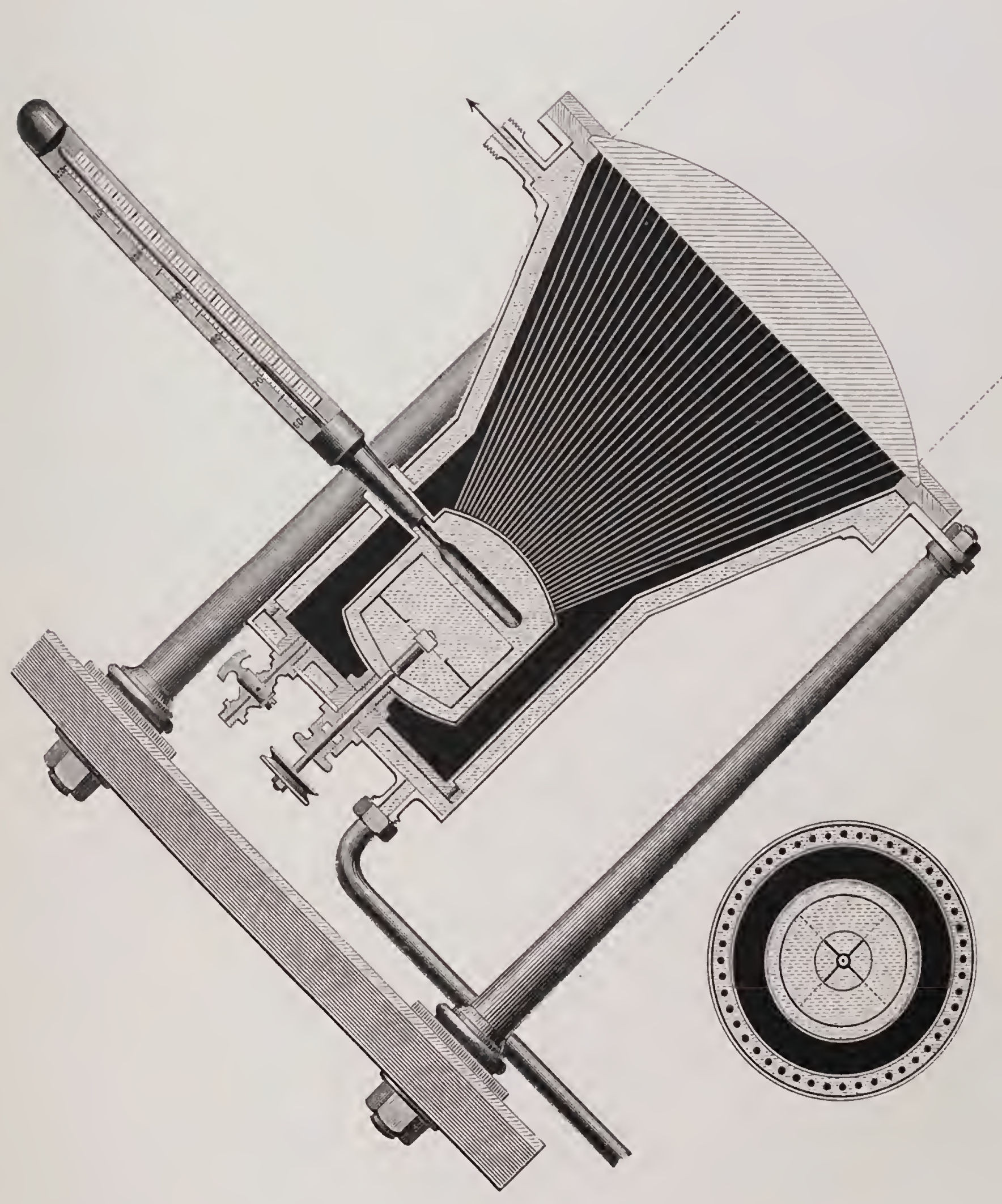

PLATE 10. SEE CHAP. T. 


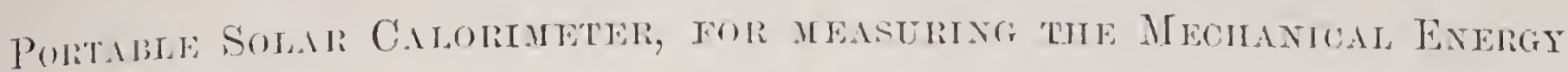

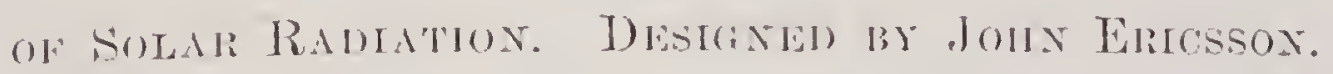

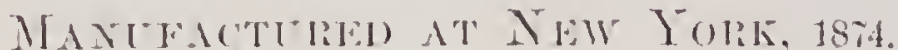

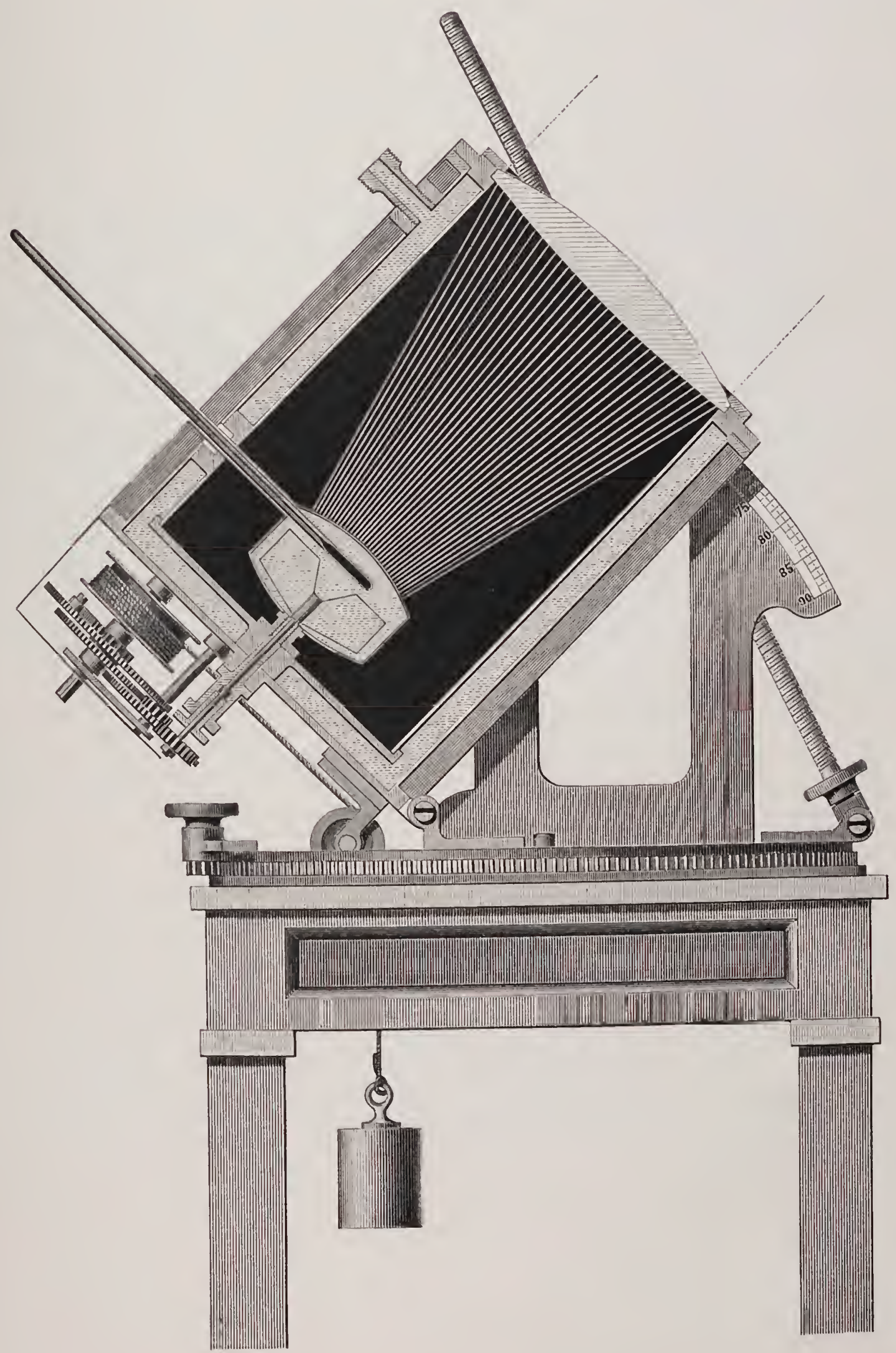

PLATE 11. SEE CHAP. T. 



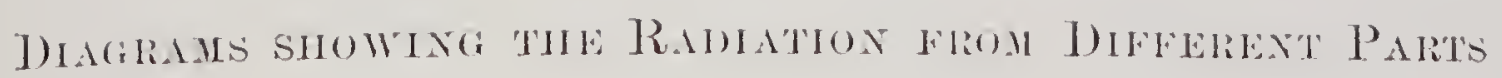
of THE SOLal: D)rse.

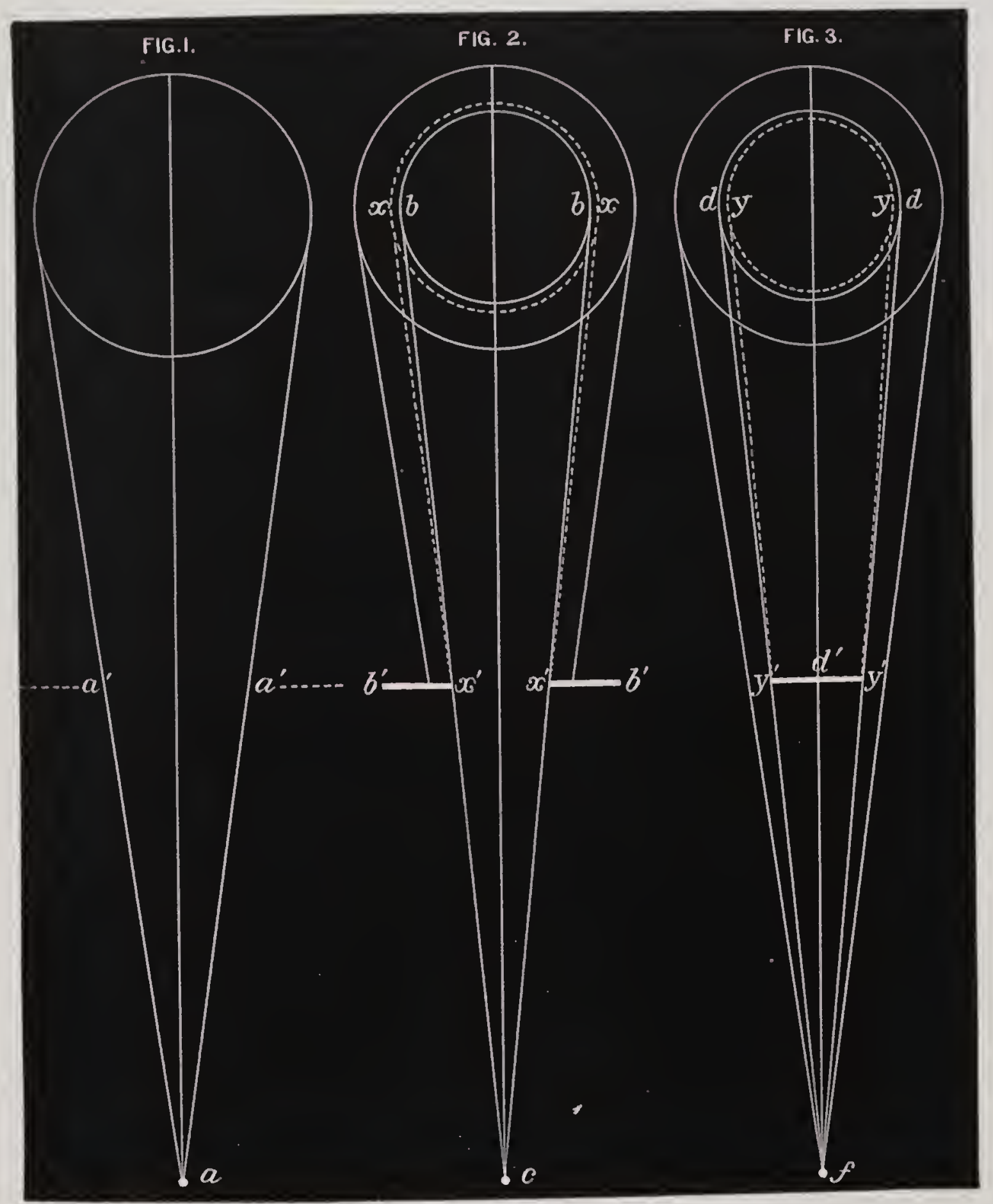





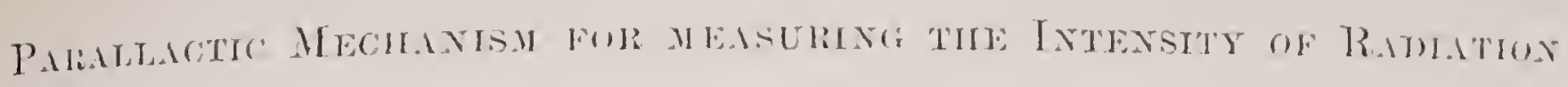

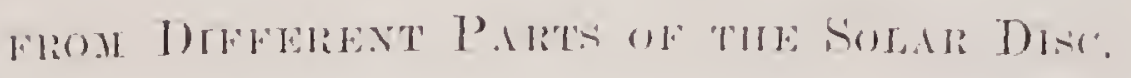

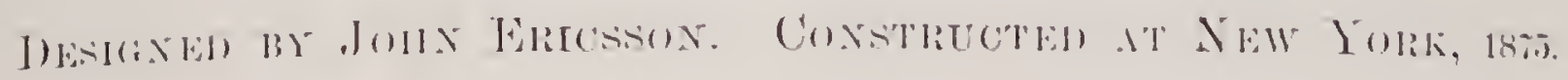
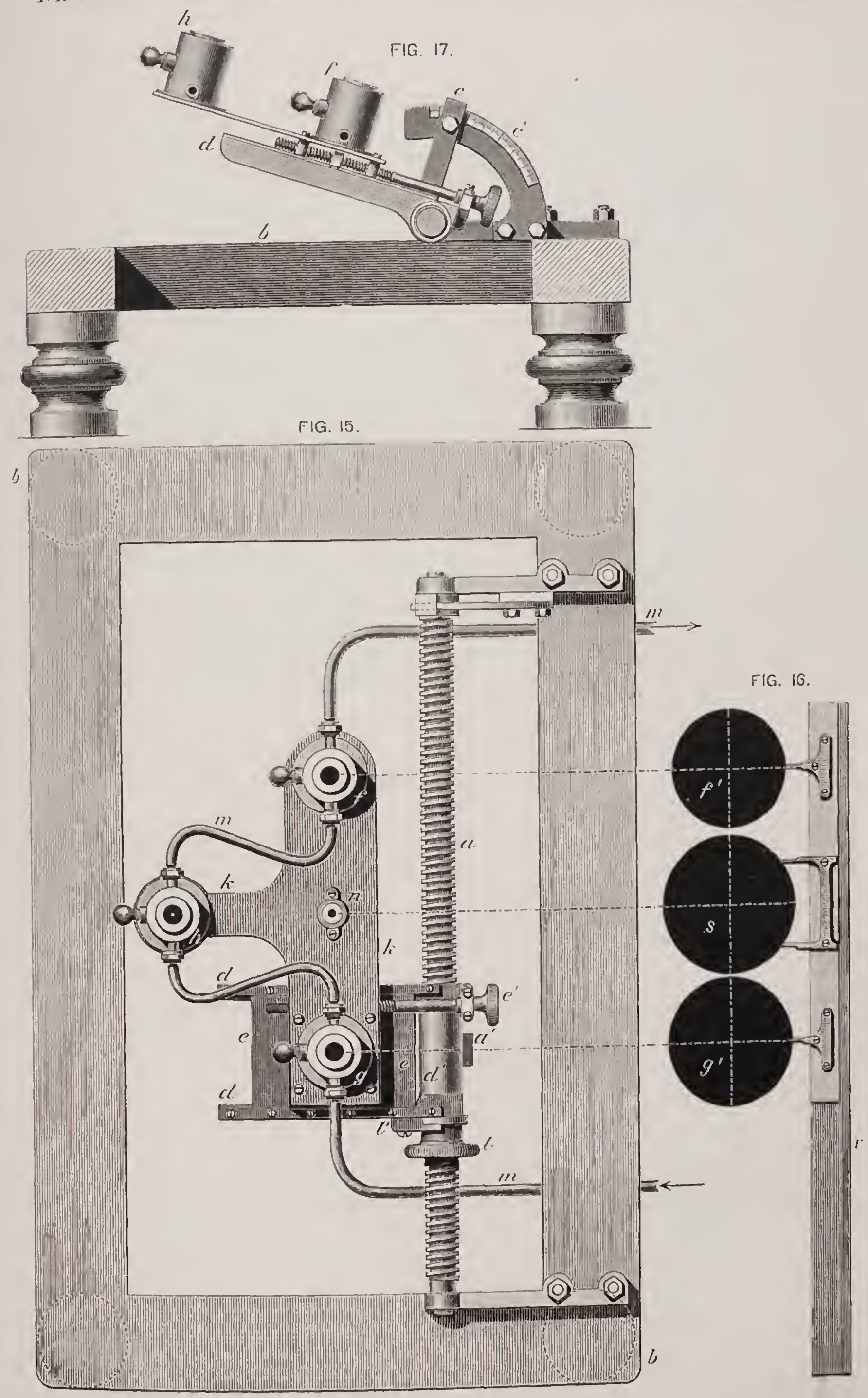

PIATE 13. SEE CHAP. VI. 



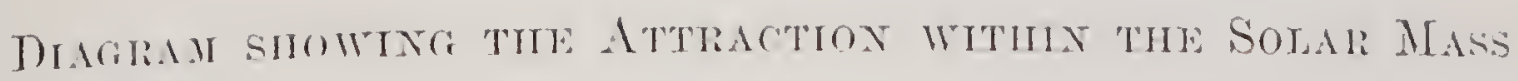

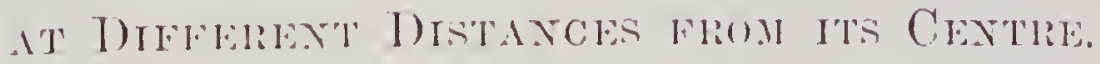

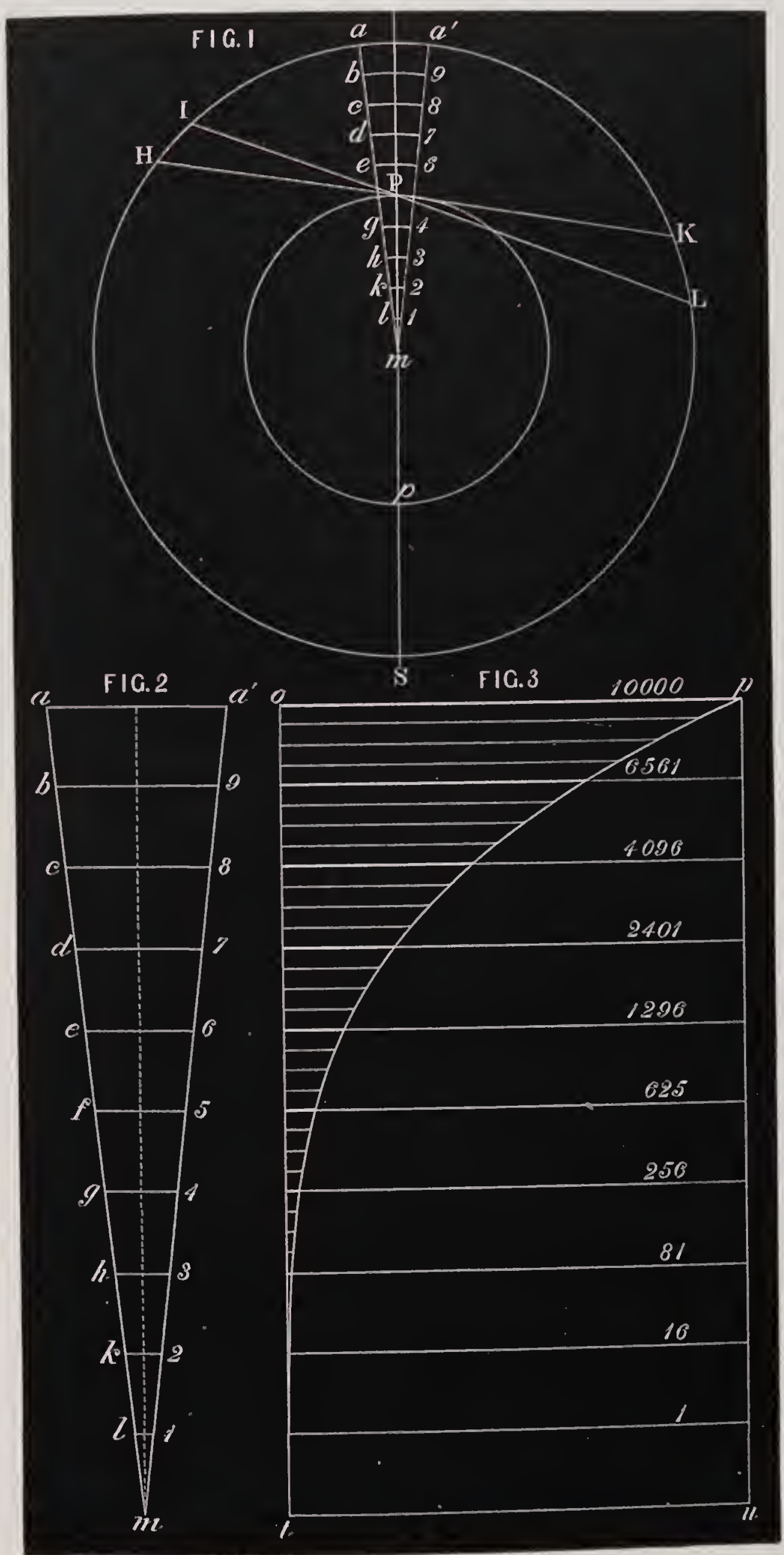



Ixstrumaxt for measurisg the Radiat Power of the Sotare

Atrospheme. Dengaxin by Johy Ericson.

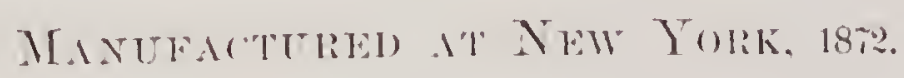

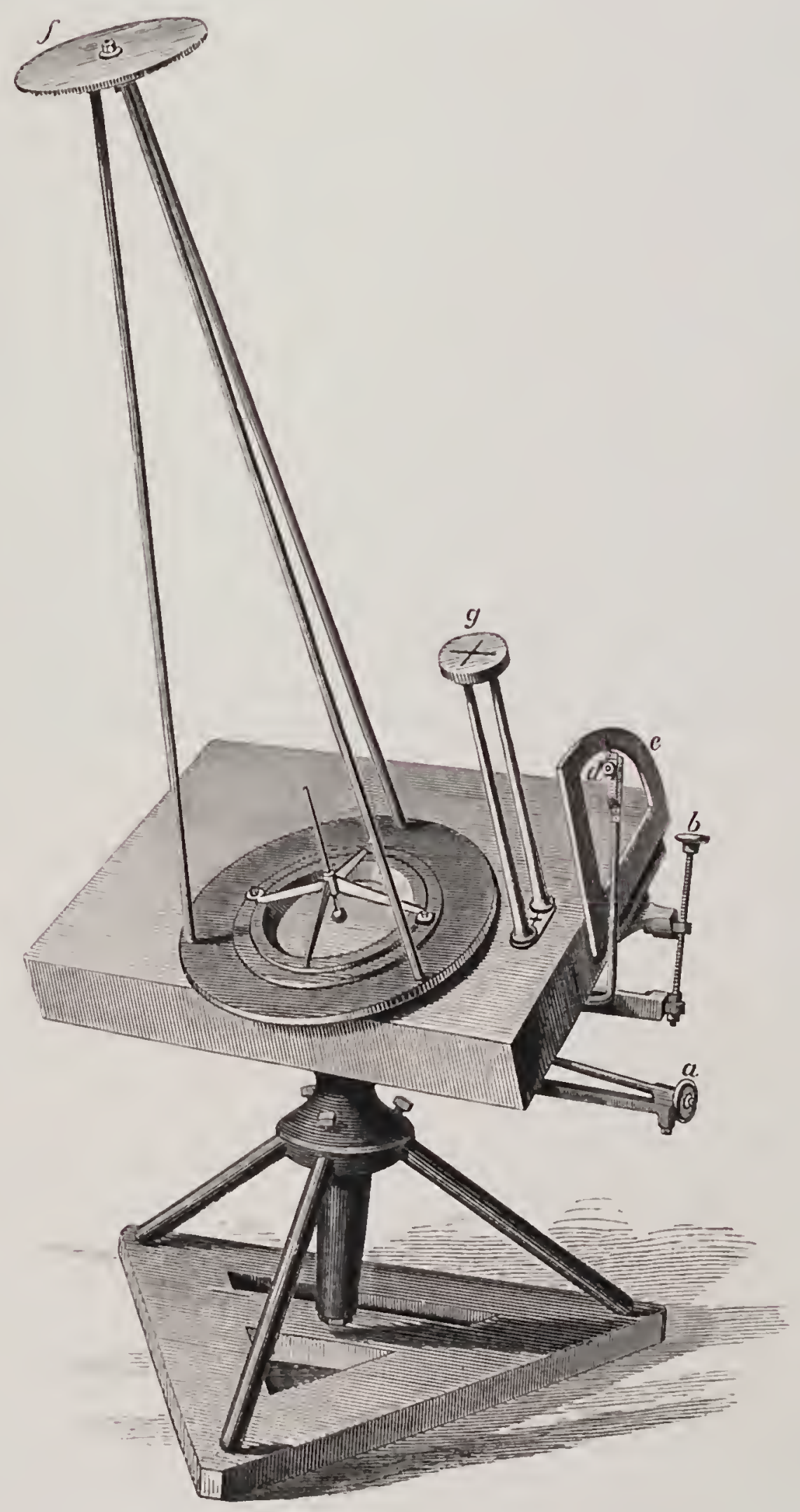





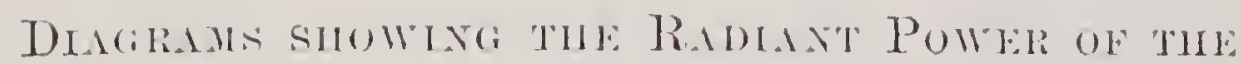

Solar Atuospheit:

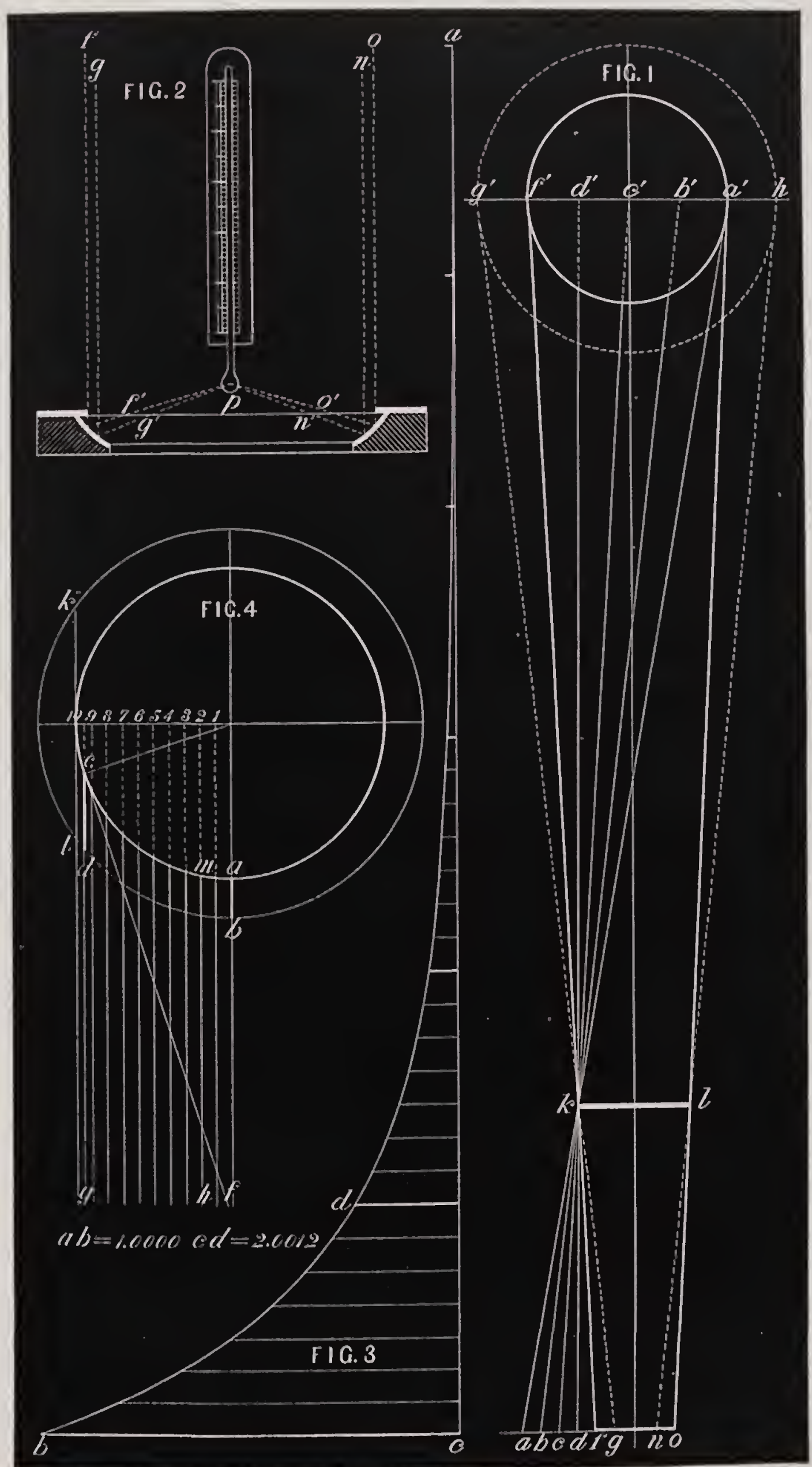



INSTRUMENT FOR MEASLRING TIIE ACTTAL. INTENSITT OF THE SUN'S RAYS.

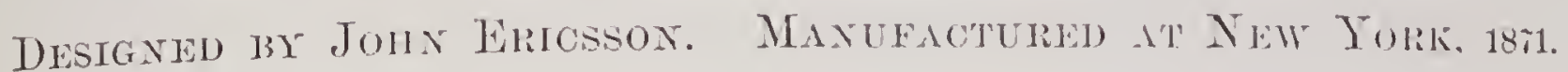

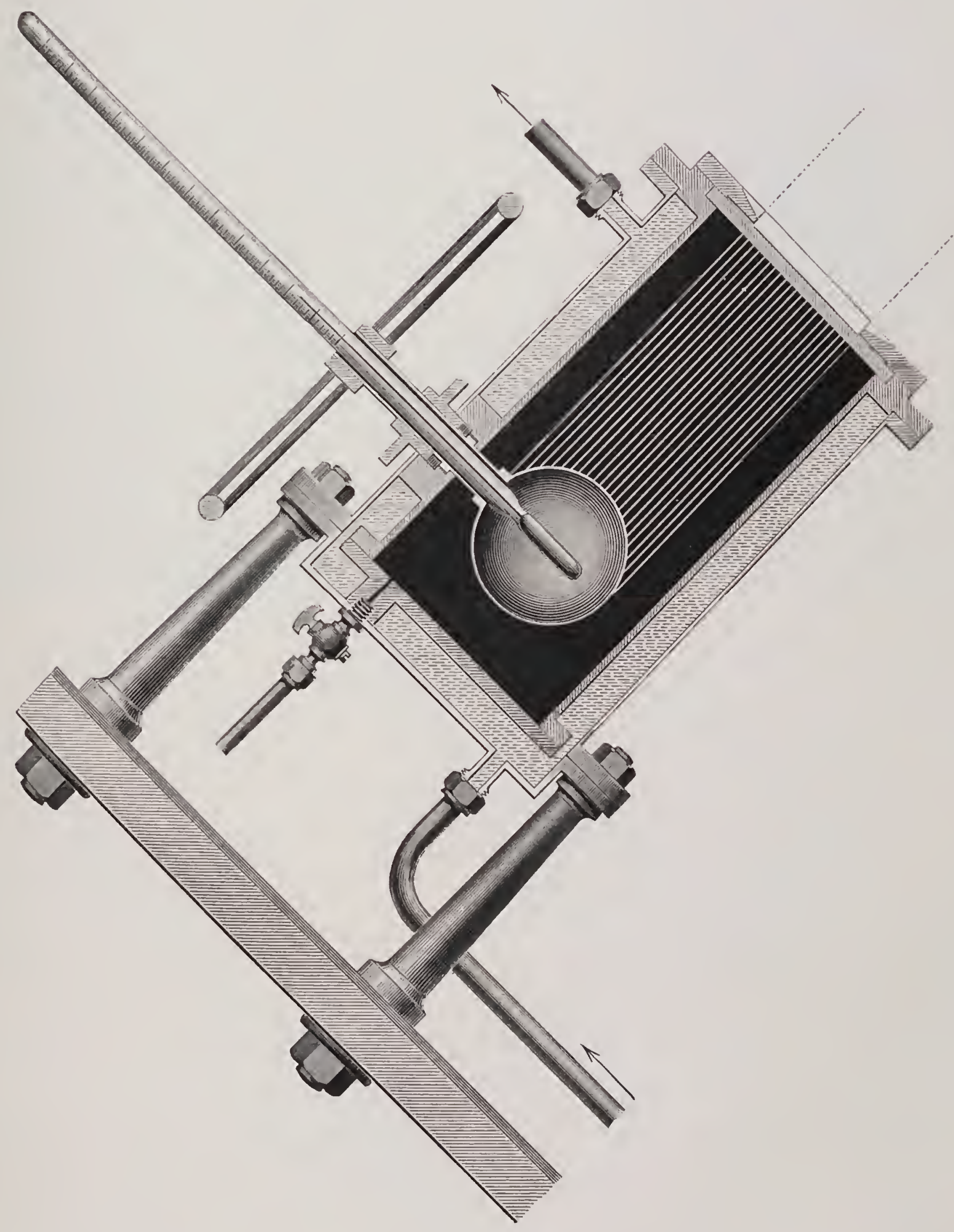

PLATE 1\%. SEE CIIAP. IX. 



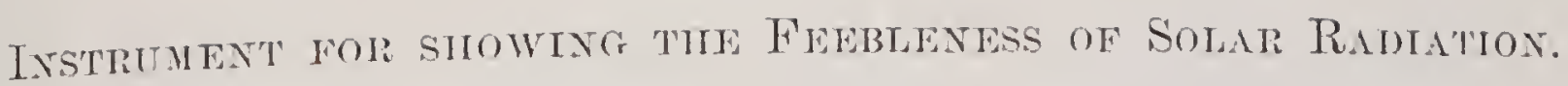

Destgated by Jom Erichson. Constructed at New York, 18 .

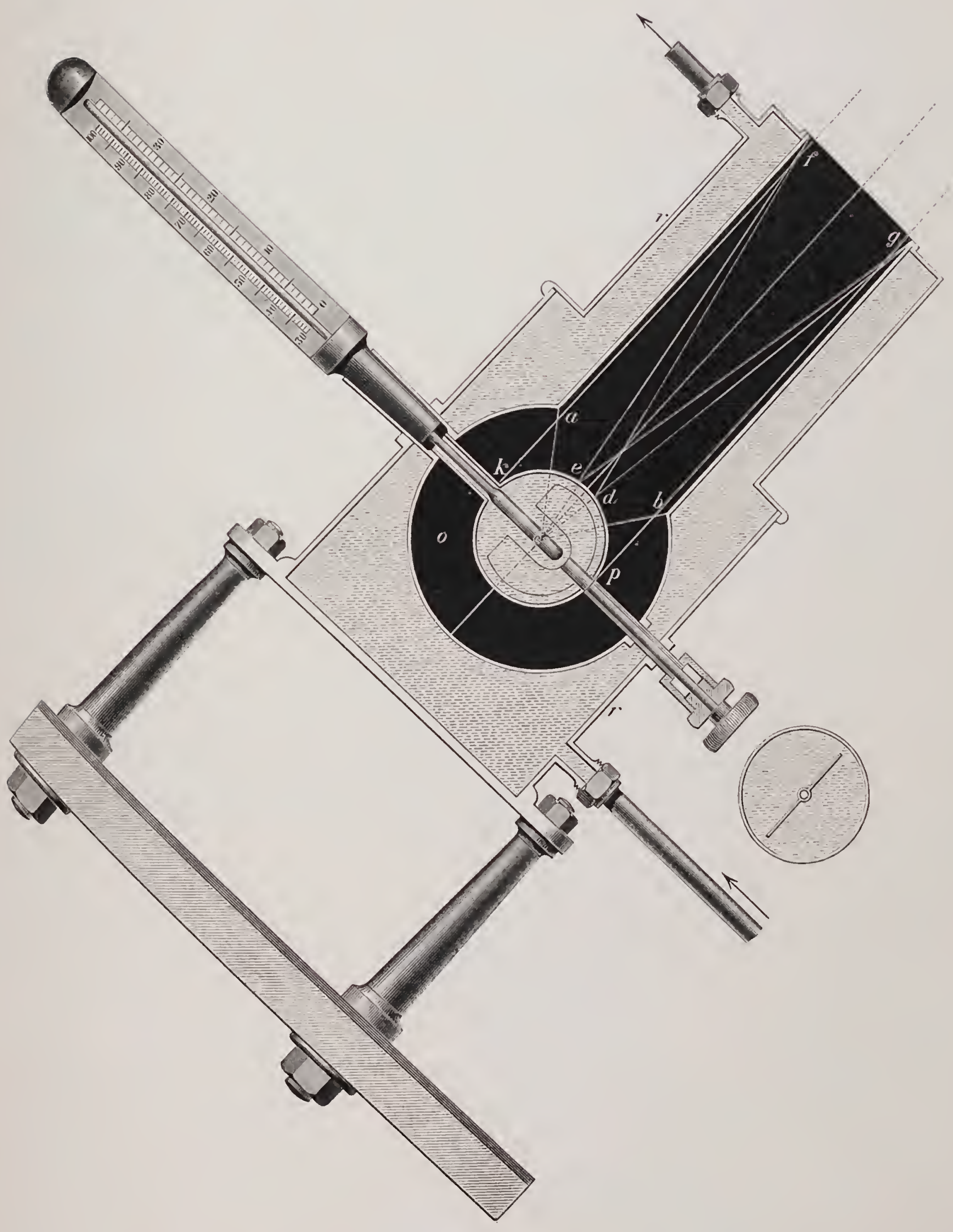



Solar Pyrometer, for ascertatnigg the Temperature of the

Solat Surfack. Destgned hy Joln Ericsson.

Constructed A'T NEW Tork, $18 \% 0$.
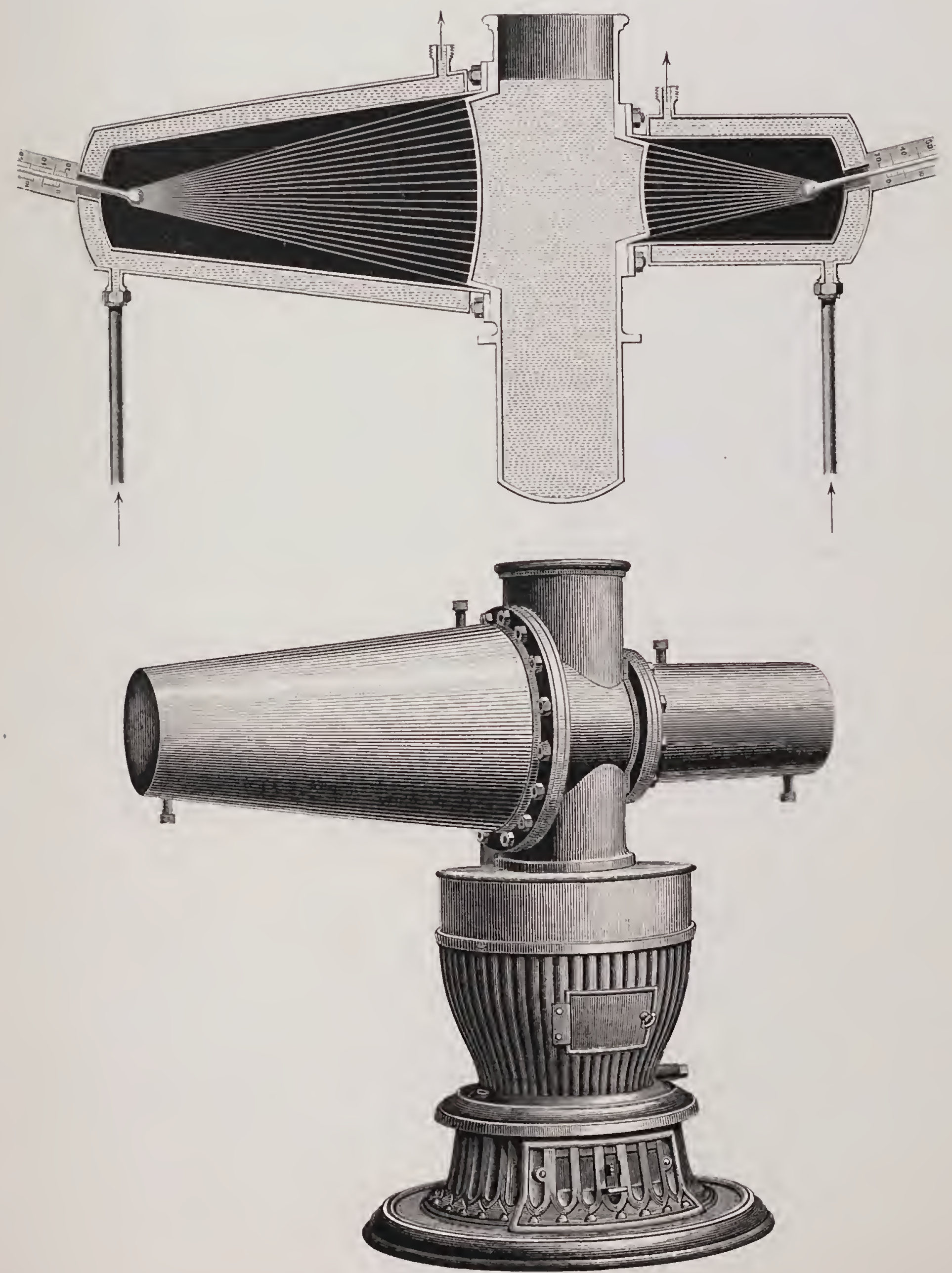

PLATE 19. SEE C'HAI. X. 


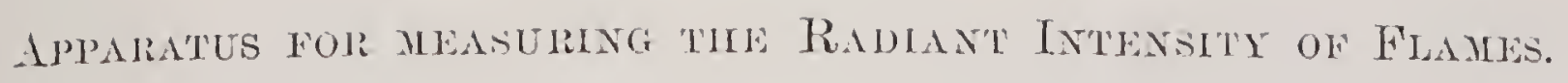

Designed bi Jom Ericsson. Constructed at New York, 187.
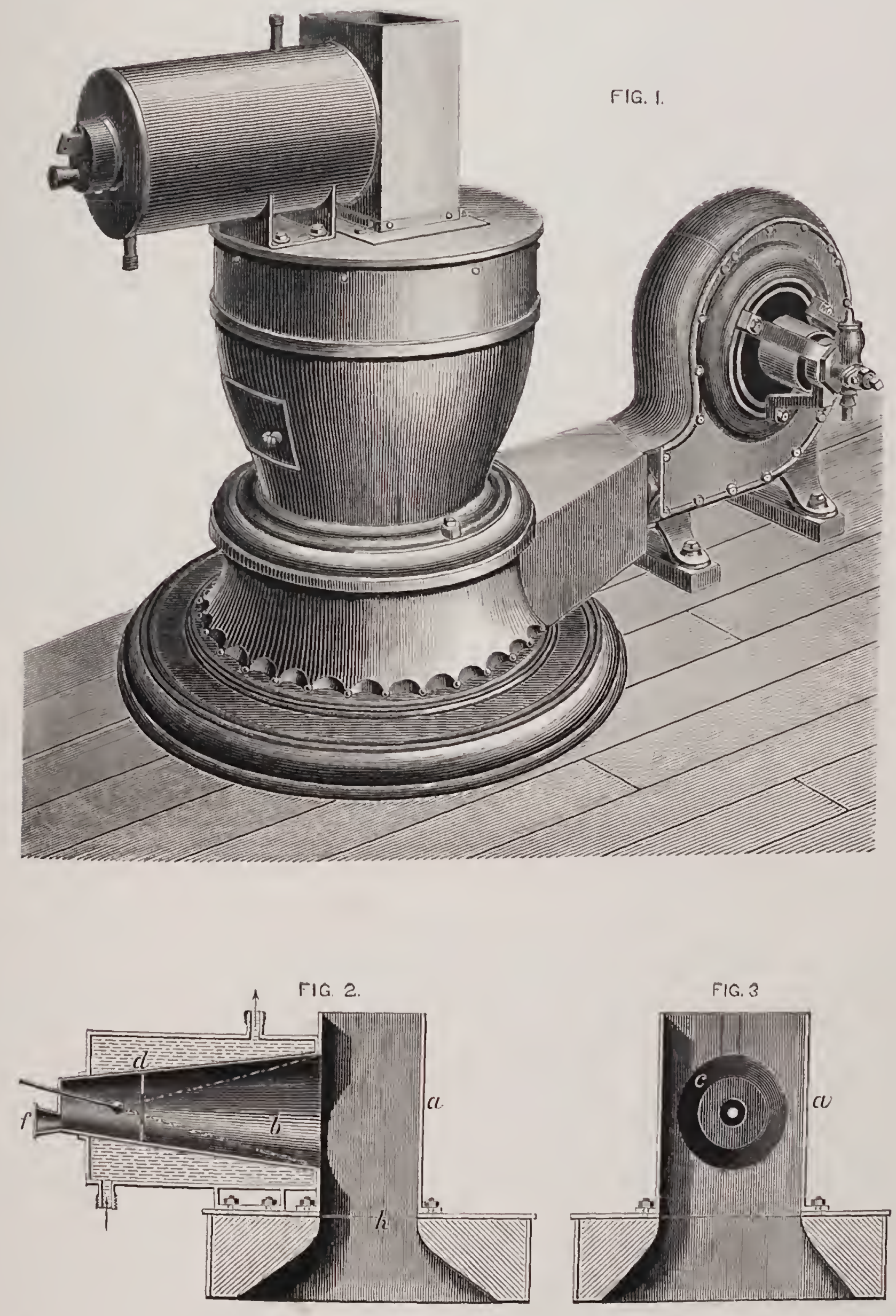



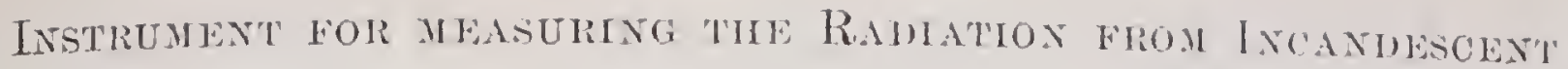

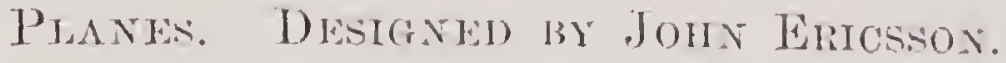

Manefactum at NeW Yom, 187.
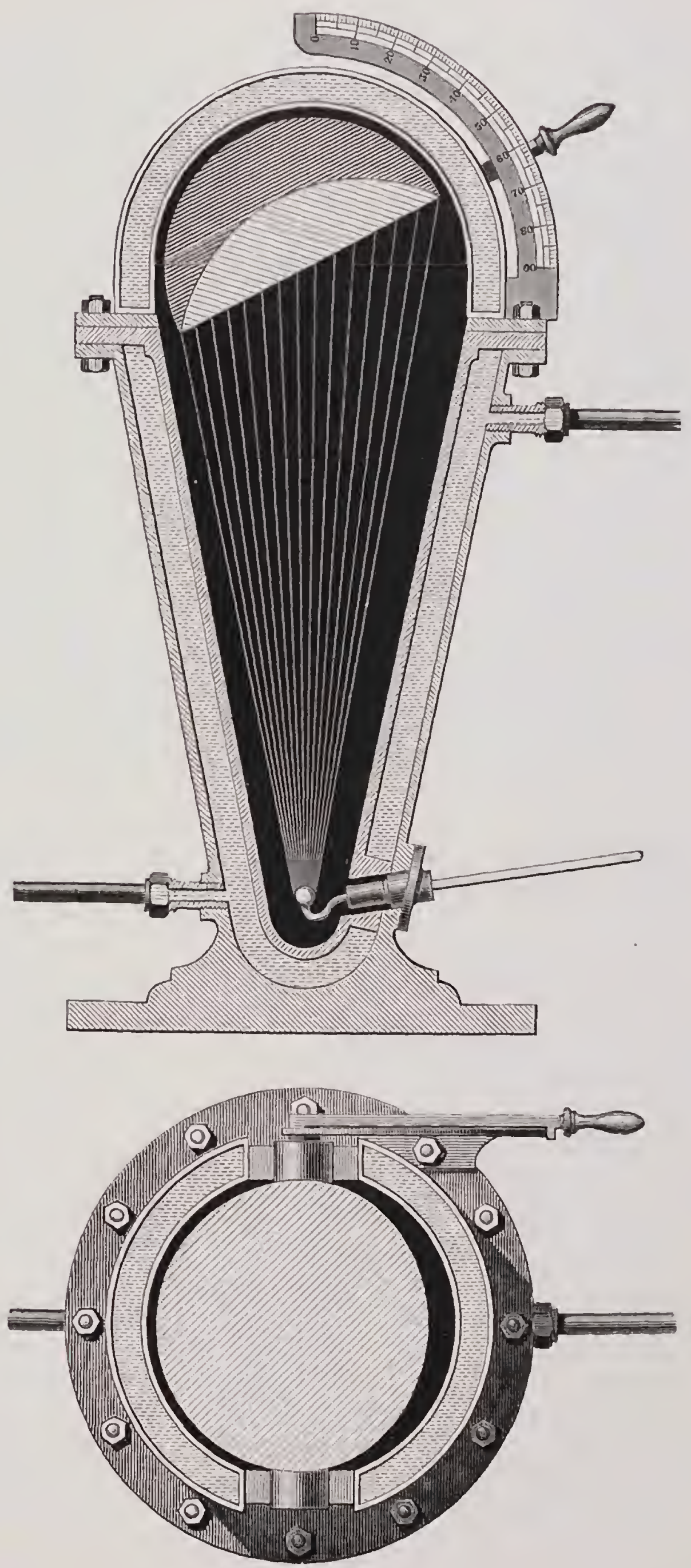

PLATE 21. SEE CHAIP. XI. 


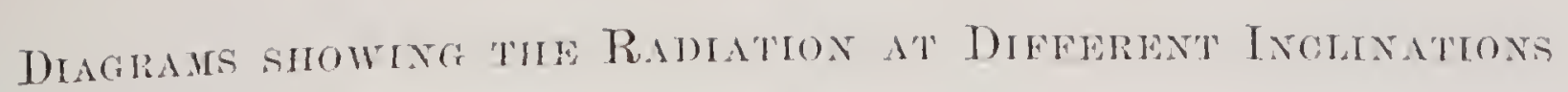

or Incandescent Pinnes.

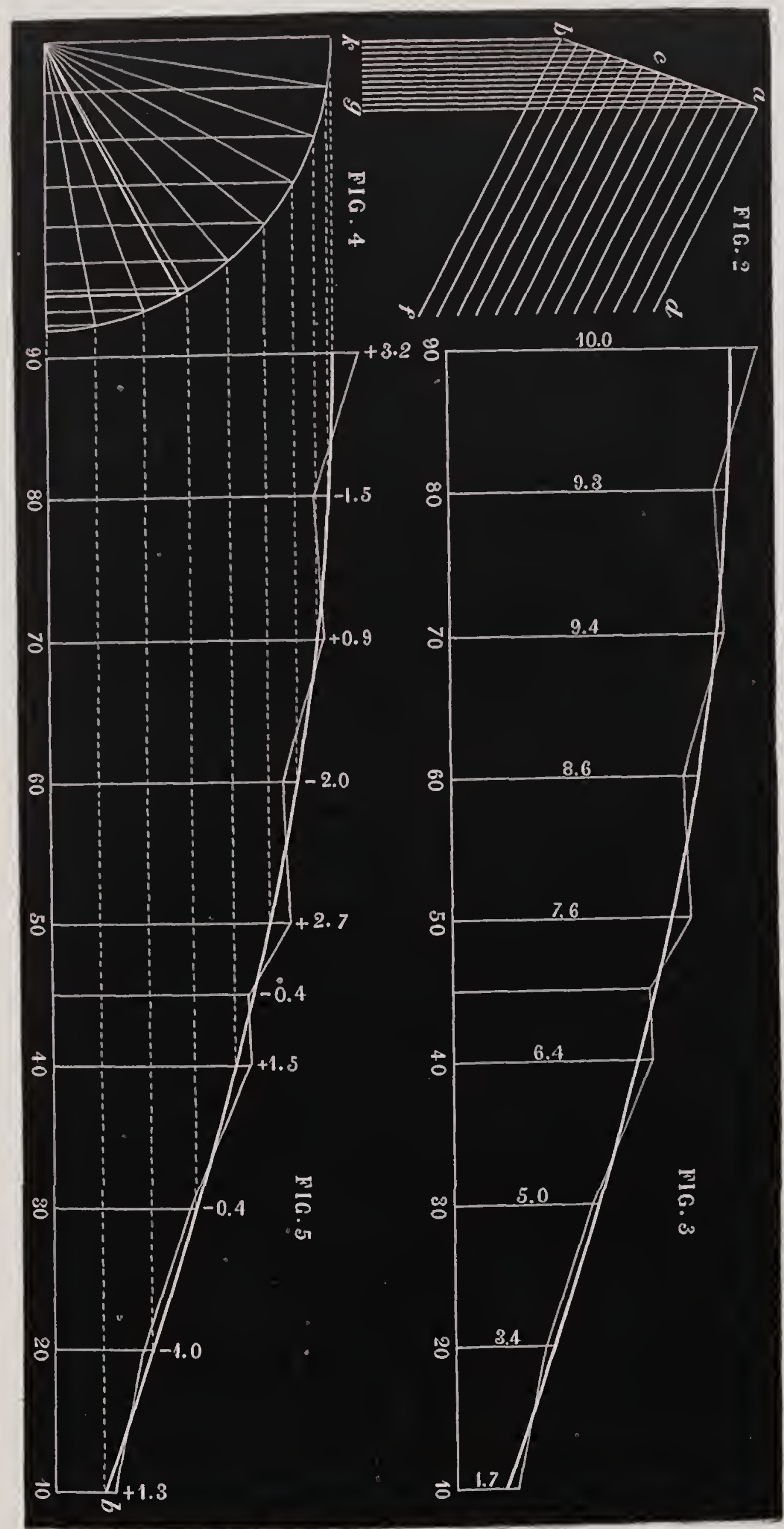





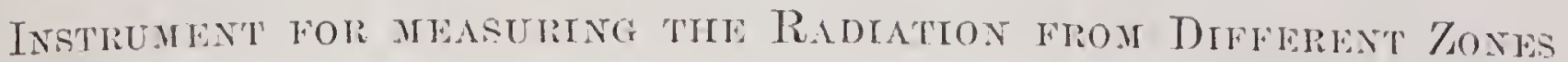

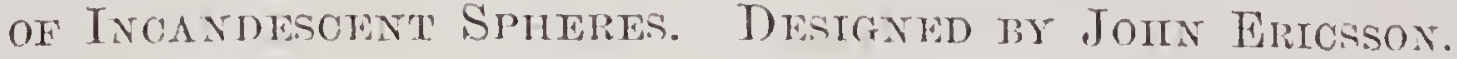

Manteareturen at New Yolik. 1872.
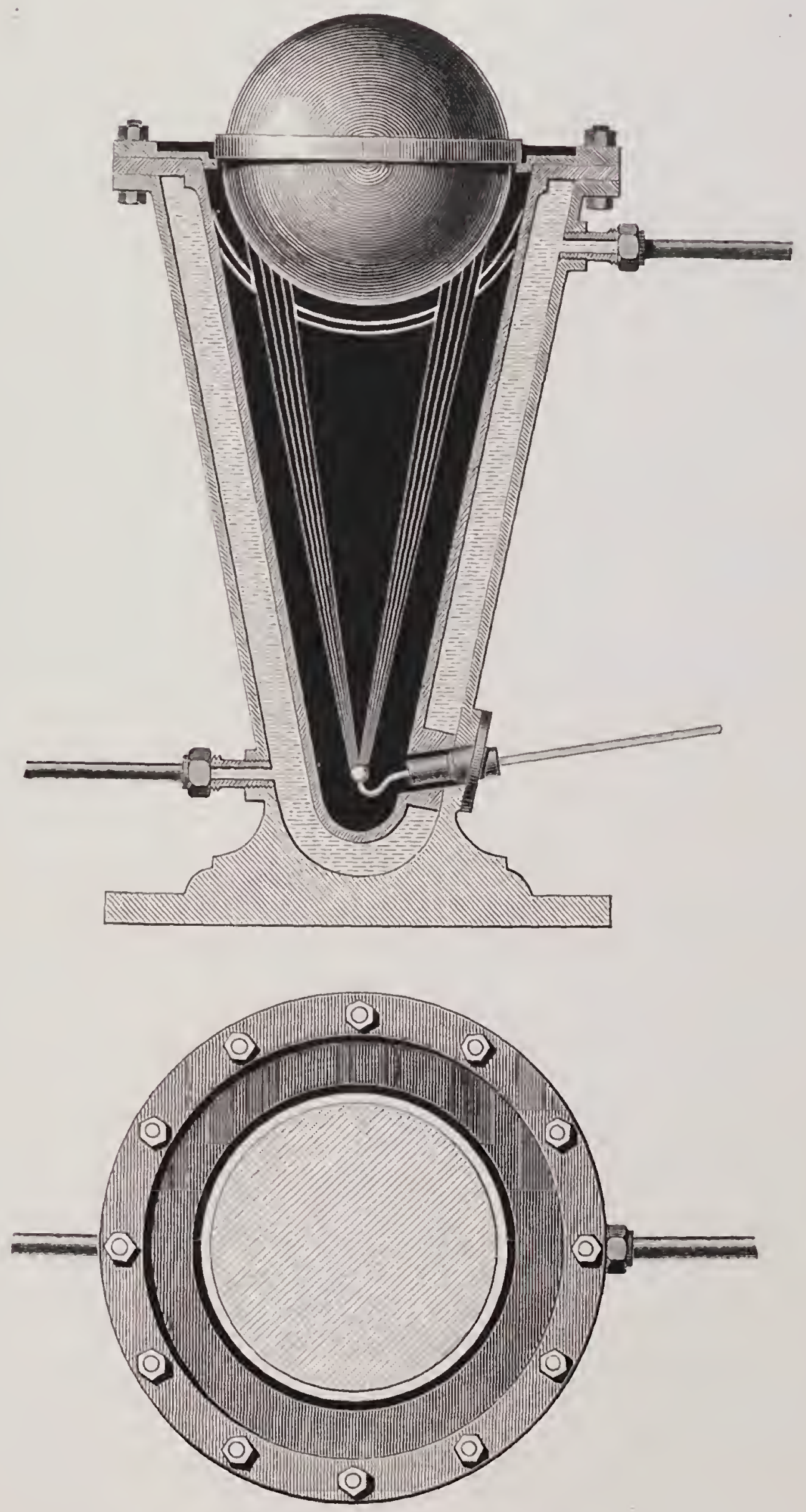

PHATE OS. SEE CHAL. TII. 


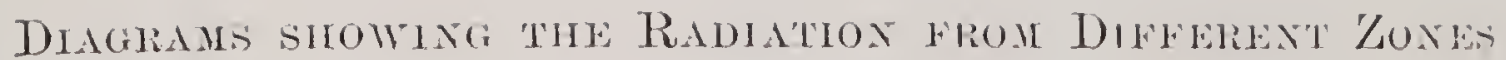
OF INCANDLACENT SPIIRES.

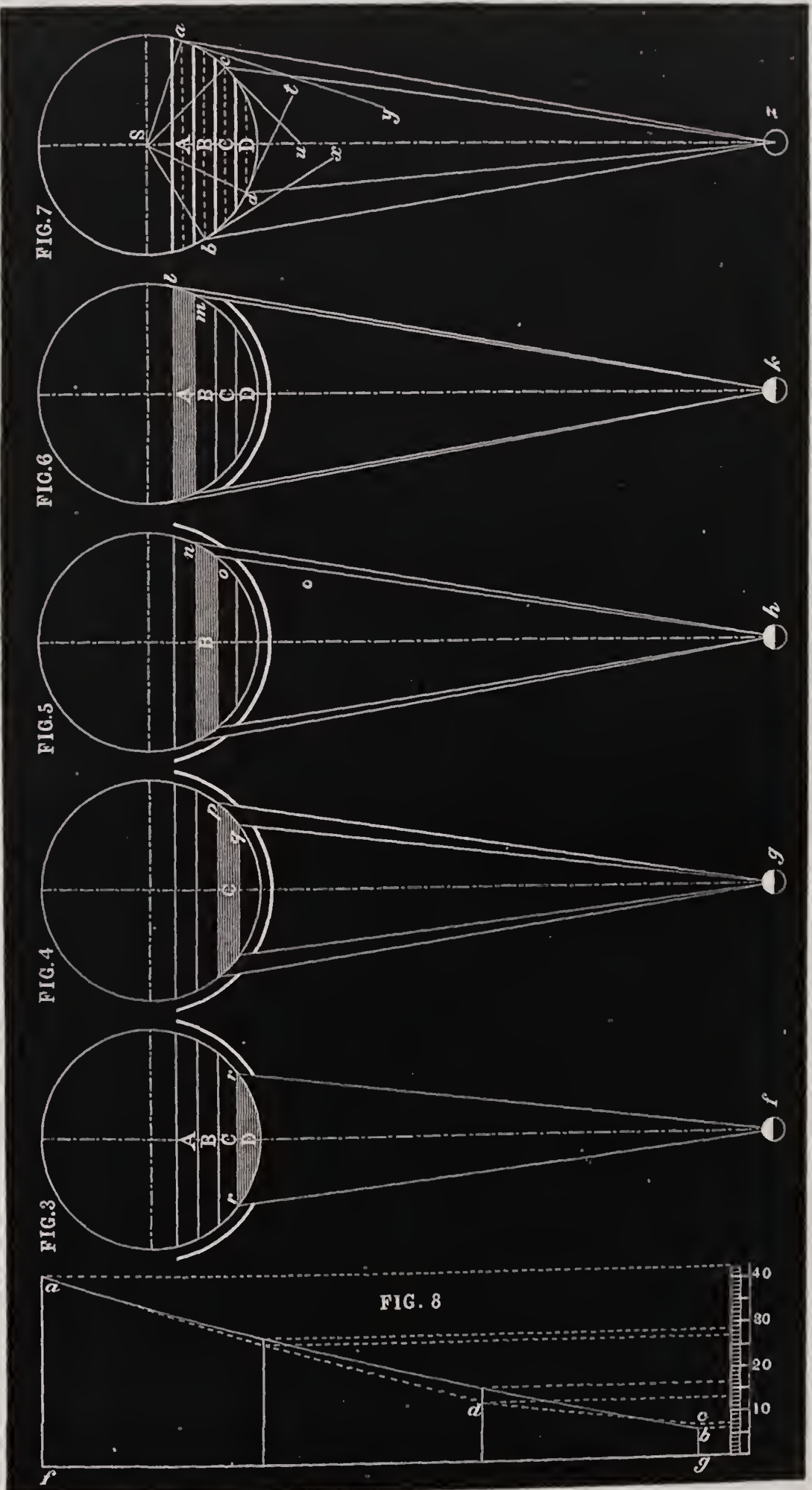





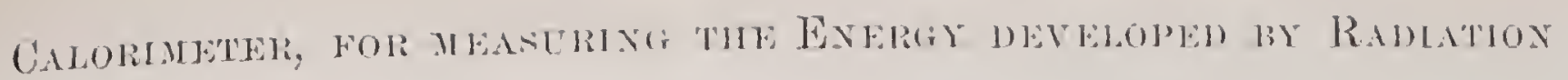

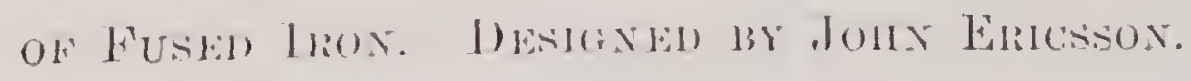

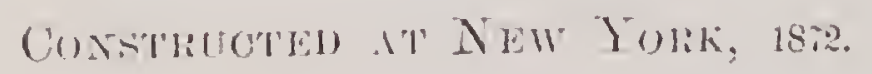
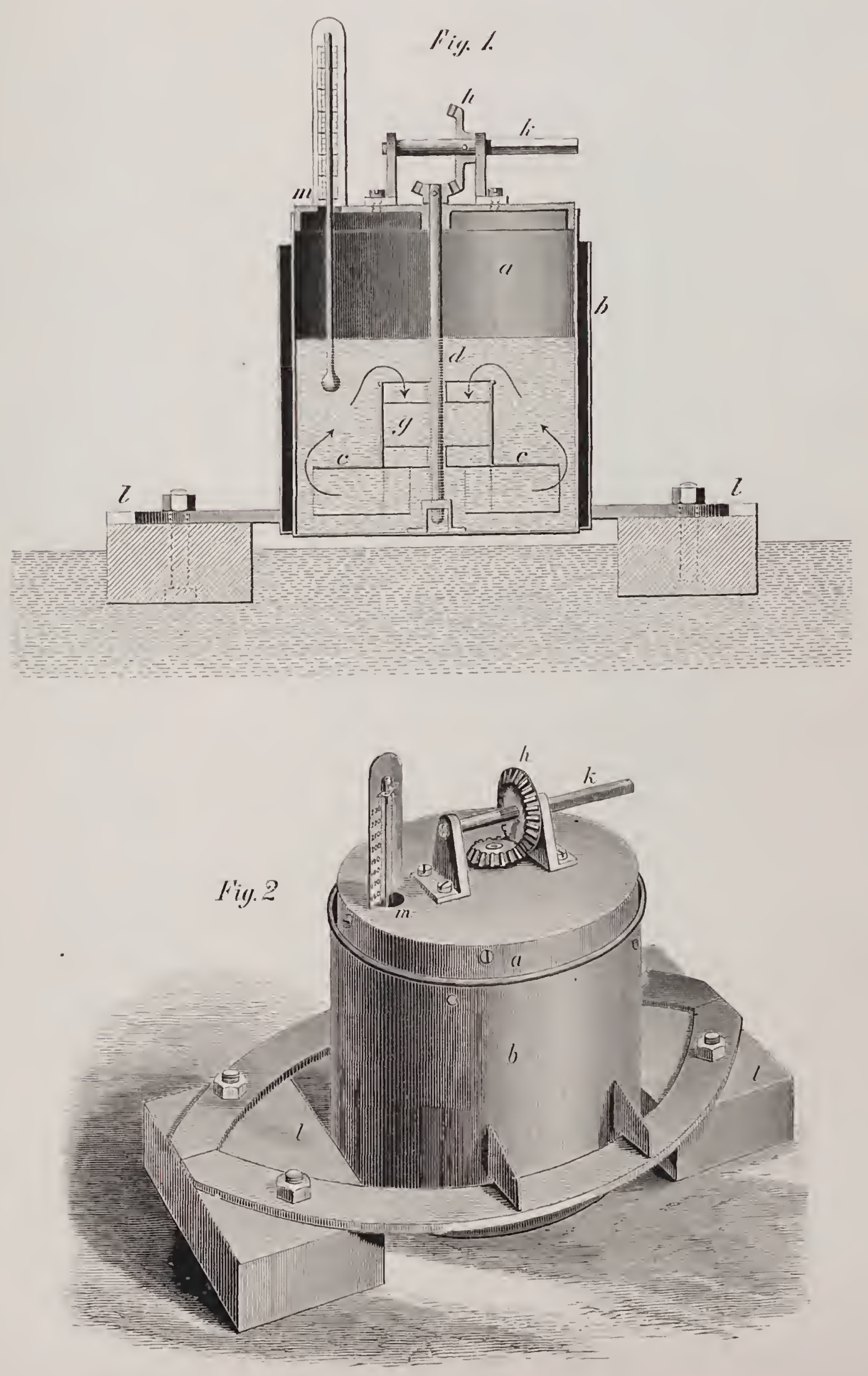

PLATE 25. SEE GHAH. IIII. 
. 


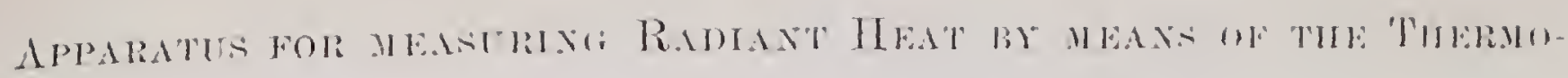

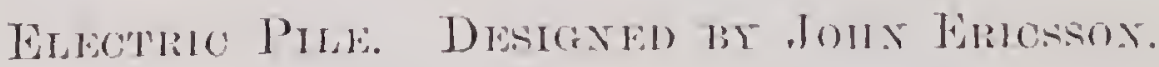

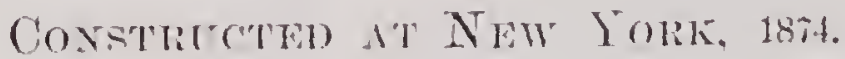

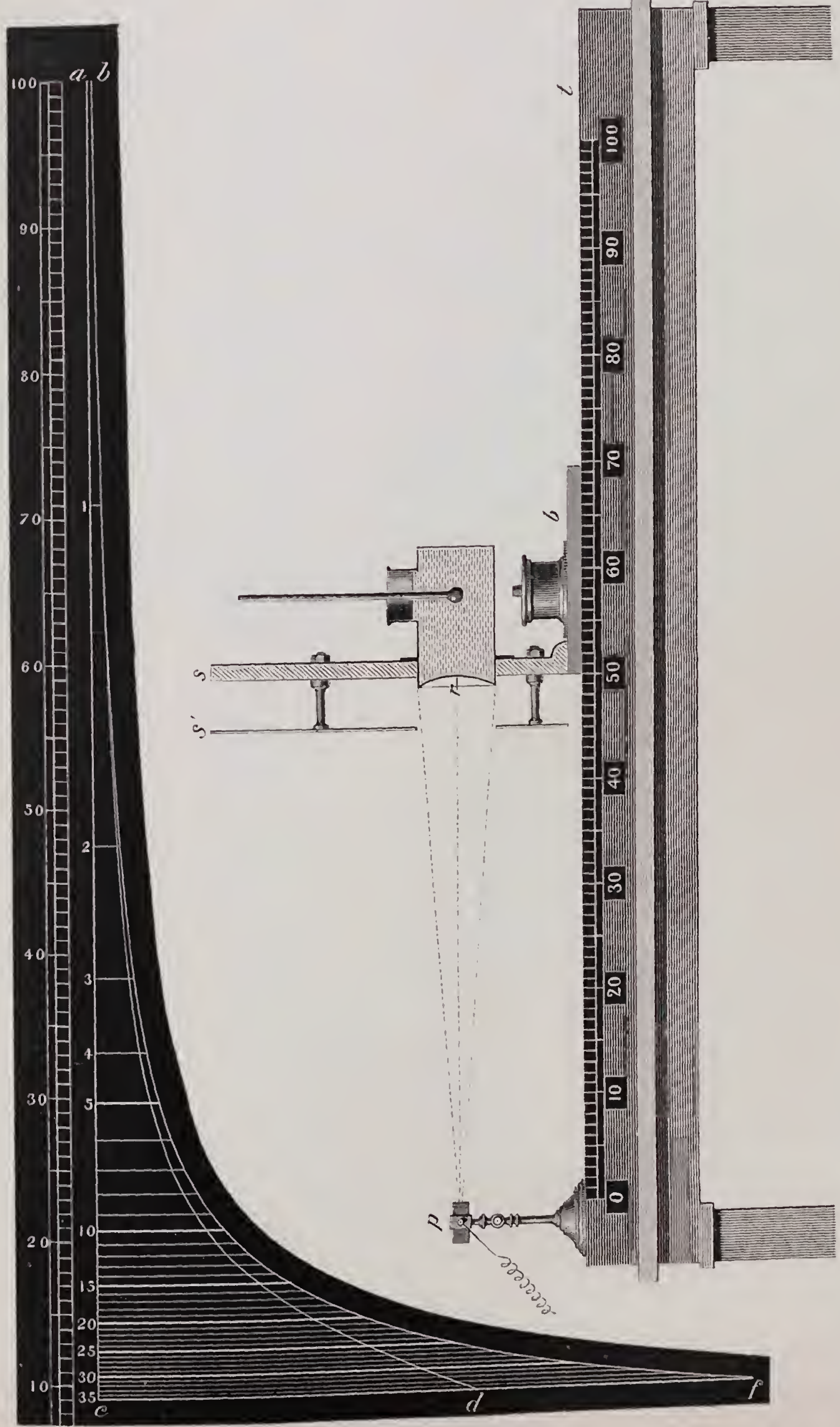

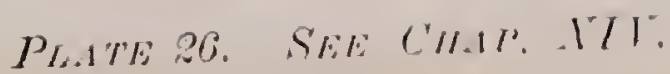





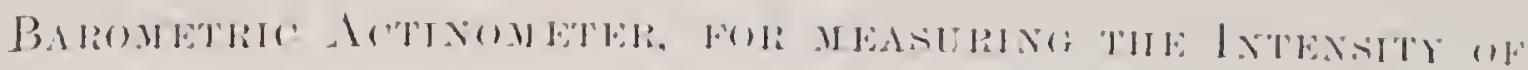

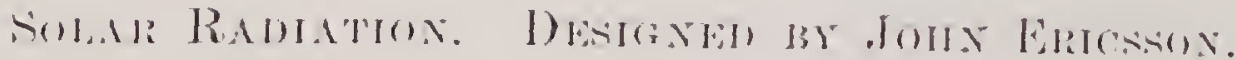

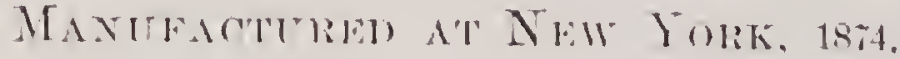

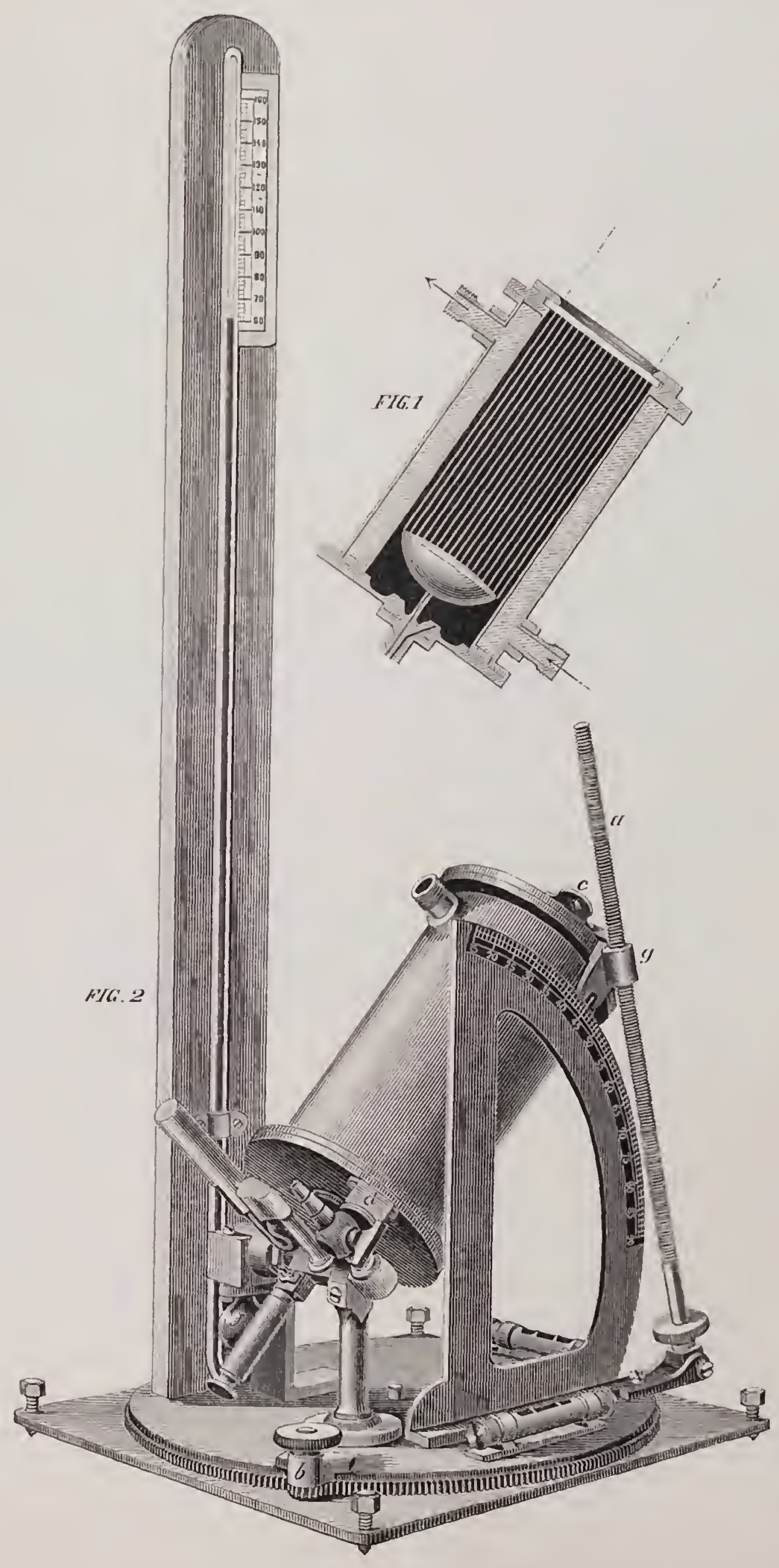

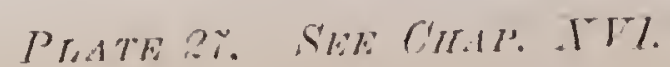




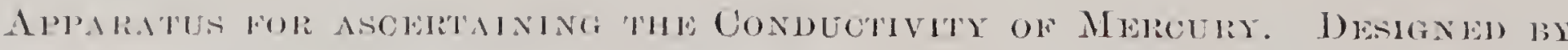

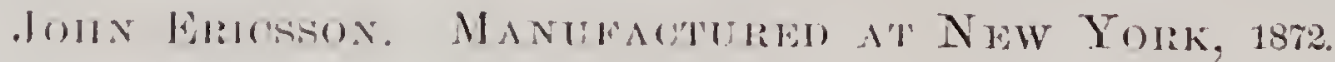

FIG. I.

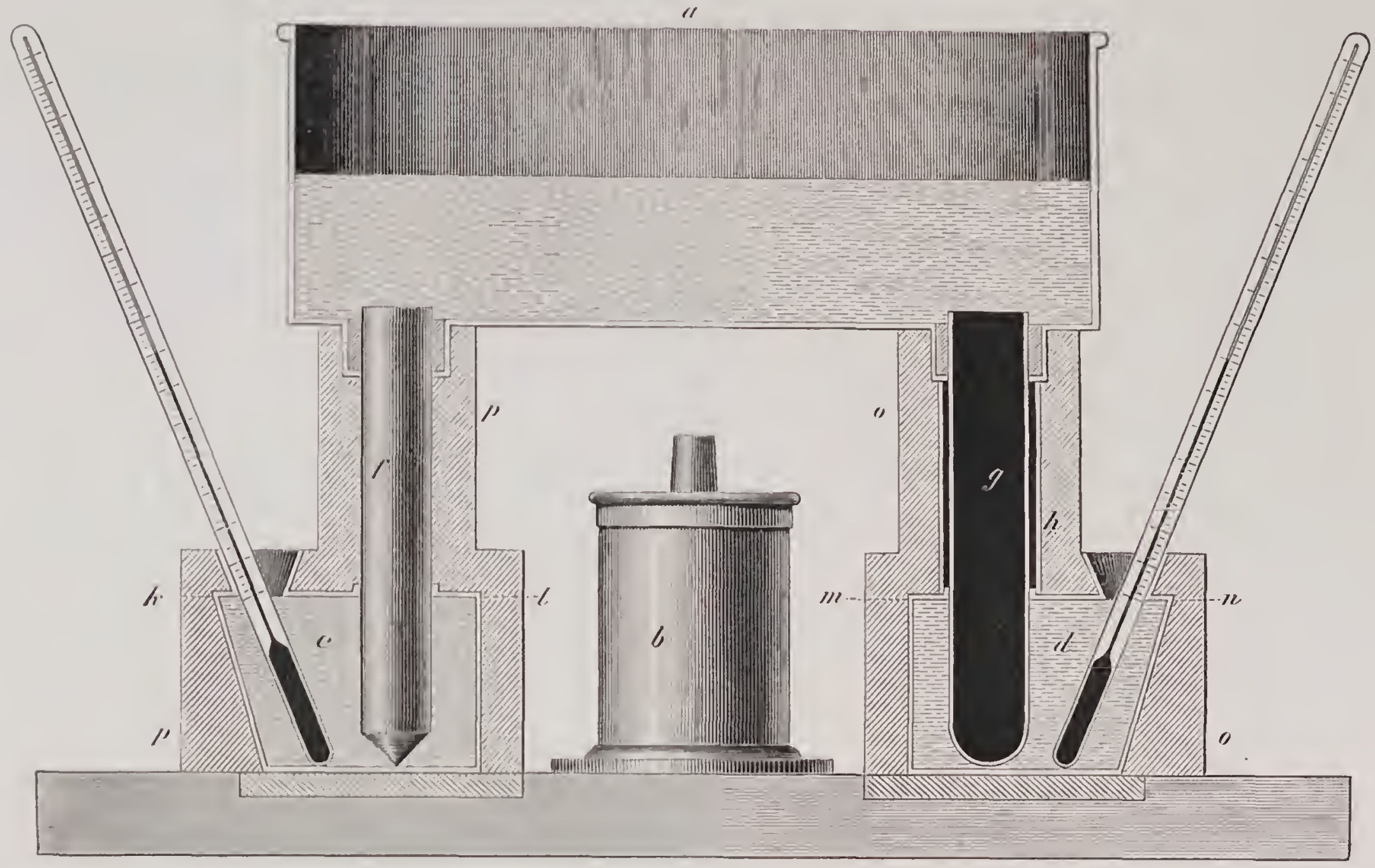





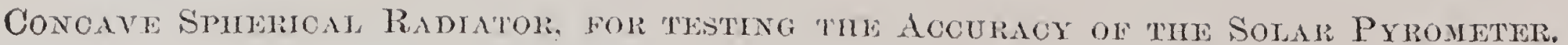

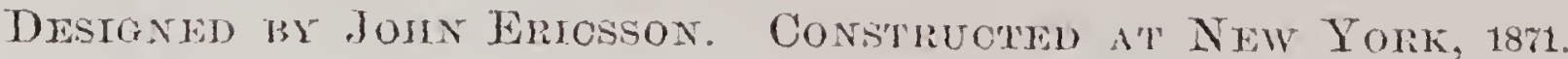

FIG. 1

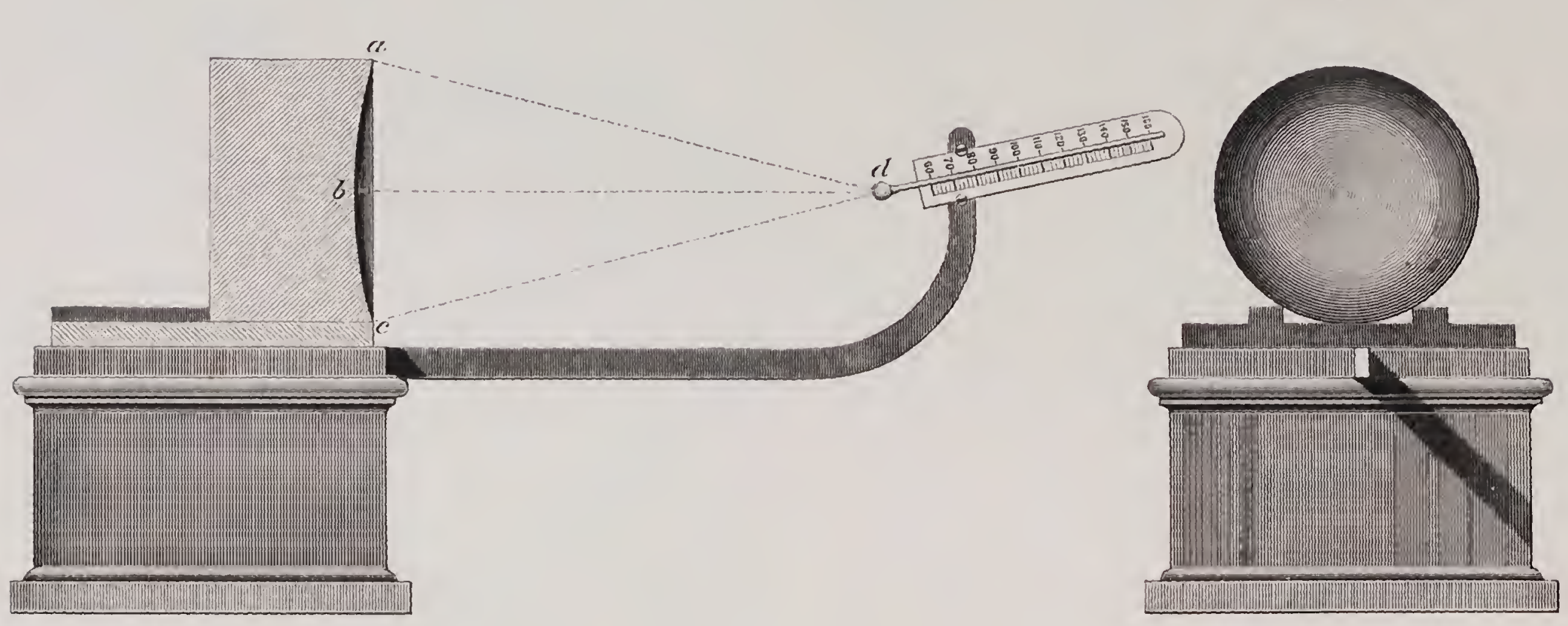



Instrumext for measurifa the Reflective Power of Silver and

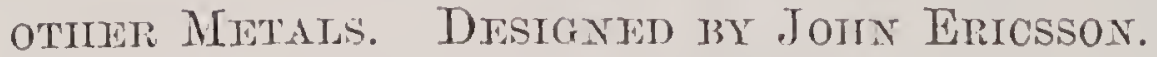

Manufactured at New York, 1874.

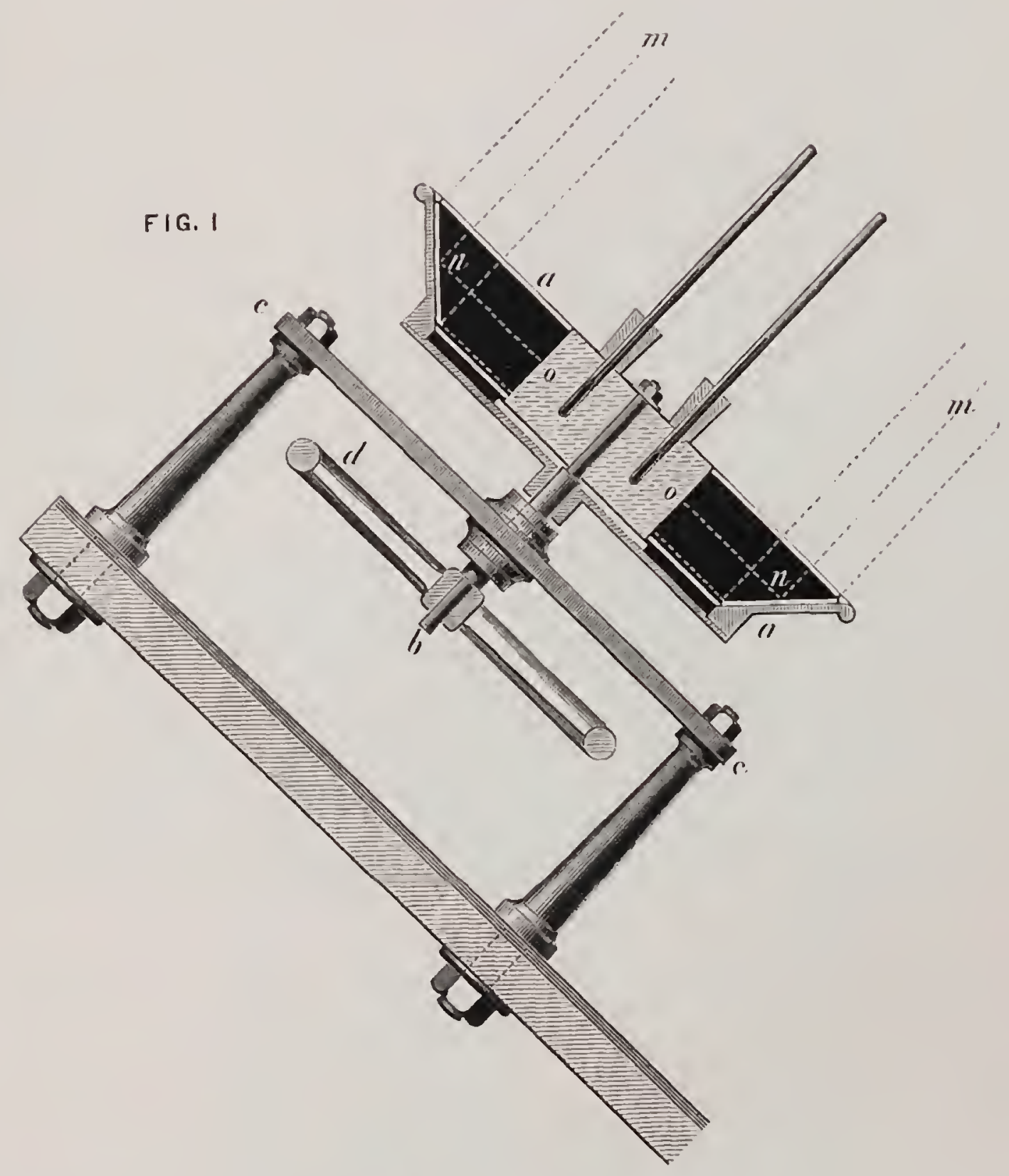

FIG. 2.

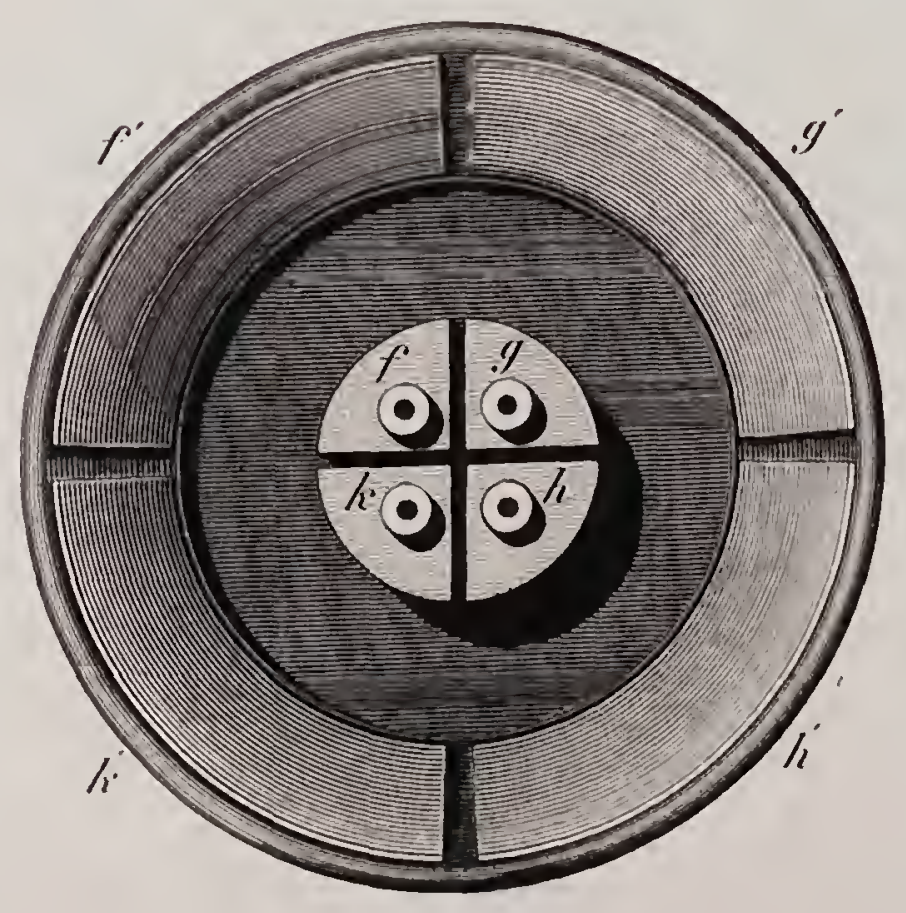

PLATE SO. SEE CHAH. TIX. 



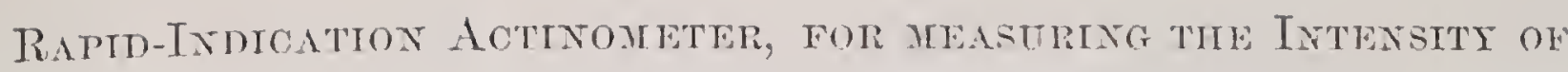

Solatr Radtation. Degignted hi Johy Eriggon.

Manumatured a't NFw York, $18 \pi$.
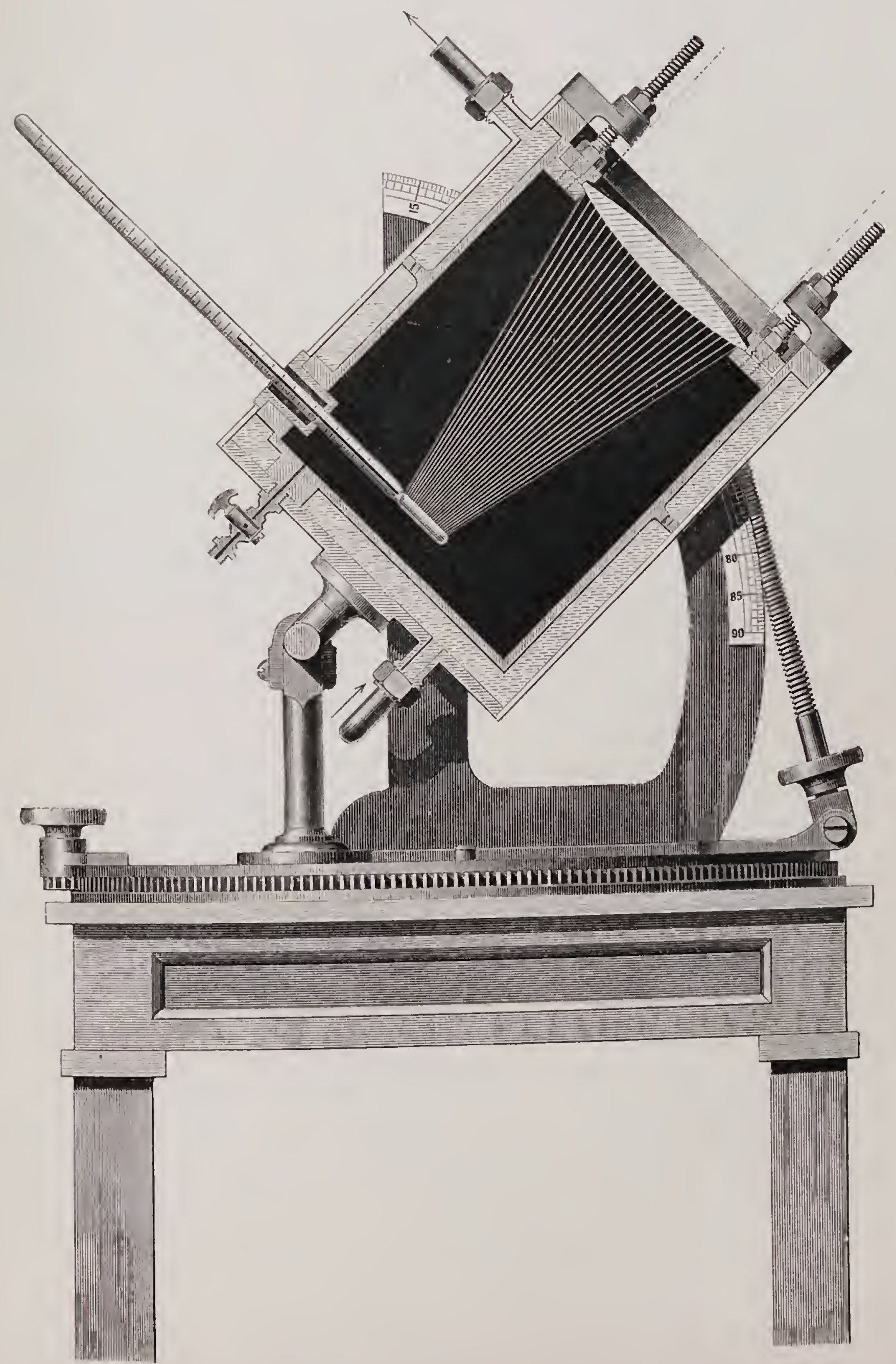

PIATE 31. SFE CHAP. TI. 

Apparated hor asclertaming the Diathermanor of Flanes.

Destaned by Jom Ericsson. Constructed at New York, $18 \%$.

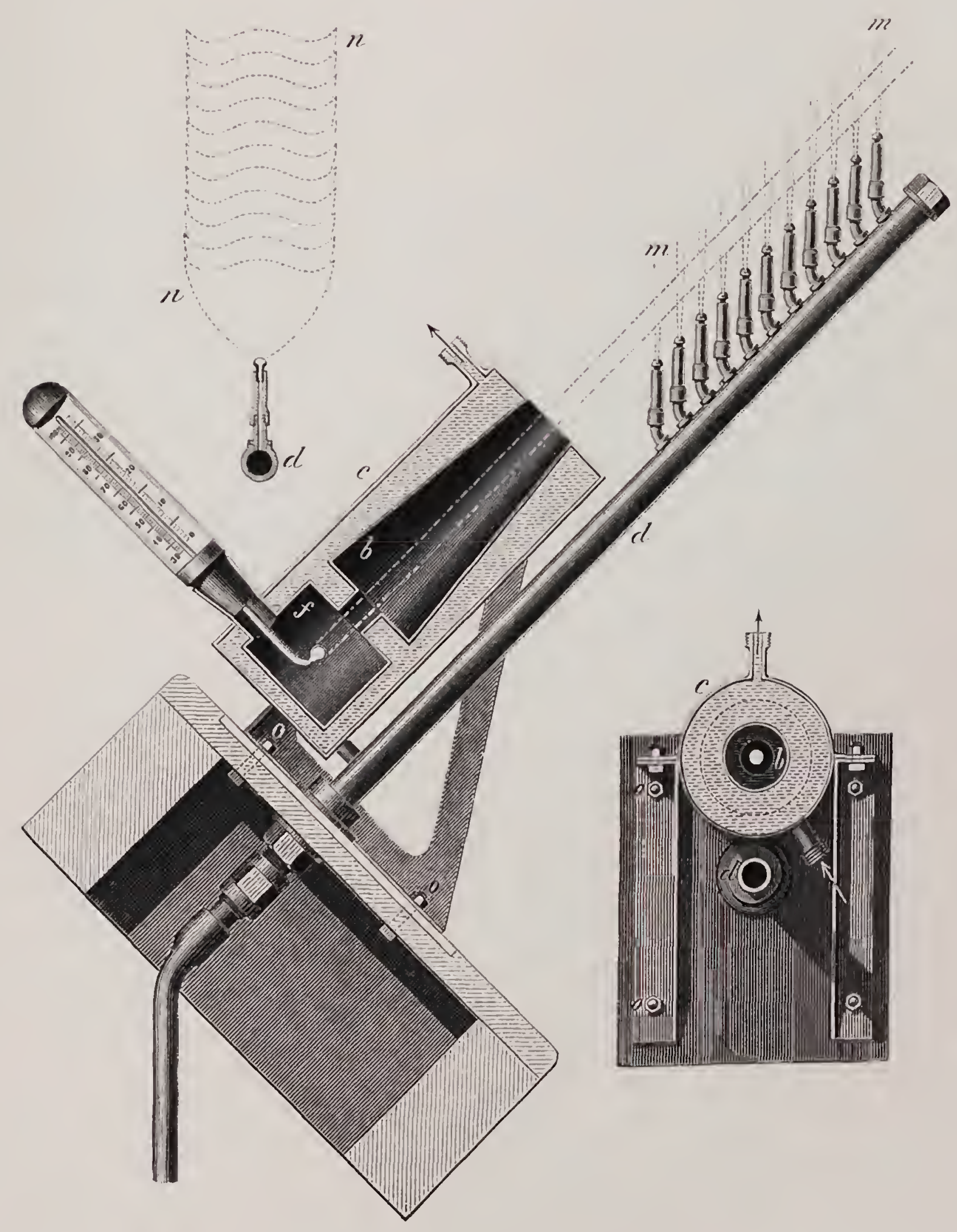

PLATE SR. SEE CHAP. XYY. 



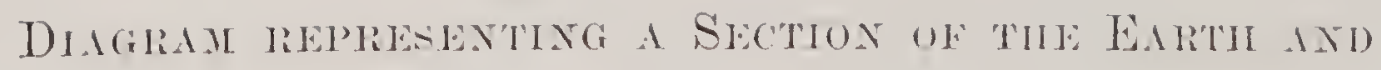

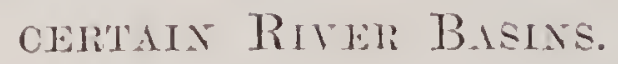

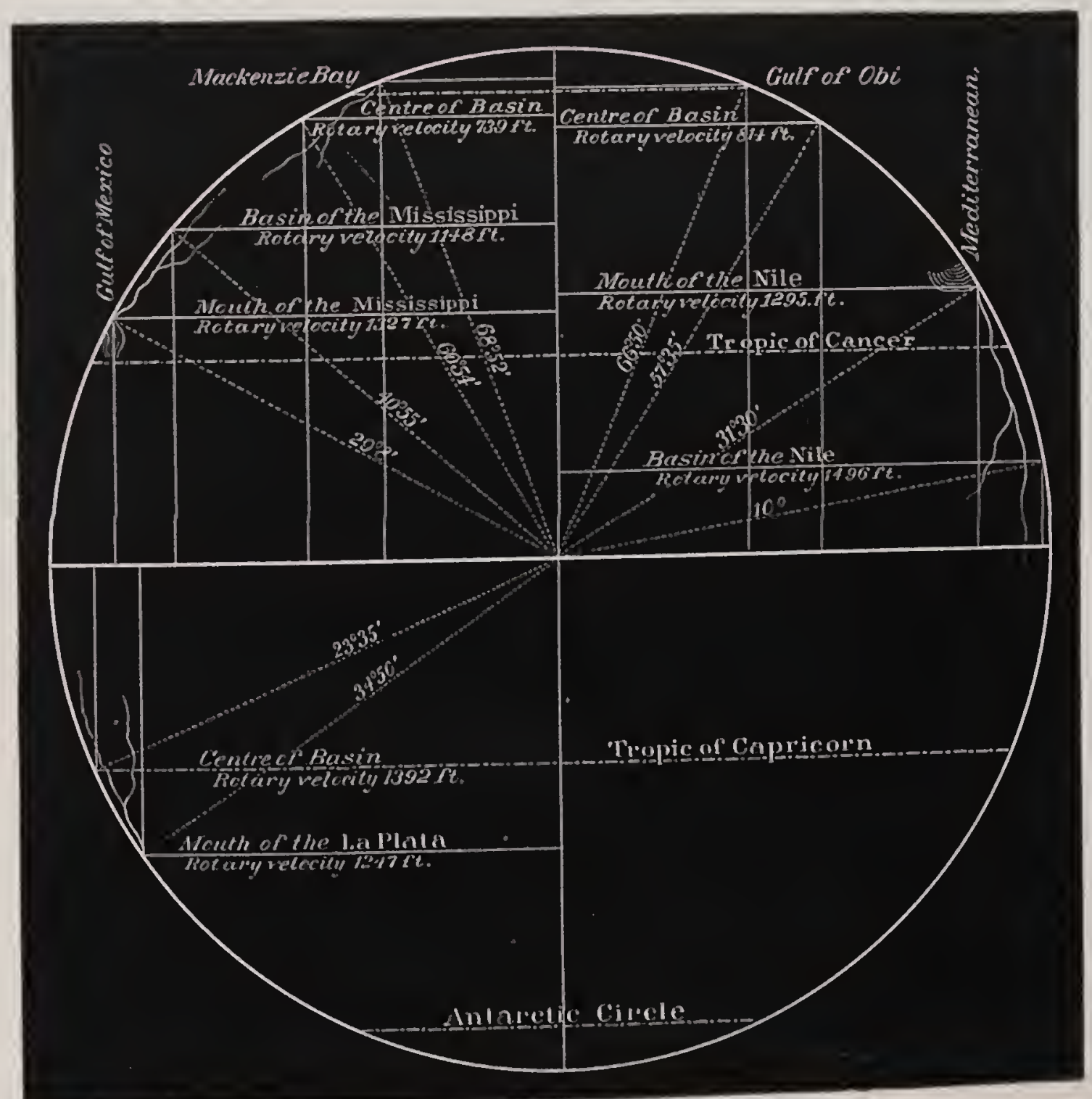





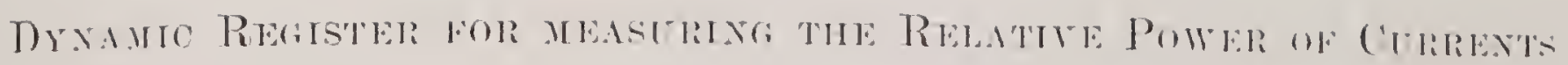

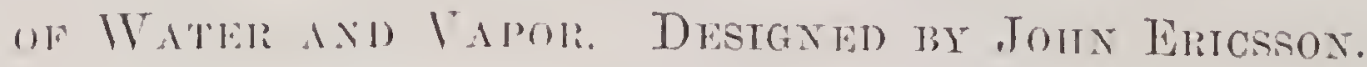

Maxikantred at NEW York, 1871.

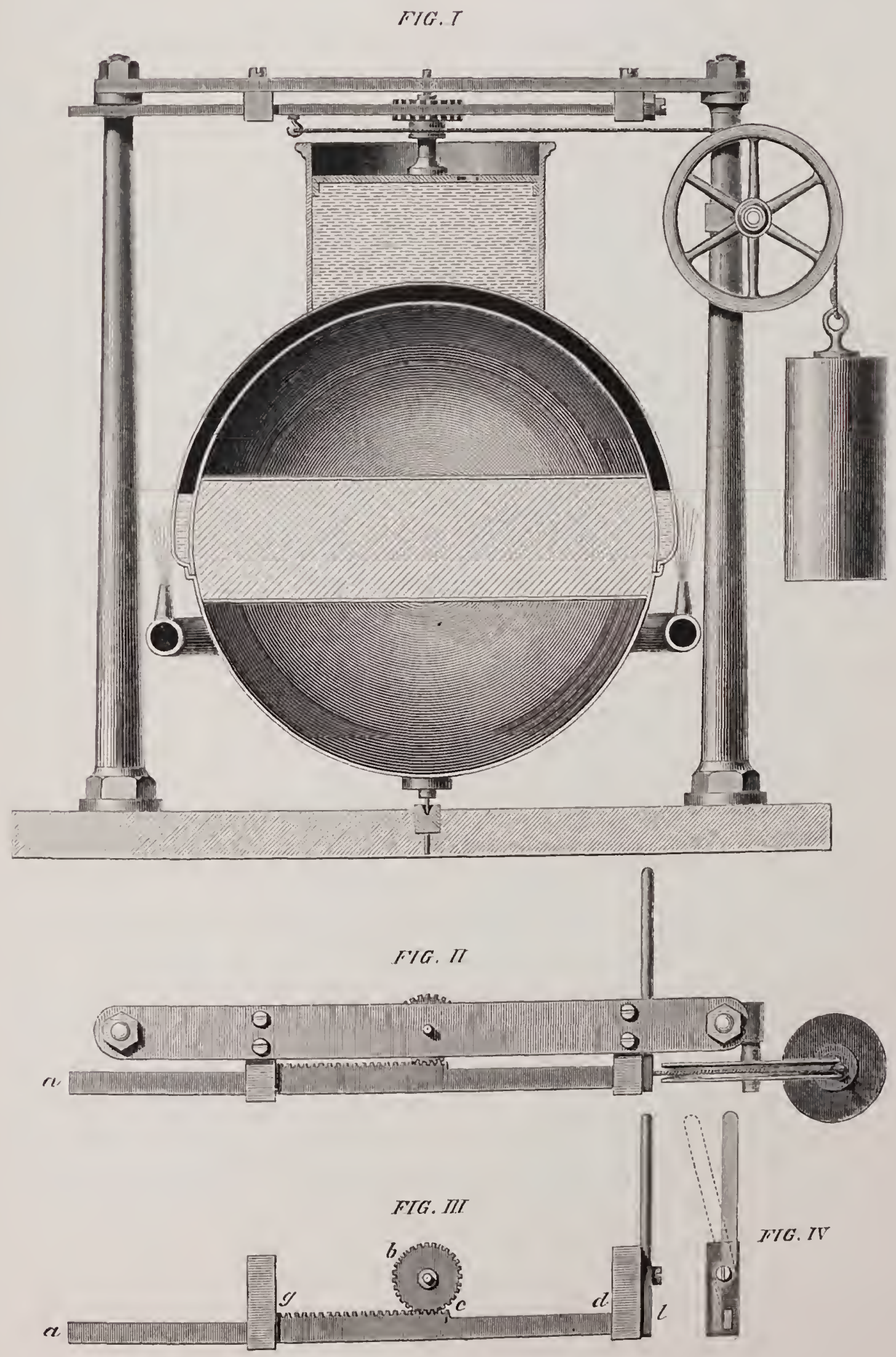





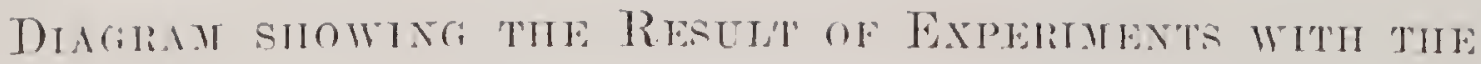

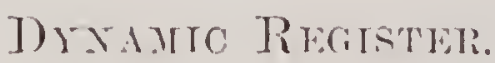

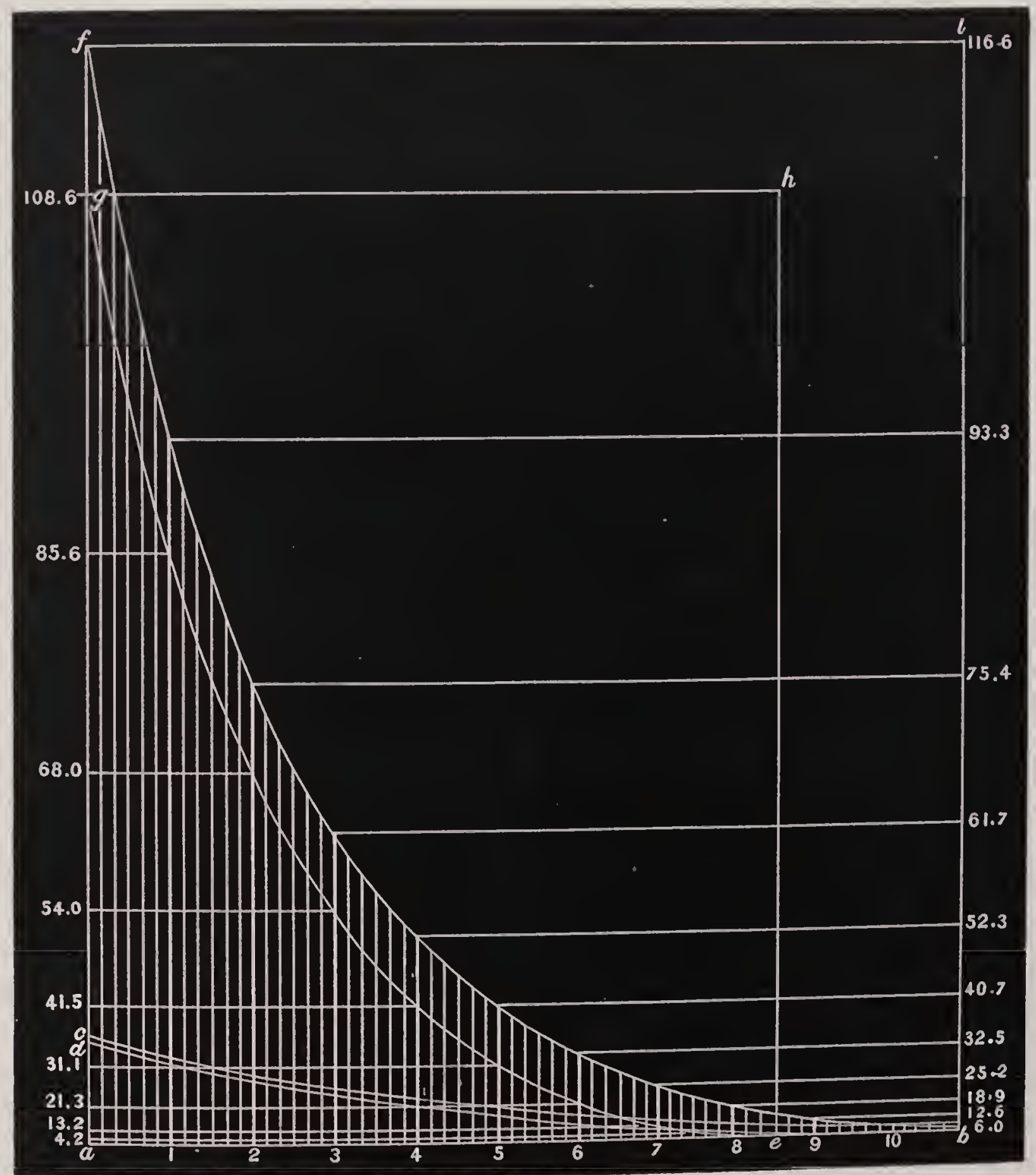





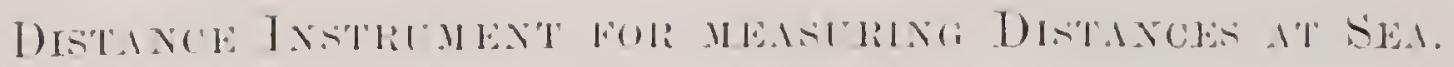

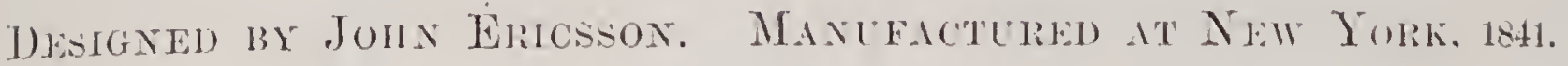
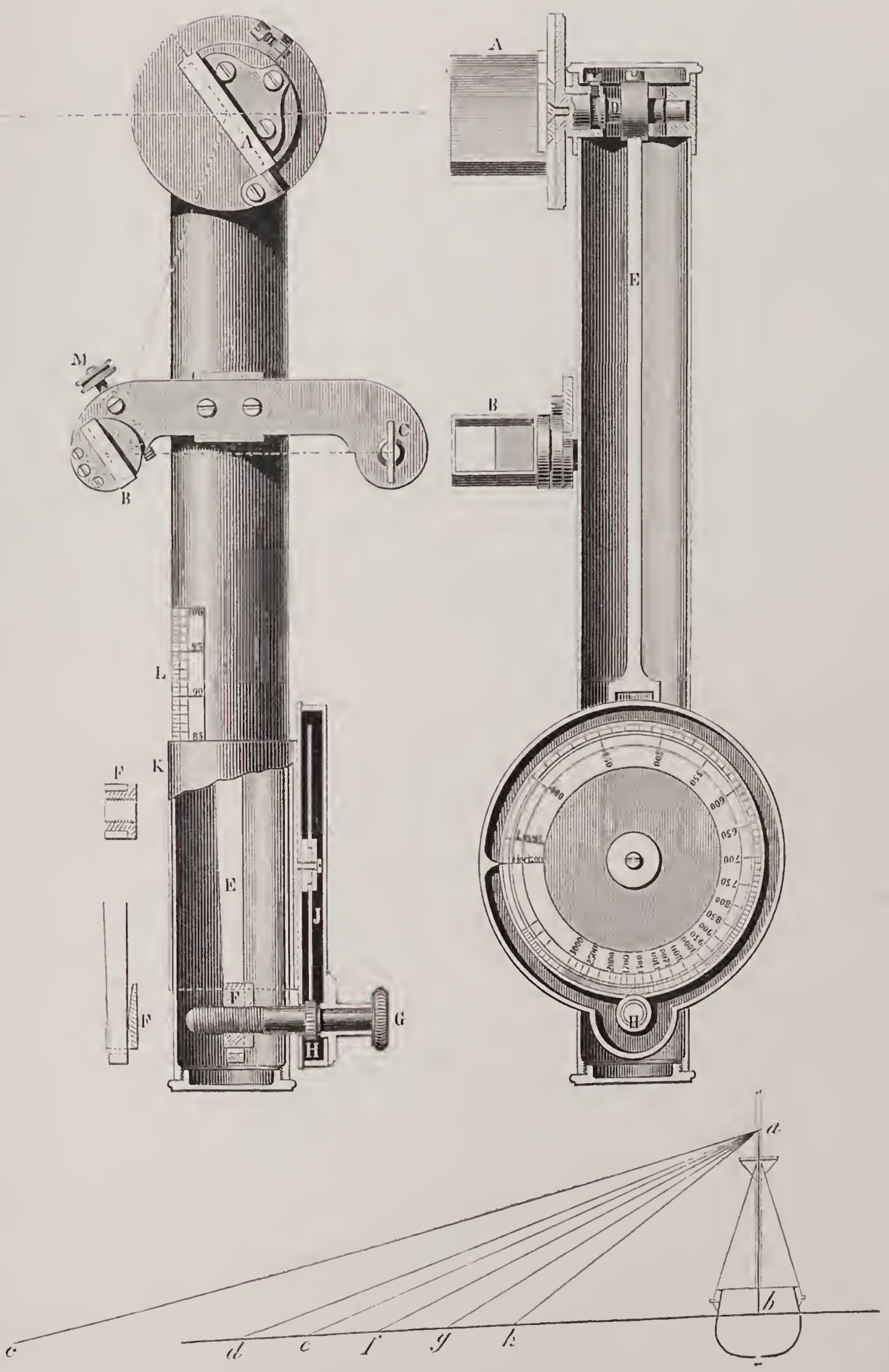

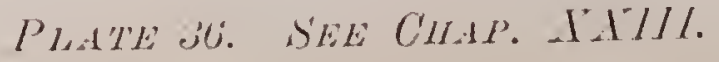





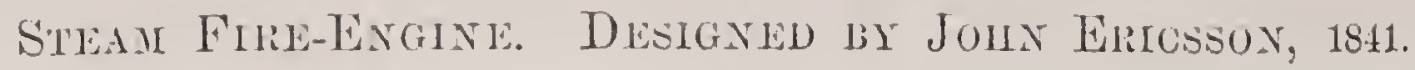
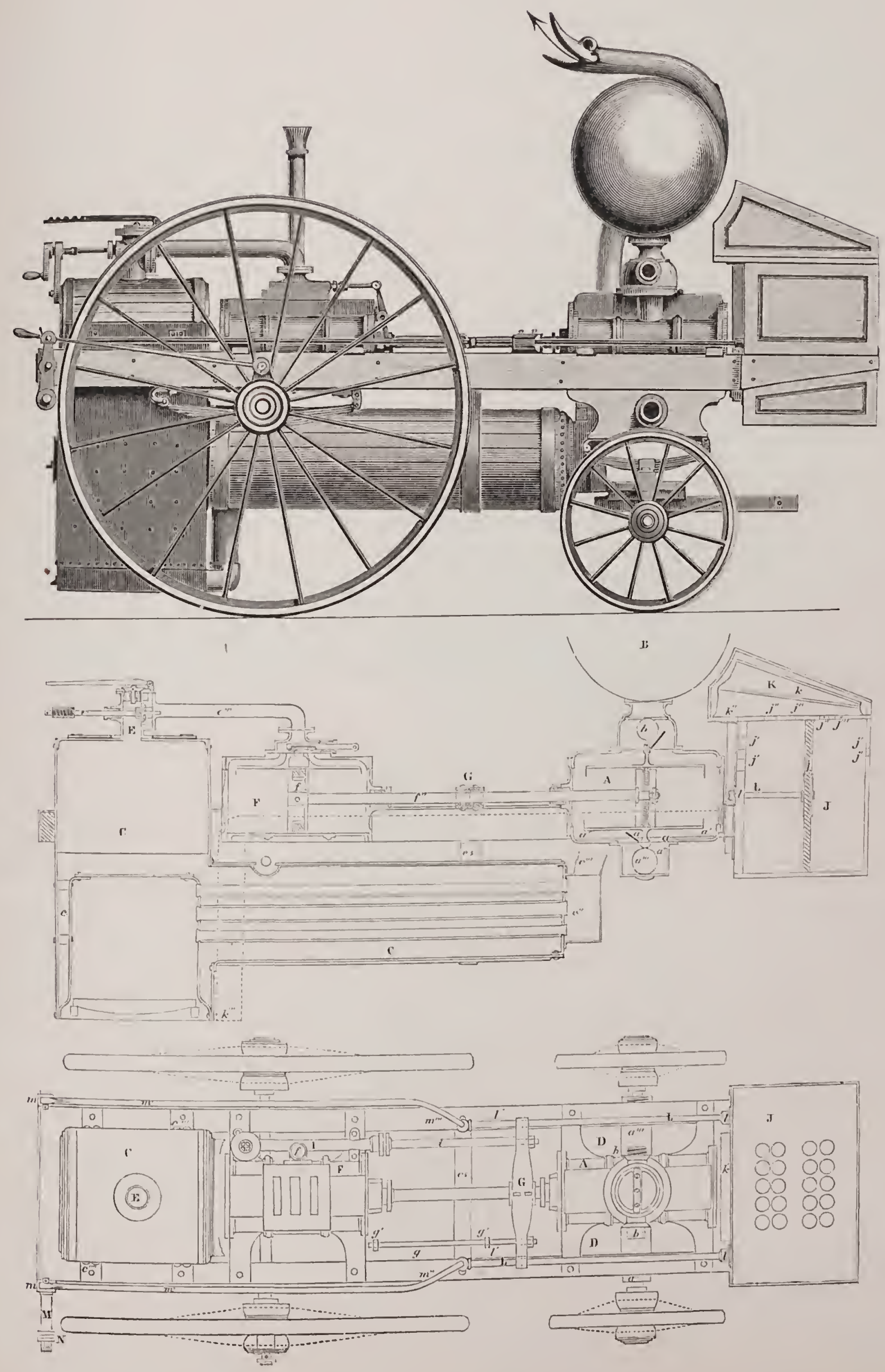

PLATE S\% SEE CHAP. XXIV. 


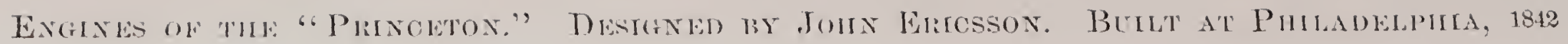
TRANSYERSE SECTION OF SEMI-CYLINDER AND PISTON.

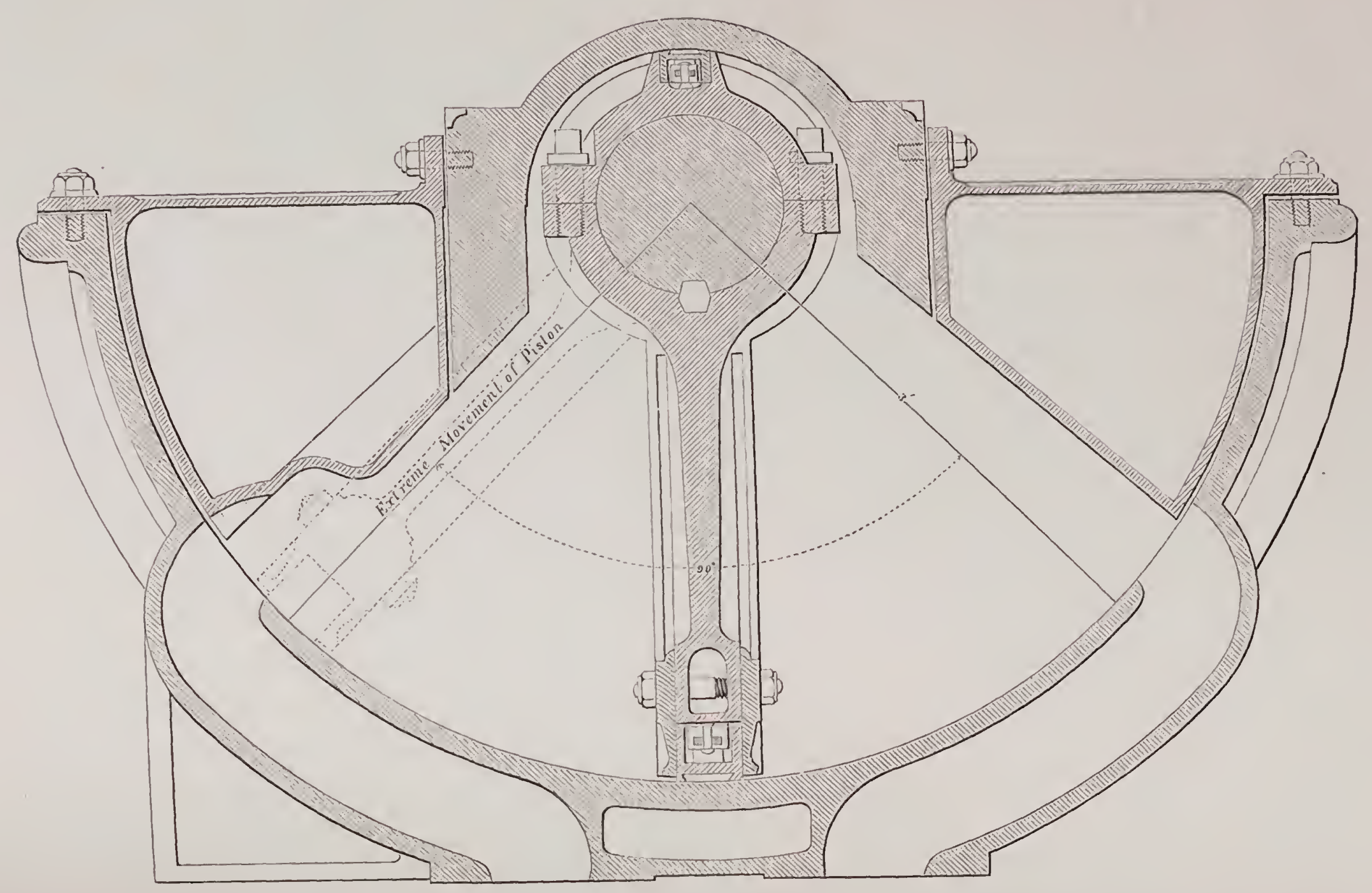




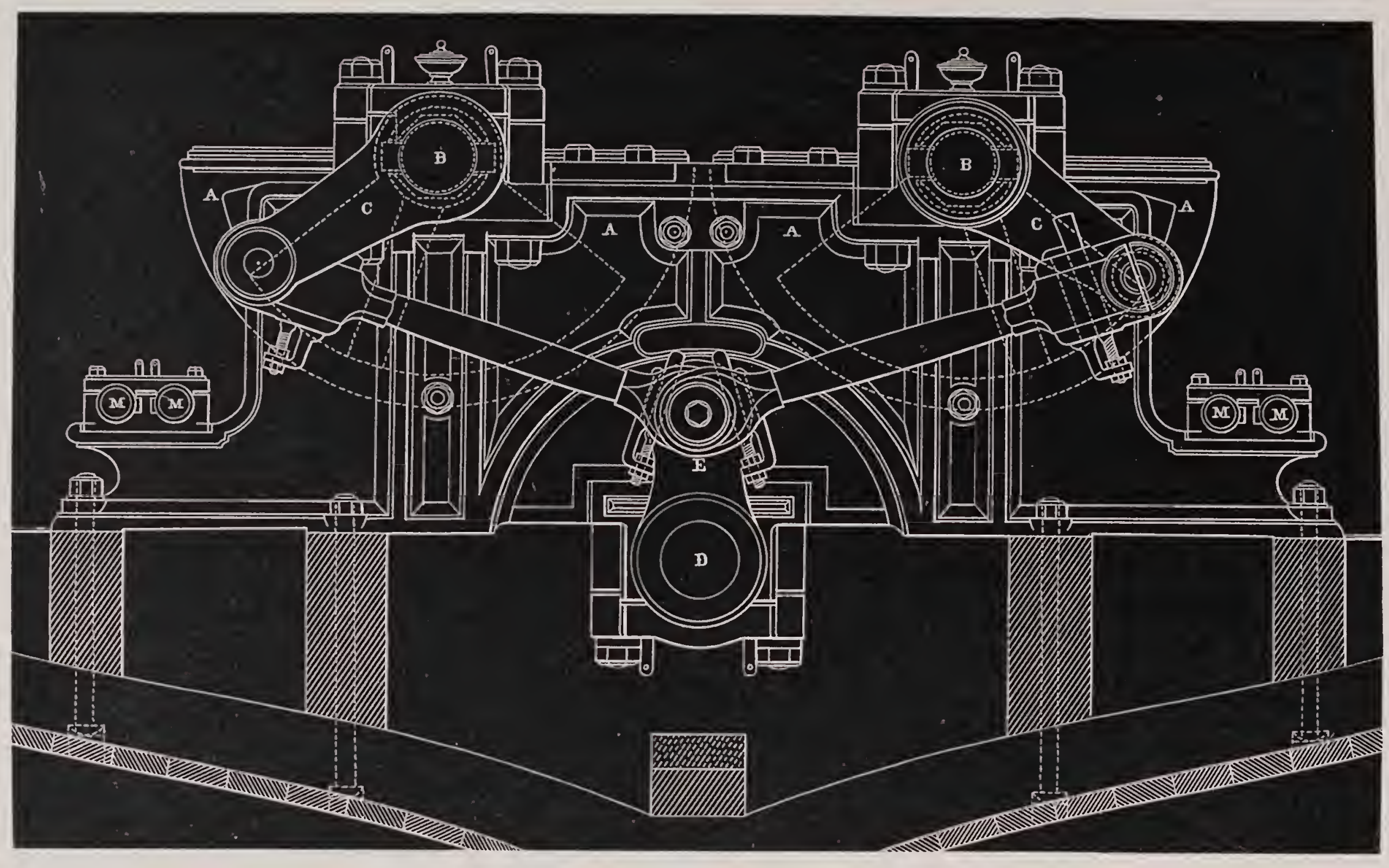





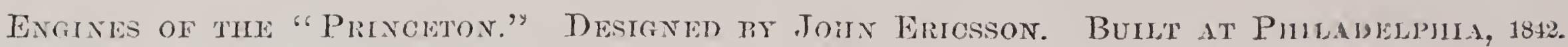
ELEVATION VIEWED HROM THE STERN.

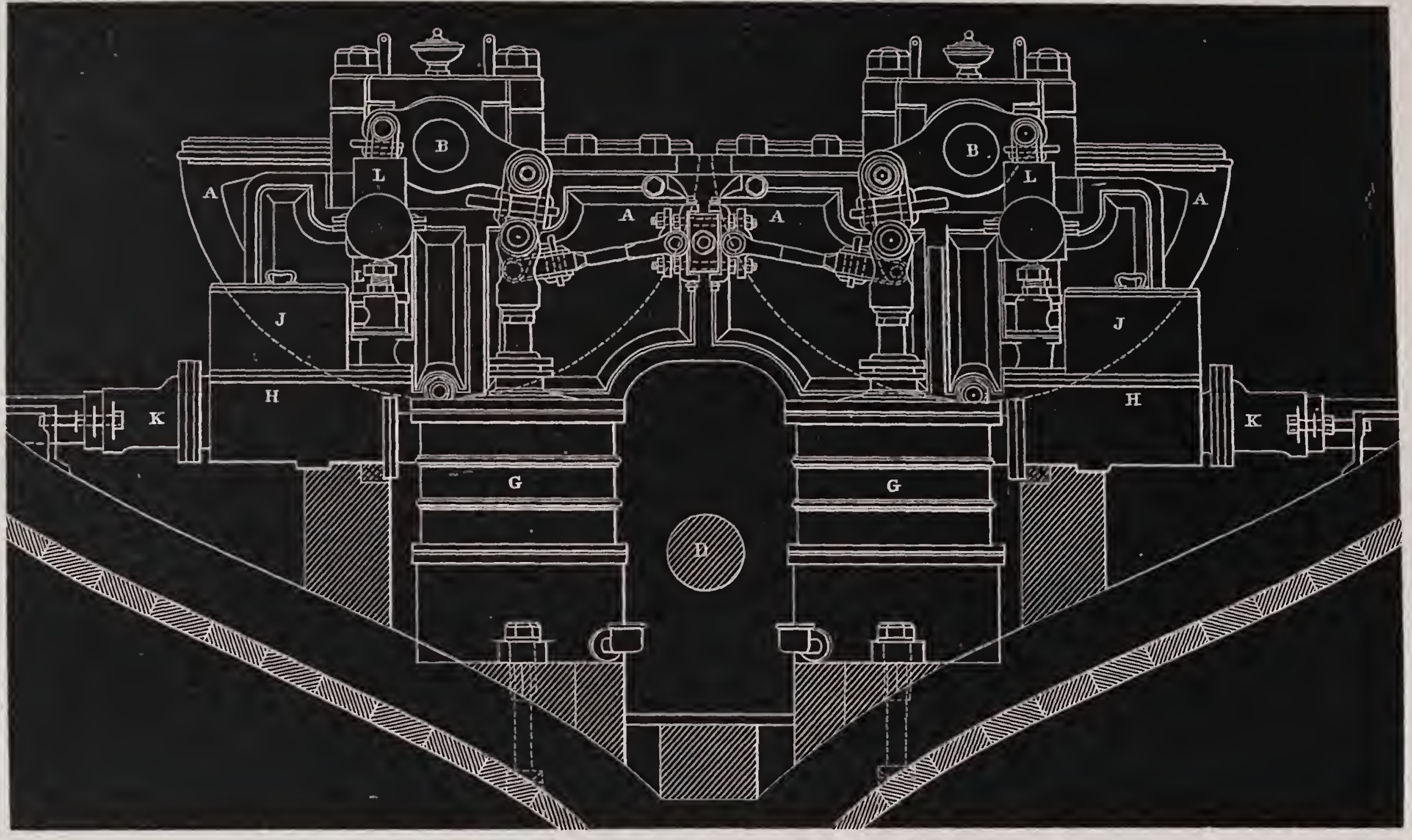




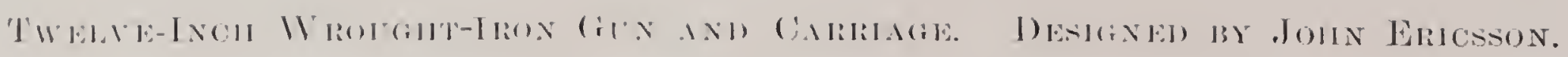
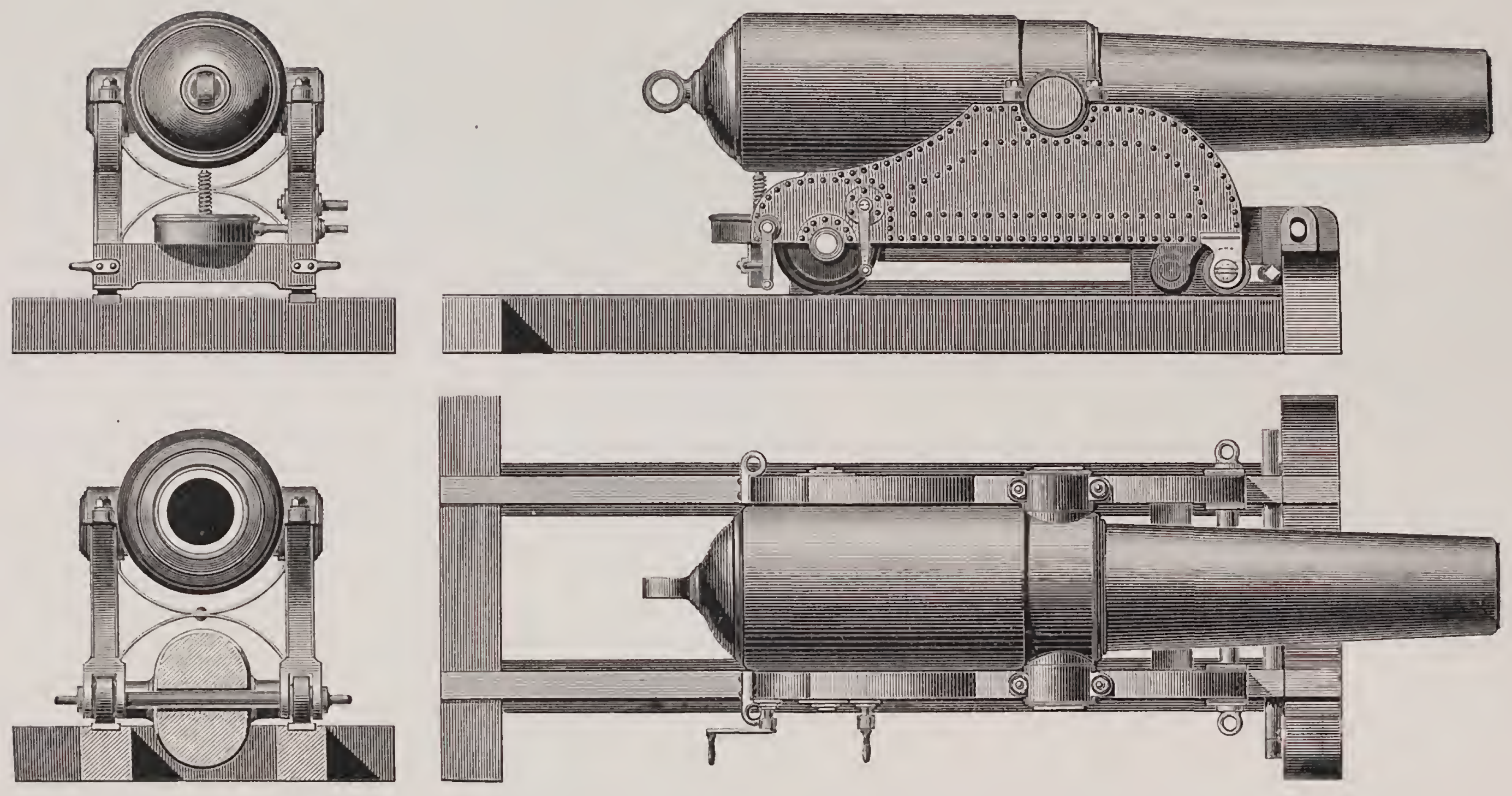



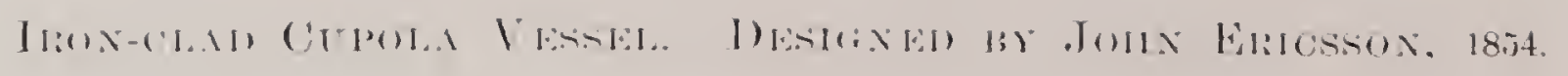

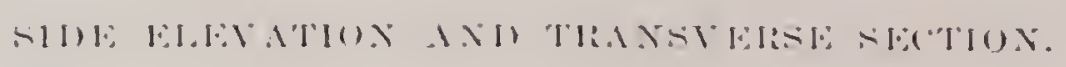

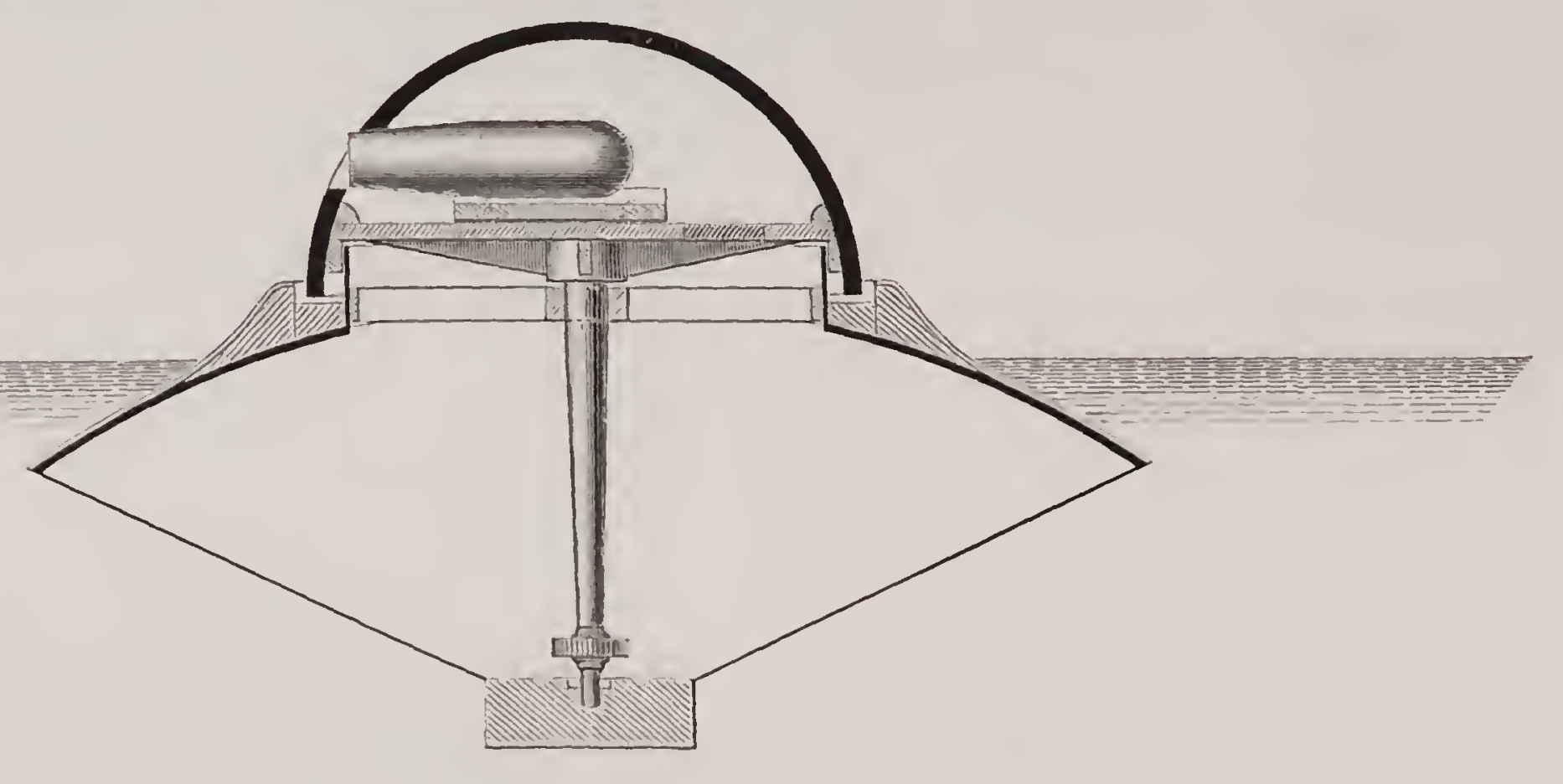





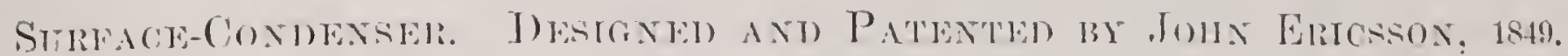
BEIT'T N'T NHE IORK.
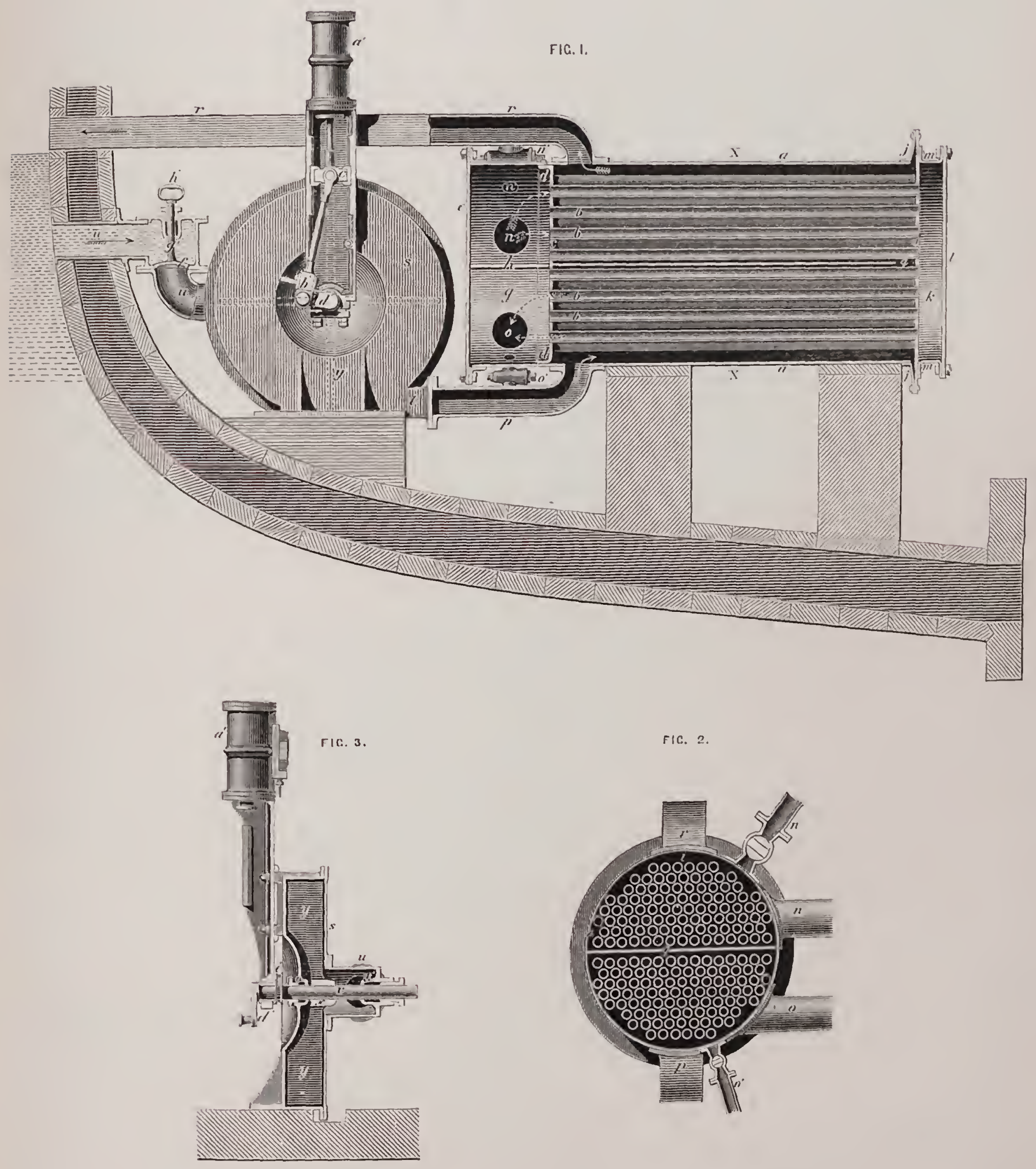

FIC. 2 .

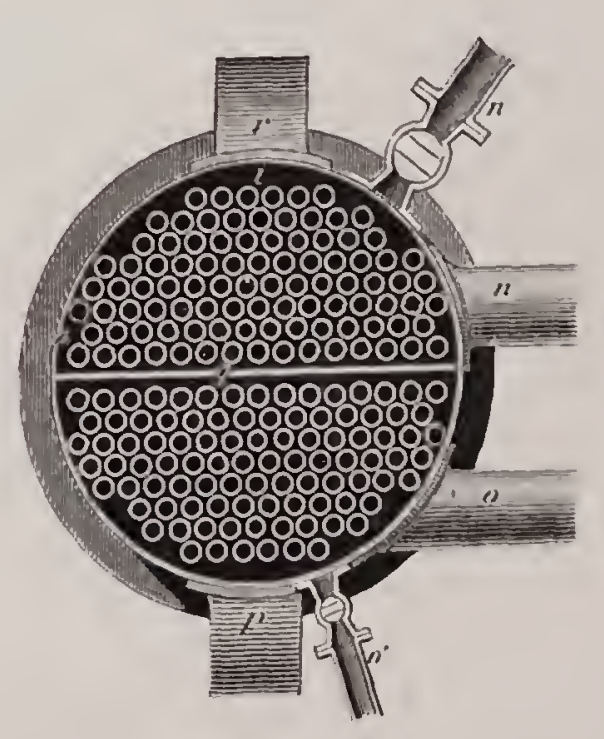

PLATE 43. SEE CHIH' ITH. 



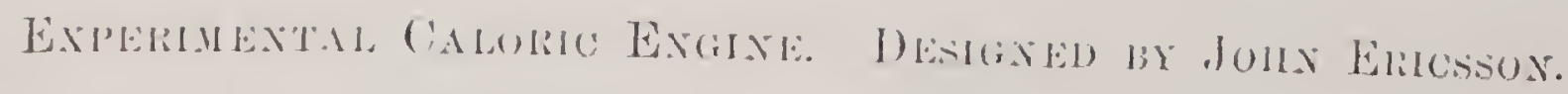

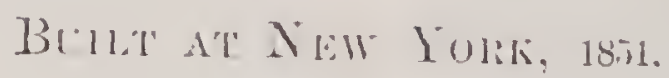

TRANAVRISE SECTIOA.

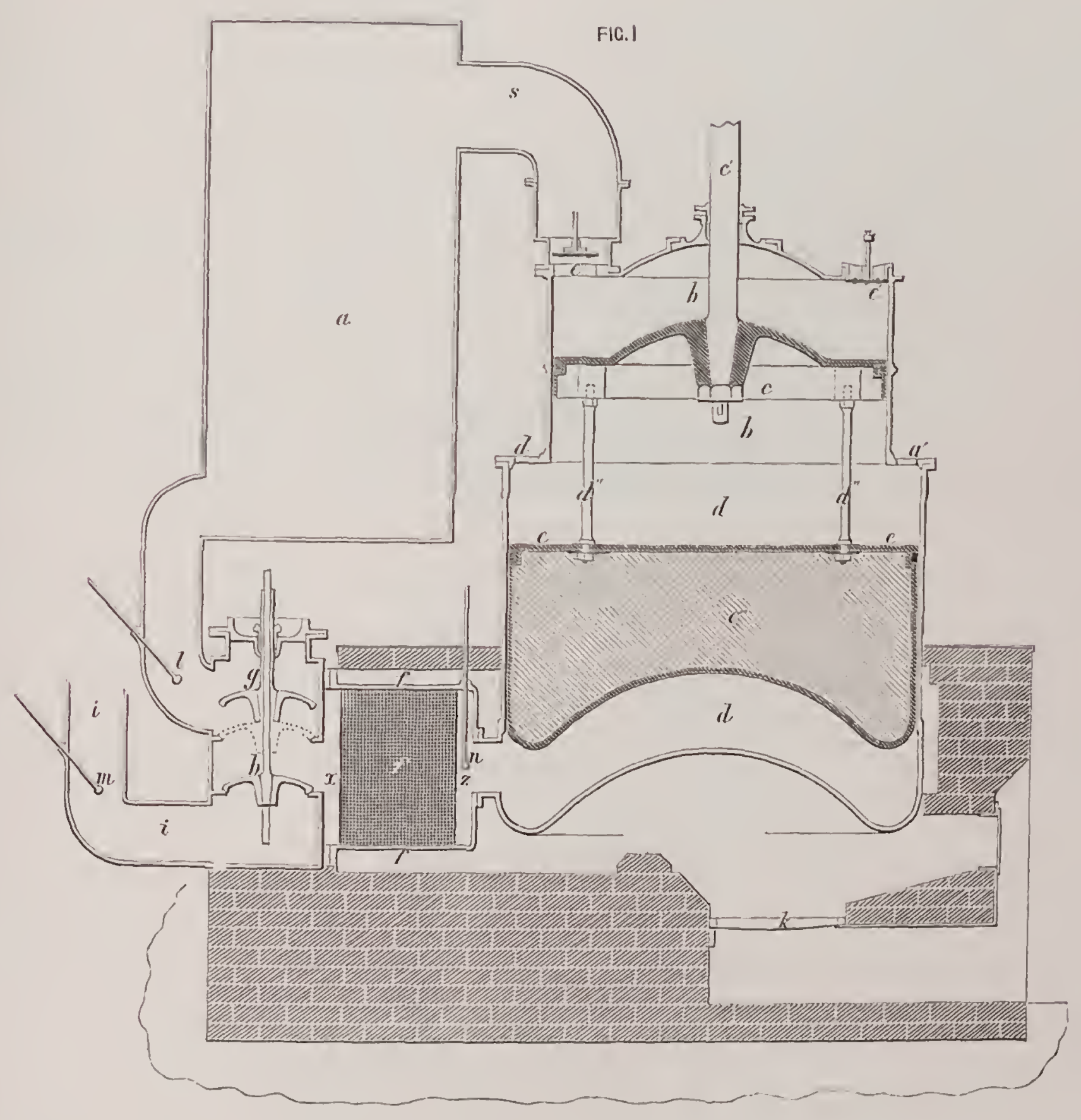





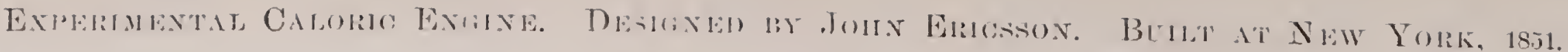
LONGITLHAXI SHeTHON.

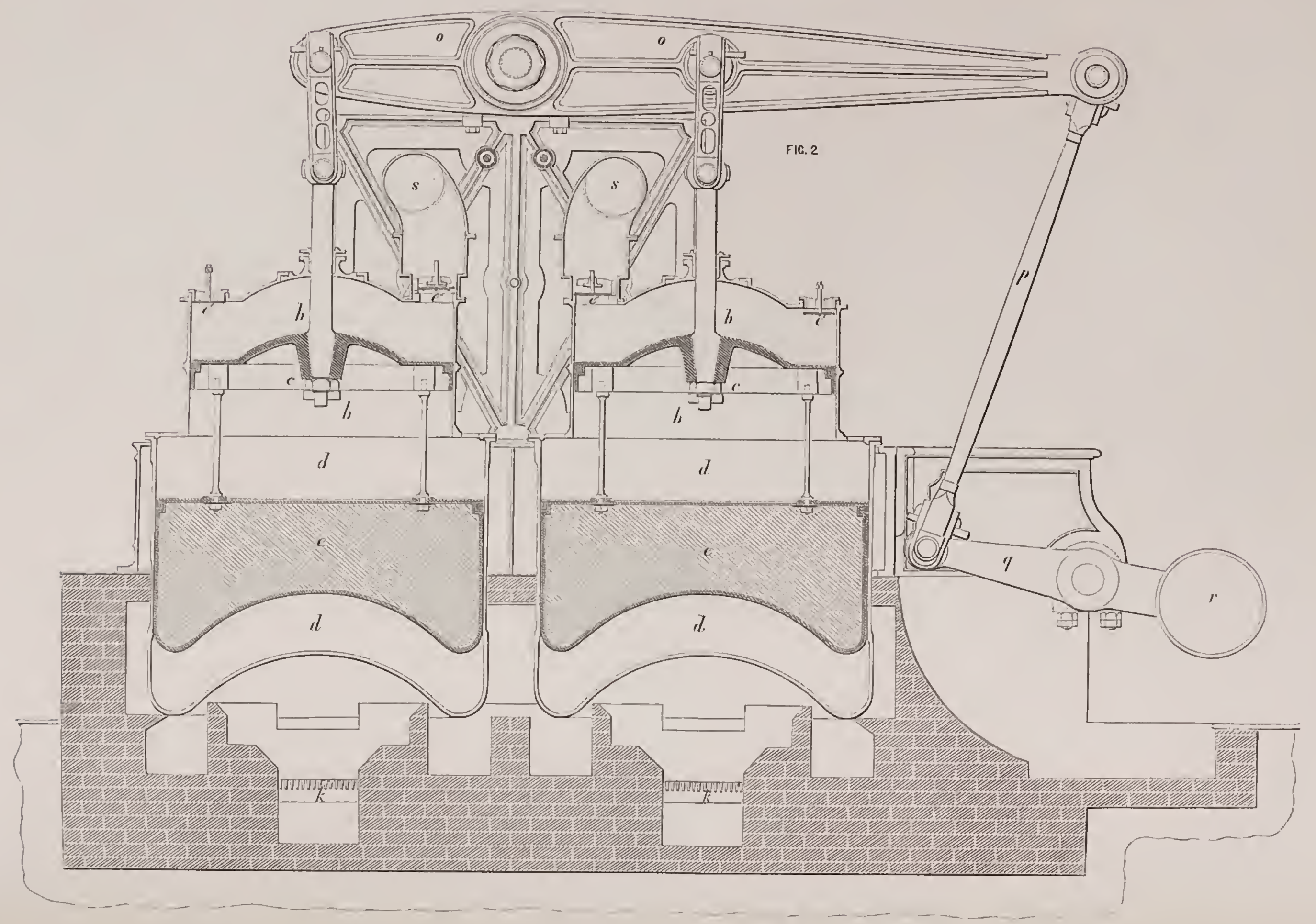




\section{.}




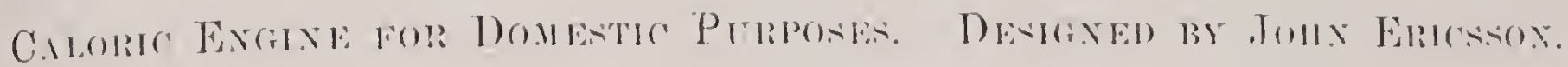

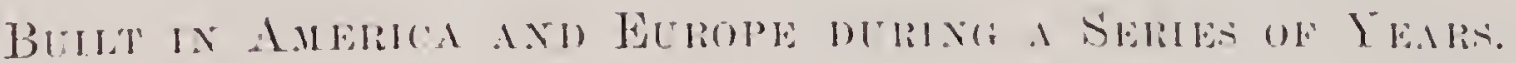

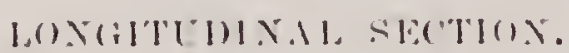

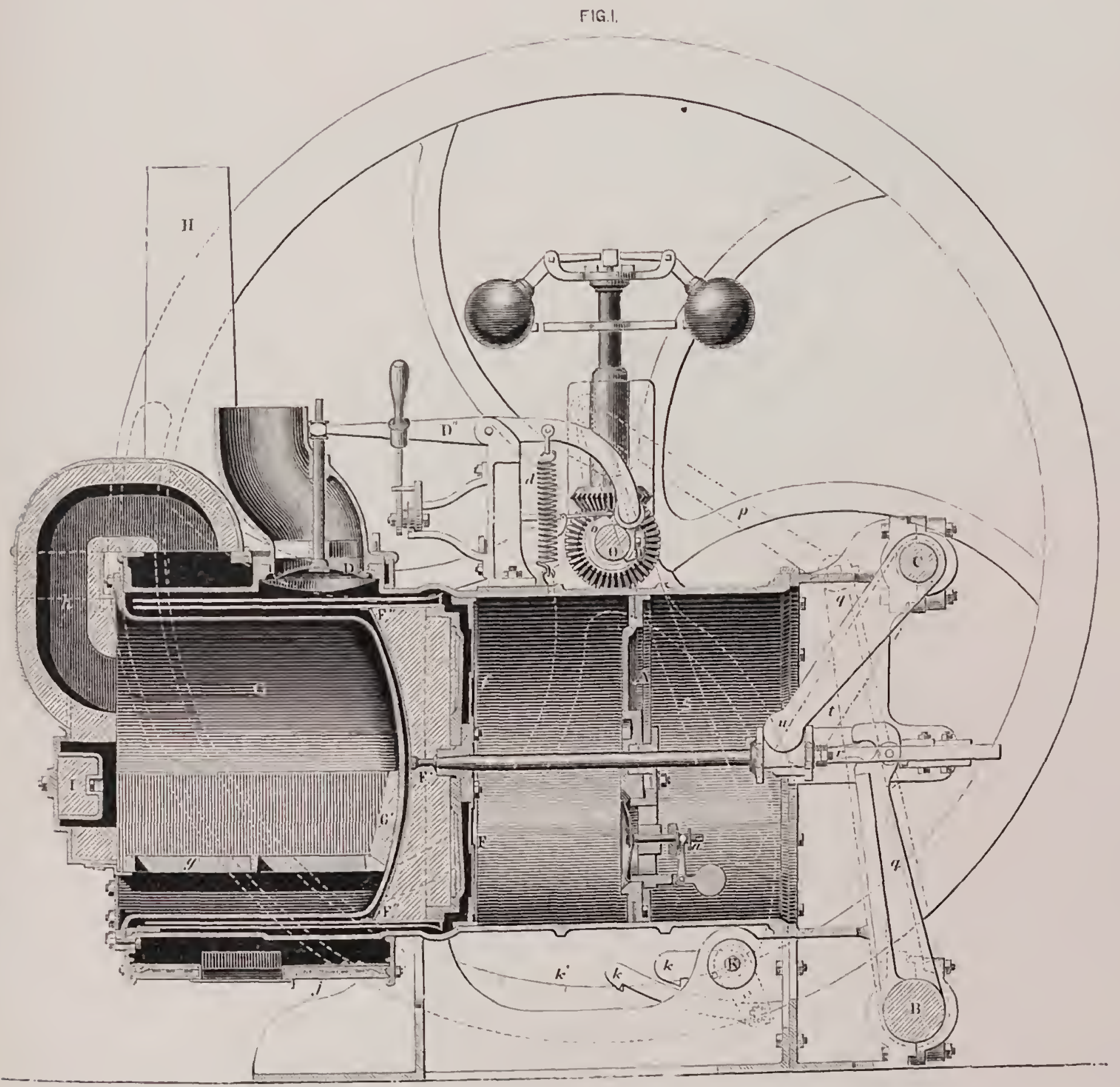





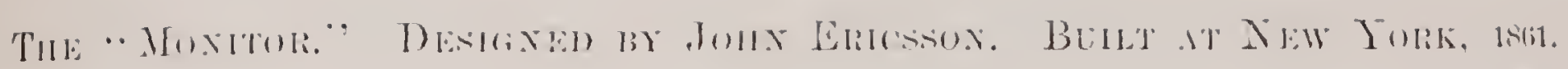
SIIF: HLRTATON.

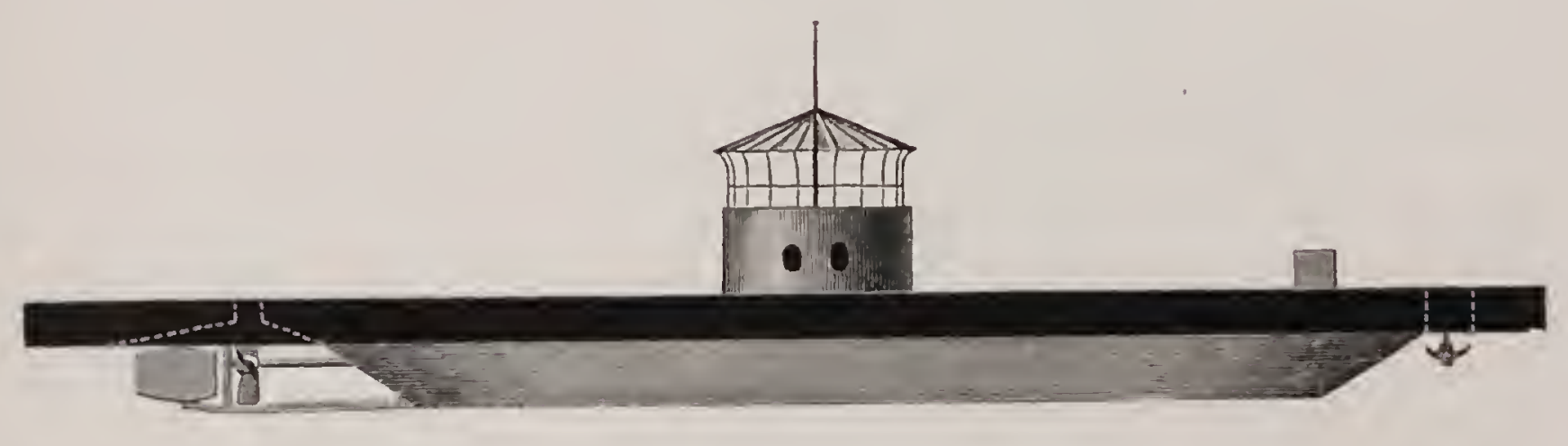

D)ECK PIAN.

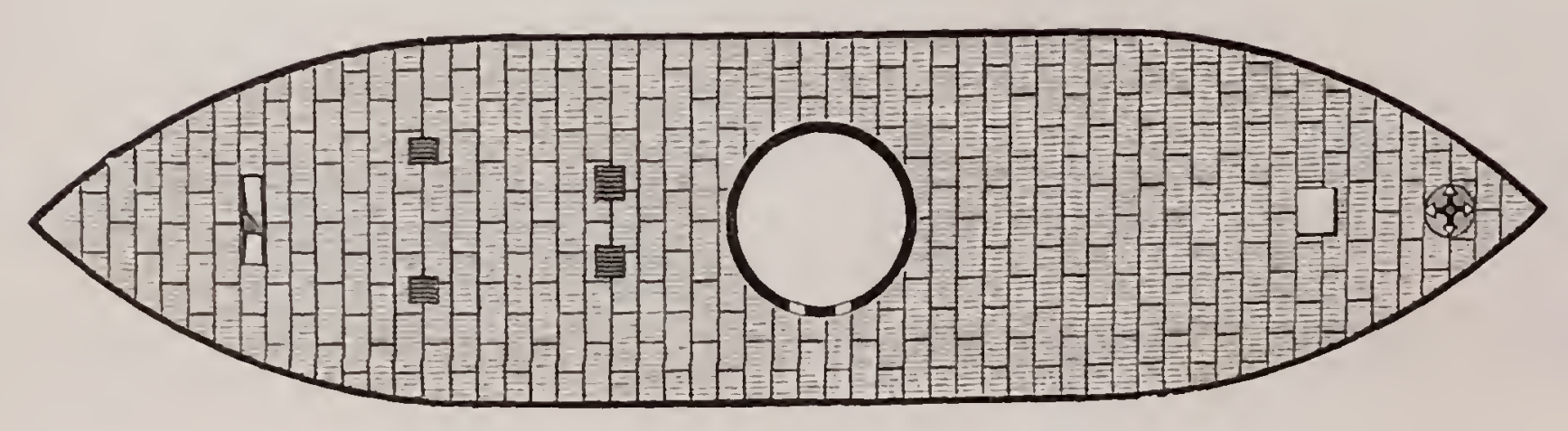

TRAXSVERSE SECTIOA OF ITTLT, AXD TTERET.

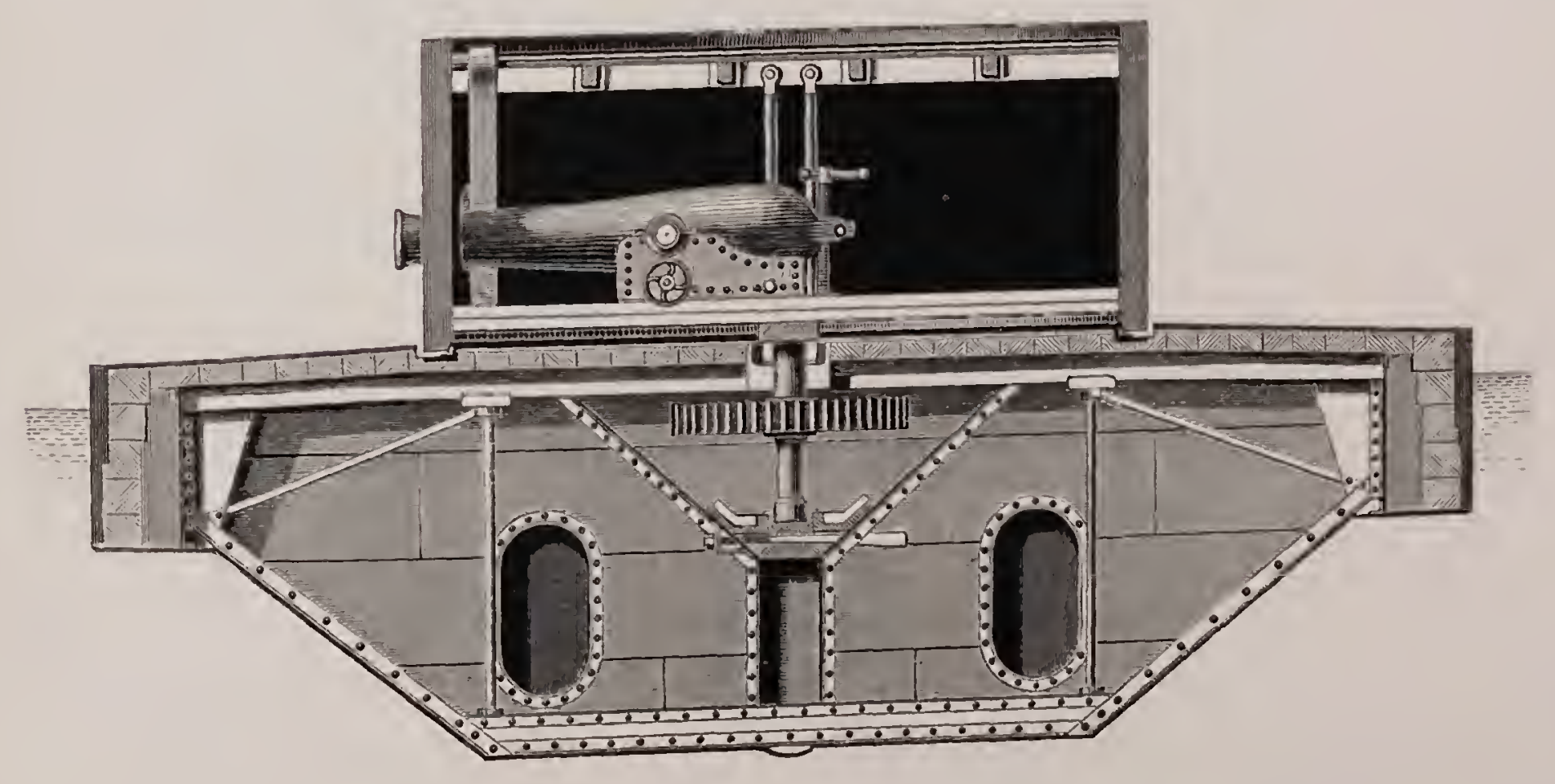

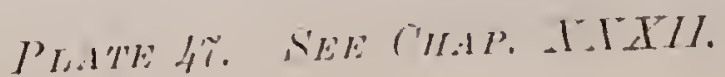




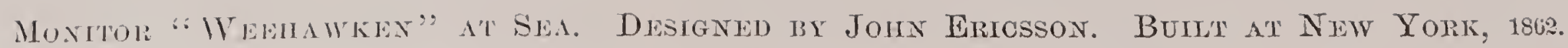

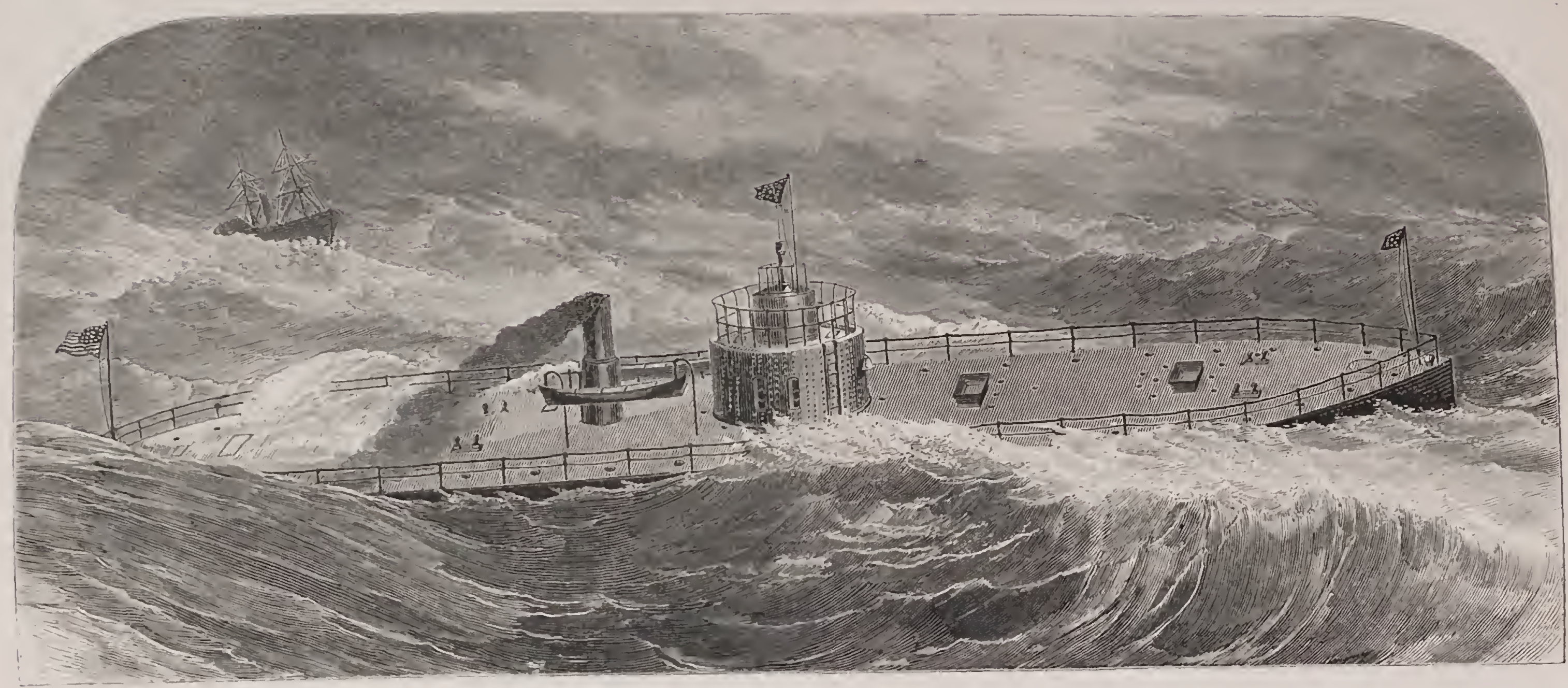





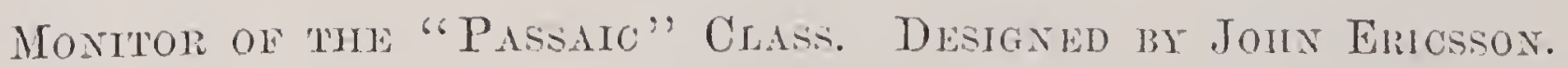

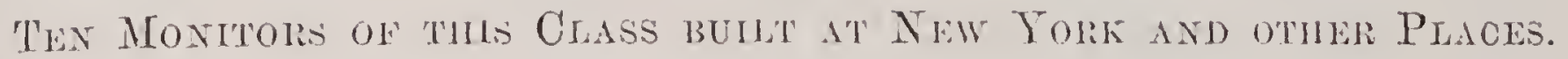

SIDE: EIEVATION.

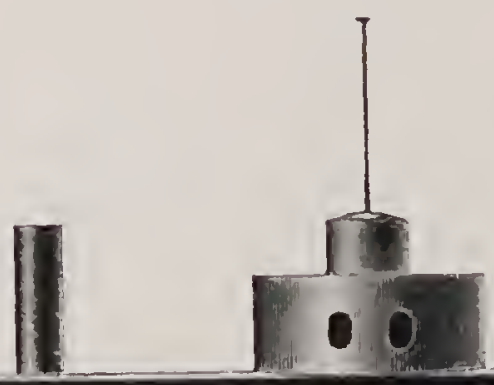

TRATSVERSE SLCTION OF TULRE' AND PILO'T-HOUSE.

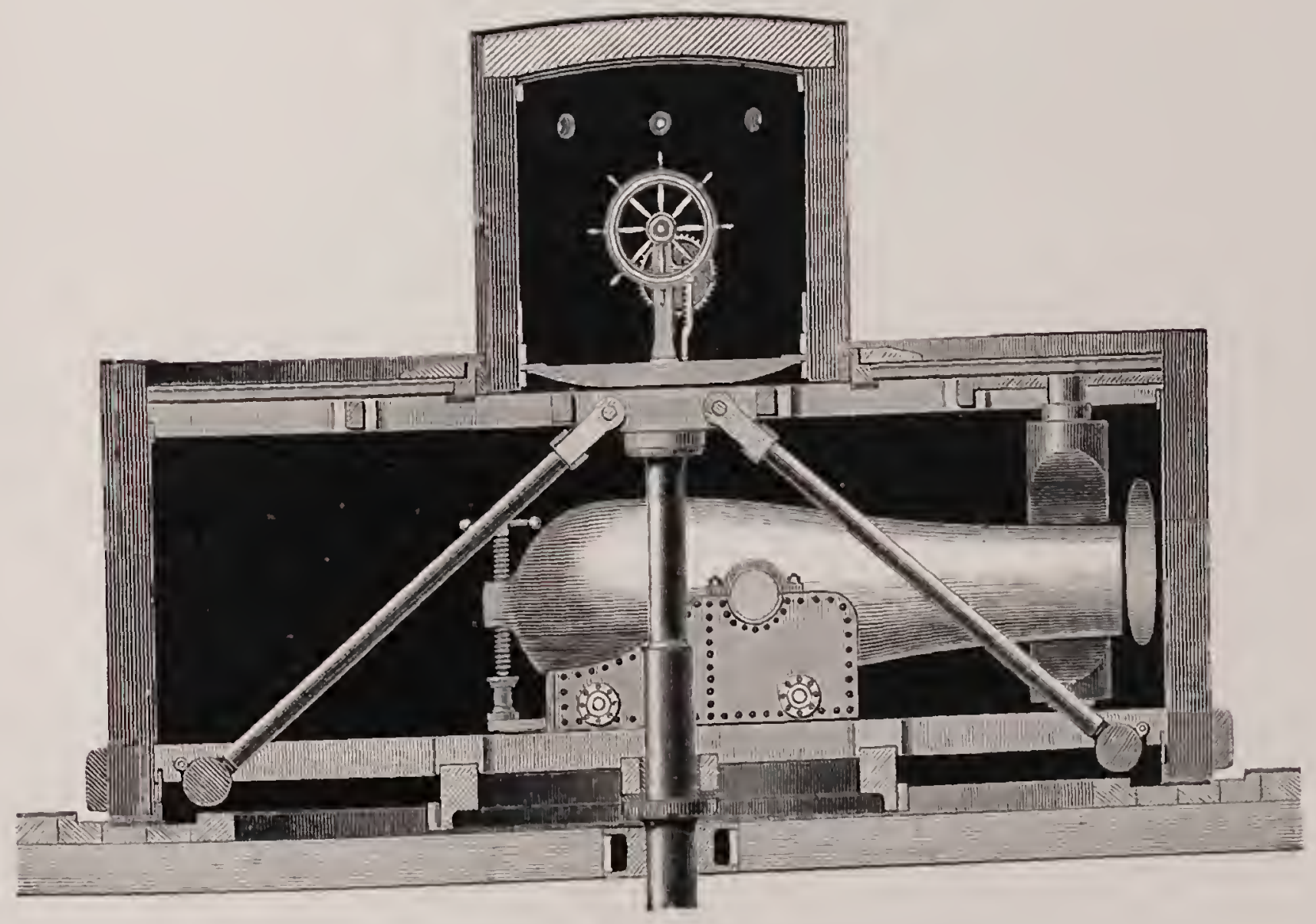

PLATE 49. SEE CHAP. TYIIII. 

T'11: Mo.N

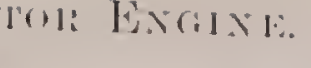

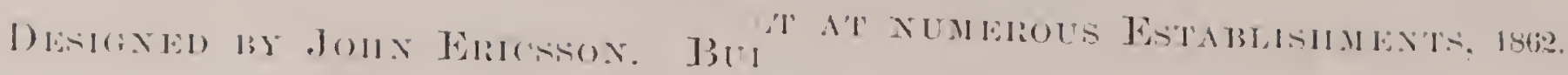
T(1) VI:

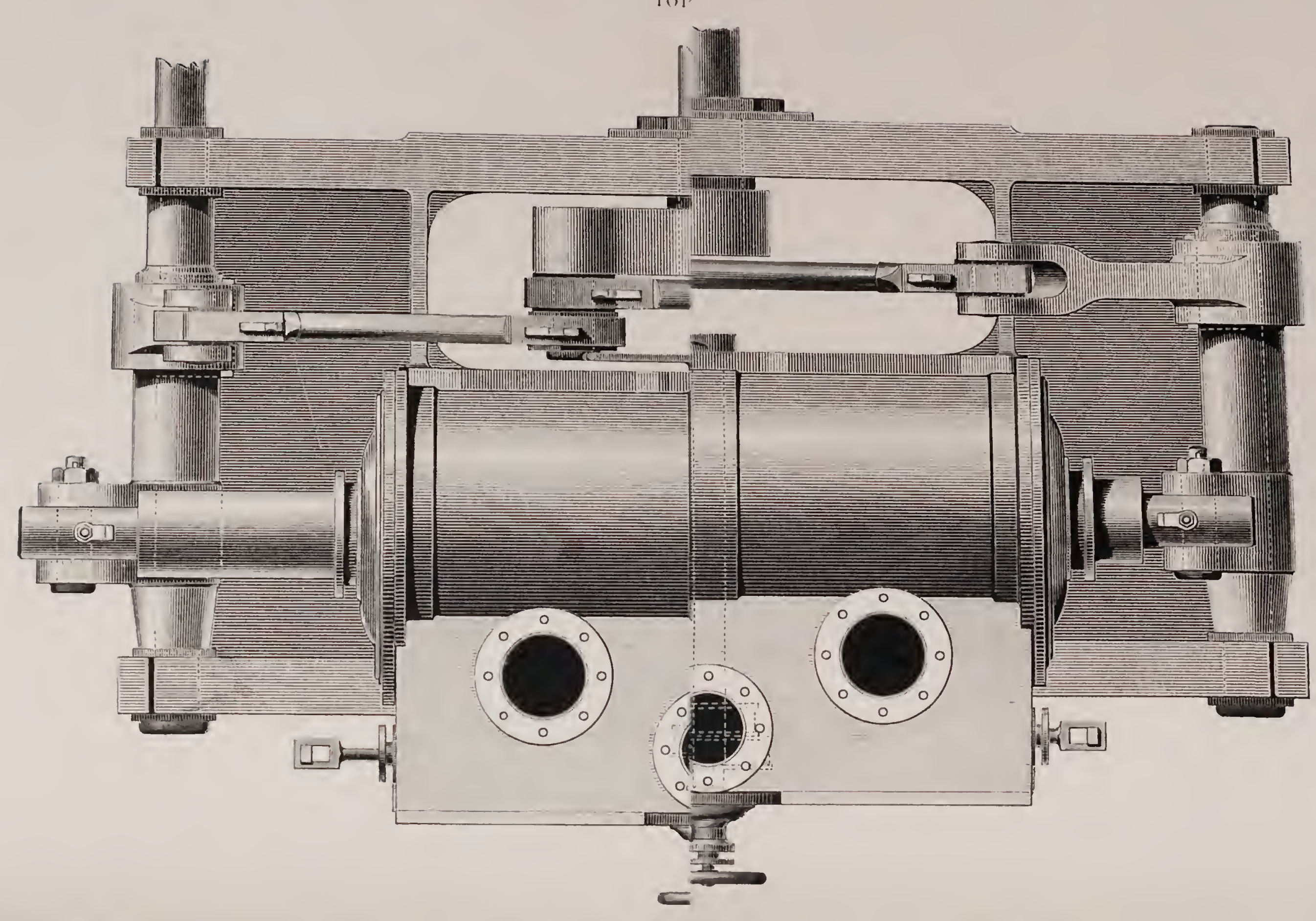


THE Monitor Exgine.

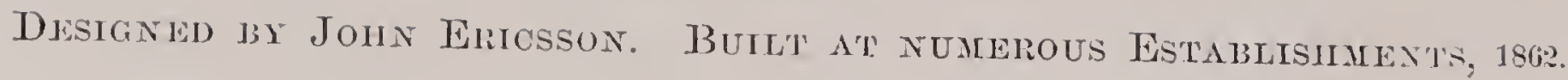
FIONT EHISVATION.

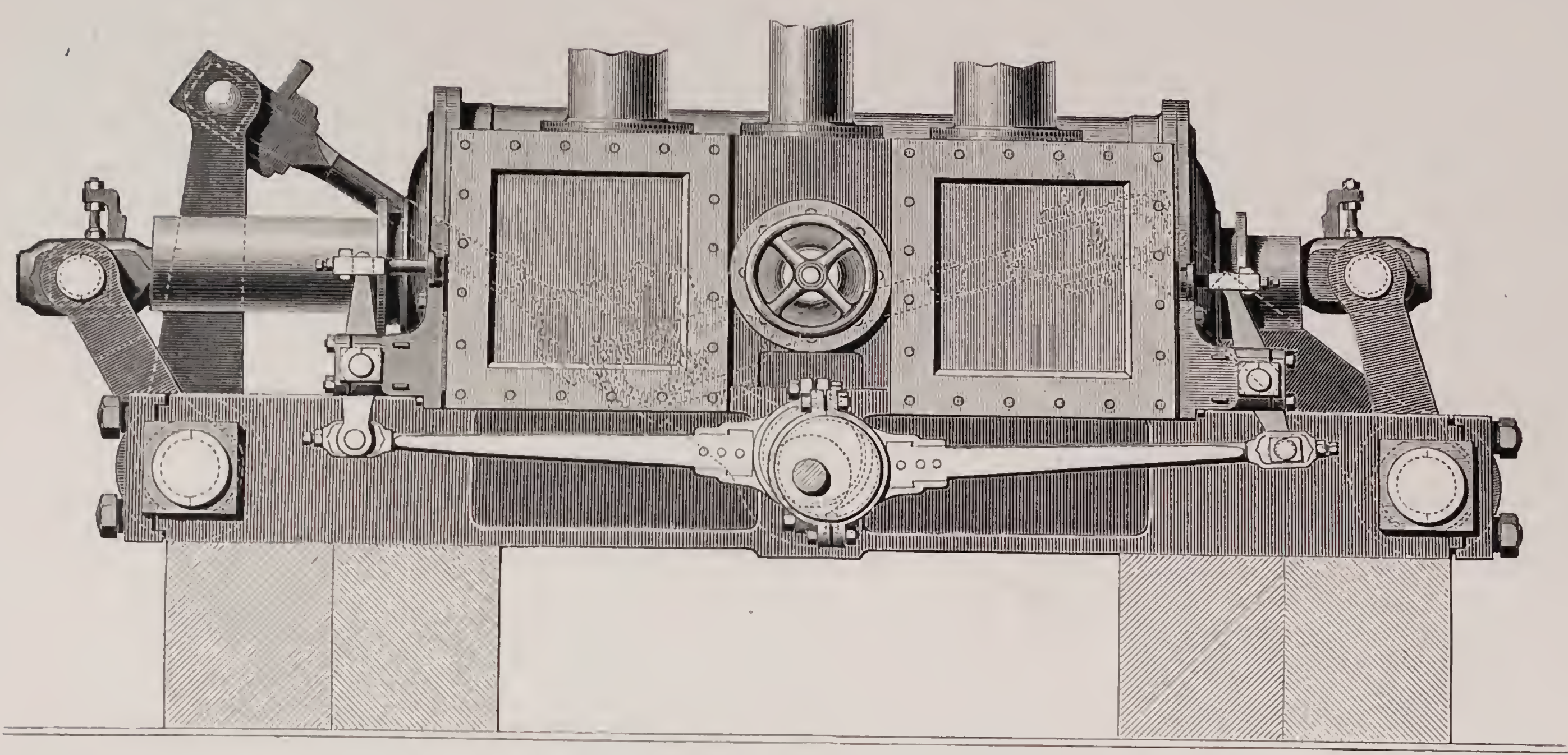





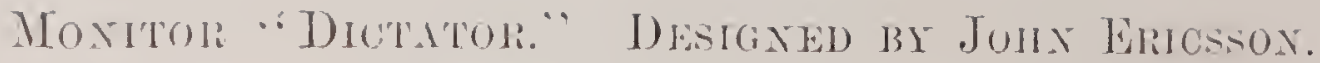

BuILT AT NEW Yolk, 186 .

SIDE ELEVA'TION.

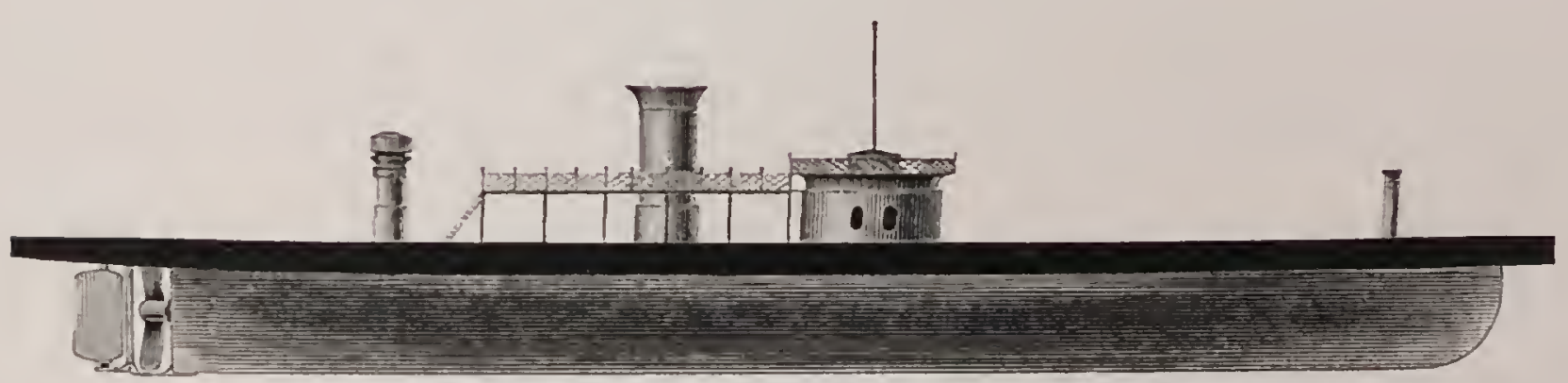

DECK PLAN.

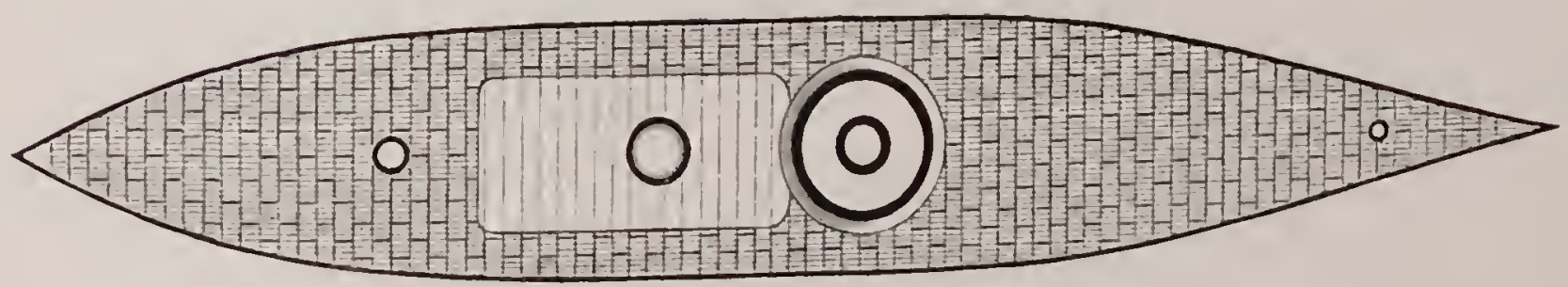

IFAGTI ON DECK, 312 FEET. BEAN, 00 FEET. DEPTI, 21 FEEI 6 IXCUES. STHAM-CYLTNDERS, 100 INCHES DIANETER, 4 FEEL STHOKF. PROPELLER, 21 FEET 6 INCHES DIAMETLR. 

Monitol: "Dichatol." Designed by John Eriosson. Buth at New Yotr, 186.

TRANSVLHSE AEOTION OF MNGINES AND SHIP.

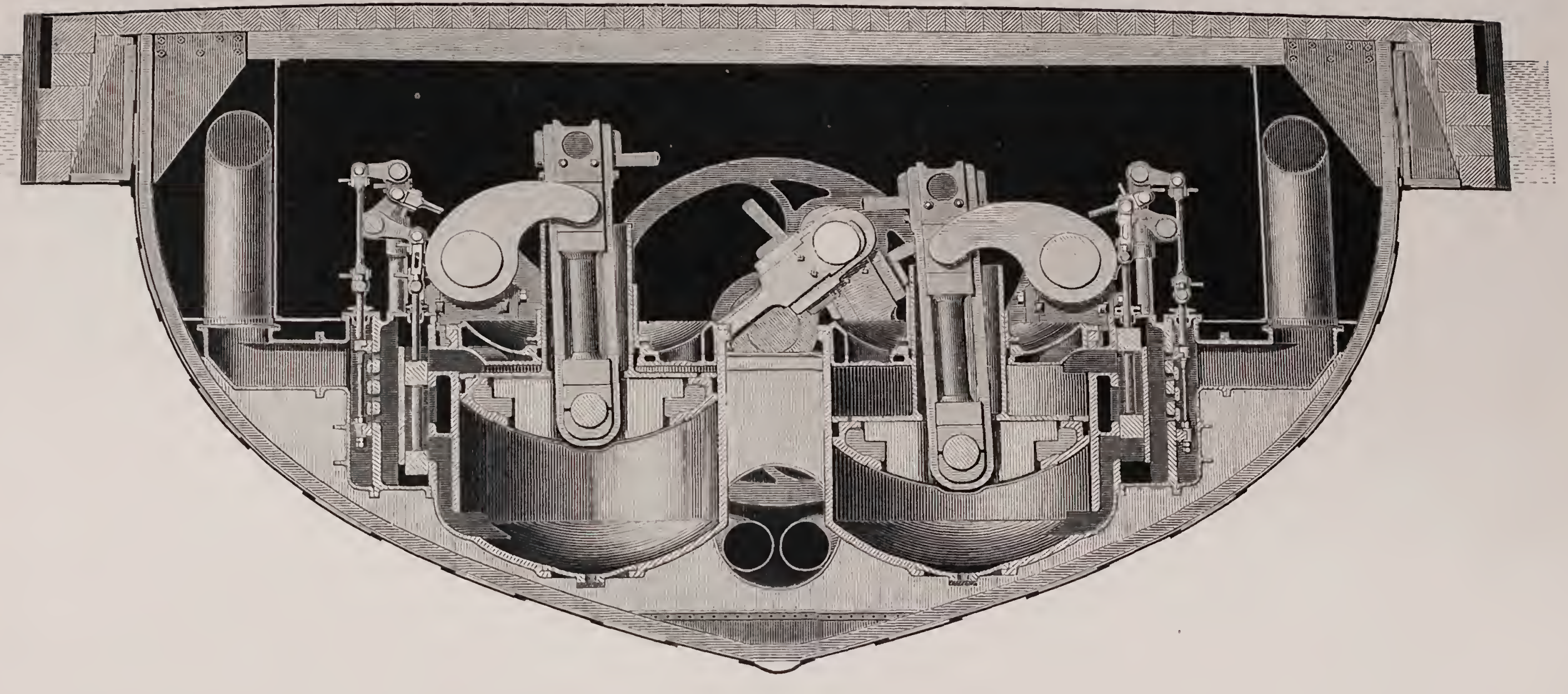




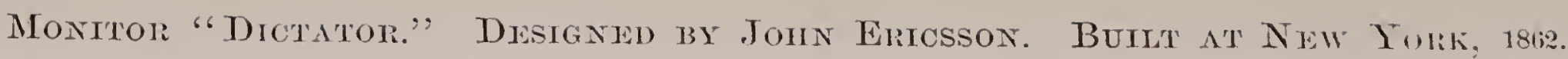
TOP VIEW OF EXGINES.

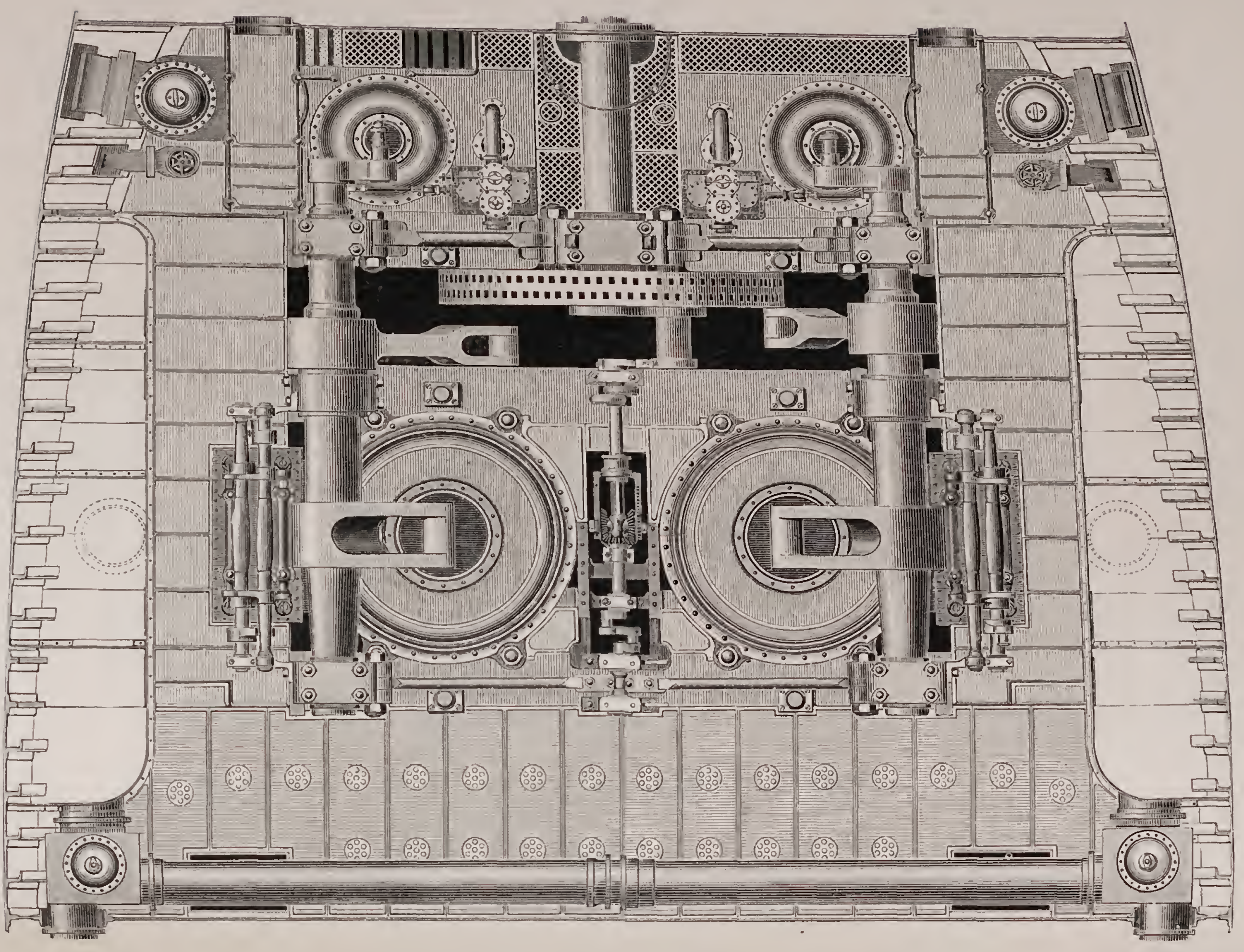




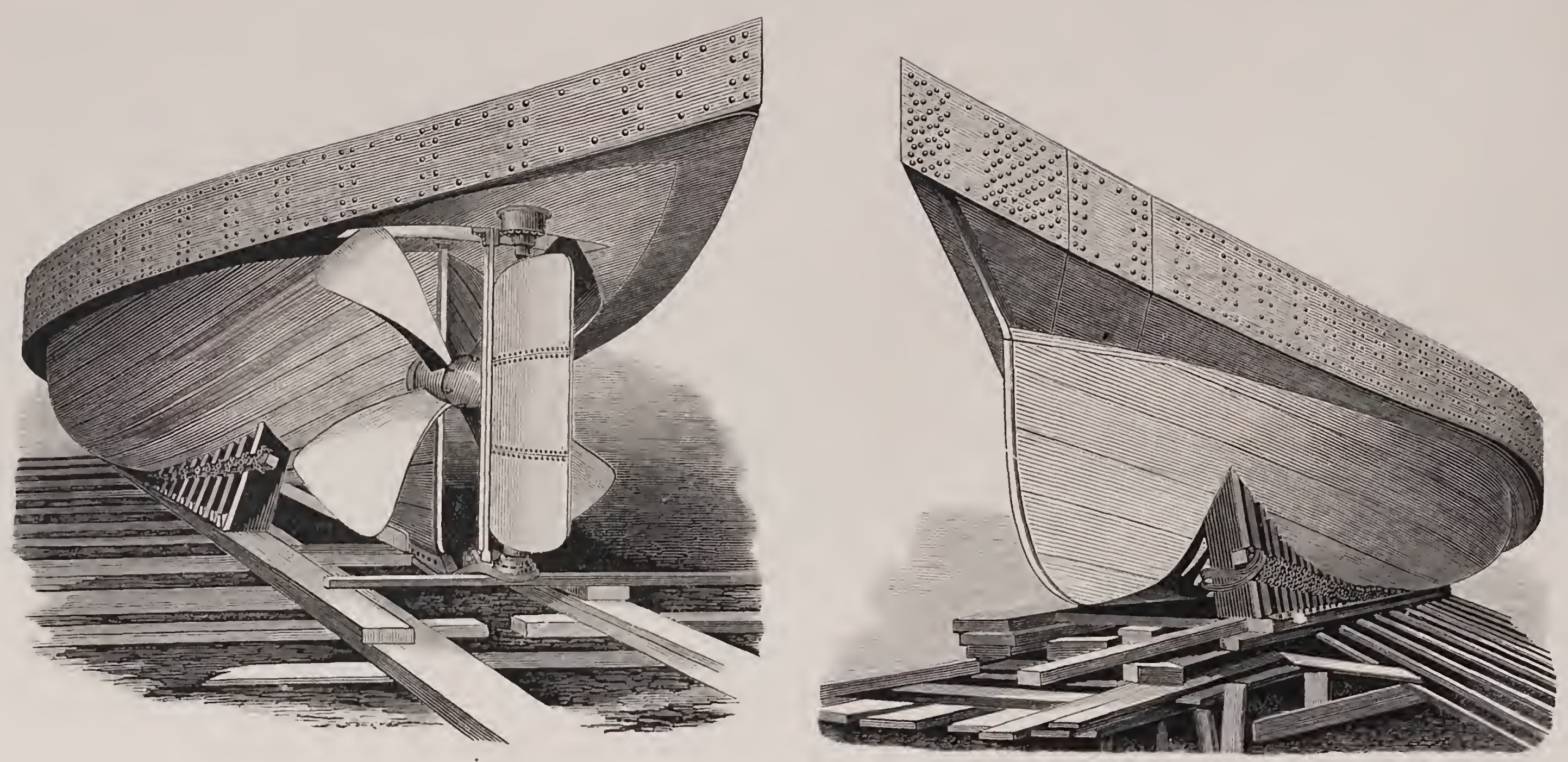

'The Monitor 'I'Urre't and the Casemate.

Deok Plan of a Monitor witil 'l'wo 'Turrets.

LENGTH, 230 FEET. BEAM, 30 FENT 6 INCHES. ARMAMENT, FOUR 24-TON GUNS.

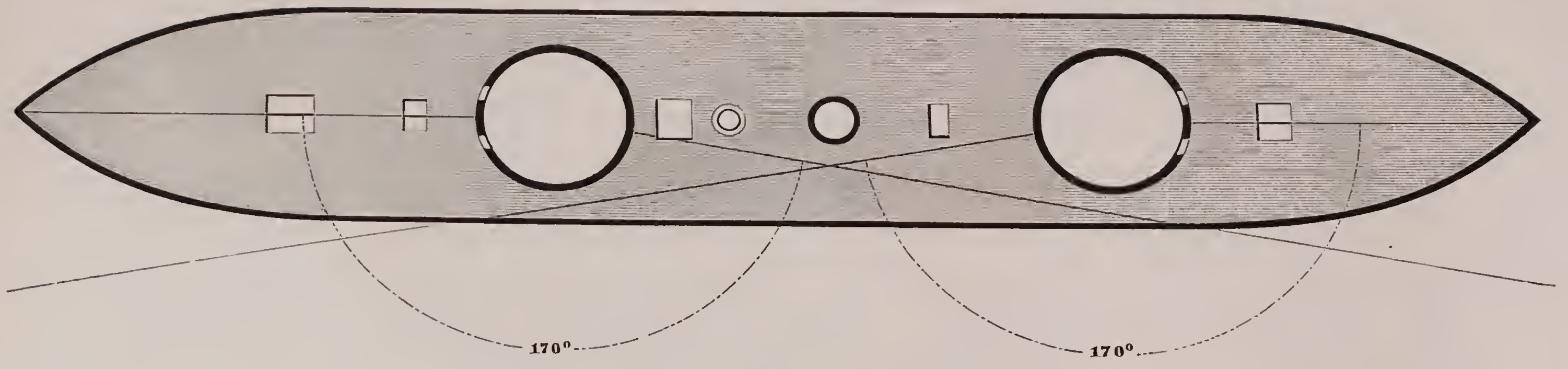

Deck Plan of THe 'Turkisit Trow-Chad "Moyint Zafeier."

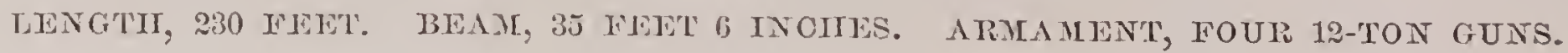

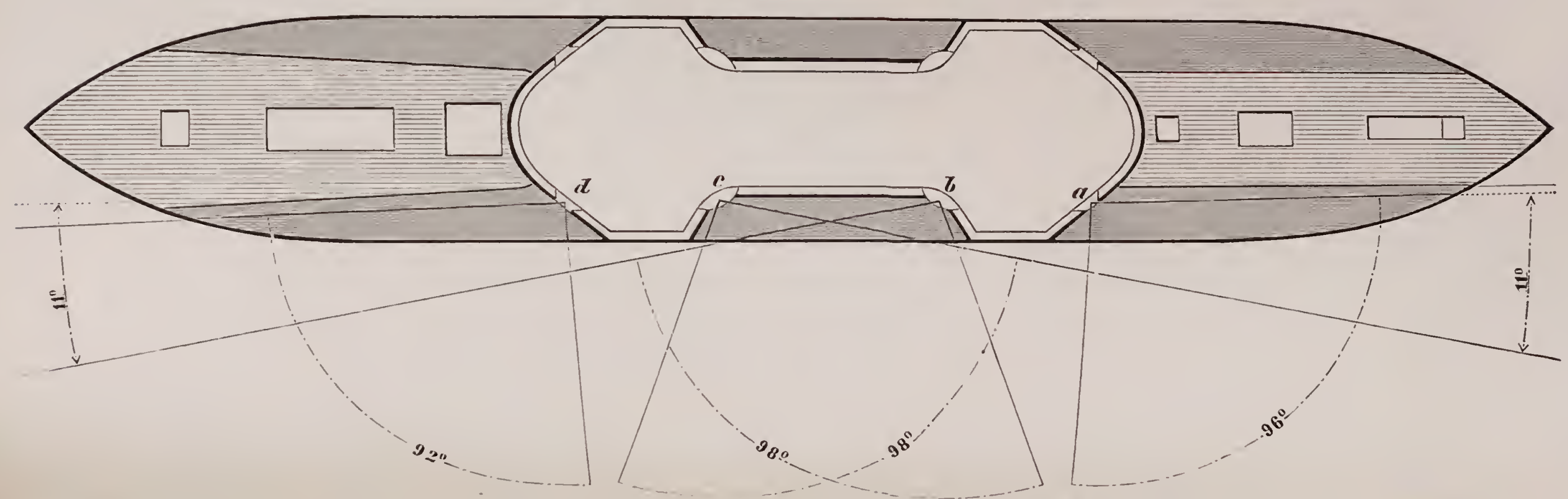





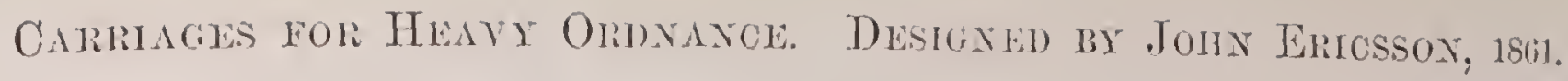

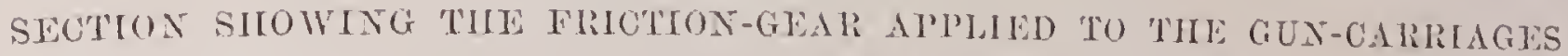
OE LIIE UNITED STATES IRON-CLAD FLENT.

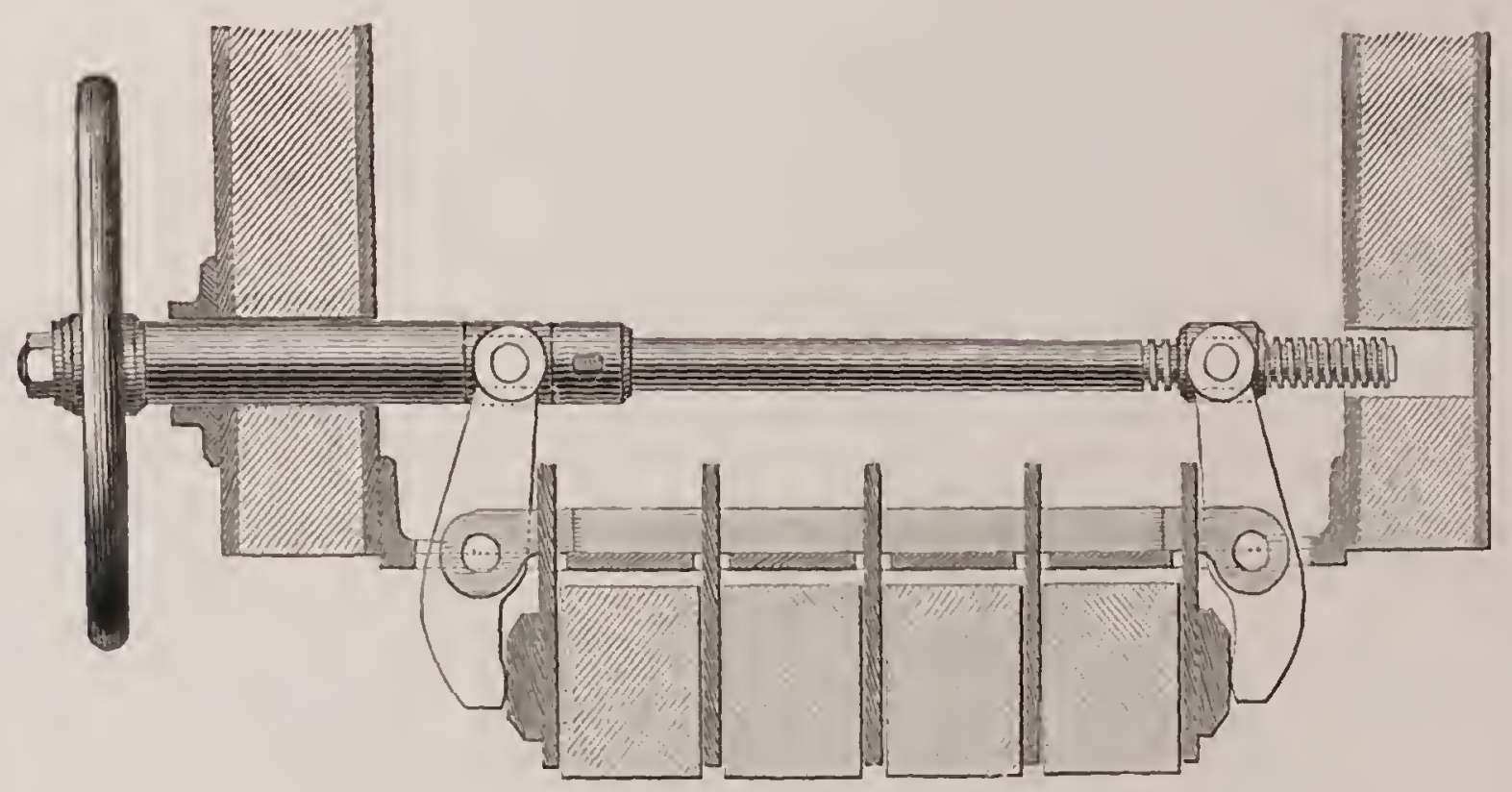

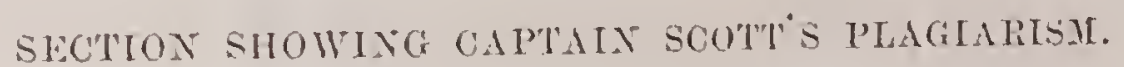

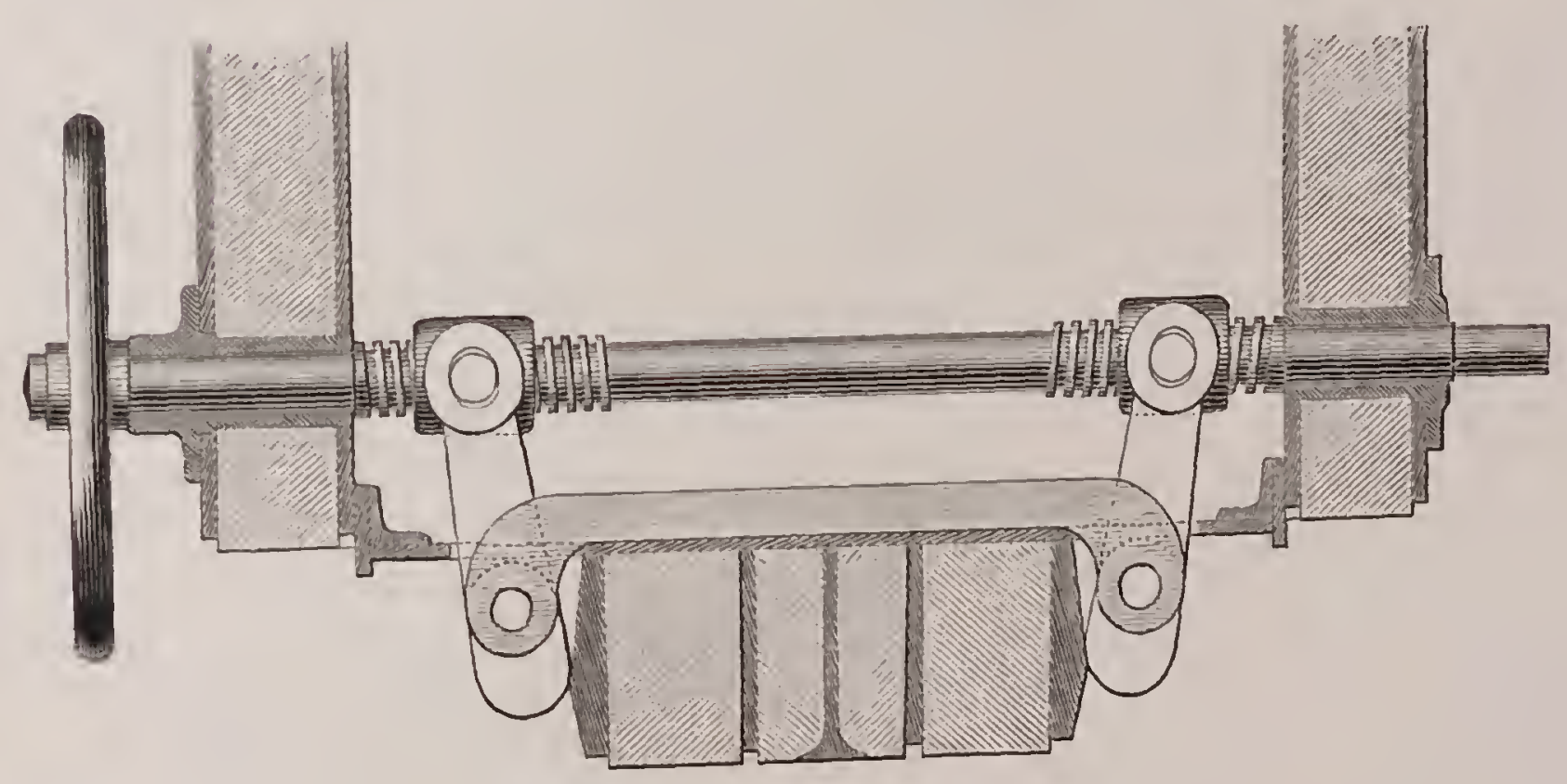

SECTIOA SIIOWING SIR WHIIAM ARMSTRONG'S PLAGLARISM.

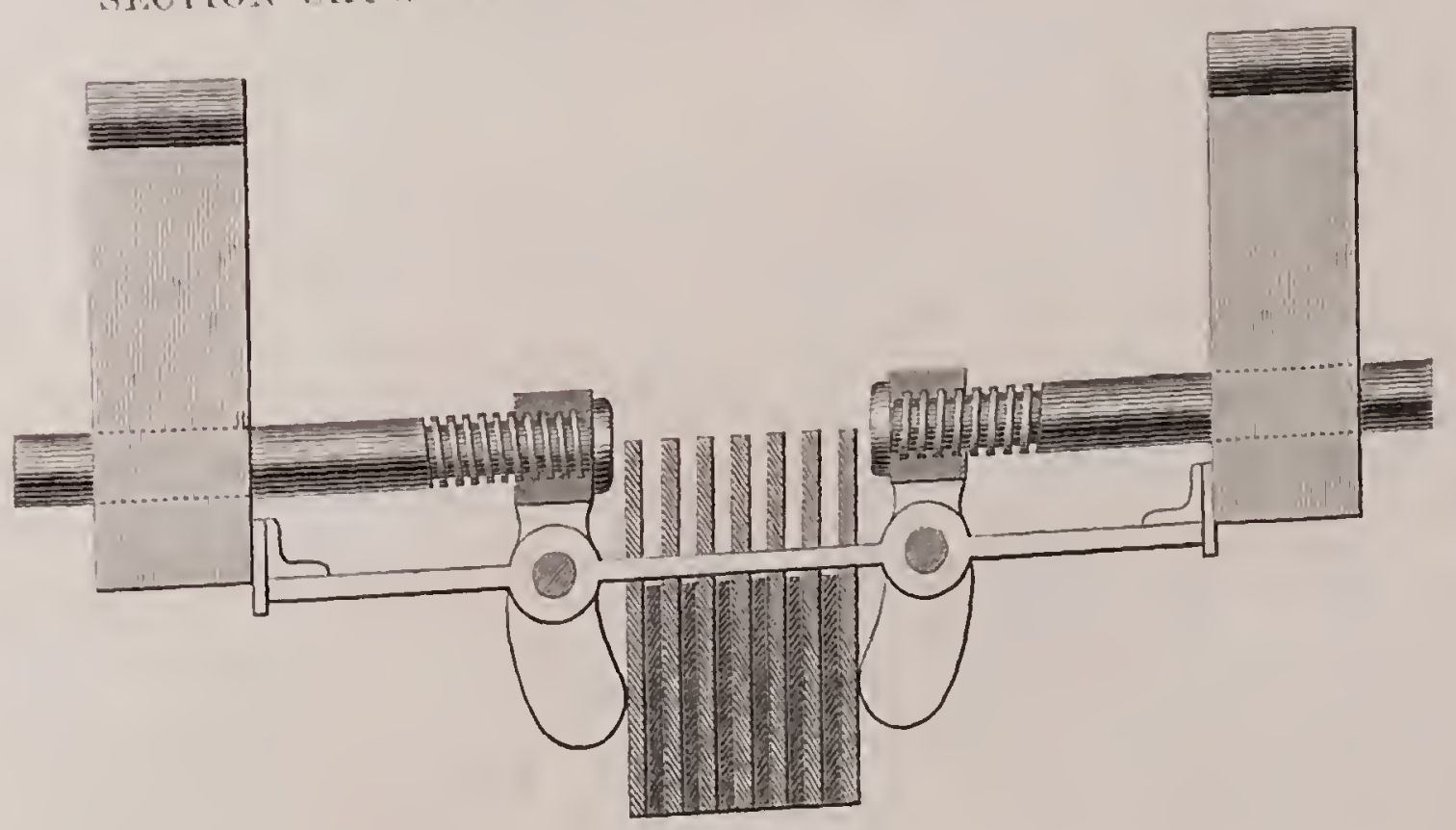





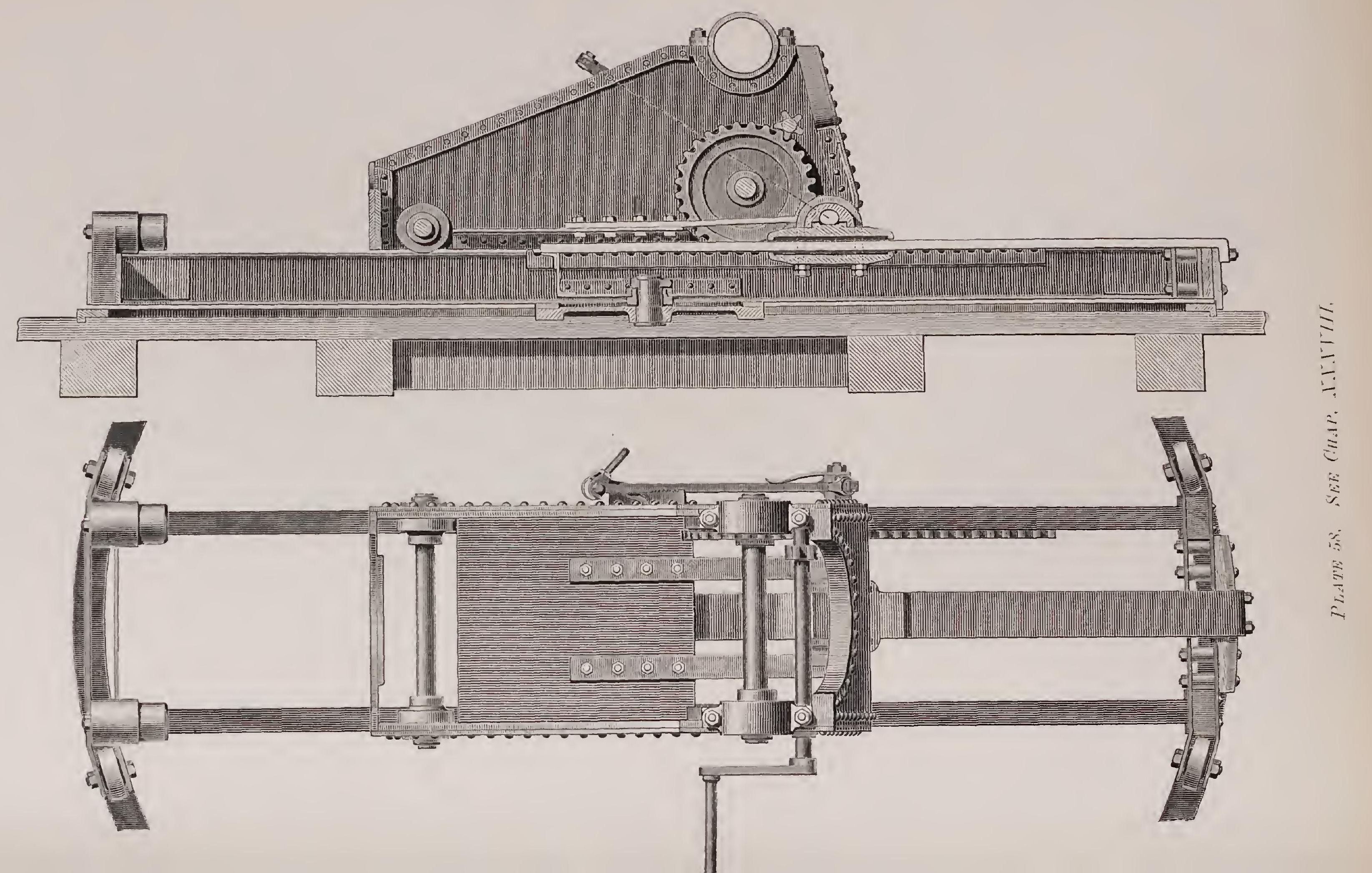





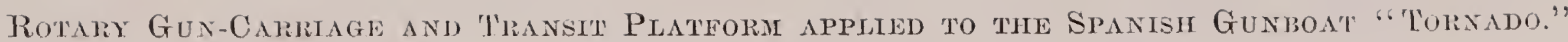

Designed by JoHn ERICsson. BuILT AT New York, 1873

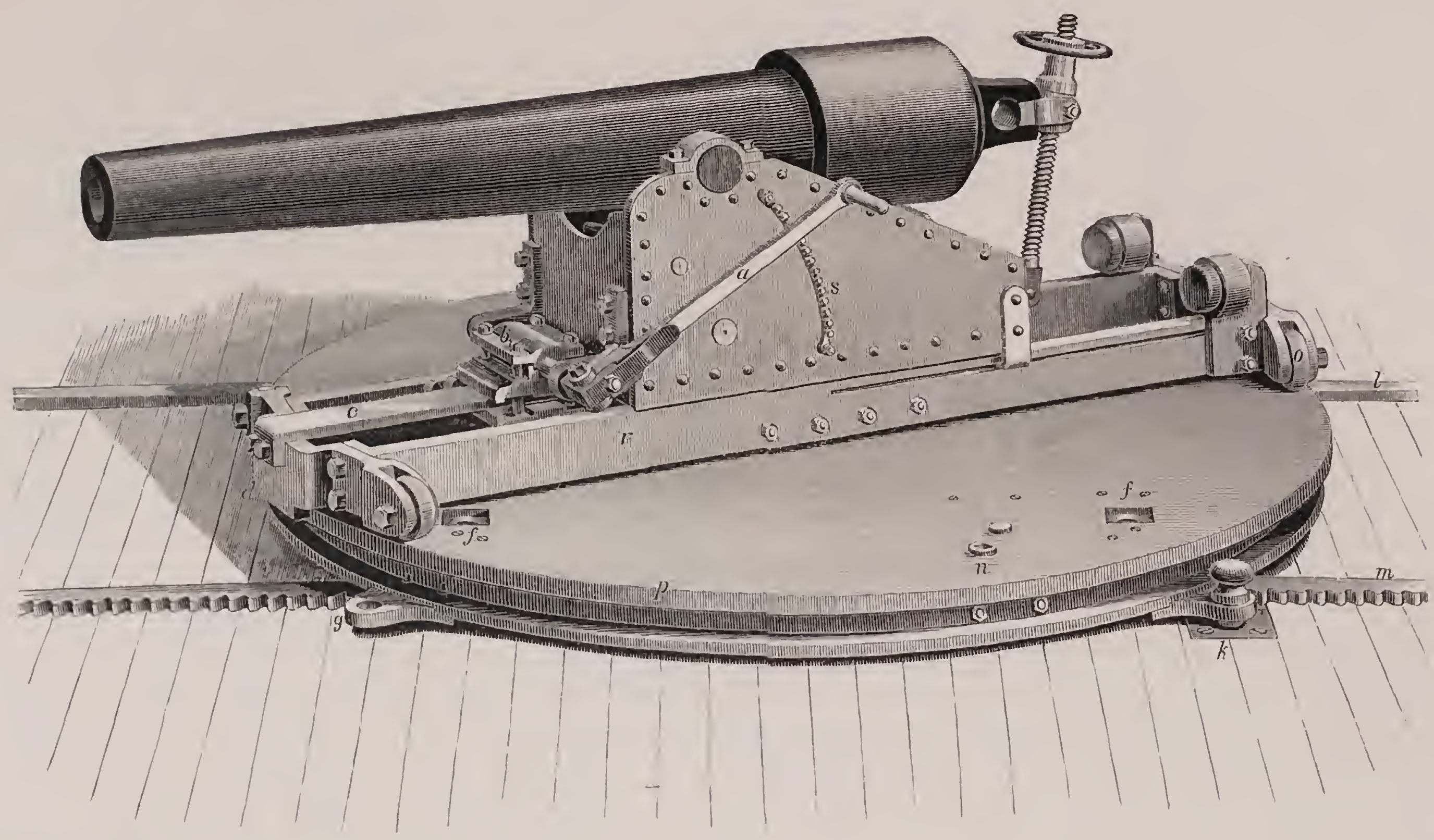





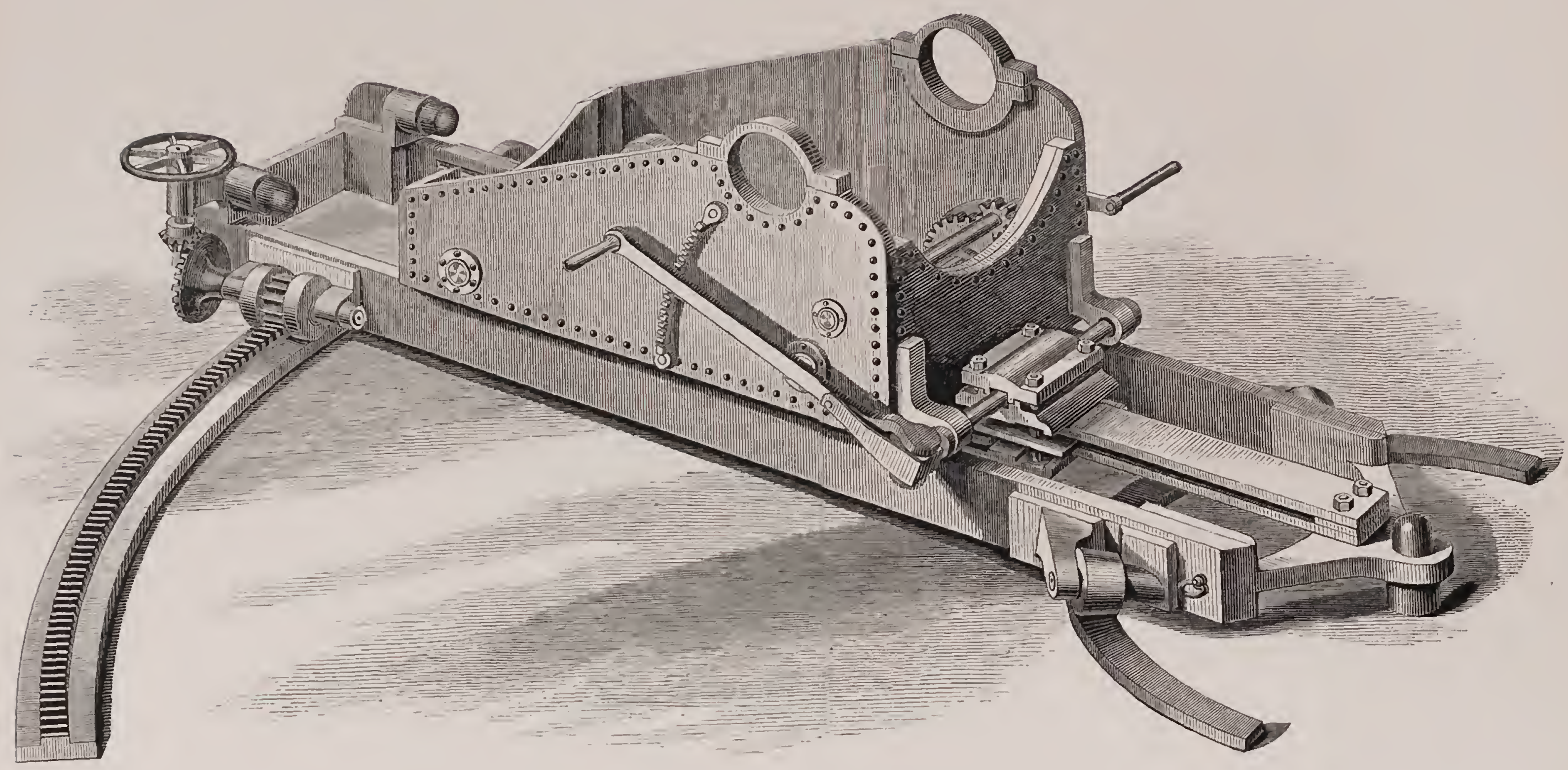



The Spanish Gunboat Exgines. Designed be Juhn Elitcson.

Bullit at New York, 1869.
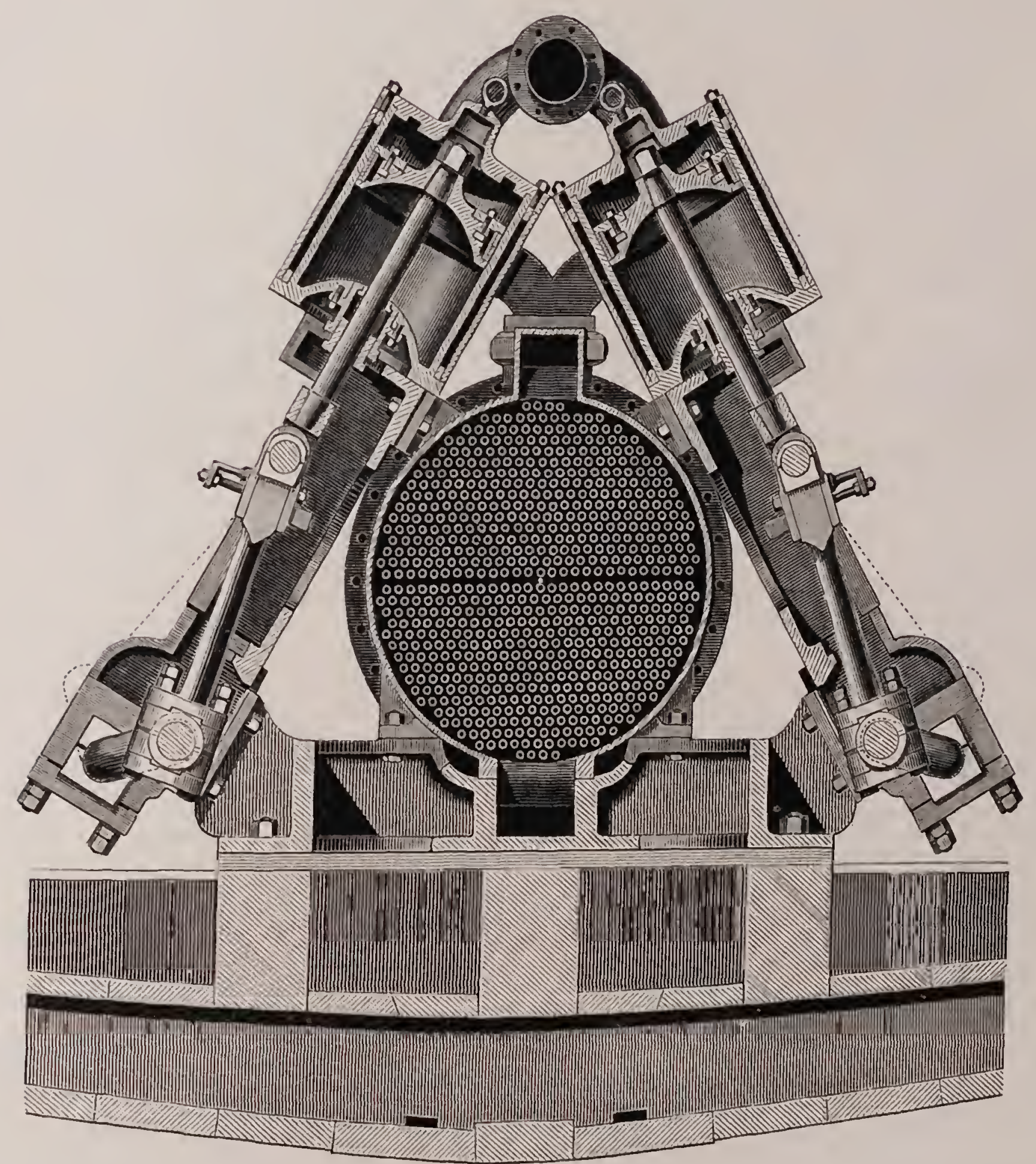



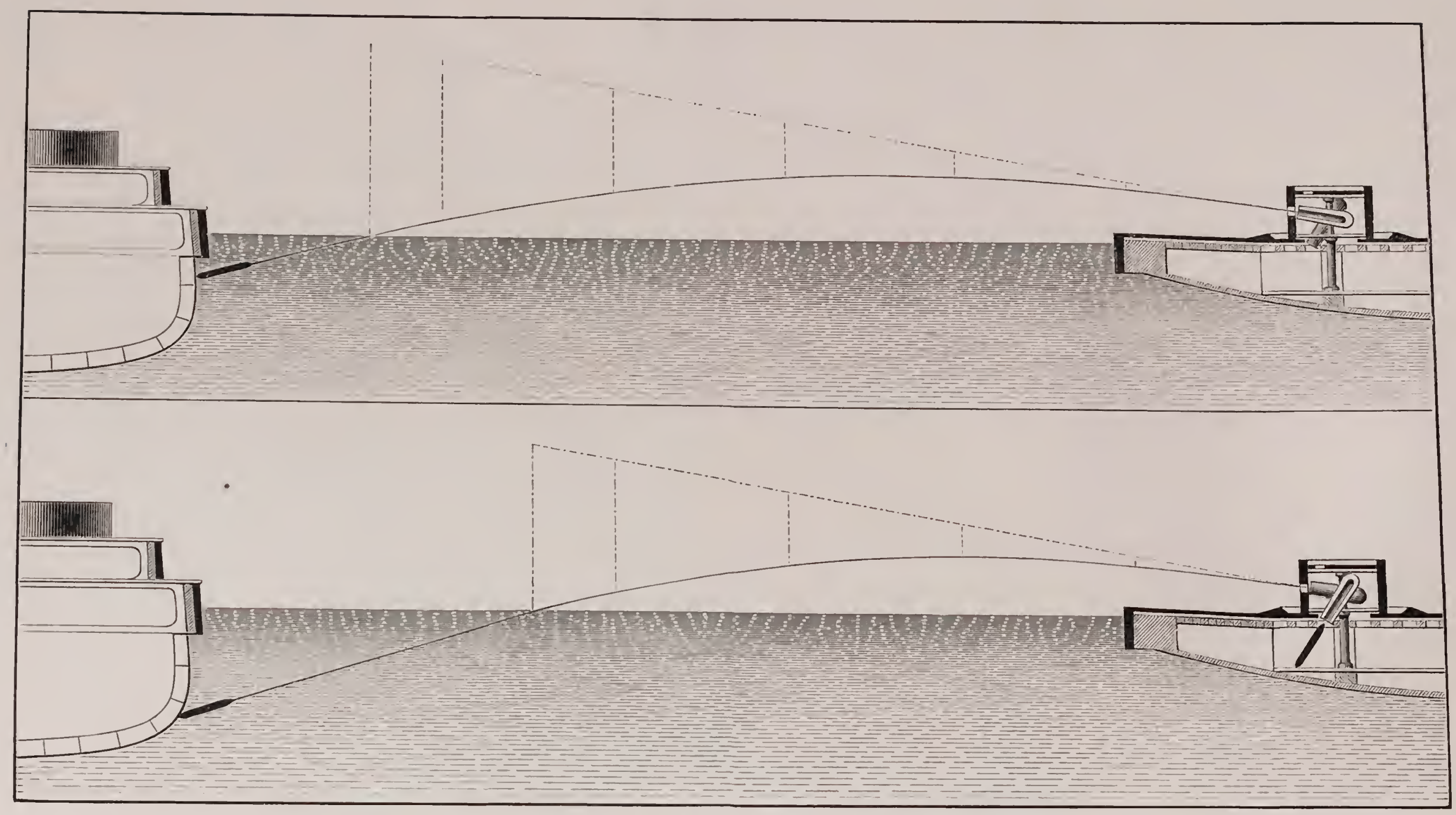




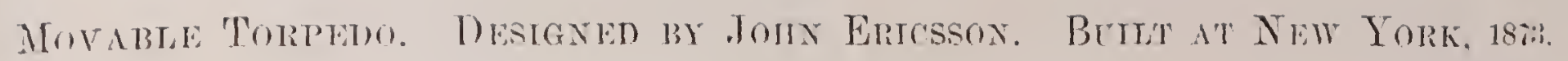
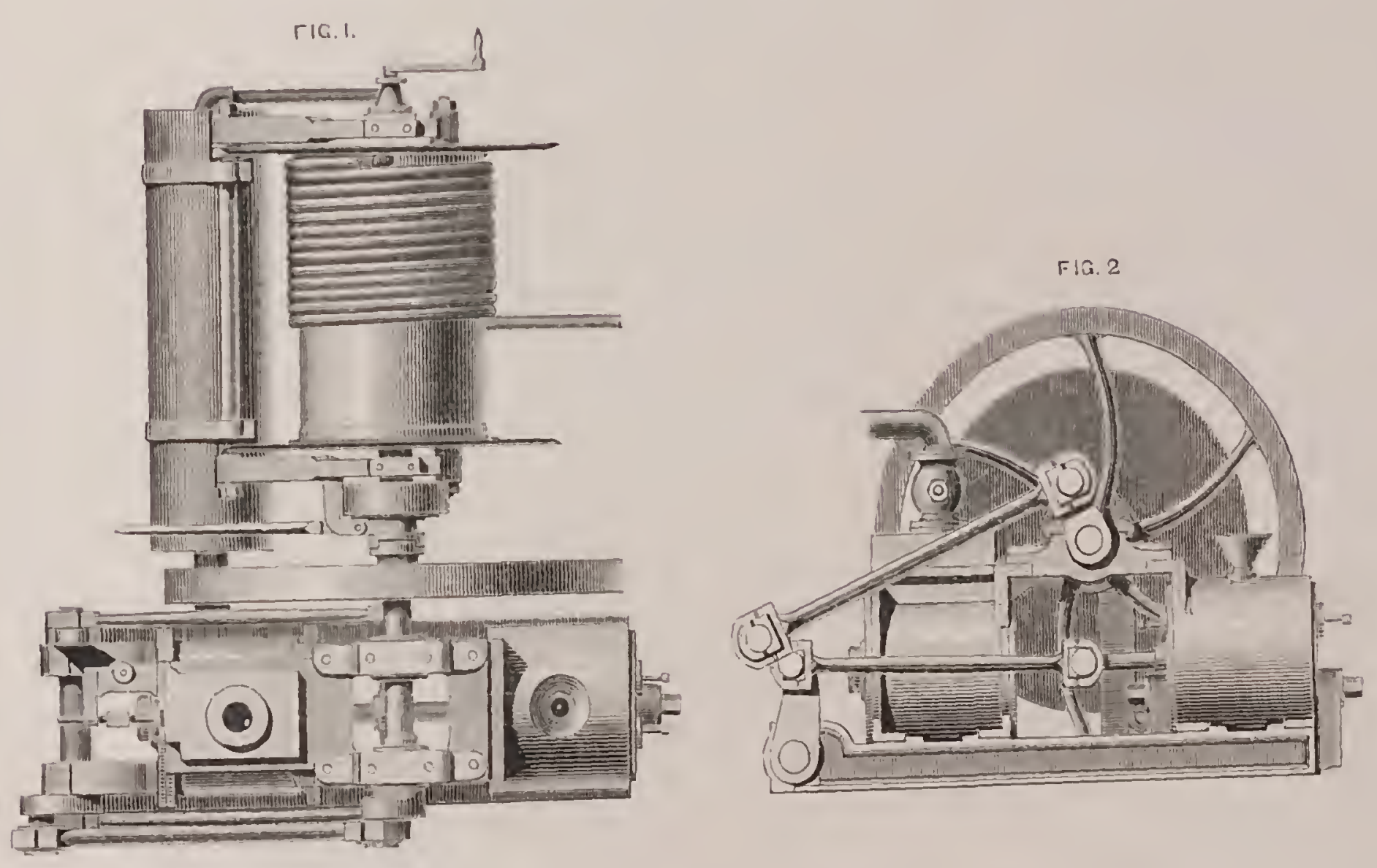

FIG. 3

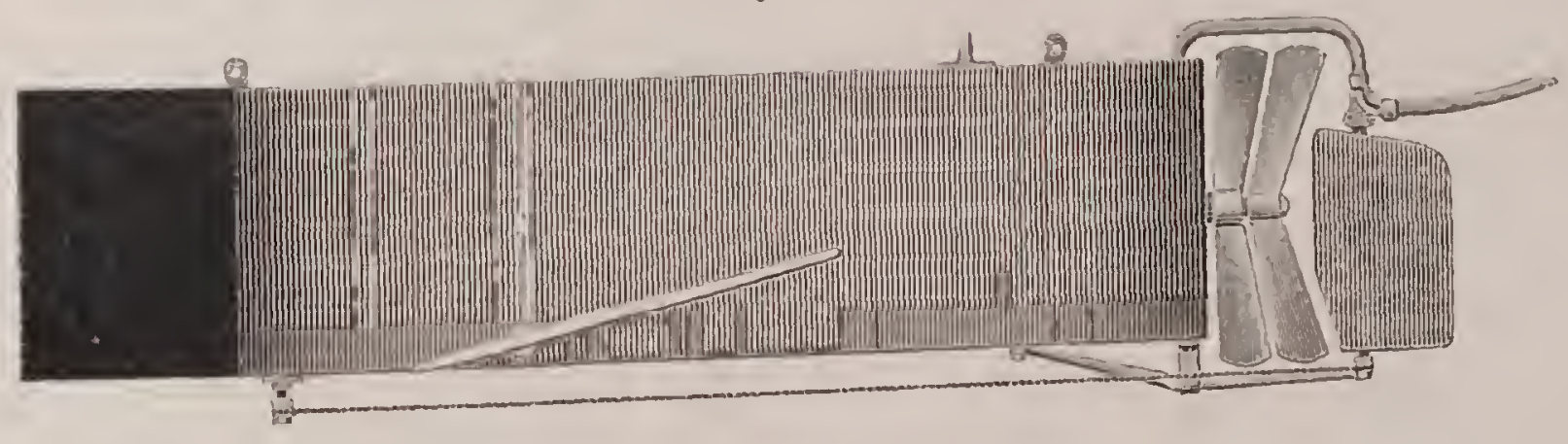

FIG. 4 .

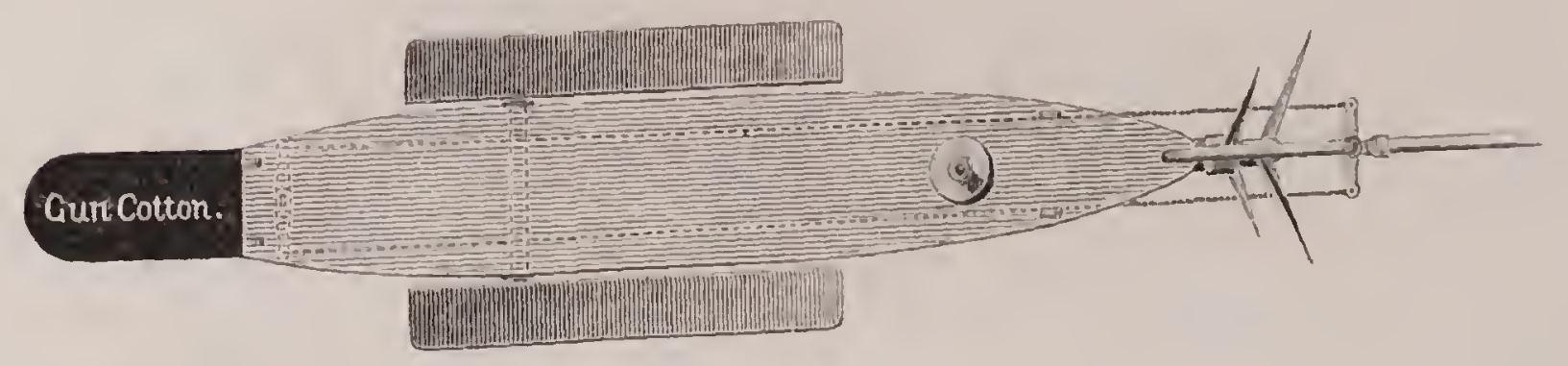



Air-Compressor, for the Transmission of Mechanical Power. Designed by John Ericsson. Bumt at New York, 1873. PERSPECTIVE VIEW.

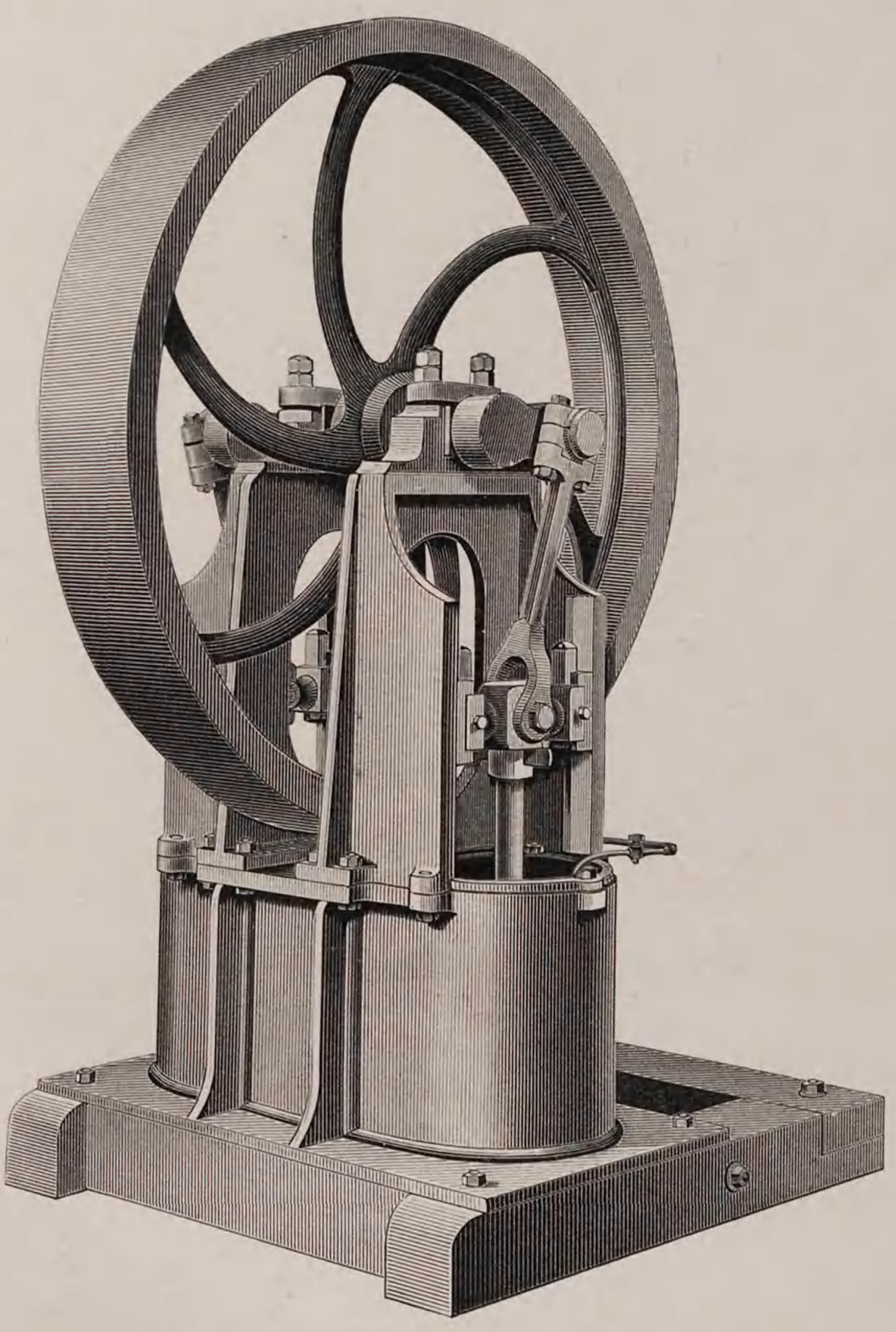


Am-Complessol, for the Transmission of Mrghanical Puwli.

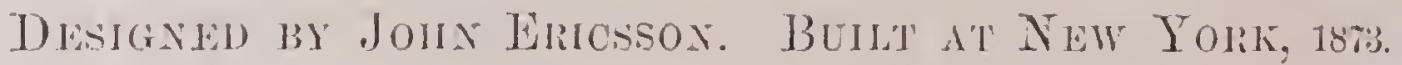

TRANSVERSE SEOTION.

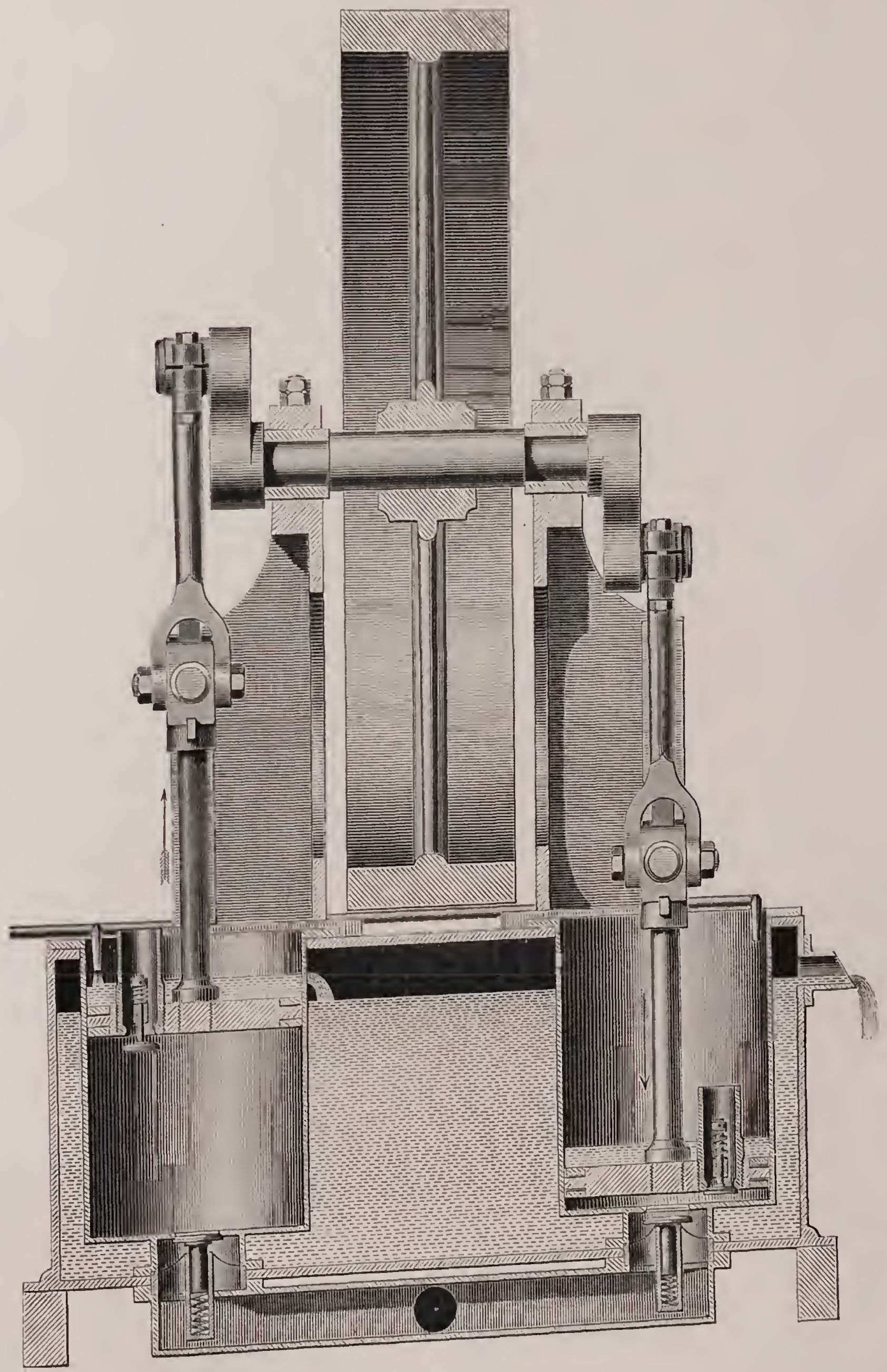


SOLAI ENGINE, OPERATED HY THE INTERVANTION OF S'TEAM.

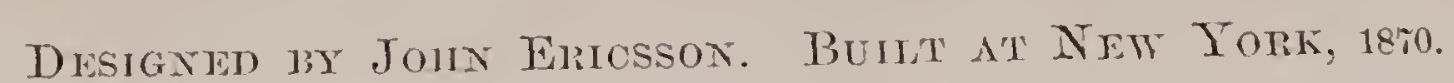

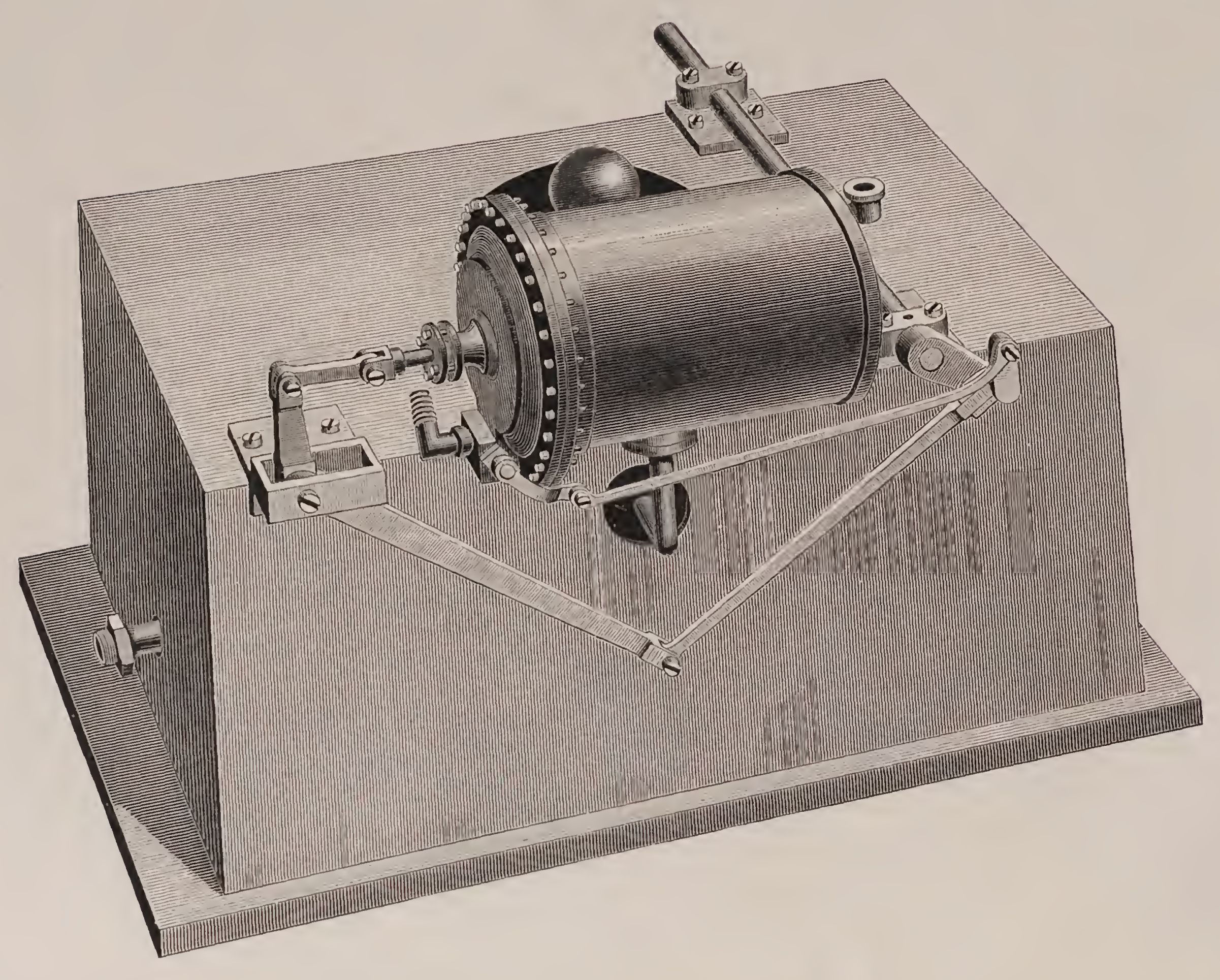





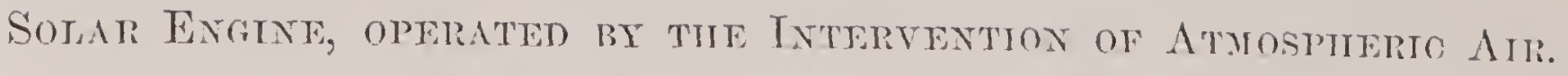

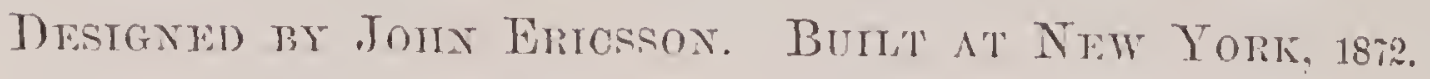

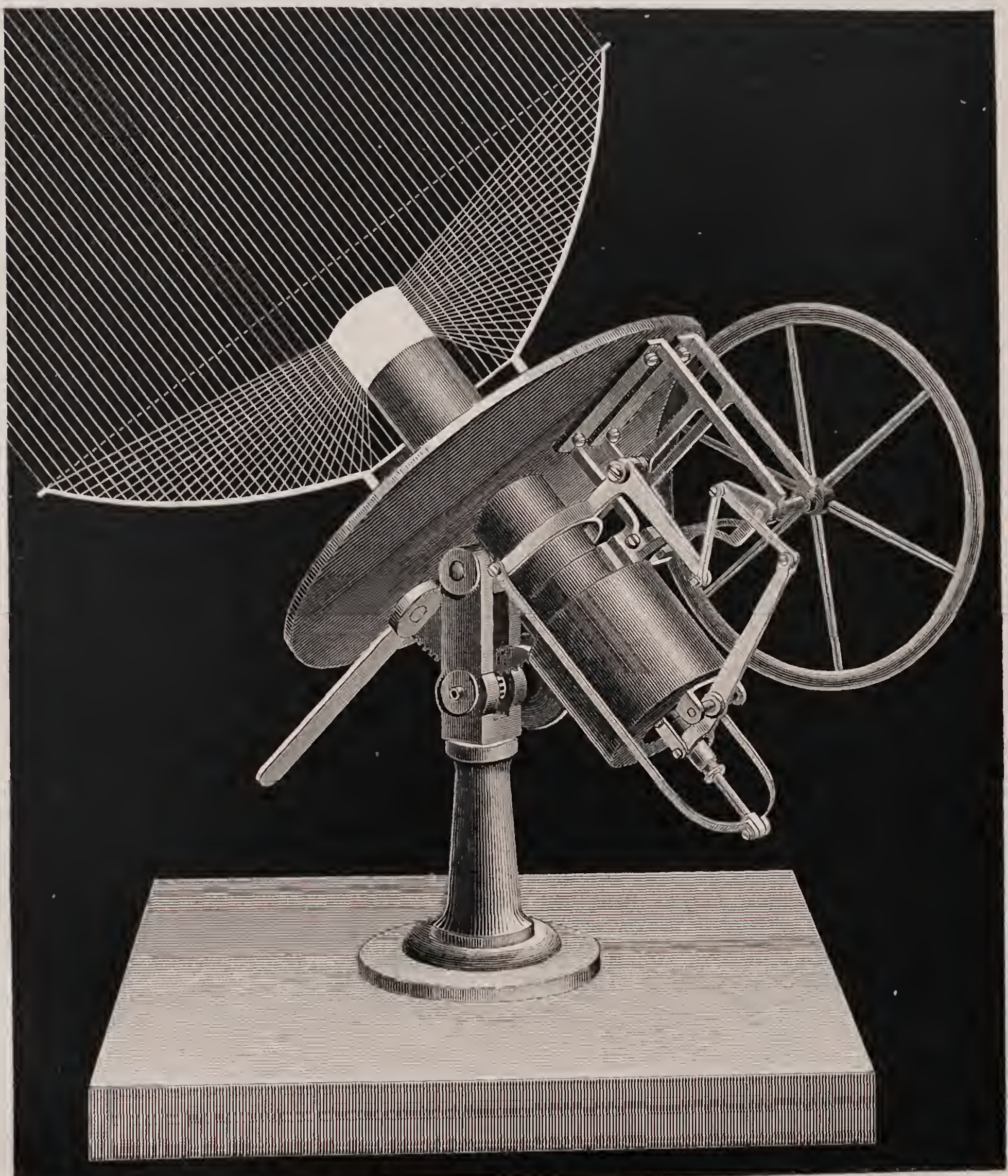









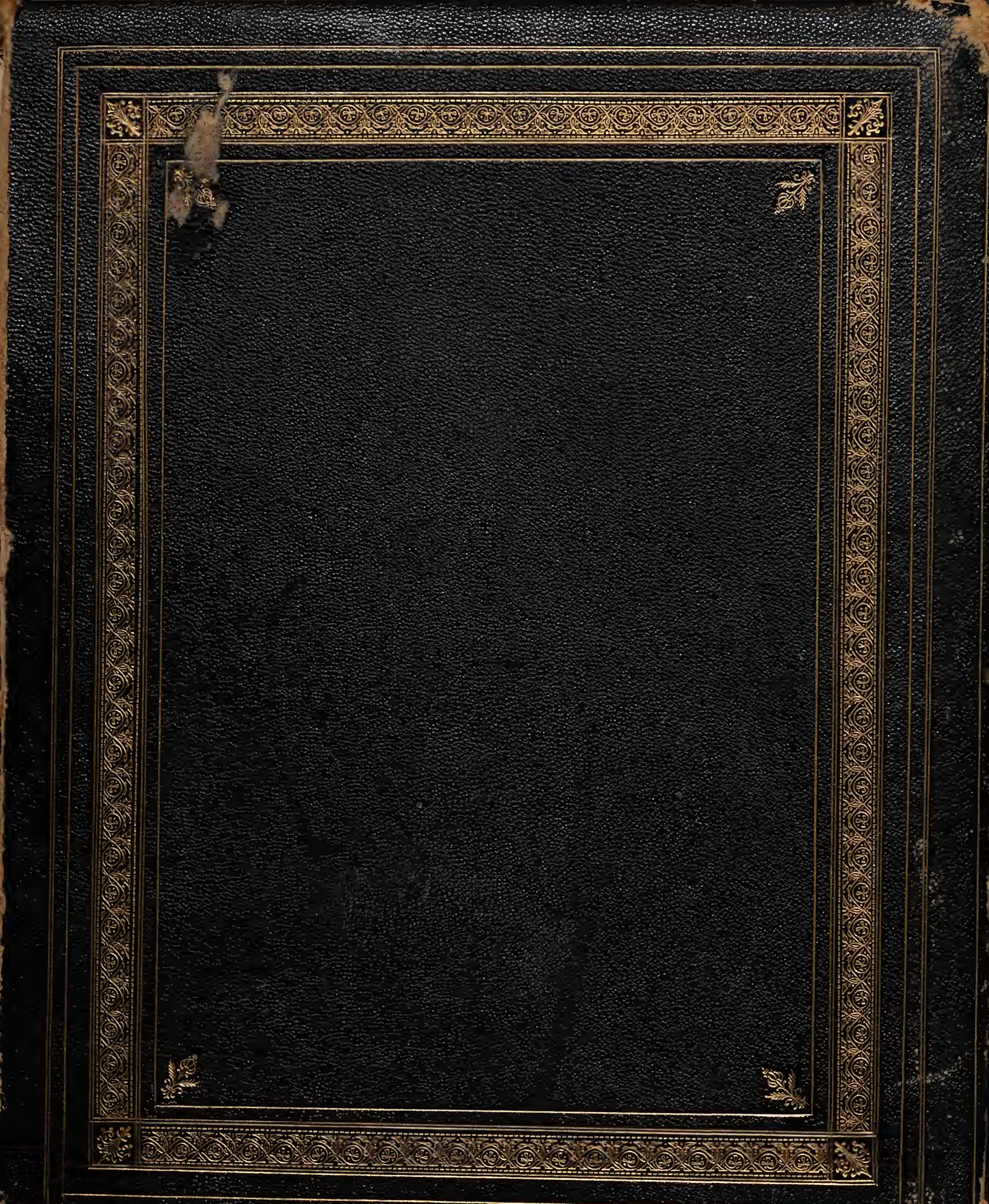

